\title{
Unorden
}

\section{Mushrooms traded as food. Vol II sec. 2}

Nordic Risk assessments and background on edible mushrooms, suitable for commercial marketing and background lists. For industry, trade and food inspection. Risk assessments of mushrooms on the four guidance lists

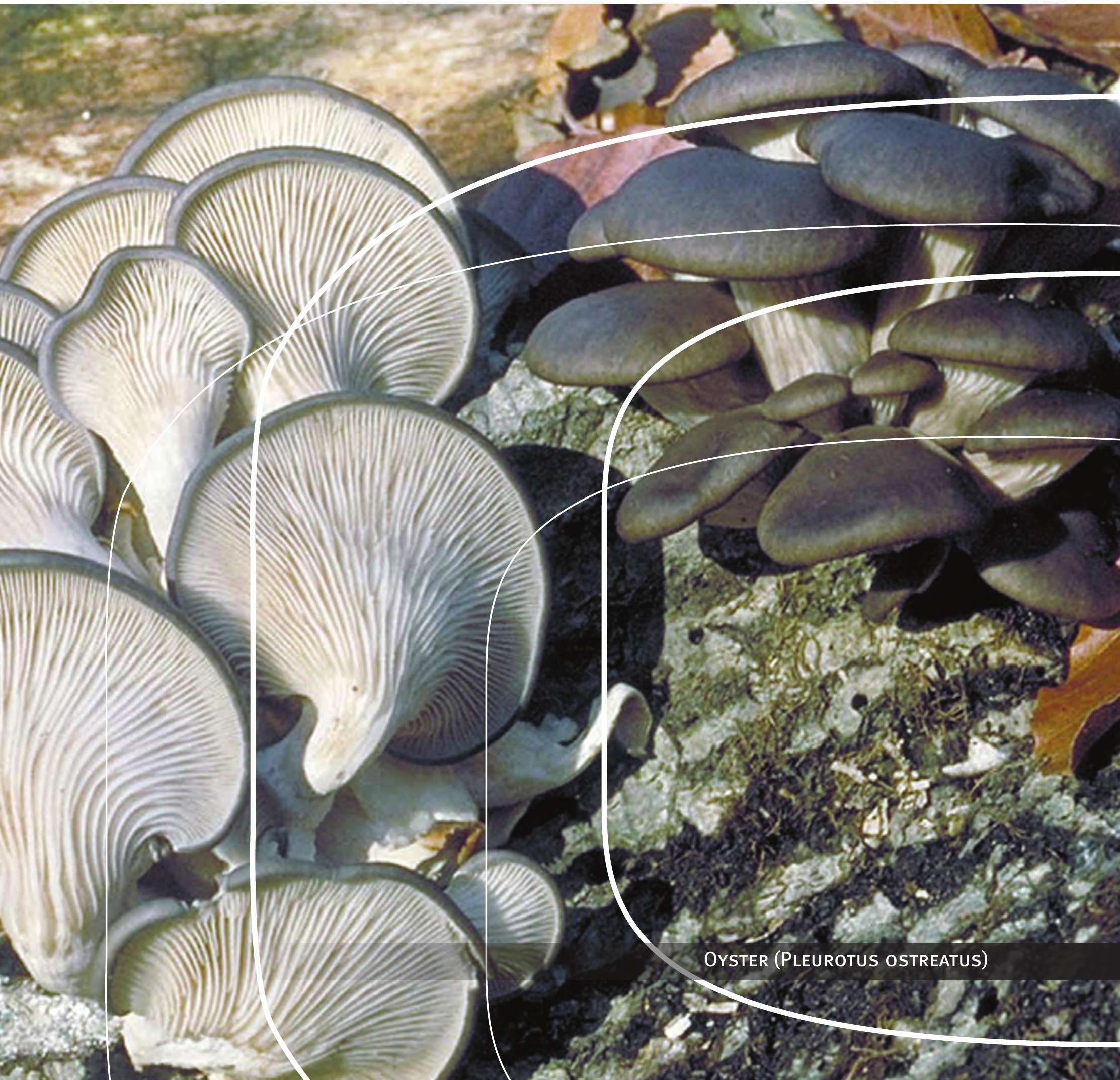



4 norden 



\section{Mushrooms traded as food. Vol II sec. 2}

Nordic risk assessments and background on edible mushrooms, suitable for commercial marketing and background lists for industry, trade and food inspection. Risk assessments of mushrooms on the four guidance lists

Jørn Gry and Christer Andersson

TemaNord 2014:507 
Mushrooms traded as food Vol II sec. 2 .

Nordic risk assessments and background on edible mushrooms, suitable for commercial marketing and background lists for industry, trade and food inspection. Risk assessments of mushrooms on the four guidance lists

Jørn Gry and Christer Andersson

ISBN 978-92-893-2705-3

http://dx.doi.org/10.6027/TN2014-507

TemaNord 2014:507

ISSN 0908-6692

(C) Nordic Council of Ministers 2014

Layout: NMR

Cover photo: ImageSelect

Photo: Jens H. Petersen and Jan Vesterholt, all, except: Amanita caesarea (Bente Fabech);

Armillaria borealis (Flemming Rune); Pleurotus citronopileatus and P. djamor (Henning Knudsen),

Tuber indicum (Christian Lange) and Volvariella volvacea (Ole Sparre Andersen).

This publication has been published with financial support by the Nordic Council of Ministers. However, the contents of this publication do not necessarily reflect the views, policies or recommendations of the Nordic Council of Ministers.

\section{www.norden.org/en/publications}

\section{Nordic co-operation}

Nordic co-operation is one of the world's most extensive forms of regional collaboration, involving Denmark, Finland, Iceland, Norway, Sweden, and the Faroe Islands, Greenland, and Åland.

Nordic co-operation has firm traditions in politics, the economy, and culture. It plays an important role in European and international collaboration, and aims at creating a strong Nordic community in a strong Europe.

Nordic co-operation seeks to safeguard Nordic and regional interests and principles in the global community. Common Nordic values help the region solidify its position as one of the world's most innovative and competitive.

\section{Nordic Council of Ministers}

Ved Stranden 18

DK-1061 Copenhagen $\mathrm{K}$

Phone (+45) 33960200

www.norden.org 


\section{Contents}

Introduction to Volume 2, section 2 .............................................................................. 11

1. Risk analysis and the steps of risk assessment.......................................................... 13

2. Introduction to mushroom risk assessments ........................................................... 17

Lists of mushrooms..................................................................................................... 17

Literature used ............................................................................................................... 18

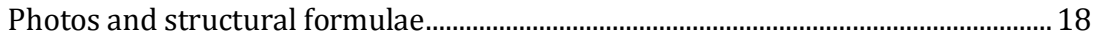

Toxic look-alikes ............................................................................................................. 19

Nomenclature............................................................................................................ 19

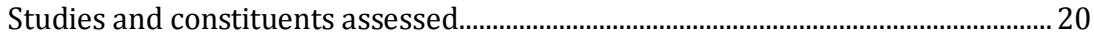

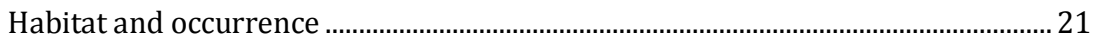

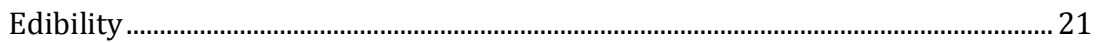

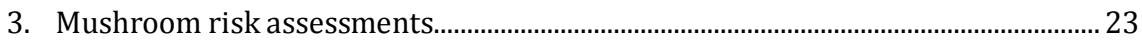

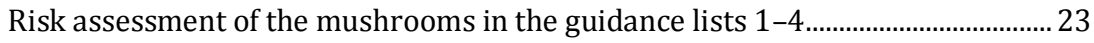

Agaricus abruptibulbus (Peck) Kauffm. s.auct .......................................................... 23

Agaricus arvensis Schaeff......................................................................................... 24

Agaricus augustus Fr. (A. perrarus Schulzer) ............................................................ 31

Agaricus bisporus (J.E. Lange) Imbach (A. hortensis (Cooke) S. Imai,

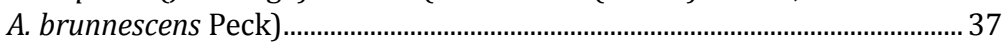

Agaricus bitorquis (Quél.) Sacc.................................................................................. 53

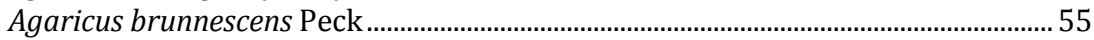

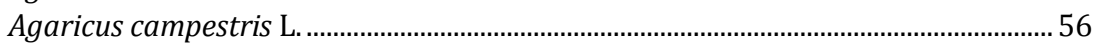

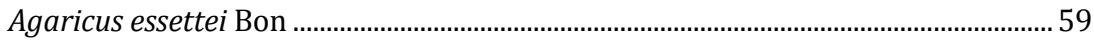

Agaricus excellens (F. H. Møller) F. H. Møller ………................................................. 59

Agaricus haemorrhoidarius Schulzer s. J. E. Lange ...................................................... 59

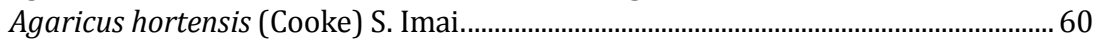

Agaricus langei (F. H. Møller) F. H. Møller.................................................................. 60

Agaricus macrosporus (F. H. Møller \& Jul. Schäff.) Pilát non Montagne..................... 60

Agaricus perrarus Schulzer............................................................................................ 60

Agaricus species, other not yellowing, e.g. A. langei (F. H. Møller)

F. H. Møller (A. haemorrhoidarius Schulzer s. J. E. Lange) and

A. sylvaticus Schaeff.

Agaricus species, other yellowing, e.g. A. essettei Bon (A. abruptibulbus

(Peck) Kauffm. s.auct, A. sylvicola (Vittad.) Peck s. str. and

A. urinascens (F. H. Møller \& Jul. Schäff.) Singer (A. excellens

(F. H. Møller) F. H. Møller, A. macrosporus (F. H. Møller \& Jul.

Schäff.) Pilát non Montagne)

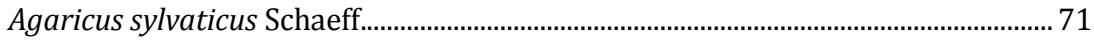

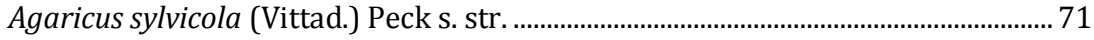

Agaricus urinascens (F. H. Møller \& Jul. Schäff.) Singer ............................................... 71

Albatrellus ovinus (Schaeff.) Kotl. \& Pouzar.................................................................... 72

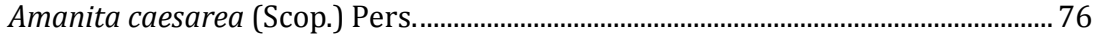

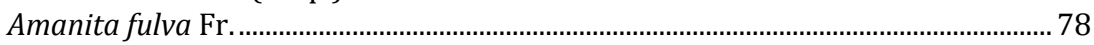

Amanita rubescens Pers............................................................................................................ 80 


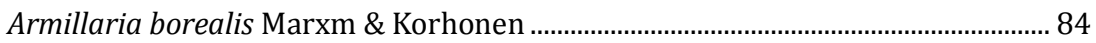

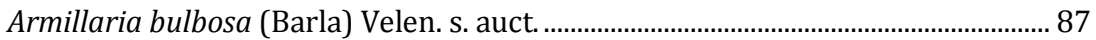

Armillaria cepistipes (Velen) X.L. Mao ....................................................................... 88

Armillaria gallica Marxm. \& Romagn. ........................................................................ 91

Armillaria lutea Gillet (A. gallica Marxm. \& Romagn., A. bulbosa (Barla)

Velen.s. auct.) ............................................................................................... 92

Armillaria mellea (Vahl.) P. Kumm. (Armillariella mellea (Vahl.) P. Karst.)........... 96

Armillaria obscura (Schaeff.) Horak s. auct............................................................... 99

Armillaria ostoyae (Romagn.) ((Armillariella ostoyae (Romagn.) Henrink, A. obscura (Schaeff.) Horak s. auct., A. polymyces (Gray) Singer \& Clémançon s. auct.) ........................................................................................100

Armillaria polymyces (Gray) Singer \& Clémanḉon s. auct............................................104

Auricularia auricula (L.) Underw.............................................................................104

Auricularia auricula-judae (Bull.) J. Schröt. (A. auricula (L.) Underw.)..................105

Auricularia polytricha (Mont.) Sacc. and other Auricularia species .......................107

Boletus aestivalis (Paulet) Fr.)................................................................................109

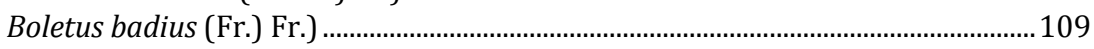

Boletus edulis Bull....................................................................................................110

B. erythropus Pers. s. Fries et auct. plur. non Persoon 1796 ....................................114

Boletus luridiformis Rostk. (B. erythropus Pers. s. Fries et auct. plur. non

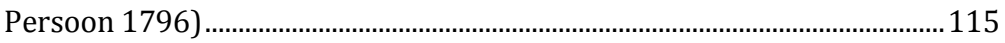

Boletus luridus Schaeff.................................................................................................11

Boletus pinicola (Vittad.) A. Venturi............................................................................119

Boletus pinophilus Pilát \& Dermek (B. pinicola (Vittad.) A. Venturi).......................120

Boletus reticulatus Schaeff. (B. aestivalis (Paulet) Fr.)..............................................122

Calocybe gambosa (Fr.) Donk (Lyophyllum gambosum (Fr.) Singer, Tricholoma gambosum (Fr.) P. Kumm., Tricholoma georgii (L.) Quél.) ........124

Camarophyllus pratensis (Fr.) P. Kumm................................................................125

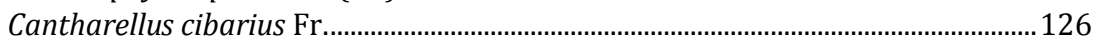

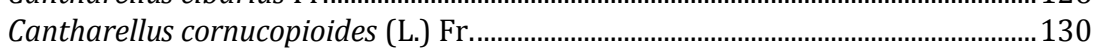

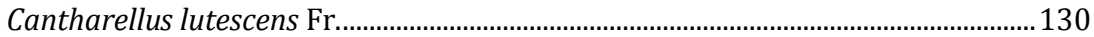

Cantharellus pallens Pilát...............................................................................................131

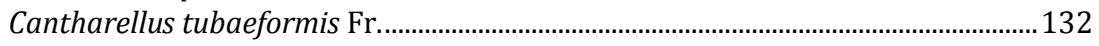

Chlorophyllum olivieri (Barla) Wellinga (Lepiota olivieri Barla, Macrolepiota olivieri (Barla) Wasser) ...............................................................133

Chlorophyllum rachodes (Vittad) Wellinga (Macrolepiota rachodes (Vittad.) Singer, Lepiota rhacodes (Vittad.) Quél.).....................................136

Clitocybe connata (Schumach.) Gillet (Lyophyllum connatum (Schumach.) Singer)

Clitocybe nebularis (Batsch) P. Kumm. (Lepista nebularis (Batsch) Harmaja).

Clitopilus prunulus (Scop.) P. Kumm..................................................................151

Coprinopsis atramentaria (Bull.) Redhead, Vilgalys \& Moncalvo (Coprinus atramentarius (Bull.) Fr.) ..................................................................................153

Coprinus atramentarius (Bull.) Fr.........................................................................159

Coprinus comatus (O.F.Müll.) Pers....................................................................160

Cortinarius caperatus (Pers.) Fr. (Rozites caperatus (Pers.) P. Karst.) ...................164

Cortinarius, other species, e.g., C. armillatus (Fr.) Fr................................................166

Craterellus cornucopioides (L.) Pers. (Cantharellus cornucopioides (L.) Fr.) ........169 
Craterellus lutescens (Pers.) Duby (Craterellus lutescens (Fr.) Fr., Cantharellus lutescens Fr.)

Craterellus tubaeformis (Fr.) Quél. (Cantharellus tubaeformis (Bull.) Fr.,

C. tubaeformis Fr.).

Flammulina velutipes (Curtis) Singer.

Gomphidius glutinosus (Schaeff.) Fr......................................................................180

Gomphus clavatus (Pers.) Gray..............................................................................182

Grifola frondosa (Dicks.) Gray.................................................................................184

Gyromitra esculenta (Pers.) Fr.................................................................................187

Hericium coralloides (Scop.) Pers. (H. ramosum (Bull.) Letell.)..............................198

Hericium erinaceus (Bull.) Pers..........................................................................................2201

Hericium ramosum (Bull.) Letell...................................................................................2207

Hydnum repandum L............................................................................................20

Hydnum rufescens Pers...............................................................................................2212

Hygrocybe pratensis (Fr.) Murrill (Camarophyllus pratensis (Fr.) P. Kumm.) ..........214

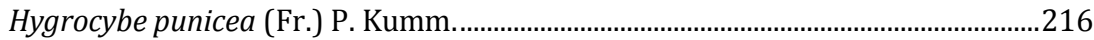

Hygrophorus camarophyllus (Alb. \& Schwein.) Dumée, Grandjean \& Maire ........218

Hygrophorus hypothejus (Fr.) Fr.............................................................................222

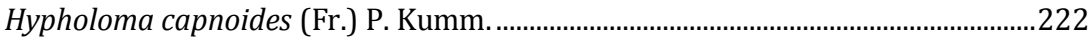

Hypsizygus marmoreus (Peck.) H.E. Bigelow.................................................................222

Kuehneromyces mutabilis (Schaeff.) Singer \& A.H. Sm. (Pholiota mutabilis

(Schaeff.) P. Kumm.)

Laccaria amethystina (Huds.) Cooke ..........................................................................2230

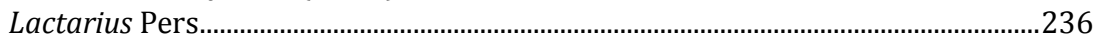

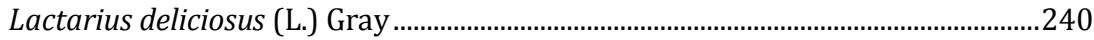

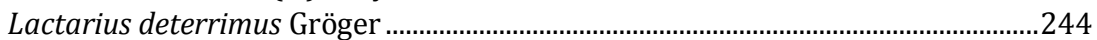

Lactarius necator (Bull.) Pers. (L. plumbeus s. auct., L. turpis (Weinm.) Fr.)........248

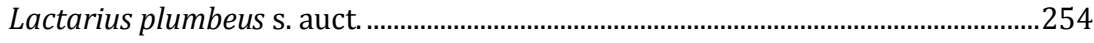

Lactarius rufus (Scop.) Fr........................................................................................225

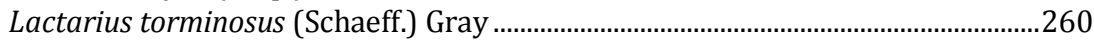

Lactarius trivialis (Fr.) Fr. (L. utilis (Weinm.) Fr.)...............................................264

Lactarius turpis (Weinm.) Fr......................................................................................2267

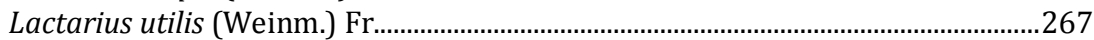

Lactarius volemus (Fr.) Fr....................................................................................268

Leccinum albostipitatum den Bakker \& Noordel. ......................................................269

Leccinum aurantiacum s. lato (L. albostipitatum den Bakker \& Noordel., L. quercinum (Pilát) E.E. Green \& Watling).....................................................22

Leccinum quercinum (Pilát) E.E. Green \& Watling).....................................................2272

Leccinum scabrum (Bull.) Gray.............................................................................22

Leccinum species, other, e.g. L. scabrum (Bull.) Gray..............................................2273

Leccinum versipelle (Fr. \& Hök) Snell.............................................................................2275

Leccinum vulpinum Watling .........................................................................................27

Lentinula edodes (Berk.) Pegler (L. edodes (Berk.) Singer).....................................279

Lentinus edodes (Berk.) Singer ....................................................................................293

Lepiota olivieri Barla .....................................................................................................293

Lepiota rhacodes (Vittad.) Quél..................................................................................293

Lepista nebularis (Batsch) Harmaja ........................................................................293 
Lepista nuda (Bull.) Cooke (Tricholoma nudum (Bull.) P. Kumm.) .........................294

Lepista personata s. auct. non (Fr.) Cooke, ................................................................29

Lepista saeva (Fr.) P.D. Orton (L. personata s. auct. non (Fr.) Cooke,

Tricholoma personatum s. auct. non (Fr.) P. Kumm.) ....................................300

Lyophyllum connatum (Schumach.) Singer................................................................. 302

Lyophyllum gambosum (Fr.) Singer....................................................................... 302

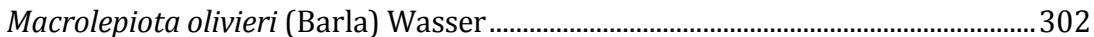

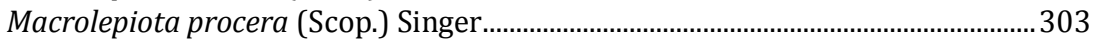

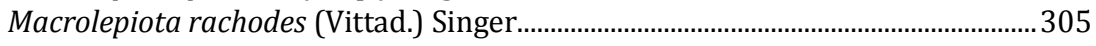

Morchella conica Pers. (M. elata Fr.) ...............................................................................306

Morchella elata Fr.............................................................................................................308

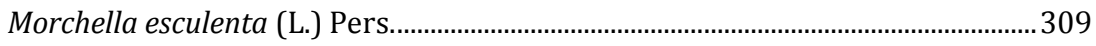

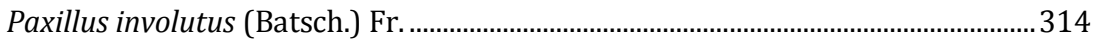

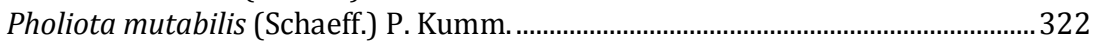

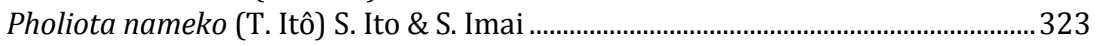

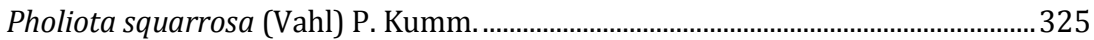

Pleurocybella porrigens (Pers.) Singer ............................................................................328

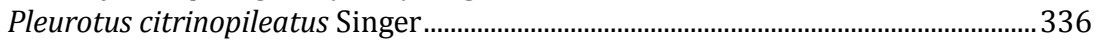

Pleurotus djamor (Rumph. ex. Fr.) Boedijn (P. salmoneostramineus Lj. N. Vassiljeva) .............................................................................................339

Pleurotus eryngii (DC.) Quél. (P. eryngii var. ferulae (Lanzi) Sacc.)......................... 341

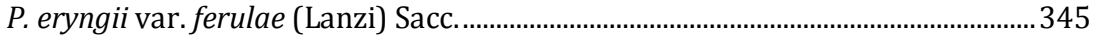

Pleurotus ostreatus (Jacq.) P. Kumm.............................................................................346

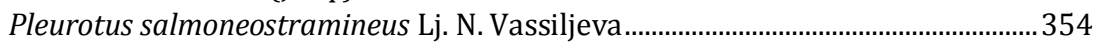

Rozites caperatus (Pers.) P. Karst................................................................................ 354

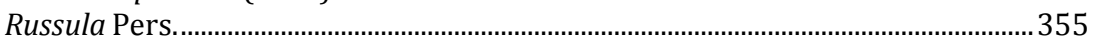

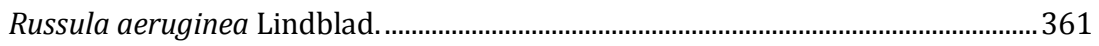

Russula claroflava Grove ( $R$. flava (Romell) Romell) ...............................................363

Russula cyanoxantha (Schaeff.) Fr..................................................................................365

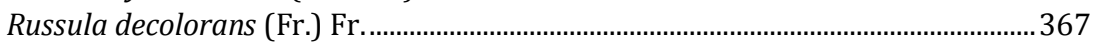

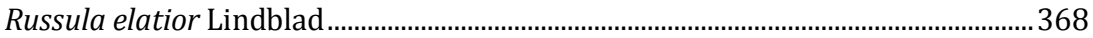

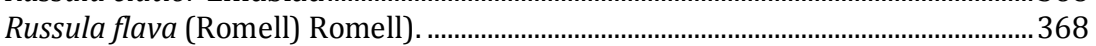

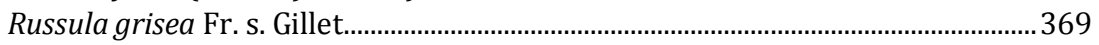

Russula integra (L.) Fr. s. Maire (R. polychromae Hora) ............................................ 371

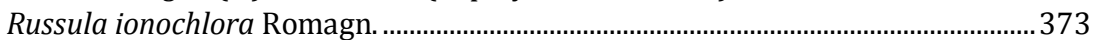

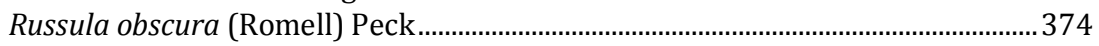

Russula paludosa Britzelm. (R. elatior Lindblad)..................................................... 375

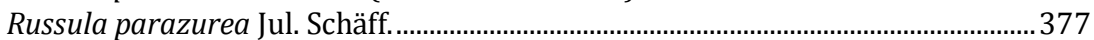

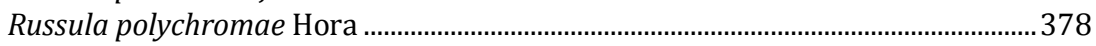

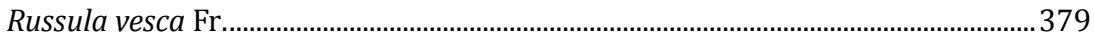

Russula vinosa Lindblad (R. obscura (Romell) Peck) ................................................381

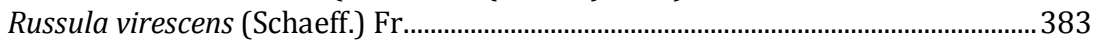

Russula xerampelina (Schaeff.) Fr. s. str .................................................................. 385

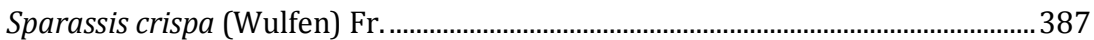

Suillus granulatus (L.) Roussel....................................................................................392

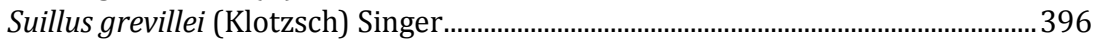

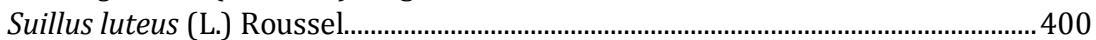

Suillus variegatus (Sw.) Kuntze.................................................................................... 405 
Tricholoma auratum (Paulet) Gillet

Tricholoma equestre (L.) P. Kumm. (T. flavovirens (Pers.) S. Lundell,

T. auratum (Paulet) Gillet)

Tricholoma flavovirens (Pers.) S. Lundell ......................................................................417

Tricholoma gambosum (Fr.) P. Kumm...................................................................... 418

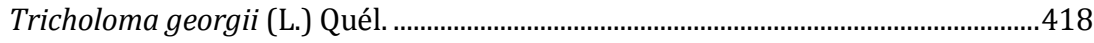

Tricholoma matsutake (S. Ito \& S. Imai) Singer (T. nauseosum (A. Blytt) Kytöv)

Tricholoma nauseosum (A. Blytt) Kytöv.................................................................... 423

Tricholoma nudum (Bull.) P. Kumm.................................................................................423

Tricholoma personatum s. auct. non (Fr.) P. Kumm................................................424

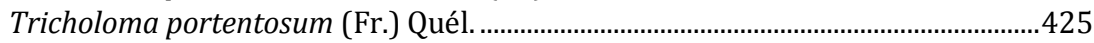

Tuber aestivum Vittad. (T. uncinatum Chat.) .............................................................427

Tuber indicum Cooke \& Massee (T. sinense X.L. Mao) .............................................. 435

Tuber magnatum Picco .............................................................................................. 439

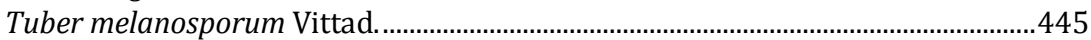

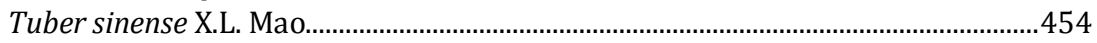

Tuber uncinatum Chat................................................................................................ 454

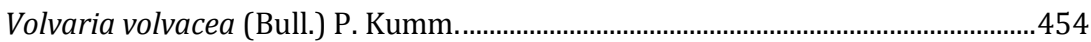

Volvariella volvacea (Bull.) Singer (Volvaria volvacea (Bull.) P. Kumm.)...............455

Xerocomus badius (Fr.) E.-J. Gilbert (Boletus badius (Fr.) Fr.)................................45 45

4. Pictures and statements on poisonous mushrooms referred to in

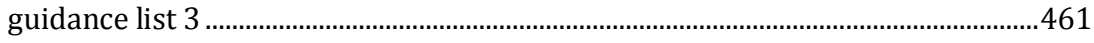

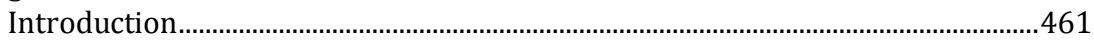

Amanita pantherina (DC.) Krombh...........................................................................462

Amanita phalloides (Vaill. ex Fr.) Link .................................................................. 463

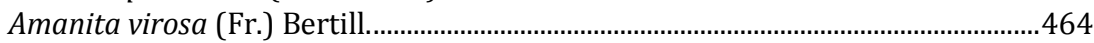

Boletus legaliae Pilát........................................................................................................465

Boletus satanas Lenz ........................................................................................... 466

Chlorophyllum brunneum (Farl. \& Burt) Vellinga (Macrolepiota bohemica

(Wichanský) Kriegslt. \& Pázmány, Macrolepiota brunneum (Farl. \&

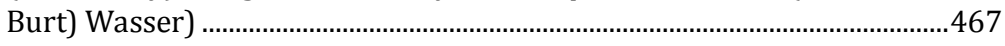

Clitocybe rivulosa (Pers.) P. Kumm. (Clitocybe dealbata (Sowerby)

P. Kumm. s. auct.).........................................................................................46

Cortinarius rubellus Cooke (C. speciosissimus Kühner \& Romagn.).......................... 469

Galerina marginata (Batsch.) Kühner (Galerina autumnalis (Peck)

A.H. Sm. \& Singer)

Hypholoma fasciculare (Huds.) P. Kumm ................................................................ 471 



\section{Introduction to Volume 2, section 2}

The project Mushrooms Traded as Food aims at improving the in-house control and thereby the safety of traded food mushrooms in the Nordic countries by basing the risk management on scientific risk assessments. ${ }^{1}$

Volume I, containing the questionnaire and the guidance lists, is available in five versions: in Danish, Icelandic, Norwegian, Swedish and English (see www.norden.org).

Volume II, section 1 and Volume II, section 2 of "Mushrooms Traded as Food" are in English and contain the background information and risk assessments of food mushrooms to be used in the in-house control by trade and industry and the public food inspection.

The two background reports compile knowledge on which the guidance in Volume I is based. The project has established guidance lists 1 to 4 on mushrooms that are suitable or not suitable to be traded as food. In order to be transparent and facilitate the decision on which mushrooms are suitable on the various lists produced within the project, a risk assessment was performed for each mushroom species in the four lists. These risk assessments were performed according to the principles laid down in the Codex Alimentarius Risk Analysis strategy. The mushroom species considered to be included on any of the lists were determined by earlier activities within the National Authorities responsible for food safety in the Nordic countries as well as information from the Nordic mycological societies.

Volume II, section 1 gives some details on mushrooms, contaminants, intoxications and relevant legislation, and presents the guiding tools for business operators and food control, not least the Nordic guidance lists on mushrooms. These guidance lists have been compiled to be used together with the questionnaire in Volume I of the project report.

1 The project is reported in two volumes, one is a questionnaire with guidance lists giving the direct advices (Volume I), the other supplying supporting background information (Volume II). 
Volume II, section 2 constitutes risk assessments of all the about 110 mushrooms in the four guidance lists. Each risk assessment contains information on the preferred scientific name, the preferred name in English and in each Nordic language, a picture of the mushroom, the chemical structure of identified natural toxicants and certain other bioactive constituents in the mushroom species and not least risk assessments of the mushrooms in the lists with recommendations and the references used for the assessments. The references comprise the scientific publications available based on searches in the databases SciFinder and possibly also PubMed up to the dates in 2012 indicated in the monographs on the 110 mushrooms and their known toxic constituents.

The project working group ${ }^{2}$ agreed on the structure of Volume II, section 2 .

The risk assessments were performed by Jørn Gry and Christer Andersson.

For acknowledgements see Volume II, section 1. For this Volume II, section 2, special thanks are given to Folmer D. Eriksen, Henning Knudsen and Thomas Læssøe for their many contributions.

\footnotetext{
2 Bente Fabech (chairperson) and Lulu Krüger, Danish Veterinary and Food Administration, Christer Andersson, National Food Agency, Sweden, Jørn Gry (consultant), Denmark, Birgitte Lyrån and Laila Jensvoll, Norwegian Food Safety Authority, Niina Matilainen and Annika Nurttila, Finnish Food Safety Authority Evira, Finland and Grímur Olafsson, Public Health Authority of Hafnarfjörður and Kópavogur, Iceland.
} 


\section{Risk analysis and the steps of risk assessment}

Since the middle of the 1990s food safety issues have been more formalized dealt with by the principle of risk analysis developed by Codex Alimentarius. When a hazard has been identified, which most often is done by scientists like food toxicologists, food microbiologists, food inspectors, medical doctors or other professionals, risk managers request a risk assessment to be performed. However, also consumers, politicians and others do initiate the process of risk analysis, when they observe potential hazards.

According to the risk analysis principle it is the task of scientists to perform the risk assessment. The risk assessment will, together with other legitimate factors, be used by risk managers in deciding on how to manage the identified risk. The other legitimate factors can be e.g., traditional use of a process like the smoking process and use of traditional foods like False Morel (Gyromitra esculenta). Even though smoking may cause contamination with carcinogenic aromatic hydrocarbons (PAH) in the smoked food, and False Morel contains inherent, suspected carcinogenic components, the smoked foods and the mushroom can be a traditional part of a national diet and therefore, the risk be accepted in the population. During the whole risk analysis process risk assessors and risk managers are entitled to communicate with communication experts and interested parties in a process called risk communication. This division of the tasks was created to increase the transparency in the decision making process and allow a wider audience to participate.

Risk assessments of mushrooms in the Nordic countries have to be performed within the legal framework of the European Community for foodstuffs. This is the case also for Norway and Iceland having co-operation agreements with the EU. However, there is no harmonized EU legislation specifically related to mushrooms. On the other hand, there are some specific legislation that might have a bearing on which mushrooms can be marketed, like the regulation on Novel Food, see Vol. II, section 1.

Overall, the risk analysis comprises three interrelated areas: 
- Risk assessment (the scientific part).

- Risk management (the administrative part).

- Risk communication (throughout the risk analysis process).

The scientific risk assessment can be described as a process developing over four phases: hazard identification, hazard characterization, exposure assessment and risk characterization.

Hazard identification is "the identification of biological, chemical, and physical agents capable of causing adverse health effects and which may be present in a particular food or group of food."

Hazard characterization: When a hazard has been identified in a risk assessment, hazard characterization follows. Codex Alimentarius defines hazard characterization as "the qualitative and/or quantitative evaluation of the nature of the adverse health effect associated with biological hazards, chemical and physical agents, which may be present in food. For chemical agents, a dose-response assessment should be performed. For biological or physical agents, a dose-response assessment should be performed if data are obtainable." Scientists often make hazard characterization based on animal testing. Included in the hazard characterization should be a description of uncertainties.

Exposure assessment: The third phase of the risk assessment is exposure assessment, which by Codex Alimentarius is defined as "the qualitative and/or quantitative evaluation of the likely intake of biological, chemical, and physical agents via food as well as exposures from other sources if relevant." Exposure assessment is a subject dealt with in many international guidelines on for example food additives, pesticides, flavourings etc. Exposure assessment is based on scientific knowledge on consumption patterns, surveys etc. Since consumption surveys are very expensive and as the consumption pattern changes over time, the assessments are in many cases based on models simulating the real intake of food. These models are often developed through international cooperation and accepted in the guidelines for risk assessment.

Exposure assessments of the bioactive compounds in mushrooms are in most cases difficult to perform. This is not only linked to a generally poor understanding of the quantities of various bioactive compounds in mushrooms, but also to a very limited knowledge on the average consumers' consumption of various types of mushrooms, or to the actual consumption (acute or long-term) by those consuming mushrooms or to sensitive consumer groups (e.g. children and elderly). The poor knowledge on mushroom consumption was illustrated in 2008 when a German Food Control Authority noted that nearly all samples of dried 
Cep (Boletus edulis) on the market contained nicotine above statutory pesticide residue levels. Reacting on the new information, the European Commission requested the European Food Safety Authority (EFSA) to estimate the mushroom intake in Europe by using food consumption data on raw cultivated and wild mushrooms provided by Member States for the development of the EFSA Pesticide Residue Intake Model. In order to respond to the request, EFSA asked Member States to deliver recent and detailed food consumption data for adults and children concerning different types of mushrooms, including wild mushrooms such as Cep (Boletus edulis). Only a few Member States were able to deliver such data. Frequently, these food descriptors were not available in the national databases. Mushroom consumption in adults was obtained from Ireland, Italy, Finland and France. The same type of data for children were available from the Netherlands, Ireland, Belgium, Italy and France. Most of these countries reported consumption figures for "total mushrooms", only Italy and Finland presented figures for the consumption of Cep. For most of the known, traded food mushroom species there will be no intake data available.

Risk characterization is the last step in the risk assessment process. Risk characterization is defined as "the qualitative and/or quantitative estimation, including attendant uncertainties, of the probability of occurrence and severity of known or potential adverse health effects in a given population based on hazard identification, hazard characterization and exposure assessment."

From the statements above it is clear that one of the important issues for the scientists involved in the risk assessment is to point out the uncertainties and assumptions made during the assessment, when reporting the risk assessment results. A general discussion on uncertainties in risk assessment is found in the project reports Food Safety in Europe: Risk Assessment of Chemicals in Food and Diet (2002) and Risk Characterisation of Chemicals in Food and Diet (2003). The uncertainties in the risk assessment, including some of the fundamental assumptions, are important for the management decisions and should be incorporated in the risk assessment as uncertainties. 



\section{Introduction to mushroom risk assessments}

\section{Lists of mushrooms}

As a basis for differentiating between mushrooms suitable to be marketed as food mushrooms and those that are not, risk assessments were performed on all mushroom species suggested by a Nordic country to be considered as a food mushroom, when the project started in 2008.

The preliminary list of mushrooms, suggested to constitute the mushrooms suitable as traded food in the Nordic countries, was produced from available national lists of food mushrooms and after consultation of Nordic mycological societies. It was also considered that the lists might not be exhaustive and that the lists established in the project would need to be reviewed, if new edible mushrooms should be included and to be in line with most recent science.

To determine whether the mushroom species present on the joint Nordic list were suitable to be kept on the list a risk assessment monograph was prepared for each species and toxic look-alike mushrooms were identified.

The resulting 110 mushroom monographs are presented in alphabetical order according to scientific name of the mushroom in the next chapter.

Based on the outcome of the risk assessments and whether there are toxic look-alikes, four new lists were established from the joint Nordic list compiled for this project. These lists are included in Volume I and in Volume II, section 1 of the reports.

The lists are:

- List 1 Edible mushrooms suitable for commercial marketing (cultivated and/or wild).

- List 2 Wild edible mushrooms, where the identity has to be documented by recognized experts, to be suitable for commercial marketing.

- List 3 Wild edible mushrooms, which may easily be mistaken for poisonous look-alikes and therefore are not regarded as suitable for commercial marketing. 
- List 4 Wild mushrooms earlier regarded as edible, but which are suspected to cause acute or long-time adverse effects after ingestion and therefore not regarded as suitable for commercial marketing.

Additionally, a list of toxic look-alikes referred to in the risk assessments on mushrooms in list 3, has been made, see Chapter 4 .

\section{Literature used}

The risk assessments are based on information in the scientific literature. The scientific literature was identified in database searches in SciFinder and when appropriate in PubMed during 2012 as indicated for each of the mushrooms assessed, and in recent reference books on mushrooms (generally, published in 2000 or later) written by recognized mycologists. ${ }^{3}$ References to these publications are given in the assessments. Other documents used when preparing these assessments included for example Codex Alimentarius standards (FAO/WHO) on mushrooms, applicable risk assessments performed by EFSA (the European Food Safety Authority) panels, and regional/national legislation/ recommendation regarding mushrooms/fungi.

\section{Photos and structural formulae}

Photos showing the typical appearance of all the mushrooms assessed are included in the 110 individual risk assessments, as well as structural formulae of bioactive constituents, ${ }^{4}$ especially toxicants in the mushroom.

Concerning photos, it has to be stressed, that one picture of a mushroom species will never cover all variations in the appearance of the mushroom in nature. The natural appearance can differ significantly.

The structural formulae have been worked out using ChemDraw Ultra Version 8.0.

\footnotetext{
${ }^{3} \mathrm{~A}$ list of such handbooks is included in Vol. II, section 1.

${ }^{4}$ Bioactive substances in mushrooms are inherent non-nutritive constituents with potential health protective and/or potential toxic effects when ingested (Gry et al., 2007).
} 


\section{Toxic look-alikes}

The toxic look-alikes referred to in the risk assessments of mushrooms in list 3 are not risk assessed, but there are scientific and vernacular names, a very short statement and a photo of each of them included in Chapter 4.

\section{Nomenclature}

All four lists give preferred scientific names as well as some commonly used synonyms. In addition to the scientific names, the preferred names in the English and Nordic languages are given. Other vernacular names used are also included, as are some of the names used in trade. The number of synonyms and trade names is not exhaustive.

If no preferred names were available from the primary sources below, the names are shown in brackets. Also synonyms are given in brackets. Trade names are additionally provided with hyphens.

General labelling regulations have to be followed regarding marketed mushrooms. In relation to this, it is recommended to use the scientific names and/or vernacular names given in the four lists.

The nomenclature used for the mushrooms in the risk assessment and in the guidance lists $1-4$ is the following:

\section{Scientific names}

Preferred scientific names are taken from Index Fungorum/Species Fungorum (2012) as far as the "Current Name" is given (by June 2012). The names in Index Fungorum/Species Fungorum and the names in "Funga Nordica", Knudsen \& Vesterholt (2012) are in most cases identical. Derivations are indicated in the risk assessment. If not available in these extensive compilations, a case by case decision was taken after consulting the Nordic mycological societies.

Common scientific synonyms are generally selected from Index Fungorum/Species Fungorum (2012) and Knudsen \& Vesterholt (2012).

\section{English names}

Preferred English names are taken from British Mycological Society (2012). If an English name is not available from this database, English names, as well as synonyms and trade names are taken from other sources (indicated within parenthesis). 


\section{Danish names}

Preferred Danish names are taken from the database of the Danish Mycological Society (2012). Danish synonyms and trade names are taken from other sources.

\section{Finnish names}

Preferred Finnish names are generally taken from the publication: Suomen helttasienten ja tattien ekologia, levinneisyys ja uhanalaisuus (2005) by the Finnish Environment Institute SYKE (Suomen ympäristökeskus).

\section{Icelandic names}

Preferred Icelandic names were taken from Sveppabókin by the Icelandic mycologist Helgi Hallgrimsson. (2010). If Icelandic names were lacking, such names have in several cases been allocated to the mushrooms by consultation with Gudridur Gyda Eyjolfsdóttir (2011), Icelandic Institute of Natural History.

\section{Norwegian names}

Preferred Norwegian names are taken from the database of the Norwegian names for fungi, prepared by the Norwegian Mushrooms Name Committee (2011).

\section{Swedish names}

Preferred Swedish names have been provided by ArtDatabanken (2011). Names of Ascomycetes are taken from Eriksson (2009). The names of some mushrooms not considered by the above sources are given names according to Aldén and Ryman (2009).

\section{Studies and constituents assessed}

Studies on whole mushrooms, extracts and fractions thereof, without any characterization of composition, especially of bioactive constituents, are generally not included in the risk assessments. The results from such studies are very difficult to reproduce, as the composition, especially of the bioactive constituents, may vary considerably.

Mono-, di- and polysaccharides, proteins and individual amino acids and lipids in mushrooms are generally not included in the assessments. However, certain proteins (e.g., lectins) and amino acids (e.g., pleurocybellaziridine) are included, as they are suspected to cause adverse effects. Pigments are only included, if they have been suspected to be 
biologically active and especially to give rise to adverse effects, e.g., in Brown Rollrim (Paxillus involutus) and Ugly Milkcap (Lactarius necator).

\section{Habitat and occurrence}

The habitat, way of growing (saprotrophic, parasitic or ectomycorrhizal), frequency and distribution (generally in the Nordic countries) are for Basidiomycetes, taken from Knudsen \& Vesterholt (2012), for other mushrooms from Hansen \& Knudsen $(1992 ; 1997 ; 2000)$ or in a few cases from other sources. Exceptions are generally given by footnote for the individual mushroom.

\section{Edibility}

Edible mushrooms or fungi are either wild mushrooms or mushrooms that have been cultivated, and which are suitable for use as a food after appropriate processing. Not all edible mushrooms are suitable as mushrooms traded as food.

The edibility is for most of the 110 mushrooms designated "edible." The edibility is further elaborated for "culinary mushrooms" like Cep (Boletus edulis), Chanterelle (Cantharellus cibarius) Morel (Morchella esculenta), and certain truffles (Tuber magnatum and T. melanosporum). 


\section{References to Chapter 2}

Aldén B \& Ryman S (2009): Våra kulturväxters namn, ursprung och användning, Forskningsrådet Formas: 1-768.

ArtDatabanken (2011): http://www.artdata.slu.se/default.asp

British Mycological Society (2012): English names for fungi.

http://www.britmycolsoc.org.uk/

Danish Mycological Society (2012): Danish-Latin database on names for fungi. http://www.svampe.dk/databaser/dansk-latinsk-navnedatabase/

Eriksson OE (2009): The non-lichenized ascomycetes of Sweden, Department of Ecology and Environmental Sciences, Umeå University: 1-461.

Gry J, Black L., Eriksen FD, Pilegaard K., Plumb J, Rhodes M, Sheehan D, Kiely M. Kroon PA (2007): EuroFIR-BASIS - a combined composition and biological activity database for bioactive compounds in plant-based foods. Trends in Food Science \& Technology 18: 434-444.

Gudridur Gyda Eyjolfsdóttir, Icelandic Institute of Natural History, personal communication, 2011.

Hansen L \& Knudsen H (1992): Nordic Macromycetes, Volume 2. Polyporales, Boletales, Agaricales, Russulales. Nordsvamp: 1-474.

Hansen L \& Knudsen H (1997): Nordic Macromycetes: Heterobasidioid, aphyllophoroid and gastromycetoid Basidiomycetes. Volume 3, Nordsvamp: 1-444.

Hansen L \& Knudsen H (2000): Nordic Macromycetes, Volume 1. Ascomycetes. Nordsvamp: 1-309.

Helgi Hallgrimsson (2010): Islenskir sveppir og sveppafrædi, Skudda: 1-632. Index Fungorum/Species Fungorum (2012): http://www.indexfungorum.org/ Knudsen H \& Vesterholt J (2012): Funga Nordica. Agaricoid, boletoid, clavarioid, cyphelloid and gastroid genera. Nordsvamp: 1-1083.

Norwegian Mushroom Name Committee (2009): (Den norske soppnavnkomiteen 2011). Norske soppnavn, $4^{\text {th }}$ Edition.

Suomen helttasienten ja tattien ekologia, levinneisyys ja uhanalaisuus (2005): Salo P, Niemelä T, Nummela-Salo U \& Ohenoja E (Editors). Suomen ympäristökeskus, Suomen ympäristö 769: 1-526. 


\title{
3. Mushroom risk assessments
}

\author{
Risk assessment of the mushrooms in the guidance \\ lists 1-4
}

The risk assessments in this chapter are listed in alphabetical order according to the scientific names of the mushrooms. The preferred vernacular names in the five Nordic languages and English are given in each assessment. If a name is only known in, e.g. Norwegian, then use the "search function" when searching in the electronic report to find the relevant risk assessment.

The nomenclature used is explained in the previous Chapter 2. Synonyms to preferred names are given in brackets and trade names are in addition provided with hyphens. Remarks to the nomenclature used are given as footnotes in the relevant risk assessments.

After each assessment, the mushroom has been allocated by the risk managers in the project to one of the lists 1-4, see Chapter 2, depending on, whether it is recommended for commercial trade (list 1 and 2) or not (list 3 and 4).

Agaricus abruptibulbus (Peck) Kauffm. s.auct

See Agaricus species, other yellowing. 


\section{Agaricus arvensis Schaeff}

Horse Mushroom (DK: Ager-Champignon, FI: Peltoherkkusieni, IS: Mókempa, NO: Åkersjampinjong, SE: Snöbollschampinjon).

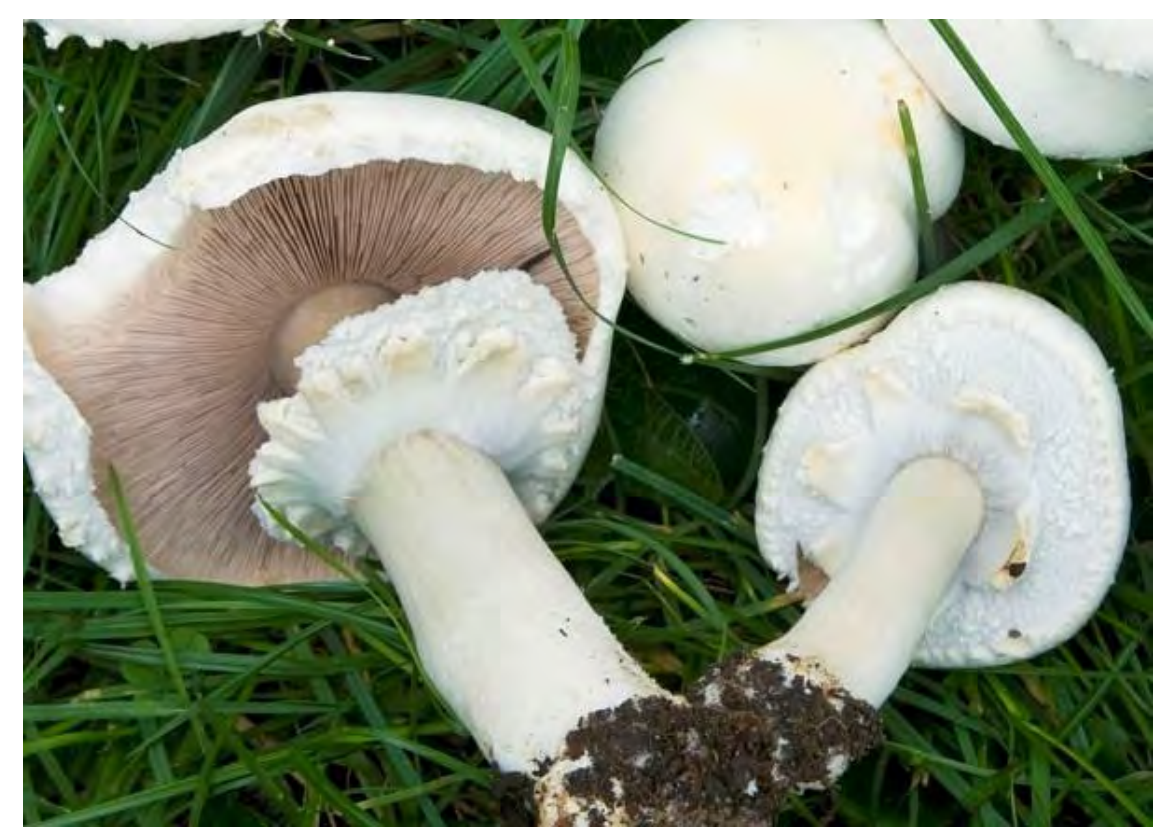

\section{Background and risk assessment}

Horse Mushroom (Agaricus arvensis) is generally regarded as edible and good.

It grows saprotrophically in meadows, pastures and garden lawns in summer to autumn and more rarely in coastal, saline meadows. The mushroom sometimes appears in fairy rings. The mushroom is common in Denmark and large parts of Norway, Sweden and Finland, occasional in subarctic regions of Iceland, and is rare in subarctic and alpine areas of Fennoscandia (Knudsen \& Vesterholt, 2012).

Occasionally, Horse Mushroom is cultivated and sold as fresh, e.g. in mixtures with other cultivated, fresh mushrooms like Oyster Mushroom (Pleurotus ostreatus) and Shiitake (Lentinula edodes).

There are no intoxications reported after consumption of Horse Mushroom. However, Horse Mushroom contains several bioactive constituents: 


\section{Bioactive constituents}

Phenylhydrazine derivatives: Horse Mushroom may contain large amounts of agaritine ( $\beta-\mathrm{N}$-[ $\gamma$-glutamyl]-4-(hydroxymethyl)phenylhydrazine). Horse Mushroom collected in the Czech Republic was found to contain 4751,550 (15 samples, mean content 987) mg agaritine per kg fresh weight (Schulzová et al., 2009), whereas Stijve et al. (1986) reported approximately 20-1,850 (8 samples, mean content 650) mg agaritine per $\mathrm{kg}$ fresh weight in mushrooms purchased or collected in various European countries or the USA. A structurally related phenylhydrazine derivative, the aldehyde agaritinal ( $\beta$-N-[ $\gamma$-glutamyl]-4-(formyl)phenylhydrazine) has also been demonstrated in significant amounts in the mushroom. Chulia et al. (1988) isolated approximately $40 \mathrm{mg}$ agaritinal per kg fresh weight of Horse Mushroom (Chuilia et al., 1988). Using a semiquantitative thin-layer chromatography method, Stijve and Pittet (2000) found dried Horse Mushroom to contain between 0.5 and 1.5\% agaritinal, corresponding to a level between 500-1,500 mg per kg fresh weight.

Horse Mushroom also contains another type of phenylhydrazine derivatives, schaefferals, which are hydrazones chemically formed by a reaction between 4-(formyl)phenylhydrazine and aromatic aldehydes. Three schaefferals were isolated in amounts of about $10 \mathrm{mg}$ per $\mathrm{kg}$ fresh mushroom (Kileci-Ksoll et al., 2010).

The structural formulae of agaritine, agaritinal and the three schaefferals are shown below.<smiles>NC(CCC(=O)NNc1ccc(CO)cc1)C(=O)O</smiles>

Agaritine<smiles>NC(CCC(=O)NNc1ccc(C=O)cc1)C(=O)O</smiles> 


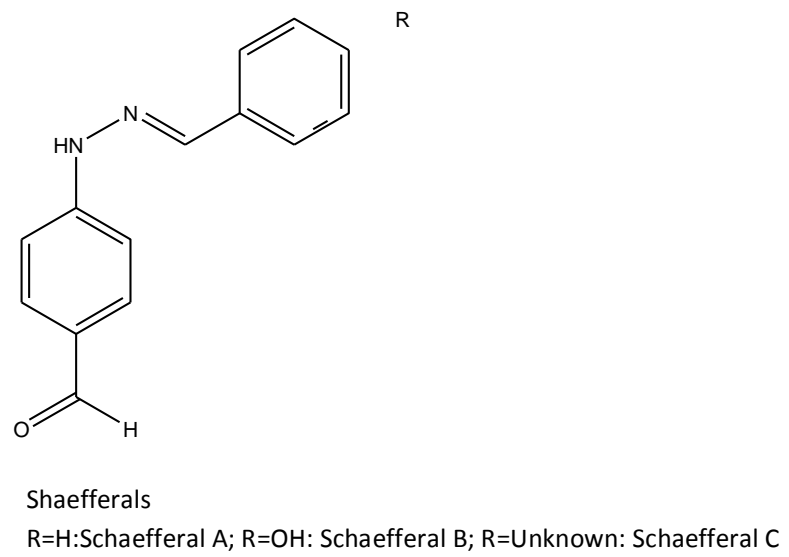

Agaritine, or at least its metabolites, are indicated to give rise to tumours in mice by a genotoxic mechanism. Therefore, it cannot be excluded that consumption of Horse Mushroom, which contains large amounts of agaritine and smaller amounts of the structurally related agaritinal, constitutes a cancer risk to humans (for further information see risk assessment of Button Mushroom, Agaricus bisporus). Neither agaritinal, nor the schaefferals have been studied for their potential toxicity and carcinogenicity, but at least agaritinal may be anticipated to give rise to similar metabolites as agaritine.

Cadmium: Horse Mushroom belongs to a group of yellowing Agaricus species ("Flavescentes"), which have an anise or bitter almond-like smell and become yellowish when rubbed or bruised. In contrast to reddishing Agaricus species ("Rubescentes"), e.g. Button Mushroom (A. bisporus) and Scaly Wood Mushroom (A. langei), which may become reddish (or brownish) when cut or rubbed, the yellowing Agaricus species bioaccumulate the highly toxic metal cadmium. It has been shown that the cadmium content of Agaricus species from the "Rubescentes" group often is at least an order of magnitude lower than the content in the "Flavescentes" group (Laub et al., 1977; Lodenius et al., 1981; Mowitz, 1980; Seeger, 1978; 1982; Woggon \& Bickerich, 1978). The bioaccumulation is apparently due to some low molecular weight cadmium-binding proteins, specific for the yellowing Agaricus species (Kruse \& Lommel, 1979; Meisch et al., 1983; Meisch \& Schmitt, 1986). It has been proposed that the bioavailability of cadmium from the yellowing Agaricus species is low due to its binding to these specific proteins in the "Flavescentes" group mushrooms (Schellmann et al., 1980; 1984) but feeding studies in rodents have subsequently demonstrated that there is no difference in cadmium bioavailability depending on whether the compound in the diet comes from mushrooms containing the cadmium accumulating 
compounds or from cadmium added to the diet in equivalent amounts in the form of cadmium chloride. This has been shown for Wood Mushroom (A. sylvicola) fed to mice (Seeger et al., 1986), for Horse Mushroom (A. arvensis) fed to rats (Gry et al., 1987; Hansen et al., 1987) and for The Prince (A. augustus) fed to mice (Lind et al., 1995).

Cadmium is a highly toxic metal with a very long half-life in humans, ranging from 10 to 30 years. It is primarily toxic to the kidney, where it accumulates and may cause renal dysfunction, which may progress to renal failure. It can also cause bone demineralisation. A health based guidance value for cadmium, a Tolerable Weekly Intake (TWI) of 2.5 microgram cadmium per kg body weight has been established by the European Food Safety Authority (EFSA), based on the renal tubular effects (EFSA, 2009; 2011). EFSA estimates that the mean weekly dietary exposure to cadmium in Europe is 2.3 microgram per kg body weight and that regular consumers of wild mushrooms have a higher dietary exposure 4.3 microgram per kg body weight per week (EFSA, 2009, 2012). Although the current dietary exposure is unlikely to cause adverse renal effects in European consumers, EFSA concludes there is a need to reduce the exposure to cadmium because of the very small safety margin (EFSA, 2012). Furthermore, WHO's International Agency for Research on Cancer has concluded "There is sufficient evidence in humans for the carcinogenicity of cadmium and cadmium compounds" and "There is sufficient evidence in experimental animals for the carcinogenicity of cadmium compounds" (IARC, 1993; 2012).

Horse Mushroom contains from 0.1 to more than $20 \mathrm{mg}$ cadmium per $\mathrm{kg}$ fresh weight, with mean values from 0.4 to $3.5 \mathrm{mg}$ per $\mathrm{kg}$ fresh weight (Andersen et al., 1982; Meisch et al., 1977; 1979; Mowitz, 1980; Stijve \& Besson, 1976).

In order to protect public health, the European Commission has set limits for cadmium in a series of food items, including a maximum limit of $1.0 \mathrm{mg}$ per $\mathrm{kg}$ fresh weigh for mushrooms, except for the most frequently traded mushrooms Button Mushroom (Agaricus bisporus), Oyster Mushroom (Pleurotus ostreatus) and Shiitake (Lentinula edodes) for which a limit of $0.20 \mathrm{mg}$ per kg fresh weight has been set (EU Commission, 2006).

Sterner et al. (1982) tested an extract of Horse Mushroom in the Ames test using the Salmonella typhimurium strains TA98, TA100 and TA2637. The extract was weakly positive in the TA98 and TA100 strains. The activity was not enhanced in the presence of microsomal enzymes. Unfortunately, Sterner et al. (1982) give no information, whether they had controlled for the potential presence of histidine in the extract. It is 
well known that false positives may be obtained in the presence of histidine. Thus, there is no strong indication that extracts of the Horse Mushroom are mutagenic.

\section{Recommendation}

- As Horse Mushroom (Agaricus arvensis) efficiently bioaccumulates cadmium and as the amount varies considerably, the content of this toxic and carcinogenic metal should be regularly controlled.

- Due to the potentially high levels of phenylhydrazine derivatives and cadmium, Horse Mushroom should not be eaten in larger amounts (see A. bisporus (Button Mushroom) risk assessment).

Listing 1 (as cultivated)

Listing 2 (as wild growing)

Database search information

SciFinder by April 2012. Keywords: Agaricus arvensis, agaritine. PubMed by May 2012. Keywords: Agaricus and cadmium.

\section{References}

Andersen A, Lykke S-E, Lange M \& Bech K (1982): Sporelementer i spiselige svampe. Publikation nr. 68. Statens Levnedsmiddelinstitut: 1-27.

Chulia AJ, Bernillon J, Favre-Bonvin J, Kaouadji M \& Arpin N (1988): Isolation of $\beta-N$ ( $\gamma$-glutamyl)-4-formylphenylhydrazine (agaritinal) from Agaricus campestris. Phytochemistry 27: 929-930.

EFSA (2009): Cadmium in Food. Scientific Opinion of the Panel on Contaminants in the Food Chain. The EFSA Journal 980: 1-139.

EFSA(2011): Statement on tolerable weekly intake for cadmium. EFSA Panel on Contaminants in the Food Chain. The EFSA Journal 9: 1975: 1-19.

EFSA (2012): Scientific Report of EFSA Cadmium dietary exposure in the European population. The EFSA Journal 10: 2551: 1-37.

EU Commission (2006): Regulation (EC) No 1881/2006 of 19 December 2006 setting maximum levels for certain contaminants in foodstuffs. OJ L 364, 20.12.2006, p. 5. (Amended).

Gry J, Hansen EW \& Pedersen E (1988): Ager-Champignon og andre gulnende champignoner bør spises med måde. Svampe 18: 69-70.

Hansen EV, Gry J \& Andersen A (1987): Rat studies on the bioavailability of cadmium from mushrooms. Report from the National Food Institute, Soeborg, Denmark.

IARC (1993): International Agency for Research on Cancer. Berylium, cadmium, mercury, and exposures in the glass manufacturing industry 58: 119-237.

IARC (2012): International Agency for Research on Cancer. Arsenic, metals, fibres, and dusts. A review of human carcinogens. Cadmium and cadmium compounds 100C: $121-145$ 
Kileci-Ksoll R, Winklhofer C \& Steglich W (2010): Synthesis of Schaefferals A and B, unusual phenylhydrazine derivatives from mushrooms of the genus Agaricus. Synthesis 2010: 2287-2291.

Knudsen H \& Vesterholt J (2012): Funga Nordica. Agaricoid, boletoid, clavarioid, cyphelloid and gastroid genera. Nordsvamp: 1-1083.

Kruse H \& Lommel A (1979): Untersuchungen über cadmiumbindende Proteine im Schaf-Champignon (Agaricus arvensis Schff. ex Fr.). Zeitschrift für LebensmittelUntersuchung und - Forschung 168: 444-447.

Laub E, Waligorski F \& Woller R (1977): Über die Cadmiumanreicherung in Champignons. Zeitschrift für Lebensmittel-Untersuchung und - Forschung 164: 269-271.

Lind Y, Glynn AW, Enman J \& Jorhem L (1995): Bioavailability of cadmium from crab hepatopancreas and mushroom in relation to inorganic cadmium: A 9-week feeding study in mice. Food Chemical Toxicology 33: 667-673.

Lodenius M, Kuusi T, Laaksovirta K, Liukkonen-Lilja H \& Piepponen S (1981): Lead, cadmium and mercury contents of fungi in Mikkeli, SE Finland. Annales Botanici Fennici 18: 185-186.

Meisch H-U, Schmitt JA \& Reinle W (1977): Schwermetalle in höheren Pilzen Cadmium, Zink and Kupfer. Zeitschrift für Naturforschung 32c: 172-181.

Meisch H-U, Schmitt JA \& Scholl A-R (1979): Growth simulation by cadmium in the mushroom Agaricus abruptibulbus. Naturwissenschaften 66: 209.

Meisch H-U, Beckmann I \& Schmitt JA (1983): A new cadmium-binding phosphoglycoprotein, cadmium-mycophosphatin, from the mushroom, Agaricus macrosporus. Biochimica et Biophysica Acta 745: 259-266.

Meisch H-U \& Schmitt JA (1986): Characterization studies on cadmiummycophosphatin from the mushroom Agaricus macrosporus. Environmental Health Perspectives 65: 29-32.

Mowitz J(1980): Höga halter cadmium i vildväxande svenska champinjoner. Vår Föda 5: 270-278.

Schellmann B, Hilz M-J \& Opitz O (1980): Cadmium- und Kupferausscheidung nach Aufname von Champignon-Mahlzeiten. Zeitschrift für Lebensmittel-Untersuchung und - Forschung 171: 189-192.

Schellmann B, Rohmer E, Schaller K-H \& Weltle D (1984): Concentration of cadmium and copper in feces, urine and blood after ingestion of wild mushrooms. Zeitschrift für Lebensmittel-Untersuchung und - Forschung 178: 445-449.

Schulzova V, Hajslova J, Peroutka R, Hlavasek J, Gry J \& Andersson HC (2009): Agaritine content of 53 Agaricus species collected from nature. Food Additives and Contaminants 26: 82-93.

Seeger R (1978): Cadmiun in Pilzen. Zeitschrift für Lebensmittel-Untersuchung und Forschung. 66: 23-34.

Seeger R (1982): Toxische Schwermetalle in Pilzen. Deutsche Apotheker Zeitung 122: $1835-1844$.

Seeger R, Schiffelbein F, Sauffart R \& Sant W (1986): Absorption of cadmium ingested with mushrooms (Abstract 110). Archives of Pharmacology 332 supplement: R28.

Sterner O, Bergman R, Kesler E, Magnusson L, Nilsson B, Wickberg B, Zimerson E \& Zetterberg G (1982): Mutagens in larger fungi I. Forty-eight species screened for mutagenic activity in the Salmonella/microsome assay. Mutation Research 101: 269-281.

Stijve T \& Besson R (1976): Mercury, cadmium, lead and selenium content of mushroom species belonging to the genus Agaricus. Chemosphere 2: 151-158. 
Stijve T \& Pittet A (2000): Absence of agaritine in Pleurotus species and in other cultivated and wild-growing mushrooms not belonging to the genus Agaricus. Deutsche Lebensmittel-Rundschau 96: 251-254.

Stijve T, Fumeaux R \& Philippossian G (1986): Agaritine, a phydroxymethylphenylhydrazine derivative in cultivated mushrooms (Agaricus bisporus), and in some of its wild-growing relatives. Deutsche LebensmittelRundschau 82: 243-248.

Woggon H \& Bickerich K (1978): Zum Vorkommen von Toxischen Schwermetallen (Cadmium, Blei, Zink und Quecksilber) in Pilzen. Die Nahrung 22: 13-15. 


\section{Agaricus augustus Fr. (A. perrarus Schulzer)}

The Prince (DK: Prægtig Champignon, FI: Veriherkkusieni, IS: No Icelandic name, NO: Kongesjampinjong; SE: Kungschampinjon).

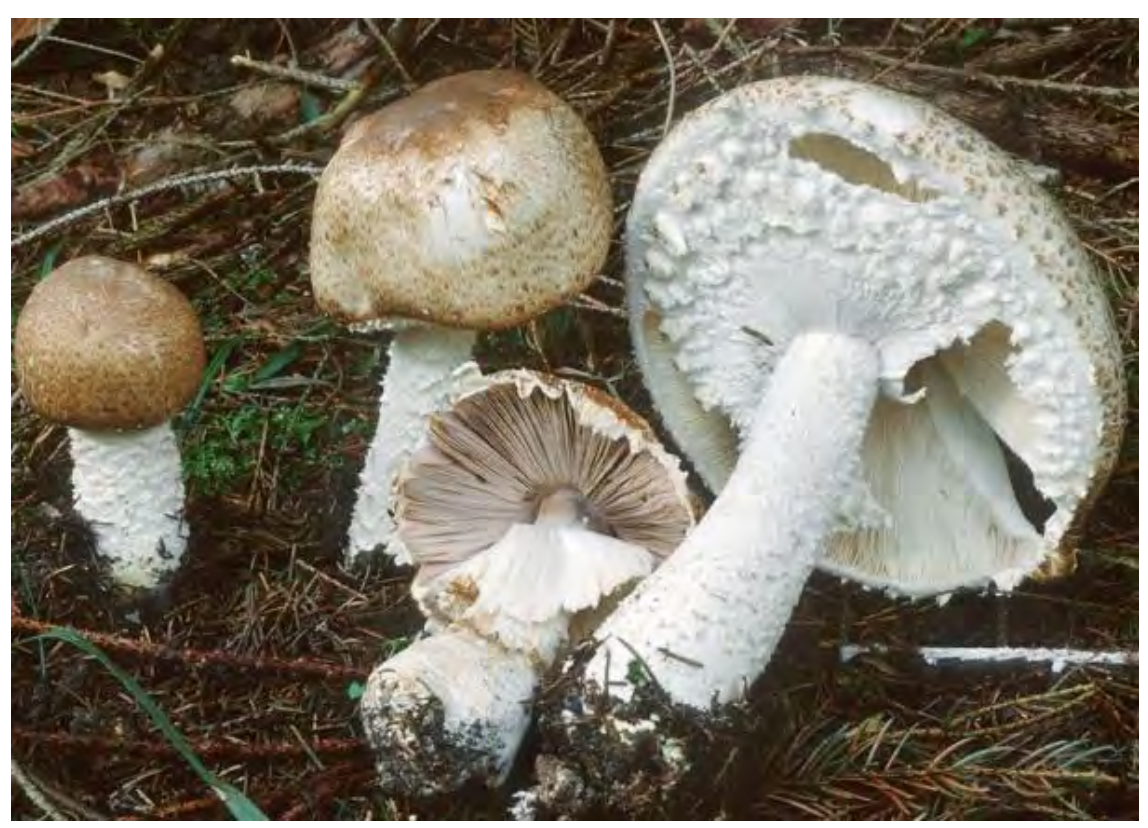

\section{Background and risk assessment}

The Prince (Agaricus augustus) 5 is generally regarded as edible and very good.

It grows saprotrophically in coniferous and deciduous forests, gardens and parks. It is occasional in Denmark, and southern parts of Norway and Sweden, but rare in Finland and in the middle boreal and subarctic areas of Norway and Sweden (Knudsen \& Vesterholt, 2012).

There are no intoxications reported after consumption of The Prince. However, The Prince contains several bioactive constituents:

5 Agaricus perrarus is now considered as a synonym for A. augustus (Index Fungorum/Species Fungorum (2012) and Knudsen \& Vesterholt (2012)). 


\section{Bioactive constituents}

Phenylhydrazine derivatives: The Prince may contain large amounts of agaritine ( $\beta$-N-[ $\gamma$-glutamyl]-4-(hydroxymethyl)phenylhydrazine. The Prince collected in the Czech Republic was found to contain very large amounts of agaritine, $2,260-7,550 \mathrm{mg} / \mathrm{kg}$ fresh weight ( 6 samples, mean content $4,000 \mathrm{mg} / \mathrm{kg}$ fresh weight; Schulzová et al., 2009), whereas, $A$. perrarus $^{5}$ contains levels from 841 to 1,170 (2 samples, mean content of $1,000) \mathrm{mg}$ per kg fresh mushroom (Schulzová et al., 2009). Stijve and coworkers have reported lower levels: $0.10-2.20 \%$ on dry matter, corresponding to, approximately 100-2,200 (6 samples, mean content 860 ) $\mathrm{mg} / \mathrm{kg}$ fresh weight (Stijve et al., 1986) or when analysed by a semiquantitative thin-layer chromatography (TLC)-method between 1,500$2,500 \mathrm{mg} / \mathrm{kg}$ fresh weight (Stijve \& Pittet, 2000). A structurally related phenylhydrazine derivative, the aldehyde agaritinal ( $\beta$ - $\mathrm{N}-[\gamma$-glutamyl]-4(formyl)phenylhydrazine) has also been demonstrated in The Prince. Using a semi-quantitative TLC-method Stijve \& Pittet (2000) reported $0.5-1.5 \%$ of the dried mushroom to be agaritinal, which would correspond to a level between 500 and 1,500 mg per kg fresh weight.

The structural formulae of agaritine and agaritinal are shown below.<smiles>NC(CCC(=O)NNc1ccc(CO)cc1)C(=O)O</smiles>

Agaritine<smiles>Cc1ccc(NNC(=O)CCC(N)C(=O)O)cc1</smiles>

Agaritinal

Agaritine, or at least its metabolites, are indicated to give rise to tumours in mice by a genotoxic mechanism. Therefore, it cannot be excluded that consumption of The Prince, which contain very large amounts of agaritine and the structurally related agaritinal may constitute a risk to humans (for further information see risk assessment of Button Mushroom, Agaricus bisporus).

Cadmium: The Prince belongs to the group of yellowing Agaricus species ("Flavescentes"), which have an anise or bitter almond-like smell and become yellowish when rubbed or bruised. In contrast to reddishing Agaricus species ("Rubescentes"), e.g. Button Mushroom (A. bisporus) 
and Scaly Wood Mushroom (A. langei), which may become reddish (or brownish) when cut or rubbed, the yellowing Agaricus species bioaccumulates the highly toxic metal cadmium. It has been shown that the cadmium content of Agaricus species from the "Rubescentes" group often is at least an order of magnitude lower than the content in the "Flavescentes" group (Laub et al., 1977; Lodenius et al., 1981; Mowitz, 1980; Seeger, 1978; 1982; Woggon \& Bickerich, 1978). The bioaccumulation is apparently due to some low molecular weight cadmium-binding proteins, specific for the yellowing Agaricus species (Kruse \& Lommel, 1979; Meisch et al., 1983; Meisch \& Schmitt, 1986). It has been proposed that the bioavailability of cadmium from the yellowing Agaricus species is low due to its binding to these specific proteins in the "Flavescentes" group mushrooms (Schellmann et al., 1980; Schellmann et al., 1984) but feeding studies in rodents have subsequently demonstrated that there is no difference in cadmium bioavailability depending on whether the compound in the diet comes from mushrooms containing the cadmium accumulating compounds or from cadmium added to the diet as equivalent amounts of cadmium chloride. This has been shown for Wood Mushroom (A. sylvocola) fed to mice (Seeger et al., 1986), for Horse Mushroom (A. arvensis) fed to rats (Gry et al., 1987; Hansen et al., 1987) and for The Prince (A. augustus) fed to mice (Lind et al., 1995).

Cadmium is a highly toxic metal with a very long half-life in humans, ranging from 10 to 30 years. It is primarily toxic to the kidney where it accumulates and may cause renal dysfunction, which may progress to renal failure. It can also cause bone demineralisation. A health based guidance value for cadmium; a Tolerable Weekly Intake (TWI) of 2.5 microgram cadmium per kg body weight has been established by the European Food Safety Authority (EFSA), based on the renal tubular effects (EFSA, 2009; 2011). EFSA estimates that the mean weekly dietary exposure to cadmium in Europe is 2.3 microgram per kg body weight and that regular consumers of wild mushrooms have a higher dietary exposure, around 4.3 microgram per kg body weight per week (EFSA, $2009 ; 2012$ ). Although the current dietary exposure is unlikely to cause adverse renal effects in European consumers, EFSA concludes there is a need to reduce the exposure to cadmium because of the very small safety margin (EFSA, 2012). Furthermore, WHO's International Agency for Research on Cancer (IARC) has concluded that "There is sufficient evidence in humans for the carcinogenicity of cadmium and cadmium compounds" and "There is sufficient evidence in experimental animals for the carcinogenicity of cadmium compounds" (IARC, 1993; 2012). 
The Prince contains $0.5-11 \mathrm{mg}$ cadmium per kg fresh weight (18 samples), with a mean value around $4 \mathrm{mg}$ per kg mushroom (Andersen et al., 1982; Meisch et al., 1977, 1979; Mowitz, 1980; Seeger, 1978; Stijve \& Besson, 1976). Lind et al. (1995) reported a level of more than $80 \mathrm{mg}$ cadmium per kg dried mushroom corresponding to more than $8 \mathrm{mg}$ cadmium per kg fresh weight.

In order to protect public health, the European Commission has set limits for cadmium in a series of food items, including a maximum limit of $1.0 \mathrm{mg}$ per kg fresh weigh for mushrooms, except for the most frequently traded mushrooms Button Mushroom (Agaricus bisporus), Oyster Mushroom (Pleurotus ostreatus) and Shiitake (Lentinula edodes) for which a limit of $0.20 \mathrm{mg}$ per kg fresh weight for has been set (EU Commission, 2006).

\section{Recommendation}

- As The Prince (Agaricus augustus) efficiently bioaccumulates cadmium, and the amounts varies considerably, the content of this toxic and carcinogenic metal should be regularly controlled.

- Due to the potentially high levels of phenylhydrazine derivatives and cadmium, The Prince should not be eaten in larger amounts (see A. bisporus (Button Mushroom) risk assessment).

\section{Listing 2}

\section{Database search information}

SciFinder by February 2012. Keywords: Agaricus augustus or Agaricus perrarus or agaritine PubMed by May 2012. Keywords: Agaricus and cadmium.

\section{References}

Andersen A, Lykke S-E, Lange M \& Bech K (1982): Sporelementer i spiselige svampe. Publikation nr. 68. Statens Levnedsmiddelinstitut: 1-27.

EFSA (2009): Cadmium in Food. Scientific Opinion of the Panel on Contaminants in the Food Chain. The EFSA Journal 980: 1-139.

EFSA (2011): Statement on tolerable weekly intake for cadmium. EFSA Panel on Contaminants in the Food Chain. The EFSA Journal 9 (2): 1975: 1-19.

EFSA (2012): Scientific Report of EFSA. Cadmium dietary exposure in the European population. The EFSA Journal 10(1): 2551: 1-37.

EU Commission (2006): Regulation (EC) No 1881/2006 of 19 December 2006 setting maximum levels for certain contaminants in foodstuffs. OJ L 364, 20.12.2006: p 5 (Amended).

Gry J, Hansen EV \& Pedersen E (1988): Ager-Champignon og andre gulnende champignoner bør spises med måde. Svampe 18: 69-70. 
Hansen EV, Gry J \& Andersen A (1987): Rat studies on the bioavailability of cadmium from mushrooms. Report from the National Food Institute.

IARC (1993): International Agency for Research on Cancer. Berylium, cadmium, mercury, and exposures in the glass manufacturing industry 58: 119-237.

IARC (2012): International Agency for Research on Cancer. Arsenic, metals, fibres, and dusts. A review of human carcinogens. Cadmium and cadmium compounds 100C: $121-145$.

Index Fungorum/Species Fungorum (2012): http://www.indexfungorum.org

Knudsen H \& Vesterholt J (2012): Funga Nordica. Agaricoid, boletoid, clavarioid, cyphelloid and gastroid genera. Nordsvamp: 1-1083.

Kruse H \& Lommel A (1979): Untersuchungen über Cadmiumbindende Proteine im Schaf-Champignon (Agaricus arvensis Schff. ex Fr.). Zeitschrift für LebensmittelUntersuchung und - Forschung 168: 444-447.

Laub E, Waligorski F \& Woller R (1977): Über die Cadmiumanreicherung in Champignons). Zeitschrift für Lebensmittel-Untersuchung und - Forschung 164: 269-271.

Lind Y, Glynn AW, Enman J \& Jorhem L (1995): Bioavailability of cadmium from crab hepatopancreas and mushroom in relation to inorganic cadmium: A 9-week feeding study in mice. Food Chemical Toxicology 33: 667-673.

Lodenius M, Kuusi T, Laaksovirta K, Liukkonen-Lilja H \& Piepponen S (1981): Lead, cadmium and mercury contents of fungi in Mikkeli, SE Finland. Annales Botanici Fennici 18: 185-186.

Meisch H-U, Schmitt JA \& Reinle W (1977): Schwermetalle in höheren Pilzen Cadmium, Zink and Kupfer. Zeitschrift für Naturforschung 32c: 172-181.

Meisch H-U, Schmitt JA \& Scholl A-R (1979): Growth simulation by cadmium in the mushroom Agaricus abruptibulbus. Naturwissenschaften 66: 209.

Meisch H-U, Beckmann I \& Schmitt JA (1983): A new cadmium-binding phosphoglycoprotein, cadmium-mycophosphatin, from the mushroom, Agaricus macrosporus. Biochimica et Biophysica Acta 745: 259-266.

Meisch H-U \& Schmitt JA (1986): Characterization studies on cadmiummycophosphatin from the mushroom Agaricus macrosporus. Environmental Health Perspectives 65: 29-32.

Mowitz J (1980): Höga halter cadmium i vildväxande svenska champinjoner. Vår Föda 5: 270-278.

Schellmann B, Hilz M-J \& Opitz O (1980): Cadmium- und Kupferausscheidung nach Aufname von Champignon-Mahlzeiten. Zeitschrift für Lebensmittel-Untersuchung und - Forschung 171: 189-192.

Schellmann B, Rohmer E, Schaller K-H \& Weltle D (1984): Concentration of cadmium and copper in feces, urine and blood after ingestion of wild mushrooms. Zeitschrift für Lebensmittel-Untersuchung und - Forschung 178: 445-449.

Schulzova V, Hajslova, J, Peroutka R, Hlavasek J, Gry J \& Andersson HC (2009): Agaritine content of 53 Agaricus species collected from nature. Food Additives and Contaminants 26: 82-93.

Seeger R(1978): Cadmiun in Pilzen. Zeitschrift für Lebensmittel-Untersuchung und Forschung. 66: 23-34.

Seeger R (1982): Toxische Schwermetalle in Pilzen. Deutsche Apotheker Zeitung 122: 1835-1844.

Seeger R, Schiffelbein F, Sauffart R \& Sant W (1986): Absorption of cadmium ingested with mushrooms (Abstract 110). Archives of Pharmacology 332 supplement: R28. 
Stijve T \& Besson R (1976): Mercury, cadmium, lead and selenium content of mushroom species belonging to the genus Agaricus. Chemosphere 2: 151-158.

Stijve T \& Pittet A (2000): Absence of agaritine in Pleurotus species and in other cultivated and wild-growing mushrooms not belonging to the genus Agaricus. Deutsche Lebensmittel-Rundschau 96: 251-254.

Stijve T, Fumeaux R \& Philippossian G (1986): Agaritine, a phydroxymethylphenylhydrazine derivative in cultivated mushrooms (Agaricus bisporus), and in some of its wild-growing relatives. Deutsche LebensmittelRundschau 82: 243-248.

Woggon H \& Bickerich K (1978): Zum Vorkommen von Toxischen Schwermetallen (Cadmium, Blei, Zink und Quecksilber) in Pilzen. Die Nahrung 22: 13-15. 


\section{Agaricus bisporus (J.E. Lange) Imbach (A. hortensis (Cooke) S. Imai, A. brunnescens Peck)}

Cultivated Mushroom (Button Mushroom) (DK: Have-Champignon, (Hvid Have-Champignon, Brun Have-Champignon, "Champignon", "Portobello"), FI: Viljelyherkkusieni, IS: Matkempa (matkempingur), NO: Dyrket sjampinjong ("Aromasopp", "Portobello"), SE: Trädgårdschampinjon (Odlade former av Trädgårdchampinjon, Vit Trädgårdschampinjon, Brun Trädgårdschampinjon, "Champinjon", "Portobello").

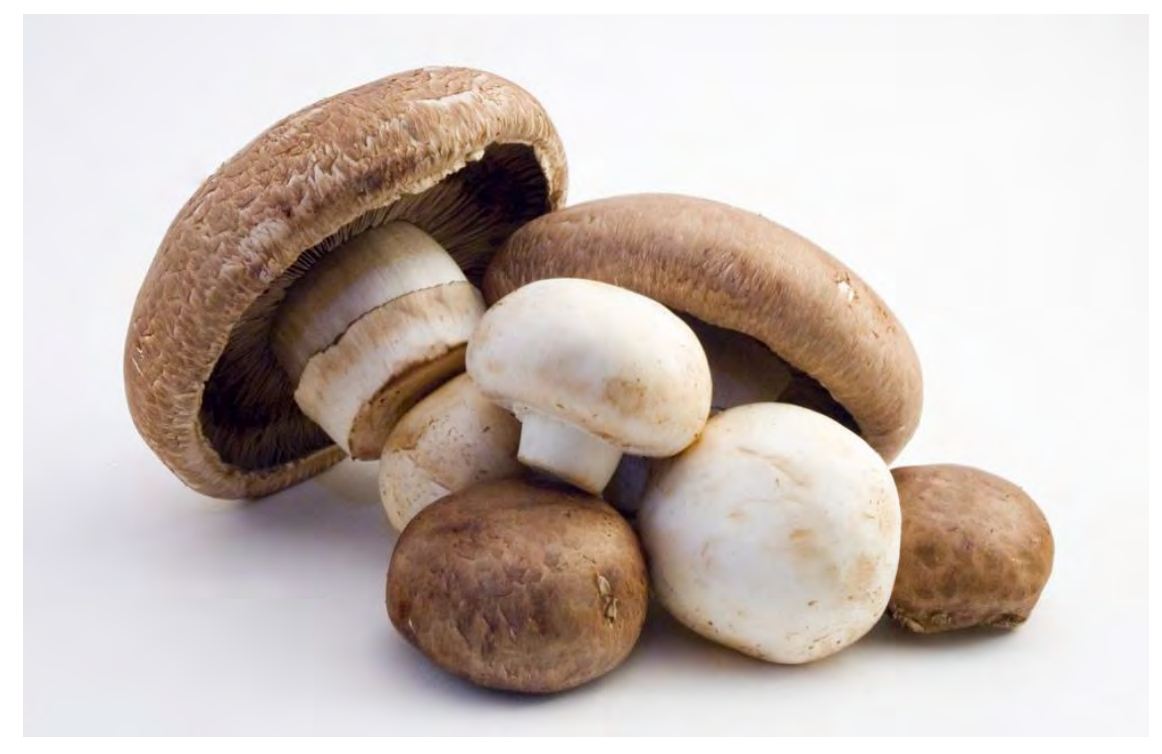

\section{Background and hazard identification}

Cultivated Mushroom (Button Mushroom) (Agaricus bisporus) is the most commonly cultivated and consumed mushroom. In 1997, the year from which the latest world production figures were found, it was cultivated in 2 million tons (Chang \& Miles, 2004). Several different varieties/forms can be found on the market, for example varieties with smaller white or brown caps (buttons) and those with larger brown caps ("Portobello"). Button Mushroom is commercially available as fresh, canned, dried, or otherwise processed.

In the wild, Button Mushroom is native to grasslands in Europe and North America. It is occasionally found from summer to autumn in Denmark, and in hemiboreal southern parts of the Nordic countries. It is likely that Button Mushroom found in the nature often originates from 
mycelia established from waste from cultivated specimens (Knudsen \& Vesterholt, 2012).

No acute intoxications are known after consumption of Button Mushroom, except for very rare cases of allergic reactions (with potential crossreactivity to moulds and spinach) (Pelzer, 2000; Dauby et al., 2002; Hegde et al., 2002; Herrera et al., 2002; Venkatesh \& Hegde, 2003; Hegde \& Venkatesh, 2004; Herrera-Mozo et al., 2006; Ho \& Hill, 2006).

As allergy was not dealt with in the Nordic report (Andersson \& Gry, 2004) being the background for the present risk assessment, the few cases of food allergy known are described in the hazard characterization. Mushroom growers disease, related to the cultivation of Button Mushroom, is described in Volume II, section 1, Annex V.

Between the early 1960s and the middle of the 1980s phenylhydrazine derivatives were identified in the Button Mushroom. These findings raised concern as the majority of all known hydrazines are genotoxic and carcinogenic agents. The concern was confirmed in subsequent carcinogenicity studies in mice. The potential human cancer risk was addressed in three Nordic reports on phenylhydrazines in the Button Mushroom (Gry \& Pilegaard, 1990/1991; Gry \& Andersson, 1998 and Andersson \& Gry, 2004). The latest mentioned report stated, that it cannot be excluded that consumption of Button Mushroom constitutes a cancer risk for the consumer.

The most abundant phenylhydrazine derivative in Button Mushroom is agaritine ( $\beta-\mathrm{N}-[\gamma-\mathrm{L}(+)$-glutamyl]-4-(hydroxymethyl)phenylhydrazine), which usually occurs in quantities between 200 and $400 \mathrm{mg}$ per $\mathrm{kg}$ in the fresh mushroom; sometimes levels as low as $80 \mathrm{mg}$ per kg or as high as 1,700 mg per kg have been found. One of the anticipated metabolites of agaritine, the 4-(hydroxymethyl)phenyldiazonium ion (HPD), is believed to be the most potent phenylhydrazine derivative in Button Mushroom but it occurs at low levels, between 0.6 and $4 \mathrm{mg}$ per $\mathrm{kg}$ fresh weight. The other phenylhydrazine derivatives in the mushroom are 4-(carboxy)phenylhydrazine (CPH; $10-11 \mathrm{mg}$ per kg fresh weight) and $\beta$ - $\mathrm{N}-[\gamma-\mathrm{L}(+)$-glutamyl]4-(carboxy)phenylhydrazine (GCPH; 16-42 mg per kg fresh weight) (Andersson \& Gry, 2004).

More recent studies have confirmed these observations, reporting levels between 200 and 1,800 mg agaritine per kg fresh weight of the mushroom (Kondo et al., 2006a, 2006b, Nagaoka et al., 2006; Koge et al., 2011). However, Nagaoka et al. (2006) did not find CPH in the Button Mushroom. Sommer et al. (2009) reported around 1,500 mg agaritine per kg fresh Agaricus bisporus. The spores from Button Mushroom have been shown to contain in average 3,040 mg agaritine per kg of spores (Janák et al., 2005). 
The structural formulae of the phenylhydrazine derivatives in the Button Mushroom and one of the potential metabolites, 4-(hydroxymethyl)phenylhydrazine (HPH) are shown below.<smiles>NC(CCC(=O)NNc1ccc(C(O)O)cc1)C(=O)O</smiles>

Agaritine<smiles>CC(Cl)(Cl)CCCCCOC(=O)c1ccc(N)cc1</smiles><smiles>N#[N+]c1ccc(CO)cc1</smiles>

4-(Hydroxymethyl)phenyldiazonium (HPD)<smiles>NC(CCC(=O)NNc1ccc(C=O)cc1)C(=O)O</smiles> 


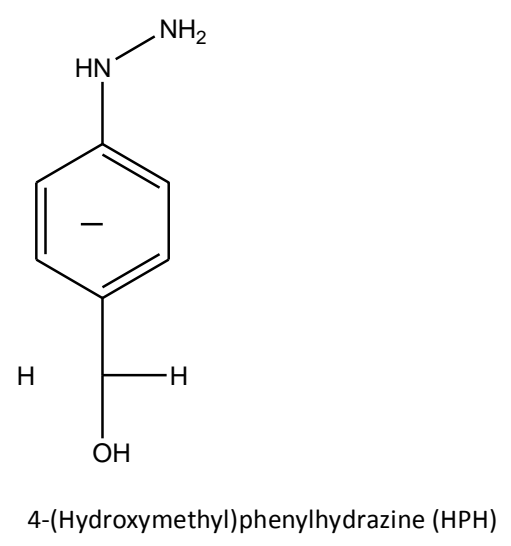

The body of the text that follows is based on data and conclusions from the Nordic report: "Phenylhydrazines in the Cultivated Mushrooms (Agaricus bisporus)" by Andersson \& Gry (2004). Newer data which have been published after this report are highlighted and referenced, and contribute to this updated risk assessment.

\section{Hazard characterisation}

The Nordic report presented the information available at the time regarding absorption and metabolism of agaritine, the acute, sub-chronic and developmental toxicity as well as DNA-binding, genotoxicity, and carcinogenicity of agaritine and other phenylhydrazines occurring in the Bottom Mushroom. In addition carcinogenicity data on mice fed raw, baked or cooked Button Mushrooms were reviewed. This information is briefly summarized below together with more recent data; more detailed information can be found in the Nordic report (Andersson \& Gry, 2004). In addition, available information on the allergenicity of the Button Mushroom is presented.

\section{Allergenicity}

A few cases of allergenicity due to the Button Mushroom have been described during the last decade. Hegde et al. (2002) described a severe case of anaphylaxis in an Indian woman who experienced facial oedema and generalized urticaria minutes after eating Button Mushroom curry. Skin prick tests with mushroom extracts prepared from raw, cooked, steamed or dried mushrooms were strongly positive, but surprisingly no mushroom specific IgE could be detected by enzyme-linked immunosorbent assay. Separation of mushroom constituents and testing each fraction in skin prick tests revealed that the allergen was mannitol, a sugar alcohol with very low molecular weight $(<1 \mathrm{kDa})$. Subsequently, 
Hegde and Venkatesh (2004) identified mannitol-specific human IgE and showed that they were specific to the D-isomer of mannitol. As mannitol is inert and cannot react with proteins to form hapten-carrier conjugates and elicit immune response, Venkatesh and Hegde (2003) hypothesised an alternative mechanism for the allergenicity. It was suggested that Dmannose reacts in vivo with exposed amino groups of proteins, forming Schiff base intermediates bearing a D-mannitoyl moiety, which closely resembles D-mannitol. The intermediate elicits the formation of mannitol-specific IgE in susceptible individuals. Once an individual is sensitized with the formation of mannitol-specific IgE, mannitol can cause anaphylactic reactions by acting either as a univalent anaphylactogen or a bivalent hapten.

Ho and Hill (2006) reported a person being allergic to the Button Mushroom (and the Field Mushroom, Agaricus campestris). Dishes containing these mushrooms as well as cooking vapours from processing resulted in discomfort in the mouth, itchy ears, nausea, diaphoresis and discomfort in the throat. Skin prick tests with Agaricus extracts gave positive reaction. Two other cases of allergy to Button Mushroom were described by Pelzer (2000). In both these cases symptoms including abdominal pain developed after intake of cooked mushrooms. Dauby et al. (2002) studied the antigenic cross-reactivity between Button Mushroom and mould spores (positive skin testing to moulds) in a patient with oral allergy symptoms to raw but not to cooked Button Mushroom. Skin prick tests with extracts of the raw Button Mushroom and four different moulds, and immune-blot assays revealed $\operatorname{IgE}$ antibodies directed against similar weight proteins (43 and $67 \mathrm{kDa}$ ) in the raw mushroom and three of the four moulds. These antigens were absent in the cooked mushroom.

A case of cross-reactivity resulting in food allergy to spinach and mushrooms has been described in a woman with persistent allergic asthma to airborne moulds (Herrera et al., 2002). Antibodies in the serum recognized a $22 \mathrm{kDa}$ large protein in extracts of the Button mushroom. Coadministration of a spinach extract or a mould extract inhibited this reaction. Subsequently the same investigators screened a group of atopic patients allergic either to moulds $(n=33)$ or to mites and/or pollen $(n=13)$ by immuno-blotting extracts from three moulds and the Button Mushroom. The analysis of the data revealed a link between allergenicity to moulds and positive skin prick tests with extracts from the Button Mushroom and/or spinach. Seven patients allergic to moulds had a strong recognition of a protein with a molecular weight of about $30 \mathrm{kDa}$ present both in spinach and mushroom extracts. The investigators concluded that a novel 
cross-reactive allergen between aeroallergens and foods had been identified (Herrera-Mozo et al., 2006).

It is concluded that only a few cases of allergy due to Button Mushroom consumption have been described. It has also been established that cross reactivity between Button Mushroom and spinach or moulds is possible.

\section{Absorption and metabolism}

Studies in experimental animals (rodents) using radio-labelled agaritine have shown that the compound and/or its degradation products are rapidly absorbed from the gastrointestinal tract. Blood levels of radioactivity were shown to peak within a few hours. No major qualitative differences in the pharmacokinetic behaviour of agaritine in rat and mouse have been observed, and, furthermore, the metabolic profile of agaritine seems to be the same in both species.

Recently Kondo and co-workers (2006a; 2008) noted that plasma levels of agaritine as determined by a sensitive LC/MS/MS method peaked at around 20 minutes after oral dosing of mice and then returned to basal levels at around 100 minutes. At the highest dose tested ( $40 \mathrm{mg}$ per kg body weight), the maximum concentration was $0.37 \mathrm{mg} / \mathrm{L}$, the time to the maximum concentration $0.33 \mathrm{~h}$, and the plasma half-life of agaritine $0.71 \mathrm{~h}$. These investigators were also able to detect in vitro the metabolite HPH after incubation of agaritine with $\gamma$-glutamyltransferase. This enzyme is present in various tissues of the body and is believed to cleave agaritine into L-glutamic acid and HPH. The latter compound is subsequently transformed to HPD that is believed to produce reactive radical species able to damage macromolecules.

\section{Acute and sub-chronic toxicity}

Very little is known about the potential acute and sub-chronic toxicity of the phenylhydrazines occurring in the Button Mushroom. According to the few and poor studies available, CPH and its $\gamma$-glutamyl derivative GCPH are significantly less toxic than other phenylhydrazines occurring in the mushroom.

Nieminen and co-workers (2009) have published a study on the potential myo- and hepatotoxic effects of different cultivated mushrooms in mice. The animals (six females per group) were for 5 days supplied large quantities of dried and powdered cultivated mushrooms in the feed. One of the cultivated mushrooms, Button Mushroom, was given as 1.8\%, 3.6\% or $5.4 \%$ of the feed. The feeding resulted in exposures corresponding to 24,46 and $69 \mathrm{~g}$, respectively, which is equivalent to $1.7,3.2$ or $4.9 \mathrm{~kg}$ per person $(70 \mathrm{~kg}$ ) per day, or when corrected for body surface constant 141 
g, $270 \mathrm{~g}$ or $404 \mathrm{~g}$ per person $(70 \mathrm{~kg}$ ) per day, respectively, of fresh Button Mushroom. All mice were healthy at the end of the study. Of the many clinical parameters studied, plasma bilirubin (indicator of liver damage) was significantly increased in a dose dependent manner. As creatine kinase (indicator of myopathy) was significantly increased only at the lowest dose level, this observation is likely to have been incidental. No histological pathological changes in studied organs were found.

\section{Developmental toxicity}

There are no indications that Button Mushroom or the phenylhydrazines occurring in the mushroom are embryotoxic or teratogenic in mammals at biologically relevant doses. However it should be stressed, that the design of the few studies available did not follow modern guidelines for these types of studies.

\section{DNA-binding and genotoxicity}

A low frequency of DNA damage has been observed in various tissues of experimental animals exposed orally to agaritine or HPD, observations indicating that these compounds may be genotoxic and possibly carcinogenic. This interpretation is supported by the observation that Button Mushroom extracts, as well as agaritine and the other phenylhydrazines occurring in this mushroom slightly increase the mutation frequency in bacterial test systems in vitro.

Recent in vivo studies in mice have revealed that the oxidative stress marker 8-OHdG increased significantly in the urine of agaritine treated mice (Kondo et al., 2008). Furthermore, in in vitro studies on the mechanism of action of the potential carcinogen CPH, Oikawa et al. (2006) showed that the compound induced DNA damage via hydrogen peroxide formation (oxidative damage) and DNA adducts via a $\mathrm{Cu}(\mathrm{II})$-dependent reaction, the latter possibly via phenyl-radical forming adducts with adenine and guanine. These new studies, as well as the observation that agaritine induces gene mutations in transgenic mice, and that HPD induces micronuclei in peripheral lymphocytes (Andersson \& Gry, 2004) indicate that DNA lesions of potential importance for tumour induction may be formed by the phenylhydrazines in the Button Mushroom. 


\section{Carcinogenicity}

Nine out of twelve carcinogenicity studies with the Button Mushroom or its phenylhydrazine constituents have shown carcinogenic effect in Swiss albino mice, whereas two studies in rats did not increase the tumour level compared to the controls.

Studies in mice: In 3 out of 4 peroral long-term studies tumours were induced in various tissues of mice fed raw, baked, or freeze-dried Button Mushroom. In the study with raw mushrooms an estimated average daily exposure of $4.7 \mathrm{~g}$ mushroom per mouse gave rise to a $38 \%$ increase in forestomach tumours (Toth \& Erickson, 1986). With baked mushrooms an exposure of $5.6 \mathrm{~g}$ mushrooms per mouse gave rise to a $20 \%$ increase in glandular stomach tumours (Toth et al., 1997a). With the freeze-dried mushrooms an exposure of $12 \mathrm{~g}$ freeze-dried mushrooms per kg body weight per day in mouse gave rise to a $22 \%$ increase in lung tumours (Toth et al., 1998). In a fourth study with baked mushrooms which had another (more balanced) feeding schedule, the increase in tumour incidence was not significant (Toth et al., 1997b).

Three of the four phenylhydrazines known to occur in Button Mushroom, CPH, GCPH, and HPD, were carcinogenic at high doses in Swiss albino mice when administered orally by gavage or in drinking water (and also when injected subcutaneously). In the study with $\mathrm{CPH}$ an estimated average daily exposure of $204 \mathrm{mg} \mathrm{CPH}$ per kg body weight gave rise to a $38 \%$ increase in tumours of the aorta and large arteries (McManus et al. 1987). With GCPH an exposure of $149 \mathrm{mg}$ GCPH per $\mathrm{kg}$ body weight gave rise to a $26 \%$ increase in tumours in the subcutaneous tissue (Toth, 1986). With HPD an exposure of $0.50 \mathrm{mg}$ per $\mathrm{kg}$ body weight per day gave rise to a $32 \%$ increase in glandular stomach tumours (Toth et al., 1982).

The fourth phenylhydrazine, agaritine, which is the most abundant one in Button Mushroom, was not found to be carcinogenic when given in drinking water or by subcutaneous injection (Toth et al., 1981; Toth \& Sornson, 1984).

However, no precautions were taken in these studies with agaritine to protect against oxidative degradation of agaritine in water. Agaritine has been shown to be very vulnerable to such degradation in aqueous solution (Hajslova et al. 2002). The low stability of agaritine in water has also recently been shown by Koge and colleagues (2011). They showed that pure agaritine in aqueous solution is very unstable at $120{ }^{\circ} \mathrm{C}$ and decompose exponentially. Around $73 \%$ of the agaritine in an extract from the Button Mushroom was destructed after $30 \mathrm{~min}$ of heating at $120^{\circ} \mathrm{C}$. 
It should be stressed that none of the long term carcinogenicity studies in mice with Button Mushroom, or the phenylhydrazines occurring in the mushroom, have been performed according to approved standard protocols for carcinogenicity studies. Thus, all cancer studies in mice have been performed only with out-bred Swiss albino mice in a single laboratory. Furthermore, the feeding regimen of the mice with mushrooms was not considered balanced and animals were exposed to the compounds/mushrooms until they died or were found in poor condition instead of for a predetermined length of time. In addition, the control groups were usually not started at the same time as the treated groups. Although at least three dose levels are recommended in carcinogenicity studies in order to identify potential dose-response effects, this requirement was only fulfilled in one study.

Studies in rats: There was no significant increase in tumour frequencies in two long-term studies in rats, but in these rather inadequate studies the number of animals was too low to detect a small increase in tumour incidence. Furthermore, the processing (pre-treatment) of the mushrooms used in the rat studies (ordinary drying and milling, or washing, combined with pressure cooking, homogenising, and mixing with tap water) has later been shown to result in a significant degradation of the potentially active phenylhydrazines in Button Mushroom (Hajslova et al., 2002; Andersson \& Gry, 2004; Koge et al. 2011).

In a more recent rat study in F344 rats Lee and colleagues (2008) investigated the carcinogenicity of another Agaricus species (A. subrufescens; syn. A. blazei) also known to contain agaritine. A diet containing powder of lyophilized aqueous extract of the mushroom was fed for 2 years to the rats. There was no increase in tumours compared to controls. This rat study is of low relevance for the evaluation of potential carcinogenicity of the Button Mushroom, as the agaritine content in the rat feed was not analysed, and, most importantly, A. subrufescens is another species than A. bisporus and is claimed to contain anti-cancer constituents.

IARC, status: In 1983 WHO's International Agency for Research on Cancer concluded that "There is limited evidence of the carcinogenicity of the derivatives of two fungal metabolites of agaritine in experimental animals. In the absence of epidemiological data, no evaluation of the carcinogenicity of agaritine to humans could be made" (IARC, 1983) and in 1987 Group 3 (IARC, 1987) "not classifiable as to its carcinogenicity to humans."

Roupas et al. statement: Recently, Roupas et al. (2010) concluded in "Mushrooms and agaritine" that "critical analysis of the studies to date leads to the conclusion that consumption of A. bisporus and other edible mushrooms does not result in any known toxicological or carcinogenic 
effects in healthy humans." Although these investigators have considered some of the studies referred to in the Nordic report "Phenylhydrazines in the Cultivated Mushroom (Agaricus bisporus)" and in the present risk assessment, they mainly base their conclusion on clinical trials lasting up to one year on patient groups with different diseases using other mushroom species than Button Mushroom. Such studies are not very relevant for the estimation of potential human cancer risk due to consumption of Button Mushroom.

Although it is difficult to conclude on the carcinogenic potential of Button Mushroom due to the shortcomings in the way the carcinogenicity studies in rodents have been performed, the comprehensive set of data on raw and on processed Button Mushroom and on the phenylhydrizine derivatives occurring in the mushroom indicates that this mushroom is carcinogenic in mice.

\section{Exposure assessment}

The estimated annual per capita intake of Button Mushroom (Agaricus bisporus) varies between the Nordic countries. Based on data available in 2004 it was $0.6 \mathrm{~kg}$ in Finland, $1.7 \mathrm{~kg}$ in Norway, $2.1 \mathrm{~kg}$ in Iceland, 2.2 $\mathrm{kg}$ in Denmark and $2.4 \mathrm{~kg}$ in Sweden. The proportion of the purchased Button Mushroom being the fresh mushroom varied between 33 and $70 \%$ among the countries, the rest being preserved, mainly canned, mushrooms (Andersson \& Gry, 2004).

Since the per capita intake is an estimation of average intake and does not take into consideration that mushrooms usually are consumed only by a part of the population, the per capita consumption is too low to express the consumption among mushroom eating consumers. For instance Danish data, based on a limited consumer study, indicate that only around $50 \%$ of the population consumes Button Mushroom, and that $5 \%$ of the population consumes five times the median intake and $0.1 \%$ thirty times the median intake (Andersson \& Gry, 2004).

As mentioned in the hazard identification, the potentially toxic compounds in Button Mushroom are the phenylhydrazine derivatives. Agaritine occurs in quantities between 80 and 1,800 mg per $\mathrm{kg}$ fresh weigh (usually between 200 and $400 \mathrm{mg} / \mathrm{kg}$ fresh mushroom). The anticipated metabolite of agaritine, HPD, occurs at low levels (0.6-4 mg per $\mathrm{kg}$ fresh weight). The other phenylhydrazine derivatives in the mushroom are CPH (10-11 mg per kg fresh weight) and GCPH (16-42 mg/kg fresh weight) (Andersson \& Gry, 2004; Koge et al., 2011; Kondo et al., 2006a; b; Nagaoka et al., 2006). 
Data on the influence of food processing on the amounts of phenylhydrazines in the consumed mushroom are scanty. Properly freezedried mushrooms seem to contain similar agaritine levels as fresh mushrooms, whereas ordinary frozen and then thawed, boiled, microwave heated, and fried mushrooms contain reduced levels (Schulzova et al., 2002; Andersson \& Gry, 2004). Canned mushrooms only contain up to $10 \%$ of the agaritine level in fresh mushrooms (Andersson \& Gry, 2004; Kondo et al., 2006b).

Taken together these data allow a rough estimation of the daily per capita exposure to these phenylhydrazines in the Nordic countries. Agaritine is used as a representative of these phenylhydrazines. With a content of 200-400 mg agaritine per kg fresh non-processed Button Mushroom the daily per capita intake of agaritine in Finland, having the lowest Button Mushroom intake in the Nordic countries, would be 0.33$0.66 \mathrm{mg}$, whereas the daily per capita intake by a consumer in Sweden, having the highest intake of Nordic countries, would to $1.3-2.6 \mathrm{mg}$ agaritine. Consumers having preference for Button Mushroom would be exposed to considerably higher amounts of agaritine. However, as processing reduces the level of agaritine in the fresh Button Mushroom, average intake estimates based on the raw mushroom would be a worst case scenario.

\section{Risk characterisation}

Carcinogenicity. As described in the hazard characterization it has been experimentally shown that Button Mushroom and some of its phenylhydrazine constituents may give rise to DNA damage of concern, e.g. mutations of relevance for the development of tumours. This indicates that the carcinogenic effects observed in mice fed raw mushrooms, processed mushrooms or the various phenylhydrazines found in the mushroom have been induced by a genotoxic mechanism. For genotoxic and carcinogenic compounds it is generally believed that even low exposures may constitute a cancer risk. The results of the carcinogenicity studies in mice and the estimated information on the exposures were used for the following quantitative risk assessment of cancer induction from consumption of Button Mushroom in the Nordic countries.

Human exposure. The estimation of the human exposure of Button Mushroom (per capita intake) is based on information on production data. The lowest intake was registered for Finland $(0.6 \mathrm{~kg} /$ person/year), whereas the other Nordic countries on average consumed around $2.1 \mathrm{~kg} /$ person/year. 
However, these consumption estimates suffer from a number of shortcomings. It is for instance indicated, as mentioned above, that, around half of the Danish adult population claims not to consume Button Mushroom, $5 \%$ eat more than five times the median intake and $0.1 \%$ thirty times more than the median intake. This means that sub-populations of "high" consumers in the Danish example would have maybe 5 or 30 times higher cancer risks than the average consumer. As described in the hazard characterization, Button Mushroom may contain levels of agaritine between 80 and 1,800 mg per $\mathrm{kg}$ fresh mushroom (usually 200-400 mg per kg), whereas the levels of the other phenylhydrazine derivatives are lower: HPD between 0.6 and $4 \mathrm{mg}$ per kg fresh weight, CPH 10-11 mg per kg fresh weight and GCPH 16-42 mg per kg fresh weight. These data only allow a rough estimation of the average daily intake of the various mushroom phenylhydrazines by the consumers.

Exposure levels in carcinogenicity studies. As given by the hazard characterization, the carcinogenicity study with the raw Button Mushroom in mice resulted in an estimated average daily exposure of $4.7 \mathrm{~g}$ mushrooms per mouse and gave rise to a $38 \%$ increase in forestomach tumours. The carcinogenicity study with baked Button Mushroom resulted in an exposure of $5.6 \mathrm{~g}$ mushrooms per mouse per day and gave rise to a $20 \%$ increase in glandular stomach tumours. The study with freeze-dried mushrooms led to an average exposure of $12 \mathrm{~g}$ freeze-dried mushrooms per kg body weight per day and resulted in a $22 \%$ increase in lung tumours. Three of the four phenylhydrazines known to occur in Button Mushroom - CPH, GCPH, and HPD - were carcinogenic in mice at high doses when administered orally by gavage or in drinking water. In the study with $\mathrm{CPH}$ an estimated average daily exposure of $204 \mathrm{mg} \mathrm{CPH}$ per kg body weight gave rise to a $38 \%$ increase in tumours of the aorta and large arteries. With GCPH an exposure of $149 \mathrm{mg} \mathrm{GCPH}$ per kg body weight gave rise to a $26 \%$ increase in tumours in the subcutaneous tissue, and with HPD an exposure of $0.50 \mathrm{mg}$ per kg body weight per day gave rise to a $32 \%$ increase in glandular stomach tumours. The fourth phenylhydrazine, agaritine, which occurs in largest amount, was not found to be carcinogenic when given in drinking water (or by subcutaneous injection). However no precautions were taken in these studies to protect against oxidative degradation of agaritine in water. Agaritine has more recently been shown to be very vulnerable to such degradation in aqueous solution.

Quantitative risk assessment. Based on the experimental data available from the cancer studies in mice and from human exposure data a quantitative risk assessment was performed. Several assumptions were 
made. One was that it is possible to perform a linear extrapolation from the high exposure levels in mice to the lower human exposure levels. Other assumptions included that man and mouse have the same metabolism and sensitivity, that the weight of a mouse is on average $25 \mathrm{~g}$ and that of a human $70 \mathrm{~kg}$, and that the survival of animals exposed to the tested compound/food is comparable to the survival of the control animals. Furthermore, the influence of processing on phenylhydrazine content of mushrooms was not taken into consideration.

Based on the studies with raw, baked and lyophilized Button mushroom fed to mice and the available information and assumptions made, an estimated life-time cancer risk of approximately 110 to 250 extra cancer cases per one million average consumers in Denmark, Iceland, Norway and Sweden can be calculated. The risk for Finnish average consumers will be lower. A linear extrapolation of the cancer data in mice for the three phenylhydrazines occurring in the Button Mushroom ( $\mathrm{CPH}$, GCPH and HPD) would result in risks from 2 to 200 extra cancer cases per million average consumers during lifetime. Overall, a risk of 2-250 extra cancer cases during lifetime per million Nordic average consumers can be estimated.

Uncertainties: There are uncertainties related to the design of the carcinogenicity studies, to the exposure assessments, to the use of linear extrapolation and to the assumptions required to perform the quantitative risk assessment. This results in a very conservative assessment (worst case).

Conclusion: It is indicated that Button Mushroom and some of its phenylhydrazine constituents may give rise to cancer in mice, presumably via a genotoxic mechanism. Therefore it cannot be excluded, that consumption of Button Mushroom may constitute a risk for humans.

\section{Recommendation}

As it is concluded from animal and in vitro studies that the phenylhydrazine derivatives occurring in Button Mushroom (A. bisporus) as well as the mushroom itself may be genotoxic and carcinogenic, a carcinogenic risk for humans cannot be excluded.

It is therefore recommended not to eat Button Mushroom in larger amounts. The average consumption has been estimated to be 1-2 kg per person per year in the Nordic countries (Andersson \& Gry, 2004).

Proper processing of the fresh mushroom reduces the amounts of potentially carcinogenic constituents. The fried, microwave-heated, boiled (especially if boiling water is discarded), and canned mushrooms contain significantly less of the potentially carcinogenic phenylhydrazines. Also 
ordinary freezing and subsequent thawing (but not freeze-drying) will reduce the content of phenylhydrazines in the mushroom.

It is therefore recommended to process/cook Button Mushroom before consumption.

Listing 1

\section{Database search information}

SciFinder by January 2012. Keywords: Agaritine. Agaricus bisporus. PubMed by January 2012: Keywords: Agaritine.

\section{References}

Andersson HC \& Gry J (2004): Phenylhydrazines in the cultivated mushroom (Agaricus bisporus).TemaNord 558: 1-123.

(www.norden.org/da/pubkijationer/publikationer/2004-558).

Chang S-T \& Miles PG (2004): Mushrooms. Cultivation, Nutritional value, Medicinal effect, and Environmental Impact. CRC Press, Boca Raton: 1-351.

Dauby PA, Whisman, BA \& Hagan L (2002): Cross-reactivity between raw mushroom and moulds in a patient with oral allergy syndrome. Annals of Allergy, Asthma \& Immunology 89: 319-321.

Gry J \& Andersson C (1998): Nordic Seminar on Phenylhydrazines in the Cultivated Mushroom (Agaricus bisporus). TemaNord 539: 1-48.

Gry J \& Pilegaard K (1990/1991): Hydrazines in the Cultivated Mushroom (Agaricus bisporus). The Nordic Working Group on Food Toxicology and Risk Evaluation. Nordic Council of Ministers. Technical Report 3/90:1-38/Vår Föda 43 Supplement 1: 1-38.

Hajslova J, Hajkova L, Schulzova V, Frandsen H, Gry J \& Andersson HC (2002): Stability of agaritine - a natural toxicant of Agaricus mushrooms. Food Additives and Contaminants 19: 1028-1033.

Hegde VL \& Venkatesh, YP (2004): Anaphylaxis to excipient mannitol: evidence for an immunoglobulin E-mediated mechanism. Clinical and Experimental Allergy 34: 1602-1609.

Hegde VL, Das JR \& Venkatesh YP (2002): Anaphylaxis caused by the ingestion of cultivated mushroom (Agaricus bisporus): Identification of allergen as mannitol. Allergology International 51: 121-129.

Herrera I, Moneo, I, Caballero ML, de Paz S, Perez Pimiento A, \& Rebollo, S (2002): Food allergy to spinach and mushroom. Allergy 57: 261-262.

Herrera-Mozo I, Ferrer B, Luís Rodriguez-Sanchez J \& Juarez C (2006): Description of a novel panallergen of cross-reactivity between moulds and foods. Immunological Investigations 35: 181-197.

Ho MH \& Hill DJ (2006): White Button Mushroom food hypersensitivity in a child. Journal of Paediatrics and Child Health 42: 555-556.

IARC (1983): International Agency for Research on Cancer. Monographs on the Evaluation of Carcinogenic Risks to Humans, Some Food Additives, Feed Additives and Naturally Occurring Substances. Agaritine (L-glutamic acid, 5[2-(4hydroxymethyl)-phenylhydrazid]) IARC Monographs 31: 63-69. 
IARC (1987): International Agency for Research on Cancer. Monographs on the Evaluation of the Carcinogenic Risks to Humans. Overall Evaluations of Carcinogenicity: An Updating of IARCs Monographs Volume 1-42, Supplement 7: 56.

Janak K, Størmer FC \& Koller GEB (2006): The content of agaritine in spores from Agaricus bisporus. Food Chemistry 99: 521-524.

Knudsen H \& Vesterholt J (2012): Funga Nordica. Agaricoid, boletoid, clavarioid, cyphelloid and gastroid genera. Nordsvamp: 1-1083.

Koge T, Komatsu W \& Sorimachi K (2011): Heat stability of agaritine in water extracts from Agaricus blazei and other edible fungi, and removal of agaritine by ethanol fractionation. Food Chemistry 126: 1172-1177.

Kondo K, Watanabe A, Iwanaga Y, Abe I, Tanaka H, Nagaoka MH, Akiyama H, Maitani $\mathrm{T}$ (2006a): Analysis of agaritine in mushrooms and in agaritine-administered mice using liquid chromatography-tandem mass spectrometry. Journal of Chromatography B 834: 55-61.

Kondo K, Watanabe A, Iwanaga Y, Abe I, Tanaka H, Nagaoka MH, Akiyama H \& Maitani T (2006b): Determination of genotoxic pheylhydrazine agaritine in mushrooms using liquid chromatography-electrospray ionization tandem mass spectrometry. Food Additives and Contaminants 23: 1179-1186.

Kondo K, Watanabe A, Akiyama H \& Maitani T (2008): The metabolisms of agaritine, a mushroom hydrazine in mice. Food and Chemical Toxicology 46: 854-862.

Lee IP, Kang BH, Roh JK \& Kim JR (2008): Lack of carcinogenicity of lyophilized Agaricus blazei Murill in a F344 rat two year bioassay. Food and Chemical Toxicology 46: 87-95.

McManus BM, Toth B \& Patil K (1987): Aortic rupture and aortic smooth muscle tumors in mice. Induction by $p$-hydrazinobenzoic acid hydrochloride of the cultivated mushroom Agaricus bisporus. Laboratory Investigation 57: 78-85.

Nagaoka MH, Nagaoka H, Kondo K, Akiyama H, \& Maitani T (2006): Measurement of a genotoxic hydrazine, agaritine, and its derivatives by HPLC with fluorescence derivatization in the Agaricus mushroom and its products. Chemical \& Pharmaceutical Bulletin 54: 922-924.

Nieminen P, Kärjä V \& Mustonen A-M (2009): Myo- and hepatotoxic effects of cultivated mushrooms in mice. Food and Chemical Toxicology 47: 70-74.

Oikawa S, Ito T, Iwayama M. \& Kawanishi S (2006): Radical production and DNA damage induced by carcinogenic 4-hydrazinobenzoic acid, an ingredient of mushroom Agaricus bisporus. Free Radical Research 40: 31-39.

Pelzer A (1999): Soforttypallergie auf Champignon. Allergologie 23: 35-36.

Roupas P, Keogh J, Noakes M, Margetts C \& Taylor P (2010): Mushrooms and agaritine: a mini-review. Journal of Functional Foods 2: 91-98.

Schulzova V, Hajslova J, Peroutka R, Gry J \& Andersson HC (2002): Influence of storage and household processing on the agaritine content of the cultivated Agaricus mushroom. Food Additives and Contaminants 19: 853-862.

Schulzova V, Hajslova J, Peroutka R., Hlavasek J, Gry J \& Andersson HC (2009): Agaritine content of 53 Agaricus species collected from nature. Food Additives and Contaminants 26: 82-93.

Simeoni S, Puccetti A, Peteriana D, Tinazzi E, Lunardi C. (2004): Occupational allergic contact dermatitis from champignon and Polish mushroom. Contact Dermatitis 51: 156-157.

Sommer I, Schwartz H, Solar S \& Sontag G (2009): Effect of $\gamma$-irradiation on agaritine, $\gamma$-glutaminyl-4-hydroxybenzene (GHB), antioxidant capacity, and total phenolic 
content of mushrooms (Agaricus bisporus). Journal of Agricultural and Food Chemistry 57: 5790-5794.

Toth B (1986): Carcinogenesis by N2-[ $\gamma$-L(+)-glutamyl]-4-carboxyphenylhydrazine of Agaricus bisporus in Mice. Anticancer Research 6: 917-920.

Toth B \& Sornson H (1984): Lack of carcinogenicity of agaritine by subcutaneous administration in mice. Mycopathogia 85: 75-79.

Toth B, Erickson J, Gannet, PM (1997b): Lack of carcinogenesis by the baked mushroom Agaricus bisporus in mice: Different feeding regimen. In Vivo 11: 227.232.

Toth B, Erickson J, Gannet, PM \& Patil, K (1997a): Carcinogenesis by the cultivated baked Agaricus bisporus mushroom in mice. Oncology Reports. 4: 931-936.

Toth B, Gannett P, Visek WJ \& Patil K (1998): Carcinogenisis studies with the lyophilized mushroom Agaricus bisporus in mice. In Vivo 12: 239-244.

Toth B, Nagel D \& Ross A (1982): Gastric Tumorigenesis by a singel dose of 4(hydroxymethyl)benzenediazonium ion of Agaricus bisporus. British Journal of Cancer 46: 417-422.

Toth B, Raha CR, Wallcave L \& Nagel D (1981): Attempted tumor induction with agaritine in mice. Anticancer Research 1: 255-258.

Venkatesh YP \& Hegde VL (2003): A hypothesis for the mechanism of immediate hypersensitivity to mannitol. Allergology International 52: 165-170. 


\section{Agaricus bitorquis (Quél.) Sacc.}

Pavement Mushroom (DK: Vej-Champignon, FI: Agaricus lajin herkkusienet, IS: No Icelandic name, NO: Bysjampinjong, SE: Vägchampinjon).

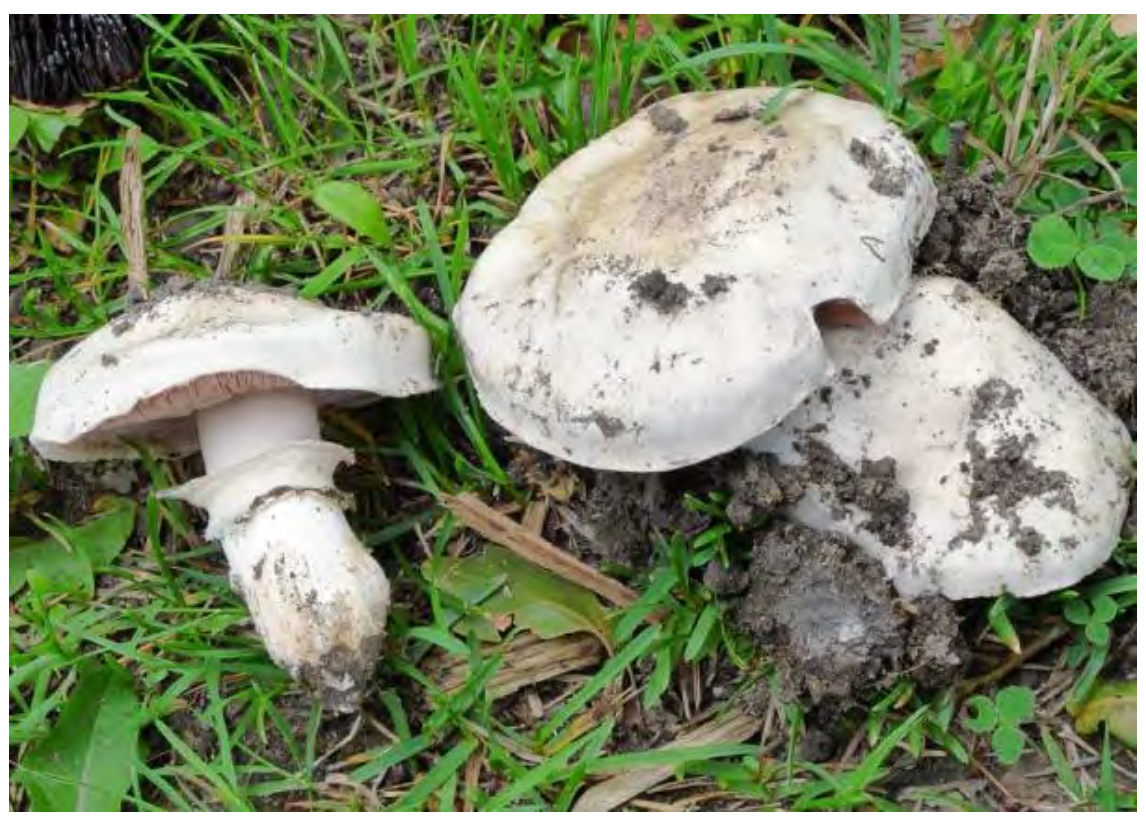

\section{Background and risk assessment}

Pavement Mushroom (Agaricus bitorquis) is generally regarded as edible and good.

It is a saprotrophic mushroom growing in dry places in cities, along roads, in gardens and parks, typically breaking up through the substrate in late spring to autumn. It is common in Denmark, occasional in southern Finland, Norway and Sweden and rare in middle boreal areas (Knudsen \& Vesterholt, 2012).

In some countries outside the Nordic countries Pavement Mushroom (A. bitorquis) is preferred for cultivation instead of the Button Mushroom (A. bisporus) (Schulzová et al., 2002; 2009).

There are no intoxications reported after consumption of Pavement Mushroom. However, Pavement Mushroom may contain very high levels of agaritine ( $\beta$ - $\mathrm{N}$-[ $\gamma$-glutamyl]-4-(hydroxymethyl)phenylhydrazine). Pavement Mushroom collected in the Czech Republic was found to contain 216-3,001 mg agaritine per kg fresh weight (11 samples, mean content $1,470 \mathrm{mg} / \mathrm{kg}$ fresh weight) (Schulzová et al., 2009), whereas Stijve and co-workers reported approximately 50-2,000 mg agaritine per $\mathrm{kg}$ 
fresh weight in mushrooms collected in different European countries (5 samples, mean content $716 \mathrm{mg} / \mathrm{kg}$ fresh weight; Stijve et al., 1986), or $1.5-2.5 \%$ of the dried mushroom being agaritine, corresponding to 1,500-2,500 mg per kg fresh weight (Stijve \& Pittet, 2000). It has been noted that the content of agaritine in cultivated strains of Pavement Mushroom is lower than in specimens collected from nature. Thus in a study on cultivated Agaricus species Schulzová et al. (2002) reported cultivated strains of Pavement Mushroom to contain 249-360 mg agaritine per kg fresh weight.

The structural formula of agaritine is shown below:<smiles>NC(CCC(=O)NNc1ccc(C(O)O)cc1)C(=O)O</smiles>

Agaritine

Agaritine, or at least its metabolites, are indicated to give rise to tumours in mice by a genotoxic mechanism. Therefore, it cannot be excluded that consumption of Pavement Mushroom, which contains considerable amounts of agaritine, may constitute a cancer risk to humans (for further information, see risk assessment of Button Mushroom, Agaricus bisporus).

Pavement Mushroom, like the Button Mushroom (A. bisporus) and Scaly Wood Mushroom (A. langei), belongs to the group of reddening Agaricus species ("Rubescentes") which may become reddish (or brownish), when cut or rubbed. Contrary to the group of yellowing Agaricus species ("Flavescentes") Pavement Mushroom and other Agaricus species from the "Rubescentes" group, the reddening Agaricus species, do not bioaccumulate the toxic metal cadmium (Laub et al., 1977; Lodenius et al., 1981; Mowitz, 1980; Seeger, 1978; 1982). 


\section{Recommendation}

Pavement Mushroom (Agaricus bitorquis):

- Due to the potentially high levels of phenylhydrazine derivatives in Pavement Mushroom, the species should not be eaten in larger amounts (see the risk assessment of Button Mushroom, Agaricus bisporus).

Listing 2

\section{Database search information}

SciFinder by April 2012. Keywords: Agaricus bitorquis.

\section{References}

Knudsen H \& Vesterholt J (2012): Funga Nordica. Agaricoid, boletoid, clavarioid, cyphelloid and gastroid genera. Nordsvamp: 1-1083.

Laub E, Waligorski F \& Woller R (1977): Über die Cadmiumanreicherung in Champignons). Zeitschrift für Lebensmittel-Untersuchung und - Forschung 164: 269-271.

Lodenius M, Kuusi T, Laaksovirta K, Liukkonen-Lilja H \& Piepponen S (1981): Lead, cadmium and mercury contents of fungi in Mikkeli, SE Finland. Annales Botanici Fennici 18: 185-186.

Mowitz J (1980): Höga halter cadmium i vildväxande svenska champinjoner. Vår Föda 5: 270-278.

Schulzova V, Hajslova J, Peroutka J, Gry J \& Andersson HC (2002): Influence of storage and household processing on the agaritine content of the cultivated Agaricus mushroom. Food Additives and Contaminants 19: 853-862.

Schulzova V, Hajslova J, Peroutka R, Hlavasek J, Gry J \& Andersson HC (2009): Agaritine content of 53 Agaricus species collected from nature. Food Additives and Contaminants 26: 82-93.

Seeger R (1978): Cadmiun in Pilzen. Zeitschrift für Lebensmittel-Untersuchung und Forschung 66: 23-34.

Seeger R (1982): Toxische Swermetalle in Pilzen. Deutsche Apotheker Zeitung 122: 1835-1844.

Stijve T \& Pittet A (2000): Absence of agaritine in Pleurotus species and in other cultivated and wild-growing mushrooms not belonging to the genus Agaricus. Deutsche Lebensmittel-Rundschau 96: 251-254.

Stijve T, Fumeaux R \& Philippossian G (1986): Agaritine, a phydroxymethylphenylhydrazine derivative in cultivated mushrooms (Agaricus bisporus), and in some of its wild-growing relatives. Deutsche LebensmittelRundschau 82: 243-248.

\section{Agaricus brunnescens Peck}

See Agaricus bisporus. 


\section{Agaricus campestris L.}

Field Mushroom (DK: Mark-Champignon, FI: Nurmiherkkusieni, IS: Túnkempa (Túnkempingur, Túnætisveppur), NO: Beitesjampinjong, SE: Ängschampinjon).

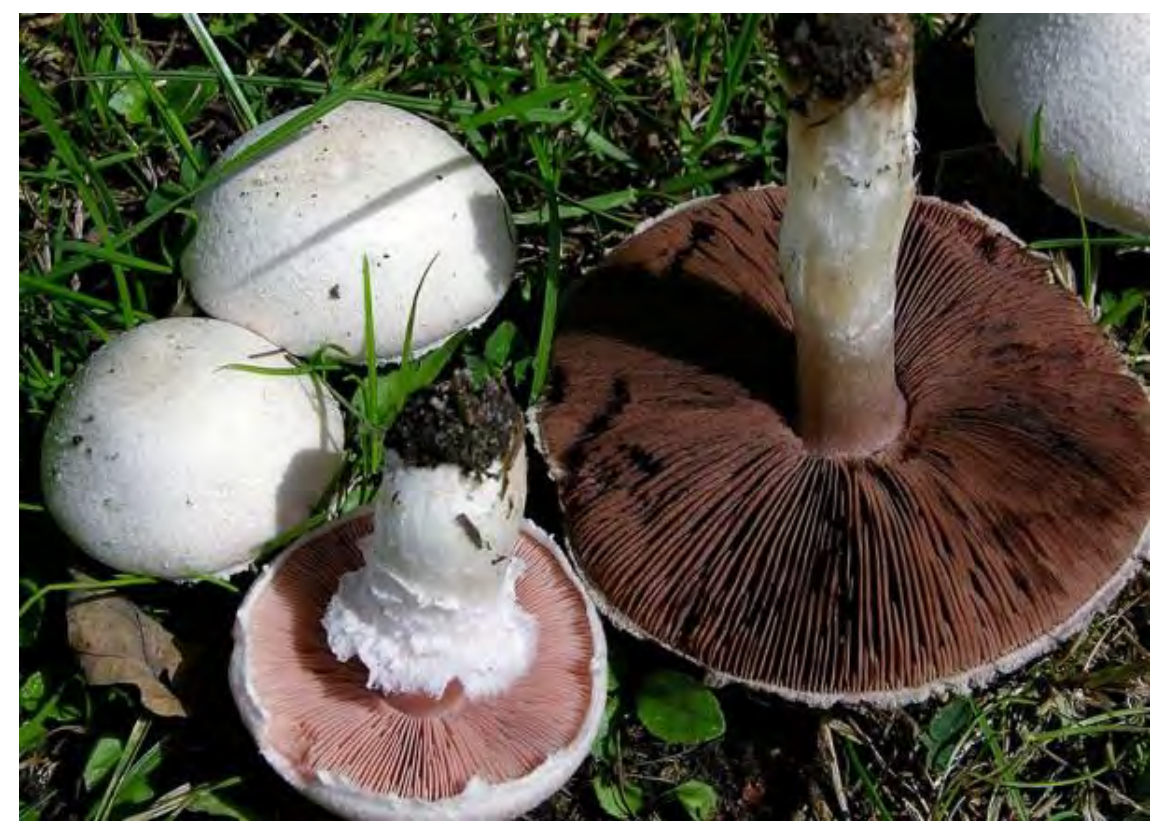

\section{Background and risk assessment}

Field Mushroom (Agaricus campestris) is generally regarded as edible and good.

It is a saprotrophic mushroom growing in open meadows, grassland, alvar areas and lawns. It is very common in most parts of the Nordic countries (Knudsen \& Vesterholt, 2012).

There are no intoxications reported after consumption of Field Mushroom except for a case reported by Ho and Hill (2006) that showed allergenic reactions to Button Mushroom (A. bisporus) and Field Mushroom. Dishes containing these mushrooms, as well as cooking vapours during processing, resulted in discomfort in the mouth, itchy ears, nausea, diaphoresis and discomfort in the throat. Skin prick tests with Agaricus extracts gave positive reaction.

However, Field Mushroom may contain large amounts of agaritine ( $\beta$ $\mathrm{N}$-[ $\gamma$-glutamyl]-4-(hydroxymethyl)phenylhydrazine). Field Mushroom collected in the Czech Republic was found to contain 0-2,230 mg agaritine per kg fresh weight (22 samples, mean content $487 \mathrm{mg} / \mathrm{kg}$ 
fresh weight) (Schulzová et al., 2009), whereas Stijve and co-workers reported approximately 20-1,000 mg agaritine per kg fresh weight in mushrooms collected in different European countries (11 samples, mean content $260 \mathrm{mg} / \mathrm{kg}$ fresh weight; Stijve et al., 1986) or $0.5-1.5 \%$ of the dried mushroom to be agaritine, corresponding to between a level of 500 and $1,500 \mathrm{mg} / \mathrm{kg}$ fresh weight (Stijve \& Pittet, 2000). A structurally related phenylhydrazine derivative, the aldehyde agaritinal $(\beta-\mathrm{N}-[\gamma-$ glutamyl]-4-(formyl)phenylhydrazine) has also been demonstrated in Field Mushroom in significant amounts. Chuilia et al. (1988) reported approximately $40 \mathrm{mg}$ per kg fresh weight and Stijve and Pittet (2000) a level between 50-500 mg per kg fresh weight.

The structural formulae of agaritine and agaritinal are shown below.<smiles>NC(CCC(=O)NNc1ccc(CO)cc1)C(=O)O</smiles>

Agaritine<smiles>Cc1ccc(NNC(=O)CCC(N)C(=O)O)cc1</smiles>

Agaritinal

Agaritine, or at least its metabolites, are indicated to give rise to tumours in mice by a genotoxic mechanism. Therefore, it cannot be excluded that consumption of Field Mushroom which contains considerable amounts of agaritine and the structurally related agaritinal constitutes a cancer risk to humans (for further information see risk assessment of Button Mushroom, A. bisporus). Agaritinal has not been studied for its potential toxic effects, but agaritinal may be anticipated to give rise to similar metabolites as agaritine.

Field Mushroom, like Button Mushroom (A. bisporus) and Scaly Wood Mushroom (A. langei), belongs to the group of reddening Agaricus species ("Rubescentes") which may become reddish (or brownish), when cut or rubbed. Contrary to the group of yellowing Agaricus species ("Flavescentes"), Field Mushroom and other Agaricus species from the "Rubescentes" group, the reddening Agaricus species, do not bioaccumulate the toxic metal cadmium (Laub et al., 1977; Lodenius et al., 1981; Mowitz, 1980; Seeger, 1978; 1982). 
Field Mushroom contains a remarkably thermostable lectin, which is a dimer with a molecular weight of $30.4 \mathrm{kDa}$. This lectin keeps its hemagglutinating activity during heating up to $90{ }^{\circ} \mathrm{C}$, but the activity is lost at $100{ }^{\circ} \mathrm{C}$. The lectin has shown anti-proliferative effects on hepatoma and breast cancer cells cultured in vitro (Zhao et al., 2011). Many lectins influence the digestibility of certain foods especially if the foods are insufficiently pre-treated/cooked. If for instance certain dried kidney beans are not thoroughly pre-treated and cooked, they may give rise to gastrointestinal adverse reactions due to remaining thermostable lectins (Liener, 1983). Also in mushrooms certain lectins are suspected to give rise to adverse reactions (Horibe et al., 2010; Gachet et al., 1996; Wang et al., 1998). However, there is no information available whether the thermostable lectin in Field Mushroom has given rise to intoxications.

\section{Recommendation}

Field Mushroom (Agaricus campestris):

- Due to the potentially high levels of phenylhydrazine derivatives in Field Mushroom, the species should not be eaten in larger amounts (see the risk assessment of Button Mushroom (Agaricus bisporus)).

\section{Listing 2}

\section{Database search information}

SciFinder by 1 April 2012. Keywords: Agaricus campestris or Agaricus campester.

\section{References}

Chulia AJ, Bernillon J, Favre-Bonvin J, Kaouadji M \& Arpin N (1988): Isolation of beta$N$-( $\gamma$-glutamyl)-4-formylphenylhydrazine (agaritinal) from Agaricus campestris. Phytochemistry 27: 929-930.

Gachet C, Ennamany R, Ohlmann P, Krause C, Creppy EE, Dirheimer G \& Cazenave JP (1996): Bolesatine induces agglutination of rat platelets and human erythrocytes and platelets in vitro. Human \& Experimental Toxicology 15: 26-29.

Ho MH \& Hill DJ (2006): White Button Mushroom food hypersensitivity in a child. Journal of Paediatrics and Child Health 42: 555-556.

Horibe M, Kobaynashi Y, Dohra H, Morita T, Murata T, Usui T, Nakamura-Tsuruta S, Kamey M, Hirabayashi J, Matsuura, M, Yamada M, Saikawa Y, Hashimoto K, Nakata M \& Kawagishi H (2010): Toxic isolectins from the mushroom Boletus venenatus. Phytochemistry 71: 648-657.

Knudsen H \& Vesterholt J (2012): Funga Nordica. Agaricoid, boletoid, clavarioid, cyphelloid and gastroid genera. Nordsvamp: 1-1083. 
Laub E, Waligor ski F \& Woller R (1977): Über die Cadmiumanreicherung in Champignons). Zeitschrift für Lebensmittel-Untersuchung und - Forschung 164: 269-271.

Liener IE (1983): Naturally occurring toxicants in food and their significance in the human diet. Archives of Toxicology Supplements 6: 153-166.

Lodenius M, Kuusi T, Laaksovirta K, Liukkonen-Lilja H \& Piepponen S (1981): Lead, cadmium and mercury contents of fungi in Mikkeli, SE Finland. Annales Botanici Fennici 18: 185-186.

Mowitz J(1980): Höga halter cadmium i vildväxande svenska champinjoner. Vår Föda 5: 270-278.

Schulzova V, Hajslova J, Peroutka R, Hlavasek J, Gry J \& Andersson HC (2009): Agaritine content of 53 Agaricus species collected from nature. Food Additives and Contaminants 26: 82-93.

Seeger R (1978): Cadmiun in Pilzen. Zeitschrift für Lebensmittel-Untersuchung und Forschung 66: 23-34.

Seeger R (1982): Toxische Schwermetalle in Pilzen. Deutsche Apotheker Zeitung 122: $1835-1844$.

Stijve T \& Pittet A (2000): Absence of agaritine in Pleurotus species and in other cultivated and wild-growing mushrooms not belonging to the genus Agaricus. Deutsche Lebensmittel-Rundschau 96: 251-254.

Stijve T, Fumeaux R \& Philippossian G (1986): Agaritine, a p-hydroxymethylphenylhydrazine derivative in cultivated mushrooms (Agaricus bisporus), and in some of its wild-growing relatives. Deutsche Lebensmittel-Rundschau 82: 243-248.

Wang H, Ng TB \& Ooi VEC (1998): Lectins from Mushrooms. Mycological Research 102: 897-906.

Zhao JK, Zhao YC, Li SH, Wang HX \& Ng TB (2011): Isolation and characterization of a novel thermostable lectin from the wild edible mushroom Agaricus arvensis. Journal of Basic Microbiology 51: 304-311.

\section{Agaricus essettei Bon}

See Agaricus species, other yellowing.

\section{Agaricus excellens (F. H. Møller) F. H. Møller}

See Agaricus species, other yellowing.

\section{Agaricus haemorrhoidarius Schulzer s. J. E. Lange}

See Agaricus species, other not yellowing. 
Agaricus hortensis (Cooke) S. Imai.

See Agaricus bisporus.

Agaricus langei (F. H. Møller) F. H. Møller

See Agaricus species, other not yellowing.

Agaricus macrosporus (F. H. Møller \& Jul. Schäff.)

Pilát non Montagne

See Agaricus species, other yellowing.

Agaricus perrarus Schulzer

See Agaricus augustus. 


\section{Agaricus species, other not yellowing, e.g. A. langei (F. H. Møller) F. H. Møller (A. haemorrhoidarius Schulzer s. J. E. Lange) and A. sylvaticus Schaeff}

Agaricus species, other not yellowing (DK: Andre ikke-gulnende champignoner, FI: Muut ei kellertävät Agaricus lajin herkkusienet, IS: Aðrar kempur sem ekki gulna við hnjask, NO: Andre ikke gulnende sjampinjonger, SE: Andra icke gulnande Agaricus arter).

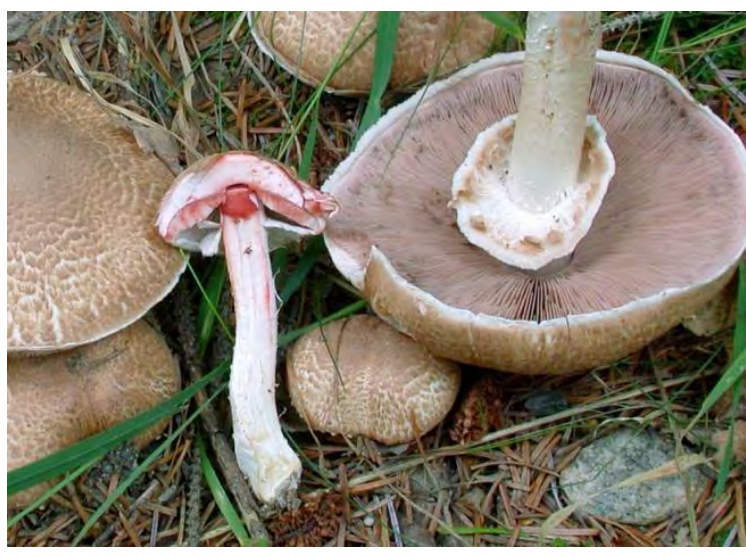

A. langei

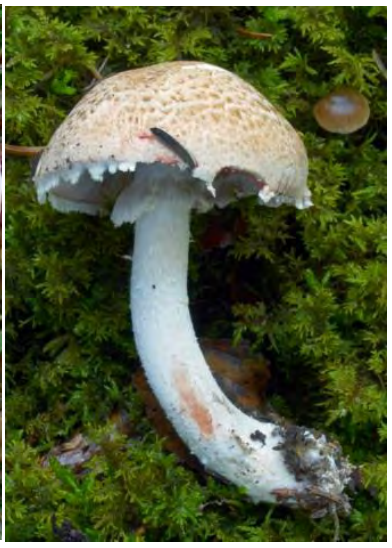

A. sylvaticus

\section{Background and risk assessment}

Besides Button Mushroom (Agaricus bisporus), Pavement Mushroom (A. bitorquis) and Field Mushroom (A. campestris) there are other Agaricus species that do not yellow when handled. Many of these other species belong to the group of reddishing ("Rubescentes") Agaricus species, like the Scaly Wood Mushroom (A. langei) and Blushing Wood Mushroom (A. sylvaticus), which both are also regarded as edible and collected for consumption.

They grow saprotrophically in coniferous and deciduous forests and parks, and are found occasionally in Denmark, but are common in hemiboreal-boreal areas of the other Nordic countries (Knudsen \& Vesterholt, 2012).

There are no intoxications reported after consumption of Scaly Wood Mushroom or Blushing Wood Mushroom. However, Scaly Wood Mushroom and Blushing Wood Mushroom contain several bioactive constituents: 


\section{Bioactive constituents}

Phenylhydrazine derivatives: Scaly Wood Mushroom and Blushing Wood Mushroom, like other edible mushrooms from the "Rubescentes" group, may contain considerable amounts of agaritine ( $\beta-\mathrm{N}-[\gamma$-glutamyl $]-4-$ (hydroxymethyl)phenylhydrazine).

According to Schulzová et al. (2009) Scaly Wood Mushroom may contain $975 \mathrm{mg}$ agaritine (1 sample) and Blushing Wood Mushroom from non-detectable to $920 \mathrm{mg} / \mathrm{kg}$ fresh weight (14 samples, mean content $210 \mathrm{mg}$ per kg fresh weight).

The structural formula of agaritine is shown below:<smiles>NC(CCC(=O)NNc1ccc(CO)cc1)C(=O)O</smiles>

Agaritine

Agaritine, or at least its metabolites, are indicated to give rise to tumours in mice by a genotoxic mechanism. Therefore, it cannot be excluded that consumption of Scaly Wood Mushroom, Blushing Wood Mushroom and other not yellowing, edible Agaricus species containing considerable amounts of agaritine may constitute a cancer risk to humans. (for further information see risk assessment of Button Mushroom, Agaricus bisporus).

Blushing Wood Mushroom has been reported to contain $\mathrm{N}$-nitraminoalanine and its decarboxylation product N-nitroethylenediamine (Chilton \& Hsu, 1975). The level of these two constituents in the mushroom is not given. Sterner et al. (1982) tested the two compounds (prepared by synthesis) for mutagenicity in the Ames test, using the Salmonella typhimurium strains TA98, TA100 and TA2637. Only, Nnitroethylenediamine was found mutagenic and only in the strain TA100 in the presence of microsomal enzymes. Sterner et al. (1982) also tested a sample of Blushing Wood Mushroom, which was found to be weakly positive in all tree Salmonella strains. However, Sterner et al. (1982) give no information, whether they had controlled for the potential presence of histidine in the extract. It is well known that false positives may be obtained in the presence of histidine. Thus, there is no strong indication 
that extracts of Blushing Wood Mushroom are mutagenic. It is remarkable, that Sterner et al. (1982) were not able to isolate nitramines from the mushroom using the same procedure as Chilton \& Hsu (1975). This apparent discrepancy do they suggest may be due to different chemical races or taxonomic problems.

Cadmium: Scaly Wood Mushroom, Blushing Wood Mushroom and other Agaricus species belong to the group of reddening Agaricus species ("Rubescentes") which may become reddish (or brownish), when cut or rubbed. Contrary to the group of yellowing Agaricus species ("Flavescentes"), these reddening Agaricus species do not bioaccumulate the toxic metal cadmium (Laub et al., 1977; Lodenius et al., 1981; Mowitz, 1980; Seeger, 1978; 1982).

\section{Recommendation}

Scaly Wood Mushroom, Blushing Wood Mushroom and other redishing (not yellowing), edible Agaricus species:

- Due to the potentially high levels of phenylhydrazine derivatives in redishing (not yellowing) Agaricus species, they should not be eaten in larger amounts (see the risk assessment of Button Mushroom (Agaricus bisporus).

\section{Listing 2}

\section{Database search information}

SciFinder by 1 February 2012. Keywords: Agaricus langii or Agaricus sylvaticus, Agaricus and cadmium, Agaricus and agaritine.

\section{References}

Chilton WS \& Hsu CP (1975): N-Nitroamines of Agaricus silvaticus. Phytochemistry 14: 2291-2292.

Knudsen H \& Vesterholt J (2012): Funga Nordica. Agaricoid, boletoid, clavarioid, cyphelloid and gastroid genera. Nordsvamp: 1-1083.

Laub E, Waligorski F \& Woller R (1977): Über die Cadmiumanreicherung in Champignons). Zeitschrift für Lebensmittel-Untersuchung und - Forschung 164: 269-271.

Lodenius M, Kuusi T, Laaksovirta K, Liukkonen-Lilja H \& Piepponen S (1981): Lead, cadmium and mercury contents of fungi in Mikkeli, SE Finland. Annales Botanici Fennici 18: 185-186.

Mowitz J(1980): Höga halter cadmium i vildväxande svenska champinjoner. Vår Föda 5: 270-278. 
Schulzova V, Hajslova J, Peroutka R, Hlavasek J, Gry J \& Andersson HC (2009): Agaritine content of 53 Agaricus species collected from nature. Food Additives and Contaminants 26: 82-93.

Seeger R (1978): Cadmiun in Pilzen. Zeitschrift für Lebensmittel-Untersuchung und Forschung 66: 23-34.

Seeger R (1982): Toxische Schwermetalle in Pilzen. Deutsche Apotheker Zeitung 122: $1835-1844$.

Sterner O, Bergman R, Kesler E, Magnusson L, Nilsson B, Wickberg B, Zimerson E \& Zetterberg G (1982): Mutagens in larger fungi I. Forty-eight species screened for mutagenic activity in the Salmonella/microsome assay. Mutation Research 101: 269-281. 
Agaricus species, other yellowing, e.g. A. essettei Bon (A. abruptibulbus (Peck) Kauffm. s.auct, A. sylvicola (Vittad.) Peck s. str. and A. urinascens (F. H. Møller \& Jul. Schäff.) Singer (A. excellens (F. H. Møller) F. H. Møller, A. macrosporus (F. H. Møller \& Jul. Schäff.)
Pilát non Montagne)

Agaricus species, other yellowing (DK: Andre gulnende champignoner, FI: Muut kellertävät Agaricus lajin herkkusienet, IS: Aðrar kempur sem gulna við hnjask, NO: Andre gulnende sjampinjonger, SE: Andra gulnande Agaricus arter).

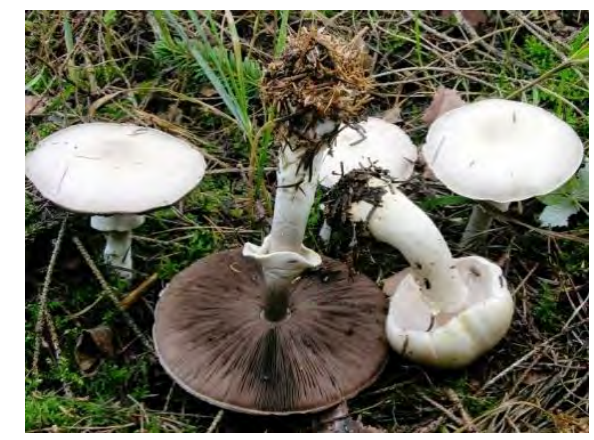

A. sylvicola

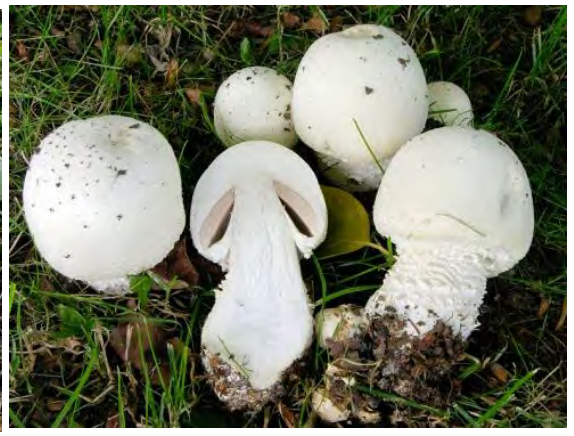

A. urinascens

\section{Background and risk assessment}

Several other yellowing Agaricus species ("Flavescentes") than Horse Mushroom (A. arvensis) and The Prince (A. augustus) are considered edible and collected for consumption, e.g., Wood Mushroom (A. sylvicola) and Macro Mushroom (A. urinascens).

They are all saprotrophic. Wood Mushroom is growing in forests, scrubs and parks and is common in Denmark and southern parts of Finland, Norway and Sweden where it is also found occasionally in subarctic/subalpine areas. It is rare in Iceland. Macro Mushroom is growing in meadows, steppes, alvar habitats and open places in forests and is occasional in Denmark and southern parts of Finland, Norway and Sweden, but rare in boreal-alpine areas (Knudsen \& Vesterholt, 2012).

No intoxications have been reported after consumption of these two or other edible yellowing Agaricus species. However, edible yellowing Agaricus species contain several bioactive constituents: 


\section{Bioactive constituents}

Phenylhydrazine derivatives: They all contain high or very high amounts of agaritine ( $\beta$-N-[ $\gamma$-glutamyl]-4-(hydroxymethyl)phenylhydrazine).

Wood Mushroom collected in the Czech Republic was found to contain 733-1,940 mg agaritine/kg fresh weight (6 samples, mean content $1,590 \mathrm{mg}$ per $\mathrm{kg}$ fresh weight, whereas 7 samples of $A$. essettii ${ }^{6}$ contained 1,740-3,960 (mean content 2,610) mg per kg fresh weight (Schulzová et al., 2009). Stijve and co-workers reported approximately 50-1,200 mg agaritine/kg fresh weight in mushrooms purchased or collected in various European countries and the USA ( 5 samples, mean content $520 \mathrm{mg}$ per kg fresh weight; Stijve et al., 1986), and between 0.5 and $1.5 \%$ of the dried mushroom as being agaritine, corresponding to a level between 500 and 1,500 mg agaritine/kg fresh weight (Stijve \& Pittet, 2000). Wood Mushroom also contains another type of phenylhydrazine derivatives, schaefferals, which are hydrazones chemically formed by reaction between 4-(formyl)phenylhydrazine and aromatic aldehydes. The schaefferals were isolated in amounts of about $10 \mathrm{mg}$ per kg fresh mushroom (Kileci-Ksoll et al., 2010).

In Macro Mushroom collected in the Czech Republic, the level of agaritine was $1,050-1,620 \mathrm{mg} / \mathrm{kg}$ fresh weight ( 4 samples, mean content $1,420 \mathrm{mg} / \mathrm{kg}$ fresh weight) (Schulzová et al., 2009). Stijve and coworkers reported levels between 30 and $2,500 \mathrm{mg} / \mathrm{kg}$ fresh weight in samples collected in various countries (5 samples, mean content $680 \mathrm{mg} / \mathrm{kg}$ fresh weight) (Stijve et al., 1986) and a level between 1,500 and 2,500 mg per kg fresh mushroom (Stijve \& Pittet, 2000). A structurally related phenylhydrazine derivative, the aldehyde agaritinal $(\beta-\mathrm{N}-[\gamma-$ glutamyl]-4-(formyl)phenylhydrazine) has also been demonstrated in Macro Mushroom at a level between 500 and 1,500 mg per kg fresh weight (Stijve \& Pittet, 2000).

The structural formulae of agaritine, agaritinal and schaefferals are shown below.

\footnotetext{
${ }^{6}$ According to Knudsen \& Vesterholt (2012) Agaricus essettei, is possibly only a large-spored variant of A. sylvicola (Wood Mushroom).
} 
<smiles>NC(CCC(=O)NNc1ccc(C(O)O)cc1)C(=O)O</smiles>

Agaritine<smiles>CN(NNC(=O)CCC(N)C(=O)O)c1ccc(C=O)cc1</smiles>

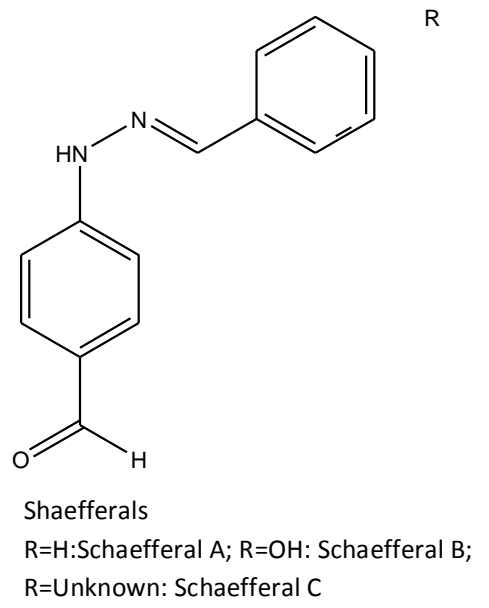

Agaritine, or at least its metabolites, are indicated to give rise to tumours in mice by a genotoxic mechanism. Therefore, it cannot be excluded that consumption of yellowing Agaricus species which may contain large amounts of agaritine and structurally related phenylhydrazine derivates may constitute a cancer risk to humans (for further information, see risk assessment of Button Mushroom, A. bisporus).

Cadmium: The group of yellowing Agaricus species ("Flavescentes"), which have an anise or bitter almond-like smell and become yellowish when rubbed or bruised bioaccumulates the highly toxic metal cadmium. Thus, in general the edible yellowing Agaricus species contain much higher cadmium levels than found in other edible mushrooms. In 10 studies, approximately 200 samples from several different edible yellowing Agaricus species have been analysed for cadmium. In most cases the levels were between 1 and $10 \mathrm{mg}$ with mean values between 3 and 8 mg cadmium per kg fresh mushroom (Andersen et al., 1982; Laub et al., 
1977; Lind et al., 1995; Lodenius et al., 1981; Meisch et al., 1977; Meisch et al., 1979; Mowitz, 1980; Seeger, 1978; Stijve \& Besson, 1976; Woggon \& Bickerich, 1978).

Cadmium is a highly toxic metal with a very long half-life in humans, ranging from 10 to 30 years. It is primarily toxic to the kidney where it accumulates and may cause renal dysfunction, which may progress to renal failure. It can also cause bone demineralisation. A health based guidance value for cadmium; a Tolerable Weekly Intake (TWI) of 2.5 microgram cadmium per kg body weight has been established by the European Food Safety Authority (EFSA), based on the renal tubular effects (EFSA, 2009; 2011). EFSA estimates that the mean weekly dietary exposure to cadmium in Europe is 2.3 microgram per kg body weight and that regular consumers of wild mushrooms have a higher dietary exposure, around 4.3 microgram per kg body weight per week (EFSA, $2009 ; 2012$ ). Although the current dietary exposure is unlikely to cause adverse renal effects in European consumers, EFSA concludes there is a need to reduce the exposure to cadmium because of the very small safety margin (EFSA, 2012). Furthermore, WHO's International Agency for Research on Cancer has concluded "There is sufficient evidence in humans for the carcinogenicity of cadmium and cadmium compounds" and "There is sufficient evidence in experimental animals for the carcinogenicity of cadmium compounds" (IARC, 1993; 2012).

In order to protect public health, the European Commission has set limits for cadmium in a series of food items, including a maximum limit of $1.0 \mathrm{mg}$ per kg fresh weight for mushrooms, except for the most frequently traded mushrooms Button Mushroom (Agaricus bisporus), Oyster Mushroom (Pleurotus ostreatus) and Shiitake (Lentinula edodes) for which a limit of $0.20 \mathrm{mg}$ per $\mathrm{kg}$ fresh weight for has been set (EU Commission, 2006).

\section{Recommendation}

- As edible yellowing Agaricus species efficiently bioaccumulate cadmium, and as the amount in the mushrooms varies considerably, the content of this toxic and carcinogenic metal in yellowing, edible Agaricus species needs to be controlled regularly.

- Due to the potentially high levels of phenylhydrazine derivatives and cadmium in the Agaricus species, yellowing, edible species of the Agaricus genus should not be eaten in larger amounts (regarding phenylhydrazine derivatives, see Agaricus bisporus (Button Mushroom) risk assessment). 
Listing 2

\section{Database search information}

SciFinder by February 2012. Keywords: Agaricus and abruptibulbus or essettei or excellens or silvicola or sylvicola or urinascens. PubMed by May 2012. Keywords: Agaricus and cadmium. Agaricus and agaritine or agaritinal.

\section{References}

Andersen A, Lykke S-E, Lange M \& Bech K (1982): Sporelementer i spiselige svampe. Publikation nr. 68. Statens Levnedsmiddelinstitut: 1-27.

EFSA (2009): Cadmium in Food. Scientific Opinion of the Panel on Contaminants in the Food Chain. The EFSA Journal 980: 1-139.

EFSA (2011): Statement on tolerable weekly intake for cadmium EFSA Panel on Contaminants in the Food Chain. The EFSA Journal 9 (2): 1975: 1-19.

EFSA, (2012): Scientific Report of EFSA Cadmium dietary exposure in the European population. The EFSA Journal 10 (1):2551. 1-37.

EU Commission (2006): Regulation (EC) No 1881/2006 of 19 December 2006 setting maximum levels for certain contaminants in foodstuffs. OJ L 364, 20.12.2006: p. 5. (Amended).

Gry J, Hansen EV \& Pedersen E (1988): Ager-Champignon og andre gulnende champignoner bør spises med måde. Svampe 18: 69-70.

Hansen EV, Gry J \& Andersen A (1987): Rat studies on the bioavailability of cadmium from mushrooms. Report from the National Food Institute.

IARC (1993): International Agency for Research on Cancer. Berylium, cadmium, mercury, and exposures in the glass manufacturing industry 58: 119-237.

IARC (2012): International Agency for Research on Cancer. Arsenic, metals, fibres, and dusts. A review of human carcinogens. Cadmium and cadmium compounds. 100C: $121-145$.

Kileci-Ksoll R, Winklhofer C \& Steglich W (2010): Synthesis of schaefferals A and B, unusual phenylhydrazine derivatives from mushrooms of the genus Agaricus. Synthesis 2010: 2287-2291.

Knudsen H \& Vesterholt J (2012): Funga Nordica. Agaricoid, boletoid, clavarioid, cyphelloid and gastroid genera. Nordsvamp: 1-1083.

Kruse H \& Lommel A (1979): Untersuchungen über cadmiumbindende Proteine im Schaf-Champignon (Agaricus arvensis Schaff. ex FR). Zeitschrift für LebensmittelUntersuchung und - Forschung 168: 444-447.

Laub E, Waligorski F \& Woller R (1977): Über die Cadmiumanreicherung in Champignons). Zeitschrift für Lebensmittel-Untersuchung und - Forschung 164: 269-271.

Lind Y, Glynn AW, Enman J \& Jorhem L (1995): Bioavailability of cadmium from crab hepatopancreas and mushroom in relation to inorganic cadmium: A 9-week feeding study in mice. Food Chemical Toxicology 33: 667-673.

Lodenius M, Kuusi T, Laaksovirta K, Liukkonen-Lilja H \& Piepponen S (1981): Lead, cadmium and mercury contents of fungi in Mikkeli, SE Finland. Annales Botanici Fennici 18: 185-186.

Meisch H-U, Schmitt JA \& Reinle W (1977): Schwermetalle in höheren Pilzen Cadmium, Zink and Kupfer. Zeitschrift für Naturforschung 32c: 172-181. 
Meisch H-U, Schmitt JA \& Scholl A-R (1979): Growth Simulation by Cadmium in the Mushroom Agaricus abruptibulbus. Naturwissenschaften 66: 209.

Meisch H-U, Beckmann I \& Schmitt JA (1983): A new cadmium-binding phosphoglycoprotein, cadmium-mycophosphatin, from the mushroom, Agaricus macrosporus. Biochimica et Biophysica Acta 745: 259-266.

Meisch H-U \& Schmitt JA (1986): Characterization studies on cadmiummycophosphatin from the mushroom Agaricus macrosporus. Environmental Health Perspectives 65: 29-32.

Mowitz J (1980): Höga halter cadmium i vildväxande svenska champinjoner. Vår Föda 5: 270-278.

Schellmann B, Hilz M-J \& Opitz O (1980): Cadmium- und Kupferausscheidung nach Aufname von Champignon-Mahlzeiten. Zeitschrift für Lebensmittel-Untersuchung und - Forschung 171: 189-192.

Schellmann B, Rohmer E, Schaller K-H \& Weltle D (1984): Concentration of cadmium and copper in feces, urine and blood after ingestion of wild mushrooms. Zeitschrift für Lebensmittel-Untersuchung und - Forschung 178: 445-449.

Schulzova V, Hajslova J, Peroutka R, Hlavasek J, Gry J \& Andersson HC (2009): Agaritine content of 53 Agaricus species collected from nature. Food Additives and Contaminants 26: 82-93.

Seeger R (1978): Cadmiun in Pilzen. Zeitschrift für Lebensmittel-Untersuchung und Forschung. 66: 23-34.

Seeger R. (1982): Toxische Schwermetalle in Pilzen. Deutsche Apotheker Zeitung 122: 1835-1844.

Seeger R, Schiffelbein F, Sauffart R \& Sant W (1986): Absorption of cadmium ingested with mushrooms (Abstract 100). Archives of Pharmacology 332 supplement: R28.

Stijve T \& Besson R (1976): Mercury, cadmium, lead and selenium content of mushroom species belonging to the genus Agaricus. Chemosphere No.2: 151-158.

Stijve T \& Pittet A (2000): Absence of agaritine in Pleurotus species and in other cultivated and wild-growing mushrooms not belonging to the genus agaricus. Deutsche Lebensmittel-Rundschau 96: 251-254.

Stijve T, Fumeaux R \& Philippossian G (1986): Agaritine, a p-

hydroxymethylphenylhydrazine derivative in cultivated mushrooms (Agaricus bisporus), and in some of its wild-growing relatives. Deutsche LebensmittelRundschau 82: 243-248.

Woggon H \& Bickerich K (1978): Zum Vorkommen von Toxischen Schwermetallen (Cadmium, Blei, Zink und Quecksilber) in Pilzen. Die Nahrung 22: 13-15. 
Agaricus sylvaticus Schaeff.

See Agaricus species, other not yellowing.

Agaricus sylvicola (Vittad.) Peck s. str.

See Agaricus species, other yellowing.

Agaricus urinascens (F. H. Møller \& Jul. Schäff.) Singer

See Agaricus species, other yellowing. 


\section{Albatrellus ovinus (Schaeff.) Kotl. \& Pouzar}

Forest Lamb (DK: Hvidlig Fåreporesvamp, FI: Lampaankääpä, IS: no Icelandic name, NO: Fåresopp, SE: Fårticka).

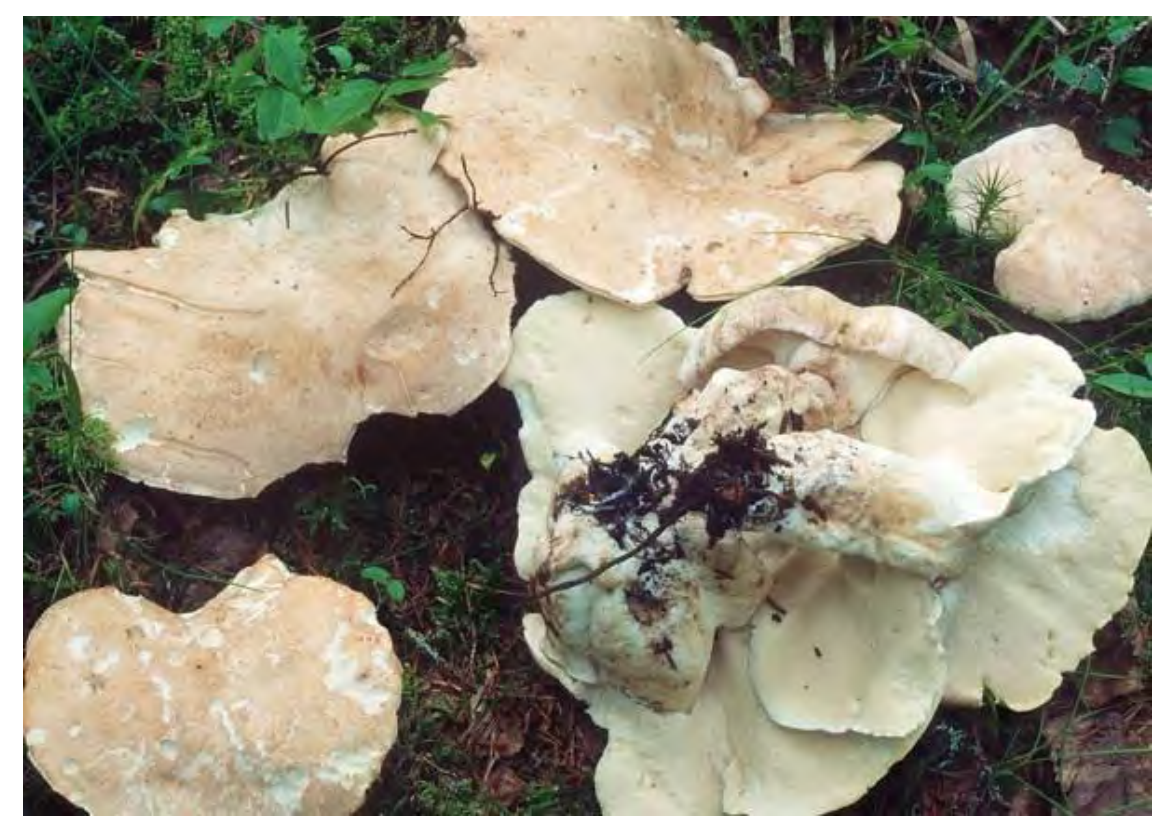

\section{Background and risk assessment}

Forest Lamb (Albatrellus ovinus) is an edible mushroom.

It forms mycorrhiza in coniferous forests, mainly with Spruce (Picea). It is very rare or extinct in Denmark, not found in Iceland but common in the other Nordic countries in temperate, hemiboreal and boreal zones (Hansen \& Knudsen, 1992).

There are no intoxications reported after consumption of Forest Lamb, and no natural toxicant constituting a risk for humans has been identified in the mushroom. However, Forest Lamb contains some potentially bioactive phenolic compounds.

\section{Bioactive constituents}

Triprenylphenolic compounds: Forest Lamb contains a number of related triprenyl(farnesyl) phenolic compounds, either grifolin or neogrifolin derivatives (Besl et al., 1977; Dekermendjian et al., 1997; Nukata et al., 2002; Vrkoc et al., 1977). The structural formulae of two of these phenols, grifolin and scutigeral are shown below. 
<smiles>CC(C)=CCC/C(C)=C/CC/C(C)=C/Cc1c(O)cc(C)cc1O</smiles><smiles>CC(C)=CCC/C(C)=C/CC/C(C)=C/Cc1c(C)c(C=O)c(O)c(O)c1O</smiles>

Several of these phenols have been demonstrated to have biological activities in vitro, e.g. effect on central nervous system receptors, inhibition of various cancer cell lines, antibacterial, antioxidative and antiinflammatory effects (Dekermendjian et al., 1997; Hellwig et al., 2003; Hirata \& Nakanishi, 1950; Jin et al., 2007; Luo et al., 2011a, 2011b; Nukata et al., 2002; Szallazi et al., 1999; Ye et al., 2005; Ye et al., 2007), but they have not been studied in vivo.

It is not possible to evaluate whether these in vitro bioactive compounds in Forest Lamb may have any effect in humans consuming this mushroom, being it beneficial or adverse effects. Furthermore, the quantitative occurrence of these constituents in the mushroom is generally not well described.

Animal studies: Nieminen and co-workers (2006) have published a study on the potential myo- and hepatotoxic effects of different wild mushrooms in mice. The animals (six females per group) were for 5 days supplied large quantities of dried and powdered wild mushrooms in the feed. One of the mushrooms, Forest Lamb, was given as $1.8 \%, 3.6 \%$ or $5.4 \%$ of the feed. The feeding resulted in exposures corresponding to 21 , 32 or $59 \mathrm{~g}$ per kg body weight of the mice per day, respectively, corresponding to a human exposure of $1.5,2.5$ or $4.2 \mathrm{~kg}$ fresh mushroom per person $(70 \mathrm{~kg})$ per day, respectively. All mice were healthy at the end of the study. Of the many clinical-chemical parameters studied the plasma LDL cholesterol concentrations were significantly lower at all doses. The plasma creatine kinase activity was significantly increased at the highest dose level. The plasma triacylglycerol concentration was significantly 
lower at the highest dose. No histological pathological changes in studied organs were found. Whether the observed increased creatine kinase (indicator of myopathy) in mice eating very high amounts of Forest Lamb may be relevant for humans eating very large amount of the mushroom is difficult to evaluate.

\section{Recommendation}

Forest Lamb (Albatrellus ovinus) is red-listed as regionally extinct in Denmark. Should only be marketed in the Nordic countries, if it is from countries where it is cultivated or not red-listed.

Listing 1

\section{Database search information}

SciFinder by January 2012. PubMed by January 2012. Keywords: Albatrellus.

\section{References}

Besl H, Hoefle G, Jendmy B, Jaegers, E \& Steglich W (1977): Farnesyl pigmente, XXXI Farnesylphenole aus Albatrellus-Arten (Basidiomycetes). Chemische Berichte 110: 3770-3776.

Dekermendjian K, Shan R, Nielsen M, Stadler M, Sterner O \& Witt MR (1997): The affinity to the brain dopamine D1 receptor in vitro of triphenyl phenols isolated from the fruit bodies of Albatrellus ovinus. European Journal of Medicinal Chemistry 32: 351-356.

Fang Y, Xin-Fang Y, Lan-bo X, Min T, Xin D. Qi-pan D, Bode AM \& Li-kai L (2011): DAPK1 mediates the G1 phase arrest in human nasopharyngeal carcinoma cells induced by grifolin, a potential antitumor natural product. European Journal of Pharmacology 670: 427-434.

Hansen L \& Knudsen H (1992): Nordic Macromycetes, Volume 2. Polyporales, Boletales, Agaricales, Russulales. Nordsvamp: 1-474.

Hellwig V, Nopper R, Maule F, Freitag J, Liu J-K, Ding Z-H \& Stadler M (2003): Activities prenylphenol derivates from fruitbodies of Albatrellus spp. on the human and rat vanilloid receptor 1 (VR1) and characterisaton of the novel natural product, confluentin. Archiv der Pharmazie 336: 119-126.

Hirata Y \& Nakamishi K (1950): Grifolin, an antibiotic from a basidiomycete. Journal of Biological Chemistry 184: 135-143.

Jin S, Pang R-P, Huang G, Wang J \& Zhou J-G (2007): Grifolin induces apoptosis via inhibition of P13K/AKT signaling pathway in human osteosarcoma cells. Apoptosis 12: 1317-1326.

Luo X-j, Li L-l, Deng Q-p, Yu X-f, Yang L-f, Luo F-j, Xiao L-b, Chen X-y, Ye M, Liu J-k \& Cao Y (2011a): Grifolin, a potent antitumour natural product upregulates deathassociated protein kinase 1 DAPK1 via p53 in nasopharyngeal carcinoma cells. European Journal of Cancer 47: 316-325. 
Luo X-j, Li W, Yang L-f, Yu X-f, Xiao L-b, Tang M, Dong X, Deng Q-p, Bode AM, Liu J-k \& Cao Y (2011b): DAPK1 mediates the G1 phase arrest in human nasopharyngeal carcinoma cells induced by grifolin, a potential antitumor natural product. European Journal of Pharmacology 670: 427-434.

Nieminen P, Kirsi M \& Mustonen A-M(2006): Suspected myotoxicity of edible wild mushrooms. Experimental Biology and Medicine 231: 221-228.

Nukata M, Hashimoto T, Yamamoto I, Iwasaki N, Tanaka M \& Asakawa Y (2002): Neogrifolin derivatives possessing anti-oxidative activity from the mushroom Albatrellus ovinus. Phytochemistry 59: 731-737.

Szallasi A, Bíro T, Szabó T, Modarres S, Petersen M, Klusch A, Blumberg PM, Krause JE \& Sterner O (1999): A non-pungent triprenyl phenol of fungal origin, scutigeral, stimulates rat dorsal root ganglion neurons via interaction at vanilloid receptors. Bristish Journal of Pharmacology 126: 1351-1358.

Vrkoc J, Budesinský M \& Dolejs L (1977): Phenolic meroterpenoids from the basidiomycete Albatrellus ovinus. Phytochemistry 16: 1409-1411.

Ye M, Liu J-k, Lu Z-x, Zhao Y, Liu S-f, Li L-l, Tan M, Weng X-x \& Cao Y (2005): Grifolin, a potential antitumor natural product from the mushroom Albatrellus confluens, inhibits tumor cell growth by inducing apoptosis in vitro. FEBS letters 579: 3437-3443.

Ye M, Luo X, Li L, Shi Y, Tan M, Weng X, Li W, Liu J \& Cao Y (2007): Grifolin, a potential antitumor natural product from the mushroom Albatrellus confluens, induces cell-cycle arrest in G1 phase via the ERK1/2 pathway. Cancer Letters 258: 199-207. 


\section{Amanita caesarea (Scop.) Pers.}

Caesar's Amanita (Caesar's Mushroom) (DK: Kejser-Fluesvamp, FI: Keisarikärpässieni, IS: Keisaraserkur, NO: Keiserfluesopp, SE: (Kejsarflugsvamp).

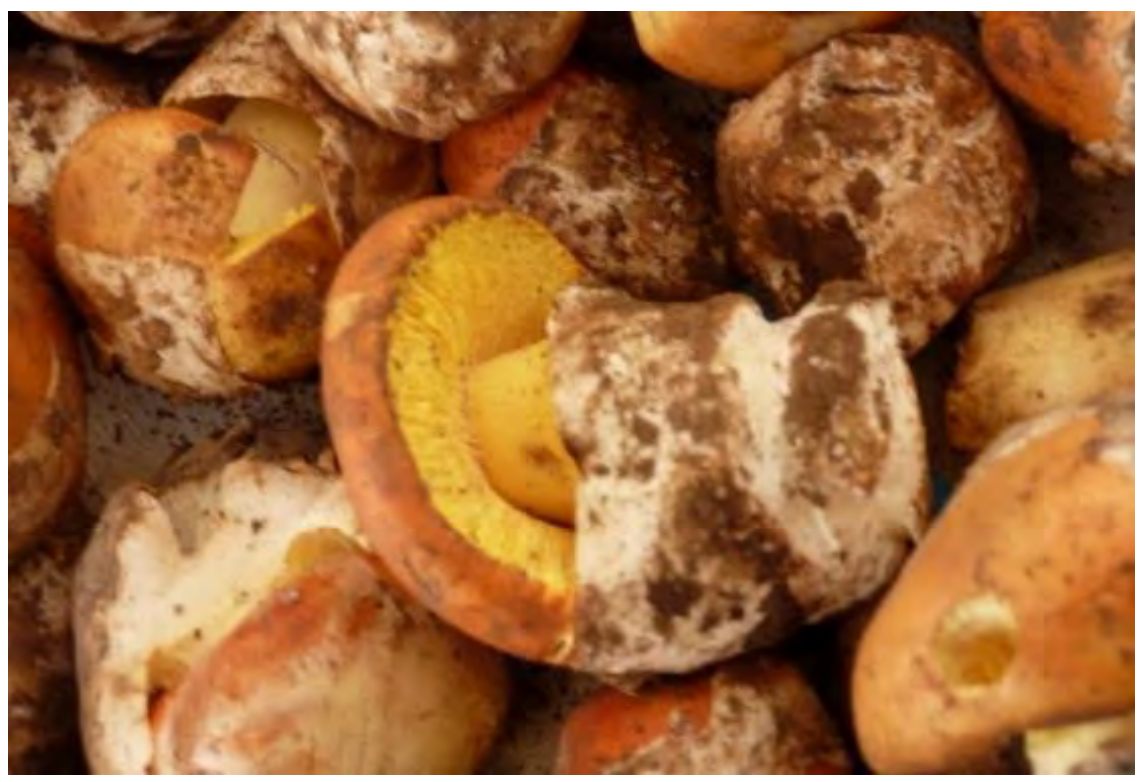

\section{Background and risk assessment}

Caesar's Amanita (Amanita caesarea) is a highly appreciated edible mushroom.

It forms mycorrhiza in both deciduous and coniferous woods with Beech (Fagus), Oak (Quercus), Chestnut (Castanea) and Pine (Pinus). It is found in Mediterranean to warm temperate areas, but also in Asia and North America. It is not found in the Nordic countries (Gminder \& Kriegelsteiner, 2003).

There are no intoxications reported after consumption of Caesar's Amanita, and no natural toxicant constituting a risk for humans has been identified in the mushroom.

\section{Recommendation}

No special recommendation. 


\section{Database search information}

PubMed by June 2012. Keywords: Amanita caesarea.

\section{References}

Gminder A \& Kriegelsteiner GJ (2003): Ständerpilze: Blätterpilze II. In: Krieglsteiner G J (ed.): Die Grosspilze Baden-Würtembergs Band 4. Verlag Eugen Ulmer: 1-467. 


\section{Amanita fulva Fr.}

Tawny Grisette (Orange-Brown Ringless Amanita) (DK: Brun KamFluesvamp, FI: Ruostekärpässieni, IS: Rauðserkur, NO: Brun kamfluesopp, SE: Brun kamskivling (Gulbrun kamskivling)).

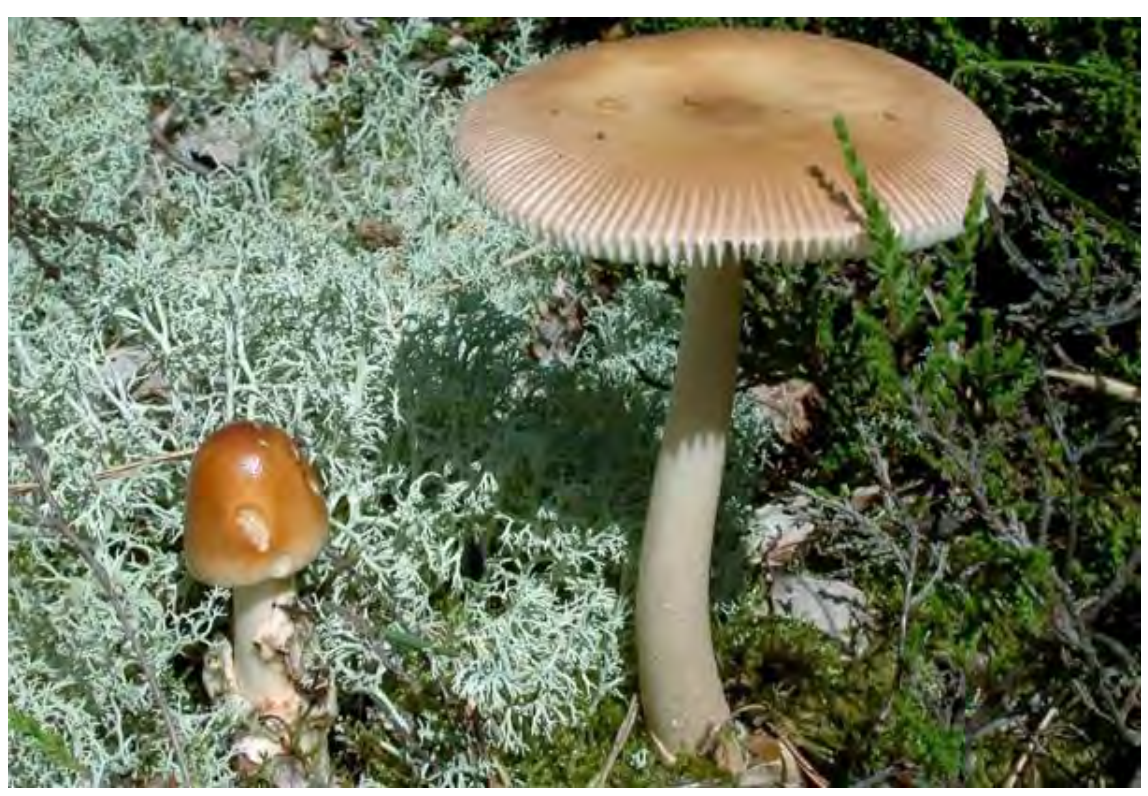

\section{Background and risk assessment}

Tawny Grisette (Amanita fulva) is an edible mushroom.

It forms mycorrhiza in deciduous and mixed forest, with Birch (Betula), Oak (Quercus), and more rarely with Beech (Fagus). It is very common in temperate and subalpine areas of the Nordic countries (Knudsen \& Vesterholt, 2012).

There are no intoxications reported after consumption of Tawny Grisette, and no natural toxicant constituting a risk for humans has been identified in the mushroom. There are no intoxications reported after consumption of Tawny Grisette, and no natural toxicant constituting a risk for humans has been identified in the mushroom.

\section{Recommendation}

Immature Tawny Grisette (especially when it looks like "small hen's eggs") may be mistaken for the deadly poisonous Deathcap (A. phalloides) or Destroying Angel (A. virosa) which also may look like "small hen's eggs," when they are very young (See Chapter 4). 
The mushroom is therefore not regarded as suitable for commercial marketing.

\section{Listing 3}

\section{Database search information}

PubMed by June 2012. Keywords: Amanita fulva.

\section{References}

Knudsen H \& Vesterholt J (2012): Funga Nordica. Agaricoid, boletoid, clavarioid, cyphelloid and gastroid genera. Nordsvamp: 1-1083. 


\section{Amanita rubescens Pers.}

Blusher (DK: Rødmende Fluesvamp, FI: Ruskokärpässieni, IS: No Icelandic name, NO: Rødnende fluesopp, SE: Rodnande flugsvamp).

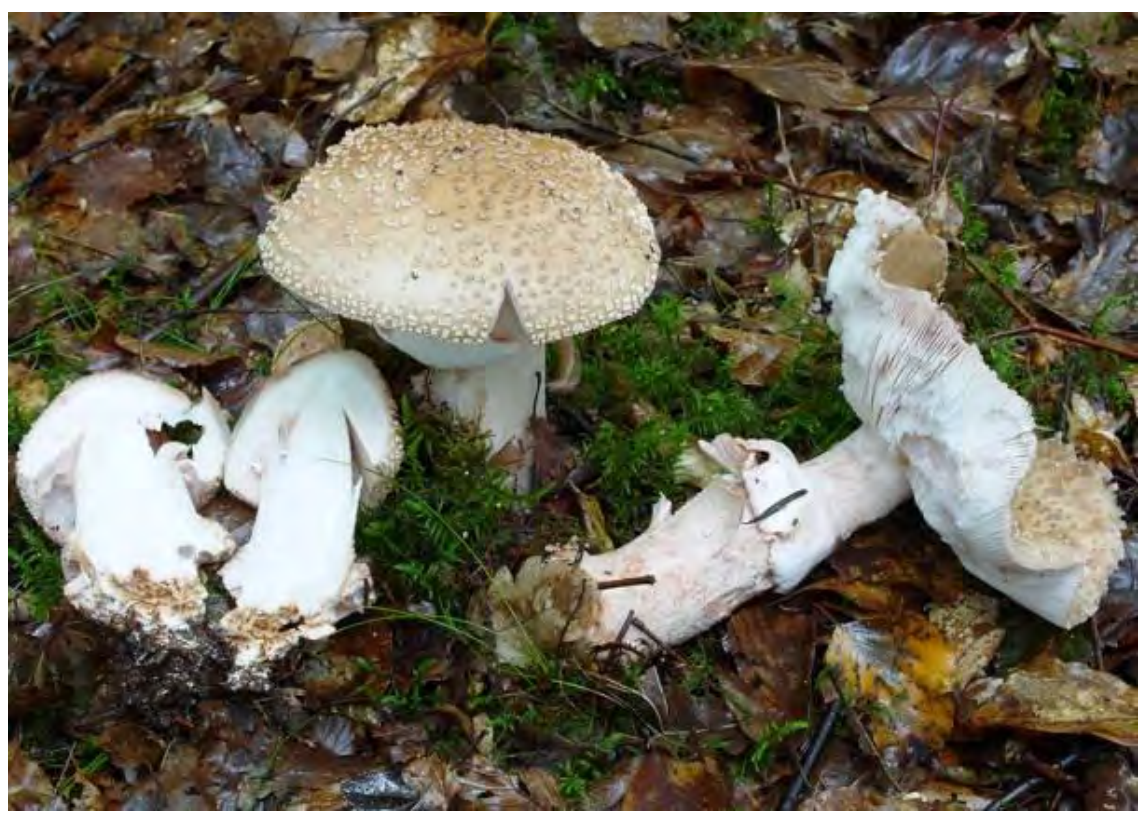

\section{Background and risk assessment}

Blusher (Amanita rubescens) is considered as an edible mushroom.

It forms mycorrhiza with both deciduous and coniferous trees. It is very common in temperate-hemiboreal areas, common in boreal areas and occasional in subarctic-subalpine areas of the Nordic countries (Knudsen \& Vesterholt, 2012).

A few reports of severe gastrointestinal symptoms after consumption of Blusher have been described, but it is not clear whether the mushrooms have been sufficiently cooked (Beug et al., 2006). Some bioactive constituents have been reported in Blusher.

\section{Bioactive constituents}

Cytolysins: Blusher contains the hemolysin rubescenslysin, which is a potent toxicant after parenteral administration to mice or rats (Seeger et al., 1981). In experimental studies rubescenslysin damages various organs and tissues, isolated from experimental animals, within a few minutes in a dose-dependent and practically irreversible manner, as well as causes lysis of human erythrocytes and leucocytes (Odenthal et al., 1982; Seeger, 
1980). However, this cytolytic protein is usually either destroyed during cooking and digestion or not absorbed from the gastrointestinal tract.

Amatoxins/phallotoxins: In a study analysing for the occurrence of amatoxins in various toxic and edible mushrooms, Faulstich \& CochetMeilhac (1976) reported extremely low levels of amatoxins in Blusher, $10^{5}$ times lower levels than in Deathcap (Amanita phalloides) and Destroying Angel (Amanita virosa). Two different analytical methods were used in these studies, a radioimmunological assay and an enzyme (RNA polymerase B) inhibition assay. It was concluded that the amounts of amatoxins found in the different edible mushrooms, including Blusher (6,5-7,5 microgram per kg fresh Blusher) in these two studies, are of no toxicological concern in relation to consumption of Blusher (Benjamin, 1995; Faulstich \& Cochet-Meilhac, 1976).

The occurrence of trace amounts of amatoxins and/or phallotoxins in Blusher has also been reported by Mullersman \& Preston (1982) and by Vargas et al. (2011), but could not be confirmed in several other studies. However, the limits of detection in the studies by Clarke et al. (2012) and Yocum \& Simons (1977) were so high that the levels reported by Faulstich \& Cochet-Meilhac (1976) would not have been detected. Using sufficiently sensitive and specific analytical methods, as for example the method developed by Enjalbert et al. $(1992,1993)$, neither Hallen et al. (2002) nor Faulstich (as referred by Wieland in 1986) could detect any amatoxin in Blusher. The chemical analytical protocol worked out by Enjalbert (1992) included high-performance liquid chromatography and confirmation by mass spectrometry and was sensitive enough to detect nanogram quantities of amatoxins (and phallotoxins). Enjalbert et al. (1993) refuted the findings of trace amounts (nanogram $/ \mathrm{kg}$ ) in Blusher (and other edible mushrooms, e.g. Cep (Boletus edulis) and Chanterelle (Cantharellus cibarius) due to methodological considerations. The levels found by Faulstich \& Cochet-Meilhac (1976), either using a radioimmunoassay (RIA) or an enzyme inhibition assay were at the limits of detection and could be accounted for by contamination. When Faulstich repeated the assay in a different laboratory using new glassware, no toxins were detected in Blusher (Wieland, 1986). Furthermore, the results obtained by bioassays, may have been interfered by other compounds in the mushroom extract (Enjalbert et al., 1993; Wieland, 1986).

Altogether, it is unlikely that Blusher contains even trace amounts of amatoxins. 


\section{Recommendation}

Blusher (Amanita rubescens) resembles Panthercap (A. pantherina), which is very poisonous (See Chapter 4).

The mushroom is therefore not regarded as suitable for commercial marketing.

\section{Listing 3}

\section{Database search information}

PubMed by June 2012. Keywords: Amanita rubescens.

\section{References}

Benjamin D (1995): Mushrooms: Poisons and panaceas. W.H. Freeman and Company: $1-422$.

Beug MW, Shaw M \& Cochran KW (2006): Thirty-plus years of mushroom poisoning: Summary of the approximately 2,000 reports in the NAMA Case Registry. Mcllvainea 16: 47-67.

Bresinsky A \& Besl H (1985): Giftpilze, Wissenschaftliche Verlagsgesellschaft mbH Stutgart: 1-295.

Clarke DB, Lloyd AS \& Robb P. (2012): Application of liquid chromatography coupled to time-to-flight mass spectrometry separation for rapid assessment of toxins in Amanita mushrooms. Analytical methods 4: 1298-1309.

Enjalbert F, Gallion C, Jehl F, Monteil H \& Faulstich H (1992): Simultaneous assay for amatoxins and phallotoxins in Amanita phalloides Fr. by high-performance liquid chromatography. Journal of Chromatography 598: 227-236.

Enjalbert F, Gallion C, Jehl F \& Monteil H (1993): Toxin content, phallotoxin and amatoxin composition of Amanita phalloides tissues. Toxicon 31: 803-807.

Faulstich H \& Cochet-Meilhac M (1976): Amatoxins in edible mushrooms. FEBS Letters 64: 73-75.

Flammer R \& Horak E (2003): Giftpilze - Pilzgifte. Schwabe. Basel: 1-204.

Hallen HE, Adams GC \& Eicker A (2002): Amatoxins and phallotoxins in indigenous South African Amanita species. South African Journal of Botany 68: 322-326.

Knudsen H \& Vesterholt J (2012): Funga Nordica. Agaricoid, boletoid, clavarioid, cyphelloid and gastroid genera. Nordsvamp: 1-1083.

Mullersman JE \& Preston JF (1982): A microassay for phallotoxins: Quantification of phallotoxins in Amanita species. Analytical Biochemistry 119: 266-273.

Odenthal KP, Seeger R, Braatz R, Petzinger E, Moshaf H \& Schmitz-Dräger C (1982): Damage in vitro to various organs and tissues by rubescenslysin from the edible mushroom Amanita rubescens. Toxicon 20: 765-781.

Roth L, Frank H \& Kormann K (1990): Giftpilze-Pilzgifte, Schimmelpilze-Mykotoxine. Ecomed Verlagsgesellschaft: 1-327.

Seeger R. (1980): Studies on rubescenslysin haemolysis. Naunyn-Schmiedeberg's Archives Pharmacology 311: 95-103.

Seeger R, Odenthal KP \& Mengs U (1981): Toxic effects in mouse and rat of rubescenslysin from Amanita rubescens. Toxicon 19: 409-417. 
Vargas N, Bernal A, Sarria V, Franco-Molano A \& Restrepo S (2011): Amatoxin and phallotoxin composition in species of the genus Amanita in Colombia: A taxonomic perspective. Toxicon 58: 583-590.

Wieland T (1986): Peptides of poisonous Amanita mushrooms. Springer Verlag: 1-256.

Yocum RR \& Simons DM (1977): Amatoxins and phallotoxins in Amanita species in the Northeastern United States. Lloydia 40: 178-190. 


\section{Armillaria borealis Marxm \& Korhonen}

No English name (DK: Nordlig Honningsvamp ("Honningsvamp"), FI: Pohjanmesisieni, IS: Hunangssveppur, NO: Skoghonningsopp, SE: Vanlig honungsskivling).

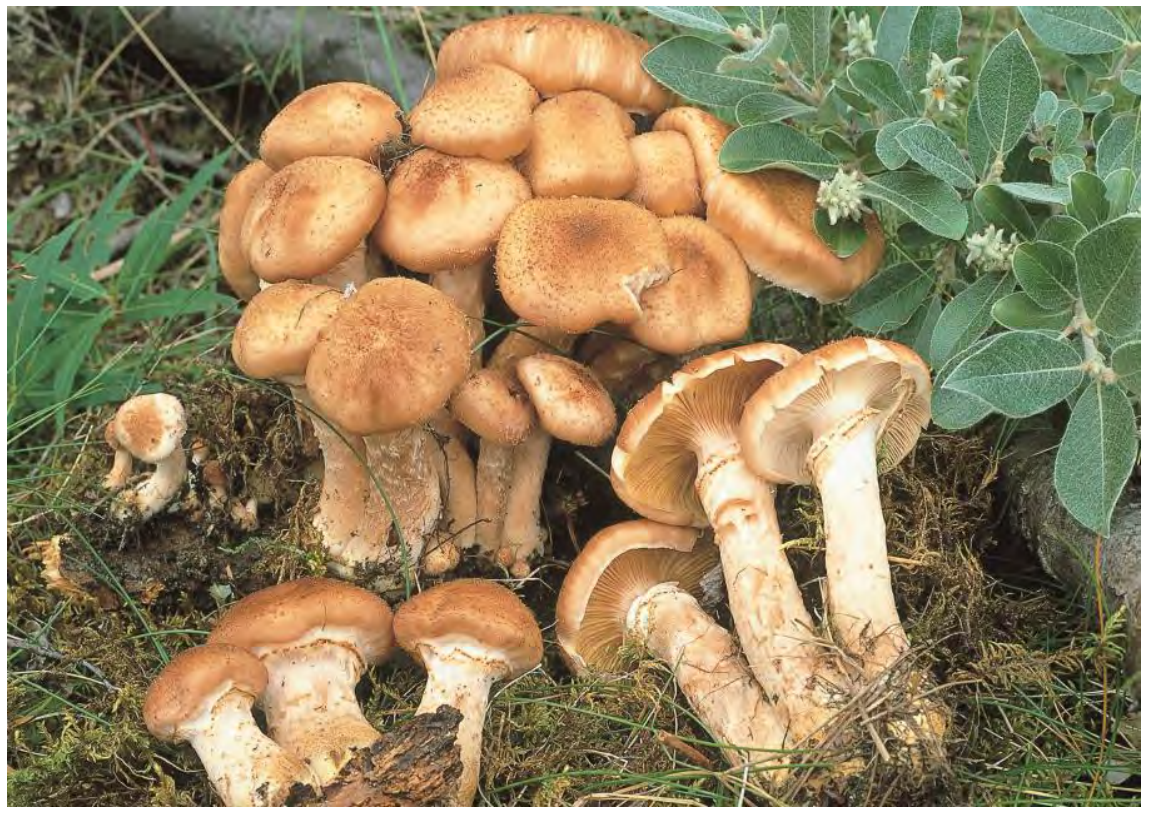

\section{Background and risk assessment}

There are six species of the genus Armillaria (Fr.) Staude (Armillaria (P. Karst.) P. Karst.), which can be found in the Nordic countries (Knudsen \& Vesterholt, 2012). Five of these have a ring: $A$. borealis and the four very similar Armillaria species ("Honey Fungus" species) A. cepistipes, A. lutea (Bulbous Honey Fungus), A. mellea (Honey Fungus) and A. ostoyae (Dark Honey Fungus) and these five are often referred to just as "Honey Fungus" (or the "Honey Fungus complex") as they are very difficult to distinguish from each other.

"Honey Fungus" is generally regarded as edible when thoroughly cooked (Knudsen \& Petersen, 2007; Mazzo, 2000; Læssøe, 2004), although it is indicated that even thoroughly cooked "Honey Fungus" sometimes may give rise to intoxications with gastrointestinal disturbances in some individuals (Bresinsky \& Besl, 1985; Holmberg \& Marklund, 1996; Roth et al., 1990; Seeger, 1995). It is often recommended only to use young caps and possibly also to boil the "Honey Fungus" and then dis- 
charge the water before further cooking (Laux, 2001; 2005; Egeland \& Myhr, 2003; Korhonen, 1986).

Consumption of insufficiently cooked or raw "Honey Fungus" does give rise to many intoxications (Beug et al., 2006; Muszynska et al., 2011a and Liebenow et al., 1994). The intoxications are relatively harmless, but unpleasant with nausea, diarrhoea and stomach pains (Roth et al., 1990; Watling, 1995). Latency time from consumption to symptoms appearing from 15 minutes to 24 hours has been reported (Roth et al., 1990; Bresinsky \& Besl, 1985; Beug et al., 2006). It has been estimated without specifying the cooking conditions - that $10-20 \%$ of people who eat specimens of the Armillaria mellea complex do get gastrointestinal disturbances (Benjamin, 1995).

Armillaria species ("Honey Fungus" species) are not listed in the Danish, Norwegian and Swedish guidance lists on edible wild mushrooms. ${ }^{7}$

It grows parasitically or saprotrophically on deciduous and coniferous wood. The occurrence of $A$. borealis is occasional in Denmark, but is very common in boreal zone and occasional in temperate-hemiboreal and subalpine zones of the other Nordic countries (Knudsen \& Vesterholt, 2012).

There is no information available on whether A. borealis is commercially available as dried mushrooms.

\section{Bioactive constituents}

The heat-labile toxicant (or toxicants) responsible for intoxication with "Honey Fungus" is unknown, but a series of natural constituents (polysaccharides, sterols, sesquiterpenoids, indole compounds, statins, ergothioneine and others) have been identified in Armillaria species (Chen et al., 2012; Lee et al., 2009 ; Guo \& Guo, 2011; Momose et al., 2000; Muszynska et al., 2011a; 2011b and Vaz et al., 2011). Several of these compounds have in in vitro and animal studies been shown to have significant biological activities (Gao et al., 2009). It is remarkable that approximately 40 sesquiterpene aryl esters (melleolides) have been identified in the Armillaria mellea complex (Gao et al., 2009). The majority of these are substituted tricyclic sesquiterpenes with a four-membered, a five-membered and a six-membered ring in which a hydroxyl group is esterified with an aromatic substituted carboxylic acid and often substituted with chlorine in the aromatic or the alicyclic part. Several of these esterified terpenes have experimentally been shown to have antimicrobial and cytotoxic effects (Gao et al., 2009; Shen et

\footnotetext{
${ }^{7}$ For the time being (June 2012) Armillaria species are legally marketed in Finland, but the status is subject to change.
} 
al., 2009; Misiek et al., 2009; Bohnert et al., 2011). It has been suggested that these biologically active esters contribute to the human toxicity of "Honey Fungus" (Teuscher \& Lindequist, 1994).

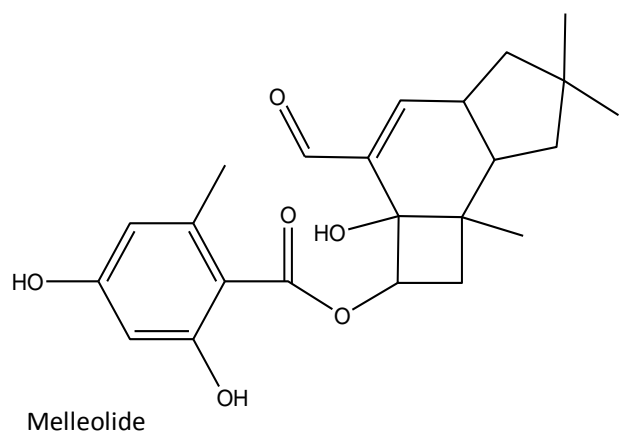

\section{Recommendation}

A. borealis (and other Honey Fungus species (A. cepistipes, A. lutea (Bulbous Honey Fungus), and A. mellea (Honey Fungus)) should never be eaten raw, should be thoroughly cooked, and should only be eaten in small amounts, when eaten for the first time.

However, A. borealis (as well as A. cepistipes, A. lutea (Bulbous Honey Fungus) and $A$. mellea (Honey Fungus)) are very difficult to distinguish from the toxic Dark Honey Fungus (A. ostoyae), and should therefore not be used for commercial marketing.

\section{Database search information}

PubMed June 2012. Keywords: Armillaria.

\section{Listing 3}

\section{References}

Benjamin D (1995): Mushrooms: Poisons and panaceas. W.H. Freeman and Company: $1-422$.

Beug MW, Shaw M \& Cochran KW (2006): Thirty-plus years of mushroom poisoning: Summary of the approximately 2,000 reports in the NAMA Case Registry. Mcllvainea 16: 47-67.

Bohnert M, Merthbauer S, Dahse H-M, Ziemen J, Nett M and Hofmester D (2011): In vitro cytotoxicity of melleolide antibiotics: Structural and mechanistic aspects. Bioorganic \& Medicinal Chemistry Letters 21: 2003-2006.

Bresinsky A \& Besl H (1985): Giftpilze, Wissenschaftliche Verlagsgesellschaft mbH Stutgart: 1-295.

Chen S-Y, Ho K-J, Hsieh Y-J, Wang L-T \& Mau J-L (2012): Contents of lovastatin, $\gamma$ aminobutyric acid and ergothioneine in mushroom fruiting bodies and mycelia. Food Science and Technology 47: 274-278. 
Egeland I L \& Myhr S (2003): Norske sopper, Gyldendal: 1-296.

Gao LW, Li WY, Zhao YL and Wang J W (2009): The cultivation, bioactive components and pharmacological effects of Armillaria mellea. African Journal of Biotechnology 8 (25): 7383-7390.

Guo J W \& Guo S X (2011): Triterpene from Armillaria mellea. Chemistry of Natural Compounds 46: 995-996.

Holmberg P \& Marklund H (1996): Nya Svampboken. Raben Prisma, Stockholm: 1-251.

Knudsen H \& Petersen J H (2007): Politikens svampebog, Politikens forlag: 1-313.

Knudsen H \& Vesterholt J (2012): Funga Nordica. Agaricoid, boletoid, clavarioid, cyphelloid and gastroid genera. Nordsvamp: 1-1083.

Korhonen M (1976): Svampe i vor natur. Gyldendal: 1-181.

Laux H E (2001): Der grosse Kosmos Pilzführer. Kosmos: 1-718.

Lee WY; Park E-J, Jin K \& Ka K-H (2009): Ergothioneine contents in fruiting bodies and their enhancement in mycelial cultures by addition of methionine. Mycobiology 37: 43-47.

Liebenow H, Nauschütz W \& Heinemeyer G (1994): Vergiftung durch Pilzverzeh im Erwachsenen - und Kindersalter. Bundesgesundheitsblatt 6: 242-247.

Læssøe T (2004): Find og spis de bedste svampe. Gyldendal: 1-89.

Mazza R (2000): Fungi commestibili e velenosi a confronto, Fabbri Editori: 1-320.

Misiek M, Williams J, Schmich K, Hüttel W, Merfort I, Salomon CE, Aldrich CC and Hoffmeister D (2009): Structure and cytotoxicity of arnamial and related fungal sesquiterpene aryl esters. Journal of Natural Products 72: 1888-1891.

Momose I, Sekizawa R, Iinuma H, Matsui S, Nakamura H, Naganawa H, Hamada M and Takeuuch, T (2000): Melleolides K, L and M, new melleolides from Armillaria mellea. Journal of Antibiotics: 137-143.

Muszynska B, Sulkowska-Ziaja K, Wolkowska M and Ekiert H (2011a): Chemical, pharmacological, and biological characterization of the culinary-medicinal Honey Mushroom, Armillaria mellea (Vahl) P. Kumm. (Agaricomycedeae): A review. International Journal of Medicinal Mushrooms 13: 167-175.

Muszynska B, Maslanka A, Ekiert H \& Sulkowska-Ziaja S (2011b): Analysis of indole compounds in Armillaria mellea fruiting body. Acta Poloniae Pharmaceutica 1: 93-97.

Peipp H \& Sonnenbichler J (1992): Occurrence of antibiotic compounds in cultures of Armillaria ostoyae growing in the presence of an antagonistic fungus in host plant cells. Biological Chemistry Hoppe-Seyler 373: 675-683.

Roth L, Frank H \& Kormann K (1990): Giftpilze - Pilzgifte: Schimmelpilze - Mykotoxine, Ecomed: 1-327.

Shen J-W, Ma B-J, Li W, Yu H-Y, Wu T-T \& Ruan Y (2009): Activity of armillarisin B invitro against plant pathogenic fungi. Zeitschrift für Naturforschung 64c: 790-792.

Teuscher E \& Lindequist U (1994): Biogene Gifte, Gustav Fischer: 1-681.

Vaz JA, Barros L, Martins A, Santos-Buelga C, Vasconcelos MH \& Ferreira ICF (2001): Chemical composition of wild edible mushrooms and antioxidant properties of their water souble polysaccharidic and ethanolic fractions. Food Chemistry 126: 610-616. Watling R (1995): Children and toxic fungi, Royal Botanic Garden, Edinburg: 1-54.

\section{Armillaria bulbosa (Barla) Velen. s. auct.}

\section{See Armillaria lutea.}




\section{Armillaria cepistipes (Velen) X.L. Mao}

No English name (DK: Knoldfodet Honningsvamp ("Honningsvamp"), FI: No Finnish name, IS: Hunangssveppur, NO: Hagehonningsopp, SE: Finfjällig honungsskivling).

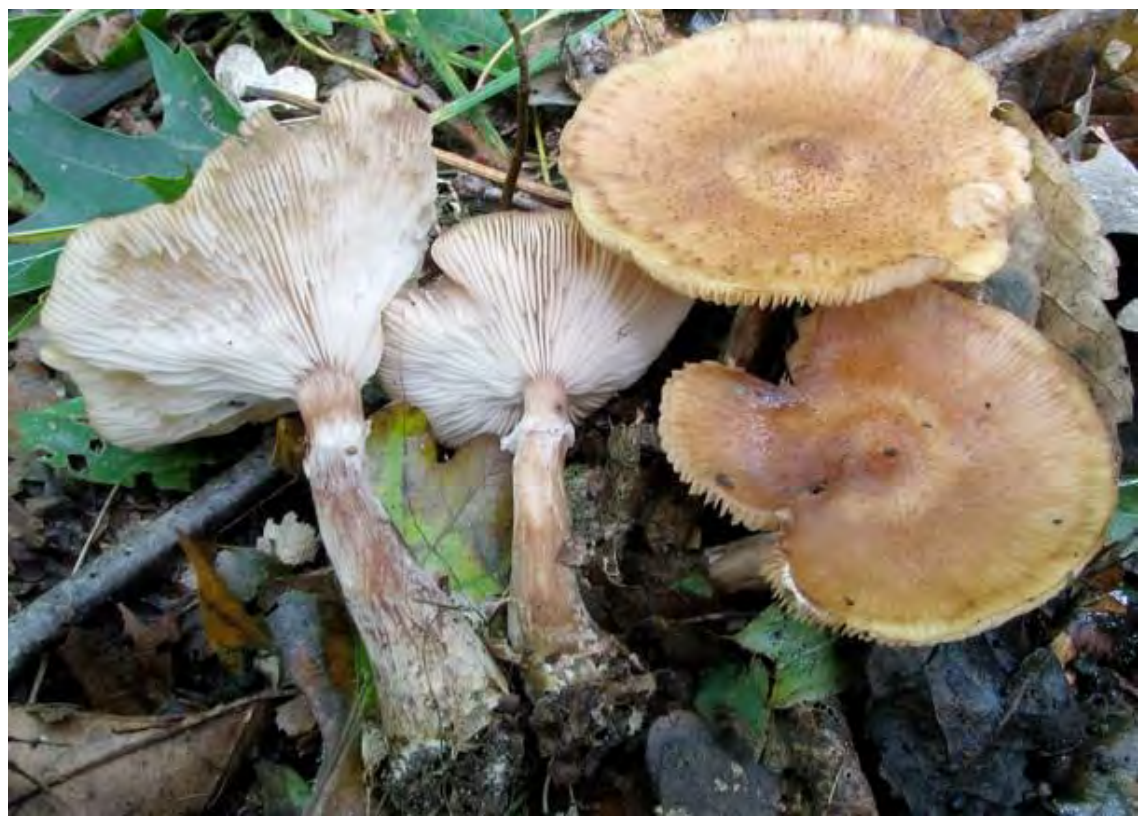

\section{Background and risk assessment}

There are six species of the genus Armillaria (Fr.) Staude (Armillaria (P. Karst.) P. Karst.), which can be found in the Nordic countries (Knudsen \& Vesterholt, 2012). Five of these have a ring: $A$. borealis and the four very similar Armillaria species ("Honey Fungus" species) A. cepistipes, A. lutea (Bulbous Honey Fungus), A. mellea (Honey Fungus) and A. ostoyae (Dark Honey Fungus) and these five are often referred to just as "Honey Fungus" (or the "Honey Fungus complex") as they are very difficult to distinguish from each other.

"Honey Fungus" is generally regarded as edible when thoroughly cooked (Knudsen \& Petersen, 2007; Mazzo, 2000; Læssøe, 2004), although it is indicated that even thoroughly cooked "Honey Fungus" sometimes may give rise to intoxications with gastrointestinal disturbances in some individuals (Bresinsky \& Besl, 1985; Holmberg \& Marklund, 1996; Roth et al., 1990; Seeger, 1995). It is often recommended only to use young caps and possibly 
also to boil the "Honey Fungus" and then discharge the water before further cooking (Laux, 2001; 2005; Egeland \& Myhr, 2003; Korhonen, 1986).

Consumption of insufficiently cooked or raw "Honey Fungus" does give rise to many intoxications (Beug et al., 2006; Muszynska et al., 2011a and Liebenow et al., 1994). The intoxications are relatively harmless, but unpleasant with nausea, diarrhoea and stomach pains (Roth et al., 1990; Watling, 1995). Latency time from consumption to symptoms appearing from 15 minutes to 24 hours has been reported (Roth et al., 1990; Bresinsky \& Besl, 1985; Beug et al., 2006). It has been estimated without specifying the cooking conditions - that $10-20 \%$ of people who eat specimens of the Armillaria mellea complex do get gastrointestinal disturbances (Benjamin, 1995).

Armillaria species ("Honey Fungus" species) are not listed in the Danish, Norwegian and Swedish guidance lists on edible wild mushrooms. ${ }^{8}$

It grows parasitically or saprotrophically on deciduous and coniferous wood. The occurrence of $A$. cepistipes is rare in Denmark and in the temperate hemiboreal and boreal zones of the other Nordic countries, but occasional in temperate-hemiboreal and subalpine zone (Knudsen \& Vesterholt, 2012).

There is no information available on whether A. cepistipes is commercially available as dried mushrooms.

\section{Bioactive constituents}

The heat-labile toxicant (or toxicants) responsible for intoxication with "Honey Fungus" is unknown, but a series of natural constituents (polysaccharides, sterols, sesquiterpenoids, indole compounds, statins, ergothioneine and others) have been identified in Armillaria species (Chen et al., 2012; Lee et al., 2009; Guo \& Guo, 2011; Momose et al., 2000; Muszynska et al., 2011a; 2011b and Vaz et al., 2011). Several of these compounds have in in vitro and animal studies been shown to have significant biological activities (Gao et al., 2009). It is remarkable that approximately 40 sesquiterpene aryl esters (melleolides) have been identified in the Armillaria mellea complex (Gao et al., 2009). The majority of these are substituted tricyclic sesquiterpenes with a four-membered, a five-membered and a six-membered ring in which a hydroxyl group is esterified with an aromatic substituted carboxylic acid and often substituted with chlorine in the aromatic or the alicyclic part. Several of these

\footnotetext{
${ }^{8}$ For the time being (June 2012) Armillaria species are legally marketed in Finland, but the status is subject to change.
} 
esterified terpenes have experimentally been shown to have antimicrobial and cytotoxic effects (Gao et al., 2009; Shen et al., 2009; Misiek et al., 2009; Bohnert et al., 2011). It has been suggested that these biologically active esters contribute to the human toxicity of "Honey Fungus" (Teuscher \& Lindequist, 1994).

\section{Recommendation}

A. cepistipes (and other Honey Fungus species (A. borealis, A. lutea (Bulbous Honey Fungus), and A. mellea (Honey Fungus) should never be eaten raw, should be thoroughly cooked, and should only be eaten in small amounts, when eaten for the first time.

However, A. cepistipes (as well as A. borealis, A. lutea (Bulbous Honey Fungus) and $A$. mellea (Honey Fungus)) are very difficult to distinguish from the toxic Dark Honey Fungus (A. ostoyae), and should therefore not be used for commercial marketing.

\section{Database search information}

PubMed June 2012. Keywords: Armillaria.

\section{Listing 3}

\section{References}

Benjamin D (1995): Mushrooms: Poisons and panaceas. W.H. Freeman and Company: $1-422$.

Beug MW, Shaw M \& Cochran KW (2006): Thirty-plus years of mushroom poisoning: Summary of the approximately 2,000 reports in the NAMA Case Registry. Mcllvainea 16: 47-67.

Bohnert M, Merthbauer S, Dahse H-M, Ziemen J, Nett M and Hofmester D (2011): In vitro cytotoxicity of melleolide antibiotics: Structural and mechanistic aspects. Bioorganic \& Medicinal Chemistry Letters 21: 2003-2006.

Bresinsky A \& Besl H (1985): Giftpilze. Wissenschaftliche Verlagsgesellschaft mbH Stutgart: 1-295.

Chen S-Y, Ho K-J, Hsieh Y-J, Wang L-T \& Mau J-L (2012): Contents of lovastatin, $\gamma$ aminobutyric acid and ergothioneine in mushroom fruiting bodies and mycelia. Food Science and Technology 47: 274-278.

Egeland I L \& Myhr S (2003): Norske sopper. Gyldendal: 1-296.

Gao LW, Li WY, Zhao YL and Wang J W (2009): The cultivation, bioactive compounents and pharmacological effects of Armillaria mellea. African Journal of Biotechnology 8: 7383-7390.

Guo J W \& Guo S X (2011): Triterpene from Armillaria mellea. Chemistry of Natural Compounds 46: 995-996.

Holmberg P \& Marklund H (1996): Nya Svampboken. Raben Prisma Stockholm: 1-251. Knudsen H \& Petersen J H (2007): Politikens svampebog. Politikens forlag: 1-313. 
Knudsen H \& Vesterholt J (2012): Funga Nordica. Agaricoid, boletoid, clavarioid, cyphelloid and gastroid genera. Nordsvamp: 1-1083.

Korhonen M (1976): Svampe i vor natur. Gyldendal 1-181.

Laux H E (2001): Der grosse Kosmos Pilzführer. Kosmos: 1-718.

Lee WY; Park E-J, Jin K \& Ka K-H (2009): Ergothioneine contents in fruiting bodies and their enhancement in mycelial cultures by addition of methionine. Mycobiology 37: 43-47.

Liebenow H, Nauschütz W \& Heinemeyer G (1994): Vergiftung durch Pilzverzeh im Erwachsenen - und Kindersalter. Bundesgesundheitsblatt 6: 242-247.

Læssøe T (2004): Find og spis de bedste svampe. Gyldendal: 1-89.

Mazza R (2000): Fungi commestibili e velenosi a confronto. Fabbri Editori: 1-320.

Misiek M, Williams J, Schmich K, Hüttel W, Merfort I, Salomon CE, Aldrich CC and Hoffmeister D (2009): Structure and cytotoxicity of arnamial and related fungal sesquiterpene aryl esters. Journal of Natural Products: 1888-1891.

Momose I, Sekizawa R, Iinuma H, Matsui S, Nakamura H, Naganawa H, Hamada M and Takeuuch, T (2000): Melleolides K, L and M, new melleolides from Armillaria mellea. Journal of Antibiotics: 137-143.

Muszynska B, Sulkowska-Ziaja K, Wolkowska M and Ekiert H (2011a): Chemical, pharmacological, and biological characterization of the culinary-medicinal Honey Mushroom, Armillaria mellea (Vahl) P. Kumm. (Agricomycedeae): A review. International Journal of Medicinal Mushrooms 13: 167-175.

Muszynska B, Maslanka A, Ekiert H \& Sulkowska-Ziaja S (2011b): Analysis of indole compounds in Armillaria mellea fruiting body. Acta Poloniae Pharmaceutica 1: 93-97.

Peipp H \& Sonnenbichler J (1992): Occurrence of antibiotic compounds in cultures of Armillaria ostoyae growing in the presence of an antagonistic fungus in host plant cells. Biological Chemistry Hoppe-Seyler 373: 675-683.

Roth L, Frank H \& Kormann K (1990): Giftpilze - Pilzgifte: Schimmelpilze - Mykotoxine. Eccomed: 1-327.

Shen J-W, Ma B-J, Li W, Yu H-Y, Wu T-T \& Ruan Y (2009): Activity of Armillarisin B invitro against plant pathogenic fungi. Zeitschrift für Naturforschung 64c: 790-792.

Teuscher E \& Lindequist U (1994): Biogene Gifte. Gustav Fischer: 1-681.

Vaz JA, Barros L, Martins A, Santos-Buelga C, Vasconcelos MH \& Ferreira ICF (2001): Chemical composition of wild edible mushrooms and antioxidant properties of their water souble polysaccharidic and ethanolic fractions. Food Chemistry 126: 610-616.

Watling R (1995): Children and toxic fungi. Royal Botanic Garden, Edinburg: 1-54.

\section{Armillaria gallica Marxm. \& Romagn.}

\section{See Armillaria lutea.}




\section{Armillaria lutea Gillet (A. gallica Marxm. \& Romagn., A. bulbosa (Barla) Velen.s. auct.)}

Bulbous Honey Fungus (DK: Køllestokket Honningsvamp ("Honningssvamp"), FI: Nuijamesisieni, IS: Hunangssveppur, NO: Klubbehonningsopp, SE: Klubbhonungsskivling).

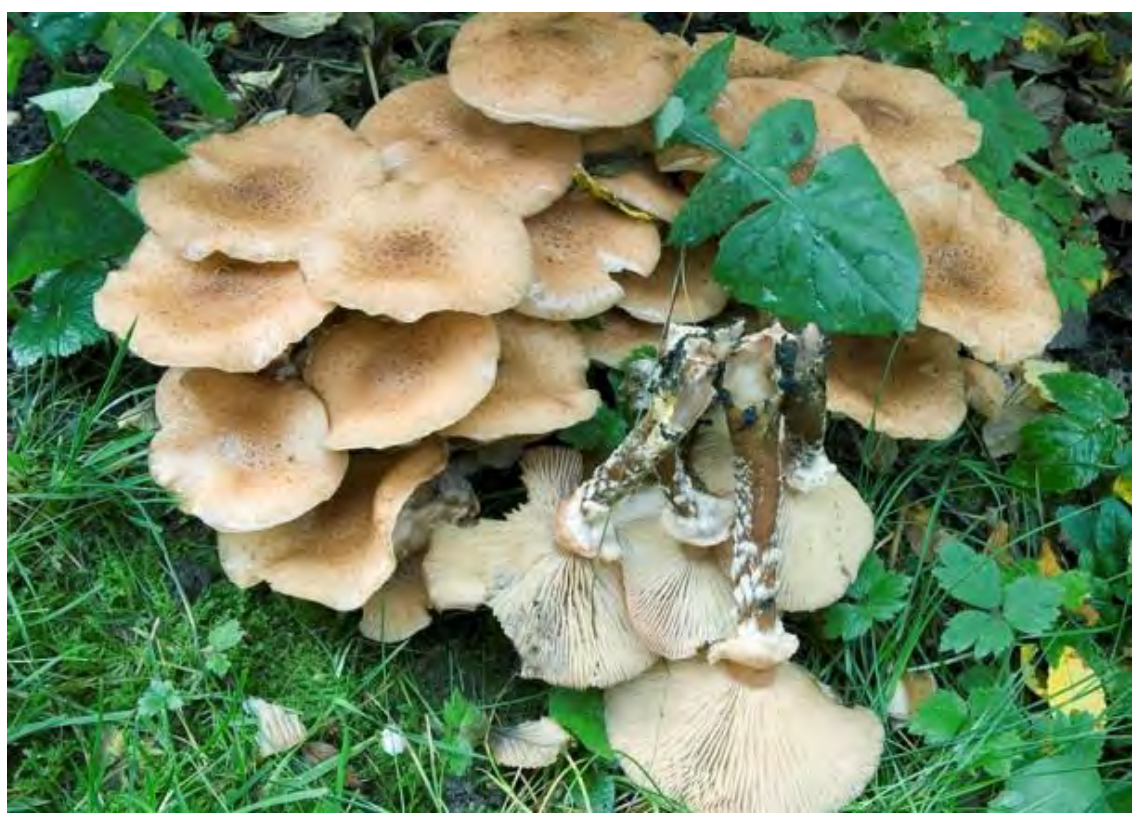

\section{Background and risk assessment}

There are six species of the genus Armillaria (Fr.) Staude (Armillaria (P. Karst.) P. Karst.), which can be found in the Nordic countries (Knudsen \& Vesterholt, 2012). Five of these have a ring: A. borealis and the four very similar Armillaria species ("Honey Fungus" species) A. cepistipes, A. lutea (Bulbous Honey Fungus), A. mellea (Honey Fungus) and A. ostoyae (Dark Honey Fungus) and these five are often referred to just as "Honey Fungus" (or the "Honey Fungus complex") as they are very difficult to distinguish from each other.

"Honey Fungus" is generally regarded as edible when thoroughly cooked (Knudsen \& Petersen, 2007; Mazzo, 2000; Læssøe, 2004), although it is indicated that even thoroughly cooked "Honey Fungus" sometimes may give rise to intoxications with gastrointestinal disturbances in some individuals (Bresinsky \& Besl, 1985; Holmberg \& Marklund, 1996; Roth et al., 1990; Seeger, 1995). It is often recommended only to use young caps and possibly 
also to boil the "Honey Fungus" and then discharge the water before further cooking (Laux, 2001; 2005; Egeland \& Myhr, 2003; Korhonen, 1986).

Consumption of insufficiently cooked or raw "Honey Fungus" does give rise to many intoxications (Beug et al., 2006; Muszynska et al., 2011a; Liebenow et al., 1994). The intoxications are relatively harmless, but unpleasant with nausea, diarrhoea and stomach pains (Roth et al., 1990; Watling, 1995). Latency time from consumption to symptoms appearing from 15 minutes to 24 hours has been reported (Roth et al., 1990; Bresinsky \& Besl, 1985; Beug et al., 2006). It has been estimated without specifying the cooking conditions - that $10-20 \%$ of people who eat specimens of the Armillaria mellea complex do get gastrointestinal disturbances (Benjamin, 1995).

Armillaria species ("Honey Fungus" species) are not listed in the Danish, Norwegian and Swedish guidance lists on edible wild mushrooms. ${ }^{9}$

It grows parasitically or saprotrophically on deciduous rarely on coniferous wood. The occurrence of A. lutea is very common in Denmark and in temperate, hemiboreal and boreal zones of the other Nordic countries, but less common towards north and rare in Iceland (Knudsen \& Vesterholt, 2012).

There is no information available on whether A. lutea is commercially available as dried mushrooms.

\section{Bioactive constituents}

The heat-labile toxicant (or toxicants) responsible for intoxication with "Honey Fungus" is unknown, but a series of natural constituents (polysaccharides, sterols, sesquiterpenoids, indole compounds, statins, ergothioneine and others) have been identified in Armillaria species (Chen et al., 2012; Lee et al., 2009; Guo \& Guo, 2011; Momose et al., 2000; Muszynska et al., 2011a; 2011b and Vaz et al., 2011). Several of these compounds have in in vitro and animal studies been shown to have significant biological activities (Gao et al., 2009). It is remarkable that approximately 40 sesquiterpene aryl esters (melleolides) have been identified in the Armillaria mellea complex (Gao et al., 2009). The majority of these are substituted tricyclic sesquiterpenes with a four-membered, a five-membered and a six-membered ring in which a hydroxyl group is esterified with an aromatic substituted carboxylic acid and often substituted with chlorine in the aromatic or the alicyclic part. Several of these

\footnotetext{
${ }^{9}$ For the time being (June 2012) Armillaria species are legally marketed in Finland, but the status is subject to change.
} 
esterified terpenes have experimentally been shown to have antimicrobial and cytotoxic effects (Gao et al., 2009; Shen et al., 2009; Misiek et al., 2009; Bohnert et al., 2011). It has been suggested that these biologically active esters contribute to the human toxicity of "Honey Fungus" (Teuscher \& Lindequist, 1994).

\section{Recommendation}

Bulbous Honey Fungus (A. lutea) and other Honey Fungus species ( $A$. cepistipes, A. borealis, and A. mellea (Honey Fungus)) should never be eaten raw, should be thoroughly cooked, and should only be eaten in small amounts, when eaten for the first time,

However, Bulbous Honey Fungus (A. lutea. as well as A. cepistipes, A. borealis and $A$. mellea (Honey Fungus)) are very difficult to distinguish from the toxic Dark Honey Fungus (A. ostoyae), and should therefore not be used for commercial marketing.

\section{Database search information}

PubMed June 2012. Keywords: Armillaria.

\section{Listing 3}

\section{References}

Benjamin D (1995): Mushrooms: Poisons and panaceas. W.H. Freeman and Company 1-422.

Beug MW, Shaw M \& Cochran KW (2006): Thirty-plus years of mushroom poisoning: Summary of the approximately 2,000 reports in the NAMA Case Registry. Mcllvainea 16: 47-67.

Bohnert M, Merthbauer S, Dahse H-M, Ziemen J, Nett M and Hofmester D (2011): In vitro cytotoxicity of melleolide antibiotics: Structural and mechanistic aspects. Bioorganic \& Medicinal Chemistry Letters 21: 2003-2006.

Bresinsky A \& Besl H (1985): Giftpilze. Wissenschaftliche Verlagsgesellschaft mbH Stutgart: 1-295.

Chen S-Y, Ho K-J, Hsieh Y-J, Wang L-T \& Mau J-L (2012): Contents of lovastatin, $\gamma$ aminobutyric acid and ergothioneine in mushroom fruiting bodies and mycelia. Food Science and Technology 47: 274-278.

Egeland I L \& Myhr S (2003): Norske sopper. Gyldendal: 1-296.

Gao LW, Li WY, Zhao YL and Wang J W (2009): The cultivation, bioactive compounents and pharmacological effects of Armillaria mellea. African Journal of Biotechnology 8: 7383-7390.

Guo J W \& Guo S X (2011): Triterpene from Armillaria mellea, Chemistry of Natural Compounds 46: 995-996.

Holmberg P \& Marklund H (1996): Nya Svampboken. Raben Prisma, Stockholm: 1-251.

Knudsen H \& Petersen J H (2007): Politikens svampebog. Politikens forlag, 1-313. 
Knudsen H \& Vesterholt J (2012): Funga Nordica. Agaricoid, boletoid, clavarioid, cyphelloid and gastroid genera. Nordsvamp: 1-1083.

Korhonen M (1976): Svampe i vor natur. Gyldendal 1-181.

Laux H E (2001): Der grosse Kosmos Pilzführer. Kosmos: 1-718.

Lee WY; Park E-J, Jin K \& Ka K-H (2009): Ergothioneine contents in fruiting bodies and their enhancement in mycelial cultures by addition of methionine. Mycobiology 37: 43-47.

Liebenow H, Nauschütz W \& Heinemeyer G (1994): Vergiftung durch Pilzverzeh im Erwachsenen - und Kindersalter. Bundesgesundheitsblatt 6: 242-247.

Læssøe T (2004): Find og spis de bedste svampe. Gyldendal: 1-89.

Mazza R (2000): Fungi commestibili e velenosi a confronto. Fabbri Editori: 1-320.

Misiek M, Williams J, Schmich K, Hüttel W, Merfort I, Salomon CE, Aldrich CC and Hoffmeister D (2009): Structure and cytotoxicity of arnamial and related fungal sesquiterpene aryl esters. Journal of National Products 72: 1888-1891.

Momose I, Sekizawa R, Iinuma H, Matsui S, Nakamura H, Naganawa H, Hamada M and Takeuuch, T (2000): Melleolides K, L and M, new melleolides from Armillaria mellea. Journal of Antibiotics: 137-143.

Muszynska B, Sulkowska-Ziaja K, Wolkowska M and Ekiert H (2011a): Chemical, pharmacological, and biological characterization of the culinary-medicinal Honey Mushroom, Armillaria mellea (Vahl) P. Kumm.(Agaricomycedeae): A review. International Journal of Medicinal Mushrooms 13: 167-175.

Muszynska B, Maslanka A, Ekiert H \& Sulkowska-Ziaja S (2011b): Analysis of indole compounds in Armillaria mellea fruiting body. Acta Poloniae Pharmaceutica 1: 93-97.

Peipp H \& Sonnenbichler J (1992): Occurrence of antibiotic compounds in cultures of Armillaria ostoyae growing in the presence of an antagonistic fungus in host plant cells. Biological Chemistry Hoppe-Seyler 373: 675-683.

Roth L, Frank H \& Kormann K (1990): Giftpilze - Pilzgifte: Schimmelpilze - Mykotoxine, Eccomed: 1-327.

Shen J-W, Ma B-J, Li W, Yu H-Y, Wu T-T \& Ruan Y (2009): Activity of armillarisin B in vitro against plant pathogenic fungi. Zeitschrift für Naturforschung 64c: 790-792.

Teuscher E \& Lindequist U (1994): Biogene Gifte. Gustav Fischer: 1-681.

Vaz JA, Barros L, Martins A, Santos-Buelga C, Vasconcelos MH \& Ferreira ICF (2001): Chemical composition of wild edible mushrooms and antioxidant properties of their water souble polysaccharidic and ethanolic fractions. Food Chemistry 126: 610-616.

Watling R (1995): Children and toxic fungi. Royal Botanic Garden, Edinburg: 1-54. 


\section{Armillaria mellea (Vahl.) P. Kumm. (Armillariella mellea (Vahl.) P. Karst.)}

Honey Fungus (DK: Ægte Honningsvamp ("Honningssvamp"), FI: Keltamesisieni, IS: Hunangssveppur, NO: Ekte honningsopp, SE: Sydlig honungsskivling).

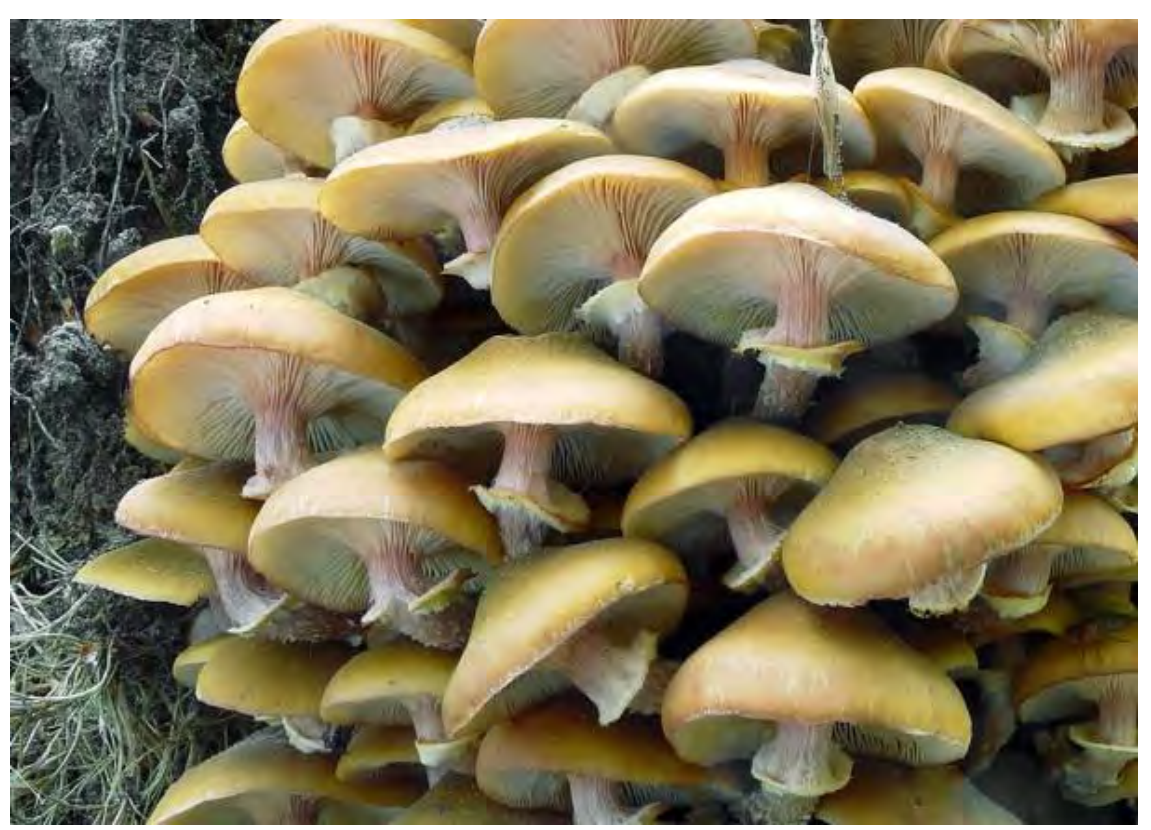

\section{Background and risk assessment}

There are six species of the genus Armillaria (Fr.) Staude (Armillaria (P. Karst.) P. Karst.), which can be found in the Nordic countries (Knudsen \& Vesterholt, 2012). Five of these have a ring: $A$. borealis and the four very similar Armillaria species ("Honey Fungus" species) A. cepistipes, A. lutea (Bulbous Honey Fungus), A. mellea (Honey Fungus) and A. ostoyae (Dark Honey Fungus) and these five are often referred to just as "Honey Fungus" (or the "Honey Fungus complex") as they are very difficult to distinguish from each other.

"Honey Fungus" is generally regarded as edible when thoroughly cooked (Knudsen \& Petersen, 2007; Mazzo, 2000; Læssøe, 2004), although it is indicated that even thoroughly cooked "Honey Fungus" sometimes may give rise to intoxications with gastrointestinal disturbances in some individuals (Bresinsky \& Besl, 1985; Holmberg \& Marklund, 1996; Roth et al., 1990; Seeger, 1995). It is often recommended only to use young caps and possibly 
also to boil the "Honey Fungus" and then discharge the water before further cooking (Laux, 2001; 2005; Egeland \& Myhr, 2003; Korhonen, 1986).

Consumption of insufficiently cooked or raw "Honey Fungus" does give rise to many intoxications (Beug et al., 2006; Muszynska et al., 2011a; Liebenow et al., 1994 and Seeger, 1995). The intoxications are relatively harmless, but unpleasant with nausea, diarrhoea and stomach pains (Roth et al., 1990; Watling, 1995). Latency time from consumption to symptoms appearing from 15 minutes to 24 hours has been reported (Roth et al., 1990; Bresinsky \& Besl, 1985; Beug et al., 2006). It has been estimated - without specifying the cooking conditions - that $10-20 \%$ of people who eat specimens of the Armillaria mellea complex do get gastrointestinal disturbances (Benjamin, 1995).

Armillaria species ("Honey Fungus" species) are not listed in the Danish, Norwegian and Swedish guidance lists on edible wild mushrooms. ${ }^{10}$

It grows parasitically or saprotrophically on deciduous and coniferous wood. The occurrence of $A$. mellea is occasional in Denmark, very rare in Sweden (Scania), but otherwise not found in the Nordic countries, (Knudsen \& Vesterholt, 2012).

There is no information available on whether A. mellea is commercially available as dried mushrooms.

\section{Bioactive constituents}

The heat-labile toxicant (or toxicants) responsible for intoxication with "Honey Fungus" is unknown, but a series of natural constituents (polysaccharides, sterols, sesquiterpenoids, indole compounds, statins, ergothioneine and others) have been identified in Armillaria species (Chen et al., 2012; Lee et al., 2009; Guo \& Guo, 2011; Momose et al., 2000; Muszynska et al., 2011a; 2011b and Vaz et al., 2011). Several of these compounds have in in vitro and animal studies been shown to have significant biological activities (Gao et al., 2009). It is remarkable that approximately 40 sesquiterpene aryl esters (melleolides) have been identified in the Armillaria mellea complex (Gao et al., 2009). The majority of these are substituted tricyclic sesquiterpenes with a four-membered, a five-membered and a six-membered ring in which a hydroxyl group is esterified with an aromatic substituted carboxylic acid and often substituted with chlorine in the aromatic or the alicyclic part. Several of these esterified terpenes have experimentally been shown to have antimicro-

\footnotetext{
${ }^{10}$ For the time being (June 2012) Armillaria species are legally marketed in Finland, but the status is subject to change.
} 
bial and cytotoxic effects (Gao et al., 2009; Shen et al., 2009; Misiek et al., 2009; Bohnert et al., 2011). It has been suggested that these biologically active esters contribute to the human toxicity of "Honey Fungus" (Teuscher \& Lindequist, 1994).

\section{Recommendation}

A. mellea (Honey Fungus) and other Honey Fungus species (A. cepistipes, A. lutea (Bulbous Honey Fungus), and A. borealis) should never be eaten raw, should be thoroughly cooked, and should only be eaten in small amounts, when eaten for the first time.

However, A.borealis (as well as A. cepistipes, A. lutea (Bulbous Honey Fungus) and $A$. mellea (Honey Fungus)) are very difficult to distinguish from the toxic Dark Honey Fungus (A. ostoyae), and should therefore not be used for commercial marketing.

\section{Database search information}

PubMed June 2012. Keywords: Armillaria.

\section{Listing 3}

\section{References}

Benjamin D (1995): Mushrooms: Poisons and panaceas. W.H. Freeman and Company: $1-422$.

Beug MW, Shaw M \& Cochran KW (2006): Thirty-plus years of mushroom poisoning: Summary of the approximately 2,000 reports in the NAMA Case Registry. Mcllvainea 16: 47-67.

Bohnert M, Merthbauer S, Dahse H-M, Ziemen J, Nett M and Hofmester D (2011): In vitro cytotoxicity of melleolide antibiotics: Structural and mechanistic aspects. Bioorganic \& Medicinal Chemistry Letters 21: 2003-2006.

Bresinsky A \& Besl H (1985): Giftpilze. Wissenschaftliche Verlagsgesellschaft mbH Stutgart: 1-295.

Chen S-Y, Ho K-J, Hsieh Y-J, Wang L-T \& Mau J-L (2012): Contents of lovastatin, $\gamma$ aminobutyric acid and ergothioneine in mushroom fruiting bodies and mycelia. Food Science and Technology 47: 274-278.

Egeland I L \& Myhr S (2003): Norske sopper. Gyldendal: 1-296.

Gao LW, Li WY, Zhao YL and Wang J W (2009): The cultivation, bioactive compounents and pharmacological effects of Armillaria mellea. African Journal of Biotechnology 8: 7383-7390.

Guo J W \& Guo S X (2011): Triterpene from Armillaria mellea, Chemistry of Natural Compounds 46: 995-996.

Holmberg P \& Marklund H (1996): Nya Svampboken. Raben Prisma, Stockholm: 1-251.

Knudsen H \& Petersen J H (2007): Politikens svampebog. Politikens forlag: 1-313.

Knudsen H \& Vesterholt J (2012): Funga Nordica. Agaricoid, boletoid, clavarioid, cyphelloid and gastroid genera. Nordsvamp: 1-1083. 
Korhonen M (1976): Svampe i vor natur. Gyldendal: 1-181.

Laux H E (2001): Der grosse Kosmos Pilzführer. Kosmos: 1-718.

Lee WY; Park E-J, Jin K \& Ka K-H (2009): Ergothioneine contents in fruiting bodies and their enhancement in mycelial cultures by addition of methionine. Mycobiology 37: 43-47.

Liebenow H, Nauschütz W \& Heinemeyer G (1994): Vergiftung durch Pilzverzeh im Erwachsenen - und Kindersalter. Bundesgesundheitsblatt 6: 242-247.

Læssøe T (2004): Find og spis de bedste svampe. Gyldendal: 1-89.

Mazza R (2000): Fungi commestibili e velenosi a confronto. Fabbri Editori: 1-320.

Misiek M, Williams J, Schmich K, Hüttel W, Merfort I, Salomon CE, Aldrich CC and Hoffmeister D (2009): Structure and cytotoxicity of arnamial and related fungal sesquiterpene aryl esters. Journal of Natural Products 72: 1888-1891.

Momose I, Sekizawa R, Iinuma H, Matsui S, Nakamura H, Naganawa H, Hamada M and Takeuuch, T (2000): Melleolides K, L and M, new melleolides from Armillaria mellea. Journal of Antibiotics: 137-143.

Muszynska B, Sulkowska-Ziaja K, Wolkowska M and Ekiert H (2011a): Chemical, pharmacological, and biological characterization of the culinary-medicinal Honey Mushroom, Armillaria mellea (Vahl) P. Kumm. (Agaricomycedeae): A review. International Journal of Medicinal Mushrooms 13: 167-175.

Muszynska B, Maslanka A, Ekiert H \& Sulkowska-Ziaja S (2011b): Analysis of indole compounds in Armillaria mellea fruiting body. Acta Poloniae Pharmaceutica 1: 93-97.

Peipp H \& Sonnenbichler J (1992): Occurrence of antibiotic compounds in cultures of Armillaria ostoyae growing in the presence of an antagonistic fungus in host plant cells. Biological Chemistry Hoppe-Seyler 373: 675-683.

Roth L, Frank H \& Kormann K (1990): Giftpilze - Pilzgifte: Schimmelpilze - Mykotoxine. Eccomed: 1-327.

Shen J-W, Ma B-J, Li W, Yu H-Y, Wu T-T \& Ruan Y (2009): Activity of Armillarisin B invitro against plant pathogenic fungi. Zeitschrift für Naturforschung 64c: 790-792.

Teuscher E \& Lindequist U (1994): Biogene Gifte. Gustav Fischer: 1-681.

Vaz JA, Barros L, Martins A, Santos-Buelga C, Vasconcelos MH \& Ferreira ICF (2001): Chemical composition of wild edible mushrooms and antioxidant properties of their water souble polysaccharidic and ethanolic fractions. Food Chemistry 126: 610-616. Watling R (1995): Children and toxic fungi. Royal Botanic Garden, Edinburg: 1-54.

\section{Armillaria obscura (Schaeff.) Horak s. auct.}

\section{See Armillaria ostoyae.}


Armillaria ostoyae (Romagn.)

((Armillariella ostoyae (Romagn.) Henrink, A. obscura

(Schaeff.) Horak s. auct., A. polymyces (Gray)

Singer \& Clémanḉon s. auct.)

Dark Honey Fungus (DK: Mørk Honningsvamp, FI: Mäntymesisieni, IS: Hunanssveppur, NO: Mørk honningsopp, SE: Mörkfjällig honungsskivling).

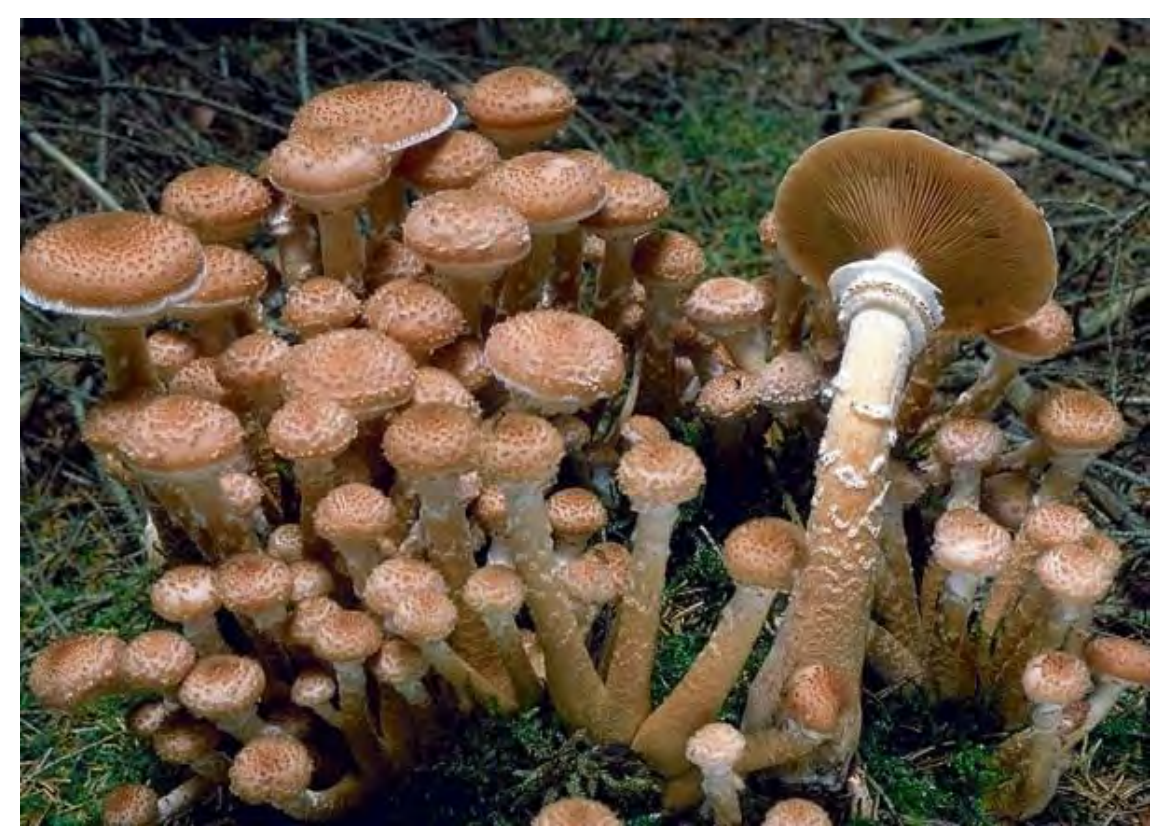

\section{Background and risk assessment}

There are six species of the genus Armillaria (Fr.) Staude (Armillaria (P. Karst.) P. Karst.) which can be found in the Nordic countries (Knudsen \& Vesterholt, 2012). Five of these have a ring: $A$. borealis and the four very similar Armillaria species ("Honey Fungus" species) A. cepistipes, A. lutea (Bulbous Honey Fungus), A. mellea (Honey Fungus) and A. ostoyae (Dark Honey Fungus) and these five are often referred to just as "Honey Fungus" (or the "Honey Fungus complex") as they are very difficult to distinguish from each other.

"Honey Fungus" is generally regarded as edible when thoroughly cooked (Knudsen \& Petersen, 2007; Mazzo, 2000; Læssøe, 2004), although it is indicated that even thoroughly cooked "Honey Fungus" sometimes may give rise to intoxications with gastrointestinal disturbances in some individuals (Bresinsky \& Besl, 1985; Holmberg \& Marklund, 1996; 
Roth et al., 1990; Seeger, 1995). It is often recommended only to use young caps and possibly also to boil "Honey Fungus" and then discharge the water before further cooking (Laux, 2001; 2005; Egeland \& Myhr, 2003; Korhonen, 1986).

Consumption of insufficiently cooked or raw "Honey Fungus" does give rise to many intoxications ((Beug et al., 2006; Muszynska et al., 2011a; Liebenow et al., 1994 and Seeger, 1995). The intoxications are relatively harmless, but unpleasant with nausea, diarrhoea and stomach pains (Roth et al., 1990; Watling, 1995). Latency time from consumption to symptoms appearing from 15 minutes to 24 hours has been reported (Roth et al., 1990; Bresinsky \& Besl, 1985; Beug et al., 2006). It has been estimated - without specifying the cooking conditions - that $10-20 \%$ of people who eat specimens of the Armillaria mellea complex do get gastrointestinal disturbances (Benjamin, 1995).

However, Dark Honey Fungus (A. ostoyae) is especially suspected to give rise to intoxications (Knudsen \& Vesterholt, 2012), even when cooked (Courtecuisse, 1994; Benjamin, 1995; Lamaison \& Polese, 2005).

Armillaria species ("Honey Fungus" species) are not listed in the Danish, Norwegian and Swedish guidance lists on edible wild mushrooms. ${ }^{11}$

Dark Honey Fungus grows parasitically or saprotrophically on coniferous, less often on deciduous wood. It is common in Denmark and temperate-hemiboreal areas of the other Nordic countries and occasional in boreal-subalpine parts (Knudsen \& Vesterholt, 2012).

There is no information available, whether Dark Honey Fungus occasionally is commercially available as dried mushrooms as has been shown to be the case for Honey Fungus (A. mellea).

\section{Bioactive constituents}

The heat-labile toxicant (or toxicants) responsible for intoxication with "Honey Fungus" is unknown, but a series of natural constituents (polysaccharides, sterols, sesquiterpenoids, indole compounds, statins, ergothioneine and others) have been identified in Armillaria species (Chen et al., 2012; Lee et al., 2009; Guo \& Guo, 2011; Momose et al., 2000; Muszynska et al., 2011a; 2011b and Vaz et al., 2011). Several of these compounds have in in vitro and animal studies been shown to have significant biological activities (Gao et al., 2009).

\footnotetext{
11 For the time being (June 2012) Armillaria species are legally marketed in Finland, but the status is subject to change.
} 
It is remarkable that approximately 40 sesquiterpene aryl esters (melleolides) have been identified in the Armillaria mellea complex (Gao et al., 2009). The majority of these are substituted tricyclic sesquiterpenes with a four-membered, a five-membered and a six-membered ring in which a hydroxyl group is esterified with an aromatic substituted carboxylic acid and often substituted with chlorine in the aromatic or the alicyclic part. Several of these esterified terpenes have experimentally been shown to have antimicrobial and cytotoxic effects (Gao et al., 2009; Shen et al., 2009; Misiek et al., 2009; Bohnert et al., 2011). It has been suggested that these biologically active esters contribute to the human toxicity of "Honey Fungus" (Teuscher \& Lindequist, 1994).

\section{Recommendation}

Dark Honey Fungus (A. ostoyae) may give rise to intoxications, even if thoroughly cooked and should therefore not be used in commercial trade.

The toxicant is not known.

\section{Database search information}

PubMed June 2012. Keywords: Armillaria.

\section{Listing 4}

\section{References}

Benjamin D (1995): Mushrooms: Poisons and panaceas. W.H. Freeman and Company: $1-422$.

Beug MW, Shaw M \& Cochran KW (2006): Thirty-plus years of mushroom poisoning: Summary of the approximately 2,000 reports in the NAMA Case Registry. Mcllvainea 16: 47-67.

Bohnert M, Merthbauer S, Dahse H-M, Ziemen J, Nett M and Hofmester D (2011): In vitro cytotoxicity of melleolide antibiotics: Structural and mechanistic aspects. Bioorganic \& Medicinal Chemistry Letters 21: 2003-2006.

Bresinsky A \& Besl H (1985): Giftpilze. Wissenschaftliche Verlagsgesellschaft mbH Stutgart: 1-295.

Chen S-Y, Ho K-J, Hsieh Y-J, Wang L-T \& Mau J-L (2012): Contents of lovastatin, $\gamma$ aminobutyric acid and ergothioneine in mushroom fruiting bodies and mycelia. Food Science and Technology 47: 274-278.

Courtecuisse, R. (1994): Les champignons de France, Eclectis: 1-448.

Egeland I L \& Myhr S (2003): Norske sopper, Gyldendal: 1-296.

Gao LW, Li WY, Zhao YL and Wang J W (2009): The cultivation, bioactive compounents and pharmacological effects of Armillaria mellea. African Journal of Biotechnology 8: 7383-7390.

Guo J W \& Guo S X (2011): Triterpene from Armillaria mellea. Chemistry of Natural Compounds 46: 995-996.

Holmberg P \& Marklund H (1996): Nya Svampboken. Raben Prisma, Stockholm: 1-251. 
Knudsen H \& Petersen J H (2007): Politikens svampebog, Politikens forlag: 1-313.

Knudsen H \& Vesterholt J (2012): Funga Nordica. Agaricoid, boletoid, clavarioid, cyphelloid and gastroid genera. Nordsvamp: 1-1083.

Korhonen M (1976): Svampe i vor natur. Gyldendal 1-181.

Lamaison J-L \& Polese J-M (2005): Encyclopédie Visuelle des Champignons, Artémis: $1-384$.

Laux H E (2001): Der grosse Kosmos Pilzführer. Kosmos: 1-718.

Lee WY; Park E-J, Jin K \& Ka K-H (2009): Ergothioneine contents in fruiting bodies and their enhancement in mycelial cultures by addition of methionine. Mycobiology 37: 43-47.

Liebenow H, Nauschütz W \& Heinemeyer G (1994): Vergiftung durch Pilzverzeh im Erwachsenen - und Kindersalter. Bundesgesundheitsblatt 6: 242-247.

Læssøe T (2004): Find og spis de bedste svampe. Gyldendal: 1-89.

Mazza R (2000): Fungi commestibili e velenosi a confronto. Fabbri Editori: 1-320.

Misiek M, Williams J, Schmich K, Hüttel W, Merfort I, Salomon CE, Aldrich CC and Hoffmeister D (2009): Structure and cytotoxicity of arnamial and related fungal sesquiterpene aryl esters. Journal of Natural Products 72: 1888-1891.

Momose I, Sekizawa R, Iinuma H, Matsui S, Nakamura H, Naganawa H, Hamada M and Takeuuch, T (2000): Melleolides K, L and M, new melleolides from Armillaria mellea. Journal of Antibiotics: 137-143.

Muszynska B, Sulkowska-Ziaja K, Wolkowska M and Ekiert H (2011a): Chemical, pharmacological, and biological characterization of the culinary-medicinal Honey Mushroom, Armillaria mellea (Vahl) P. Kumm. (Agaricomycedeae): A review. International Journal of Medicinal Mushrooms 13: 167-175.

Muszynska B, Maslanka A, Ekiert H \& Sulkowska-Ziaja S (2011b): Analysis of indole compounds in Armillaria mellea fruiting body. Acta Poloniae Pharmaceutica 1: 93-97.

Peipp H \& Sonnenbichler J (1992): Occurrence of antibiotic compounds in cultures of Armillaria ostoyae growing in the presence of an antagonistic fungus in host plant cells. Biological Chemistry Hoppe-Seyler 373: 675-683.

Roth L, Frank H \& Kormann K (1990): Giftpilze - Pilzgifte: Schimmelpilze - Mykotoxine, Eccomed Verlagsgesellschaft: 1-327.

Shen J-W, Ma B-J, Li W, Yu H-Y, Wu T-T \& Ruan Y (2009): Activity of armillarisin B invitro against plant pathogenic fungi. Zeitschrift für Naturforschung 64c: 790-792.

Teuscher E \& Lindequist U (1994): Biogene Gifte. Gustav Fischer: 1-681.

Vaz JA, Barros L, Martins A, Santos-Buelga C, Vasconcelos MH \& Ferreira ICF (2001): Chemical composition of wild edible mushrooms and antioxidant properties of their water souble polysaccharidic and ethanolic fractions. Food Chemistry 126: 610-616. Watling R (1995): Children and toxic fungi. Royal Botanic Garden, Edinburg: 1-54. 
Armillaria polymyces (Gray) Singer \& Clémanḉon s. auct.

See Armillaria ostoyae.

Auricularia auricula (L.) Underw.

See Auricularia auricular-judae. 


\section{Auricularia auricula-judae (Bull.) J. Schröt.}

(A. auricula (L.) Underw.)

Jelly Ear (Jew's Ear, Judae's Ear Fungus (DK: Almindelig Judasøre, FI: Auricularia -puunkorvat, IS: Eyrasveppir, NO: Judasøre, SE: Judasöra).

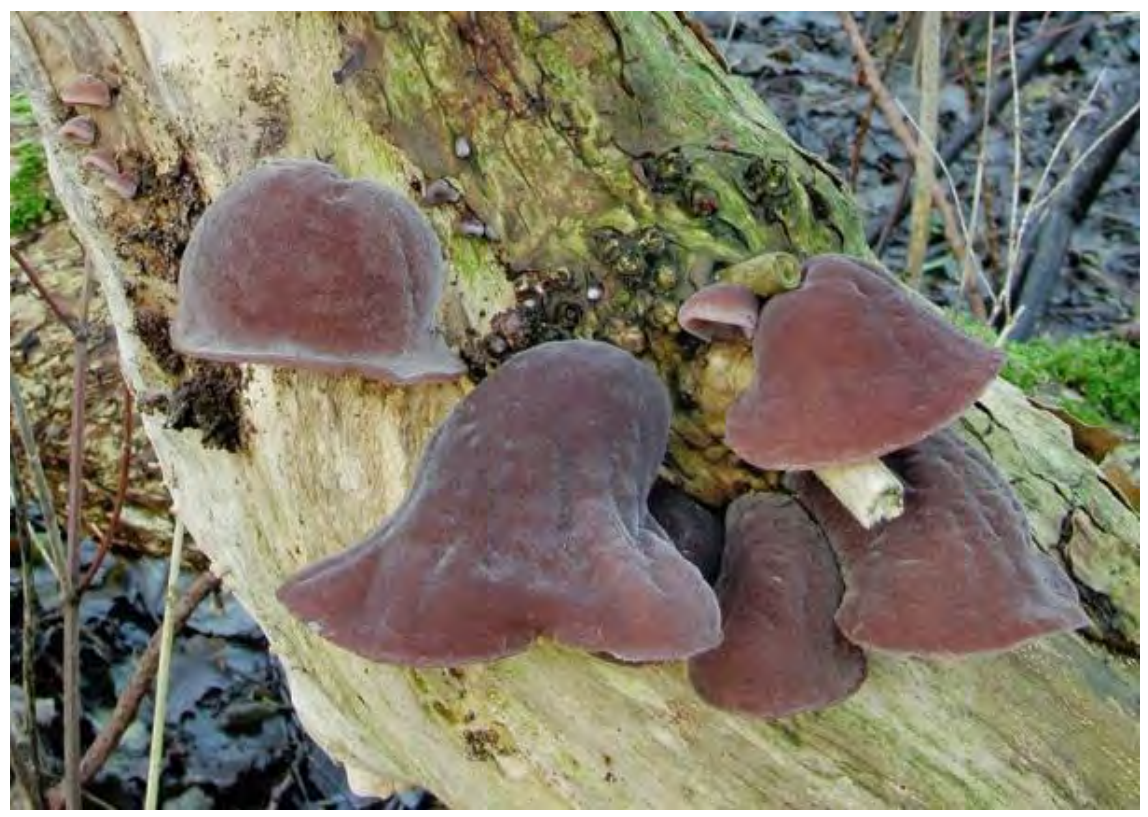

\section{Background and risk assessment}

Jelly Ear (Auricularia auricula-judae) ${ }^{12}$ is an edible mushroom.

It is common in Denmark, occasional in western Scania of Sweden, but otherwise not found in the Nordic countries. It is a saprotrophic mushroom growing on especially Elder (Sambucus nigra) close to the sea, but sometimes also on other deciduous trees (Hansen \& Knudsen, 1997).

There are no intoxications reported after consumption of Jelly Ear, and no natural toxicant constituting a risk for humans has been identified in the mushroom. Except for trace amounts of hydrogen cyanide and except for potential bioactive polysaccharides, there are no publications available dealing with identified bioactive constituents in Jelly Ear. In

12 Danish Mycological Society (2012) uses A. auricula-judae with the combination (Bull.) J.Schröt. [1888], which is older than the combination (Bull.) Wetts. [1897] used by ArtDatabanken (2011) but younger than the combination (Bull.)Quél. [1886] used by Index Fungorum/Species Fungorum (2012). 
one study, hydrogen cyanide was identified at a level of $0.11 \mathrm{mg} / \mathrm{kg}$ of fresh mushroom (Shindo et al., 1999). Such low levels are of no health concern in relation to consumption of Jelly Ear.

\section{Recommendation}

No special recommendation.

\section{Listing 1}

\section{Database search information}

SciFinder by January 2012. Keywords: Auricularia.

\section{References}

ArtDatabanken (2011): http://www.artdata.slu.se/default.asp

Danish Mycological Society (2012): Danish-Latin database on names for fungi. http://www.svampe.dk/databaser/dansk-latinsk-navnedatabase/

Hansen L \& Knudsen H (1997): Nordic Macromycetes, Volume 3. Heterobasidioid, aphyllophoroid and gastromycetoid basidiomycetes. Nordsvamp: 1-444.

Index Fungorum/Species Fungorum (2012): http://www.indexfungorum.org/

Shindo T, Ushiyama H, Kan K \& Yasuda K (1999): Study on content of cyanide in basidiomycetes and the effect of cooking. Journal of Food Hygiene Society of Japan 40: 29-35 (Japanese, English abstract available). 


\section{Auricularia polytricha (Mont.) Sacc. and other Auricularia species}

Ear species (DK: Kinesisk Judasøre og andre Judasøre-arter, FI: Auricularia -puunkorvat, IS: Eyrasveppir, aðrir Eyrasveppir, NO: Geléøre-arter, SE: Skogsöra och andra arter inom geléöronsläktet).

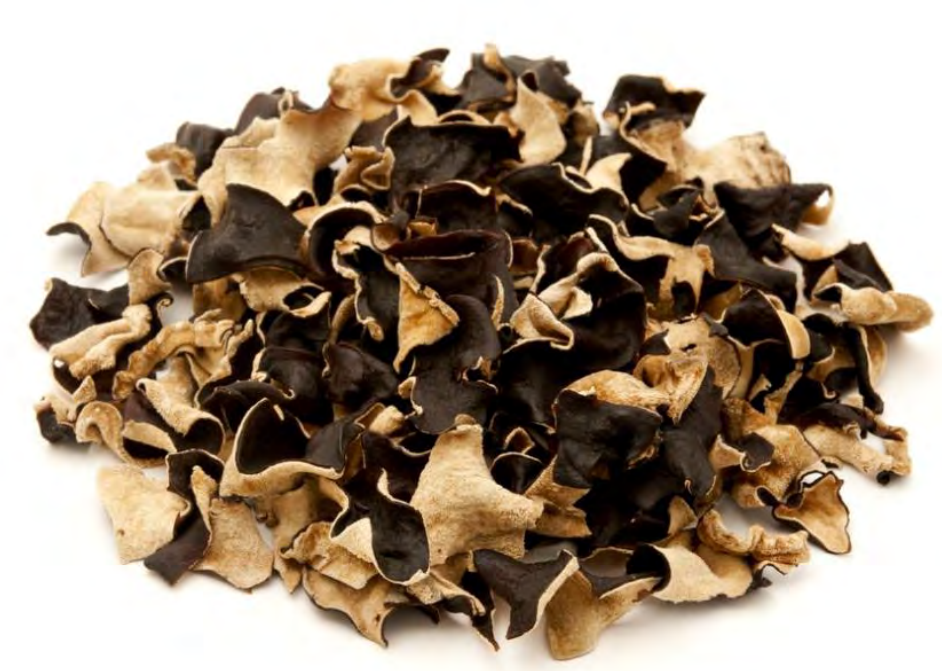

\section{Background and risk assessment}

Auricularia polytrich ${ }^{13}$ and other Auricularia species ("Ear species") are edible mushrooms.

They are saprotrophs and have a worldwide distribution from the temperate to the tropics, growing on living and dead deciduous trees, decayed stomps or logs (Du et al., 2011; Mao, 2000). The mushroom is cultivated, especially in South-East Asia and China, in large amounts.

There are no intoxications reported after consumption of $A$. polytricha, and no natural toxicant constituting a risk for humans has been identified in the mushroom.

${ }^{13}$ Auricularia cornea Ehrenb. is a preferred name instead of $A$. polytricha (Mont.) Sacc. by several authors (e.g., Roberts, 2001). The latter name is preferred by ArtDatabanken (2011) and Index Fungorum/Species Fungorum (2012) and by other authors (e.g., Du et al., 2011). 
Besides studies on potential bioactive polysaccharides, there are only a few publications available on bioactive constituents in A. polytricha.

\section{Bioactive constituents}

Statins: Lo et al. (2012) have identified small amounts $(16 \mathrm{mg} / \mathrm{kg})$ of lovastatin in dried fruit bodies of $A$. polytricha, corresponding to approximately $2 \mathrm{mg} / \mathrm{kg}$ fresh mushroom. For further information on lovastatin, see Pleurotus ostreatus.

Ergothioneine: Traces of ergothioneine, $1.4 \mathrm{mg} / \mathrm{kg}$ dry weight, have been identified in fruit bodies of $A$. polytricha (Lo et al., 2012).

Lectins: A lectin with a molecular weight of approximately $23 \mathrm{kDa}$ was isolated from $A$. polytricha. Its hemagglutinating activity was demonstrated using human and rabbit erythrocytes (Yagi \& Tadera, 1987) but it is not known whether its carbohydrate binding capacity remains after processing of the mushroom.

Mutagens: Extracts prepared from commercial fruit bodies of Auricularia sp. were examined for mutagenic activity in a histidine-independent bacterial test system using the Salmonella typhimurium strain TM677 as indicator organisms for mutagenic activity. The extract was claimed to be weakly positive in S. typhimurium TM677. However, this could be questioned and the authors remark that more information is required to interpret the observation (Grüter et al., 1991).

\section{Recommendation}

No special recommendation.

Listing 1

\section{Database search information}

SciFinder by December 2012. Keywords: Auricularia.

\section{References}

ArtDatabanken (2011): http://www.artdata.slu.se/default.asp

Du P, Cui BK \& Dai YC (2011): Genetic diversity of wild Auricularia polytricha in Yunnan province of south-western China revealed by sequence-related amplified polymorphism (SRAP) analysis. Journal of Medicinal Plants Research 5: 1374-1381.

Grüter A, Friederich U \& Würgler FE (1991): The mutagenicity of edible mushrooms in a histidine-independent bacteral test system. Food Chemical Toxicology 29: 159-65.

Index Fungorum/Species Fungorum (2012): http://www.indexfungorum.org/

Lo YG, Lin SY, Ulzijargal E, Chen SY, Chien RC, Tzou YJ \& Mau JL (2012): Comparative study of contents of several bioactive components in fruiting bodies and mycelia of culinary-medicinal mushrooms. International Journal of Medicinal Mushrooms 14: 357-363. 
Mao XL (2000): The Macrofungi in China: 1-719.

Roberts P (2001): Heterobasiodiomycetes from Korup National Park. Kew Bulletin 56: 163-187.

Yagi F \& Tadera K (1988): Purification and characteriazation of lectin from Auricularia polytricha. Agricultural Biology and Chemistry 52: 2077-2079.

\section{Boletus aestivalis (Paulet) Fr.)}

See Boletus reticulatus.

\section{Boletus badius (Fr.) Fr.)}

See Xerocomus badius. 


\section{Boletus edulis Bull.}

Penny Bun, Cep (DK: Spiselig Rørhat, Karl Johan (Karl Johan-Rørhat), FI: Herkkutatti, IS: Kóngssveppur (Ætiboldungur), NO: Steinsopp, SE: Stensopp, Karljohan (“Karljohansvamp”)).

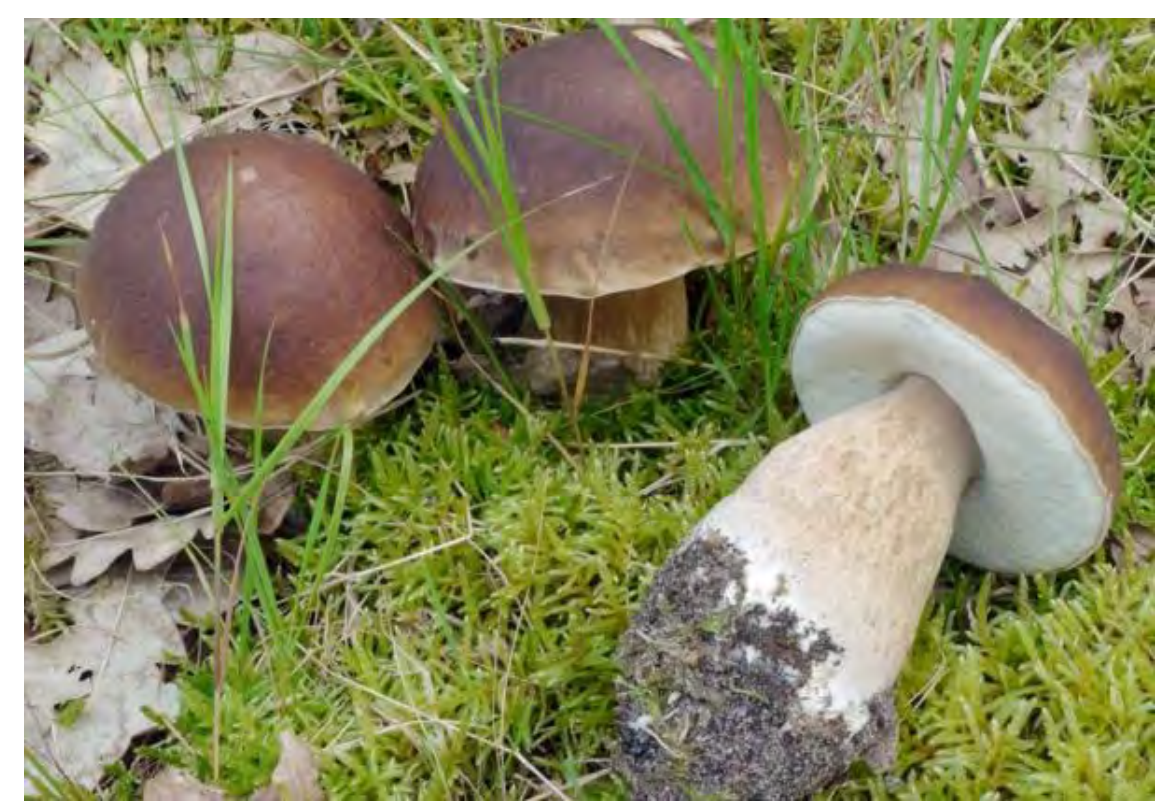

\section{Background and risk assessment}

Cep (Boletus edulis) is a very much appreciated edible mushroom. It is traded as fresh, frozen, canned and dried.

It forms mycorrhiza in both deciduous and coniferous forests. It is very common in Denmark and southern parts of Finland, Norway and Sweden, but rare in subalpine-arctic/alpine areas. It has not been found in arctic/alpine parts of Iceland (Knudsen \& Vesterholt, 2012).

There are no intoxications reported after consumption of Cep (except that in total seven cases of food allergy to Cep are available in the literature, as well as a case of occupational allergic contact dermatitis described by Simeoni et al. (2004) from handling Cep). Beyond allergens also other potential bioactive constituents have been reported in Cep.

\section{Bioactive constituents}

Allergens: Two cases after inhalation/ingestion of the mushroom and two cases of anaphylactic reaction after consumption of Cep were identified during a 20-year period at the university hospital in Zürich (Torricelli et al., 1997). The clinical manifestation in the cases differed from 
oral allergy syndrome with oropharyngeal itching, tingling, and swelling of the lips to asthma and anaphylactic episodes with severe diarrhoea, generalized urticaria, asthma attacks with dizziness, hypotension and tachycardia, leading to hospitalization. Skin prick tests with unprocessed Cep were strongly positive, and in three of the four cases specific IgE could be identified. In a subsequently reported Italian case of food allergy to Cep general itching and diarrhoea appeared 1 hour after mushroom consumption. Serum immunoglobulins from the patient bound to Cep proteins were separated by Roncarolo et al., (1998) using sodium dodecyl sulfate polyacrylamide gel electrophoresis (SDS-PAGE). The immune-blotting identified three bands, two being clear (26 and 39 $\mathrm{kDa}$ ), and one at approximately $14 \mathrm{kDa}$ (weak). Thus, in this case allergy to Cep was confirmed by specific IgE in the patient serum. Helbling et al. (2002a) mention two additional subjects with anaphylaxis following ingestion of Boletus sp. Further insight into the allergens of Cep was given by Helbling et al. (2002b). They exposed Cep extracts to simulated gastric fluid and separated the protein digest by SDS-PAGE before supplying sera from two Cep allergic patients to the gels. Serum from one of the patients reacted positively with a $75-80 \mathrm{kDa}$ protein assumed to be digestion-resistant.

Ergothioneine: Ergothioneine has been demonstrated in quite high amounts in the fruit bodies of Cep, $0.53 \mathrm{~g} / \mathrm{kg}$ (fresh weight) (Ey et al., 2007). It has also been found in an amount of $260 \mathrm{mg} / \mathrm{kg}$ (dry weight, mean of 3 samples) in the mycelia (Lo et al., 2012). For further information on ergothioneine, see Lepista nuda.

Statins: Lo et al. (2012) reported a content of $130 \mathrm{mg} / \mathrm{kg}$ (dry weight, mean of 3 samples) in the mycelia of Cep. It is not known whether lovastatin also is formed in the fruit bodies. For further information on statins, see Pleurotus ostreatus.

Amatoxins: In a study on amatoxins in various toxic and edible mushrooms Faulstich \& Cochet-Meilhac (1976) found extremely low levels of amatoxins in Cep, $10^{5}-10^{6}$ times lower levels than in Deathcap (Amanita phalloides) and Destroying Angel (Amanita virosa). Two different analytical methods were used, a radioimmunological assay and an enzyme (RNA polymerase B) inhibition assay. The amounts of amatoxins found in the different edible mushrooms including Cep $(<0.2-9$ microgram per $\mathrm{kg}$ fresh mushroom) are of no toxicological concern in relation to consumption of Cep (Faulstich \& Cochet-Meilhac, 1976).

Enjalbert et al. (1993) refuted the findings of trace amounts (nanogram $/ \mathrm{kg}$ ) in Cep (and other edible mushrooms, e.g. Blusher (Amanita rubescens) and Chanterelle (Cantharellus cibarius) due to methodological 
considerations. The levels found by Faulstich \& Cochet-Meilhac (1976), either using a radioimmunoassay (RIA) or an enzyme inhibition assay, were at the limits of detection and could be accounted for by contamination. When Faulstich repeated the assay in a different laboratory using new glassware, no toxins were detected in Cep, or the other edible mushrooms studied by Faulstich and Cochet-Meilhac in 1976 (Wieland, 1986). Furthermore, the results obtained by bioassays, may have been interfered by other compounds in the mushroom extract (Enjalbert et al., 1993; Wieland, 1986).

Altogether, it is unlikely that Cep contains even trace amounts of amatoxins.

Lectins: At least two bioactive lectins have been isolated from Cep (Bovi et al., 2011; Zheng et al., 2007). Generally, lectins are not thermostable and will be destroyed during cooking. One of the lectins in Cep has been examined during heating and its hemagglutinating activity was reduced to $50 \%$ at $65^{\circ} \mathrm{C}$ and completely abolished above $75^{\circ} \mathrm{C}$ (Zheng et al., 2007). The toxicity (gastrointestinal adverse effects) of some poisonous Boletus species (B. satanas and B. venenatus) is probably due to their content of thermostable lectins as shown by e.g. Gachet et al. (1996) and by Horibe et al. (2010), respectively. Whether the lectins in Cep could give rise to discomfort in some people eating raw or poorly processed Cep is not known.

Mutagens: According to von Wright and colleagues (1982) extracts of Cep are mutagenic in the Ames test. As this test system detects backmutations from histidine requirement to histidine auxotrophy, presence of histidine in the test solution has the capability of inducing false positives. The publication of von Wright et al. (1982) does not mention whether the potential extraction of histidine in the solution tested was controlled for. The presence of histidine could have resulted in false positives. However, also Grüter et al. (1991) could demonstrate a weakly mutagenic activity of extracts of Cep using a histidine-independent bacterial system. Whether the mutagens are destroyed during food preparation is unknown.

Sesquiterpenoids: Three hydroxylated botryane sesquiterpenoids have been identified in Cep. One of them, boledulin A, has in in vitro studies been investigated for potential health promoting effects and shown moderate cytotoxic effects, but none of these terpenoids have been studied for potentially adverse effects (Feng et al., 2011).

Indole constituents: Cep contains a series of simple biologically active indole compounds (L-tryptophan, 5-hydroxytryptophan, serotonin, melatonin and tryptamine) (Muszynska et al., 2011, 2012). It was demon- 
strated that boiling of Cep fruit bodies significantly changed the content of these indoles. 5-Hydroxytryptophan, melatonin and serotonin were completely decomposed, and tryptophan had been formed in amounts of $84 \mathrm{mg} / \mathrm{kg}$ (dry weight) corresponding to approximately $8 \mathrm{mg} / \mathrm{kg}$ (fresh weight). Some of these constituents are tissue hormones and neurotransmitters and high intakes of tryptophan can damage the nervous system (Stone et al., 2003).

Animal studies: In a feeding study on Yellow Knight (Tricholoma equestre) in mice, a reference group receiving $9 \mathrm{~g}$ dried, powdered Cep was included. This dose corresponds to $62 \mathrm{~g}$ of fresh Cep, or for a person weighing $70 \mathrm{~kg}$ to $4.3 \mathrm{~kg} \mathrm{Cep} /$ day. The animals were sacrificed after 5 days feeding. Body mass, feed and water intake, liver and kidney weights and biochemical parameters were measured. Feed and water intake and creatine kinase activity were significantly increased compared to the control animals receiving a regular mouse feed (Nieminen et al., 2005).

\section{Recommendation}

No special recommendation.

\section{Listing 1}

\section{Database search information}

SciFinder by January 2012. Keywords: Boletus. PubMed by January 2012. Keywords: Boletus.

\section{References}

Bovi M, Carrizo ME, Capaldi S, Massimilano P, Chiarelli LR, Galliano M \& Monaco HL (2011): Structure of a lectin with antitumoral properties in king bolete (Boletus edulis) mushroom. Glycobiology 21: 1000-1009.

Enjalbert F, Gallion C, Jehl F \& Monteil H (1993): Toxin content, phallotoxin and amatoxin composition of Amanita phalloides tissues. Toxicon 31: 803-807.

Ey J, Schömig E \& Taubert D (2007): Dietary sources and antioxidant effects of ergothioneine. Journal of Agricultural and Food Chemistry 55: 6466-6474.

Faulstich H \& Cochet-Meilhac M (1976): Amatoxins in edible mushrooms. FEBS Letters 64: 73-75.

Feng T, Zheng-Hui L, Dong Z-J, Li Y \& Liu J-K (2011): Non-isoprenoid botryane sesquiterpenoids from basiodiomycete Boletus edulis and their cytotoxic activity. Natural Products and Bioprospecting 1: 29-32.

Gachet C, Ennamany R, Ohlmann P, Krause C, Creppy EE, Dirheimer G \& Cazenave JP (1996): Bolesatine induces agglutination of rat platelets and human erythrocytes and platelets in vitro. Human \& Experimental Toxicology 15: 26-29.

Grüter A, Friederich U \& Würgler FE (1991): The mutagenicity of edible mushrooms in a histidine-independent bacterial test system. Food and Chemical Toxicology 29: 159-165. 
Helbling A, Brander KA, Horner WE \& Lehrer SB (2002a): Allergy to basidiomycetes. In: Fungal Allergy and Pathogenicity, Breitenbach M, Crameri R \& Lehrer SB (Eds.), Chemical Immunology Basel, Karger, 81: 28-47.

Helbling A, Bonadies N, Brander KA \& Pichler WJ. (2002b) Boletus edulis: a digestionresistant allergen may be relevant for food allergy. Clinical and Experimental Allergy 32: 771-775.

Horibe M, Kobaynashi Y, Dohra H, Morita T, Murata T, Usui T, Nakamura-Tsuruta S, Kamey M, Hirabayashi J, Matsuura, M, Yamada M, Saikawa Y, Hashimoto K, Nakata M \& Kawagishi H (2010): Toxic isolectins from the mushroom Boletus venenatus. Phytochemistry 71: 648-657.

Knudsen H \& Vesterholt J (2012): Funga Nordica. Agaricoid, boletoid, clavarioid, cyphelloid and gastroid genera. Nordsvamp: 1-1083.

Lo Y-C, Lin S-Y, Ulziijargal E, Chen S-Y, Chien R-C, Tzou Y-J \& Mau J-L (2012): Comparative study of contents of several bioactive components in fruiting bodies and mycelia of culinary-medicinal mushrooms. International Journal of Medicinal Mushrooms 14: 357-363.

Muszyńska B, Sułkowska-Ziaja K \& Ekiert H (2011): Indole compounds in some culinary-medicinal higher basidiomycetes from Poland. International Journal of Medicinal Mushrooms 13: 449-454.

Muszyńska B \& Sułkowska-Ziaja K (2012): Analysis of indole compounds in edible Basidiomycota species after thermal processing. Food Chemistry 132: 455-459.

Nieminen, P, Mustonen A-M \& Kirsi M (2005): Increased plasma creatine kinase activities triggered by edible wild mushroom. Food and Chemical Toxicology 43 : 133-138.

Roncarolo D, Minale P, Mistrello G, Voltolini S \& Falagiani P (1998): Food allergy to Boletus edulis. Journal of Allergy and Clinical Immunology 101: 850-851.

Simoni S, Puccetti A, Peteriana D, Tinazzi E, Lunardi C (2004): Occupational allergic contact dermatitis from champignon and Polish mushroom. Contact Dermatitis 51: 156-157.

Stone TW, Mackay GM, Forrest CM, Clark CJ, Darlington LG (2003): Tryptophan metabolites and brain disorders. Clinical Chemistry and Laboratory Medicine 41: 852-859.

Torricelli R, Johansson SG \& Wüthrich B (1997): Ingestive and inhalative allergy to the mushroom Boletus edulis. Allergy 52: 747-751.

von Wright A, Knuutinen J, Lindroth S \& Pellinen N (1982): The mutagenicity of some edible mushrooms in the Ames test. Food and Chemical Toxicology 20: 265-267.

Zheng S, Li C, Ng TB \& Wang HX (2007): A lectin with mitogenic activity from the edible wild mushroom Boletus edulis. Process Biochemistry 42: 1620-1624.

Wieland T (1986): Peptides of poisonous Amanita mushrooms. Springer Verlag: 1-256.

\section{B. erythropus Pers. s. Fries et auct. plur. non Persoon 1796}

See Boletus luridiformis. 


\section{Boletus luridiformis Rostk. (B. erythropus Pers. s. Fries et auct. plur. non Persoon 1796)}

Scarletina Bolete (Dotted-Stemmed Bolete) (DK: Punktstokket IndigoRørhat, FI: Veritatti, IS: Kóngssveppur, Ætiboldungur, NO: Blodrørsopp, SE: Blodsopp).

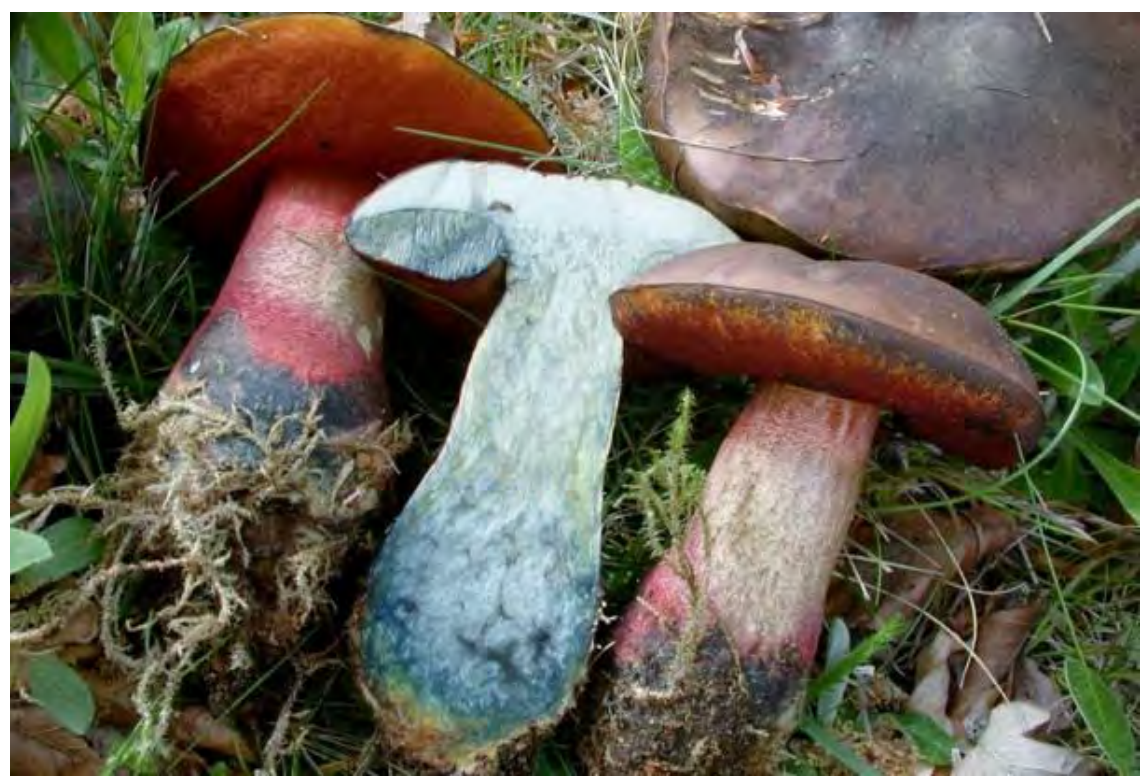

\section{Background and risk assessment}

Scarletina Bolete (Boletus luridiformis) is regarded as an edible mushroom in the Nordic countries.

It forms mycorrhiza with both deciduous and coniferous trees. It is common in Denmark and southern parts of Finland, Norway and Sweden, occasional in the hemiboral zone of the Nordic countries and more rare in the boreal zone (Knudsen \& Vesterholt, 2012).

No intoxications have been reported after consumption of Scarletina Bolete. It is probably moderately toxic when eaten raw as indicated in many mushroom textbooks and field guides (e.g. Knudsen \& Petersen, 2007; Philips \& Jacobsson, 1996; Roth et al., 1990). However, there are no publications available which show that consumption of thoroughly cooked Scarletina Bolete could give rise to discomfort with or without accompanying alcoholic beverages. 


\section{Recommendation}

Scarletina Bolete resembles Devils Bolete (Boletus satanas) and Boletus legaliae, which both are poisonous (see Chapter 4).

The mushroom is therefore not regarded as suitable for commercial marketing.

\section{Listing 3}

\section{Database search information}

SciFinder by January 2012. Keywords: Boletus. PubMed by January 2012. Keywords: Boletus.

\section{References}

Knudsen H \& Petersen J H (2007): Politikens svampebog. Politikens forlag: 1-313.

Knudsen H \& Vesterholt J (2012): Funga Nordica. Agaricoid, boletoid, clavarioid, cyphelloid and gastroid genera. Nordsvamp: 1-1083.

Philips R \& Jacobsson S (1996): Norstedts stora svampbok. Norsteds Förlag AB: 1-288. Roth L, Frank H \& Kormann K (1990): Giftpilze - Pilzgifte: Schimmelpilze - Mykotoxine. Ecomed Verlagsgesellschaft: 1-327. 


\section{Boletus luridus Schaeff.}

Lurid Bolete (DK: Netstokket Indigo-Rørhat, FI: Tauriontatti, IS: No Icelandic name, NO: Ildrørsopp, SE: Eldsopp).

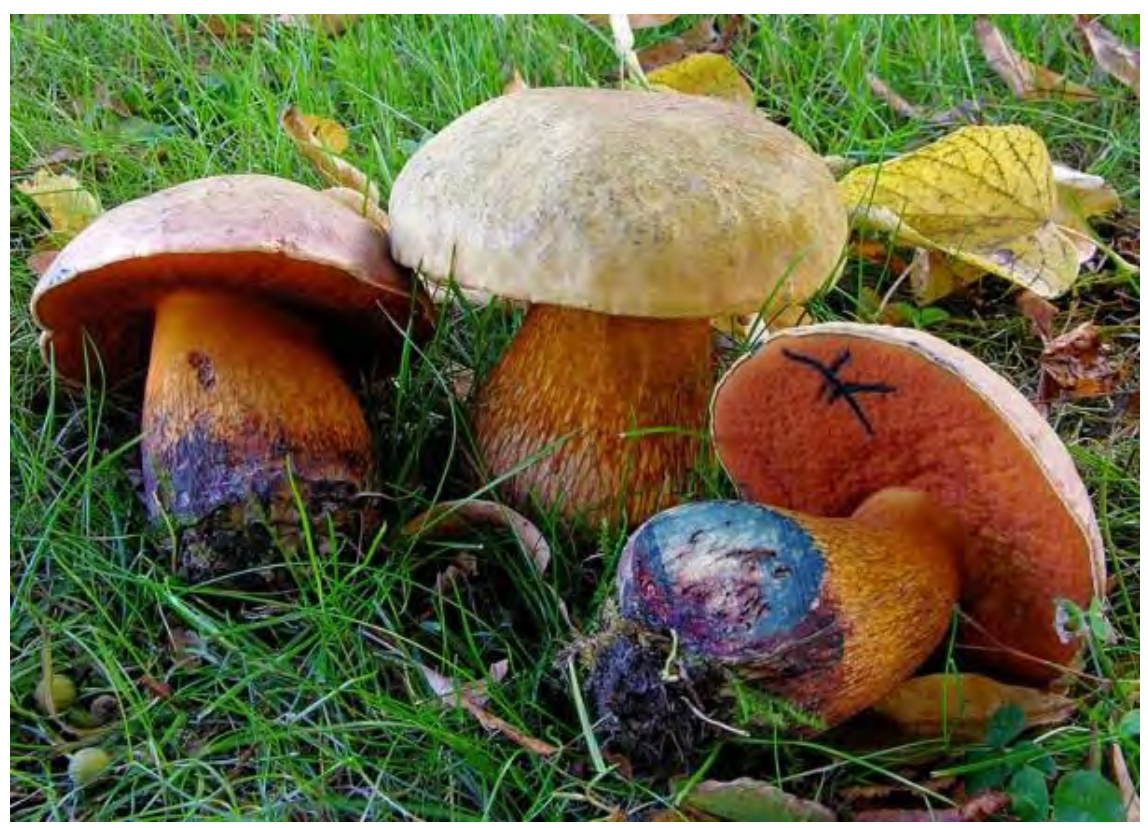

\section{Background and risk assessment}

Lurid Bolete (Boletus luridus) is regarded as an edible mushroom in the Nordic countries.

It forms mycorrhiza in deciduous forests, parks and gardens. It is occasional in Denmark and the most southern parts of Norway and Sweden and rare in the hemiboreal zone of the Nordic countries and boreal zone of Norway (Knudsen \& Vesterholt, 2012).

No intoxications have been reported in the Nordic countries after consumption of Lurid Bolete, but several mushroom field guides and toxicity textbooks state that consumption of raw or insufficiently cooked Lurid Bolete may give rise to gastrointestinal distress (e.g. Knudsen \& Petersen, 2007; Philips \& Jacobsson, 1996; Roth et al., 1990). The thermolabile toxicant(s) is unknown.

Low concentrations of L-(+)muscarine, up to $20 \mathrm{mg} / \mathrm{kg}$ dry weight (corresponding to up to $2 \mathrm{mg} / \mathrm{kg}$ fresh weight) have been found in Lurid Bolete. Such low amounts (up to $2 \mathrm{mg} \mathrm{L}-(+)$-muscarine per $\mathrm{kg}$ fresh weight) is of no toxicological concern in relation to consumption 
of Lurid Bolete (Breskinsky \& Besl, 1985; Stadelmann et al., 1976). L$(+)$-Muscarine is also found in other boletes; in trace amounts in Boletus calopus (Stadelmann et al., 1976) and in very high amounts in $R u$ binoboletus species (Pauli \& Foot, 2005).

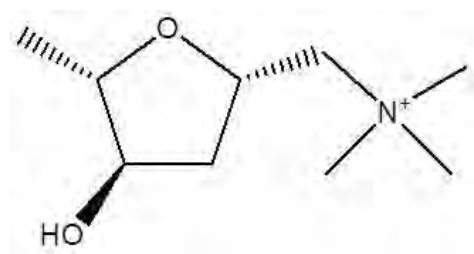

L-(+)- Muscarine

Lurid Bolete is sometimes referred to as giving rise to alcohol intolerance after consumption of the mushroom (Benjamin, 1995, Gerhardt, 1997; Holmberg \& Marklund, 1996), but only one scientific publication has described this type of Lurid Bolete-disulfiram like reaction (Budmiger \& Kocher, 1982). In this case the intoxication involved three adults consuming a dish containing a mixture of Lurid Bolete and Grey Knight (Tricholoma terreum) and Umber-Brown Puffball (Lycorperdon umbrinum) together with drinking red wine. Some minutes after the consumption all tree became unwell with symptoms such as nausea, vomiting, heart palpitation, dizziness, sweating and others. All three mushroom species had been identified by mycological experts.

As no newer reports have confirmed that intake of Lurid Bolete in combination with alcoholic beverages could give rise to such adverse reactions, it has been speculated, whether the adverse effects reported by Budmiger and Kocher (1982) could have been due to consumption of insufficiently cooked Lurid Bolete (Breskinsky \& Besl, 1985).

\section{Recommendation}

Lurid Bolete resembles Devils Bolete (Boletus satanas) and Boletus legaliae, which are both poisonous (see Chapter 4).

The mushroom is therefore not regarded as suitable for commercial marketing.

\section{Listing 3}

\section{Database search information}

SciFinder by January 2012. Keywords: Boletus. PubMed by January 2012. Keywords: Boletus. 


\section{References}

Benjamin D (1995): Mushrooms: Poisons and panaceas. WH Freeman and company: $1-422$.

Bresinsky A \& Besl H (1985): Giftpilze. Wissenshaftliche Verlagsgesellschaft mbH: 1-295. Budmicher H \& Kocher F (1982): Hexenrörhling (Boletus luridus) mit Alcohol. Schweizerische Medizinische Wochenschrift 112: 1179-1181.

Gerhardt E (1997): Der grosse BLV Pilzführer für Unterwegs. BLV München: 1-718. Holmberg P \& Marklund H (1996): Nya svampboken. Rabén Prisma: Stockholm: 1-251. Knudsen H \& Vesterholt J (2012): Funga Nordica. Agaricoid, boletoid, clavarioid, cyphelloid and gastroid genera. Nordsvamp: 1-1083.

Philips R \& Jacobsson S (1996): Norstedts stora svampbok. Norsteds Förlag AB: 1-288. Pauli JL \& Foot CL (2005): Fatal muscarinic syndrome after eating wild mushrooms. The Medical Journal of Australia 182: 294-295.

Roth L, Frank H \& Kormann K (1990): Giftpilze - Pilzgifte: Schimmelpilze - Mykotoxine. Ecomed Verlagsgesellschaft: 1-327.

Stadelmann RJ, Müller E \& Eugster CH (1976): Über die Verbreitung der stereomeren Muscarine innerhalb der Ordnung der Agaricales. Helvetica Chimica Acta 59: 2432-2436.

\section{Boletus pinicola (Vittad.) A. Venturi}

See Boletus pinophilus. 


\section{Boletus pinophilus Pilát \& Dermek}

\section{(B. pinicola (Vittad.) A. Venturi)}

Pine Bolete ("Pine Cep") (DK: Rødbrun Rørhat ("Karl Johan”), FI: Männynherkkutatti, IS: Greniboldungur, NO: Rødbrun Steinsopp, SE: Rödbrun stensopp).

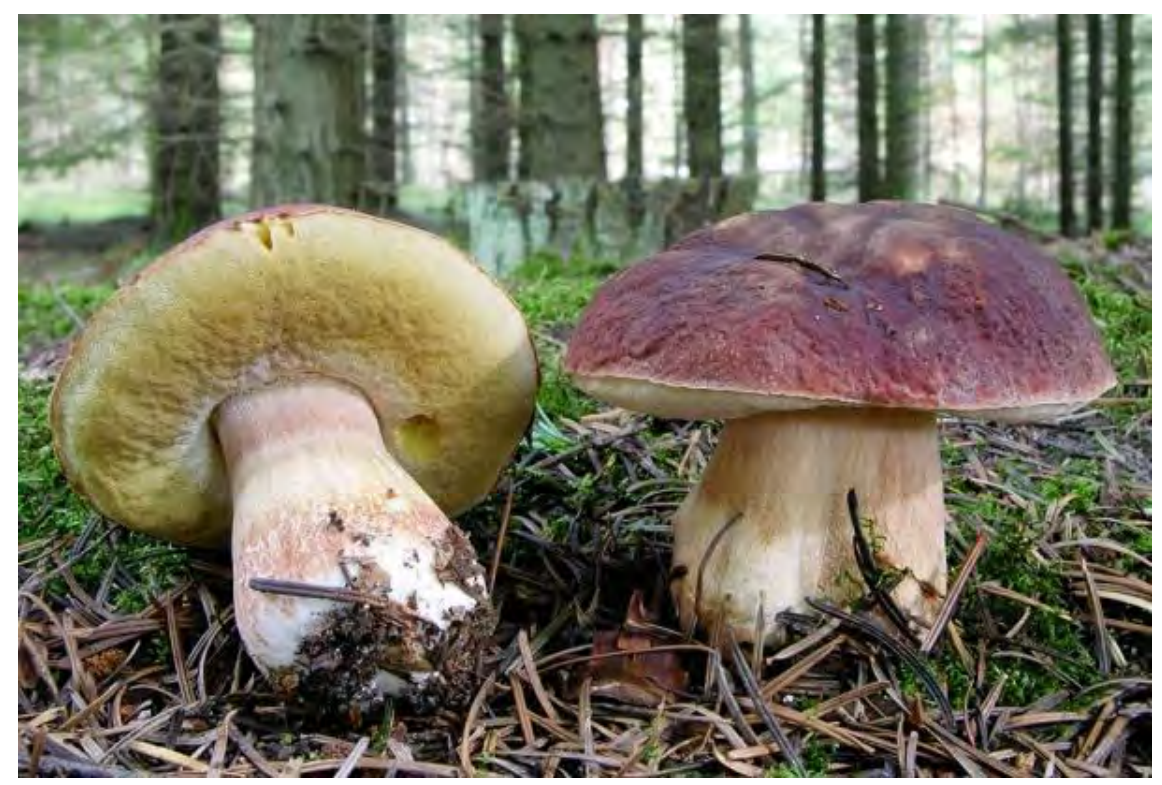

\section{Background and risk assessment}

Pine Bolete (Boletus pinophilus) is a very good edible mushroom like the similar Cep.

It grows mycorrhizal with Pine (Pinus). It is common in Denmark and the southern parts of Finland, Norway and Sweden and very common in the boreal zone of the Nordic countries (Knudsen \& Vesterholt, 2012).

There are no intoxications reported after consumption of Pine Bolete, and no inherent toxicants have been identified in the mushroom.

\section{Recommendation}

No special recommendation.

Listing 1 


\section{Database search information}

SciFinder by January 2012. Keywords: Boletus. PubMed by January 2012. Keywords: Boletus.

\section{References}

Knudsen H \& Vesterholt J (2012): Funga Nordica. Agaricoid, boletoid, clavaroid, cyphelloid and gastroid genera. Nordsvamp: 1-1083. 


\section{Boletus reticulatus Schaeff. (B. aestivalis (Paulet) Fr.)}

Summer Bolete, "Summer Cep" (DK: Sommer-Rørhat ("Karl Johan”), FI: Tammenherkkutatti, IS: No Icelandic name, NO: Bleklodden steinsopp, SE: Finluden stensopp).

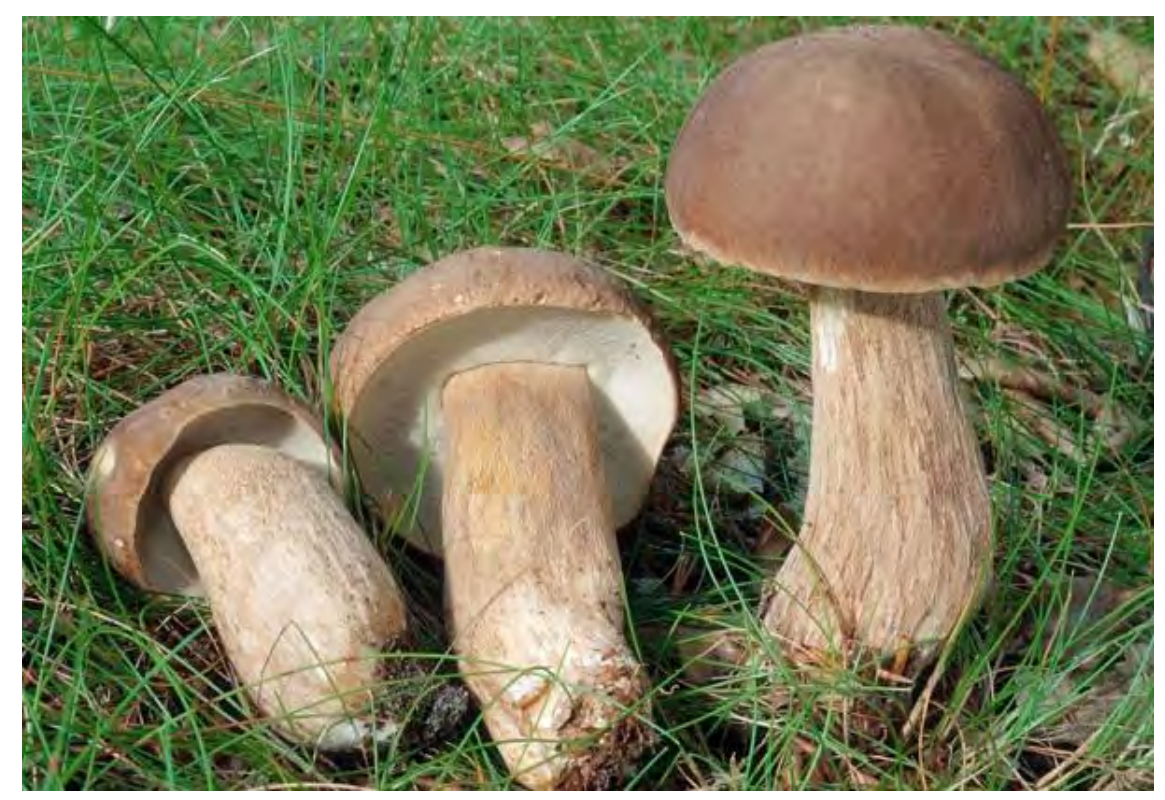

\section{Background and risk assessment}

Summer Bolete (Boletus reticulatus) is a very good, edible mushroom, like the similar Cep.

It grows mycorrhizal with different deciduous trees. It is common in Denmark and in the southern (temperate) parts of Norway and Sweden. It is occasional in the hemiboreal zone of Finland, Norway and Sweden. Otherwise, it is rare in the Nordic countries (Knudsen \& Vesterholt, 2012).

No intoxications have been reported after consumption of Summer Bolete and no inherent toxicants have been identified.

Two lectin systems have been isolated from Summer Bolete: lectin system A, composed of 4 isolectins and lectin system B composed of lectins B1 and B2 (Kozmik \& Entlicher, 1997). Whether these lectins, in some individuals, could give rise to discomfort after consumption of raw Summer Bolete is not known.

\section{Recommendation}

No special recommendation. 
Listing 1

\section{Database search information}

SciFinder by January 2012. Keywords: Boletus. PubMed by January 2012. Keywords: Boletus.

\section{References}

Knudsen H \& Vesterholt J (2012): Funga Nordica. Agaricoid, boletoid, clavarioid, cyphelloid and gastroid genera. Nordsvamp: 1-1083.

Kozmik K \& Entlicher G (1997): Lectins with different binding affinity in Boletus:[Boletus aestivalis (Paulet) ex. Fr.]. International Journal of Bio-Chromatography 3: 293-312. 
Calocybe gambosa (Fr.) Donk (Lyophyllum gambosum (Fr.) Singer, Tricholoma gambosum (Fr.) P. Kumm., Tricholoma georgii (L.) Quél.)

St. George's Mushroom (DK: Vårmusseron, FI: Kevätkaunolakki, IS: Vorkolla, NO: Vårmusserong, SE: Vårmusseron).

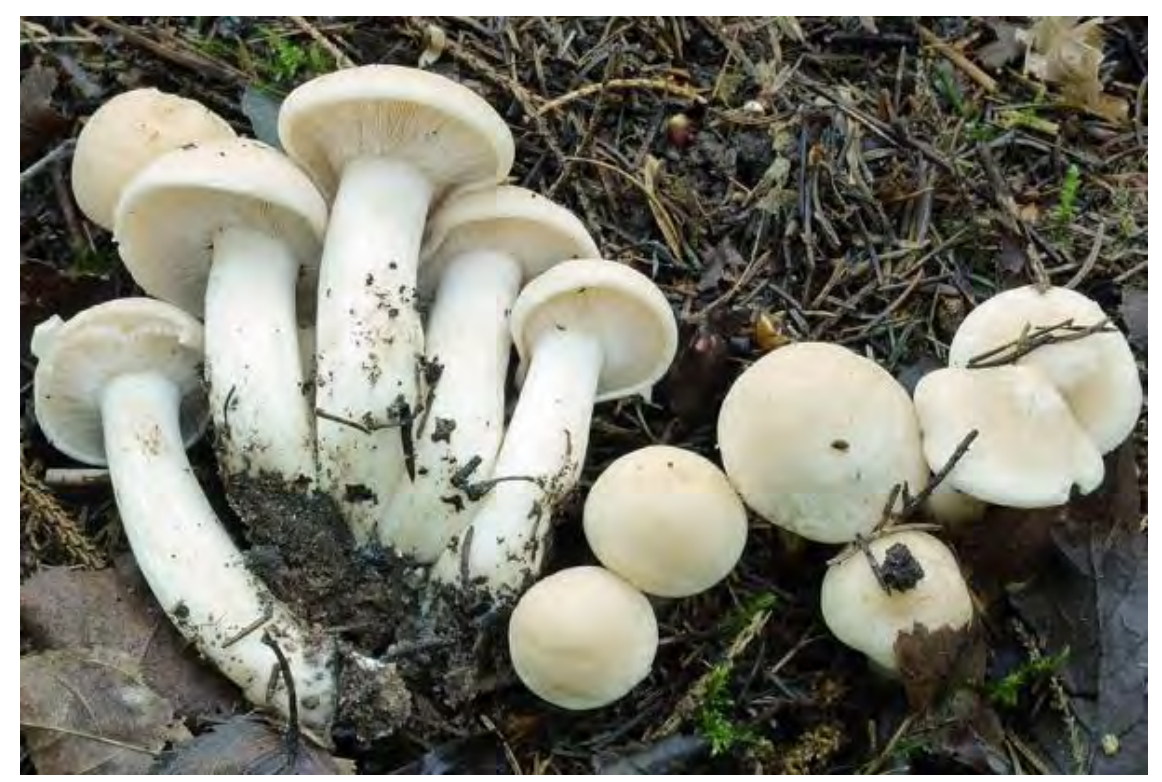

\section{Background and risk assessment}

St. George's Mushroom (Calocybe gambosa) is an appreciated, edible mushroom.

It is a saprotrophic mushroom, growing in fairy rings on rich soil in meadows, pastures, gardens and forests in spring, rarely in autumn. It is common in temperate and occasional in hemiboreal and southern boreal areas of the Nordic countries (Knudsen \& Vesterholt, 2012).

There are no intoxications reported after consumption of St. George's Mushroom, and no natural toxicants constituting a risk for humans have been identified in the mushroom.

\section{Recommendation}

No special recommendation.

Listing 2 


\section{Database search information}

SciFinder by September 2012. Keywords: Calocybe.

\section{References}

Knudsen H \& Vesterholt J (2012): Funga Nordica. Agaricoid, boletoid, clavarioid, cyphelloid and gastroid genera. Nordsvamp: 1-1083.

\section{Camarophyllus pratensis (Fr.) P. Kumm.}

See Hygrocybe pratensis. 


\section{Cantharellus cibarius Fr.}

Chanterelle ("Girolle") (DK: Almindelig Kantarel ("Kantarel"), FI: Keltavahvero, IS: Kantarella, NO: Kantarell, SE: Kantarell).

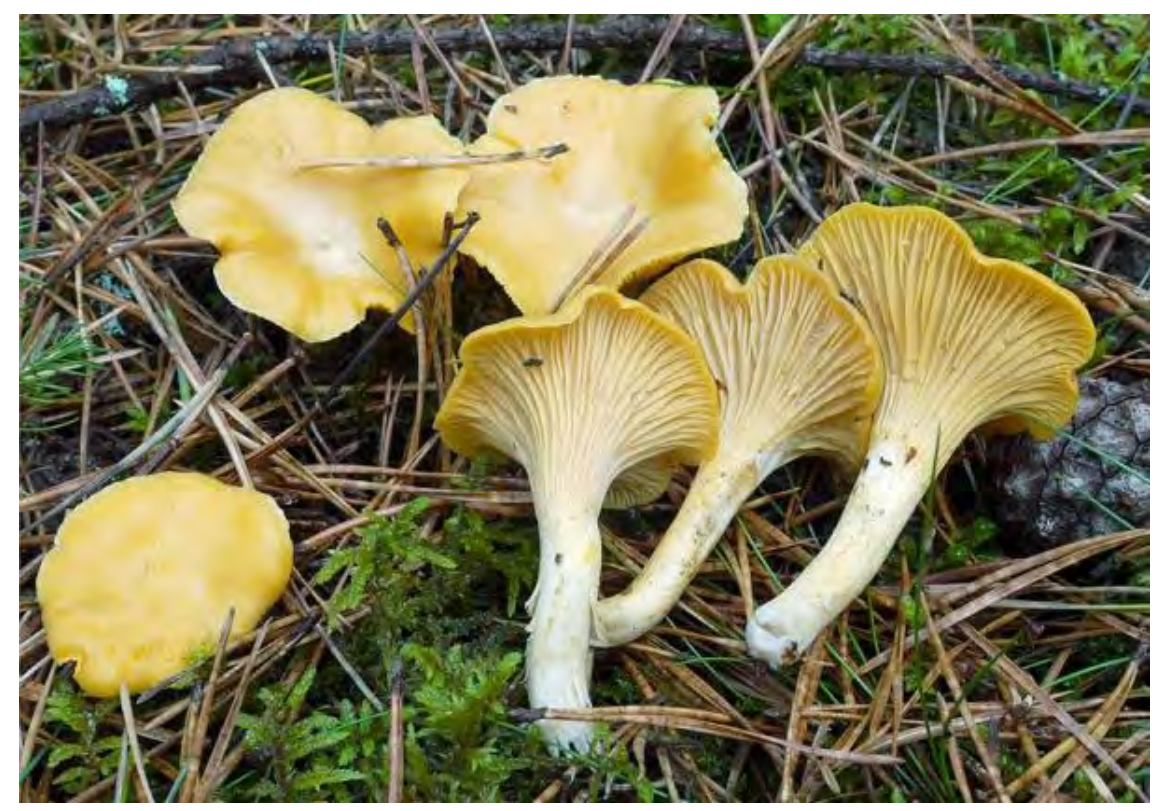

\section{Background and risk assessment}

Chanterelle (Cantharellus cibarius) is edible and much appreciated.

It is a common wild mushroom, which is found in poor coniferous or deciduous forests in the Nordic countries, except in Iceland, where it is occasional (Hansen \& Knudsen, 1997). It is mostly sold fresh, but may also be sold as dried or canned.

There are no intoxications reported after consumption of Chanterelle. However, some bioactive constituents have been identified in the mushroom:

\section{Bioactive constituents}

Polyunsaturated long-chain fatty acids: When injured Chanterelle may form cibaric acid ((9Z, 13Z, 15E)-14,18-dihydroxy-12-keto-9,13, 15 octadecatrienoic acid) in amounts of up to $100 \mathrm{mg}$ per $\mathrm{kg}$ fresh weight (Anke et al., 1996; Pang \& Sterner, 1991, Pang et al., 1992). Cibaric acid is not found in the undamaged Chanterelle. It is anticipated to be formed enzymatically from 14,15-dehydrocrepenyic acid, one of the major fatty acids in the fresh Chanterelle. The structural formulae for cibaric acid and 14,15-dehydroxycrepenyic acid are shown below. 
<smiles>O=C(O)CCCCCCC/C=C/CC(=O)/C=C(O)/C=C/CCO</smiles>

Cibaric acid

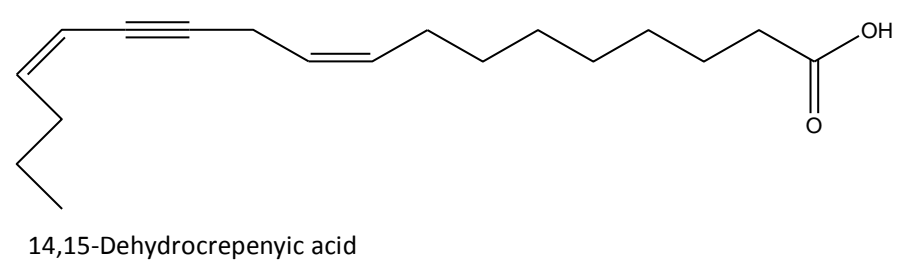

As cibaric acid is an $\alpha, \beta$-unsaturated ketone and potentially may form a beta-diketone by $\beta$-diktone-enol tautomerism (EFSA, 2004; 2007), cibaric acid could be suspected to be a mutagen. However, it is negative in Salmonella typhimurium tester strains TA98 and TA100 with and without activation with S-9 mix (Anke et al., 1996). Cibaric acid shows very weak antimicrobial and cytotoxic activity and only in five of seventeen bacteria, fungi or cell lines tested (Anke et al., 1996). Cibaric acid has also been shown to have a weak nematicidal activity (Stadler et al., 1994).

As cibaric acid is destroyed by heating at $100{ }^{\circ} \mathrm{C}$ for 10 minutes in water, cibaric acid is not of concern with respect to consumption of cooked Chanterelle (Anke et al. 1996). Recently, trace amounts of two acetylenic C-18 carboxylic acids have been isolated from Chanterelle: (10E,14Z)-9oxooctadeca-10,14-dien-12-ynoic acid and the corresponding 9-hydroxy compound. From $9 \mathrm{~kg}$ dried fruit bodies were isolated 10.4 and $35.5 \mathrm{mg}$ of the two acids, respectively (Hong et al., 2012). There are no data on heatstability and the potential toxicity of these two constituents.

Amatoxins: In a study analysing for the occurrence of amatoxins in various toxic and edible mushrooms, Faulstich \& Cochet-Meilhac (1976) reported extremely low levels of amatoxins in Chanterelle, $10^{5}$ times lower levels than in Deathcap (Amanita phalloides) and Destroying Angel (Amanita virosa). Two different analytical methods were used in these studies, a radioimmunological assay and an enzyme (RNA polymerase B) inhibition assay. It was concluded that the amounts of amatoxins found in the different edible mushrooms, including Chanterelle (4.8-5.3 microgram per kg fresh Chanterelle) in these two studies, are of no toxicological concern in relation to consumption of Chanterelle (Benjamin, 1995; Faulstich \& Cochet-Meilhac, 1976).

Enjalbert et al. (1993) refuted the findings of trace amounts (microgram $/ \mathrm{kg}$ ) in Chanterelle (and other edible mushrooms, e.g. Cep (Bole- 
tus edulis) and Blusher (Amanita rubescens) due to methodological considerations. The levels found by Faulstich \& Cochet-Meilhac (1976), either using a radioimmunoassay (RIA) or an enzyme inhibition assay were at the limits of detection and could be accounted for by contamination. When Faulstich repeated the assay in a different laboratory using new glassware, no amatoxins were detected in Chanterelle or the other edible mushrooms studied by Faulstich \& Cochet-Meilhac in 1976 (Wieland, 1986). Furthermore, the results obtained by bioassays, may have been interfered by other compounds in the mushroom extract (Enjalbert et al., 1993; Wieland, 1986).

Alltogether, it is unlikely that Chanterelle contains even trace amounts of amatoxins.

Ergothioneine: Lee et al. (2009) found $4.1 \mathrm{~g} / \mathrm{kg}$ of ergothioneine in dried fruit bodies of Chanterelle, corresponding to approximately 400 $\mathrm{mg} / \mathrm{kg}$ (fresh weight), whereas Ey et al. (2007) only found traces, less than $1 \mathrm{mg} / \mathrm{kg}$ (fresh weight).

Indole compounds: Chanterelle contains a series of simple biologically active indole compounds (5-hydroxytryptophan, serotonin and tryptamine), but only serotonin in significant amounts, approximately $30 \mathrm{mg} / \mathrm{kg}$ (fresh weight) (Muszynska et al., 2011, 2012). It was demonstrated that boiling of Chanterelle fruit bodies significantly changed the content of these indoles. 5-Hydroxytryptophan and serotonin were completely decomposed and tryptophan, tryptamine, melatonin and 5-methyltryptophan had been formed in amounts between 33 and 49 $\mathrm{mg} / \mathrm{kg}$ (dry weight) corresponding to approximately $3-5 \mathrm{mg} / \mathrm{kg}$ of these indoles (fresh weight). Some of these constituents are tissue hormones and neurotransmitters and high intakes of tryptophan can damage the nervous system (Stone et al., 2003).

Mutagens: Grüter et al. (1991) has shown that freeze-dried extract of Chanterelle is weakly mutagenic in a histidine-independed bacterial test system. The mutagenic activity was enhanced by metabolic activation. It is not known, if the mutagens are destroyed during cooking of the mushroom.

Animal studies: Nieminen and co-workers (2006) have published a study on the potential myo- and hepatotoxic effects of different wild mushrooms in mice. The animals (six females per group) were for 5 days supplied large quantities of dried and powdered wild mushrooms in the feed. One of the mushrooms, Chanterelle, was given as $1.8 \%, 3.6 \%$ or $5.4 \%$ of the feed. The feeding resulted in exposures corresponding to 22 , 42 or $64 \mathrm{~g}$ per kg body weight of the mice per day, respectively or corresponding to $1.5,2.9$ or $4.5 \mathrm{~kg}$ mushroom per person $(70 \mathrm{~kg})$ per day of fresh mushroom, respectively. All mice were healthy at the end of the 
study. Of the many clinical-chemical parameters studied the plasma creatine kinase activity was significantly increased at the lowest and highest dose level. No histological pathological changes in studied organs were found. Whether the observed (but not dose-related) increased creatine kinase (indicator of myopathy) in mice, eating very high amounts of Chanterelle, may be relevant for humans, eating very large amounts of the mushroom, is difficult to evaluate.

\section{Recommendation}

No special recommendations.

\section{Database search information}

SciFinder by December 2012. Keywords: Cantharellus, Craterellus.

\section{Listing 1}

\section{References}

Anke H, Morales P, \& Sterner O (1996): Assays of the biological activities of two fatty acid derivatives formed in the edible mushroom Cantharellus cibarius and C. tubaeformis as a response to injury. Planta Medica 62: 181-183.

Benjamin D (1995): Mushrooms: Poisons and panaceas. W.H. Freeman and Company: 1-422.

EFSA (2004): Opinion of the Scientific Panel on Food Additives, Flavourings, Processing Aids and Materials in contact with Food (AFC) on a request from the Commission related to Flavouring Group Evaluation 11 (FGE.11): Aliphatic dialcohols, diketones, and hydroxyketones from chemical group 10 (Commission Regulation (EC) No 1565/2000 of 18 July 2000) Section 9. Conclusion: 13-15.

EFSA (2007): Minutes of the 26th plenary meeting of the Scientific Panel on Food Additives, Flavouring, Processing Aids and Materials in Contact with Food. Section 9 Flavourings. 9.1.1 FGE 19 (EFSA- Q-2003-162). (Q)SAR predictions on alpha, beta-unsaturated substances including predicted metabolism products of flavouring precursors for alpha, beta-unsaturated aldehydes and ketones. Status of the predictions and outcome of the validation of the genotoxicity studies: 6-9.

Enjalbert F, Gallion C, Jehl F \& Monteil H (1993): Toxin content, phallotoxin and amatoxin composition of Amanita phalloides tissues. Toxicon 31: 803-807.

Ey J, Schömig E \& Taubert D (2007): Dietary sources and antioxidant effects of ergothioneine. Journal of Agricultural and Food Chemistry 55: 6466-6474.

Faulstich H \& Cochet-Meilhac M (1976): Amatoxins in edible mushrooms. FEBS Letters 64: 73-75.

Grüter A, Friederich U \& Würgler FE (1991): The mutagenicity of edible mushrooms in a histidine-independent bacterial test system. Food and Chemical Toxicology 29: 159-165.

Hansen L \& Knudsen H (1997): Nordic Macromycetes, Volume 3. Heterobasidioid, aphyllophoroid and gastromycetoid basidiomycetes. Nordsvamp: 1-444. 
Hong SS, Lee JH, Jeong W, Kim N, Jin HZ, Hwang BY, Lee H-J, Lee S-J, Jang DS \& Lee D (2012): Acetylenic acid analogues from the edible mushroom Chanterelle (Cantharellus cibarius) and their effects on the gene expression of peroxisome proliferator-activated receptor-gamma target genes. Bioorganic \& Medicinal Chemistry Letters 22: 2347-2349.

Lee WY; Park E-J, Jin K \& Ka K-H (2009): Ergothioneine contents in fruiting bodies and their enhancement in mycelial cultures by addition of methionine. Mycobiology 37: 43-47.

Muszynska B, Sulkowska- Ziaja K \& Ekert H (2011): Indole compounds in fruiting bodies of some edible Basidiomycota species. Food Chemistry 125: 1306-1308.

Muszyńska B \& Sułkowska-Ziaja K (2012): Analysis of indole compounds in edible Basidiomycota species after thermal processing. Food Chemistry 132: 455-459.

Pang Z \& Sterner 0 (1991): Cibaric acid, a new fatty acid derivative formed enzymatically in damaged fruit bodies of Cantharellus cibarius (Chanterelle). Journal of Organic Chemistry 56: 1233-1235.

Pang Z, Sterner O \& Anke H (1992): (8E)-10-Hydroxy-8-decenoic acid: Its isolation from injured fruit bodies of Cantharellus tubaeformis and synthetic preparation. Acta Chemica Scandinavica 46: 301-303.

Stadler M, Mayer A, Anke, H \& Sterner O (1994): Fatty acids and other coumpounds with nematicidal activity from cultures of Basiodiomycetes. Planta Medica 60: 128-132.

Wieland T (1986): Peptides of poisonous Amanita mushrooms. Springer Verlag: 1-256.

\section{Cantharellus cornucopioides (L.) Fr.}

See Craterellus cornucopiodes.

\section{Cantharellus lutescens Fr.}

See Craterellus lutescens. 


\section{Cantharellus pallens Pilát}

No English name (DK: Bleg Kantarel, ("Kantarel”), FI: Kalvasvahvero, IS: No Icelandic name, NO: Blek kantarell, SE: Blek kantarell).

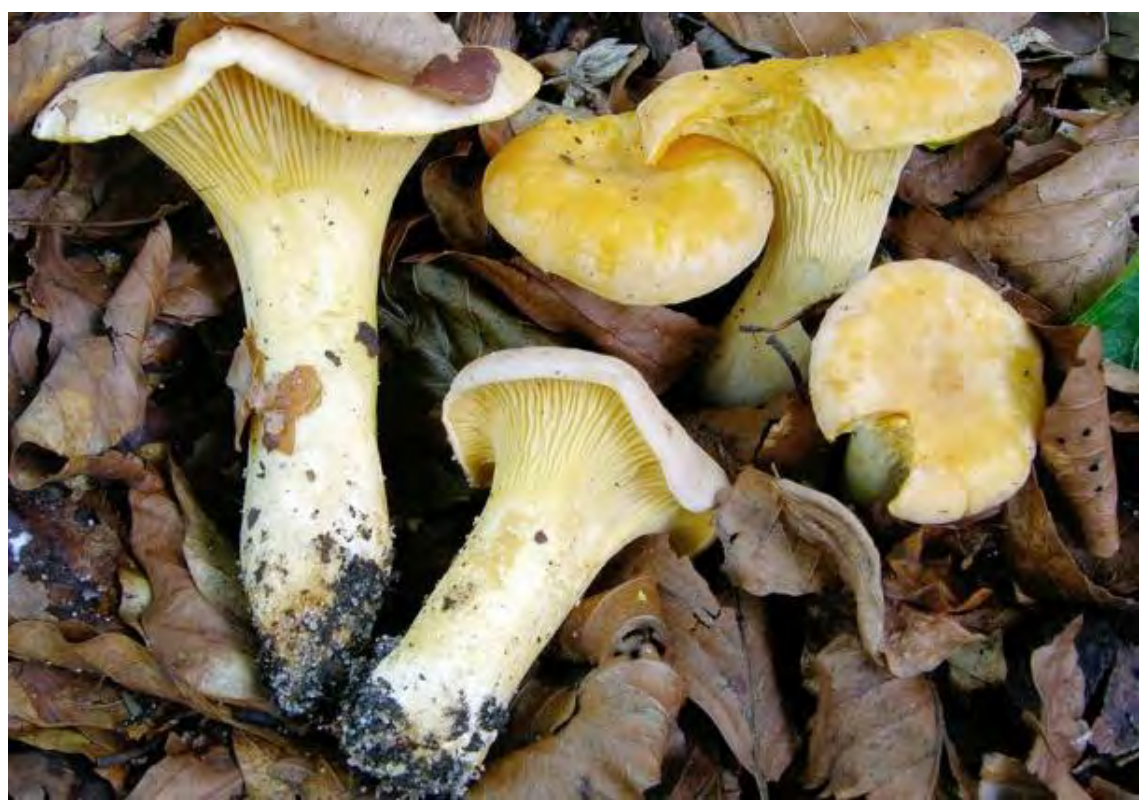

\section{Background and risk assessment}

Cantharellus pallens ${ }^{14}$ is edible and much appreciated.

It is common in Denmark and southern Sweden, occasional in Norway. It is found in Finland, but the frequency is unknown (Hansen \& Knudsen, 1997). It is found in rich deciduous forests. It is occasionally sold fresh, dried or canned like the very similar looking Chanterelle (C. cibarius).

There are no intoxications reported after consumption of Cantharellus pallens.

Due to the close relationship to Chanterelle and, therefore, anticipated compositional similarity, it is possible that Cantharellus pallens by injury may form cibaric acid ((9Z, 13Z, 15E)-14,18-dihydroxy-12-keto-9,13, 15 octadecatrienoic acid). This compound has been shown to be formed in

14 Contrary to the Nordic mycological societies, Index Fungorum/Species Fungorum (2012) does not consider Cantharellus pallens Pilat as a separate species, but as a synonym for C. cibarius Fr. 
injured Chanterelle (Anke et al., 1996; Pang \& Steemer, 1991, Pang et al., 1992). On damage of the mushroom it is anticipated to be formed enzymatically from 14,15-dehydrocrepenyic acid, which is one of the major fatty acids in the fresh Cantharellus pallens. For further information on the biological activity of cibaric acid, see the monograph on Chanterelle (Cantharellus cibarius). As cibaric acid is destroyed by heating at $100{ }^{\circ} \mathrm{C}$ for 10 minutes in water (Anke et al. 1996), cibaric acid is not of concern with respect to consumption of cooked Chantharellus pallens, should it occur also in this mushroom species.

\section{Recommendation}

No special recommendations.

Database search information

SciFinder by December 2012. Keywords: Cantharellus, Craterellus.

\section{Listing 1}

\section{References}

Anke H, Morales P, \& Sterner O (1996): Assays of the biological activities of two fatty acid derivatives formed in the edible mushrooms Cantharellus cibarius and C. tubaeformis as a response to injury. Planta Medica 62: 181-183.

Hansen L \& Knudsen H (1997): Nordic Macromycetes, Volume 3. Heterobasidioid, aphyllophoroid and gastromycetoid basidiomycetes. Nordsvamp: 1-444.

Index Fungorum/Species Fungorum (2012): http://www.indexfungorum.org/

Pang Z \& Sterner O (1991): Cibaric acid, a new fatty acid derivative formed enzymatically in damaged fruit bodies of Cantharellus cibarius (Chanterelle). Journal of Organic Chemistry 56: 1233-1235.

Pang Z, Sterner O \& Anke H (1992): (8E)-10-Hydroxy-8-decenoic acid: Its isolation from injured fruit bodies of Cantharellus tubaeformis and synthetic preparation. Acta Chemica Scandinavica 46: 301-303.

Stadler M, Mayer A, Anke H \& Sterner O (1994): Fatty acids and other compounds with nematicidal activity from cultures of Basidiomycetes. Planta Medica 60: 128-132.

\section{Cantharellus tubaeformis Fr.}

See Craterellus tubaeformis. 


\section{Chlorophyllum olivieri (Barla) Wellinga (Lepiota olivieri Barla, Macrolepiota olivieri (Barla) Wasser)}

No UK name (DK: Almindelig Rabarberhat ("Rabarber-Parasolhat"), FI: No Finnish name IS: Garðskermill, NO: Maurtueparasollsopp, SE: No Swedish name).

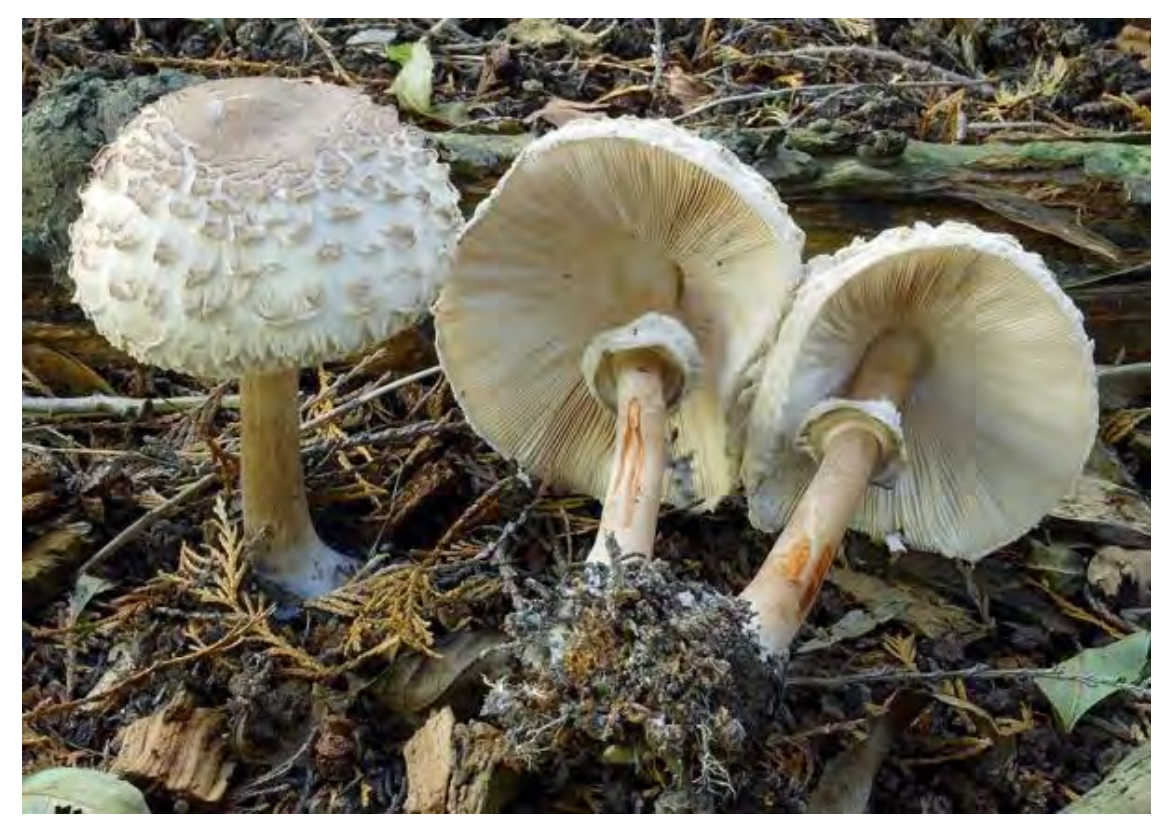

\section{Background and risk assessment}

Chlorophyllum olivieri is generally regarded as an edible mushroom (e.g., Knudsen \& Vesterholt, 2012). However, it should be thoroughly cooked before consumption (Lohmeyer \& Künkele, 2006; Roth et al., 1990).

Some textbooks on mushrooms indicate that Shaggy Parasol may give rise to gastrointestinal distress in some people (Philips, 2006; Ryman \& Holmåsen, 1996) or at least that some garden forms or varieties cause gastrointestinal upsets (Bresinski \& Besl, 1985; Holmberg \& Marklund, 1996; Krikorev, 2007: Lamaison \& Poelese, 2004; Læssøe, 2004). Beug et al. (2006) have reported 15 cases in the USA in the period 1976-2005 with mild to severe gastrointestinal symptoms and an onset time of 0.110 hours (average 4 hours).

It has more recently been established that the mushroom traditionally named Shaggy Parasol, with the scientific name Macrolepiota rachodes/M. rhacodes (Lepiota rachodes/L. rhacodes), comprises three very similar species belonging to the genus Chlorophyllum. These species are 
C. brunneum, C. olivieri and C. rachodes (Knudsen \& Vesterholt, 2012; Lange \& Vellinga, 2004). Besides C. olivieri, also C. rachodes is regarded as edible, whereas $C$. brunneum is considered to be poisonous (Knudsen \& Vesterholt, 2012; Lange \& Vellinga, 2004). Therefor many earlier reported intoxications after consumption of "Shaggy Parasol" may be due to $C$. brunneum. The English name Shaggy Parasol now covers only C. rachodes (British Mycological Society, 2012), but not C. olivieri or C. brunneum.

C. olivieri grows in coniferous woods, in old ant-hills or litter beds, often forming fairy rings. It is common in temperate hemiboreal and boreal zones, but very rare in subalpine/subarctic zones of the Nordic countries. In Iceland, it is only found in gardens (Knudsen \& Vesterholt, 2012; Lange \& Vellinga, 2004).

No natural toxicant constituting a risk for humans has been identified in the mushroom.

In 1982, Sterner et al. reported that a Macrolepiota rachodes ("Shaggy Parasol") extract was weakly mutagenic as detected by the histidinerequiring Salmonella typhimurium strains TA98, TA100 and TA2637 in the Ames assay. The extract was positive in all three strains but the mutagenicity was not enhanced when including a metabolizing system (S9 mix). Sterner et al. (1982) gave no information, whether they controlled for the potential presence of histidine in the mushroom extract tested. The presence of histidine could have resulted in false positives. A further uncertainty might be that the mushroom studied could be any of the three Chlorophyllum species mentioned.

\section{Recommendation}

Chlorophyllum olivieri resembles Chlorophyllum brunneum, which is suspected to be poisonous (see Chapter 4). The mushroom is therefore not regarded as suitable for commercial marketing.

\section{Listing 3}

\section{Database search information}

SciFinder by January 2012. Keywords: Chlorophyllum or Lepiota or Macrolepiota. PubMed by December 2012. Keywords: Chlorophyllum or Lepiota or Macrolepiota. 


\section{References}

Beug MW, Shaw M \& Cochran KW (2006): Thirty-plus years of mushroom poisoning: Summary of the ap0proximately 2,000 reports in the NAMA Case Registry. McIlvainea 16: 47-67.

Bresinsky A \& Besl H (1985): Giftpilze. Wissenschaftliche Verlagsgesellschaft mbH: 1-295.

British Mycological Society (2012): English Names for Fungi. http://www.britmycolsoc.org.uk/library/english-names/

Holmberg P \& Marklund H (1996): Nya Svampboken. Raben Prisma, Stockholm: $1-251$.

Knudsen H \& Vesterholt J (2012): Funga Nordica. Agaricoid, boletoid, clavarioid, cyphelloid and gastroid genera. Nordsvamp: 1-1083.

Krikorev M (2007): De bedste spisesvampe. Aschehoug Dansk Forlag: 1-112.

Lamaison J-L \& Polese J-M (2005): Encyclopédie Visuelle des Champignons, Artémis: $1-384$.

Lange C \& Vellinga EC (2004): Rabarber-Parasolhat holder flyttedag - molekylærgenetiske studier omkring slægten Macrolepiota. Svampe 50: 23-42.

Lohmeyer TR \& Künkele U (2006): Svampe. Parragon Books: 1-256.

Læssøe T (2004): Find de bedste spisesvampe. Gyldendal: 1-89.

Philips R (2006): Mushrooms. MacMillan: 1-384.

Roth L, Frank H \& Kormann K (1990): Giftpilze-Pilzgifte, Schimmelpilze-Mykotoxine; Ecomed Verlagsgesellschaft: 1-327.

Ryman S \& Holmåsen I (1986): Svampar. Interpublishing. 1-718.

Sterner O, Bergman R, Kesler E, Magnusson L, Nilsson B, Wickberg B, Zimerson E \& Zetterberg G (1982): Mutagens in larger fungi I. Forty-eight species screened for mutagenic activity in the Salmonella/microsome assay. Mutation Research 101: 269-281. 


\section{Chlorophyllum rachodes (Vittad) Wellinga \\ (Macrolepiota rachodes (Vittad.) Singer, Lepiota rhacodes (Vittad.) Quél.)}

Shaggy Parasol (DK: Ægte Rabarberhat ("Rabarber-Parasolhat"), FI: Akansieni, IS: No Icelandic name, NO: Rødnende parasollsopp, SE: Rodnande fjällskivling).

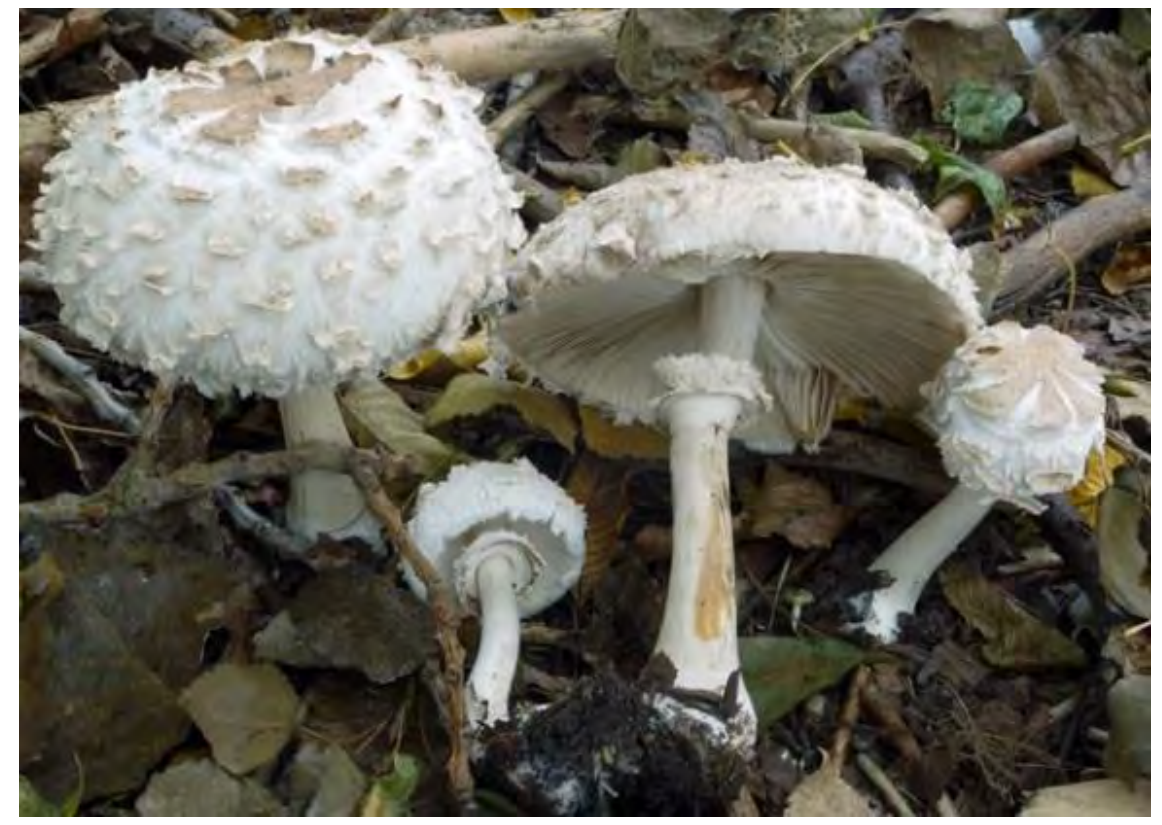

\section{Background and risk assessment}

Shaggy Parasol (Chlorophyllum rachodes) is generally regarded as an edible mushroom (e.g., Knudsen \& Vesterholt, 2012). However, it should be thoroughly cooked before consumption (Lohmeyer \& Künkele, 2006; Roth et al., 1990).

Some textbooks on mushrooms indicate that Shaggy Parasol may give rise to gastrointestinal distress in some people (Philips, 2006; Ryman \& Holmåsen, 1996) or at least that some garden forms or varieties cause gastrointestinal upsets (Bresinski \& Besl, 1985; Holmberg \& Marklund, 1996; Krikorev, 2007; Lamaison \& Poelese, 2004; Læssøe, 2004). Beug et al. (2006) have reported 15 cases in the USA in the period 1976-2005 with mild to severe gastrointestinal symptoms and an onset time of 0.110 hours (average 4 hours). 
It has more recently been established that the mushroom traditionally named Shaggy Parasol with the scientific name Macrolepiota rachodes/M. rhacodes (Lepiota rachodes/L. rhacodes) comprises three very similar species belonging to the genus Chlorophyllum. These species are C. brunneum, C. olivieri and C. rachodes (Knudsen \& Vesterholt, 2012; Lange \& Vellinga, 2004). Besides C. rachodes (Shaggy Parasol) also C. olivieri are regarded as edible, whereas $C$. brunneum is considered to be poisonous (Knudsen \& Vesterholt, 2012; Lange \& Vellinga, 2004). Therefore many earlier reported intoxications after consumption of "Shaggy Parasol" may be due to C. brunneum. The English name Shaggy Parasol now covers only C. rachodes (British Mycological Society, 2012), but not C. olivieri or C. brunneum.

Shaggy Parasol (C. rachodes) grows in deciduous woods, shrubs, parks and gardens, more rarely in coniferous woods, often forming fairy rings. It is occasional or common in temperate and hemiboreal areas of the Nordic countries (Knudsen \& Vesterholt, 2012).

No natural toxicant constituting a risk for humans has been identified in the mushroom.

In 1982, Sterner et al. reported that a Macrolepiota rachodes ("Shaggy Parasol") extract was weakly mutagenic as detected by the histidinerequiring Salmonella typhimurium strains TA98, TA100 and TA2637 in the Ames assay. The extract was positive in all three strains but the mutagenicity was not enhanced when including a metabolizing system (S9 mix). Sterner et al. (1982) gave no information, whether they controlled for the potential presence of histidine in the mushroom extract tested. The presence of histidine could have resulted in false positives. A further uncertainty might be that the mushroom studied could be any of the three Chlorophyllum species mentioned.

\section{Recommendation}

Shaggy Parasol resembles Chlorophyllum brunneum, which is suspected to be poisonous (see Chapter 4).

The mushroom is therefore not regarded as suitable for commercial marketing.

Listing 3 


\section{Database search information}

SciFinder by January 2012. Keywords: Chlorophyllum or Lepiota or Macrolepiota. PubMed by December 2012. Keywords: Chlorophyllum or Lepiota or Macrolepiota.

\section{References}

Beug MW, Shaw M \& Cochran KW (2006): Thirty-plus years of mushroom poisoning: Summary of the approximately 2,000 reports in the NAMA Case Registry. Mcllvainea 16: 47-67.

Bresinsky A \& Besl H (1985): Giftpilze. Wissenschaftliche Verlagsgesellschaft mbH: 1-295.

British Mycological Society (2012): English names for fungi. http://www.britmycolsoc.org.uk/library/english-names/

Holmberg P \& Marklund H (1996): Nya Svampboken. Raben Prisma, Stockholm: $1-251$.

Knudsen H \& Vesterholt J (2012): Funga Nordica. Agaricoid, boletoid, clavarioid, cyphelloid and gastroid genera. Nordsvamp: 1-1083.

Krikorev M (2007): De bedste spisesvampe. Aschehoug Dansk Forlag: 1-112.

Lamaison J-L \& Polese J-M (2005): Encyclopédie Visuelle des Champignons, Artémis: $1-384$.

Lange C \& Vellinga EC (2004): Rabarber-Parasolhat holder flyttedag - molekylærgenetiske studier omkring slægten Macrolepiota. Svampe 50: 23-42.

Lohmeyer TR \& Künkele U (2006): Svampe. Parragon Books: 1-256.

Læssøe T (2004): Find de bedste spisesvampe. Gyldendal: 1-89.

Philips R (2006): Mushrooms. MacMillan: 1-384.

Roth L, Frank H \& Kormann K (1990): Giftpilze-Pilzgifte, Schimmelpilze-Mykotoxine. Ecomed Verlagsgesellschaft: 1-327.

Ryman S \& Holmåsen I (1986): Svampar. Interpublishing: 1-718.

Sterner O, Bergman R, Kesler E, Magnusson L, Nilsson B, Wickberg B, Zimerson E \& Zetterberg G (1982): Mutagens in larger fungi I. Forty-eight species screened for mutagenic activity in the Salmonella/microsome assay. Mutation Research 101: 269-281. 


\section{Clitocybe connata (Schumach.) Gillet (Lyophyllum connatum (Schumach.) Singer)}

White Domecap (DK: Knippe-Gråblad, FI: Nurmitupaskynsikäs, IS: Gráspyrða (Gráknipplingur), NO: Hvit knippesopp, SE: Vit tuvskivling).

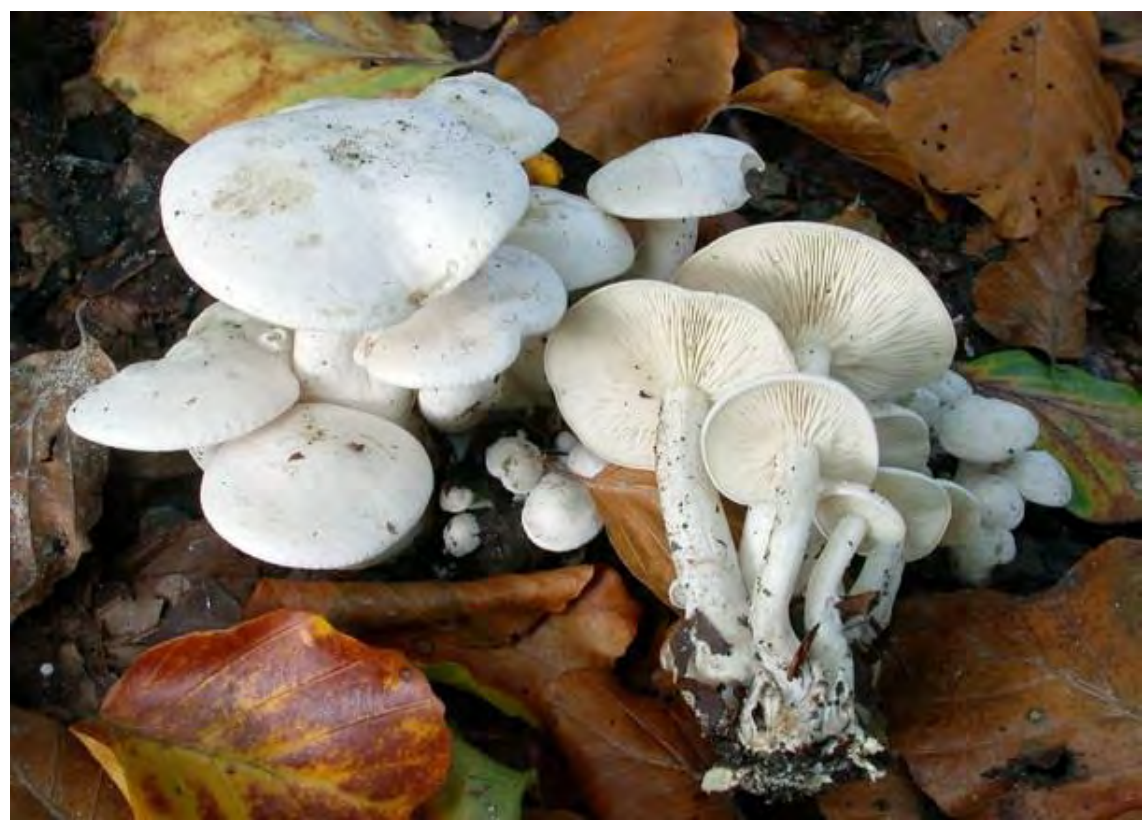

\section{Background and risk assessment}

White Domecap (Clitocybe connata) is no longer considered as an edible mushroom.

It grows on soil in deciduous forests, parks and ruderal areas. It is common in Denmark and in large parts of Finland, Norway and Sweden but occasional in subarctic/subalpine areas (Knudsen \& Vesterholt, 2012).

White Domecap was earlier considered edible (e.g., Korhonen, 1976; Lange \& Lange, 1970; Ryman \& Holmåsen, 1986) and it still is in some more recent textbooks on mushrooms (Mazza, 2000; Nylén, 2012; Philips \& Jacobsson, 1996). There are no intoxications reported after consumption of White Domecap. However, some bioactive constituents with potential toxicity have been isolated from the mushroom. 


\section{Bioactive constituents}

Azoxy compounds: Fugmann \& Steglich (1984) have isolated an azoxy compound, lyophyllin, occurring in significant amounts, more than 400 mg per $\mathrm{kg}$, in the fresh mushroom. More recently the presence of lyophyllin in White Domecap was confirmed by Ye et al. (1997), who showed that it is formed from $\mathrm{N}$-hydroxy- $\mathrm{N}^{\prime}, \mathrm{N}^{\prime}$-dimethylurea and $\mathrm{N}$ methylhydroxylamine in the mushroom. Lyophyllin is suspected to be mutagenic and carcinogenic due to its similarity to other aliphatic azoxy compounds such as elaiomycin, which is carcinogenic in rats (Schoental, 1969), and methylazoxymethanol, the aglycone of the two toxic cycad glycosides cycasin and macrozamin, which are mutagenic both in vitro and in vivo and are known to be carcinogenic in experimental animals and suspected to be so also in humans (Hoffmann \& Morgan, 1984; Toth, 2000; IARC, 1976; 1987).

Hydroxyurea derivatives: Fugmann \& Steglich (1984) also isolated another potentially bioactive constituent, $\mathrm{N}$-hydroxy- $\mathrm{N}^{\prime}, \mathrm{N}^{\prime}$-dimethylurea from the mushroom. The levels were in the range 100-200 mg per $\mathrm{kg}$ (fresh weight). The presence of this constituent has been confirmed (Kimura et al., 2005). Like the DNA inhibitor hydroxyurea (hydroxycarbamate), $\mathrm{N}$ - or $\mathrm{N}^{\prime}$-monomethylated hydroxyurea have shown antimitotic effects on female mice vaginal mucosa (Yu \& van Scott, 1974). It is not known whether the N', N'-dimethylated hydroxyurea also has antimitotic effects in vivo.

\section{Other bioactive constituents}

In addition to the suspected toxicants already described in White Domecap, the mushroom contains more than $2 \mathrm{~g}$ per $\mathrm{kg}$ fresh weight of the chromogen connatin (Fugmann \& Steglich, 1984) and unknown quantities of 2-(3,4-dihydroxyphenyl)glycine (Keller et al., 2002). Keller et al. (2002) observed that methanol extracts of the mushroom fruit bodies exhibit both radical scavenging and anti-oxidant activity in in vitro systems. Kimura et al. (2005) confirmed the occurrence of connatin in the mushroom, and in addition noted that the mushroom contains traces of ergothioneine and $\beta$-hydroxyergothioneine (approximately 30 $\mathrm{mg} / \mathrm{kg}$, fresh weight), both compounds with radical scavenging activity. For further information on ergothioneine, see Lepista nuda.

The structural formulae of the bioactive constituents in White Domecap, lyophyllin, $\mathrm{N}$-hydroxy- $\mathrm{N}^{\prime} \mathrm{N}^{\prime}$ - dimethylurea, connatin and $\beta$ hydroxyergothioneine, are shown below. 
<smiles>CN(C)C(=O)N(O)CCCC(N)C(=O)O</smiles>

Connatin<smiles>C[N+](C)(C)C(C(=O)O)C(O)c1c[nH]c(=S)[nH]1</smiles>

$\beta$-Hydroxyergothioneine<smiles>CN(C)C(=O)NO</smiles>

$\mathrm{N}$-Hydroxy- $\mathrm{N}^{\prime}, \mathrm{N}^{\prime}$-dimethylurea

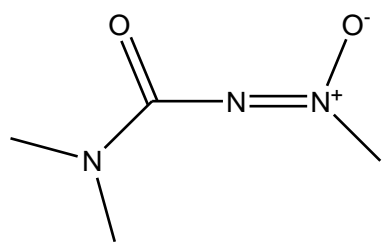

Lyophyllin

\section{Recommendation}

Heat-stable constituents in White Domecap are suspected to be genotoxic and carcinogenic.

\section{Listing 4}

\section{Database search information}

SciFinder by December 2012. Keywords: Lyophyllum. PubMed by December 2012. Keywords: Lyophyllum or Clitocybe connata.

\section{References}

Fugmann B \& Steglich W (1984): Ungewöhnliche Inhaltsstoffe des Blätterpilzes Lyophyllum connatum (Agaricales). Angewandte Chemie 96: 71-72.

Hoffmann GR \& Morgan RW (1984): Review: Putative mutagens and carcinogens in foods V. Cycad azoxyglycosides. Environmental Mutagenesis 6: 103-116. 
IARC (1976): International Agency for Research on Cancer - IARC Monographs on the Evaluation of Carcinogenic Risks of Chemicals to Humans. Some naturally occuring substances. Cycasin. 10: 121-138.

IARC (1987): International Agency for Research on Cancer - IARC Monographs on the Evaluation of Carcinogenic Risks of Chemicals to Humans. Overall evaluations of the carcinogenicity: An updating of IARC Monographs Volumes 1-42:61,71..

Keller C, Maillard M, Keller J \& Hostettmann K (2002): Screening of European fungi for antibacterial, antifungal, larvicidal, molluscicidal, antioxidant and free-radical scavenging activities and subsequent isolation of bioactive compounds. Pharmaceutical Biology 40: 518-525.

Kimura C, Nukina M, Igarashi K \& Sugawara Y (2005): $\beta$-Hydroxyergothioneine, a new ergothioneine derivative from the mushroom Lyophyllum connatum, and its protective activity against carbon tetrachloride-induced injury in primary culture hepatocytes. Bioscience, Biotechnology and Biochemistry 69: 357-363.

Knudsen H \& Vesterholt J (2012): Funga Nordica. Agaricoid, boletoid, clavarioid, cyphelloid and gastroid genera. Nordsvamp: 1-1083.

Korhonen M (1976): Svampe i vor natur. Gyldendals Bogklub: 1-181.

Lange JE \& Lange M (1970): Illustreret svampeflora. GEC Gads Forlag: 1-242.

Mazza R (2000): Funghi commestibili e velenosi a confronto. Fabbri Editori: 1-320.

Nylén B (2012): Svampar i skog och mark. Nordstedts: 1-448.

Phillips R \& Jacobsson S (1996): Nordstedts Stora svambok. Nordstedts: 1-288.

Ryman S \& Holmåsen I (1986): Svampar. Interpublishing, Stockholm: 1-718.

Schoental R (1969): Carcinogenic action of elaiomycin in rats. Nature 221: 765-766.

Toth B (2000): Hydrazines and cancer. Hardwood Academic Publishers: 1-245.

Ye Y, Aulinger K, Arnold N, Spahl W \& Steglich W (1997): Biosynthesis of the azoxycarboxamide lyophyllin and formation of some of its unnatural analogues in fruit-bodies of Lyophyllum connatum. Tetrahedron Letters 38: 8013-8016.

Yu RJ \& van Scott EJ (1974): Antimitotic effects of hydroxyurea and its derivatives: structure activity relationships. Journal of Investigative Dermatology 63: 279-283. 


\section{Clitocybe nebularis (Batsch) P. Kumm. (Lepista nebularis (Batsch) Harmaja)}

Clouded Funnel (DK: Tåge-Tragthat, FI: Härmämalikka, IS: -trektla, NO: Puddertraktsopp, SE: Pudrad trattskivling).

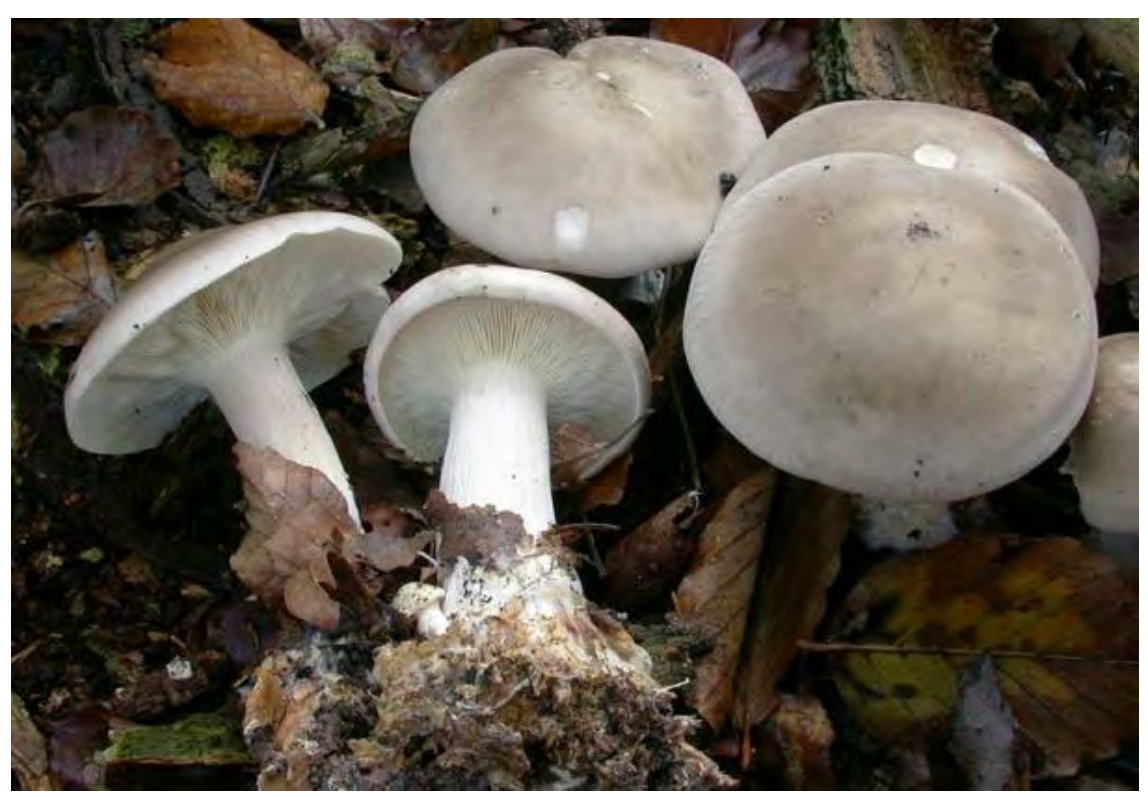

\section{Background and risk assessment}

It is questionable whether Clouded Funnel (Clitocybe nebularis) can be considered an edible mushroom. It is poisonous when eaten raw (Bresinsky \& Besl, 1985; Gerhardt, 1997; Roth et al., 1990) and it does sometimes give rise to intoxications with gastrointestinal distress, even after thorough cooking (Alder, 1960; Knudsen \& Petersen, 2007; Lamaison \& Polese, 2005; Laux, 2001; Lohmeyer \& Künkele, 2006; Læssøe, 2004; Philips, 2006).

Clouded Funnel is a saprotrophic mushroom growing on soil in deciduous and coniferous woods, parks, gardens and ruderal areas, often in fairy rings. It is very common in temperate and hemiboreal zones, and common in boreal zones of the Nordic countries (Knudsen \& Vesterholt, 2012).

The toxic constituents in Clouded Funnel are not known. However, several biologically active compounds have been identified in the mushroom. 


\section{Bioactive constituents}

Nebularine: Already in 1946 Ehrenberg and co-workers isolated nebularine as the active antibiotic compound in the press juice of Clouded Funnel. Nebularine was subsequently identified as 9 - $\beta$-D-ribofuranosyl-9H-purine (Löfgren \& Lüning, 1953; Löfgren et al., 1954), which was confirmed by chemical synthesis of the compound (Brown and Weliky 1953). Its structure makes it likely to be an adenosine analogue. The level of nebularine in the fruit body was small, around $0.002 \%$ (Löfgren et al., 1954). Its biosynthesis has been studied in mycelial cultures of the mushroom, which showed that nebularine is produced by a specific enzymatic activity using adenosine as substrate (Brown \& Konuk, 1995). Nebularine was shown to have selective antibiotic activity against pathogenic and non-pathogenic bacteria (Ehrenberg et al., 1946; Löfgren and Lüning, 1953) and microfungi (Kim et al., 2008), and to be cytotoxic to cultivated mammalian cells (Biesele et al., 1955). Germination of seeds of various plant species in the presence of $0.013 \%(\mathrm{w} / \mathrm{v})$ aqueous solutions of nebularine resulted in severe inhibition of growth and appearance of chromosomal abnormalities in the root tip cells. Seedlings died after a few days (Milton et al., 1992). Nebularine has also been demonstrated to be toxic to rodents (Brown and Weliky, 1953; Philips et al., 1954).

It seems as nebularine is taken up by cells and phosphorylated, possibly by the enzyme adenosine kinase (Bohr, 1978; Divekar et al., 1972; Lindberg et al., 1967; Schnebli et al., 1967). The triphosphate of nebularine was shown not to be a substrate for the Escherichia coli RNA polymerase, but it acts as a competitive inhibitor with ATP for this enzyme, possibly by binding to the polymerase (Bohr, 1978). Further studies by the same investigator showed that nebularine strongly inhibits RNA and DNA synthesis in cancer ascites cells. The most potent inhibition was on the ribosomal components.

Gordon and Brown (1956) studied the metabolism of 9- $\beta$-Dribofuranocyl-9H-purine in Sherman rats. Four hours after intraperitoneal injection of the compound at least three nucleotide-containing purines could be detected in the liver (possibly phosphorylated compounds). No appreciable oxidation to carbon dioxide was noted. A portion is converted to adenine and guanine. It is extensively catalysed to urinary allantoin.

It is not known, whether the small quantities of nebularine, approximately $20 \mathrm{mg} / \mathrm{kg}$ (fresh weight) in Clouded Funnel could give rise to adverse effects after consumption of the mushroom. The structural formula of nebularine is shown below. 


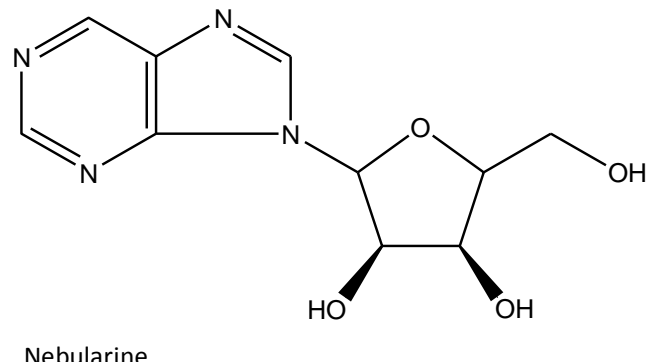

Lectins: Zaremba (1973) partially purified a substance from an extract of fruit bodies of Clouded Funnel and showed that it agglutinated erythrocytes from several animal species. This early publication gave no data on molecular mass, purity or stability. Subsequently, Horejsi et al. (1978) isolated a lectin from fruit bodies of Clouded Funnel, the hemagglutinating action of which was inhibited by $\mathrm{N}$-acetylgalactosamine. It was estimated to consist of two subunits with molecular masses of 19 and $14.5 \mathrm{kDa}$, but otherwise few details were given. More recently, comprehensive studies have been performed by Pohleven and co-workers. These investigators isolated and characterized a lectin from the fruit bodies of Clouded Funnel. The lectin is a homodimeric protein with each subunit having a molecular mass of 15.9 kDa (Pohleven et al., 2009). It agglutinates bovine and human erythrocytes, in particular blood group A erythrocytes and binding requires the unique glycan $\mathrm{N}, \mathrm{N}^{\prime}$-diacetyllactosediamine. The mechanism of action was deduced and revealed bivalent carbohydrate binding for biological activity (Pohleven et al., 2012). Each monomer of the homodimeric protein has a carbohydrate-binding domain. Due to the similarity of the amino acid sequence of the $C$. nebularis lectin with the ricin B-chain, the lectin was characterized as a ricin B-like lectin. The lectin showed selective antiproliferative effects on human cells cultured in vitro; some types of cells were insensitive, others, like leukemic $\mathrm{T}$ cells, were sensitive. The lectin was partially resistant to heat-treatment. It had unchanged hemagglutinating activity after 30 minutes of heating up to $50{ }^{\circ} \mathrm{C}$ and kept $14 \%$ of the activity after 30 minutes at $100^{\circ} \mathrm{C}$. Svaiger et al. (2011) demonstrated that the ricin B-like lectin from Clouded Funnel has immunostimulatory effects, inducing maturation and activation of human dendritic cell via the toll-like receptor 4 pathway. The increased understanding on the mechanism of lectin-binding allowed Pohlevin et al. (2011) to isolate five additional agglutinating lectins from the Clouded Funnel, these being characterized by glucose-, galactose-, sucrose-, lactose-, and sepharose-binding and molecular weights in the region 15-31 $\mathrm{kDa}$. Individual lectins were demonstrated to have insecticidal activity against Fruit Fly (Drosophila melanogastere), with the activity descending in 
the order sucrose-binding lectin, $\mathrm{N}$-acetylgalactoseamine-binding lectin, lactose-sepharose-binding lectin and galactose-sepharose-binding lectin (the other having no activity), and the $\mathrm{N}$-acetylgalactoseamine-binding lectin showing anti-nutritional effect on the larvae from Colorado Potatoe Beetle (Leptinotarsa decemlineata).

There were no data on the thermostability of the five lectins. It is known from lectins of plants that certain lectins, especially the thermostabile ones, may give rise to gastroinstestinal discomfort (Liener, 1983).

Protease inhibitors: Brzin et al. (2000) isolated a cysteine proteinase inhibitor with an apparent molecular mass of $34 \mathrm{kDa}$ from fruit bodies of Clouded Funnel and called the proteinase inhibitor clitocypin. The clitocypin expression appears to be uniform throughout the fruiting body (Sabotič et al., 2011). The inhibitor was characterized as a homodimer of two $17 \mathrm{kDa}$ units. The 150 amino acid long molecule did not contain any cysteine or methionine residues and accordingly no intersubunit disulfide bonds and also no carbohydrate linkage. The monomer sequence showed no similarity to any other known cysteine proteinase inhibitor but had some similarity to a lectin-like family of proteins specifically found in mushrooms. It demonstrated tight binding to proteins such as papain, cathepsin B and bromelain but was inactive towards cathepsin $\mathrm{H}$, trypsin and pepsin. The binding of the clitocypin with papain-like cysteine proteases has been studied in crystalized material (Renko et al., 2010). By inhibiting protein degradation, proteinase inhibitors have anti-nutritional effects. Proteinase inhibitors are frequently destroyed by processing but the clitocypin retained its activity and dimer composition after boiling in water.

Sesquiterpenoids: Four sesquiterpenoids, two named nebularic acid A and $\mathrm{B}$ and two named nebularic lactones $\mathrm{A}$ and $\mathrm{B}$, were isolated from a cultured strain of Clouded Funnel and their structures elucidated. The nebularic acids are $\alpha, \beta$-unsaturated ketones, the two lactones have an $\alpha, \beta$-unsaturated carbonyl moiety, and nebularic acid B in addition has an epoxy group conjugated with a carbonyl group, which means that all four sesquiterpenoids are potentially biologically active compounds (EFSA, 2007). Nebularic lactone A has been shown to exhibit moderate antibacterial activity and nebularic acid B to exhibit both significant antifungal and antibacterial activity (Wangun et al., 2006). The chemical structure of one of these $\alpha, \beta$-unsaturated carbonyl compounds, nebularic acid $B$, is shown below. 
<smiles>CC1(C)CCC[C@]2(C)[C@H]3O[C@@]3(C(=O)O)C(=O)C[C@]12C</smiles>

Nebularic acid B

Other $\alpha, \beta$-unsaturated constituents: The $\alpha, \beta$-unsaturated aldehyde, 2,4diphenyl-2-butenal was isolated in small quantities from fruiting bodies of Clouded Funnel. The compound was shown to have a weak antifungal and antibacterial activity in vitro. Injuring fruit bodies by grounding 15 minutes before analysis, resulted in other potentially biologically active $\alpha, \beta$ unsaturated carbonyl compounds being formed (Pang et al., 1994). It is not known, whether the $\alpha, \beta$-unsaturated constituents (including the sesquiterpenoids) from Clouded Funnel may have adverse effects in humans.

The structural formula of 2,4-diphenyl-2-butenal is shown below.<smiles>O=C/C(=C/Cc1ccccc1)c1ccccc1</smiles>

2,4-Diphenyl-2-butenal

Muscarine: According to some toxicology textbooks on mushrooms, Clouded Funnel may contain muscarine (e.g., Benjamin, 1995; Lincoff \& Mitchel, 1977). There are, however, no analytical studies available, confirming that muscarine may occur in this mushroom.

Hydrogen cyanide: Stijve \& de Meijer (1999) found traces (less than 1 $\mathrm{mg} / \mathrm{kg}$, fresh weight) of hydrogen cyanide in Clouded Funnel. So low levels are of no health concern in relation to consumption of this mushroom. 


\section{Recommendation}

Clouded Funnel gives rise to intoxication with gastrointestinal distress in some people, even after thorough cooking. The toxicant is not known. It should therefore not be used in commercial trade.

\section{Listing 4}

\section{Database search information}

SciFinder by December 2012. Keywords: Lepista nebularis or Clitocybe nebularis. PubMed by December 2012. Keywords: Clitocybe or Lepista or Tricholoma.

\section{References}

Alder AE (1960): Die Pilzvergiftungen in der Schweiz wâhrend 40 Jahren. Schweizerische Zeitschrift für Pilzkunde 39: 65-73.

Benjamin D (1995): Mushrooms: Poisons and panaceas. WH Freeman and company: 1-422.

Biesele JJ, Slautterback MC \& Margolis M (1955): Unsubstituted purine and its riboside as toxic antimetabolites in mouse tissue cultures. Cancer 8: 87-95.

Bleuler-Martinez S, Butschi A, Garbani M, Wälti MA, Wohlschalger T, Potthoff E, Sabotic J, Pohleven J, Lûthy P, Hengartner MO, Aebi M \& Kûnzler M (2011): A lectinmediated resistance of higher fungi against predators and parasites. Molecular Ecology 20: 056-3070.

Bohr V (1978): Effects of purine riboside on nucleic acid synthesis in ascites cells. Biochimica et Biophysica Acta 519: 125-137.

Bresinsky A \& Besl H (1985): Giftpilze. Ein Handbuch für Apotheker, Ärzte und Biologen. Wissenschaftliche Verlagsgesellschaft mbH Stuttgart: 1-295.

Brown EG \& Konuk M (1994): Plant cytotoxicity of nebularine (purine riboside). Phytochemistry 37: 1589-1592.

Brown EG \& Konuk M (1995): Biosynthesis of nebularine (purine 9- $\beta$-Dribofuranoside) involves enzymic release of hydroxylamine from adenosine. Phytochemistry 38: 61-71.

Brown GB \& Weliky VS (1953): The synthesis of 9- $\beta$-D-ribofuranosylpurine and the identity of nebularine. The Journal of Biological Chemistry 204: 1019-1024.

Brzin J, Rogelj B, Popovic T, Strukelj B \& Ritonja A (2000): Clitocypin, a new type of cysteine proteinase inhibitor from fruit bodies of mushroom Clitocye nebularis. The Journal of Biological Chemistry 275: 20104-20109.

Divekar AY, Fleysher MH, Slocum HK, Kenny LN \& Hakala MT (1972): Changes in sarcoma 180 cells associated with drug-induced resistance to adenosine analogs. Cancer Research 32: 2530-2537.

EFSA (2007): Minutes of the 26th Plenary Meeting of the Scientific Panel on Food Additives, Flavourings, Processing Aids and Materials in Contact with Food. Section 9 Flavourings. 9.1.1 FGE 19 (EFSA-Q-2003-162). (Q)SAR predictions on alpha, beta-unsaturated substances including predicted metabolism products of flavouring precursors for alpha, beta-unsaturated aldehydes and ketones.Status of the predictions and outcome of the validation of the genotoxicity studies: 6-9. 
Ehrenberg L, Hedström H, Löfgren N \& Takman B (1946): Antibiotic effect of agarics on Tubercle bacilli. Svensk Kemisk Tidskrift 58: 269-270.

Evans B \& Wolfenden R ((1970): A potential transition state analog for adenosine deaminase. Journal of American Chemical Society 92: 4751-4752.

Gerhardt E (1997): Der grosse BLV Pilzführer für Unterwegs, BLV 1-718.

Gordon MP \& Brown GB (1956): A study of the metabolism of purine riboside. The Journal of Biological Chemistry 220: 927-937.

Horejsi V \& Kokourek J (1978): Studies of lectins. XXXVI. Properties of some lectins prepared by affinity chromatography on O-glycosyl polyacrylamide gels. Biochimica et Biophysica Acta 538: 299-315.

Kim Y-S, Lee I-K, Seok S-J \& Yun B-S (2008): Chemical constituents of the fruiting bodies of Clitocybe nebularis and their antifungal activity. Mycobiology 36: 110-113.

Knudsen H \& Petersen JH (2007): Politikens Svampebog. Politikens Forlag: 1-313.

Knudsen H \& Vesterholt J (2012): Funga Nordica. Agaricoid, boletoid, clavarioid, cyphelloid and gastroid genera. Nordsvamp: 1-1083.

Lamaison J-L \& Polese J-M (2005): Encyclopédie Visuelle des Champignons, Artémis: 1-384.

Laux H E (2001): Der grosse Kosmos Pilzführer. Kosmos: 1-718.

Liener IE (1983): Naturally occurring toxicants in food and their significance in the human diet. Archives of Toxicology Supplements 6: 153-166.

Lincoff G \& Mitchel DH (1977): In Willams WK (Editor): Toxic and hallucinogenic mushroom poisoning. Van Nostrand Reinhold Company: 1-267.

Lindberg B, Klenow H \& Hansen K (1967): Some properties of partially purified mammalian adenosine kinase. The Journal of Biological Chemistry 242: 350-356.

Lohmeyer TR \& Künkele U (2006): Svampe. Parragon Books: 1-256.

Læssøe T (2004): Find de bedste spisesvampe. Gyldendal: 1-89.

Löfgren N \& Lüning B (1953): On the structure of nebularine. Acta Chemica Scandinavica 7: 15 .

Löfgrem N, Lüning B \& Hedström H (1954): The isolation of nebularine and the determination of its structure. Acta Chemica Scandinavica 8: 670-680.

Milton JM, Konuk M \& Brown EG (1992): Lepista nebularis - producer of nebularine. The Mycologist 6: 44-45.

Pang Z, Anke H \& Sterner O (1994): A chemical investigation of the fruit bodies of Lepista nebularis. Acta Chemica Scandinavica 48: 408-410.

Philips FS, Sternberg SS, Hamilton L \& Clarke DA (1954): The toxic effects of 6mercaptopurine and related compounds. Annales of the New York Academy of Science 60: 283-296.

Philips R (2006): Mushrooms. MacMillan: 1-384.

Pohleven J, Brzin J, Vrabec L, Leonardi A, Čoki A, Štrukelj B, Kos J \& Sabotić J (2011): Basidiomycete Clitocybe nebularis is rich in lectins with insecticidal activities. Applied Microbiology and Biotechnology 91: 1141-1148.

Pohleven J, Obermajer N, Sabotič J, Anžlovar S, Sepčić K, Kos J, Kralj B, Štrukelj B \& Brzin J (2009): Purification, characterization and cloning of a ricin B-like lectin from mushroom Clitocybe nebularis with antiproliferative activity against human leukemic T cells. Biochimica et Biophysica Acta 1790: 173-181. 
Pohleven J, Renko M, Magister S, Smith DF, Künzler M, Štrukelj B, Turk D, Kos J \& Sabotič J (2012): Bivalent carbohydrate binding is required for biological activity of Clitocybe nebularis lectin (CNL), the N,N'-diacetyllactosediamine (GalNAc $\beta 1$ 4GlcNAc LacdiNAc)-specific lectin from basidiomycete $C$. nebularis. The Journal of Biological Chemistry 287: 10602-10612.

Renko M, Sabotic J, Mihelic M, Brzin J, Kos J \& Turk D (2009): Versatile loops in mycocypins inhibit three protase families. The Journal of Biological Chemistry 285: 308-316.

Roth L, Frank H \& Kormann K (1990): Giftpilze-Pilzgifte, Schimmelpilze-Mykotoxine. Ecomed Verlagsgesellschaft: 1-327.

Sabotic J, Kilaru S, Budic M, Gasparic MB, Gruden K, Bailey AM, Foster GD \& Kos J (2011): Protease inhibitors clitocypin and macrocypin are differentially expressed within basidiomycete fruiting bodies. Biochimie 93: 1685-1693.

Schnebli HP, Hill DL \& Bennett LL Jr. (1967): Purification and properties of adenosine kinase from human tumor cells of type H. Ep. No. 2. The Journal of Biological Chemistry 242: 1997-2004.

Stijve T \& de Meijer (1999): Hydrocyanic acid in mushrooms, with special reference to wild-growing and cultivated edible species. Deutsche Lebenmittels-Rundschau 95: 366-373.

Švajger U, Pohleven J, Kos J, Štrukelj B \& Jeras M (2011): CNL, a ricin B-like lectin from mushroom Clitocybe nebularis, induces maturation and activation of dendritic cells via the toll-like receptor 4 pathway. Immunology 134: 409-418.

Wangun HVK, Dörfelt H \& Hertweck C (2006): Nebularic acids and nebularilactones, novel drimane sesquiterpenoids from the fungus Lepista nebularis. European Journal of Organic Chemistry: 1643-1646.

Zaremba S (1973): Studies on the influence of a specific type of factors on agglutination of erythrocytes of selected species of animals. Activity of phytohaemagglutinins (PHA) against erthrocytes of different species of animals. Folia Biologica 21: 391-410. 


\section{Clitopilus prunulus (Scop.) P. Kumm.}

The Miller (DK: Gråhvid Melhat, FI: Jauhosieni, IS: Voðhöttur, Vatthöttur, NO: Melsopp, SE: Mjölskivling).

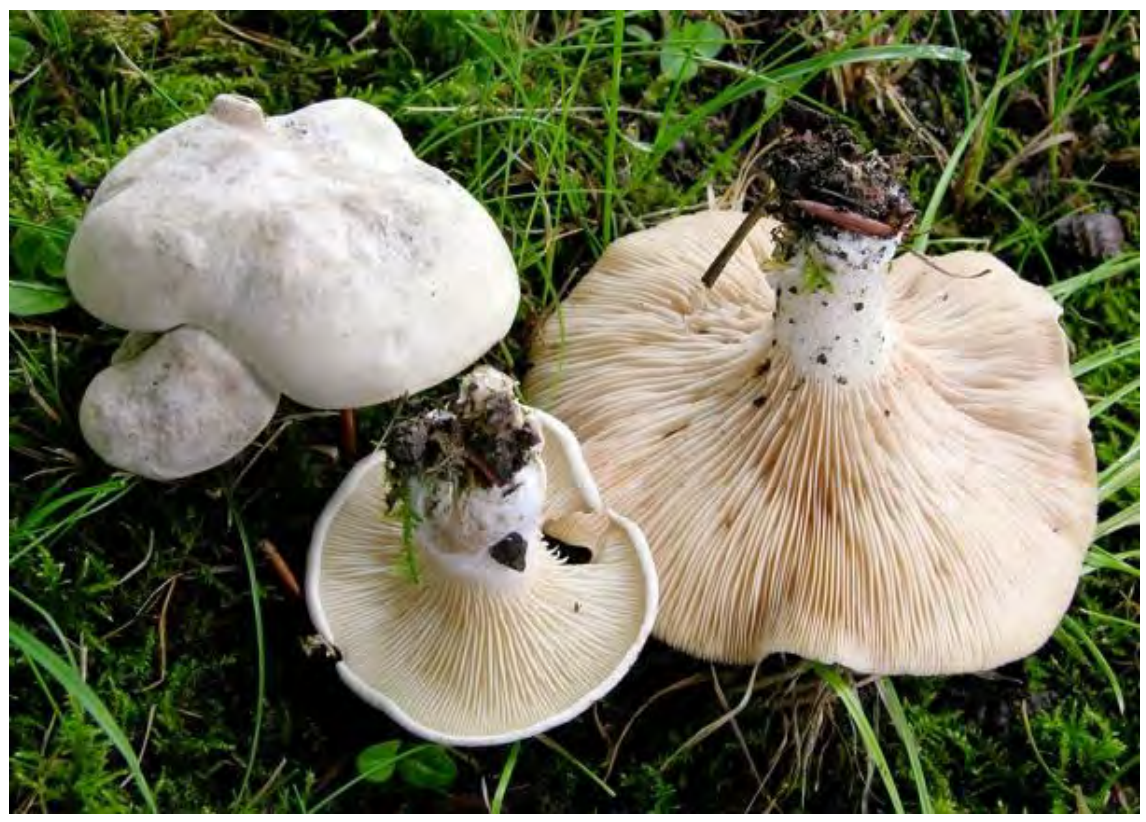

\section{Background and risk assessment}

The Miller (Clitopilus prunulus) is an edible mushroom.

The Miller is a saprotrophic mushroom. It grows mainly on soil in deciduous and coniferous forests. It is common in temperate and up to the middle boreal areas, but occasional or rare in northern boreal and subarctic/subalpine areas of the Nordic countries (Knudsen \& Vesterholt, 2012).

There are no intoxications reported after consumption of The Miller, and no natural toxicants constituting a risk for humans have been identified in the mushroom.

\section{Recommendation}

The Miller resembles some small Funnel species (Clitocybe species) like Fools Funnel (Clitocybe rivulosa), which are very poisonous (see Chapter 4). Therefore, the Miller is not regarded as suitable for commercial marketing.

Listing 3 


\section{Database search information}

SciFinder by February 2012. Keywords: Clitopilus.

\section{References}

Knudsen H \& Vesterholt J (2012): Funga Nordica. Agaricoid, boletoid, clavarioid, cyphelloid and gastroid genera. Nordsvamp: 1-1083. 


\section{Coprinopsis atramentaria (Bull.) Redhead, Vilgalys \& Moncalvo (Coprinus atramentarius (Bull.) Fr.)}

Common Inkcap (DK: Almindelig Blækhat, FI: Harmaamustesieni, IS: Slöttblekil, NO: Grå blekksopp, SE: Grå bläcksvamp).

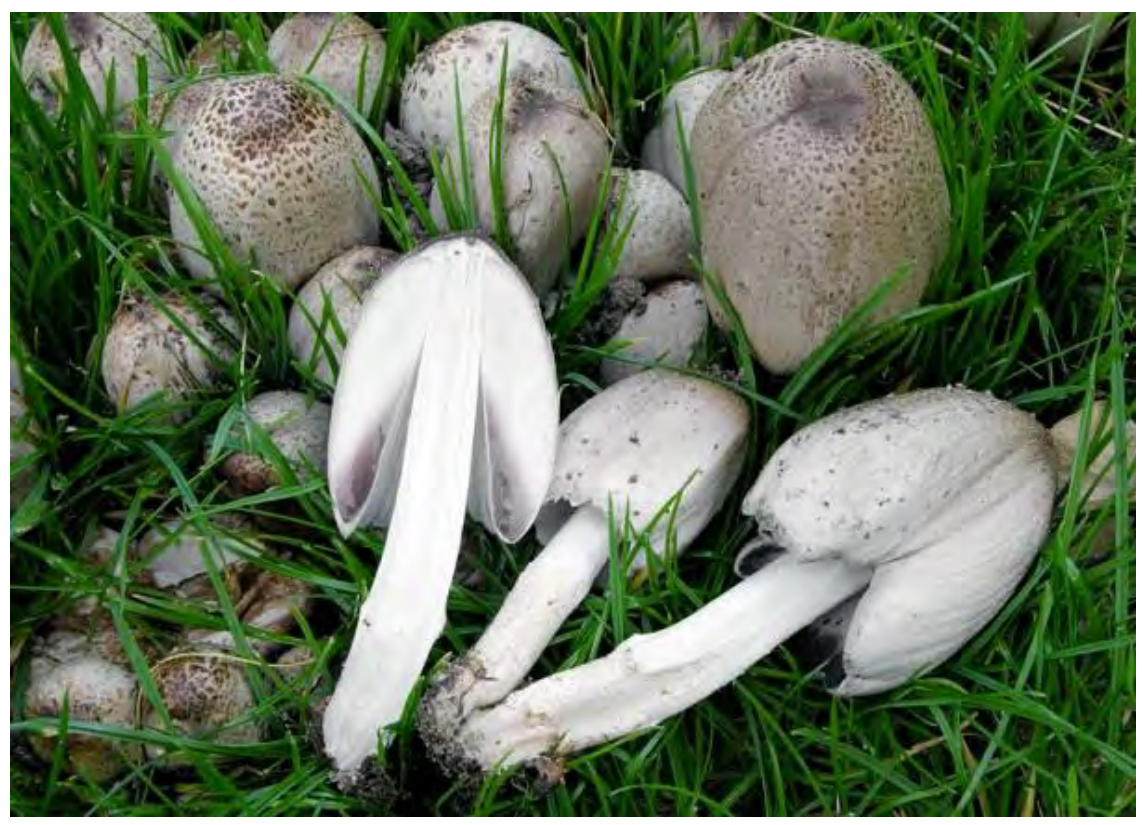

\section{Background and hazard identification}

Common Inkcap (Coprinopsis atramentaria) is not an edible mushroom.

It is a saprotrophic mushroom having a solitary or fasciculate growth around dead wood. It is very common in temperate to boreal zones, and occasional in subalpine/subarctic zones of the Nordic countries (Knudsen \& Vesterholt, 2012).

Several intoxications have been reported after consumption of Common Inkcap, when it is combined with intake of alcoholic beverages. Repeated oral doses of one of its constituents, coprine have given rise to severe damages of germ cells and other adverse effects in male rats similar to those of alkylating compounds. Furthermore, coprine is mutagenic in in vitro tests. Therefore, Common Inkcap should not be used for consumption.

Already in the beginning of the $20^{\text {th }}$ century it was observed that consumption of Common Inkcap together with alcoholic beverages could give rise to poisonings with "antabuse" (disulfiram)-like effects with flushing of face, headache, rapid heart rate, nausea and metallic taste 
(Alder, 1960; Matthies \& Laatsch, 1992; Chilton, 1994; Trestrail, 1991). Nevertheless, it was considered as an edible mushroom, and (unfortunately) in several mushroom textbooks and field guides, it still is, provided that alcohol is not consumed at the same time (e.g., Gerhardt, 1997; Knudsen \& Petersen, 2007; Laux, 2001; Lincoff, 2010; Lohmeyer \& Künkle, 2006; Roth, 1990).

However, in 1975 Lindberg and colleagues, and independently of them Hatfield and Schaumberg, isolated and structure-elucidated the causative agent, which the two groups agreed to name coprine (Lindberg et al., 1975; Hatfield \& Schaumberg, 1975). Subsequently, the structure of coprine was confirmed by synthesis (Lindberg et al., 1977). Coprine is a non-protein amino acid with an unusual structure, including a cyclopropane ring. It can be described as a condensate of cyclopropanone and glutamine. It is a relatively stable compound, which is not destroyed during cooking, but can be hydrolysed to 1-aminocyclopropanol and/or cyclopropanone hydrate in acidic environment or in vivo (Lindberg et al., 1977; Wiseman \& Abeles, 1979). The structural formulae for coprine, 1-aminocyclopropanol and cyclopropanone hydrate are shown below.<smiles>NC(CCC(=O)NC1(O)CC1)C(O)O</smiles>

Coprine

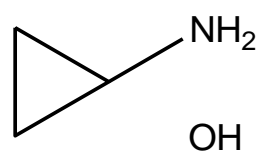

1-Aminocyclopropanol

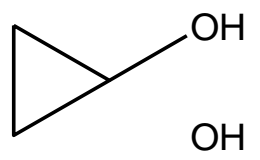

Cyclopropanone hydrate 


\section{Hazard characterisation}

Human observations: After consumption of Common Inkcap together with alcohol the most common symptoms are very similar to those observed after application of the drug disulfiram ("antabuse") to discourage alcoholics from drinking alcoholic beverages. Typical symptoms of the Coprinus ("antabuse") syndrome include flushing of the face, tingling in arms and legs, throbbing headache, tachycardia, sweating, nausea, vomiting, metallic taste, possibly cardiovascular arythmia, and hypotension, whereas colic and diarrhoea are rare. The severity of the symptoms depends on the amounts of mushroom and alcohol consumed and the time between these intakes. The first symptoms may appear within 15(5) minutes to 2 hours, generally 3-6 hours after the combined exposure, but the sensitivity to alcohol may persist 2-3 days after consumption of the mushroom. Usually the symptoms last from 30 minutes to a few hours with complete recovery. There are no documented data available on the content of coprine in Common Inkcap or the amount of Common Inkcap and alcohol consumed in the published cases on intoxications (Barceloux, 2008; Benjamin, 1995; Bresinsky \& Besl, 1985; Chilton, 1994; Michelot, 1992; Rumack, 1994).

Causative agent: In order to isolate, identify and study the constituents in Common Inkcap responsible for the disulfuram-like effects reported in humans after consumption of the mushroom in combination with alcoholic beverages, several in vivo studies have been performed. It was shown that experimental animals such as rats and mice got an elevated level of acetaldehyde in the blood after combined intake of ethanol and Common Inkcap, with some of the same symptoms reported above in humans, e.g. rats had swollen faces and lachrymation and reduced blood pressure (e.g. Coldwell et al., 1969; Hatfield \& Schaumberg, 1975; Lindberg et al., 1975; 1977). Studies with coprine administered orally at different doses in combination with ethanol (intraperitoneally injected) and with different time intervals demonstrated the blocking of acetaldehyde dehydrogenase, resulting in different levels of acetaldehyde in the blood. The lowest pharmacologically, active oral dose in rats was found to be approximately $10 \mathrm{mg}$ coprine per $\mathrm{kg}$ body weight (Carlsson et al., 1978; Lindberg et al., 1977).

In a 14-day repeated dose oral toxicity study on male rats doses of 20 or $200 \mathrm{mg}$ coprine per kg body weight were applied (Jönsson et al., 1979). At $200 \mathrm{mg}$ per $\mathrm{kg}$, coprine caused severe changes in the testis, probably due to direct effects on the germ cells. Pronounced lymphopenia and thrombocytopenia were also documented at the high dose of coprine and the histological examination showed bone marrow depres- 
sion and hypercellularity of spleen, thymus and lymph nodes. At the low dose (20 mg per kg) no treatment-related effects were observed except a small but significant reduction in thrombocyte count. It was noted that the effects caused by coprine are similar to those observed after exposure to alkylating agents. Furthermore, coprine was found to be mutagenic in vitro in the Ames test using Salmonella thyphimurium as indicator organism for mutagenic activity (industrial report referred to by Jönsson et al., 1979). These observations indicate that it is possible that coprine might be a genotoxic carcinogen, for which it is not possible to give a NOAEL, based on the data available.

Mechanism of acute intoxication: It is rendered probable that coprine inactivates aldehyde dehydrogenase (Hatfield \& Schaumberg, 1975; Tottmar \& Lindberg, 1977). This, inhibition could cause the effects seen after intake of Common Inkcap and alcoholic beverages (ethanol). However, coprine does not inhibit aldehyde dehydrogenase in vitro, and it has been concluded that the active principle must be as metabolite of coprine (Hatfield \& Schaumberg, 1975; Tottmar \& Lindberg, 1977; Wiseman \& Abeles, 1979). Initially coprine may be hydrolysed to 1-aminocyclopropanol and/or cyclopropanone hydrate. Both these compounds have shown activity in vitro and in vivo. Further metabolism may yield highly reactive metabolites which can react with a thiol group of the dehydrogenase and block the enzyme, increasing the acetaldehyde concentration in blood. This can explain many of the acute intoxication symptoms seen after consumption of Common Inkcap together with alcoholic beverages (Michelot, 1992; Wiseman \& Abeles, 1979).

Other bioactive constituents: Two illudins designated $\mathrm{C}_{2}$ and $\mathrm{C}_{3}$ have been isolated from cultures of Common Inkcap. Like other illudins, they are sesquiterpenes with an unusual structure, including a spirocyclopropane group. Both compounds have been shown to have antimicrobial effects in vitro (Lee et al., 1996). The structures of these two illudins are very similar to the structure of illudin S. This compound is anticipated to give the intoxications observed when Jack O'Lantern (Omphalotus olearius) is consumed (particularly in middle and southern Europe) (Bresinsky \& Besl, 1985). It is not known to what extent illudin $\mathrm{C}_{2}$ and $\mathrm{C}_{3}$ are formed in the fruit bodies of the Common Inkcap and whether they, like illudin S in Jack O'Lantern, are toxic to humans. The structural formula of one of these sesquiterpenoids, illudin $\mathrm{C}_{2}$ is shown below. 


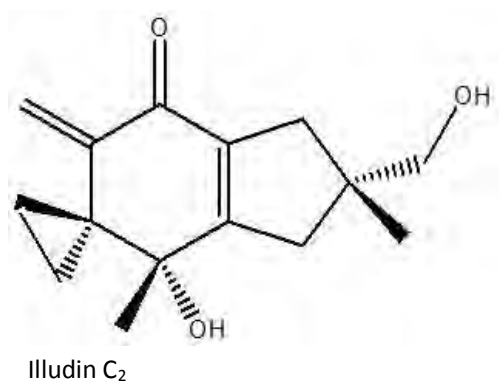

\section{Exposure}

Common Inkcap is reported to contain on average $160 \mathrm{mg}$ coprine per $\mathrm{kg}$ (fresh weight), more in older mushrooms and half as much in young ones (Lindberg et al., 1977). Matthies and Laatsch (1992) reported 160-360 mg coprine per kg fruit body (fresh weight). Coprine has also been found in other, but not edible Coprinopsis species and may also occur in relatively small amounts, approximately 10-15 mg per kg (fresh weight) in the edible Shaggy Inkcap (Coprinus comatus) (Matthies \& Laatsch, 1992). However, there are no data available on the content of coprine in Common Inkcap or the amount of Common Inkcap and alcohol consumed in the published cases on intoxications.

\section{Risk characterization}

In animal studies, the lowest pharmacologically active oral dose of coprine, $10 \mathrm{mg} / \mathrm{kg}$ body weight in rats and a NOAEL below $20 \mathrm{mg} / \mathrm{kg}$ body weight has been identified in two-week oral studies in rat. It is, however, indicated that coprine acts similarly to alkylating agents and that it is mutagenic in bacterial tests. Therefore, it cannot be excluded that coprine is a genotoxic carcinogen, and based on the studies available, it is not possible to give a safe level of intake of Common Inkcap.

\section{Recommendation}

Common Inkcap may give rise to acute intoxications when consumed together with alcoholic beverages. Furthermore, the causative constituent, coprine, has in experimental studies been shown to damage germ cells and to have other adverse effects, possibly including the potential to induce irreversible long term effects such as cancer. Common Inkcap should not be considered as an edible mushroom.

\section{Listing 4}




\section{Database search information}

SciFinder by January 2012. Keywords: Coprinus or Coprinopsis. SciFinder by August 2012. Keywords: Coprine. PubMed by December 2012. Keywords: Coprinus or Coprinopsis and atramentarius or atramentaria.

\section{References}

Alder AE (1960): Die Pilzvergiftungen in der Schweiz während 40 Jahren. Schweizerische Zeitschrift für Pilzkunde 38: 65-73.

Barceloux DG (2008): Medical Toxicology of Natural Substances: Foods, Fungi, Medicinal Herbs, Plants, and Venomous Animals. John Wiley \& Sons, Inc.: 1-1200.

Bresinsky A \& Besl H (1985): Giftpilze. Wissenschaftliche Verlagsgesellschaft mbH Stuttgart: 1-295.

Carlsson A, Henning M, Lindberg P, Martinsson P, Trolin G, Waldeck B \& Wickberg B (1978): On the disulfiram-like effect of coprine, the pharmacologically active principle of Coprinus atramentarius. Acta Pharmacologica et Toxicologica 42: 292-297.

Chilton WS (1994): The chemistry and mode of action of mushroom toxins. In: Spoerke DG \& Rumack BH (Eds): Mushroom poisoning. Diagnosis and treatment, CRC Press: $1-456$.

Coldwell BB, Genest K \& Hughes DW (1969): Effect of Coprinus alimentarius on the metabolism of ethanol in mice. The Journal of Pharmacy and Pharmacology 21: 176-179.

Diaz JH (2005): Syndromic diagnosis and management of confirmed mushroom poisonings. Critical Care Medical Journal 33: 427-436.

Gerhardt E (1997); Der grosse BLV Pilzführer für Unterwegs. BLV: 1-718.

Hatfield GM \& Schaumberg JP (1975): Isolation and structural studies of coprine, the disufiram-like constituent of Coprinus atramentarius. Lloydia 38: 489-496.

Jönsson M, Lindquist NG; Plöen L, Ekvärn S \& Kronevi T (1979): Testicular lesions of coprine and benzcoprine. Toxicology 12: 89-100.

Knudsen H \& Petersen JH (2007): Politikens Svampebog. Politikens Forlag: 1-313.

Knudsen H \& Vesterholt J (2012): Funga Nordica. Agaricoid, boletoid, clavarioid, cyphelloid and gastroid genera. Nordsvamp: 1-1083.

Laux H E (2001): Der grosse Kosmos Pilzführer. Kosmos: 1-718.

Lee I-K, Jeong C-Y, Cho S-M, Yun B-S, Kim Y-S. Yu S-H, Koshino H \& Yoo I-D (1996): Illudins $\mathrm{C}_{2}$ and $\mathrm{C}_{3}$, new illudin $\mathrm{C}$ derivatives from Coprinus atramentarius. The Journal of Antibiotics 49: 821-822.

Lincoff GH (2010): Field guide to North American Mushrooms. Alfred A Knopf: 1-926.

Lindberg P, Bergman R \& Wickberg B (1975): Isolation and structure of coprine, a novel physiologically active cyclopropanone derivative from Coprinus atramentarius and its synthesis via 1-aminocyclopropanol. Journal of the Chemical Society. Chemical Communications 1975: 946-947.

Lindberg P, Bergman R \& Wickberg B (1977): Isolation and structure of coprine, the in-vivo aldehyde dehydrogenase inhibitor in Coprinus atramentarius: syntheses of coprine and related cyclopropanone derivatives. Journal of the Chemical Society. Perkin I: 684-691.

Lohmeyer TR \& Künkele U (2006): Svampe. Parragon Books: 1-256.

Matthies L \& Laatsch H (1992): Ungewöhnliche Pilzvergiftungen: Coprin, ein Hemmstoff des Alkohol-Abbaus. Pharmazie in unserer Zeit 21: 14-20.

Roth L, Frank H \& Kormann K (1990): Giftpilze-Pilzgifte, Schimmelpilze-Mykotoxine. Ecomed Verlagsgesellschaft: 1-327. 
Rumack BH (1994.): Symptomatic diagnosis and treatment of mushroom poisoning. In: Spoerke DG \& Rumack BH (Editors.) Mushroom poisoning. Diagnosis and treatment CRC Press: 1-456.

Tottmar $O$ \& Lindberg P (1977): Effects on rat liver acetaldehyde dehydrogenases in vitro and in vivo by coprine, the disulfiram-like constituent of Coprinus atramentarius. Acta Pharmacologica et Toxicologica 40: 476-481.

Trestrail JH (1991): Mushroom poisoning in the United States - an analysis of 1989 United States poison center data. Clinical Toxicology 29: 495-465.

Wiseman JS \& Abeles RH (1979): Mechanism of inhibition of aldehyde dehydrogenase by cyclopropanone hydrate and the mushroom toxin coprine. Biochemistry 18: 427-435.

\section{Coprinus atramentarius (Bull.) Fr.}

See Coprinopsis atramentaria. 


\section{Coprinus comatus (O.F.Müll.) Pers.}

Shaggy Inkcap, Lawyer's Wig, (Shaggy Mane) (DK: Stor Parykhat (ParykBlækhat), FI: Suomumustesieni, IS: Ullblekill, NO: Matblekksopp, SE: Fjällig bläcksvamp).

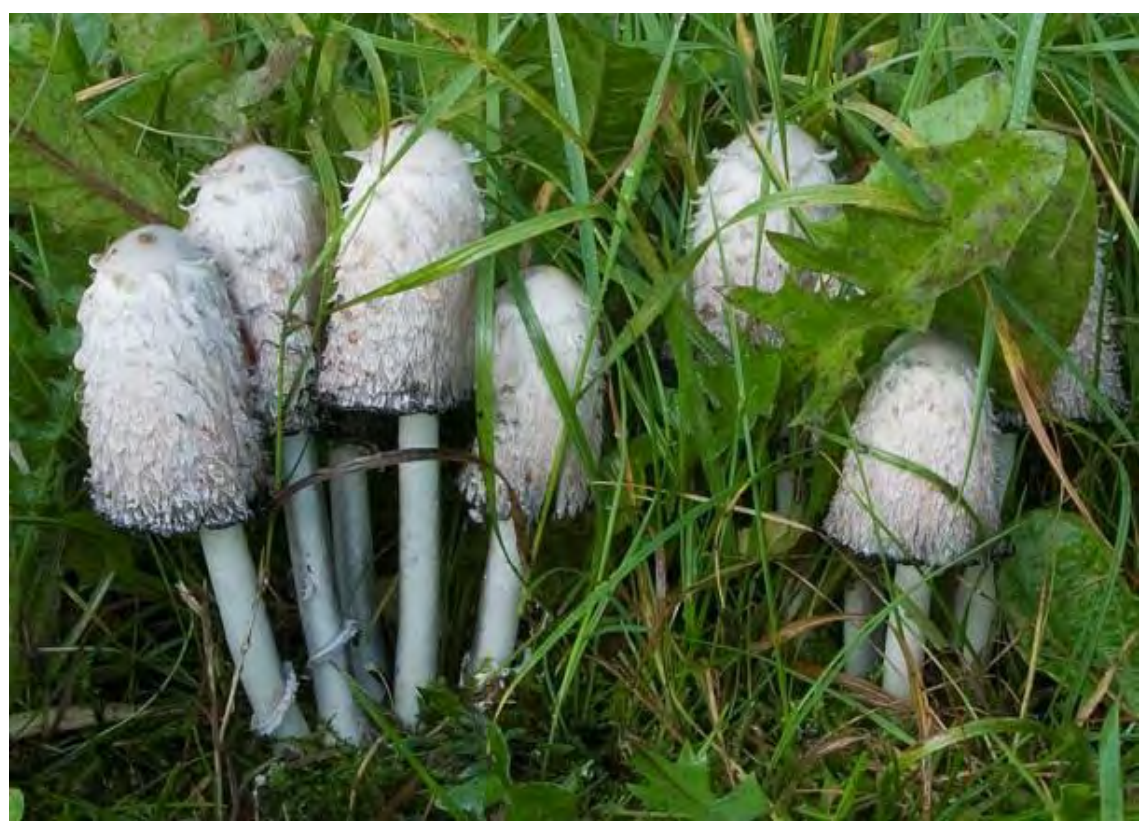

\section{Background and risk assessment}

Shaggy Inkcap (Coprinus comatus) is an edible mushroom.

It is a saprotrophic mushroom growing in open land, lawns, stubblefields and other fertilized areas, also in forests. It is very common in temperate to boreal zones, and occasional in subarctic to alpine zones of the Nordic countries (Knudsen \& Vesterholt, 2012).

Some reports describe rather unspecific poisonings after consumption of Shaggy Inkcap - and these descriptions are not always welldocumented. It is not always clear, if the intoxications have occurred in combination with alcohol consumption. Symptoms such as gastrointestinal distress and chills have begun within 0.5-8 hours after consumption of the mushroom (Beug, 2009; 2012; Beug et al., 2006; Trestrail, 1991). Some bioactive constituents have been identified in Shaggy Inkcap: 


\section{Bioactive constituents}

Coprine: The causative agent has not been identified, but at least in some of the cases, it has been suggested to be the small amounts of coprine which may occur in Shaggy Inkcap. Michelot (1992) in his thorough review on coprine poisonings refers to a level of $26 \mathrm{mg}$ coprine per $\mathrm{kg}$ mushroom (fresh weight) based on data from Laatsch (1990). However, Matthies \& Laatsch (1992) reports a level of approximately 10-15 mg coprine/kg Shaggy Inkcap (fresh weight). The presence of coprine was confirmed by comparing the compound isolated from the mushroom with authentic coprine using mass spectrometry.

Coprine has been shown to damage germ cells and to give other toxic effects in experimental animals and in combination with alcohol to give disulfiram(antabuse)-like effects in humans. Whether the relatively small amounts of coprine which may occur in Shaggy Inkcap have the potential to raise concern in relation to antabuse-effects or the toxic effects in animals is not known (for further details on coprine toxicity, see Coprinopsis atramentaria).

Lectins: Mikiashvili et al. (2006) have demonstrated lectin activity in extracts from fruit bodies of Shaggy Inkcap on rabbit erythrocytes. However, the lectin is not well characterized with respect to binding capacity, stability or to molecular mass.

Statins: Small amounts of lovastatin have been identified in cultured mycelia of Shaggy Inkcap. Chen et al. (2012) reported an average level of $110 \mathrm{mg} / \mathrm{kg}$ dry weight (mean of 3 samples), whereas Lin et al. (2013) reported a level of $1.2 \mathrm{mg} / \mathrm{kg}$ dry weight (mean of 3 samples). For further data on statins, see Pleurotus ostreatus.

Ergothioneine: Relatively small amounts of ergothioneine were demonstrated by List (1957) who isolated approximately $60 \mathrm{mg}$ per $\mathrm{kg}$ of fruit bodies of Shaggy Inkcap (dry weight), and by Chen et al. (2012) who found $399 \mathrm{mg}$ (mean of 3 samples) and by Lin et al. (2013) who found $67 \mathrm{mg}$ (mean of 3 samples) per kg of mycelia (dry weight). For further data on ergothioneine, see Lepista nuda.

Furan derivatives: Luo et al. (2007) have isolated six nematicidal furan and hydrogenated furan derivatives from cultivated mycelia. There are no studies on occurrence in the fruit bodies, and the potential biological effects in humans are unknown.

Mutagens: Sterner et al. (1982) investigated the mutagenic activity of an extract of Shaggy Inkcap in the Ames test, using the Salmonella typhimurium strains TA98, TA100 and TA2637 as indicators. The extract was positive in all three Salmonella strains but the activity was not influenced by introducing a metabolizing rat microsomal system in the test 
assay. Unfortunately, Sterner et al. (1982) give no information on whether they had controlled for the potential presence of histidine in the extract, as it is well known that false positives may be obtained in the presence of this amino acid. Also Morales et al. (1990) studied Shaggy Inkcap extracts in the Ames test. Extracts of freshly harvested mushrooms were reported to be weakly mutagenic in the Salmonella typhimurium strains TA98 and TA100 (less than doubling in mutation frequency). Apparently, Morales et al. (1990) did not control for possible histidine in the extracts for the Ames test. It is concluded that there is no strong indication that extracts of Shaggy Inkcap are mutagenic.

\section{Recommendation}

No special recommendation.

\section{Listing 2}

\section{Database search information}

SciFinder by September 2012. Keywords: Coprinus, coprine. PubMed by December 2012. Keywords: Coprinus comatus.

\section{References}

Beug MW (2009): NAMA Toxicology Committee Report for 2008: Recent Mushroom Poisonings in North America. McIlvainea 18: 45-54.

Beug MW (2012): 2011 NAMA Toxicology Committee Report. North American mushroom poisonings. Mclllvainea 21: 1-14.

Beug MW, Shaw M \& Cochran KW (2006): Thirty-plus years of mushroom poisoning: Summary of the approximately 2,000 reports in the NAMA Case Registry. Mcllvainea 16: 47-68.

Chen S-Y, Ho K-J, Hsieh Y-J, Wang L-T \& Mau J-L (2012): Contents of lovastatin, $\gamma$ aminobutyric acid and ergothioneine in mushroom fruiting bodies and mycelia. Food Science and Technology 47: 274-278.

Knudsen H \& Vesterholt J (2012): Funga Nordica. Agaricoid, boletoid, clavarioid, cyphelloid and gastroid genera. Nordsvamp: 1-1083.

Laatsch H (1990): Wie giftig sind unesere Speisepilze? Teil 1. Forum Mikrobiologie 10: 460-465.

Lin S-Y, Chen Y-K, Yu H-T, Barseghyan GS, Asatiani MD, Wasser SD \& Mau J-L (2013): Comparative study of contents of several bioactive component in fruiting bodies and mycelia of culinary-medicinal mushrooms. International Journal of Medicinal Mushrooms 15: 313-327.

List PH (1957): Über das Vorkommen von Ergothionein im Schopftintling, Coprinus comatus. Archiv der Pharmazie 290/62: 517-520.

Luo H, Liu Y, Fang L, Li X, Tang N \& Zhang K (2007): Coprinus comatus damages nematode cuticles mechanically with spiny balls and produces potent toxins to immobilize nematodes. Applied and Environmental Microbiology 73: 3916-3923. 
Matthies L \& Laatsch H (1992): Ungewöhnliche Pilzevergiftungen: Coprin, ein Hemmstoff des Alkohol-Abbaus. Pharmazie in unserer Zeit 21: 14-20.

Michelot D (1992): Poisoning by Coprinus atramentarius. Natural Toxins 1: 73-80.

Mikiashivili N, Elisashvili V, Wasser SP \& Nevo E (2006): Comparative study of lectin activity of higher basidiomycetes. International Journal of Medicinal Mushrooms 8: 31-33.

Morales P, Bermudez E, Hernandez PE \& Sanz B (1990): The mutagenicity of some Spanish edible mushrooms in the Ames test. Food Chemistry 38: 279-288.

Sterner O, Bergman R, Kesler E, Magnusson L, Nilsson B, Wickberg B, Zimerson E \& Zetterberg G (1982): Mutagens in larger fungi I. Forty-eight species screened for mutagenic activity in the Salmonella/microsome assay. Mutation Research 101: 269-281.

Trestrail JH (1991): Mushroom poisoning in United States - an analysis of 1989 United States poison center data. Clinical Toxicology 29: 459-465. 


\section{Cortinarius caperatus (Pers.) Fr. (Rozites caperatus (Pers.) P. Karst.)}

The Gypsy (DK: Klidhat, FI: Kehnäsieni, IS: Hrukkuhössveppus, NO: Rimsopp, SE: Rimskivling (Rynkad tofsskivling)).

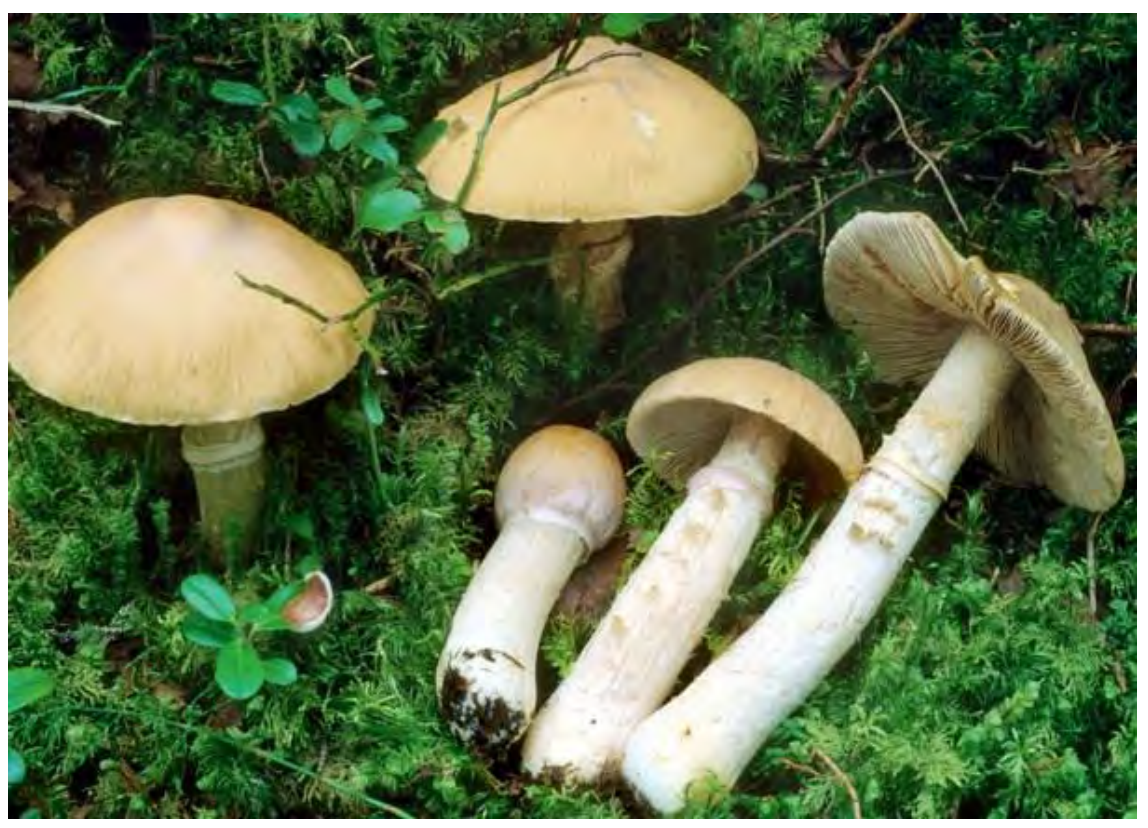

\section{Background and risk assessment}

The Gypsy (Cortinarius caperatus) is an edible mushroom.

It forms mycorrhiza in coniferous forests with Spruce (Picea) and Pine (Pinus) and in deciduous forests with Beech (Fagus) and Oak (Quercus), in subalpine forests with Dwarf Birch (Betula nana). It is rare in Denmark and Iceland, but otherwise common in the Nordic countries (Knudsen \& Vesterholt, 2012).

The Gypsy is distinguished from all other Webcap (Cortinarius) species, as it has a distinct ring. The ring is protruding and comes off easily (Knudsen \& Vesterholt, 2012).

No intoxications have been reported after consumption of The Gypsy and no natural toxicants constituting a risk for humans have been identified in the mushroom.

Grüter et al. (1991) have demonstrated a weakly mutagenic activity of extracts of The Gypsy using a histidine-independent bacterial system. Whether the mutagens are destroyed during food preparation is unknown. 


\section{Recommendation}

No special recommendation.

\section{Listing 2}

\section{Database search information}

SciFinder by February 2012. Keywords: Rozites caperatus, Cortinarius caperatus.

\section{References}

Grüter A, Friederich U \& Würgler FE (1991): The mutagenicity of edible mushrooms in a histidine-independent bacteral test system. Food Chemical Toxicology 29: 159-165.

Knudsen H \& Vesterholt J (2012): Funga Nordica. Agaricoid, boletoid, clavarioid, cyphelloid and gastroid genera. Nordsvamp: 1-1083. 


\section{Cortinarius, other species, e.g., C. armillatus (Fr.) Fr}

Webcap species e.g. Red Banded Webcap (DK: Visse slørhatte, fx Cinnoberbæltet Slørhat, FI: Cortinarius lajin seitikit, esim. Punavyöseitikki Cortinarius, IS: Einstaka kögrar t.d. no Icelandic name, NO: Slørsopper f. eks. Rødbelteslørsopp, SE: Cortinarius-arter, t.ex. rödbandad spindling, Vissa spindlingar (Spindelskivlingar)).

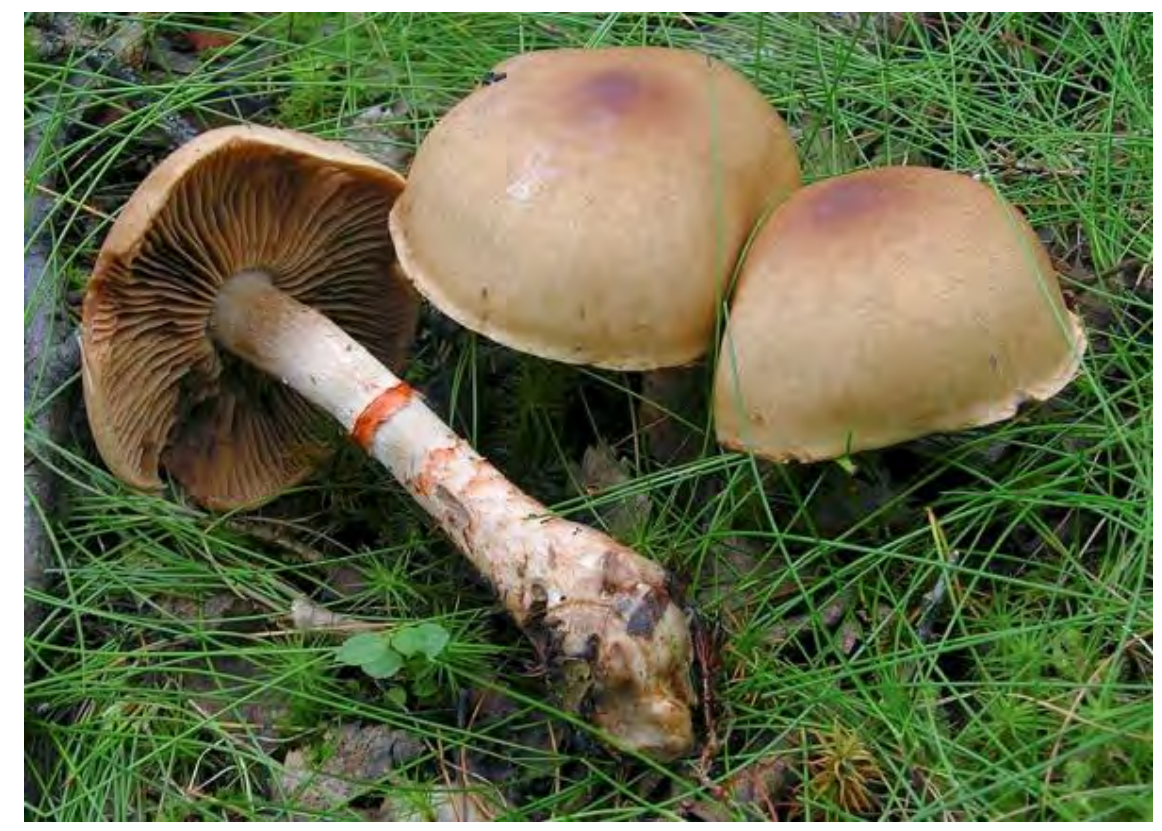

\section{Background and risk assessment}

Webcap (Cortinarius) is the biggest genus of fungi in the Nordic countries with 369 species described in Funga Nordica and, based on phylogenetic studies, it is assumed that at least 900 species occur in the Nordic countries (Knudsen \& Vesterholt, 2012). The Webcap species form mycorrhiza with all kinds of deciduous and coniferous trees. With few exceptions, e.g., The Gypsy (C. caperatus), most of the Webcap species are difficult to identify for non-specialists. Some Webcab species are deadly poisonous, e.g., Deadly Webcap (Cortinarius rubellus) and Fool's Webcap (C. orellanus), several are suspicious, e.g., species from the section Dermocybe, containing anthraquinones, some of which are laxative and/or mutagenic in vitro (Barceloux, 2008; von Wright et al., 1992; Besl et al., 1978), and other Webcap species indicated to contain orellanine, the toxicant in Deadly Webcap and in Fools Webcap (Oubrahim et al., 
1997; Danel et al., 2001; Matthies \& Laatsch, 1991). The edibility of most Webcap species is unknown and only a few are reported as edible, e.g. Red Banded Webcap (C. armillatus) (Gerhardt, 1997; Knudsen \& Petersen, 2007; Lohmeyer \& Künkele, 2006).

Red Banded Webcap forms mycorrhiza in deciduous and mixed forests. It is rare in temperate zone, but very common in hemiboreal and subalpine/subarctic zones of the Nordic countries (Knudsen \& Vesterholt, 2012).

No intoxications have been reported after consumption of Red Banded Webcap. However, it contains several anthraquinone derivatives, endocrocin, dermolutein and dermorubin (Besl et al., 1978). The structural formula of one of the major anthraquinones in Red Banded Webcap, dermolutein, is shown below.<smiles>COc1cc(O)cc2c1C(=O)c1c(cc(C)c(C(=O)O)c1O)C2=O</smiles>

Dermolutein

\section{Recommendation}

Many webcaps (Cortinarius species) are difficult to identify, and some of them are deadly poisonous, e.g., Deadly Webcap (Cortinarius rubellus) (See Chapter 4). Webcap species are therefore, with the exception of The Gypsy (C. caperatus), not regarded as suitable for commercial marketing.

\section{Database search information}

SciFinder by February 2012. Keywords: Cortinarius armillatus.

\section{References}

Barceloux DG (2008): Medical Toxicology of Natural Substances: Foods, Fungi, Medicinal Herbs, Plants, and Venomous Animals. John Wiley \& Sons, Inc.: 1-1200.

Besl H, Halbauer R \& Steglich W (1978): 34. New anthraquinone pigments from Cortinarius armillatus and C. miniatopus (Agaricales). Zeitschrift für Naturforschung, 33C: 294-295.

Danel VC, Saviuc PF \& Garon D (2001): Main features of Cortinarius spp. poisoning: A literature review. Toxicon 39: 1053-1060.

Gerhardt E (1997): Der grosse BLV Pilzführer für Unterwegs, BLV 1-718. 
Gerhardt E (1997): Der grosse BLV Pilzführer für Unterwegs. BLV: 1-718.

Knudsen H \& Petersen JH (2007): Politikens Svampebog. Politikens Forlag: 1-313.

Knudsen H \& Vesterholt J (2012): Funga Nordica. Agaricoid, boletoid, clavarioid, cyphelloid and gastroid genera. Nordsvamp: 1-1083.

Lohmeyer TR \& Künkele U (2006): Svampe. Parragon Books: 1-256.

Matthies L \& Laatsch H (1991): Cortinarins in Cortinarius speciocissimus? A critical review. Experientia 47: 634-640.

Oubrahim H, Richard J-M, Cantin-Esnault D, Seigle-Murandi F \& Trécourt F (1997): Novel methods for identification and quantification of the mushroom nephrotoxin orellanine. Thin-layer chromatography and electrophoresis screening of mushrooms with electron spin resonance of the toxin. Journal of Chromatography A 758: 145-157.

von Wright A, Raatikainen O, Taipale H, Kärenlampi S \& Mäki-Paakkanen J (1992): Directly acting geno- and cytotoxic agents from a wild mushroom, Dermocybe sanguinea. Mutation Reseach 269: 27-33. 


\section{Craterellus cornucopioides (L.) Pers. (Cantharellus cornucopioides (L.) Fr.)}

Horn of Plenty (DK: Trompetsvamp, FI: Mustatorvisieni, IS: Svartlúður, NO: Svart trompetsopp, SE: Svart trumpetsvamp).

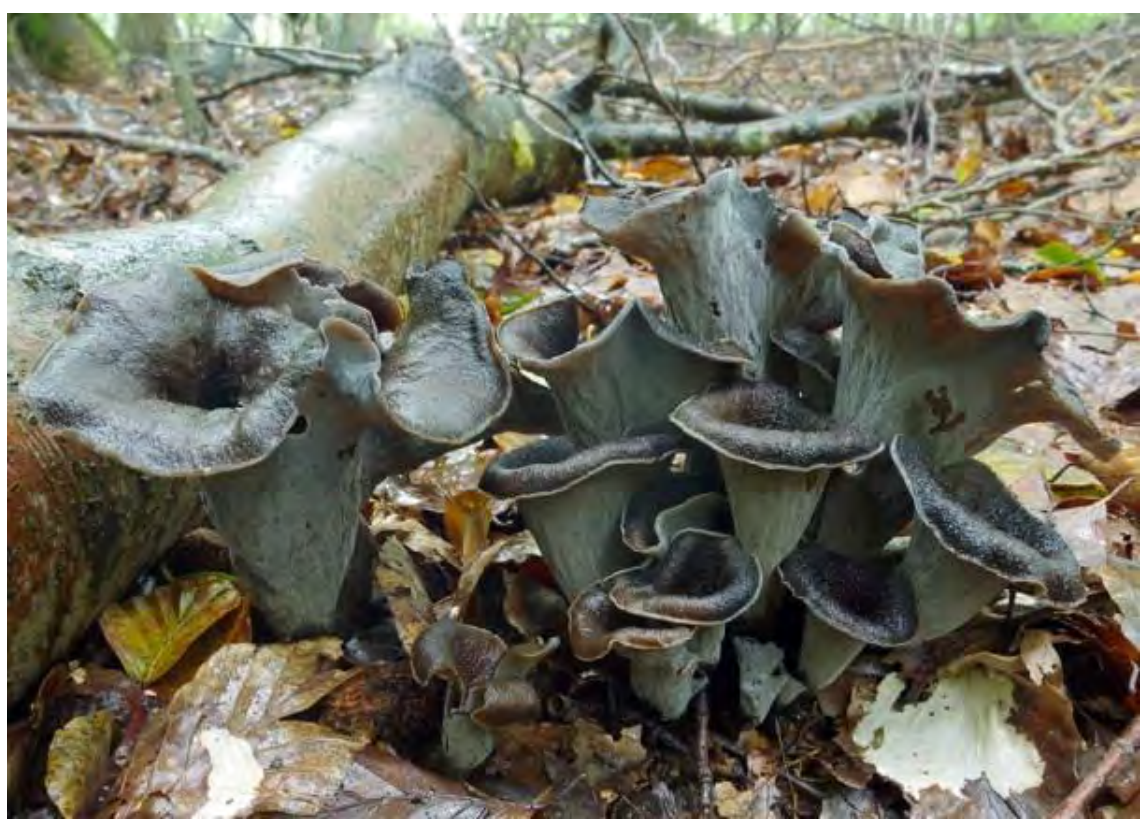

\section{Background and risk assessment}

Horn of Plenty (Craterellus cornucopioides) is an appreciated, edible mushroom.

It is a common in rich deciduous forests, with Beech (Fagus) and Oak (Quercus) in Denmark and in southern parts of Finland, but occasional or rare in northern parts of Finland, Norway and Sweden with Hazel (Corylus) and Spruce (Picea). It is occasional in Iceland and can be found, most abundantly in the late autumn (Hansen \& Knudsen, 1997). It is available on the market both as fresh and dried.

There are no intoxications reported after consumption of Horn of Plenty. However, some potentially bioactive compounds may occur in Horn of Plenty. 


\section{Bioactive constituents}

Ketoesters: Three ketoesters have recently been identified in Horn of Plenty: 4-oxohex-1,6-diyl diacetate, 4-oxohex-5-enyl acetate and 4-oxo6-hexyl acetate (Liu et al., 2010). The structures of these esters do not indicate concern with respect to potential toxicity.

Sesquiterpenes: It should be remarked that four unusual sesquiterpenes (craterellins) have been isolated from cultures of the related Craterellus odoratus. These constituents have inhibitory effects against 11ß-hydroxysteroid dehydrogenases (Zhang et al., 2010).

\section{Recommendation}

It should be examined whether Horn of Plenty (C. cornucopiodes), like C. odoratus, contains craterellins and if so, in which amounts?

\section{Database search information}

SciFinder by December 2012. Keywords: Craterellus, Cantharellus.

\section{Listing 1}

\section{References}

Hansen L \& Knudsen H (1997): Nordic Macromycetes, Volume 3. Heterobasidioid, aphyllophoroid and gastromycetoid basidiomycetes. Nordsvamp: 1-444.

Liu R, Zhou Z-Y \& Liu J-K (2010): Three new ketoesters from cultures of the basidiomycete Craterellus cornucopioides. Zhongguo Tianran Yaowu 8: 88-90 (Chinese, English abstract available).

Zhang L, Shen Y, Wang F, Leng Y \& Liu J-K (2010): Rare merosesquiterpenoids from basidiomycete Craterellus odoratus and their inhibition of $11 \beta$-hydroxysteroid dehydrogenases. Phytochemisty 71: 100-103. 


\section{Craterellus lutescens (Pers.) Duby (Craterellus lutescens (Fr.) Fr., Cantharellus lutescens Fr.)}

Yellow Foot (DK: Rødgul Kanterel/Rødgul Trompetsvamp, FI: Kosteikkovahvero, IS: Gulllúður, NO: Gul trompetkanarell/Gul trompetsopp, S: Rödgul trumpetsvamp).

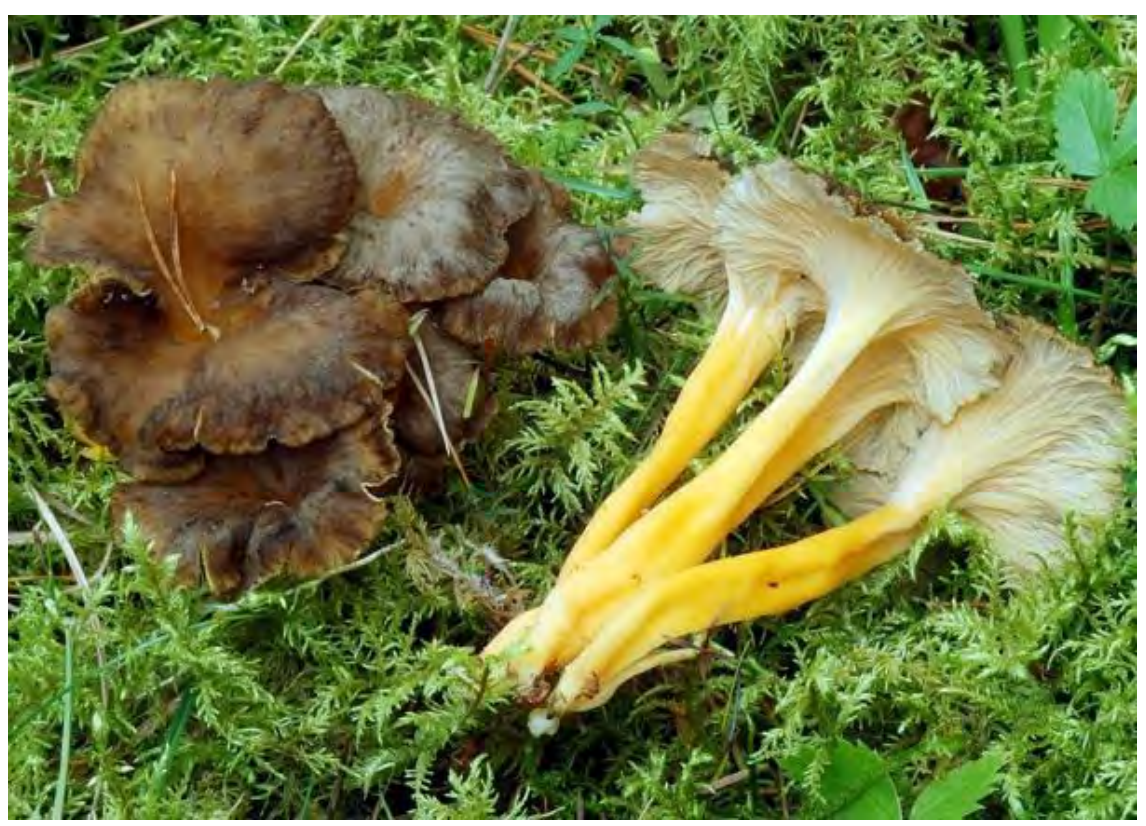

\section{Background and risk assessment}

Yellow Foot (Craterellus lutescens) is an appreciated edible mushroom.

It is not found in Denmark. It grows with Spruce (Picea) on calcareous soil and is occasional or rare in hemiboreal and boreal zones of Finland, Norway and Sweden and common in southern parts of Sweden (Hansen \& Knudsen, 1997). It is available on the market, mainly as fresh.

Consumption of Yellow Foot is not reported to give rise to intoxications.

Due to its genetic relationship to the Trumpet Chanterelle (C. tubaeformis) and, therefore, anticipated compositional similarity, it is possible that $C$. lutescens by injury may form (8E)-10-hydroxy-8-decenoic acid. This compound has been shown to be formed in injured Trumpet Chanterelle (Anke et al., 1996; Pang et al., 1992). By damage of the mushroom it is anticipated to be formed enzymatically from linoleic acid, which is an important fatty acid in the fresh mushroom. Further information on the biological activity of (8E)-10-hydrox-8- decenoic acid is given in the monograph on 
Trumpet Chanterelle. (8E)-10-Hydroxy-8-decenoic acid is not significantly degraded in boiling water (Anke et al., 1996).

\section{Recommendations}

Yellow Foot (Craterellus lutescens) may like the closely related Trumpet Chanterelle (Craterellus tubaeformis) form weakly mutagenic compounds if injured.

\section{Listing 1}

\section{Database search information}

SciFinder by December 2012. Keywords: Craterellus, Cantharellus.

\section{References}

Anke H, Morales P, \& Sternes O (1996): Assays of the biological activities of two fatty acid devitatives formed in the edible mushroom Cantharellus cibarius and $C$. tubaeformis as a response to injury. Planta Medica 62: 181-183.

Hansen L \& Knudsen H (1997): Nordic Macromycetes, Volume 3. Heterobasidioid, aphyllophoroid and gastromycetoid basidiomycetes. Nordsvamp: 1-444.

Pang Z, Sterner O \& Anke H (1992): (8E)-10-Hydroxy-8-decenoic acid: Its isolation from injured fruit bodies of Cantharellus tubaeformis and synthetic preparation. Acta Chemica Scandinavica 46: 301-303.

Stadler M, Mayer A, Anke H \& Sterner O (1994): Fatty acids and other compounds with nematicidal activity from cultures of Basidiomycetes. Planta Medica 60: 128-132. 
Craterellus tubaeformis (Fr.) Quél. (Cantharellus tubaeformis (Bull.) Fr., C. tubaeformis Fr.)

Trumpet Chantarelle ("Chanterelle gris", "Winter Chanterelle") (DK: Tragt-Kantarel, FI: Suppilovahvero, IS: Gralúður; NO: Traktkantarell, SE: Trattkantarell).

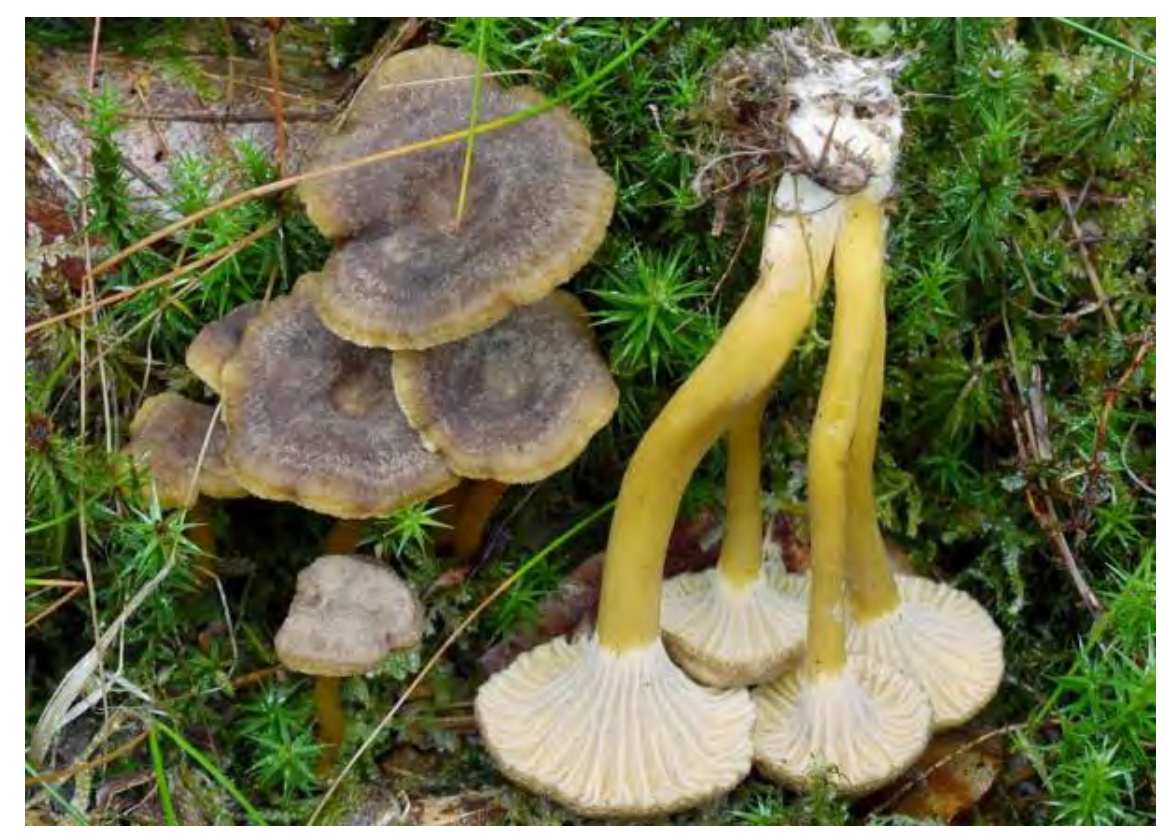

\section{Background and risk assessment}

Trumpet Chanterelle (Craterellus tubaeformis) is an appreciated edible mushroom.

It is commonly found in the Nordic countries, except in Iceland, in both coniferous and deciduous forests with Spruce (Picea) and Beech (Fagus) (Hansen \& Vesterholt, 1997). It is marketed both as fresh and dried.

Consumption of Trumpet Chanterelle is not reported to have given rise to intoxications.

When injured, the Trumpet Chanterelle may form the fatty acid derivative (8E)-10-hydroxy-8-decenoic acid in amounts of up to $50 \mathrm{mg}$ per $\mathrm{kg}$ fresh weight (Anke et al., 1996; Pang et al., 1992). 
<smiles>O=C(O)CCCCCC/C=C/CO</smiles>

(8E)-10-Hydroxydec-8-enoic acid

This fatty acid derivative is anticipated to have the potential to be biologically oxidized to the corresponding $\alpha, \beta$-unsaturated aldehyde, having a structural alert for genotoxic activity (EFSA 2007). In fact, (8E)-10hydroxy-8-decenoic acid has been shown to be a very weak directly acting mutagen when tested in Salmonella typhimurium strain TA100 in the absence of S-9 mix, whereas the compound was negative in this test strain with metabolic activation (S-9 mix) and in strain TA98 with and without S-9 mix (Anke et al., 1996). (8E)-10-Hydroxy-8-decenoic acid shows very weakly antimicrobial and cytotoxic activities in a few of the altogether seventeen bacteria, fungi and cell lines tested (Anke et al., 1996). The acid has also shown weakly nematicidal activity (Stadler et al., 1994). (8E)-10-Hydroxy-8-decenoic acid is not significantly degraded in boiling water (Anke et al., 1996).

\section{Recommendations}

Trumpet Chanterelle (C. tubaeformis) may form weakly mutagenic compounds if injured.

\section{Listing 1}

\section{Database search information}

SciFinder by December 2012. Keywords: Craterellus, Cantharellus.

\section{References}

Anke H, Morales P \& Sterner O (1996): Assays of the biological activities of two fatty acid derivatives formed in the edible mushrooms Cantharellus cibarius and $C$. tubaeformis as a response to injury. Planta Medica 62: 181-183.

EFSA (2007): Minutes of the 26th Plenary Meeting of the Scientific Panel on Food Additives, Flavourings, Processing Aids and Materials in Contact with Food. Section 9 Flavourings. 9.1.1 FGE 19 (EFSA- Q-2003-162). (Q)SAR predictions on alpha, beta-unsaturated substances including predicted metabolism products of flavouring precursors for alpha, beta-unsaturated aldehydes and ketones. Status of the predictions and outcome of the validation of the genotoxicity studies: 6-9.

Hansen L \& Knudsen H (1997): Nordic Macromycetes, Volume 3. Heterobasidioid, aphyllophoroid and gastromycetoid basidiomycetes. Nordsvamp: 1-444. 
Pang Z, Sterner O \& Anke H (1992): (8E)-10-Hydroxy-8-decenoic acid: Its isolation from injured fruit bodies of Cantharellus tubaeformis and synthetic preparation. Acta Chemica Scandinavica 46: 301-303.

Stadler M, Mayer A, Anke H \& Sterner O (1994): Fatty acids and other compounds with nematicidal activity from cultures of basidiomycetes. Planta Medica 60: 128-132. 


\section{Flammulina velutipes (Curtis) Singer}

Velvet Shank, (Enoki-take, Golden Needle Mushroom) (DK: Almindelig Fløjlsfod ("Enoki”), FI: Talvijuurekas, IS: Veturfönungur (Loðfótur), NO: Vintersopp ("Enoki" og "Enokitake"), SE: Vinterskivling (Vinternagelskivling)).

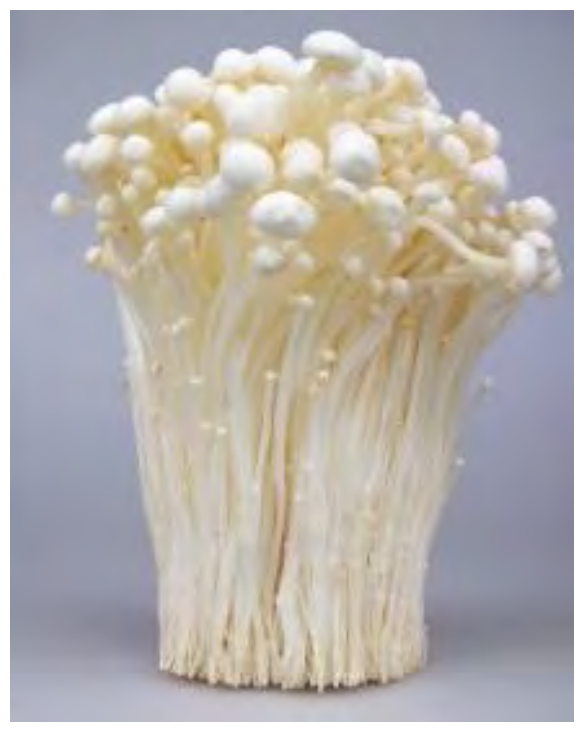

\section{Background and risk assessment}

Velvet Shank (Flamulina velutipes) is an edible mushroom.

It grows on dead or living wood or roots of deciduous trees, rarely on conifers, mainly in late autumn or winter. It is very common in temperate and hemiboreal, common in boreal/subalpine/subarctic and occasional in arctic/alpine zones of the Nordic countries (Knudsen \& Vesterholt, 2012).

Commercially, only the cultivated forms of Velvet Shank are of importance. It is mainly cultivated in south-eastern parts of Asia, but also to some extent in e.g. the Nordic countries.

There are no intoxications reported after consumption of Velvet Shank except for a questionable case (Beug et al., 2006). However, it contains different potentially bioactive compounds: 


\section{Bioactive constituents}

Ergothioneine: Velvet Shank contains $57 \mathrm{mg}$ (Lin et al., 2013) or $455 \mathrm{mg}$ of ergothioneine per kg of dried mushroom (Chen et al., 2012) (for further data on ergothioneine, see Lepista nuda).

Statins: Velvet Shank contains lovastatin. Lee et al. (2006) reported, 4$5 \mathrm{mg}$ - and Chen et al. (2012) reported $91 \mathrm{mg}$ per kg dried fruit bodies (Chen et al., 2012).(for further data on lovastatin, see Pleuroteus ostratus).

Ribosome inactivating proteins are enzymes that depurinate tRNA's. This depurination inactivates the ribosomes, thus inhibiting protein synthesis (Stirpe \& Battelli, 2006; Nielsen \& Boston, 2001). At least four ribosome inactivating proteins have been characterized in Velvet Shank: Flammulin (molecular mass $40 \mathrm{kDa}$; velutin (molecular mass $13.8 \mathrm{kDa}$ ), flamin (molecular mass $30 \mathrm{kDa}$ ) and velin (molecular mass $19 \mathrm{kDa}$ ). These four proteins all inhibit translation in a rabbit reticulocyte lysate system (Ng \& Wang, 2004). Generally, ribosome inactivating proteins have been shown to have various biological activities e.g. antimitogenic, antiproliferative, and antifungal effects in in vivo and in vitro experimental test systems (Lam \& Ng, 2001). There are no data available demonstrating whether these proteins in Velvet Shank have any biological effects in relation to consumption of the mushroom.

Cytolytic proteins: A cytolytic protein, flammutoxin has been isolated from Velvet Shank. It causes significant eletrocardiographical changes when administered parenterally to cats. It also gives rise to swelling and inhibition of respiration of Ehrlich ascites tumour cells (Lin et al., 1974; 1975) and hemolyses human as well as many different experimental animal erythrocytes (Lin et al., 1975; Bernheimer \& Oppenheim, 1987). Tomita et al. (1998) and Tadjibaeva et al. (2000) did show that flammutoxin has a molecular mass of $31 \mathrm{kDa}$, and that it assembles into a ring-shaped oligomer on target cells, e.g. membranes of erythrocytes. As heat-treatment at temperatures higher than $60^{\circ} \mathrm{C}$ for 30 minutes completely abolished the hemolytic activity of flammutoxin (Lin et al., 1975) it is also likely, it is destroyed during cooking. It may also be inactivated in or not absorbed from the gastrointestinal tract.

Lectins: A dimeric lectin with a molecular mass of $20 \mathrm{kDa}$ has been isolated from Velvet Shank and characterized. It consists of two subunits of 8 and $12 \mathrm{kDa}$. Only the $12 \mathrm{kDa}$ subunit exhibits hemagglutinating and mitogenic activity. The hemagglutinating effects are reduced at temperatures beyond $60{ }^{\circ} \mathrm{C}$ and are undetectable above $80^{\circ} \mathrm{C}$. As the lectin in Velvet Shank apparently will be destroyed during cooking, the content of lectin in the mushroom is of no health concern. 


\section{Recommendation}

No special recommendation.

\section{Listing 1 (as cultivated), Listing 2 (as wild)}

\section{Database search information}

SciFinder by January 2012. Keywords: Flammulina.

\section{References}

Bernheimer AW \& Oppenheim JD (1987): Some properties of flammutoxin from the edible mushroom Flammulina velutipes. Toxicon 25: 1145-1152.

Beug MW, Shaw M \& Cochran KW (2006): Thirty-plus years of mushroom poisonings. Summary of the approximately 2,000 reports in the NAMA Case Registry. Mcllvainea 16: 47-67.

Chen S-Y, Ho K-J, Hsieh Y-J, Wang L-T \& Mau J-L (2012): Contents of lovastatin, $\gamma$ aminobutyric acid and ergothioneine in mushroom fruiting bodies and mycelia. Food Science and Technology 47: 274-278.

Knudsen H \& Vesterholt J (2012): Funga Nordica. Agaricoid, boletoid, clavarioid, cyphelloid and gastroid genera. Nordsvamp: 1-1083.

Lam SK \& Ng TB (2001): Hypsin, a novel thermostable ribosome-inactivating protein with antifungal and antiproliferative activities from fruiting bodies of the edible mushroom Hypsizigus marmoreus. Biochemical and Biophysical Reseach Communication 285: 1071-1075.

Lee J-W, Lee S-M, Gwak K-S, Lee J-Y \& Choi I-G (2006): Screening of edible mushrooms for the production of lovastatin and its HMG-CoA redutase inhibitory activity. The Korean Journal of Microbiology 42: 83-88 (Korean, English abstract available).

Lin J-Y, Lin Y-J, Chen C-C, Wu H-L, Shi G-Y \& Jeng T-W (1974): Cardiotoxic protein from edible mushrooms. Nature 252: 235-237.

Lin J-Y, Wu H-L \& Shi G-Y (1975): Toxicity of the cardiotoxic protein, flammutoxin, isolated from the edible mushroom Flammulina velutipes. Toxicon 13: 323-331.

Lin S-Y, Chen Y-K, Yu H-T, Barseghyan GS, Asatiani MD, Wasser SD \& Mau J-L (2013): Comparative study of contents of several bioactive components in fruiting bodies and mycelia of culinary-medicinal mushrooms. International Journal of Medicinal Mushrooms 15: 313-327.

Ng TB \& Wang HX (2004): Flammin and velin: new ribosome inactivating polypeptides from the mushroom Flammulina velutipes. Peptides 25: 929-933.

Ng TB, Ngai HK \& Xia L (2006): An agglutinin with mitogenic and antiproliferative activities from the mushroom Flammulina velutipes. Mycologia 98: 167-171.

Nielsen K \& Boston RS (2001): Ribosome-inactivating proteins: A plant perspective. Annual Review of Plant Physiology and Plant Molecular Biology 52: 785-816.

Stirpe F \& Battelli MG (2006): Ribosome-inactivating proteins: progress and problems. Cellular and Molecular Life Sciences 63: 1850-1866. 
Tadjibaeva G, Sabirov R \& Tomita T (2000): Flammutoxin, a cytolysin from the edible mushroom Flammulina velutipes, forms two different types of voltage-gated channels in lipid bilayer membranes. Biochimica et Biophysica Acta 1467: 431-443.

Tomita T, Ishikawa D, Noguchi T, Katayama E \& Hashimoto Y 1998): Assembly of flammutoxin, a cytolytic protein from the edible mushroom Flammulina velutipes, into a pore-forming ring-shaped oligomer of the target cell. Biochemical Journal 333: 129-137.

Tsuda M (1979): Purification and characterization of a lectin from the mushroom, Flammulina velutipes. Journal of Biochemistry 86: 1463-1468. 


\section{Gomphidius glutinosus (Schaeff.) Fr.}

Slimy Spike (DK: Grå Slimslør, FI: Limanuljaska, IS: Slímgumpur (Slímstautull), NO: Sleipsopp, SE: Citronslemskivling (Citrongul slemskivling)).

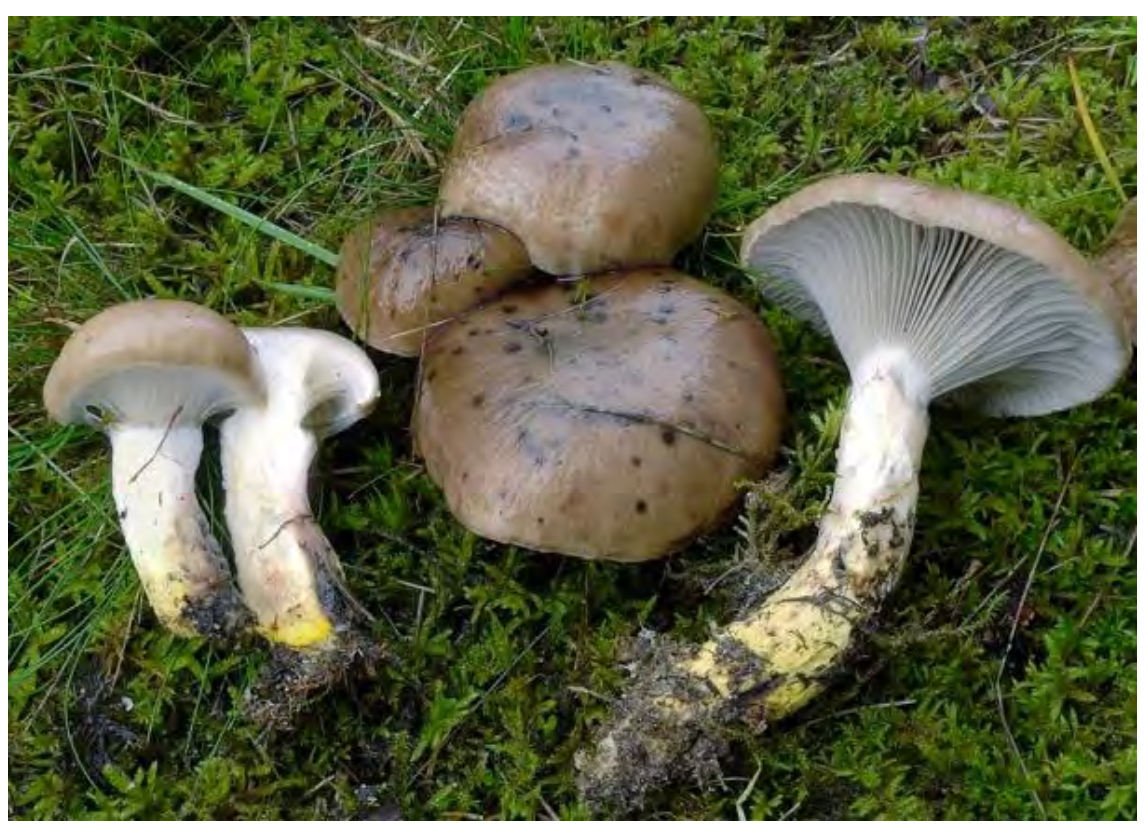

\section{Background and risk assessment}

Slimy Spike is an edible mushroom.

It is mycorrhizal with Spruce (Picea). It is very common in the Nordic countries up to the subalpine/subarctic zones, where it is rare, but locally occasional (Knudsen \& Vesterholt, 2012).

There are no intoxications reported after consumption of Slimy Spike, and no natural toxicants constituting a risk for humans have been identified in the mushroom.

\section{Recommendation}

No special recommendation.

Listing 2 


\section{Database search information}

SciFinder by February 2012. Keywords: Gomphidius.

\section{References}

Knudsen H \& Vesterholt J (2012): Funga Nordica. Agaricoid, boletoid, clavarioid, cyphelloid and gastroid genera. Nordsvamp: 1-1083. 


\section{Gomphus clavatus (Pers.) Gray}

Pig's Ear (DK: Køllekantarel, FI: Pölkkysieni, IS: Fjólusteðji, NO: Fiolgubbe, SE: Violgubbe).

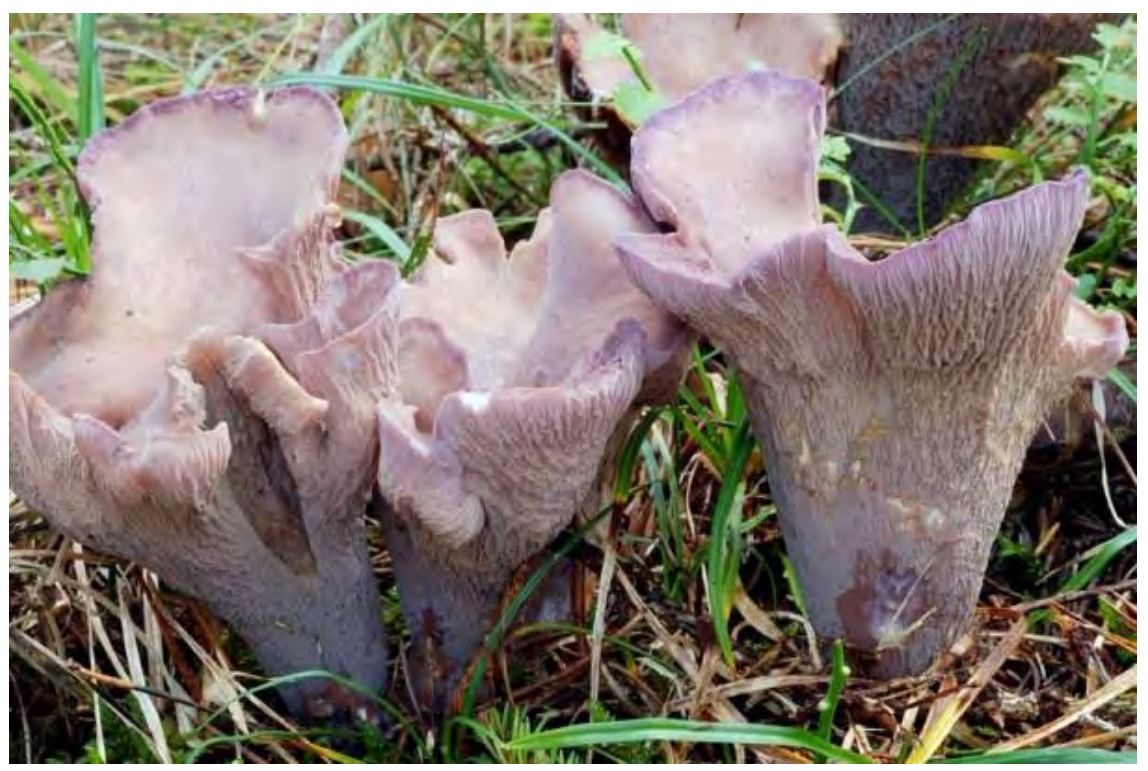

\section{Background and risk assessment}

Pig's Ear (Gomphus clavatus) is an edible mushroom.

It grows preferably on calcareous soil in coniferous, rarely deciduous forests. It is not found in Iceland, is occasional in parts of Norway and rare in Denmark, Finland and Sweden (Hansen \&Knudsen, 1997).

There are no intoxications reported after consumption of Pig's Ear, and no natural toxicants constituting a risk for humans have been identified in the mushroom. In a study on cantharelloid mushrooms the toxicant norcaperatic acid was found in high amounts, 2-4 g/ $\mathrm{kg}$ fresh weight in two related Gomphus-species, G. floccosus and G. kauffmanii, but not in Pig's Ear (Henry \& Suillivan, 1969).

\section{Recommendation}

Red-listed in Denmark and in Sweden as vulnerable and in Norway as near threatened.

Should only be marketed in the Nordic countries, if it is from countries, where it is not red-listed. 
Listing 2

\section{Database search information}

SciFinder by February 2012. Keywords: Gomphus clavatus.

\section{References}

Hansen L \& Knudsen H (1997): Nordic Macromycetes, Volume 3. Heterobasidioid, aphyllophoroid and gastromycetoid basidiomycetes. Nordsvamp: 1-444.

Henry ED \& Suillivan G (1969): Phytochemical evaluation of some cantherelloid fungi. Journal of Phamaceutical Scienses 58: 1497-1500. 


\section{Grifola frondosa (Dicks.) Gray}

Hen of the Woods (DK: Tueporesvamp, FI: Koppelokääpä, IS: Blöðkubora, NO: Korallkjuke, SE: Korallticka).

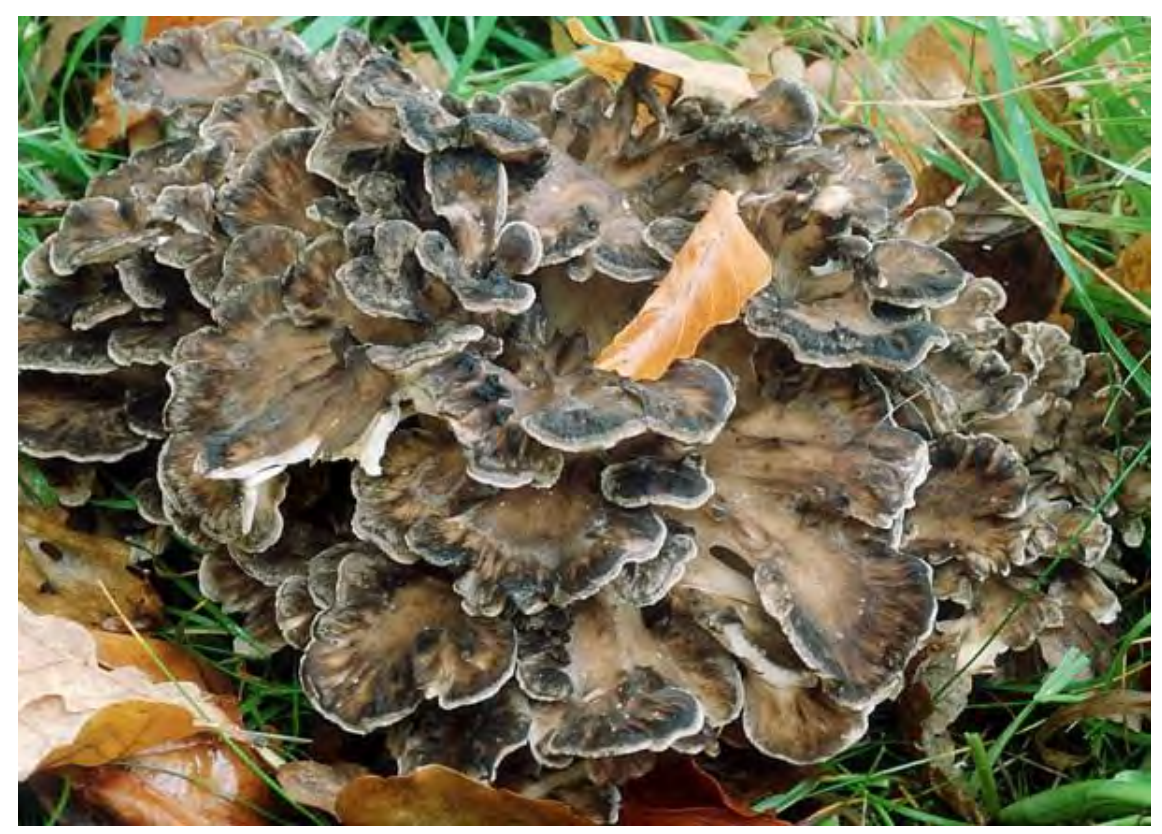

\section{Background and risk assessment}

Hen of the Woods (Grifola frondosa) is an edible mushroom.

It is a weakly parasitic mushroom growing at the basis of living trees, especially Oak (Quercus), but occasionally also as a saprotroph on decaying wood. It is not found in Iceland and is otherwise rare in the Nordic countries (Hansen \& Knudsen, 1992). It is cultivated, especially in south-eastern parts of Asia, where it is a very popular culinary and medicinal mushroom.

There are no intoxications reported after consumption of Hen of the Woods, except for one very special and not well documented case (Gonmori \& Yokoyama, 2009). This was a female in her late 40's, who had received dialysis for more than 35 years and was hospitalized due to illness. During the hospital stay she ate two cooked meals at different days with $5 \mathrm{~g}$ and $10 \mathrm{~g}$ of Hen of the Woods, respectively. Some 1418 days after these meals, she developed cramps and fell into coma. Ten days later she died. The authors suggest, that hydrogen cyanide from the mushroom could have been the causative agent. This is found unlikely, as described below. 
The role of Hen of the Woods in this intoxication, and which constituent could have contributed to the fatality, is not clear. Some bioactive constituents have been isolated from the mushroom:

\section{Bioactive constituents}

Cyanogenic compounds: Hen of the Woods contains small amounts of cyanogenic compounds, on average corresponding to $13 \mathrm{mg}$ hydrogen cyanide per kg fresh mushroom ( $\mathrm{n}=5$, range 1.8-46 mg per kg) (Shindo et al., 1999). Such small amounts of hydrogen cyanide are not of concern in relation to consumption of the mushroom. Furthermore, a significant fraction of the hydrogen cyanide will disappear during cooking (Stijve \& de Meijer, 1999).

Lectins: An N-acetylgalactosamine-specific lectin was isolated from the fruit bodies of Hen of the Woods. Gel filtration using various buffers and matrices showed it had a molecular mass between 30 and $52 \mathrm{kDa}$, whereas determination by gel electrophoresis indicated 33, 66 and 100 $\mathrm{kDa}$. A faint band was also observed at $65 \mathrm{kDa}$. The isolated lectin agglutinated human erythrocytes regardless of blood type. The hemagglutinating activity was highest at $\mathrm{pH}$ 4.5. The lectin was cytotoxic against HeLa cells (Kawagishi et al., 1990). As no information on the thermostability of the lectin is available, it is difficult to estimate whether the lectin could be of any concern in the cooked mushroom.

Statins: Traces of lovastatin $(3.2 \mathrm{mg} / \mathrm{kg}$ dried biomass) were detected in the fruit bodies of Hen of the Woods by Lin et al. (2013), whereas Chen et al. (2012) were unable to detect the compound (for further data on statins, see Pleurotus ostreatus).

Ergothioneine: High but various amounts of ergothioneine have been demonstrated in the mushroom. Dubost et al. (2006) found the average level in fruit bodies to be $1,840 \mathrm{mg} / \mathrm{kg}$ dry weight ( $\mathrm{n}=9)$, whereas Chen et al. (2012) reported $553 \mathrm{mg} / \mathrm{kg}$ dry weight $(\mathrm{n}=3)$ and Lin et al. (2013) $143 \mathrm{mg} / \mathrm{kg}$ dry weight $(\mathrm{n}=3)$. Chen et al. (2012) also analysed the mycelia and found $296 \mathrm{mg} / \mathrm{kg}$ (dry weight, $\mathrm{n}=3$ ). For further data on ergothioneine see Lepista nuda.

\section{Recommendation}

Red-listed in Denmark, Norway and Sweden as near threatened. Should only be marketed in the Nordic countries, if it is from countries, where it is cultivated or not red-listed. 


\section{Database search information}

SciFinder by August 2012. Keywords: Grifola. PubMed by August 2012. Keywords: Grifola frondosa.

\section{References}

Chen S-Y, Ho K-J, Hsieh Y-J, Wang L-T \& Mau J-L (2012): Contents of lovastatin, $\gamma$ aminobutyric acid and ergothioneine in mushroom fruiting bodies and mycelia. Food Science and Technology 47: 274-278.

Dubost NJ, Beelman RB, Petersson D \& Royse DJ (2006): Identification and quantification of ergothioneine in cultivated mushrooms by liquid chromotography-mass spectroscopy. International Journal of Medicinal Mushrooms 8: 215-222.

Gonmori K \& Yokoyama K (2009): Acute encephalopathy caused by cyanogenic fungi in 2004, and magic mushroom regulation in Japan. Japanese Journal of Clinical Toxicology 22: 61-69 (Japanese, English abstract available).

Hansen L \& Knudsen H (1992): Nordic Macromycetes, Volume 2. Polyporales, Boletales, Agaricales, Russulales. Nordsvamp Copenhagen: 1-474.

Kawagishi H, Nomura A, Mizuno T, Kimura A \& Chiba S (1990): Isolation and characterization of a lectin from Grifola frondosa fruiting bodies. Biochimica et Biophysica Acta 1034: 247-252.

Lin S-Y, Chen Y-K, Yu H-T, Barseghyan GS, Asatiani MD, Wasser SP \& Mau J-L (2013): Comparative study of contents of several bioactive components in fruiting bodies and mycelia of culinary-medicinal mushrooms. International Journal of Medicinal Mushrooms 15: 313-323.

Shindo T, Ushiyama H, Kan K \& Yasuda K (1999): Study on content of cyanide in Basidiomycetes and the effect of cooking. Journal of Food Hygiene Society of Japan 40: 29-35 (Japanese, English abstract available).

Stijve T \& de Meijer AAR (1999): Hydrocyanic acid in mushrooms, with special reference to wild-growing and cultivated edible species. Deutsche LebenmittelsRundschau 95: 366-373. 


\section{Gyromitra esculenta (Pers.) Fr.}

False Morel, (Turban, Brain Mushroom) (DK: Spiselig Stenmorkel, FI: Korvasieni, IS: Krymplusveppur, Krymplumyrkill, NO: Sandmorkel, SE Stenmurkla).

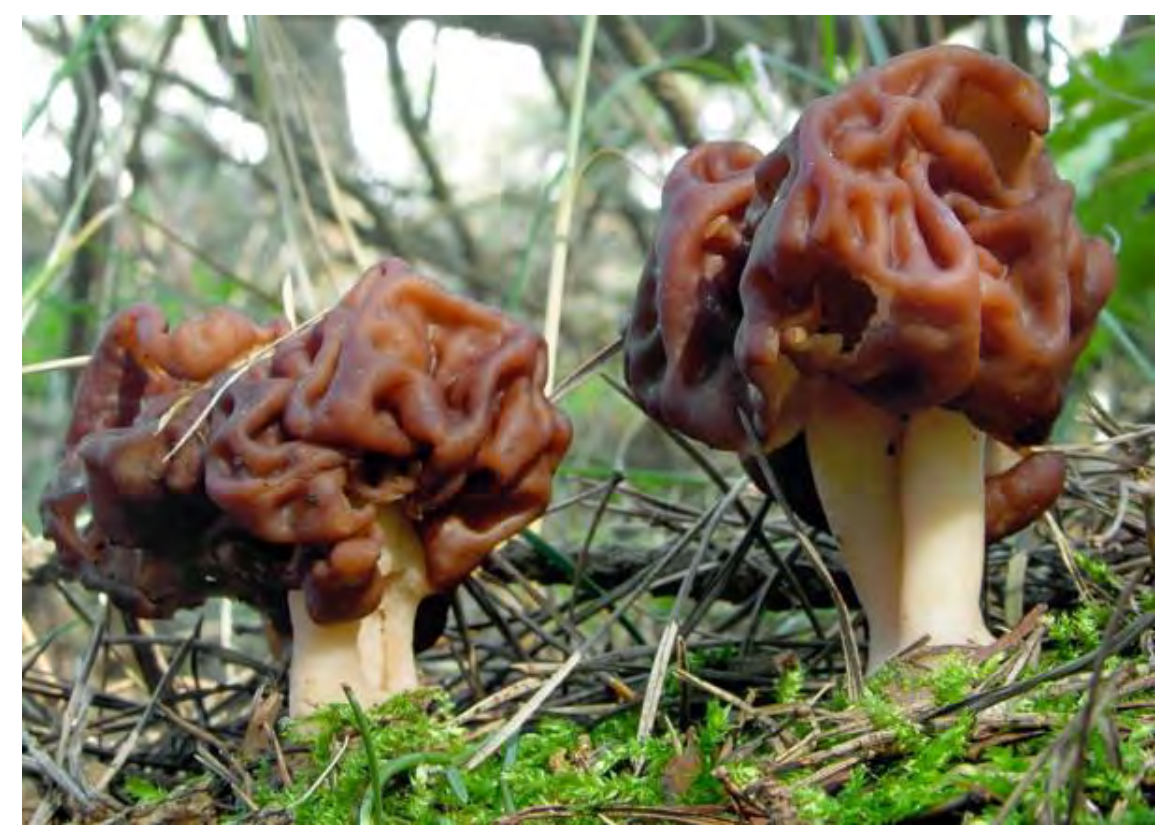

\section{Background and hazard identification}

False Morel (Gyromitra esculenta) is a toxic mushroom.

It is a saprotroph and grows in sandy coniferous woods in the springtime. It is not found in Iceland, is uncommon in Denmark, but more common in the other Nordic countries. In Finland more than 100 tons are marketed some years. It also grows in Central and Eastern Europe, Asia and North America.

False Morel is commercially available in several countries as fresh, canned or dried mushroom, generally together with a warning that it is needed to pre-treat the mushroom to reduce the content of toxicants before consumption.

The toxicity of False Morel has been known for centuries. Acute intoxications have occurred after consumption of raw, dried or insufficiently cooked mushrooms, but there are also reports on intoxications after consumption of thoroughly pre-treated mushrooms (boiled in large volumes of water for five minutes twice, water being discarded each 
time or dried for at least one month). More than 100 fatal cases have been described (Beug, 2006; 2008; Beug et al., 2006; Bianchi et al. 1999; Franke et al., 1967; Leathem \& Dorran, 2007; Liang et al., 1998; Vitte et al., 1997). However, in several countries, it is considered edible and delicious after thorough pre-treatment.

The toxic constituents in False Morel were elucidated in the 1960s and 1970s, and were shown to be gyromitrin (ethylidene gyromitrin) and eight other hydrazones, and their degradation products/metabolites $\mathrm{N}$-methyl-N-formylhydrazine (MFH) and monomethylhydrazine (MMH).

The structural formulae of the most abundant hydrazone in the False Morel, gyromitrin, and the two hydrazines MFH and MMH formed on degradation/metabolism are shown below.

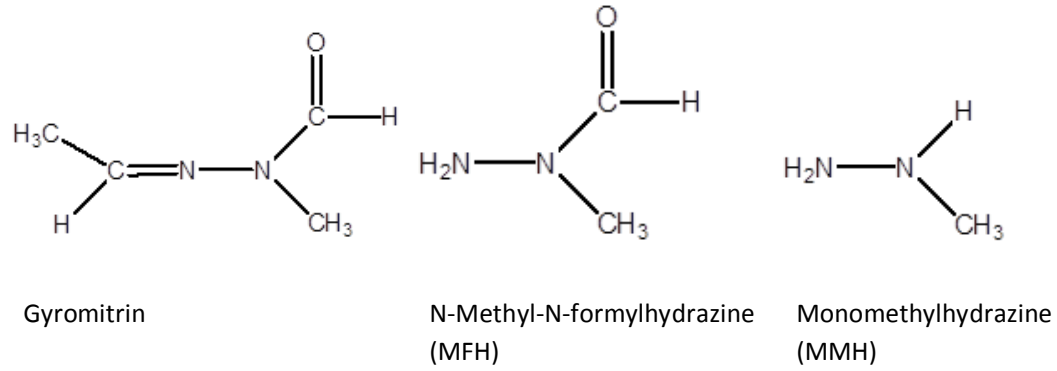

The content of gyromitrin in False Morel depends on the environmental conditions at the site of growth and the conditions during storage (Andary \& Privat, 1985; Andersson et al., 1985; Stijve, 1978). The content of gyromitrin and its degradation product/metabolite MMH has been studied in fresh, dried, canned and parboiled False Morel. Stijve (1978) demonstrated that the greater part of gyromitrin and probably also MFH is chemically bound in the mushroom. Therefore earlier studies using for example diethyl ether to extract the hydrazones/hydrazines only analysed the volatile, not chemically bound minor fraction of the hydrazones/hydrazines in False Morel. This has subsequently been confirmed by several authors, and, consequently, methods for their analysis have been modified (Andary et al., 1984a; Chilton, 1994; Larsson \& Eriksson, 1989).

Fresh False Morel has been reported to contain between 40 and 760 mg gyromitrin per kg fresh mushroom. Fresh False Morel collected in France contained 109-760 mg gyromitrin (measured as 50-350 mg total MMH in 7 samples) per kg fresh mushroom (Andary, 1984b), while mushrooms collected in Sweden contained 87-326 mg gyromitrin (measured as $40-150 \mathrm{mg}$ total MMH in 14 samples) per $\mathrm{kg}$ of fresh mushroom (Larsson \& Eriksson, 1989). 
Pyysalo \& Niskanen (1977) demonstrated that gyromitrin (ethylidene gyromitrin) constitutes $85-90 \%$ of the total amount of diethyl ether extractable hydrazones in False Morel. In total 9 different hydrazones were found; the remaining 8 hydrazones $(10-15 \%)$ were identified as propylidene, butylidene, 3-methylbutylidene, pentylidene, hexylidene, octylidene, E-2-octenylidene and Z-2-octenylidene gyromitrin. No investigations have studied whether also the 8 minor hydrazones, like gyromitrin, may occur as chemically bound constituents in False Morel, but this is likely.

Air-dried False Morel has been reported to contain very different amounts of gyromitrin, possibly depending on the original content in the fresh mushroom and on the drying conditions. Usually, about $30-80 \%$ may be removed by drying (Andary et al., 1985; Larsson \& Eriksson, 1989). Typically, levels corresponding to $650-1,760 \mathrm{mg}$ gyromitrin (measured as $300-810 \mathrm{mg}$ total MMH) have been found (Andary et al., 1985; Larsson \& Eriksson, 1989), although commercially dried samples have contained up to 2,170 mg gyromitrin (1,000 mg total MMH) (Andary, 1984b) or up to 2,600 mg gyromitrin (1,200 mg total MMH) (Larsson \& Eriksson, 1989). Contrary to most studies on gyromitrin/MMH in dried False Morel, Arshadi et al. (2006) reported very low levels in an apparently pooled sample of about $220 \mathrm{~g}$ of air-dried False Morel obtained locally in Sweden, of $22 \mathrm{mg} \mathrm{MMH,} \mathrm{corresponding} \mathrm{to} 48 \mathrm{mg}$ gyromitrin per kg dry weight. However, this study reports very low recovery of MMH in the sample(s), the quantitative aspects are not well described and the validation of the method used is incomplete.

Canned False Morel was studied by Larsson and Eriksson (1984). Fifteen samples showed levels in the range 6-66 mg gyromitrin (measured as 3-30 mg MMH).

Parboiled False Morel (5 samples boiled twice for 5 minutes and water discarded each time) that originally contained 44-130 mg MMH per kg dry weight, corresponding to 95-282 mg gyromitrin per kg dry weight, after boiling contained 13-27 mg MMH, corresponding to 28-59 mg gyromitrin per kg dry weight. Thus, the properly pre-treated False Morel still contains in average $10 \%$ of the gyromitrin/MMH content in the pretreated mushroom (Larsson \& Eriksson, 1989).

The occurrence of hydrazine derivatives in False Morel is of concern because the majority of known hydrazines, beyond being acutely toxic, have been found to be carcinogenic in experimental animals. Subsequent experiments substantiated the concern as peroral studies in rodents with False Morel hydrazones, with MMH or MFH, or the mushroom itself did result in significantly increased tumour frequencies in the dosed 
animals compared to the control animals as reviewed by Andersson et al. (1995). For a comprehensive review on "Hydrazines and cancer", see Toth (2000).

The International Agency for Research on Cancer (IARC) concluded in 1983 "Results on studies on gyromitrin itself, supported by studies on two of its metabolites provide sufficient evidence for the carcinogenicity of gyromitrin in experimental animals. No data on humans were available." (IARC, 1983) and in 2012 that gyromitrin is "Not classifiable as to its carcinogenicity to humans" (IARC, 2012).

The Nordic report "Hydrazones in the False Morel" was published in 1995 and contains a risk assessment of consumption of False Morel (Andersson et al., 1995). Data and conclusions from this report are summarized below and form the basis of the present updated risk assessment.

\section{Hazard characterization}

The Nordic report gives information on the hydrazones occurring in False Morel, their absorption and metabolism, acute toxicity, subchronic toxicity, developmental toxicity, DNA-binding and genotoxicity, and carcinogenicity. In addition, it reviews the influence of the intact mushroom on these parameters (Andersson et al., 1995). Together with more recent information, the data in the Nordic report are summarized in the following.

\section{Absorption and metabolism}

In False Morel gyromitrin, and probably also MFH, can be found in both free and bound form as mentioned above. Gyromitrin rapidly hydrolyses to MFH and acetaldehyde. This takes place spontaneously at room temperature and in the stomach, when False Morel is consumed. MFH is further hydrolysed under physiological conditions to form $\mathrm{MMH}$ and formic acid, but this takes place at a slower rate. Experimental studies have shown that firmly bound gyromitrin is very resistant to boiling and drying. However, studies with simulated gastric fluid indicate that the bound gyromitrin can at least partly be liberated during digestion in the stomach. This implies that a mixture of unhydrolysed gyromitrin and other hydrazones, MFH and MMH may be available for absorption from the gastrointestinal tract. It is not known how the intestinal bacterial flora influences the metabolism of these compounds. Hydrazine derivatives are reported to be well absorbed from the gastrointestinal tract, but otherwise, there are only limited experimental data available on the fate of these hydrazone and hydrazine derivatives in the body of both animals and humans. 
After absorption the two hydrazines MFH and MMH, which are believed to be the active toxic agents derived from the mushroom constituents, may react directly with carbonyl group-containing cell components like folic acid and pyridoxal 5-phosphate, the active form of vitamin B6. The reaction between these molecules produces a hydrazone that is a powerful inhibitor of the phosphokinase required for phosphorylation of pyridoxal, and it therefore depletes the cell of pyridoxal 5-phosphate. The depletion of active vitamin B6 might lead to glutamic acid decarboxylase inhibition and decrease of $\gamma$-aminobutyric acid (GABA) synthesis, with profound effect on the central nervous system. Specific treatment of poisoned patients with neurological symptoms is a high dose of pyridoxine hydrochloride. MFH and MMH can also, as other unsymmetric hydrazines, be metabolised to electrophilic diazonium and carbonium ions. These very reactive metabolites may react with cellular macromolecules like DNA and with cytochrome P-450. The anticipated metabolic pathways are described in more details in the Nordic report (Andersson et al., 1995).

Notably, a reaction detoxifying MFH competes with its activation to reactive molecules. Instead of being activated to $\mathrm{MMH}$, the compound can be acetylated and thereby be protected from being activated. As there are various variants of the acetylating P450 enzyme, having different activities, consumers may carry different alleles of the genes coding for detoxifying enzymes and be more or less prone to be damaged after consumption of False Morel. This may at least partly explain the different sensitivity of consumers to the toxic constituents of False Morel observed.

\section{Acute toxicity}

The acute intoxication of humans by False Morel may be biphasic. The first phase, the gastrointestinal phase, usually starts 4-8 hours after the consumption but sometimes as early as after 2 hours and occasionally as late as 24 hours after consumption (Diaz, 2005; Karlson-Stiber \& Persson, 2003). This phase is characterized by a feeling of being bloated, stomach pain, nausea, continuous vomiting and on occasion watery or bloody diarrhoea. Other common symptoms are tiredness, headache and dizziness. Most cases do not go beyond this phase and recovery begins after 2 to 6 days. In the more severe cases a second phase follows after a symptomfree period, this being a hepatorenal phase with symptoms of liver damage and sometimes also of hemolysis. In addition serious neurological symptoms may appear. Two to three days into the second phase circulatory collapse and respiratory arrest may lead to death while in coma.

A fatal dose of gyromitrin has been estimated to $10-30 \mathrm{mg}$ gyromitrin per kg body weight for children and 20-50 mg gyromitrin per kg body weight for adults (Flammer, 1985). 


\section{Subchronic toxicity}

Very little is known about the sub-chronic toxicity of the hydrazone and hydrazine constituents of False Morel in experimental animals and man.

\section{Developmental toxicity}

Teratogenicity studies have been performed with MMH in female rats. These studies showed a clear dose-dependent decrease in pregnancy rate and an increase in the number of resorptions in the exposed animals as compared to the controls. The "Lowest Observed Effect Level" (LOEL) for MMH in this study was $3.0 \mathrm{mg} \mathrm{MMH/kg} \mathrm{body} \mathrm{weight/day}$ after intravenous infusion and $5.0 \mathrm{mg} \mathrm{MMH} / \mathrm{kg}$ body weight/day after peroral application.

\section{DNA-binding and genotoxicity}

Studies have shown that the mushroom hydrazones and degradation products are able to induce DNA lesions, probably via a reactive methyl radical. Among the lesions identified are $\mathrm{N}-7$-methylguanine and $\mathrm{O}^{6}-$ methylguanine; the latter type of lesion being correlated to mutagenic and carcinogenic activity.

\section{Carcinogenicity}

A series of long-term peroral carcinogenicity studies in mice have been performed with gyromitrin, three other hydrazones present in False Morel, their degradation products/metabolites MFH and MMH and False Morel itself. In all studies, when fed to the experimental animals, the hydrazine/hydrazone constituents as well as False Morel itself gave rise to significantly increased tumour frequencies as compared to the tumour frequencies in non-treated animals.

It should be underpinned, that the carcinogenic studies have not been performed in accordance with approved standard protocols for carcinogenicity studies. The diets for experimental animals were not always balanced, and the animals were exposed to the hydrazones/hydrazines/mushroom until they died or were in poor condition instead of for a pre-determined length of time. In addition, the control groups were usually not started at the same time as the treated groups. Although at least three dose levels are recommended in carcinogenicity studies in order to identify potential doseresponse effects, this requirement was only partially fulfilled.

Though the design of these carcinogenicity studies are not of satisfying standard, the accumulated data indicate that the hydrazine and hydrazone derivatives in False Morel (gyromitrin and three other hydrazones, MFH and MMH), as well as False Morel itself, are carcinogenic in experimental animals. The lowest observed effect level "LOEL" for MMH 
(sulfate) in mice was calculated to $1.0-1.3 \mathrm{mg} \mathrm{MMH} / \mathrm{kg}$ body weight/day (36\% increase of lung cancer in males, 33\% increase in females) (Toth, 1972), $6.58 \mathrm{mg}$ gyromitrin/kg body weight/day (44\% increase of lung cancer in females), $6.58 \mathrm{mg}$ gyromitrin $\mathrm{kg}$ body weight/day $(90 \%$ increase of cancer in preputial glands in males) (Toth et al., 1981) and 0.8$1.2 \mathrm{mg} \mathrm{MFH} / \mathrm{kg}$ body weight/day (35\% increase of lung cancer in males, $33 \%$ increase in females) (Toth and Patil, 1982).

\section{Exposure assessment}

In the absence of information on the consumption of False Morel, assumptions are required for the exposure assessment. The exposure assessments in this risk assessment are based on an anticipated consumption twice a month of a meal with $25 \mathrm{~g}$ parboiled (boiled twice and boiling water discarded) fresh False Morel, $25 \mathrm{~g}$ canned False Morel or $2.5 \mathrm{~g}$ dried False Morels on average containing hydrazine/hydrazone derivatives equivalent to $25 \mathrm{mg} \mathrm{MMH} / \mathrm{kg}$ mushroom. For a consumer weighing $70 \mathrm{~kg}$ this intake would correspond to an exposure of $5.95 \times 10^{-4} \mathrm{mg}$ $\mathrm{MMH} / \mathrm{kg}$ body weight/day. If the dried False Morel is boiled twice and the water discarded both times, the estimated exposure from the dried mushrooms will be lower, but there are apparently no published data on the content of hydrazines in the mushrooms treated this way.

\section{Risk characterization}

\section{Teratogenic effects}

As the "LOEL" for developmental toxicity after peroral application of $\mathrm{MMH}$ to rats was determined to be $5.0 \mathrm{mg} \mathrm{MMH}$ per $\mathrm{kg}$ rat/day, and a human consumer of dried, canned or properly parboiled False Morel (see above) would be exposed to $5.95 \times 10^{-4} \mathrm{mg} \mathrm{MMH} / \mathrm{kg}$ body weight/day, the calculated margin to humans having the risk of teratogenic effects would be around 800 (assuming humans and rats reacting the same way to $\mathrm{MMH}$ ).

\section{Carcinogenic effects}

Since the metabolism of False Morel hydrazones/hydrazines produces metabolites with a potential to give rise to DNA damage and genotoxic effects, and no threshold has been established for genotoxic carcinogenic substances, the cancer risk can be roughly estimated using a quantitative risk assessment approach. In the approach a linear extrapolation from the high exposure levels in mice to the lower human exposure level is 
performed, which requires several assumptions. Thus, in addition to assumptions mentioned above, it is also assumed that man and mouse have the same metabolism and sensitivity, that the survival of mice in the MMH-exposed and control groups are comparable, and that the average weight of a mouse is $25 \mathrm{~g}$ and that of man $70 \mathrm{~kg}$. This approach estimates the probability of an increase in human cancer rate, e.g., as extra cancer cases per $10^{6}$ individuals during lifetime exposure. It is then possible to estimate the human cancer risk by relating the outcome of the cancer studies in mice administered MMH in drinking water for lifetime with the estimated amount of MMH consumed by humans through the consumption of False Morel.

In the cancer studies in mice the "LOEL" of MMH (sulfate) after peroral application of the compound in drinking water $(10 \mathrm{mg} / \mathrm{L})$ corresponds to an exposure of $1.3 \mathrm{mg} \mathrm{MMH} / \mathrm{kg}$ body weight in males, and $1.0 \mathrm{mg}$ $\mathrm{MMH} / \mathrm{kg}$ body weight in females. An average consumer being exposed to $5.95 \times 10^{-4} \mathrm{mg} \mathrm{MMH} / \mathrm{kg}$ body weight/day from parboiled, canned or dried False Morel would have an increased cancer risk of approximately 160$200 \times 10^{-6}$ based on linear dose-response for cancer induction by MMH. This means that consumers would have an additional lifetime risk of around 160-200 per million of individuals. Overall, a risk of 40-250 extra cancer cases during lifetime per million of Nordic consumers eating the mushroom twice a month $(25 \mathrm{~g}$ of canned or $25 \mathrm{~g}$ of properly pre-treated and cooked or $2.5 \mathrm{~g}$ dried False Morel) could be estimated.

Using the "LOEL" from the cancer studies in mice with gyromitrin or with MFH and using the same risk assessment approach as for $\mathrm{MMH}$, gyromitrin would induce 40-80 cancer cases and MFH 170-250 cancer cases per million of individuals during lifetime.

Uncertainties: The quantitative risk assessment suffers from several uncertainties: The use of a linear extrapolation model, the unsatisfactory design of the carcinogenicity studies and the lack of human data, including intake data. Therefore the risk assessment is conservative (worstcase-scenario).

Conclusion: It has been shown that False Morel and its constituents gyromitrin and other hydrazones, as well as the degradation/metabolism products of the hydrazones, N-methyl-N-formylhydrazine (MFH) and monomethylhydrazine $(\mathrm{MMH})$ are carcinogenic in rodents, presumably via a genotoxic mechanism. Therefore, consumption of False Morel may constitute a risk for humans. 


\section{Recommendation}

False Morel (Gyromitra esculenta) ${ }^{15}$ should not be consumed as it even after months of drying or after repeated parboiling and discarding of the water, still contains significant amounts of acutely toxic compounds that also are suspected to be genotoxic and carcinogenic.

Listing 4

\section{Database search information}

SciFinder by February 2012. Keywords: Gyromitra, gyromitrin. PubMed by February 2012. Keywords: Gyromitrin.

\section{References}

Andary C, Privat G \& Bourrier M-J (1984a): Microdosage spectrofluorimétrique sur couches minces de la mono-methylhydrazine chez Gyromitra esculenta. Journal of Chromatography 287: 419-424.

Andary C, Bourrier M-J \& Privat G (1984b): Teneur en toxine et instance de l'intoxication gyromitrienne. Bulletin Trimestriel de la Société mycologique de France 100: 273-283.

Andary C, Privat G \& Bourrier M-J (1985): Variations of monomethylhydrazine content in Gyromitra esculenta. Mycologia 77: 259-264.

Andersson HC, Slanina P \& Koponen A (1995): Hydrazones in the False Morel. Nordic Council of Ministers. TemaNord 561: 1-58.

Arshadi M, Nilsson C \& Magnusson B (2006): Gas chromatography-mass spectrometry determination of the pentafluorobenzoyl derivative of methylhydrazine in false morel (Gyromitra esculenta) as a monitor for the content of the toxin gyromitrin. Journal of Chromatography A 1125: 229-233.

Baltarowich L, Blaney B, White S \& Smolinske S (1996): Acute hepatotoxicity following ingestion of Gyromitra esculenta (False Morel) mushrooms. Journal of Toxicology: Clinical Toxicology 37: 602. (Abstract only).

Barceloux DG (2008): Medical Toxicology of Natural Substances: Foods, Fungi, Medicinal Herbs, Plants, and Venomous Animals. Chapter 38: False Morel and gyromitrin poisoning. John Wiley \& Sons, Inc.: 1-1200.

15 False Morel can legally be sold in Sweden and Finland under specific conditions.

In Sweden, False Morel is not permitted to be sold to the final consumer as fresh or dried mushrooms. However, the preserved mushroom is permitted for sale to the final consumer. For commercial use in restaurants, where adequate knowledge on the preparation of the mushroom is expected to be available, the fresh, dried and preserved False Morel is permitted.

In Finland, the fresh and dried mushroom can be sold to the final consumer with the following, obligatory labelling: False Morel is poisonous. False Morel shall be boiled in water ( 3 portions of water for 1 portion of mushroom). Dried False Morel shall be soaked in water for at least 2 hours before use ( $200 \mathrm{~g}$ water for $10 \mathrm{~g}$ mushroom). After having been soaked, the mushrooms shall be boiled like the fresh mushrooms. When False Morel is dried or boiled good ventilations shall be used. Water used for soaking or boiling shall not be used in foods. 
Beug MW (2006): The Mushroom Poisonings 2001-2004. Mcllvainea 16: 56-69.

Beug MW (2007): NAMA Toxicology Committee Report for 2006: Recent Mushroom Poisonings in North America. McIlvainea 17: 63-72.

Beug MW (2009): NAMA Toxicology Committee Report for 2008: Recent Mushroom Poisonings in North America. McIlvainea 18: 45-54.

Beug MW, Shaw M \& Cochran KW (2006): Thirty-Plus Years of Mushroom Poisoning: Summary of the Approximately 2,000 reports in the NAMA Case Registry. McIlvainea 16: 47-68.

Bianchi A, Cavallo R, Imeneo MR, Manno E, Riva M \& Vacca R (1999): Sindrome gyromitriana da spugnola falsa. Minerva Anestesiologica 65: 811-813.

Diaz JH (2005): Syndromic diagnosis and management of confirmed mushroom poisonings. Critical Care Medicine. 33: 427-436.

Flammer R (1985): Das Gyromotrinsyndrom: Vergiftung durch die Frühjahrslorchel. Schweizerische Rundschau für Medizin Praxis 74: 983-984.

Franke S, Freimuth U \& List PH (1967): Über die Giftigkeit der Frühjahrslorchel Gyromitra (Helvella) esculenta Fr. Archiv für Toxikologie 22: 293-332.

IARC (1983): Monographs on the Evaluation of Carcinogenic Risks to Humans, Some Food Additives, Feed Additives and Naturally Occurring Substances. Gyromitrin (Acetaldehyde formylmethylhydrazone) 31: 163-170.

IARC (2012): Monographs on the Evaluation of Carcinogenic Risks to Humans, Agents classified by the IARC Monographs, Volumes 1-105: 1-33.

Karlson-Stiber C \& Persson H (2003): Cytotoxic fungi - an overview. Toxicon 42: 339-349.

Larsson BK \& Eriksson AT (1989a): The analysis and occurrence of hydrazine toxins in fresh and processed false morel, Gyromitra esculenta. Zeitschrift fiir Lebensmittel-Untersuchung und-Forschung 189: 438-442.

Larsson BK \& Eriksson AT (1989b): Methylhydrazin i stenmurkla. Vår Föda 41: 75-83.

Leathem AM, Dorran TJ \& Kroeger P (1999): Poisoning due to raw Gyromitra esculenta (false morels). Journal of Toxicology: Clinical Toxicology 37: 616. (Abstract only).

Leathem AM \& Dorran (2007): Poisoning due to raw Gyromitra esculenta (False Morels) west of the Rockies. Canadian Journal of Emergency Medicine 9: 127-130.

Liang Y-H, Eisenga BH, Trestrail JT III \& Kuslikis B (1998a): Gyromitra mushroom species and their monomethylhydrazine content. Journal of Toxicology: Clinical Toxicology 36: 527 (Abstract only).

Liang Y-H, Eisenga BH, Trestrail JT III \& Kuslikis B (1998b): Gas chromatographic procedure for the analysis of monomethylhydrazine (MMH) in Gyromitra. Journal of Toxicology: Clinical Toxicology 36: 527-528. (Abstract only).

Pyysalo H \& Niskanen A (1977): On the occurrence of $N$-methyl- $N$-formylhydrazones in fresh and processed false morel, Gyromitra esculenta. Journal of Agricultural and Food Chemistry 25: 644-647.

Stijve T (1978): Ethylidene gyromitrin and N-methyl-N-formylhydrazine in commercially available dried false morels, Gyromitra esculenta Fr. ex Pers. Travaux de Chimie Alimentaire et d'Hygiène 69: 492-504.

Toth B (1972): Hydrazine, methylhydrazine and methylhydrazine sulfate carcinogenesis in Swiss mice. Failure of ammonium hydroxide to interfere in the development of tumours. International Journal of Cancer 9: 109-118.

Toth B (2000): Hydrazines and Cancer. Harwood academic publishers, USA: 1-245.

Toth B \& Patil K (1982): Tumorigenicity of minute dose levels of N-methyl-Nformylhydrazine of Gyromitra esculenta. Mycopathologia 78: 11-16. 
Toth B, Smith JW \& Patil KD (1981): Cancer induction in mice with acetaldehyde methylformylhydrazone of the False Morel mushroom. Journal of the National Cancer Institute 67: 881-887.

Viernstein H, Jurenitsch J \& Kubelka W (1980): Vergleich des Giftgehaltes der Lorchelarten Gyromitra gigas, Gyromitra fastigiata und Gyromitra esculenta. Ernährung/Nutrition 4: 392-395.

Vitte R-L, Artru P, Tennenbaum R, Benfiguig K \& Eugene C (1997): Intoxication aux gyromitres (fausses morilles) avec hépatite. Gastroentérologie Clinique et Biologique 21: 89-90. 


\section{Hericium coralloides (Scop.) Pers. (H. ramosum (Bull.) Letell.)}

Coral Tooth (DK: Koralpigsvamp, FI: Siiliorakas, IS: Broddkórall, NO: Korallpiggsopp, SE: Koralltaggsvamp).

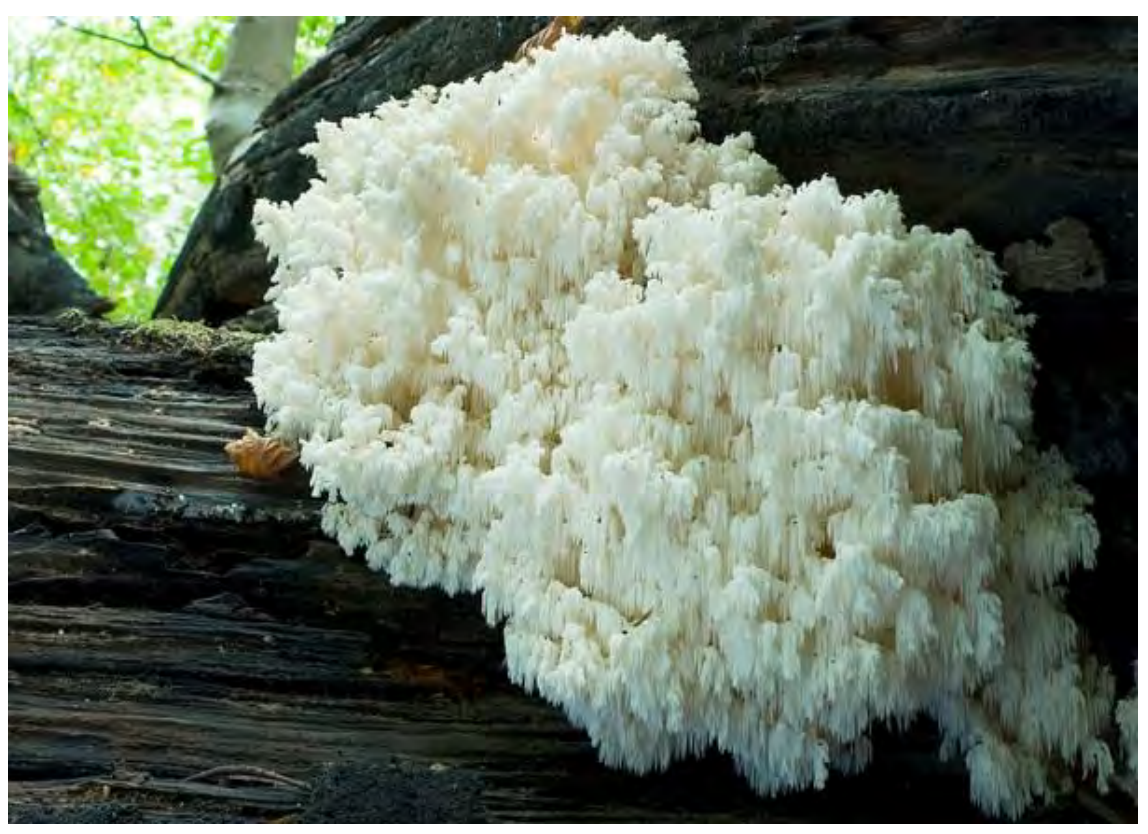

\section{Background and risk assessment}

Coral Tooth (Hericium coralloides) is an edible mushroom.

It is saprotrophic and possibly parasitic on hardwood stumps and fallen branches, rarely on living hardwood. It is rare in Denmark, Norway, Sweden and Finland and not found in Iceland (Hansen \& Knudsen, 1997). It may occasionally be cultivated.

There are no intoxications reported after consumption of Coral Tooth and no natural toxicant constituting a risk for humans has been identified in the mushroom, and there are only few data available on potential bioactive constituents in the mushroom:

Cyathane diterpenoids: Saito et al. (1998) have isolated erinacine E, a cyathane xyloside diterpenoid from a culture of Coral Tooth. Erinacine E was shown to be a highly selective binding inhibitor for the kappa opioid receptor in different in vitro systems (Kawagishi et al., 1994; 1996a, 1996b). This diterpenoid has also been reported to be a stimulator of nerve growth factor (NGF) synthesis. Anke et al. (2002) have isolated 
another cyathane xyloside, originally called herical, but later designated erinacine P. Erinacine P was shown to inhibit growth of a large spectrum of fungi and bacteria and to have cytotoxic and hemolytic properties.

It is not known to what extent erinacine $\mathrm{E}$ and $\mathrm{P}$ (or other cyathane terpenoids) occur in the fruit bodies of Coral Tooth.

The structural formula for erinacine $\mathrm{E}$ is shown below.

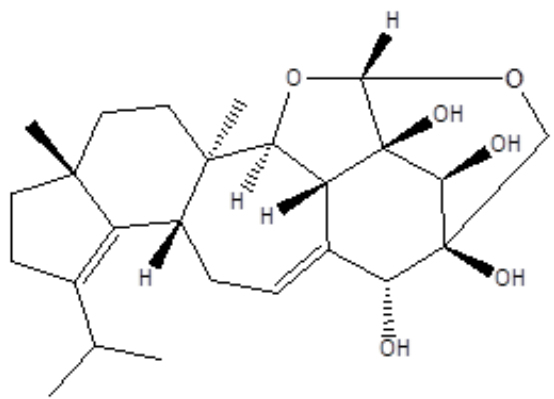

Erinacine E

\section{Recommendation}

Coral Tooth is red-listed in Denmark, Norway and Sweden as near threatened.

It should only be marketed in the Nordic countries, if it is from countries, where it is cultivated or not red-listed.

Listing 1

\section{Database search information}

PubMed by December 2012. Keywords: Hericium.

\section{References}

Anke T, Rabe U, Schu P, Eizenhöfer T, Schrage M \& Steglich W (2002): Studies on the biosynthesis of striatal-type diterpenoids and the biological activity of herical. Zeitschrift für Naturforschung 57c: 263-271.

Hansen L \& Knudsen H (1997): Nordic Macromycetes, Volume 3. Heterobasidioid, aphyllophoroid and gastromycetoid basidiomycetes. Nordsvamp: 1-444.

Kawagishi H, Shimada A, Hosokawa S, Mori H, Sakamoto H, Ishiguro Y, Sakemi S, Bordner J, Kojima N \& Furukawa S (1996b): Erinacines E, F and G stimulators of nerve growth factor (NGF)-synthesis, from the mycelia of Hericium erinaceum. Tetrahedron Letters 37: 7399-7402.

Kawagishi H, Shimada A, Shirai R, Okamoto K, Ojima F, Sakamoto H, Ishiguro Y \& Furukawa S (1994): Erinacines A, B and C, strong simulators of nerve growth factor (NGF)-synthesis, from the mycelia of Hericium erinaceum. Tetrahedron Letters 35: 1569-1572. 
Kawagishi H, Shimada A, Shizuki K, Mori H, Okamoto K, Sakamoto H \& Fukukawa S (1996a): Erinacine D, a stimulator of NGF-synthesis, from the mycelia of Hericium erinaceum. Heterocyclic Communication 2: 51-54.

Saito T, Aoki F, Hirai H, Inagaki T, Matsunaga Y, Sakakibara T, Sakemi S, Suzuki Y, Watanabe S, Suga O, Sujaka T, Smogowicz AA, Truesdell SJ, Wong JW, Nagahisa A, Kojima Y \& Kojima N (1998): Erinacine $E$ as a kappa opioid receptor agonist and its new analogs from a basidiomycete, Hericium ramosum. Journal of Antibiotics 51: 983-990. 


\section{Hericium erinaceus (Bull.) Pers.}

Bearded Tooth (Lion's Mane Mushroom, Pom Pom) (DK: Pindsvinepigsvamp ("Pom-Pom"), FI: No Finnish name, IS: Ígulbroddkórall, NO: Piggsvinsopp, SE: Igelkottaggsvamp (“Pom-Pom”)).

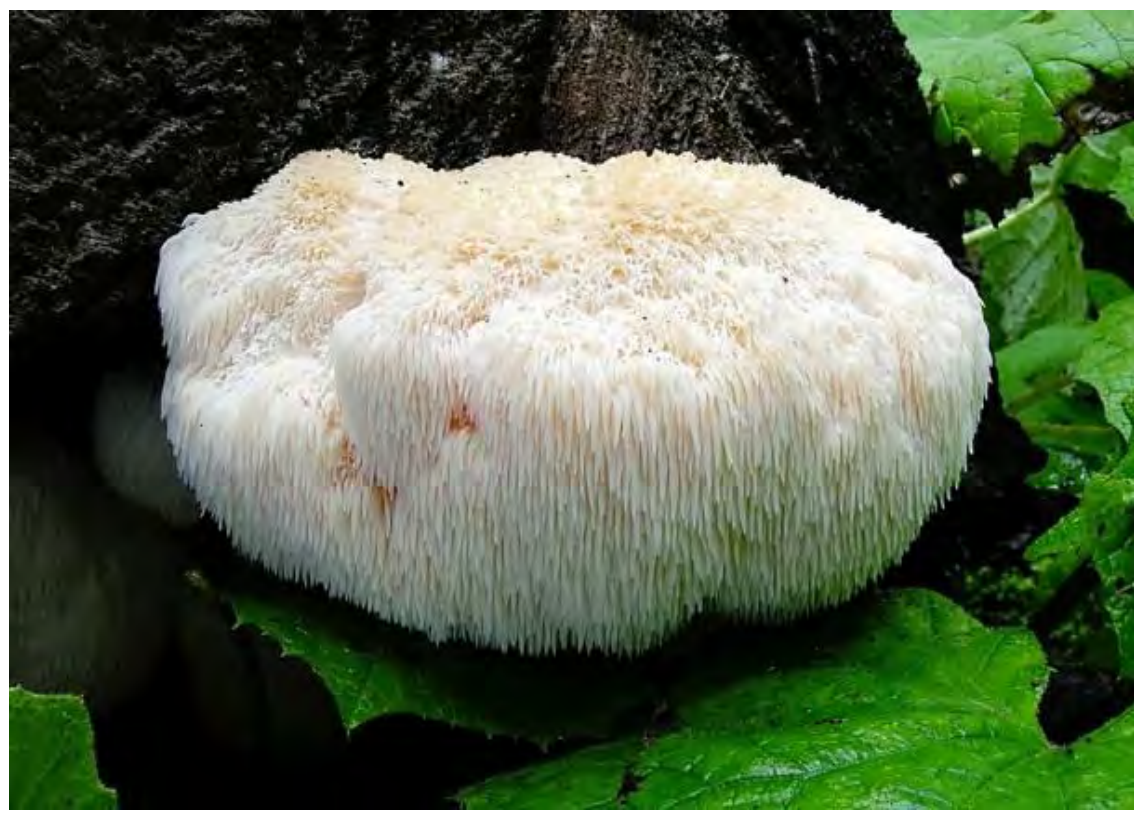

\section{Background and risk assessment}

Bearded Tooth (Hericium erinaceus) is an edible mushroom.

It is saprotrophic and possibly parasitic on trunks of hardwood and large diameter branches from living and fallen old deciduous trees, occasionally also on younger damaged growing trees. It is rare in Denmark and Sweden. No data are available for the other Nordic countries (Hansen \& Knudsen, 1997).

It is widely cultivated, mainly in Asia (China, Japan, Malaysia and others), not least for being used to promote health and supply medicinal effects. Both fresh and dried fruit bodies are commercialised. When included in products for health-beneficial uses, also mycelial products, fruit body extracts and isolated fractions are used (Kawagishi \& Zuang, 2008; Khan et al., 2013; Lindequist et al., 2010; Ma et al., 2010a; Mizuno, 1999).

There are no intoxications reported after consumption of Bearded Tooth. However, due to the extensive use of Bearded Tooth for healthbeneficial/medicinal purposes, the mushroom has been thoroughly studied for its content of potentially bioactive constituents. A very 
large number of potentially bioactive compounds have been isolated, characterized and investigated for beneficial effects in in vitro studies. A few of these compounds have also been tested in experimental animals and in preclinical trials in humans:

\section{Bioactive constituents}

Many of the bioactive compounds are aromatic, i.e. contains a benzene ring:

Benzyl derivatives: About twenty constituents which can be derived from benzyl alcohol have been isolated from the fruit bodies of the mushroom, with trivial names such as hericenone A, C to L, 3hydroxyhericenones, erinacerin B, and hericene A to D (Ma et al., 2012; Ueda et al., 2008; Yaoita et al., 2005; Kawagishi et al., 2008; Ma et al., 2010a). Several of the hericenones have in in vitro studies been shown to stimulate the synthesis of nerve growth factor (NGF). This has been interpreted as an "anti-dementia" effect, which has some support in experimental studies in rats and preliminary trials in humans (Kawagishi et al., 2008). Other biological effects of certain benzyl derivatives demonstrated in vitro include cytotoxic effects (Ma et al. 2010b) and protective activity against endoplasmic reticulum stress-dependent cell death (Ueda et al., 2008).

The structural formula for one of these benzyl derivatives, hericene $\mathrm{C}$, is shown below.<smiles>CCCCCCCOCc1cc(OC)c(C/C=C(\C)CCC=C(C)C)c(O)c1C=O</smiles>

Hericene C

Monochlorobenzene compounds: Three 2,5-dimethoxy-monochlorobenzenes were isolated from cultures of $H$. erinaceus (Quian et al., 1990). Two differently substituted 2,5-dimethoxy-chlorobenzenes have been isolated from scrap cultivation beds of Bearded Tooth. In vitro these compounds showed protective activity against endoplasmic reticulum stress-dependent cell death (Ueda et al., 2009). It is not known whether these chlorobenzenes are also synthesized in the fruit bodies.

The structural formula for one of these chlorobenzenes, methyl 4-chloro-3,5-dimethoxybenzoate, is shown below. 
<smiles>COC(=O)c1cc(OC)c(Cl)c(OC)c1</smiles>

Methyl 4-chloro-3,5-dimethoxybenzoate

Isoindolinone compounds: At least four different isoindolinone alkaloids have been isolated from the fruit bodies of Bearded Tooth: Hericenone B (isohericenone), erinacerin $A$, hericerin and a hericerin related compound (without phenylethyl substitution at the nitrogen) (Kawagishi et al., 1990; Kim et al., 2012; Kimura et al., 1991; Kobayashi et al., 2012; Miyazawa et al., 2012; Yaoita et al., 2005; 2012). Only a few studies, all being in vitro studies, have explored the potential biological effects of these constituents. Hericenone B showed cytotoxic activity (Kim et al., 2012; Mori et al., 2010), and hericerin inhibitory effects on pollen growth (Kimura et al., 1991).

The structural formula of one of these isoindolinones, hericenone B, is shown below.<smiles>COc1cc2c(c(O)c1C/C=C(\C)CC(=O)C=C(C)C)CN(CCc1ccccc1)C2=O</smiles>

Hericenone B

A second group of bioactive constituents in Bearded Tooth containing a number of potentially bioactive constituents are the diterpenoids:

Cyathane diterpenoids: More than twenty diterpenoids have been isolated from mycelia of Bearded Tooth. They have all a cyathane skeleton, a tricyclic diterpene structure with an angularly condensed five-, sixand seven-membered ring. Several of these terpenes induce biosynthesis of NGF in cell cultures in vitro, e.g. the cyathane terpenoids erinacine A to G (Kawagishi et al., 1994b, 1996a, 1996b). These constituents have been investigated for potential "anti-dementia" effects and to some ex- 
tent there are in vivo studies in rats and preliminary clinical trials in patients with dementia supporting such an effect (for reviews see Kawagishi \& Zhuang, 2007; Ma et al., 2010a). Two of these terpenoids, erinacine $\mathrm{A}$ and $\mathrm{B}$, were also demonstrated in vitro to reduce activity of methilin-resistant Staphylococcus aureus (Kawagishi, 2005).

The structural formula of one of these cyathane derivatives, erinacine $\mathrm{E}$, is shown below.

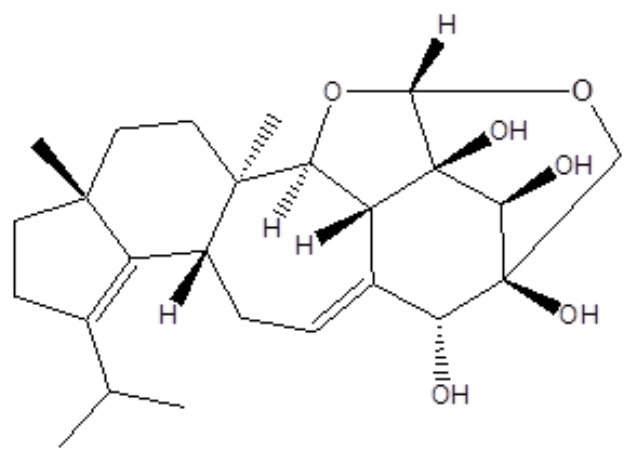

Erinacine $\mathrm{E}$

Other potentially bioactive constituents in Bearded Tooth are 4pyranones, statins, ergothioneine and lectins:

4-Pyranones: Two 4-pyranones, 6-methyl-2,5-dihydroxymethyl- and 2-hydroxymethyl-5-hydroxyethyl-4-pyranone, have been isolated from a culture of Bearded Tooth (Quian et al., 1990). Two other 4-pyranones, the dihydropyranones erinapyrone A and B, could also be isolated from cultivated mycelium of the mushroom. The latter two compounds inhibited growth of HeLa cells in vitro (Kawagishi et al., 1992; Mizuno, 1999).

The structural formula of one of these pyranones, erinapyrone $A$, is shown below.<smiles>C[C@H]1CC(=O)C=C(CO)O1</smiles>

Erinapyrone A 
Statins: Small amounts of lovastatin (188 mg/kg; mean of 3 samples) have been identified in cultured mycelia of Bearded Tooth by Chen et al. (2012) - for further information on statins, see Pleurotus ostreatus.

Ergothioneine: Also ergothioneine $376 \mathrm{mg} / \mathrm{kg}$; (dry weight; mean of 3 samples) have been reported to occur in mycelia of Bearded Tooth (Chen et al., 2012) and in the fruit bodies $960 \mathrm{mg} / \mathrm{kg}$ (dry weight; mean of 3 samples) (Lee et al., 2009) - for further information on ergothioneine, see Lepista nuda.

Lectins: Kawagishi et al. (1994a) have isolated a tetrameric lectin from fresh fruit bodies of Bearded Tooth. The lectin has a molecular mass estimated to $54 \mathrm{kDa}$ with two subunits of $15 \mathrm{kDa}$ and two of $16 \mathrm{kDa}$. The lectin agglutinates human type A, B and 0 erythrocytes and pig erythrocytes. The hemagglutinating activity was inhibited by several monosaccharides and sialic acids. The lectin was quite stable at $\mathrm{pH}$ 5-10.5 and at temperatures up to $70{ }^{\circ} \mathrm{C}$. At $80^{\circ} \mathrm{C}$ only about $25 \%$ of the hemagglutinating activity on rabbit erythrocytes remained (Gong et al., 2004). In a study on different lectins from edible mushrooms, the Bearded Tooth lectin, contrary to the other lectins, did not induce mitogenesis (Ho et al., 2004). More recently, another lectin was isolated from the dried fruit bodies of Bearded Tooth. It is a monomer with a molecular mass of $51 \mathrm{kDa}$. This lectin agglutinates rabbit erythrocytes and this activity is only inhibited by inulin, not by simple sugars. It is stable in the $\mathrm{pH}$ range $2-12$ and relatively heat-stable up to $70^{\circ} \mathrm{C}$, but loses half of its activity at $80^{\circ} \mathrm{C}$. It is biologically active in different in vitro tests. For example, it has been reported to have mitogenic, anti-proliferative and anti-fungal activity (Li et al., 2010). Some lectins in foods, particularly in legumes (and probably also in mushrooms as indicated for Boletus satanas) are known to give rise to gastrointestinal distress (Liener, 1983). This is especially the case, if the foods are not sufficiently heat-treated.

Conclusion: Overall, it is not possible to evaluate whether the abovementioned bioactive compounds in Bearded Tooth may have any healthbeneficial or adverse effects in humans consuming this mushroom, as they have mainly been studied in vitro and as the quantitative occurrence of these constituents is generally not well described.

\section{Recommendation}

Bearded Tooth is red-listed in Denmark, Sweden and Norway as critically endangered.

It should only be marketed in the Nordic countries, if it is from countries where it is cultivated or not red-listed. 


\section{Database search information}

SciFinder by December 2012. Keywords: Hericium. PubMed by December 2012. Keywords: Hericium.

\section{References}

Chen S-Y, Ho K-J, Hsieh Y-J, Wang L-T \& Mau J-L (2012): Contents of lovastatin, $\gamma$ aminobutyric acid and ergothioneine in mushroom fruiting bodies and mycelia. Food Science and Technology 47: 274-278.

Gong M, An J, Lü H-Z, Wu C-F, Li Y-J, Cheng J-Q \& Bao J-K. (2004): Effects of denaturation and amino acid modification on fluorescens spectrum and hemagglutinating activity of Hericium erinaceum lectin. Acta Biochimica et Biophysica Sinica 36: 343-350.

Hansen L \& Knudsen H (1997): Nordic Macromycetes, Volume 3. Heterobasidioid, aphyllophoroid and gastromycetoid Basidiomycetes. Nordsvamp: 1-444.

Ho JCK, Sze SCW; Shen WZ \& Liu WK (2004): Mitogenic activity of edible mushroom lectins. Biochimia et Biophysica Acta 1671: 9-17.

Kawagishi H (2005): Anti-MRSA compounds from Hericium erinaceus (Bull: Fr.) Pers. International Journal of Medicinal Mushrooms 7: 350.

Kawagishi H \& Zhuang C (2007): Bioactive compounds from mushrooms. Heterocycles 72: 45-52.

Kawagishi H \& Zhuang C (2008): Compounds for dementia from Hericium erinaceum. Drugs of the Future 33: 149-155.

Kawagishi H, Ando M \& Mizuno T (1990): Hericenone A and B as cytotoxic principles from the mushroom Hericium erinaceum. Tetrahedron Letters 31: 373-376.

Kawagishi H, Mori H, Uno A, Kimura A \& Chiba S (1994a): A sialic acid-binding lectin from the mushroom Hericium erinaceum. FEBS Letters 340: 56-58.

Kawagishi H, Shimada A, Shiraj R, Okamoto K, Ojima F, Sakamoto H, Ishiguro Y \& Furukawa S (1994b): Erinacines A, B and C, strong stimulators of nerve growth factor (NGF)-synthesis from the mycelia of Hericium erinaceum. Tetrahedron Letters 35: 1569-1572.

Kawagishi H, Simada A, Shizuki K, Mori H \& Okamoto K (1996a): Erinacine D, a stimulator of NGF-synthesis, from the mycelia of Hericium erinaceum. Heterocyclic Communications 2: 51-54.

Kawagishi H, Shimada A, Hosokawa S, Mori H, Sakamoto H, Ishiguro Y, Sakemi S, Bordner J, Kojima N \& Furukawa (1996b): Erinacines E, F and G, stimulators of nerve growth factor (NGF)-synthesis, from the mycelia of Hericium erinaceum. Tetrahedron Letters 37: 7399-7402.

Kawagishi H, Shirai R, Sakamoto H, Yoshida S, Ojima F \& Ishiguro Y (1992): Erinapyrones A and B from the cultured mycelia of Hericium erinaceum. Chemistry Letters 21: $2475-2476$

Khan MA, Tania M, Liu R \& Rahman MM (2013): Hericium erinaceus: an edible mushroom with medicinal values. Journal of Complementary and Integrative Medicine 10: 1-6.

Kim KH, Noh HJ, Choi SU \& Lee KR (2012): Isohericenone, a new cytotoxic isoindolinone alkaloid from Hericium erinaceum. The Journal of Antibiotics 65: 575-577.

Kimura Y, Nishibe M, Nakajima H, Hamasaki T, Shimada A, Tsuneda A \& Shigematsu $N$ (1991): Hericerin, a new pollen growth inhibitor from the mushroom Hericium erinaceum. Agricultural and Biological Chemistry 55: 2673-2674.

Kobayashi S, Inoue T, Ando A, Tamanoi H, Ryu I \& Masuyama A (2012): Total synthesis and structural revision of hericerin. The Journal of Organic Chemistry 77: 5819-5822. 
Lee WY; Park E-J, Jin K \& Ka K-H (2009): Ergothioneine contents in fruiting bodies and their enhancement in mycelial cultures by addition of methionine. Mycobiology 37: 43-47.

Li Y, Zhang G, Ng TB \& Wang H (2010): A novel lectin with antiproliferative and HIV1 reverse transcriptase inhibitory activities from dried fruiting bodies of the Monkey Head Mushroom Hericium erinaceum. Journal of Biomedicine and Biotechnology 2010: 9 pages doi:10.1155/2010/716515

Lindequist U, Rausch R, Füssel A \& Hanssen HP (2010): Höhere Pilze in der traditionellen Heilkunde und Medizin. Medizinische Monatsheft für Pharmazeuten 33: 40-48.

Ma B-J, Shen J-W, Yu H-Y, Ruan Y, Wu T-T \& Zhao X (2010a): Hericenones and erinacines: stimulators of nerve growth factor (NGF). Mycology 1: 92-98.

Ma B-J, Yu H-Y, Shen J-W, Ruan Y, Zhao X, Zhou H \& Wu T-T (2010b): Cytotoxic aromatic compounds from Hericium erinaceum. The Journal of Antibiotics 63: 713-715.

Ma B-J, Ma J-C \& Ruan Y (2012): Hericenone L, a new aromatic compound from the fruiting bodies of Hericium erinaceum. Chinese Journal of Natural Medicines 10: 363-365.

Miyazawa M, Takahashi T, Horibe I \& Ishikawa R (2012): Two new aromatic compounds and a new D-arabinitol ester from the mushroom Hericium erinaceum. Tetrahedron 68: 2007-2010.

Mizuno T (1999): Bioactive substances in Hericium erinaceus (Bull.: Fr.) Pers. (Yamabushitake), and its medicinal utilization. International Journal of Medicinal Mushrooms 1: 105-119.

Mori K, Kikuchi H, Obara Y, Iwashita M, Azumi Y, Kinugasa S, Inatomi S, Oshima Y \& Nakahata N (2010): Inhibitory effect of hericenone B from Hericium erinaceus on collagen-induced platelet aggregation. Phytomedicine 17: 1082-1085.

Quian FG, Xu GY, Du SJ \& Li MH (1990): Isolation and identification of two new pyrone compounds from the culture of Hericium erinaceus. Yao Xue Xue Bao. 25: 522525 (Chinese, English abstract available).

Ueda K, Kodani S, Kubo M, Masuno K, Sekiya A, Nagai K \& Kawagishi H (2009): Endoplasmic reticulum (ER) stress-suppressive compounds from scrap cultivation beds of the mushroom Hericium erinaceum. Bioorganic and Medicinal Chemistry 73: 1908-1910.

Ueda K, Tsujimori M, Kodani S, Chiba A, Kubo M, Masuno K, Sekiya A, Nagai K \& Kawagishi $H$ (2008): An endoplasmic reticulum (ER) stress-suppressive compound and its analogues from the mushroom Hericium erinaceum. Bioorganic \& Medicinal Chemistry 16: 9467-9470.

Yaoita Y, Danbara K \& Kikuchi M (2005): Two new aromatic compounds from Hericium erinaceus (Bull.: Fr.) Pers. Chemical and Pharmateutical Bulletin 53: 1202-1203.

Yaoita Y, Yonezawa S, Kikuchi M \& Machida K (2012): A geranylated aromatic compound from the mushroom Hericium erinaceus. Natural Product Communications 7: $527-528$

\section{Hericium ramosum (Bull.) Letell.}

See Hericium coralloides. 


\section{Hydnum repandum $\mathrm{L}$.}

Wood Hedgehog, ("Pied de Mouton", "Hedgehog”) (DK: Almindelig Pigsvamp ("Pigsvamp"), FI: Vaaleaorakas, IS: Gulbroddi, NO: Blek piggsopp, SE: Blek taggsvamp).

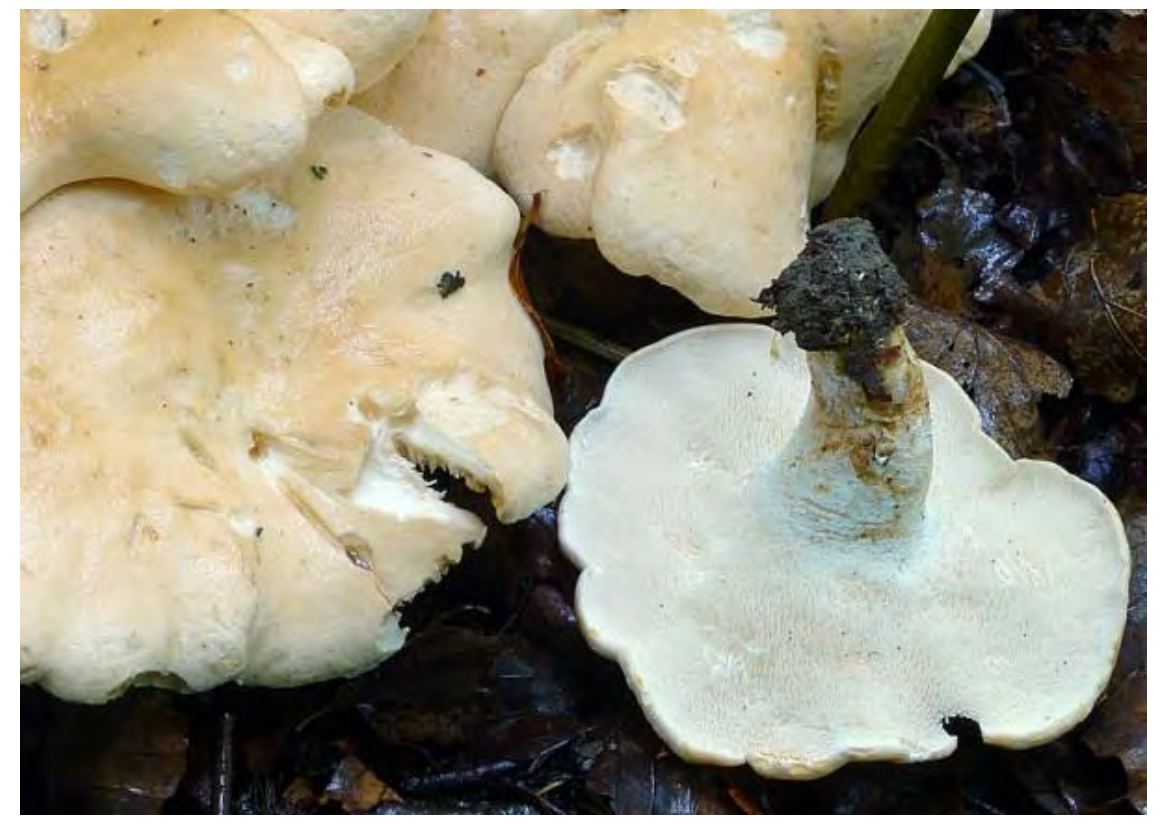

\section{Background and risk assessment}

Wood Hedgehog (Hydnum repandum) is an edible mushroom.

It is terrestrial in both deciduous and coniferous forests. It is common in the Nordic countries up to the subarctic zone (Hansen \& Knudsen, 1997).

There are no intoxications reported after consumption of Wood Hedgehog, and no natural toxicants constituting a risk for humans have been identified in the mushroom. However, some biologically active constituents have been identified in Wood Hedgehop:

\section{Bioactive constituents}

Polyacetylenic compounds: An acetylenic diepoxide named repandiol has been isolated from the fruit bodies of Wood Hedgehog in an amount corresponding to $150 \mathrm{mg} / \mathrm{kg}$ (fresh weight) (Takahishi et al., 1992) or $20 \mathrm{mg} / \mathrm{kg}$ (fresh weight) (Millard et al., 2004). The chemical structure was elucidated as (2R,3R,8R,9R)-diepoxy-4,6-decadiyne-1,10-diol and confirmed by synthesis (Takahashi et al., 1992; Millard et al., 2004). 
Repandiol was shown to have potent cytotoxic activity against different tumour cells cultivated in vitro (Takahashi et al., 1992). Repandiol is a bifunctional alkylating agent. Like for many other bifunctional, alkylating compounds, repandiol alkylates DNA and forms inter-strand cross-links, as demonstrated by in vitro incubation of repandiol with restriction fragment of DNA. Such DNA binding and cross-linking activity in vivo may result in antitumour and/or carcinogenic activity as demonstrated for many other cross-linking compounds (Rajski \& Williams, 1998). However, the cross-linking capability of repandiol was substantially lower than for other, more efficiently cross-linking diepoxyalkanes such as diepoxy-butane and diepoxy-octane, probably due to its reduced rotational flexibility and an increased sterical hindrance (Millard et al., 2004). The structural formula of repandiol is shown below.

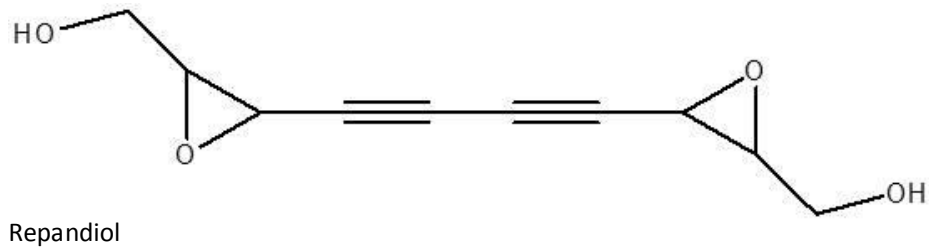

Cyathane diterpenoids: Wang et al. (2005) have isolated two diterpenoids from fruit bodies of Wood Hedgehog, sarcodonin A and scabronine B with a cyathane skeleton (a fused 5-6-7 tricarbocyclic structure) (Engquist \& Stoltz, 2009). It has been demonstrated that scabronine B stimulates the synthesis of nerve growth factor (NFG) in rat cells cultivated in vitro (Kita et al., 1998). The structural formula of one of these cyathan diterpenoids, sarcodonin A is shown below.

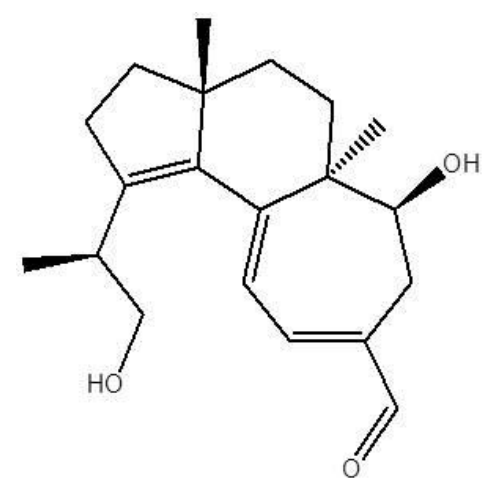

Sarcodonin A 
Ergothioneine: Lee et al. (2009) have identified $780 \mathrm{mg} / \mathrm{kg}$ (dry weight; mean of tree samples) of ergothioneine in the fruit bodies of Wood Hedgehog. For further information on ergothioneine: see Lepista nuda.

Mutagens: Extracts of fruit bodies from Wood Hedgehog were examined for mutagenic activity in a histidine-independent bacterial test system using the Salmonella typhimurium strains strain TM677. The mushroom extract was weakly positive. It is plausible that the mutagenic activity was due to repandiol occurring in the mushroom. However, more information is needed to interpret e.g. whether the mutagen is destroyed during the processing of the mushroom for consumption (Grüter et al., 1991).

Overall it is concluded that Wood Hedgehog contains a compound(s) which in in vitro studies may damage DNA and be mutagenic. However, there are no in vivo studies available on the mushroom or its potential bioactive constituents. Therefore, it is not possible to evaluate whether consumption of Wood Hedgehog may give rise to any adverse effects, in particular after exposure over an extended period of time.

\section{Recommendation}

No special recommendation.

\section{Listing 1}

\section{Database search information}

SciFinder by February 2012. Keywords: Hydnum.

\section{References}

Engquist JA \& Stoltz BM (2009): Synthetic efforts toward cyathane diterpenoid natural products. Natural Product Reports 26: 661-680.

Grüter A, Friederich U \& Würgler FE (1991): The mutagenicity of edible mushrooms in a histidine-independent bacteral test system. Food Chemical Toxicology 29: 159-165.

Hansen L \& Knudsen H (1997): Nordic Macromycetes, Volume 3. Heterobasidioid, aphyllophoroid and gastromycetoid basidiomycetes. Nordsvamp: 1-444.

Kita T, Takaya Y, Oshima Y, Ohta T, Aizawa K, Hirano T \& Inakuma T (1998): Scabronines B, C, D, E and F, novel diterpenoids showing stimulating activity of nerve growth factor-synthesis, from the mushroom Sarcodon scabrosus. Tetrahedron 54: 11877-11886.

Lee WY; Park E-J, Jin K \& Ka K-H (2009): Ergothioneine contents in fruiting bodies and their enhancement in mycelial cultures by addition of methionine. Mycobiology 37: 43-47. 
Millard JT, Katz JL, Goda J, Frederick ED, Pierce SE, Speed TJ \& Thamattoor DM (2004): DNA interstrand cross-linking by a mycotoxic diepoxide. Biochimie 86: 419-423.

Rajski SR \& Williams RM (1998): DNA cross-linking agents as antitumor drugs. Chemical Review 98: 2723-2795.

Takahashi A, Endo T \& Nozoe S (1992): Repandiol, a new cytotoxic diepoxide from the mushroom Hydnum repandum and H. repandum var. album. Chemical and Pharmaceutical Bulletin 40: 3181-3184.

Wang X-n, Du J-c, Tan R-x \& Liu J-k (2005): Chemical constituents of basidiomycete Hydnum repandum. Chinese Traditional and Herbal Drugs 36: 1126-1130 (Chinese, English abstract available). 


\section{Hydnum rufescens Pers.}

Terracotta Hedgehog (DK: Rødgul Pigsvamp ("Pigsvamp”), FI: Ruskoorakas, IS: Rauðbroddi, NO: Rødgul piggsopp, SE: Rödgul taggsvamp).

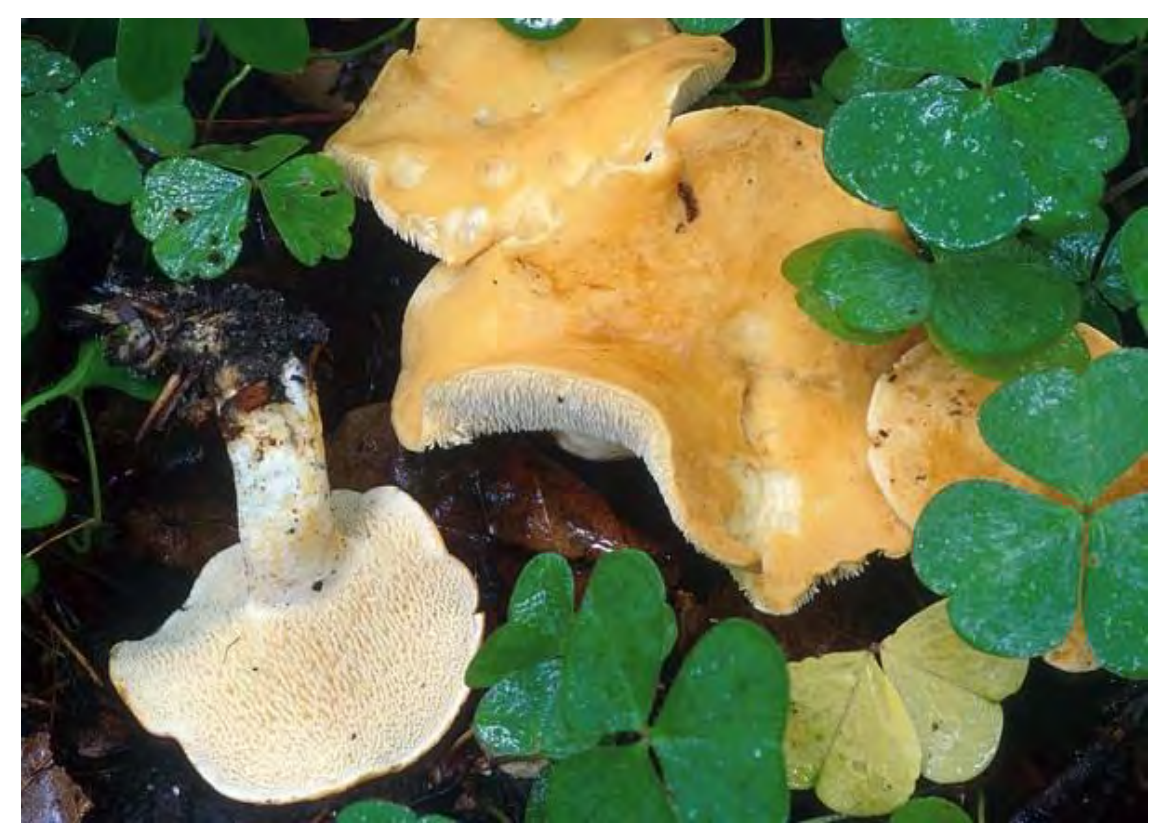

\section{Background and risk assessment}

Terracotta Hedgehog (Hydnum rufescens) is an edible mushroom.

It is mycorrhizal with both deciduous and coniferous trees. It is common in the Nordic countries up to the subarctic zone (Hansen \& Knudsen, 1997).

There are no intoxications reported after consumption of Terracotta Hedgehog, and no natural toxicant constituting a risk for humans has been identified in the mushroom.

As Terracotta Hedgehog is closely related to Wood Hedgehog (H. repandum) and $H$. albidum, which have both been shown to contain constituents that are bioactive in in vitro test systems (e.g., cyathanediterpenoids and an acetylenic diexpoide), it is plausible that also Terracotta Hedgehog contains these compounds (see H. repandum). 


\section{Recommendation}

No special recommendation.

\section{Listing 1}

\section{Database search information}

SciFinder by February 2012. Keywords: Hydnum.

\section{References}

Hansen L \& Knudsen H (1997): Nordic Macromycetes, Volume 3. Heterobasidioid, aphyllophoroid and gastromycetoid basidiomycetes. Nordsvamp: 1-444. 


\section{Hygrocybe pratensis (Fr.) Murrill (Camarophyllus pratensis (Fr.) P. Kumm.)}

Meadow Waxcap (Buffcap) (DK: Eng-Vokshat, FI: Niittyvahakas, IS: Vallhnúfa, NO: Engvokssopp, SE: Ängsvaxskivling (Ängvaxing)).

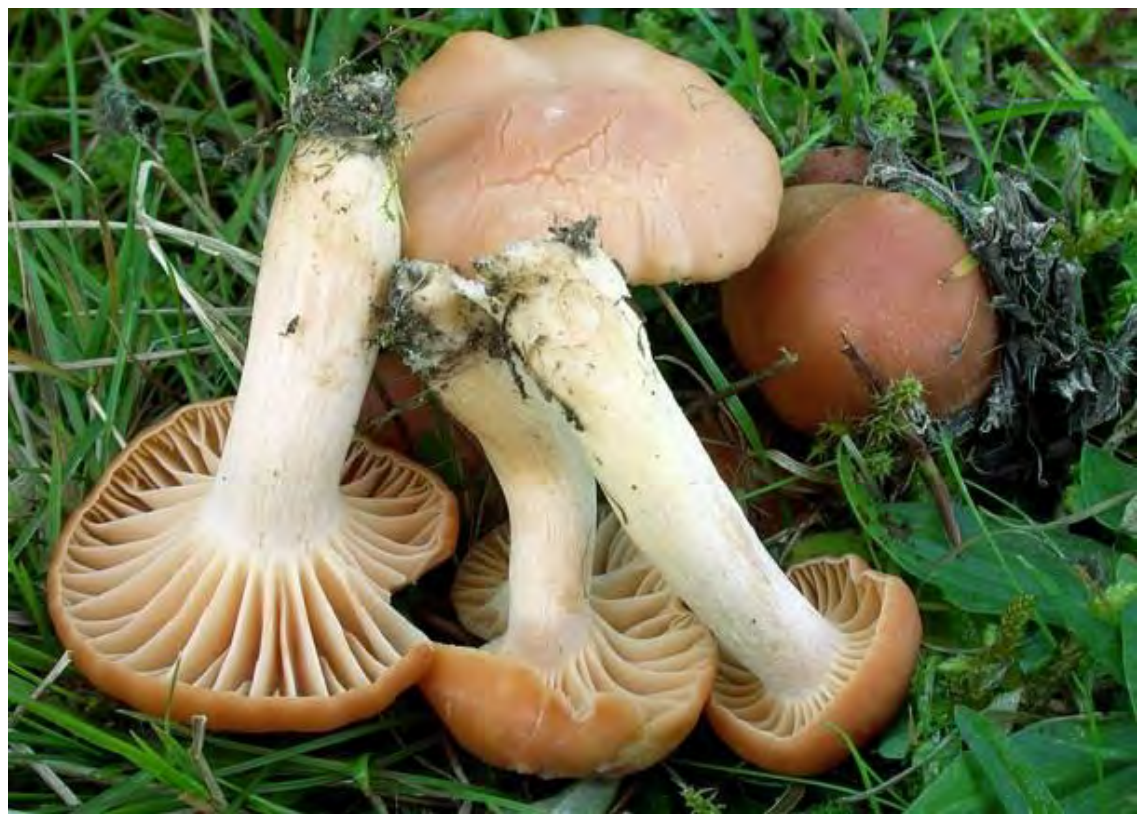

\section{Background and risk assessment}

Meadow Waxcap (Hygrocybe pratensis) is an edible mushroom.

It is probably saprotrophic, growing mostly on unfertilized grassland and pastures. It is common up to the arctic/alpine zones of the Nordic countries, though less common in northern parts of Finland (Knudsen \& Vesterholt, 2012).

There are no intoxications reported after consumption of Meadow Waxcap, and no natural toxicants constituting a risk for humans have been identified in the mushroom.

\section{Recommendation}

No special recommendation.

Listing 2 


\section{Database search information}

SciFinder by December 2012. Keywords: Hygrocybe, Camarophyllus. PubMed by December 2012. Keywords: Hygrocybe.

\section{References}

Knudsen H \& Vesterholt J (2012): Funga Nordica. Agaricoid, boletoid, clavarioid, cyphelloid and gastroid genera. Nordsvamp: 1-1083. 


\section{Hygrocybe punicea (Fr.) P. Kumm.}

Crimson Waxcap (DK: Skarlagen-Vokshat, FI: Punikkivahakas, IS: Skarlattoppa, NO: Skarlagenvokssopp, SE: Scharlakansvaxskivling).

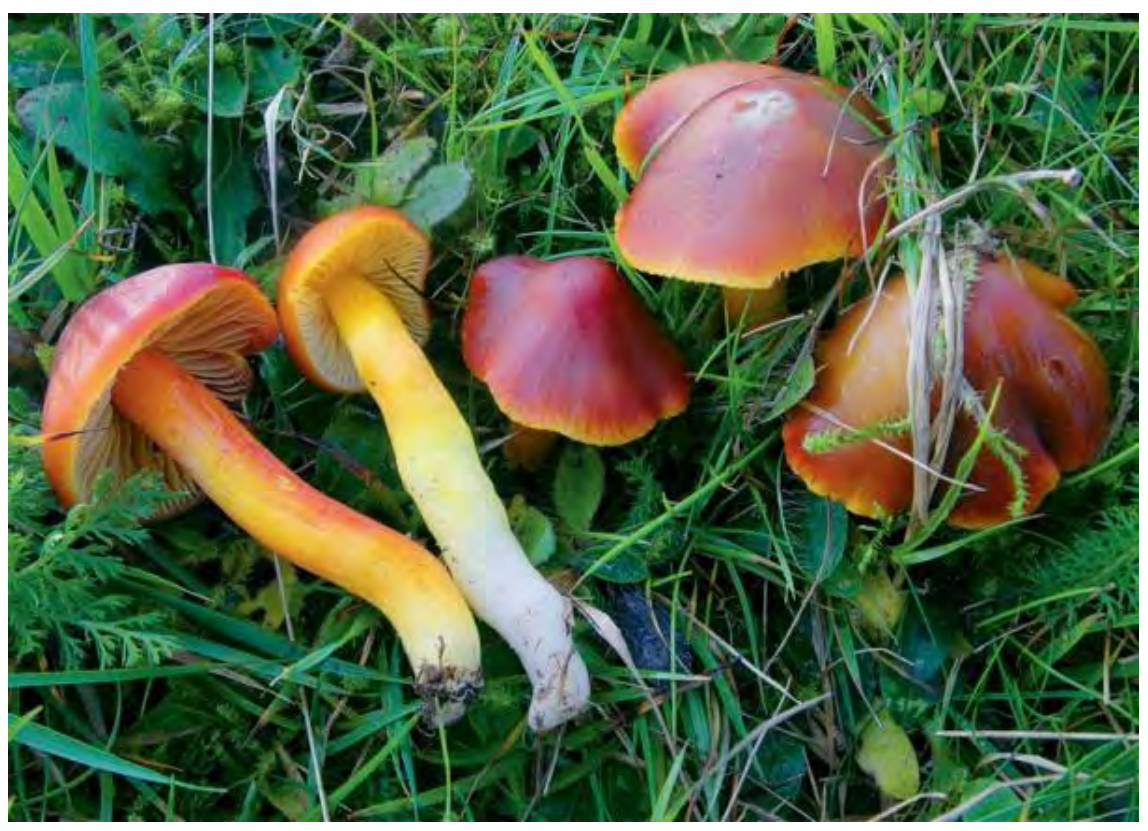

\section{Background and risk assessment}

Crimson Waxcap (Hygrocybe punicea) is an edible mushroom.

It is probably saprotrophic and grows on seminatural, high diversity grassland and fixed dunes. It is occasional, but locally common in temperate to subarctic/subalpine zones of the Nordic countries, though with a more southern distribution in Finland (Knudsen \& Vesterholt, 2012).

There are no intoxications reported after consumption of Crimson Waxcap, and no natural toxicants constituting a risk for humans have been identified in the mushroom.

The colouring matters in yellow and red Hygrocybe species are generally, as shown for Crimson Waxcap, anticipated to be related to the pigments secodopas, muscaflavin and betalamic acid in Fly Agaric (Amanita muscaria). The pigments are all indicated to be formed enzymatically from L-3,4-dihydroxyphenylalanine (L-DOPA) (Mueller et al., 1997; Steglich \& Preuss, 1975; Terradas \& Wyler, 1991; von Ardenne et al., 1974). The potential biological effects of these pigments are unknown. 


\section{Recommendation}

Red-listed as near threatened in Sweden and Denmark. Should only be marketed in the Nordic countries, if it is from countries, where it is not red-listed.

\section{Listing 2}

\section{Database search information}

SciFinder by December 2012. Keywords: Hygrocybe. PubMed by December 2012. Keywords: Hygrocybe.

\section{References}

Knudsen H \& Vesterholt J (2012): Funga Nordica. Agaricoid, boletoid, clavarioid, cyphelloid and gastroid genera. Nordsvamp: 1-1083.

Mueller LA, Hinz U \& Zryd J-P (1997): The formation of betalamic acid and muscaflavin by recombinant DOPA-dioxygenase from Amanita. Phytochemistry 44: 567-569.

Steglich W \& Preuss R (1975): L-3,4-Dihydroxyphenylalanine from carpophores of Hygrocybe conica and H. ovina. Phytochemical Reports 14: 1119.

Terradas F \& Wyler H (1991): The secodopas, natural pigments in Hygrocybe conica and Amanita muscaria. Phytochemistry 30: 3251-3253.

von Ardenne R, Döpp H, Musso H \& Steglich W (1974): Über das Vorkommen von Muscaflavin bei Hygrocyben (Agaricales) und seine Dihydroazepin-Struktur. Zeitschrift für Naturforschung 29c: 637-639. 


\section{Hygrophorus camarophyllus (Alb. \& Schwein.) Dumée, Grandjean \& Maire}

Arched Woodwax (DK: Sodbrun Sneglehat, FI: Mustavakakas, IS: Sötsniglingur NO: Sotvokssopp, SE: Sotvaxskivling (Sotväxing)).

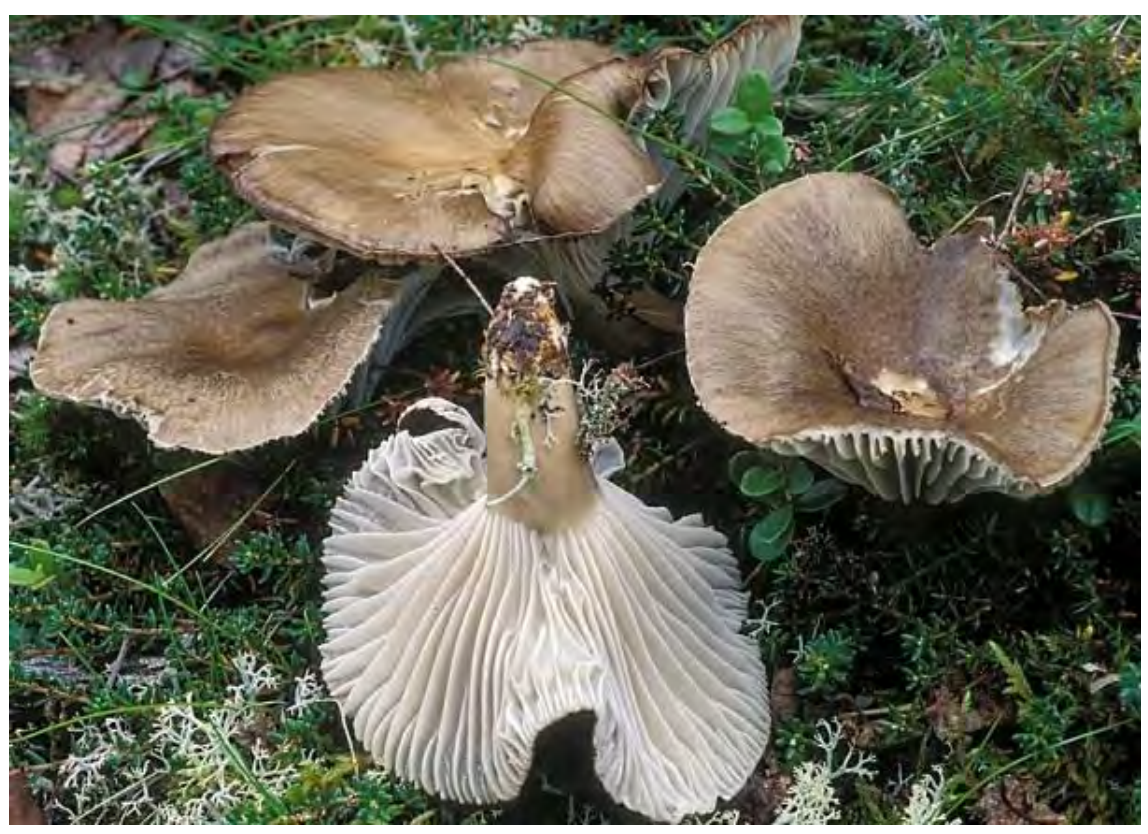

\section{Background and risk assessment}

Arched Woodwax (Hygrophorus camarophyllus) is an edible mushroom.

It grows in mycorrhizal association with Pine (Pinus) and Spruce (Picea). It is very common in hemiboreal and up to subalpine/subarctic zones but very rare in temperate zone (Denmark and the most southern Sweden and Norway) (Knudsen \& Vesterholt, 2012).

There are no intoxications reported after consumption of Arched Woodwax, and no natural toxicants constituting a risk for humans have been identified in the mushroom.

\section{Recommendation}

Arched Woodwax is red-listed in Denmark as critically endangered. Should only be marketed in the Nordic countries, if it is from countries, where it is not red-listed. 
Listing 2

\section{Database search information}

SciFinder by December 2012. Keywords: Hygrophorus. PubMed by December 2012. Keywords: Hygrophorus

\section{References}

Knudsen H \& Vesterholt J (2012): Funga Nordica. Agaricoid, boletoid, clavarioid, cyphelloid and gastroid genera. Nordsvamp: 1-1083. 


\section{Hygrophorus hypothejus (Fr.) Fr.}

Herald of Winter (DK: Frost-Sneglehat, FI: Hallavahakas, IS: No Icelandic name, NO: Frostvokssopp, SE: Frostvaxskivling (Frostvaxing)).

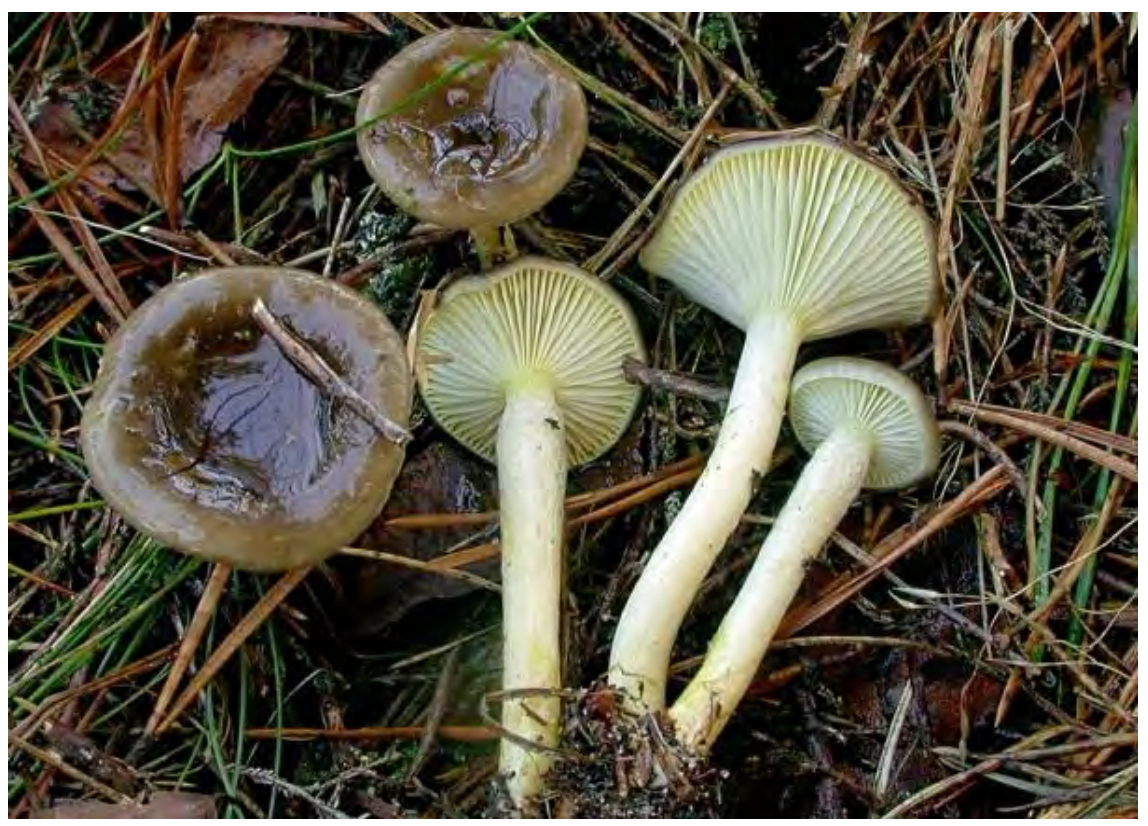

\section{Background and risk assessment}

Herald of Winter (Hygrophorus hypothejus) is an edible mushroom.

It forms mycorrhiza in coniferous forests, often along tracks. It is widespread and common in temperate, hemiboreal and boreal areas of the Nordic countries (Knudsen \& Vesterholt, 2012).

There are no intoxications reported after consumption of Herald of Winter, and no natural toxicants constituting a risk for humans have been identified in the mushroom. However, one potential bioactive constituent has been identified in the mushroom. It is a lectin having hemagglutinating activity against human erythrocytes and binding specifically to lactose and $\mathrm{N}$-acetyl-D-galactosamine (Guillot \& Coulet, 1974; Veau et al., 1999). The lectin is tetrameric with a molecular mass of $68 \mathrm{kDa}$ with four identical subunits, each with a molecular mass of $17 \mathrm{kDa}$. The lectin shows a sharp fall in hemagglutinating activity when heated to a temperature above $40{ }^{\circ} \mathrm{C}$ (Veau et al., 1999). Cooking of the mushroom will probably destroy the lectin's potentially biological effect. 


\section{Recommendation}

No special recommendation.

\section{Listing 2}

\section{Database search information}

SciFinder by December 2012. Keywords: Hygrophorus. PubMed by December 2012. Keywords: Hygrophorus.

\section{References}

Guillot J \& Coulet M (1974): Etude de quelques propriétés de la lectine anti $(A+B)$ d'Hygrophorus hypothejus Fr. Revue Francaise de Transfusion 1: 49-57.

Knudsen H \& Vesterholt J (2012): Funga Nordica. Agaricoid, boletoid, clavarioid, cyphelloid and gastroid genera. Nordsvamp: 1-1083.

Veau B, Guilot J, Damez M, Dusser M, Konska G \& Botton B (1999): Purification and characterization of an anti- $(\mathrm{A}+\mathrm{B})$ specific lectin from the mushroom Hygrophorus hypothejus. Biochimica et Biophysica Acta 1428: 39-44. 


\section{Hypholoma capnoides (Fr.) P. Kumm.}

Conifer Tuft (DK: Gran-Svovlhat, FI: Kuusilahokka, IS: Viðarnollur (Kirkjugarðsnollur), NO: Svovelsopp, SE: Rökslöjskivling).

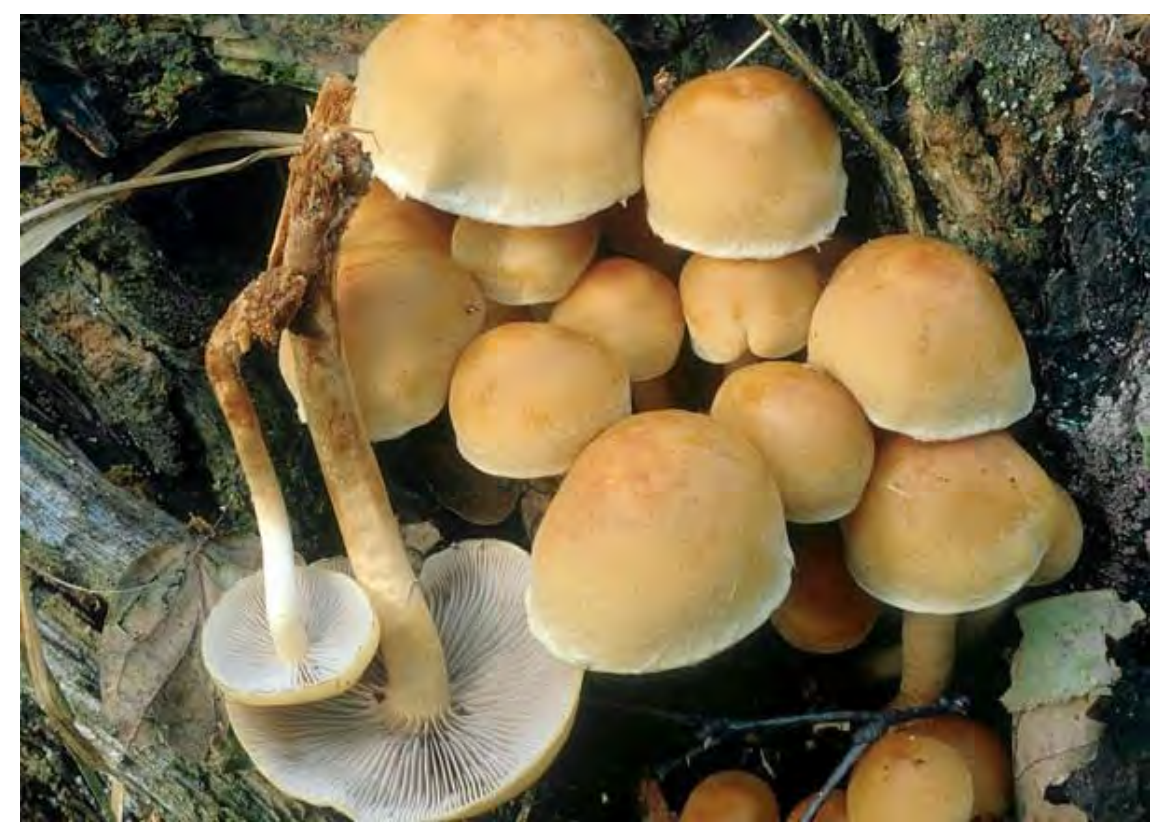

\section{Background and risk assessment}

Conifer Tuft (Hypholoma capnoides) is an edible mushroom.

It is a saprotrophic, mostly fasciculate mushroom found on stumps and roots, of Spruce (Picea) and Pine (Pinus), mainly in late autumn but also in spring. It is very common in most areas, but rare in subarctic/subalpine and arctic/alpine areas of the Nordic countries (Hansen \& Knudsen, 1992; Knudsen \& Vesterholt, 2012).

There are no intoxications reported after consumption of Conifer Tuft, and no natural toxicants constituting a risk for humans have been identified in the mushroom.

According to Sterner et al. (1982) extracts of Conifer Tuft are mutagenic in the Ames test using the Salmonella typhimurium strains TA98, TA100 and TA2637. The extract was found positive in all three strains. The activity was not enhanced in presence of microsomal enzymes. Unfortunately, Sterner et al (1982) give no information, whether they had controlled for the potential presence of histidine in the extract. It is well known that false positives may be obtained in the presence of histidine. 


\section{Recommendation}

Conifer Tuft (Hypholoma capnoides) resembles Sulphur Tuft (Hypholoma fasciculare) which is poisonous. See Chapter 4.

The mushroom is therefore not regarded as suitable for commercial marketing.

Listing 3

\section{Database search information}

SciFinder by February 2012. Keywords: Hypholoma.

\section{References}

Hansen L \& Knudsen H (1992): Nordic Macromycetes, Volume 2. Polyporales, Boletales, Agaricales, Russulales. Nordsvamp: 1-474.

Knudsen H \& Vesterholt J (2012): Funga Nordica. Agaricoid, boletoid, clavarioid, cyphelloid and gastroid genera. Nordsvamp: 1-1083.

Sterner O, Bergman R, Kesler E, Magnusson L, Nilsson B, Wickberg B, Zimerson E \& Zetterberg G (1982): Mutagens in larger fungi I. Forty-eight species screened for mutagenic activity in the Salmonella/microsome assay. Mutation Research 101: 269-281. 


\section{Hypsizygus marmoreus (Peck.) H.E. Bigelow}

Beech Leech (Brown Beech Mushroom, "Brown Shimeji", White Beech Mushroom, "White Shimeji") (DK: Bøgehat, FI: Runkovalmuska, IS: No Icelandic name, NO: No Norwegian name, SE: No Swedish name).

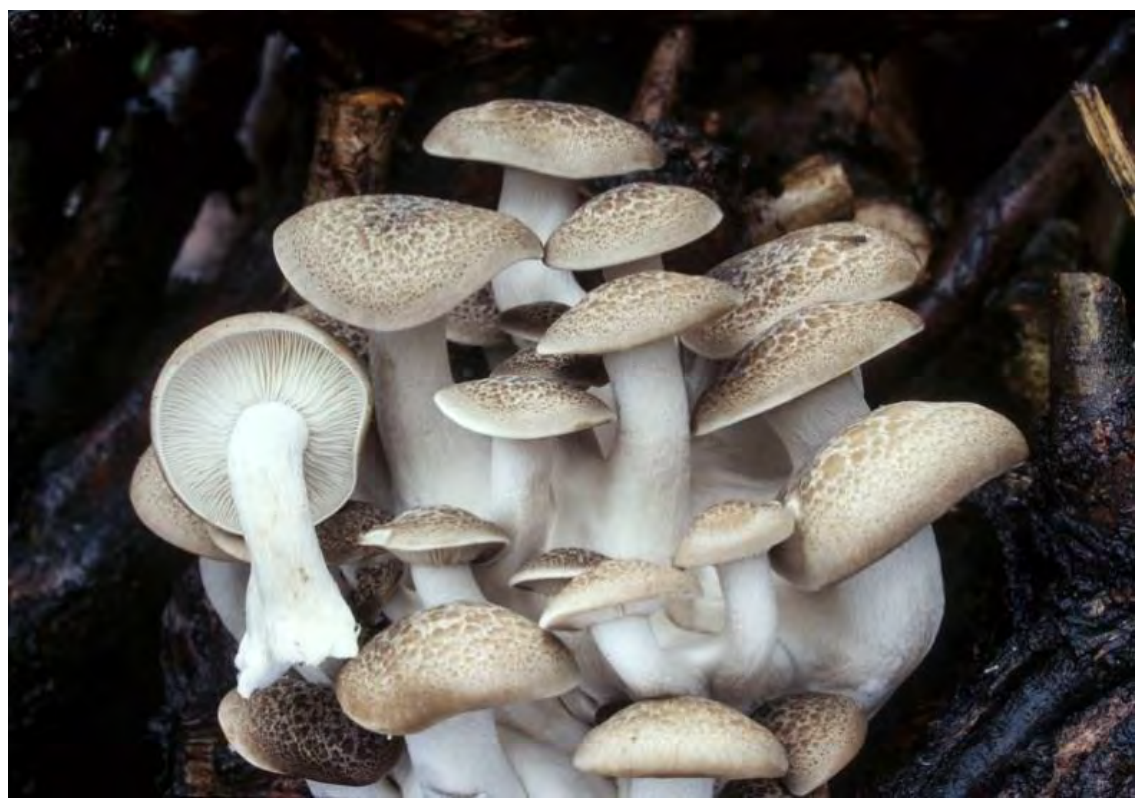

\section{Background and risk assessment}

Beech Leech (Hypsizygus marmoreus) is an edible mushroom.

It is a saprotrophic mushroom, which grows on wood of deciduous trees, especially in Japan and China (Hongo \& Izawa, 2006). It is widely cultivated, especially in East Asia, and traded both as a white form, White Beech Mushroom, and as a brown form, Brown Beech Mushroom.

There are no intoxications reported after consumption of Beech Leech, and no natural toxicant constituting a risk for humans has been identified in the mushroom, except for traces of hydrogen cyanide.

Several bioactive constituents with potentially biological effects in humans have been identified in Beech Leech.

\section{Bioactive constituents}

Cyanogenic compounds: Only traces of cyanogenic compounds, $0.2 \mathrm{mg}$ per $\mathrm{kg}$ of the mushroom have been found in Beech Leech (Shindo et al., 1999). This level of hydrogen cyanide in the fresh mushroom is of no health concern in relation to consumption of Beech Leech. 
Statins: High amounts of lovastatin have been found in the mycelia of two forms of Beech Leech, $455 \mathrm{mg} / \mathrm{kg}$ dry weight (mean of 35 samples) in a white strain and $424 \mathrm{mg} / \mathrm{kg}$ dry weight (mean of 3 samples) in a coloured strain, respectively (Chen et al., 2012). The same investigators reported lower levels, $258 \mathrm{mg} / \mathrm{kg}$ dry weight, in fruit bodies of the coloured strain, but gave no information on the white strain. Lo et al. (2012), on the other hand, found $628 \mathrm{mg} / \mathrm{kg}$ dry weight in the fruit bodies (mean of 3 samples). Lovastatin inhibits the rate limiting enzyme in the production of cholesterol in mammals, including in humans. In rare cases, when statins like lovastatin have been used as drugs, they may give rise to myopathy, characterised by muscular weakness and/or pain and in very rare cases rhabdomyolysis ${ }^{16}$ (for further data on statins, see Pleurotus ostreatus). These serious adverse effects have not been seen after consumption of Beech Leech.

Ergothioneine: Relatively high amounts of ergothioneine were reported in the mycelia of two forms of Beech Leech, 207 and $221 \mathrm{mg} / \mathrm{kg}$ dry weight (for each mean of 3 samples) (Chen et al., 2012). The level was higher in fruit bodies where a normal coloured strain contained 410 $\mathrm{mg} / \mathrm{kg}$ dry weight. The level in the white strain was not reported. Other investigators have reported much lower levels in dried fruit bodies, 46 $\mathrm{mg} / \mathrm{kg}$ (mean of 3 samples) (Lo et al., 2012). Ergothioneine in mushrooms has in numerous in vitro and in a few in vivo studies been shown to have antioxidative and cytoprotective properties against a wide range of cellular stressors and it is anticipated to have a potential as a physiological antioxidant (e.g. Song et al., 2010). For further data on ergothioneine, see Lepista nuda.

Ribosome-inactivating protein: A heat tolerant ribosome-inactivating protein, named hypsin, with a molecular mass of $20 \mathrm{kDa}$, having antifungal and antiproliferative properties, has been isolated from the fruit bodies of Beech Leech (Lam \& Ng, 2001).

Polyacetylenic compounds: Three polyacetylenic alcohols have been isolated from liquid mycelium culture of Beech Leech, 2(E)-decene4,6,8-triyn-1-ol, decene-4,6,8-triyn-1-ol and 8(E)-decene-4,6-diyn1,2,10-triol. Although the isolated acetylenic constituents were unstable at room temperature, the two triyns were demonstrated to have inhibitory activity against the Oak (Quercus) pathogenic fungus Raffaelea

\footnotetext{
${ }^{16}$ Rhabdomyolysis is the breakdown of muscle fibers that leads to the release of muscle fiber contents (myoglobin) into the blood stream. Myoglobin is harmful to the kidney and often causes kidney damage (MedlinePlus Medical Enclyclopedia, 2012).
} 
quercivora (Shiona et al., 2013). Due to their instability even at room temperature, it is not likely that these polyacetylenic constituents have any activity in the cooked mushroom.

The structural formula of one of these three acetylenic compounds, 2(E)-decene-4,6,8-triyn-1-ol is show below.

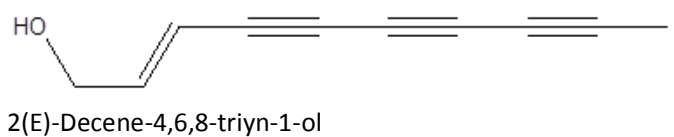

Polyisoprenepolyols: Sawabe et al. (1996; 1999) have isolated and elucidated the structure of at least 17 homologous polyisoprenepolyols with 40-70 carbon atoms from the fruit bodies of Beech Leech. The compounds have been name hypsiziprenols. Two of these polyols, hypsiziprenol $\mathrm{A}_{9}$ and $\mathrm{B}_{10}$ were shown to have inhibitory activities against a strain of Mycobacterium tuberculosis (Akihisa et al., 2005). Hypsiziprenol $A_{9}$ has also been shown to have antiproliferative activity against human cells cultured in vitro (Chan et al., 2004). Whether the two hypsiziprenols have biological effects also in-vivo is not known.

The structural formula of one of these polyols, hypsiziprenol $B_{10}$ is shown below.<smiles>C=CC(C)(O)CCC=C(C)CCC(O)C(C)(O)C(C)CCC(C)(O)CCC=C(C)C</smiles>

Hypsiziprenol $B_{10}$

\section{Recommendation}

No special recommendation.

Listing 1

Database search information

SciFinder by December 2012. Keywords: Hypsizygus. 


\section{References}

Akihisa T, Franzblau SG, Tokuda H, Tagata M, Ukiya M, Matsuzawa T, Metori K, Kimura Y, Suzuki T \& Yasukawa K (2005): Antitubercular activity and inhibitory effect on Epstein-Barr virus activation of sterols and polyisoprenepolyols from an edible mushroom Hypsizigus marmoreus. Biological and Pharmaceutical Bulletin 28: 1117-1119.

Chang J-S, Son J-K. Li G, Oh E-J, Kim J-Y, Park S-H, Bae J-T, Kim H-J, Lee I-S, Kim O-M, Kozukue N, Han J-S, Hirose M \& Lee K-R (2004): Inhibition of cell cycle progression on HepG2 cells by hypsiziprenol $\mathrm{A}_{9}$, isolated from Hypsizigus marmoreus. Cancer Letters 212: 7-14.

Chen S-Y, Ho K-J, Hsieh Y-J, Wang L-T \& Mau J-L (2012): Contents of lovastatin, $\gamma$ aminobutyric acid and ergothioneine in mushroom fruiting bodies and mycelia. Food Science and Technology 47: 274-278.

Hongo T \& Izawa M (2006): Kinoko (Fungi): 1-383 (Japanese).

Lam SK \& Ng TB (2001): Hypsin, a novel thermostable ribosome-inactivating protein with antifungal and antiproliferative activities from fruiting bodies of the edible mushroom Hypsizigus marmoreus. Biochemical and Biophysical Reseach Communication 285: 1071-1075.

Lo Y-C, Lin S-Y, Ulziijargal E, Chen S-Y, Chien R-C, Tzou Y-J \& Mau J-L (2012): Comparative study of contents of several bioactive components in fruiting bodies and mycella of culinary-medicinal mushrooms. International Journal of Medicinal Mushrooms 14: 357-363.

Sawabe A, Morita M, Ouchi S \& Okamoto T (1996): Fast atom bombardment mass spectrometry and linked scan analysis at constant $B / E$ in the structural characterization of new polyisoprenepolyols isolated from an edible mushroom (Hypsizigus marmoreus). Journal of Mass Spectrometry 31: 921-925.

Sawabe A, Masanori M, Seiji O \& Tadashi O (1999): B/E linked scan fast atom bombardment analysis of new polyisoprenepolyols isolated from mushroom. Advances in Mass Spectrometry 47: 588-593.

Sawabe A, Morita M, Kiso T, Kishine H, Ohtsubo Y; Ouchi S \& Okamoto T (1999): Structural analyses of a precursory substance of bitterness: New polyisoprenepolyols isolated from an edible mushroom (Hypsizygus marmoreus) by fast atom bombardment mass spectrometry. Journal of Agricultural and Food Chemistry 47: 588-593.

Shindo T, Ushiyama H, Kan K \& Yasuda K (1999): Study on content of cyanide in Basidiomycetes and the effect of cooking. Journal of Food Hygiene Society of Japan 40: 29-35 (Japanese, English Abstract available).

Shione Y, Haga M, Koyama H, Murayama T \& Koseki T (2013): Antifungal activity of a polyacetylene against the fungal pathogen of Japanese Oak from the liquid culture of the edible mushroom, Hypsizygus marmoreus. Zeitschrift für Naturforschung 68b: 293-295.

Song T-Y, Chen C-L, Liao J-W, Ou H-C \& Tsai M-S (2010): Ergothioneine protects against neuronal injury induced by cisplatin both in vitro and in vivo. Food and Chemical Toxicology 48: 3492-3499. 


\section{Kuehneromyces mutabilis (Schaeff.) Singer \& A.H. Sm. (Pholiota mutabilis (Schaeff.) P. Kumm.)}

Sheathed Woodtuft ("Two-tone Pholiote") (DK: Foranderlig Skælhat, FI: Koivunkantosieni, IS: Hverfiskrýfa Hverfisveppur, NO: Stubbeskjellsopp, SE: Föränderlig tofsskivling).

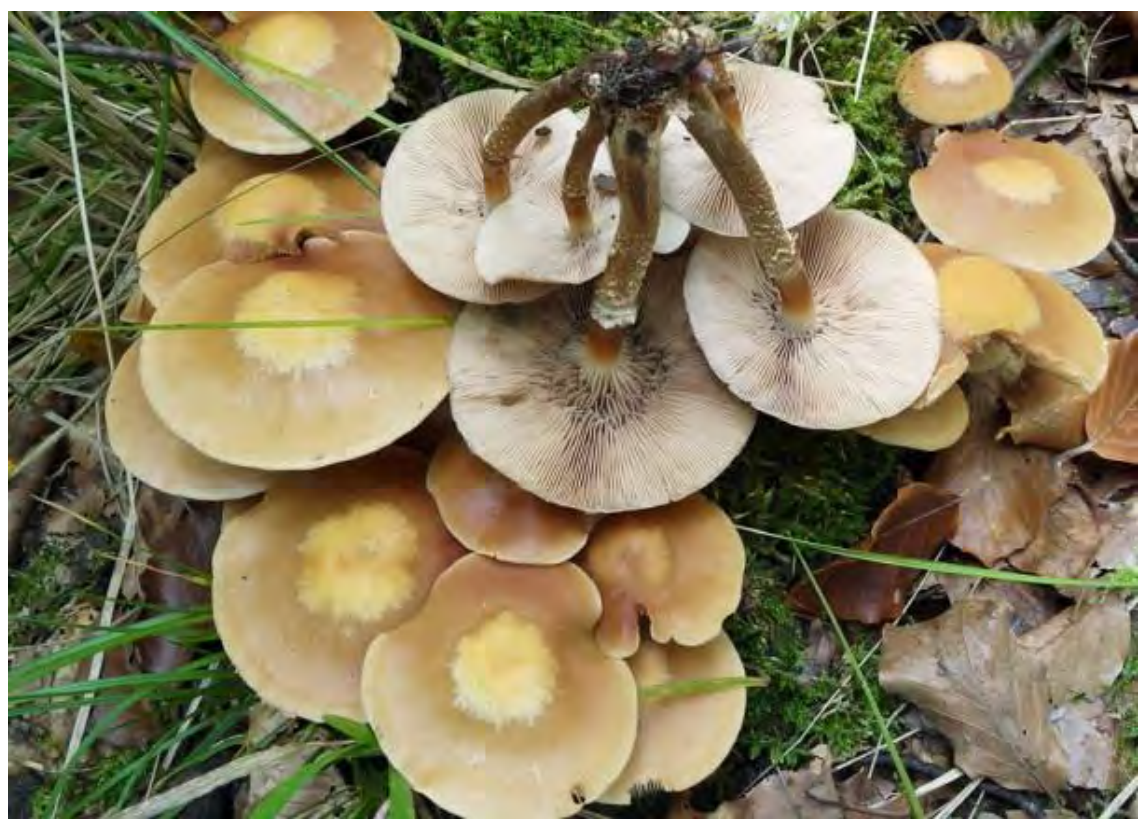

\section{Background and risk assessment}

Sheathed Woodtuft (Kuehneromyces mutabilis) is an edible mushroom.

The mushroom is saprotrophic on deciduous wood, rarely on Spruce (Picea) from late spring to late autumn. It is very common in most parts of the Nordic countries (Knudsen \& Vesterholt, 2012).

There are no intoxications reported after consumption of Sheathed Woodtuft, and no natural toxicants constituting a risk for humans have been identified in the mushroom.

\section{Recommendation}

Sheathed Woodtuft (Kuehneromyces mutabilis) resembles Funeral Bell (Galerina marginata) which is deadly poisonous. See Chapter 4.

The mushroom is therefore not regarded as suitable for commercial marketing. 
Listing 3

\section{Database search information}

SciFinder by February 2012. Keywords: Kuehneromyces, Pholiota.

\section{References}

Knudsen H \& Vesterholt J (2012): Funga Nordica. Agaricoid, boletoid, clavarioid, cyphelloid and gastroid genera. Nordsvamp: 1-1083. 


\section{Laccaria amethystina (Huds.) Cooke}

Amethyst Deceiver (DK: Violet Ametysthat, FI: Lehtolohisieni, IS: Fjólulakka, NO: Ametystsopp, SE: Ametistskivling).

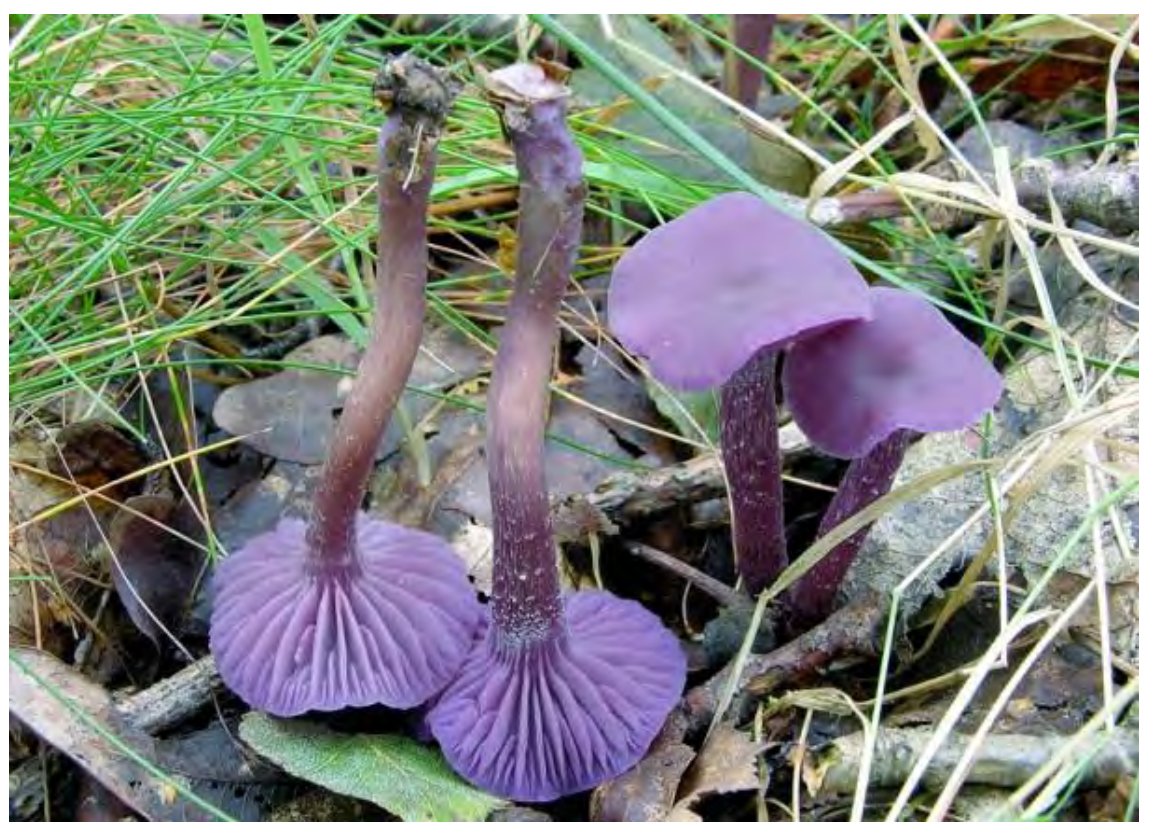

\section{Background and hazard identification}

Amethyst Deceiver (Laccaria amethystina) is generally considered edible although some more recent handbooks may warn against the intake due to the high content of arsenic, e.g. Knudsen \& Petersen (2009).

It is mycorrhizal with deciduous trees, especially Beech (Fagus) but also with coniferous trees. It is very common in Denmark and the southern parts of Norway, Sweden and Finland, and occasional in boreal areas of the same three countries (Knudsen \& Vesterholt, 2012).

There are no intoxications reported after consumption of Amethyst Deceiver, but Amethyst Deceiever (and some other Laccaria species) bioaccumulate efficiently the toxic element arsenic contrary to other edible mushrooms (Stijve \& Bourqui, 1991). Generally, the content of total arsenic is low in mushrooms used as food. The European Food Safety Authority (EFSA) has compiled data on arsenic in 710 samples of various mushroom species from EU countries (EFSA, 2009). The mean level of total arsenic among the mushrooms was in the region of $0.06-0.07 \mathrm{mg} / \mathrm{kg}$ fresh weight. The $95^{\text {th }}$ percentile contained about $0.12 \mathrm{mg}$ total arsenic per kg fresh weight. 


\section{Exposure/content of arsenic compounds}

A series of studies on totally about 80 samples of Amethyst Deceiver, collected in various European countries, show that this species contains 25-250 (mean values 60-180) mg total arsenic per kg dried mushroom (Andersen et al., 1982; Byrne \& Tušek-Žnidarič, 1983, Byrne et al., 1979, 1991, 1995; Larsen et al., 1998; Slekovec \& Irgolic, 1996; Slekovic et al., 1999; Stijve \& Bouqui, 1991; Stijve et al., 1990; Vetter, 2004). This corresponds to approximately 2.5-25 (mean values 6-18) mg per kg fresh Amethyst Deceiver. Amethyst Deceiver growing in arsenic contaminated soils may contain particularly high levels of arsenic. Thus Larsen et al. (1998) found a concentration of 1,420 mg per kg dried mushroom, corresponding to approximately $142 \mathrm{mg}$ per kg of fresh weight, in Amethyst Deceiver growing in an area formerly used for wood impregnation with mixtures containing arsenic compounds.

In most mushrooms, arsenic is present in different chemical forms, but is mainly organically bound. The dominant arsenic compound in many mushrooms is arsenobetaine (Slekovec et al., 1997; 1999), a compound of much lower toxicity than most other organic as well as inorganic arsenic compounds as it is not metabolized before excretion by humans (EFSA, 2009). However, in Amethyst Deceiver dimethylarsinic (V) acid (DMA) is the most abundant arsenic species, constituting more than 50\% of total arsenic in this mushroom (Byrne et al., 1995; Larsen et al., 1998; Slekovec et al., 1999). Other chemical forms of arsenic occurring in small amounts in Amethyst Deceiver include: methylarsonic acid, trimethylarsine oxide, arsenic acid and traces of arsenobetaine (Larsen et al., 1998; Slekovec et al., 1999).

The structural formula of DMA is shown below:<smiles>C[As](=O)O</smiles>

$\mathrm{CH}_{3}$

Dimethylarsinic acid (DMA) 


\section{Hazard characterisation}

The most abundant arsenic compound in Amethyst Deciver, DMA, is used under the name cacodylic acid in pesticides. Cacodylic acid has been investigated for its biological effects in several biochemical/toxicological studies. EFSA's panel on Contaminants in the Food Chain has recently made a risk assessment on arsenic in food (EFSA, 2009). The following text is to a large extent based on this EFSA opinion, focussing on the sections dealing with the biological properties of DMA.

Absorption of organic arsenic compounds is generally greater than 70\%. After absorption, DMA is widely distributed to almost all organs and readily crosses the placental barrier. The biotransformation of DMA is not well understood. However it is recognised that arsenic compounds are frequently excreted in urine, often in the form of DMA. Studies in rats have recently demonstrated that DMA may be reduced in vivo by a gluthathione-dependent enzymatic process to the highly toxic dimethlyarsinous acid (Németi \& Gregus, 2013). However, the mechanism of this process remains unclear. The EFSA Opinion refers to acute toxicity studies demonstrating oral $\mathrm{LD}_{50}$ values for DMA in rodents: depending on study approximately 1,200 and $1,800 \mathrm{mg} / \mathrm{kg}$ body weight (male mouse), $640 \mathrm{mg} / \mathrm{kg}$ bw (female rat) and 1,310 and $1,430 \mathrm{mg} / \mathrm{kg}$ bw (male rat). In food context, the more relevant repeated dose toxicity studies with DMA indicate organ effects on the urinary bladder, kidneys, and thyroid gland as well as on foetal development. The most sensitive effect is considered to be carcinogenicity of the bladder. No histological alterations were observed in tissues following exposure of rats and mice to high doses of dimethylarsinate $(7.8,94 \mathrm{mg} / \mathrm{kg} \mathrm{bw} /$ day $)$. DMA is transferred from the mother's circulation through the placenta and crosses the immature blood-brain barrier easily. In developmental toxicity studies with DMA using daily oral (gavage) doses of $0,4,12$ and $36 \mathrm{mg} / \mathrm{kg}$ bw/day in pregnant rat and $0,3,12$ and $48 \mathrm{mg} / \mathrm{kg}$ bw/day in pregnant rabbit during the foetal phase of organogenesis no dose-related effects occurred at exposure levels that were not toxic to the mother. However, maternal and developmental toxicity were observed in the rat at 36 $\mathrm{mg} / \mathrm{kg}$ bw/day. In the rabbits, at $48 \mathrm{mg} / \mathrm{kg} \mathrm{bw} /$ day, there was marked maternal toxicity, culminating for most females in abortion and with no surviving foetuses for evaluation. Chronic animal studies with DMA in rats and mice showed no clinical signs of neurotoxicity in rodents at chronic exposure levels of 7.8 and $94 \mathrm{mg} /$ dimethylarsinate/kg bw/day.

An interesting finding is that of Cohen et al. (2006; 2007) who demonstrated that DMA $(>50 \mathrm{mg} / \mathrm{L}$ in drinking water) was carcinogenic in rats (urinary bladder) but not in mice. The mechanism for the car- 
cinogenic effects of DMA has been extensively investigated but no firm conclusions have been drawn. Although organic arsenic compounds did not induce direct DNA damage at modest concentrations, genetic damage can be induced at high doses and indirectly via oxidative mechanisms. Tokar et al. (2012) recently showed that repeated DMA exposure in adulthood promotes tumours or lesions in the kidney and liver initiated by prenatal inorganic arsenic, but acted independently in the urinary bladder, lung and adrenal. Arsenic compounds also cause significant changes in DNA methylation and histone modification, leading to epigenetic silencing or reactivation of gene expression. Genotoxicity experiments in vitro and recent animal carcinogenicity studies provide strong support for the suggestion that DMA can act as co-carcinogen in combination with non-metal carcinogens (Yamamoto et al., 1995; Wanibuchi et al., 1996; Nishikawa et al., 2002; Tokar et al., 2012). However, the mechanism for this co-carcinogenic activity is unclear. Overall, arsenic carcinogenesis appears to require the formation of chromosomal damage, and activation of signal transduction pathways promoting survival and expansion of genetically/epigenetically altered cells.

Thus, it is not clear whether DMA is carcinogenic via a genotoxic mechanism, thereby always constituting a risk, or via other mechanisms such as epigenetic, requiring a threshold level to be reached.

Huang et al. (2012), in an epidemiological case-control study, recently investigated the correlation between the DNA damage marker 8hydroxydeoxyguanosine (8-OHdG) in urine or urinary species of arsenic, and the incidence of renal cell carcinoma. Urinary levels of 8-OHdG was significantly related to urinary total arsenic and the odds ratio for renal cell carcinoma had a dose-response relationship. Huang et al. (2012) concluded that higher urinary $8-\mathrm{OHdG}$ in arsenic exposed subjects is a strong predictor of renal cell carcinoma.

The EFSA panel on contaminants concluded - although a considerable number of studies have been performed - that there was lack of data on DMA in order to complete a risk characterisation. Furthermore, the Panel identified a need for improved understanding of the human metabolism of organoarsenicals in foods, and the human health implications (EFSA, 2009).

\section{Risk characterization}

In the absence of enough data on the mechanism for a potential carcinogenicity risk for humans exposed to DMA, it is concluded that dimethylarsinic acid (DMA) occurring in Amethyst Deceiver cannot be ex- 
cluded to be genotoxic and carcinogenic, and accordingly, this mushroom should not be traded as food.

\section{Recommendation}

Amethyst Deceiver bioaccumulates efficiently arsenic, particularly in various organic forms, including in specially high amounts dimethylarsinic acid. This compound cannot be excluded to be genotoxic and carcinogenic, and the mushroom should therefore not be traded as food.

\section{Listing 4}

\section{Database search information}

SciFinder by February 2012. Keywords: Laccaria and arsenic/and dimethylarsinic acid/and cacodylic acid/and constituents/and toxicity. Dimetylarsinic acid. PubMed 2009-2012. Keywords: Dimetylarsinic acid.

\section{References}

Andersen A, Lykke S-E, Lange M \& Bech K (1982): Sporelementer i spiselige svampe. Publikation nr. 68. Statens Levnedsmiddelinstitut: 1-27.

Byrne A R \& Tušek-Žnidarič M (1983): Arsenic accumulation in the mushroom Laccaria amethystina. Chemosphere 12: 1113-1117.

Byrne A R, Dermelj M \& Vakselj T (1979): Silver accumulation by fungi. Chemosphere 10: 815-812.

Byrne A R, Tušek-Žnidarič M, Puri B K \& Irgolic K J (1991): Studies of the uptake and binding of trace metals in fungi, part II. Arsenic compunds in Laccaria amethystina. Applied Organometallic Chemistry 5: 25-32.

Byrne A R, Šlejkovec, Z, Stijve T, Gössler W, Gailer J \& Irgolic K J (1995): Arsenobetaine and other arsenic species in mushrooms. Applied Organometallic Chemistry 9: 305-313.

Cohen SM, Arnold LL, Eldan M, Lewis AS \&Beck BD (2006): Methylated arsenicals: the implications of metabolism and carcinogenicity studies in rodents to human risk assessment. Critical Reviews in Toxicology 36: 99-133.

Cohen SM, Ohnishi T, Arnold LL \& Le XC (2007): Arsenic-induced bladder cancer in an animal model. Toxicology and Applied Pharmacology 222: 258-263.

EFSA (2009): EFSA Panel on Contaminants in the Food Chain (CONTAM) Scientific Opinion on Arsenic in Food. EFSA Journal; 7(10):1351: 1-199. www.efsa.eu

Huang CY, Su CT, Chung CJ, Pu YS, Chu JS, Yang HY, Wu CC \& Hsueh YM (2012): Urinary total arsenic and 8-hydroxydeoxyguanosine are associated with renal cell carcinoma in an area without obvious arsenic exposure. Toxicology and Applied Pharmacology 262: 349-354.

Knudsen H \& Petersen J H (2007): Politikens svampebog, Politikens forlag: 1-313. Knudsen H \& Vesterholt J (2012): Funga Nordica. Agaricoid, boletoid, clavarioid, cyphelloid and gastroid genera. Nordsvamp: 1-1083. 
Larsen EH, Hansen M \& Gössler W (1998): Speciation and health risk considerations of arsenic in the edible mushroom Laccaria amethystina collected from contaminated and uncontaminated locations. Applied Organometallic Chemistry 12: 285-291.

Németi B \& Gregus Z (2013): Reduction of dimethylarsinic acid to the highly toxic dimethylarsinous acid by rats and rat liver cytosol. Chemical Research in Toxicology 26: 432-443.

Nishikawa T, Wanibuchi H, Ogawa M, Kinoshita A, Morimura K, Hiroi T, Funae Y, Kishida H, Nakae D \& Fukushima S (2002): Promoting effects of monomethylarsonic acid, dimethylarsinic acid and trimethylarsine oxide on induction of rat liver preneoplastic glutathione S-tranferase placental form positive foci: a possible reactive oxygen species mechanism. International Journal of Cancer 100: 136-139.

Šlekovec, M \& Irgolic, K J (1996): Uptake of arsenic by mushrooms from soil. Chemical Speciation and Bioavailability 8: 67-73.

Šlekovec M, Goessler W \& Irgolic K J (1999): Inorganic and organic arsenic compounds in Slovenian mushrooms: comparison of arsenic specific detectors for liquid chromatography. Chemical Speciation and Bioavailability 11: 115-123.

Šlekovec Z, Byrne A R, Stijve T, Goessler W \& Irgolic K J (1997): Arsenic compounds in higher fungi. Applied Organometallic Chemistry 11: 673-682.

Stijve T, Vellinga EC \& Hermann A (1990): Arsenic accumulation in some higher fungi. Persoonia 14: 161-166.

Stijve T \& Bourqui B (1991): Arsenic in edible mushrooms. Deutsche LebensmittelRundschau 87: 307-310.

Tokar EJ, Diwan BA \& Waalkes MP (2012): Renal, hepatic, pulmonary and adrenal tumors induced by prenatal inorganic arsenic followed by dimethylarsinic acid in adulthood in CD1 mice. Toxicology Letters 209: 179-185.

Vetter J (2004): Arsenic content of some edible mushroom species. European Food Research and Technology 219: 71-74.

Wanibuchi H, Yamamoto S, Chen H, Yoshida K, Endo G, Hori T \& Fukushima (1996): Promoting effects of dimethylarsinic acid on N-butyl-N-(4-

hydroybutyl)nitrosamine-induced urinary bladder carcinogenesis in rats. Carcinogenesis 17: 2435-2439.

Yamamoto S, Konishi Y, Matsuda T, Murai T, Shibata MA, Matsuiyuasa I, Otani S, Kuroda K, Endo G \& Fukushima S (1995): Cancer induction by an organic arsenic compound, dimethylarsinic acid (Cacodylic acid), in F344/DUCRJ rats after pretreatment with 5 carcinogens. Cancer Research 55: 43-50. 


\section{Lactarius Pers}

Milkcap (DK: Mælkehat; FI: Rousku; IS: Lekta NO: Riske; SE: Riska).

The genus Milkcap (Lactarius) comprises 92 species in the Nordic countries. The genus forms mycorrhiza with trees and shrubs in nearly all types of forests, in dunes and alpine habitats. The Milkcap (Lactarius) and the Brittlegill (Russula) genera are related and belong to the same family, Russulaceae. The fruit bodies are characterised by crumbling texture but contrary to the Brittlegill species, the Milkcap species exude a milky juice (latex) after injury (Knudsen \& Vesterholt, 2012). Furthermore, a major group of colouring matters, the nitrogen-containing russupteridines in the Brittlegill genus, are not found in the Milkcap genus.

Orange milked species, e.g. Saffron Milkcap (L. deliciosus) and False Saffron Milkcap ( $L$. deterrimus) and the white milked Fishy Milkcap ( $L$. volemus) are considered as edible and good. In Finland, also L. trivialis, Rufous Milkcap (L. rufus), Woolly Milkcap (L. torminosus) and other pungent/acrid tasting Milkcap species are consumed after pretreatment, especially salting.

The pungent/acrid taste, e.g. of Rufous Milkcap and Woolly Milkcap arises from a few fatty acid esters of the sesquiterpene, velutinal, occurring as an emulsion in specialized hyphae of the fruit body. By physical injury of the fruit body by parasites, insects or mammals these tasteless esters are within seconds or minutes converted to pungent, unsaturated sesquiterpene dialdehydes such as velleral, isovelleral and others (Camazine \& Lupo, 1984; Daniewski \& Vidari, 1999; Favre-Bonvin et al., 1982; Sterner et al., 1983). The pungent dialdehydes have experimentally been shown to produce their irritant effects by interacting with vanilloid receptors on capsaicin-sensitive sensory neurons (Szallasi et al., 1996; 1998). During time, especially after further injury of the fruit body, e.g. pre-treatment before cooking, the pungent sesquiterpenes are further converted by a cascade of enzymatic and chemical reactions, thereby producing a very large number of non-pungent sesquiterpenes, e.g., a series of furanoid sesquiterpenes of which some are artefacts and some like the dihydroxyfuran shown below are true natural metabolites (Sterner et al., 1988). Each Milkcap species produces a characteristic pattern of such compounds. These reactions may change the colour and taste of the milky juice (Ayer \& Browne, 1981; Clericuzio et al., 2008; Sterner \& Anke, 1995; Sterner et al., 1988). Insufficiently pre-treated and/or cooked, pungent Milkcap species, e.g. Rufous Milkcap, have given rise to mild gastrointestinal intoxications (Barceloux, 2008; Benjamin, 1995; Bresinsky \& Besl, 1985; Flammer \& Horak, 2003; Roth et al., 1990). 
The structural formulae of the precursor ester stearoylvelutinal, two of the pungent dialdehydes, velleral and isovelleral and one non-pungent metabolite, a dihydroxyfuran sesquiterpene, are shown below.

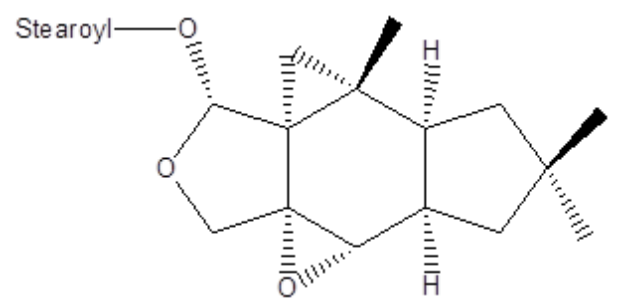

Stearoylvelutinal

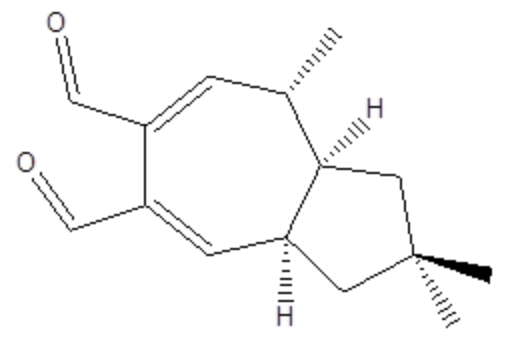

Velleral

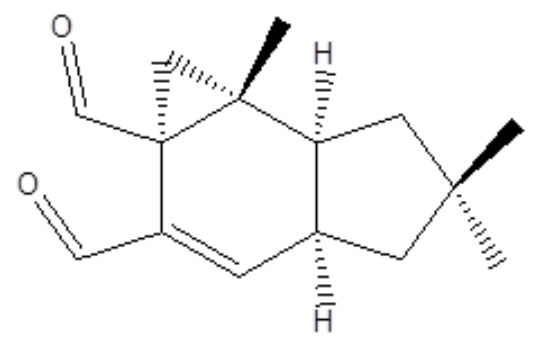

Isovelleral

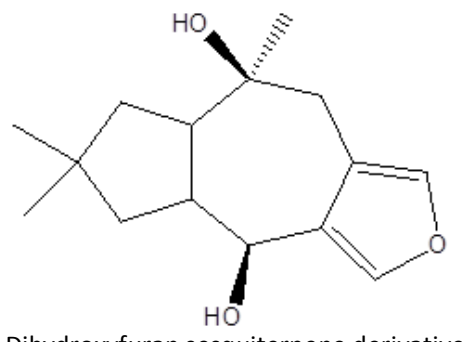

Dihydroxyfuran sesquiterpene derivative 
Many of these sesquiterpene metabolites are biologically active in experimental studies, where they have shown irritant, antifeedant, cytotoxic, antifungal, insecticidal and mutagenic activities (Clericuzio et al., 2008; Daniewski \& Vidari, 1999; Daneiwski et al., 1995; Jonassohn et al., 1997; Szallasi et al., 1996). Especially, the antifeedant properties have been demonstrated, and it is believed that the sesquiterpene metabolites constitute a sort of defence system for the Milkcap (Anke \& Sterner, 1991; Anke et al., 1989; Camazine \& Lupo, 1984; Camazine et al., 1983; Daniewski et al., 1995; Sterner et al., 1985a, b; Vidari \& Vita-Finzi, 1995).

\section{Database search information}

SciFinder by September 2011. Keywords: Lactarius. PubMed: 2011August 2012. Keywords: Lactarius.

\section{References}

Anke H \& Sterner O (1991): Comparison of the antimicrobial and cytotoxic activities of twenty unsaturated sesquiterpene dialdehydes from plants and mushrooms. Planta Medica 57: 344-346.

Anke H, Bergendorff O \& Sterner O (1989): Assays of the biological activities of guaiane sesquiterpenoids isolated from the fruit bodies of edible Lactarius species. Food and Chemical Toxicology 6: 393-397.

Ayer WA \& Browne LM (1981): Terpenoid metabolites of mushrooms and related basiodiomycetes. Tetrahedron Report no 110. Tetrahedron 37: 2199-2248.

Barceloux DG (2008): Medical Toxicology of Natural Substances: Foods, Fungi, Medicinal Herbs, Plants, and Venomous Animals. John Wiley \& Sons, Inc.: 1-1200.

Benjamin D (1995): Mushrooms: Poisons and panaceas. WH Freeman and company: 1-422.

Bresinsky A \& Besl H (1985): Giftpilze. Wissenschaftliche Verlagsgesellschaft mbH: 1-295.

Camazine S \& Lupo AT (1984): Labile toxic compounds of the Lactarii: The role of the lacticiferous hyphae as a storage depot for the precursors of pungent dialdehydes. Mycologia 76: 355-358.

Camazine SM, Resch JF, Eisner T \& Meinwald J (1983): Mushroom chemical defense: Pungent sesquiterpenoid dialdehyde antifeedant to opossum. Journal of Chemical Ecology 9: 1439-1447.

Clericuzio M, Gillardoni G, Malagòn 0, Vidari G \& Finzi PV (2008): Sesquiterpenes of Lactarius and Russula (Mushrooms): An update. Natural Product Communcations 3: 951-974.

Daniewski WM \& Vidari G (1999): Consituents of Lactarius (Mushroom). Progress in the Chemistry of Organic Natural Compounds 77: 69-171.

Daniewski MW, Gumulka M, Prezesmycka D, Ptaszynska K, Bloszyk E \& Drozdz B (1995): Sesquiterpenes of Lactarius origin, antifeedant structure-activity relationships. Phytochemistry 38: 1161-1168.

Favre-Bonvin J, Gluchoff-Fiasson K \& Bernillon J (1982): Structure du stearylvelutinal, sesquiterpenoide naturel de Lactarius velutinus Bert. Tetrahedron Letters 23: 1907-1908.

Flammer R \& Horak E (2003): Giftpilze - Pilzgifte. Schwabe. Basel: 1-204. 
Jonassohn M, Hjertberg R, Anke H, Dekermendjian K, Szallasi A, Thines E, Witt R \& Sterner $O$ (1997): The preparation and bioactivities of (-)-isovelleral. Bioorganic \& Medicinal Chemistry 5: 1363-1367.

Knudsen H \& Vesterholt J (2012): Funga Nordica. Agaricoid, boletoid, clavarioid, cyphelloid and gastroid genera. Nordsvamp: 1-1083.

Roth L, Frank H \& Kormann K (1990): Giftpilze-Pilzgifte, Schimmelpilze-Mykotoxine: Ecomed Verlagsgesellschaft: 1-327.

Sterner O \& Anke H (1995): Toxic terpenoids isolated from higher fungi. Czech Mycology Journal 48: 39-52.

Sterner O, Bergman R, Kesler E, Nilsson L, Oluwadiya J \& Wockberg B (1983): Velutinal esters of Lactarius vellereus and L. necator. The preparation of free velutinal. Tetrahedronal Letters 24: 1415-1418.

Sterner O, Bergman R, Kihlberg J \& Wickberg B (1985a): The sesquiterpenes of Lactarius vellereus and their role in a proposed chemical defense system. Journal of Natural Products 48: 279-288.

Sterner O, Bergman R, Franzén C \& Wickberg B (1985b): New sesquiterpenes in a proposed Russulaceae chemical defense system. Tetrahedron Letters 26: 3163-3166

Sterner O, Wik O \& Carter RE (1988): The structure of a novel fungal sesquiterpene. Acta Chemica Scandinavica B42: 43-47.

Szallasi A, Jonassohn M, Ács G, Bíró T, Ács P, Blumberg PM \& Sterner O (1996): The stimulation of capsaicin-sensitive neurons in a vanilloid receptor-mediated fashion by pungent terpenoids possessing an unsaturated 1,4-dialdehyde moiety. British Journal of Pharmacology 119: 283-290.

Szallasi A, Bíró T, Modarres S, Garlaschelli L, Petersen M, Klusch A, Vidari G, Jonassohn M, de Rosa S, Sterner O, Blumberg PM \& Krause JE (1998): Dialdehyde sesquiterpenes and other terpenoids as vanilloids. European Journal of Pharmacology 356: 81-89.

Vidari C \& Vita-Finzi P (1995): Sesquterpenes and other secondary metabolites of genus Lactarius (Basidiomycetes): Chemistry and biological activity. Studies in Natural Products Chemistry Part D 17: 153-206. 


\section{Lactarius deliciosus (L.) Gray}

Saffron Milkcap (DK: Velsmagende Mælkehat, FI: Männynleppärousku, IS: Matglætingur Ljúflekta, NO: Furumatriske, SE: Läcker riska (Läckerriska, Tallblodriska)).

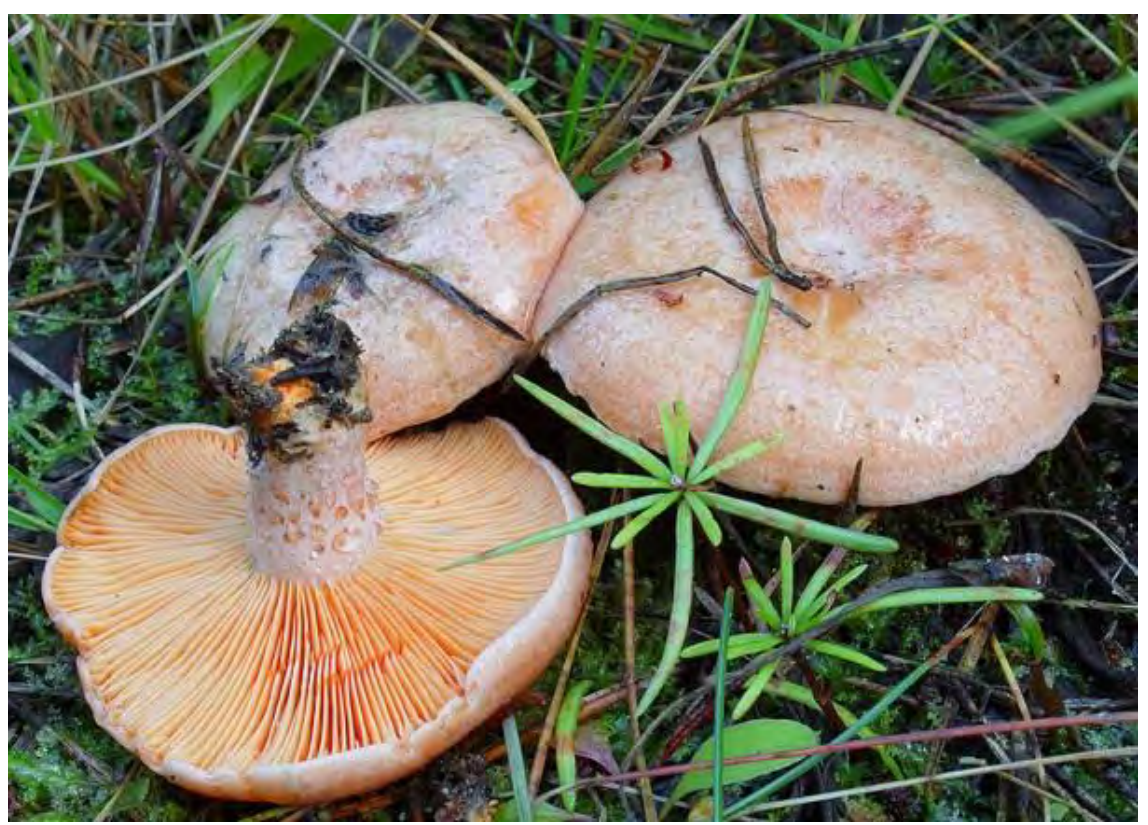

\section{Background and risk assessment}

Saffron Milkcap (Lactarius deliciosus) is an appreciated, edible mushroom.

It forms mycorrhiza with Pine (Pinus). It is common in the temperate and hemiboreal zones and occasional in boreal-subalpine/subarctic zones in the Nordic countries (Knudsen \& Vesterholt, 2012).

There are no intoxications reported after consumption of Saffron Milkcap. However, some constituents with potentially bioactive activity have been reported.

\section{Bioactive constituents}

Sesquiterpenes: Contrary to most species of Milkcap (Lactarius) no velutinal esters have been detected in Saffron Milkcap. The only sesquiterpenes detected in the intact mushroom are two different orange-yellow guaiane esters having the same azulene alcohol moiety (Bergendorff \& Sterner, 1988; Clericuzio et al., 2008; Daniewski \& Vidari, 1999). By injury or during ageing, these esters are hydrolysed, forming a series of blue, violet and red sesquiterpenes having an azulene structure (Clericuzio et 
al., 2008; Daniewski \& Vidari, 1999; Liu, 2007). The biological activity of one of the guaiane esters and the mushroom metabolites deterrol (an alcohol) and its corresponding aldehyde lactaroviolin has been studied. The three sesquiterpenes are weakly mutagenic in the Ames test, deterrol and lactaroviolin are moderately cytotoxic, and lactaroviolin also exhibits weakly antibacterial activity in in vitro studies (Anke et al., 1989). The green colour formed after physical injury or with ageing emerges from a mixture of the orange-yellow coloured precursors and the violet-blue metabolites lactaroviolin and deterrol (Sterner \& Anke, 1995). The redbrown discolouration of urine, which can be seen after consumption of Saffron Milkcap (and the related False Saffron Milkcap (L. deterrimus)) are caused by metabolites of the azulene pigments and are considered to be of no safety concern (Bresinsky \& Besl, 1985; Kunzfeld, 1953).

The structural formulae of the two guaiane metabolites, lactaroviolin and deterrol are shown below.

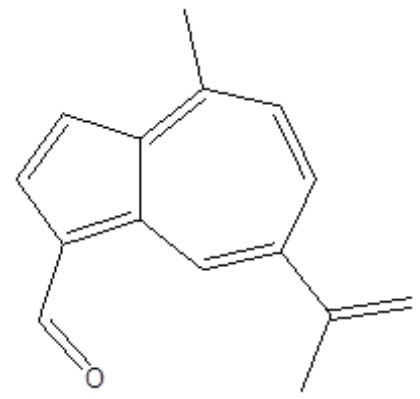

Lactaroviolin

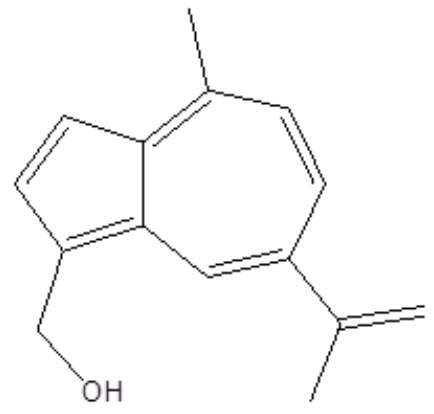

Deterrol 
Indole compounds: Muszynska et al. $(2011 ; 2012)$ isolated the indole compounds 5-hydroxytryptophan, serotonin and melatonin, as well as the tryptophan metabolite kynurenine sulfate from fruit bodies of Saffron Milkcap. It was shown that boiling of Saffron Milkcap significantly changed the content of these indoles. 5-Hydroxytryptophan and serotonin were completely destroyed, and tryptophan, 5-methyltryptophan and tryptamine had been formed in amounts of 88,38 and $32 \mathrm{mg} / \mathrm{kg}$ (dry weight) corresponding to approximately 9,4 and $3 \mathrm{mg} / \mathrm{kg}$ of fresh mushroom, respectively. Some of these compounds may act as tissue hormones and neurotransmitters, which in higher amounts may damage the nervous systems (Stone et al., 2003).

Mutagens: Sterner et al. (1982) tested an extract of Saffron Milkcap in the Ames test using the Salmonella typhimurium strains TA98, TA100 and TA2637. The extract was positive in all three strains. The activity was not enhanced in the presence of microsomal enzymes. Unfortunately, Sterner et al. (1982) give no information, whether they had controlled for the potential presence of histidine in the extract. It is well known that false positives may be obtained in the presence of histidine. Also Morales et al. (1990a, 1990b) studied mushroom extracts in the Ames test. Extracts of freshly harvested and frozen Saffron Milkcap mushrooms were reported to be weakly mutagenic in the Salmonella strains TA98 and TA100 (for the fresh mushroom less than doubling in mutation frequency). Extracts of canned Saffron Milkcap were negative both in the Ames test and in the Chinese Hamster Ovary (CHO/HPRT) cell mutation assay. Apparently, Morales et al. (1990a, 1990b) did not control for possible histidine in the extracts for the Ames test. Thus, there is no strong indication that extracts of the Saffron Milkcap are mutagenic. However, one of the constituents, a sesquiterpene stearate and two metabolites of this ester, are weakly mutagenic in the Ames test (see above).

Lectins: One dimeric lectin with a molecular weight of about $37 \mathrm{kDa}$ (subunits with molecular weights of about 19 and $18 \mathrm{kDa}$ ) has been isolated from Saffron Milkcap and characterised (Guillot et al., 1991). Some lectins, especially those that are thermostabile, may give rise to gastrointestinal discomfort (Liener, 1983), but the lectin in Saffron Milkcap has not been studied for biological activity or thermostability.

\section{Recommendation}

No special recommendation.

Listing 2 


\section{Database search information}

SciFinder by September 2011. Keywords: Lactarius. PubMed: 2011August 2012. Keywords: Lactarius deliciosus.

\section{References}

Anke H, Bergendorff O \& Sterner O (1989): Assays of the biological activities of guaiane sesquiterpenoids isolated from the fruit bodies of edible Lactarius species. Food and Chemical Toxicology 6: 393-397.

Bergendorff 0 \& Sterner O (1988): The sesquiterpenes of Lactarius deliciosus and Lactarius deterrimus. Phytochemistry 27: 97-100.

Bresinsky A \& Besl H (1985): Giftpilze. Wissenschaftliche Verlagsgesellschaft mbH: 1-295.

Clericuzio M, Gillardoni G, Malagòn O, Vidari G \& Finzi PV (2008): Sesquiterpenes of Lactarius and Russula (mushrooms): An update. Natural Product Communcations 3: 951-974.

Daniewski WM \& Vidari G (1999): Consituents of Lactarius (Mushroom). Progress in the Chemistry of Organic Natural Compounds 77: 69-171.

Guillot J, Giollant M, Damez M \& Dusser M (1991): Isolation and characterization of a lectin from the mushroom Lactarius deliciosus. Journal of Biochemistry 109: 840-845.

Knudsen H \& Vesterholt J (2012): Funga Nordica. Agaricoid, boletoid, clavarioid, cyphelloid and gastroid genera. Nordsvamp: 1-1083.

Kunzfeld M (1953): Temporary report on urine discoloration and antibiotic effect after eating Lactarius deliciosus. Münchener Medicinische Wochenschrift 20: 235-236.

Liener IE (1983): Naturally occurring toxicants in food and their significance in the human diet. Archives of Toxicology Supplements 6: 153-166.

Liu J-K (2007): Secondary metabolites from higher fungi in China and their biological activity. Drug Discovery Therapeutic Journal 2: 94-105.

Morales P, Bermudez E, Sanz B \& Hernandez PE (1990a): A study of the mutagenicity of some commercially canned Spanish mushrooms. Food and Chemical Toxicology 28: 607-611.

Morales P, Bermudez E, Hernandez PE \& Sanz B (1990b): The mutagenicity of some Spanish edible mushrooms in the Ames test. Food Chemistry 38: 279-288.

Muszynska B, Sulkowska-Ziaja K \& Ekiert H (2011): Indole compounds in fruiting bodies of some edible Basidiomycota species. Food Chemistry 125: 1306-1308.

Muszyńska B \& Sułkowska-Ziaja K (2012): Analysis of indole compounds in edible Basidiomycota species after thermal processing. Food Chemistry 132: 455-459.

Sterner 0 \& Anke H (1995): Toxic terpenoids isolated from higher fungi. Czech Mycology Journal 48: 39-52.

Sterner O, Bergman R, Kesler E, Magnusson L, Nilsson B, Wickberg B, Zimerson E \& Zetterberg G (1982): Mutagens in larger fungi I. Forty-eight species screened for mutagenic activity in the Salmonella/microsome assay. Mutation Research 101: 269-281.

Stone TW, Mackay GM, Forrest CM, Clark CJ \& Darlington LG (2003): Tryptophan metabolites and brain disorders. Clinical Chemistry and Laboratory Medicine 41: 852-859. 


\section{Lactarius deterrimus Gröger}

False Saffron Milkcap (DK: Gran-Mælkehat, FI: Kuusenleppärousku, IS: Matlekta, NO: Granmatriske, SE: Blodriska (Granblodriska)).

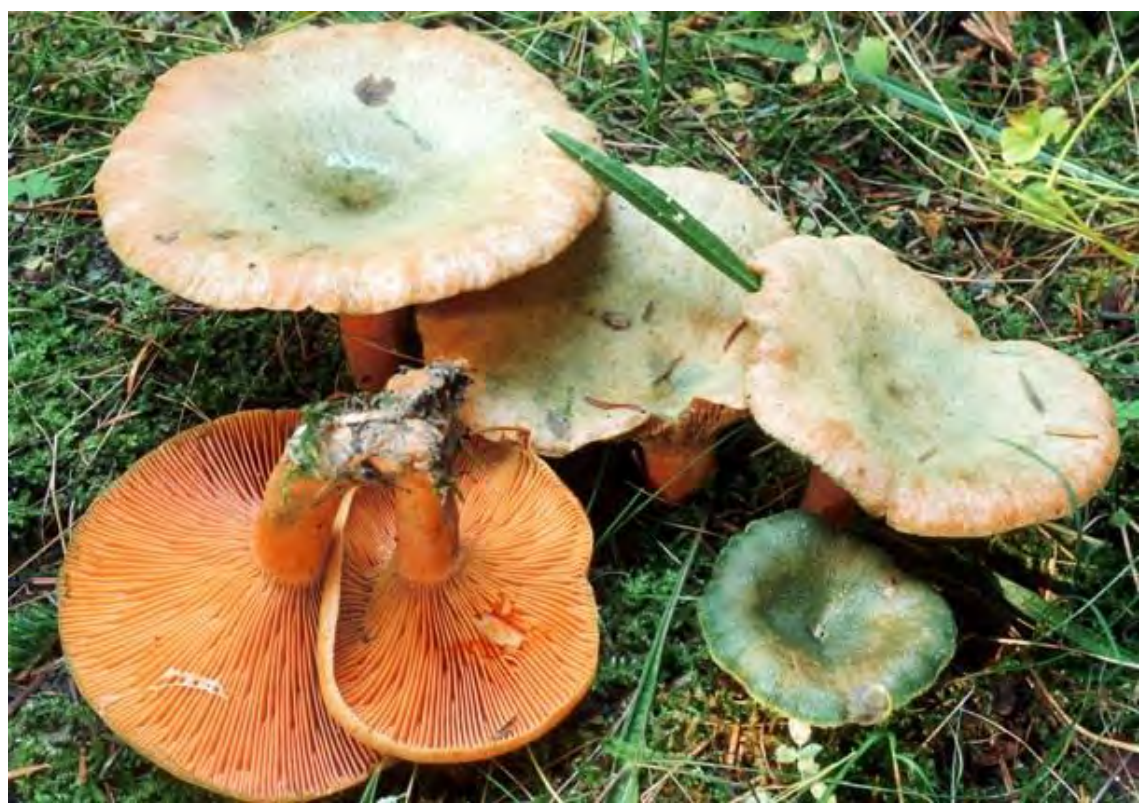

\section{Background and risk assessment}

False Saffron Milkcap (Lactarius deterrimus) is an appreciated, edible mushroom.

It forms mycorrhiza with Spruce (Picea), often with young stands. It is very common in temperate-boreal zones and rare, but locally occasional, in subalpine/subarctic zones in the Nordic countries (Knudsen \& Vesterholt, 2012).

There are no intoxications reported after consumption of False Saffron Milkcap. However, some potentially bioactive constituents have been reported.

\section{Bioactive constituents}

Sesquiterpenes: Contrary to most species of Milkcap (Lactarius) no velutinal esters have been detected in False Saffron Milkcap. The only sesquiterpenes detected in the intact mushroom are two orange-yellow guaiane esters having the same azulene alcohol moity (Bergendorff \& Sterner, 1988; Clericuzio et al., 2008; Daniewski \& Vidari, 1999). By injury or during ageing, these esters are hydrolysed, forming a series of blue, violet and red sesquiterpenes with azulene structure (Clericuzio et al., 
2008; Daniewski \& Vidari, 1999; Liu, 2007). The biological activity of the guaiane stearate esters and the mushroom metabolites deterrol (an alcohol) and its corresponding aldehyde lactaroviolin, has been studied. The three sesquiterpenes are weakly mutagenic in the Ames test, deterrol and lactaroviolin are moderately cytotoxic, and lactaroviolin also exhibits weak antibacterial activity in in vitro studies (Anke et al., 1989). The green colour formed after physical injury of the mushroom or with ageing emerges from a mixture of the orange-yellow coloured precursors and the violet-blue metabolites lactaroviolin and deterrol (Sterner \& Anke, 1995). The redbrown discolouration of urine, which can be seen after consumption of False Saffron Milkcap (and the related Saffron Milkcap (L. deliciosus)) is caused by metabolites of the azulene pigments and are considered to be of no safety concern (Bresinsky \& Besl, 1985; Kunzfeld, 1953).

The structural formulae of the metabolites lactaroviolin and deterrol are shown below.

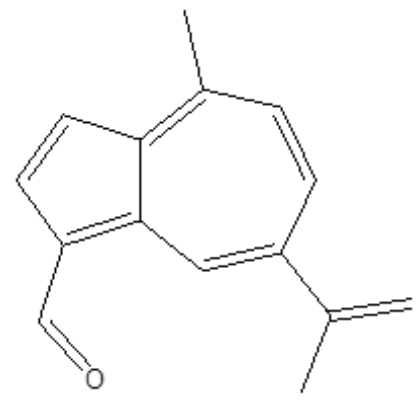

Lactaroviolin

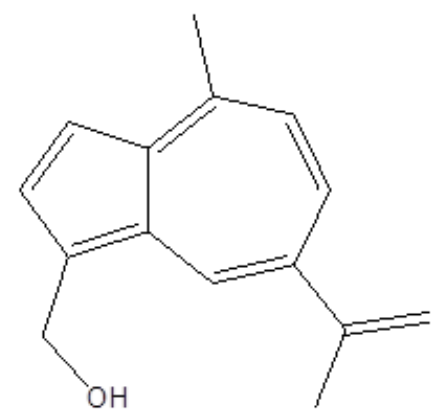

Deterrol 
Mutagens: Sterner et al. (1982) tested an extract of False Saffron Milkcap in the Ames test using the Salmonella typhimurium strains TA98, TA100 and TA2637. The extract was found positive in all three strains. The activity was not enhanced in presence of microsomal enzymes. Unfortunately, Sterner et al. (1982) give no information, whether they had controlled for the potential presence of histidine in the extract. It is well known that false positives may be obtained in the presence of histidine. In the same study, the pungent sesquiterpene velleral was negative, whereas the pungent isovelleral was positive in two of the Salmonella strains (TA100 and TA2637). However, extracts of False Saffron Milkcap were also weakly positive in a histidine-independent bacterial strain. More information is needed to interpret e.g. whether the mutagen is destroyed during the processing of the mushroom for consumption (Grüter et al., 1991).

Indole compounds: Muszynska et al. (2007) isolated a series of simple biologically active indole compounds including tryphophan, tryptamine and melatonine. Some of these constituents are tissue hormones and neurotransmitters and high intakes of tryptophan can damage the nervous system (Stone et al., 2003).

Lectins: One dimeric lectin with a molecular weight of about $31 \mathrm{kDa}$ with two identical subunits has been isolated from False Saffron Milkcap and characterised (Giollant et al., 1993). Some lectins, especially thermostabile ones may give rise to gastrointestinal discomfort (Liener, 1983), but the lectin in the False Saffron Milkcap has not been studied for biological activity or thermostability.

\section{Recommendation}

No special recommendation.

\section{Listing 2}

\section{Database search information}

SciFinder by September 2011. Keywords: Lactarius. PubMed: 2011August 2012. Keywords: Lactarius deterrimus. 


\section{References}

Anke H, Bergendorff O \& Sterner O (1989): Assays of the biological activities of guaiane sesquiterpenoids isolated from the fruit bodies of edible Lactarius species. Food and Chemical Toxicology 6: 393-697.

Bergendorff O \& Sterner O (1988): The sesquiterpenes of Lactarius deliciosus and Lactarius deterrimus. Phytochemistry 27: 97-100.

Bresinsky A \& Besl H (1985): Giftpilze. Wissenschaftliche Verlagsgesellschaft mbH: 1-295.

Clericuzio M, Gillardoni G, Malagòn O, Vidari G \& Finzi PV (2008): Sesquiterpenes of Lactarius and Russula (Mushrooms: An update). Natural Product Communcations 3: 951-974.

Daniewski WM \& Vidari G (1999): Consituents of Lactarius (Mushroom). Progress in the Chemistry of Organic Natural Compounds 77: 69-171.

Giollant M, Guillot J, Damez M, Dusser M, Didier P \& Didier E (1993): Characterization of a lectin from Lactarius deterrimus. Plant Physiology 101: 513-522.

Grüter A, Friederich U \& Würgler FE (1991): The mutagenicity of edible mushrooms in a histidine-independent bacteral test system. Food Chemical Toxicology 29: 159-165.

Knudsen H \& Vesterholt J (2012): Funga Nordica. Agaricoid, boletoid, clavarioid, cyphelloid and gastroid genera. Nordsvamp: 1-1083.

Kunzfeld M (1953): Temporary report on urine discoloration and antibiotic effect after eating Lactarius deliciosus. Münchener Medizinische Wochenschrift 20: 235-236.

Liener IE (1983): Naturally occurring toxicants in food and their significance in the human diet. Archives of Toxicology Supplements 6: 153-166.

Liu J-K (2007): Secondary metabolites from higher fungi in China and their biological activity. Drug Discovery Therapeutic Journal 2: 94-105.

Muszynska B, Maslanka A, Sulkowska-Ziaja K \& Krzek J (2007): TLC-UV analysis of indole compounds and other nitrogen-containing bases in the fruiting bodies of Lactarius deterrimus. Journal of Planar Chromatography 20: 57-60.

Sterner O \& Anke H (1995): Toxic terpenoids isolated from higher fungi. Czech Mycology Journal 48: 39-52.

Sterner O, Bergman R, Kesler E, Magnusson L, Nilsson B, Wickberg B, Zimerson E \& Zetterberg G (1982): Mutagens in larger fungi I. Forty-eight species screened for mutagenic activity in the Salmonella/microsome assay. Mutation Research 101: 269-281.

Stone TW, Mackay GM, Forrest CM, Clark CJ, Darlington LG (2003): Tryptophan metabolites and brain disorders. Clinical Chemistry and Laboratory Medicine 41: 852-859. 


\section{Lactarius necator (Bull.) Pers.}

\section{(L. plumbeus s. auct., L. turpis (Weinm.) Fr.)}

Ugly Milkcap (DK: Olivenbrun Mælkehat, Manddraber-Mælkehat, FI: Mustarousku, IS: Grænlekta, NO: Svartriske, SE: Svartriska).

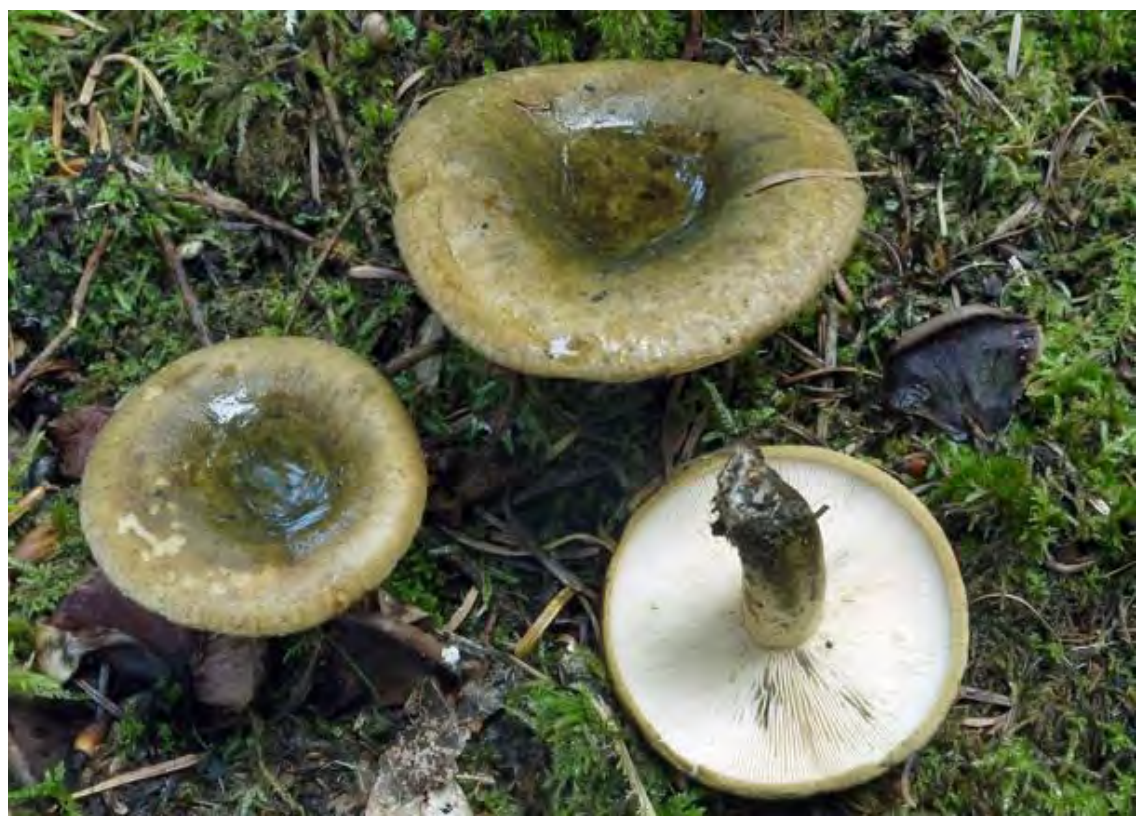

\section{Background and risk assessment}

Ugly Milkcap (Lactarius necator) ${ }^{17}$ is no longer considered as an edible mushroom.

It grows mycorrhizal with Spruce (Picea) and Birch (Betula). It is very common in temperate-hemiboreal zones in the Nordic countries, except in Iceland, where it is very rare (Knudsen \& Vesterholt, 2012).

It has given rise to several cases of gastroenteritis, probably due to insufficient pre-treatment, e.g. salting and/or parboiling (Barceloux, 2008; Benjamin, 1995; Bresinsky \& Besl, 1985; Roth et al., 1990).

Ugly Milkcap contains several bioactive constituents:

17 Index Fungorum/Species Fungorum (2012) uses L. turpis as current name, but Knudsen \& Vesterholt (2012), ArtDatabanken (2011) and Danish Mycological Society (2012) use L. necator as preferred name. 


\section{Bioactive constituents}

Sesquiterpenes: Ugly Milkcap contains stearoylvelutinal and 6-ketostearoylvelutinal which both by physical injury of the fruit body are degraded/metabolised to pungent unsaturated dialdehyde sesquiterpenes such as velleral and epi-piperdial as well as to non-pungent sesquiterpenes (Sterner, 1989; Sterner \& Anke, 1995; Daniewski \& Vidari, 1999). Contrary to other Lactarius species, where the velutinal esters are completely converted within few minutes after injury, the main part of the esters in the Ugly Milkcap remains unchanged even several hours after injury (Sterner, 1989).

The structural formulae of the two velutinal esters and the two pungent dialdehydes velleral and epi-piperdial are shown below.

Stearoylvelutinal
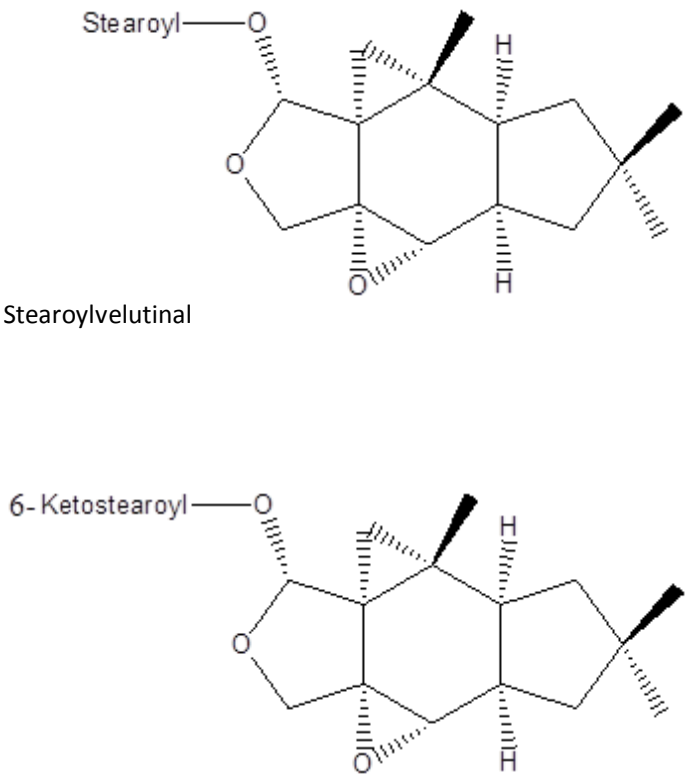

6-Ketostearoyl velutinal

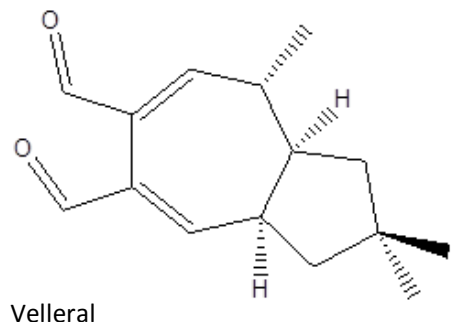

Vellera 


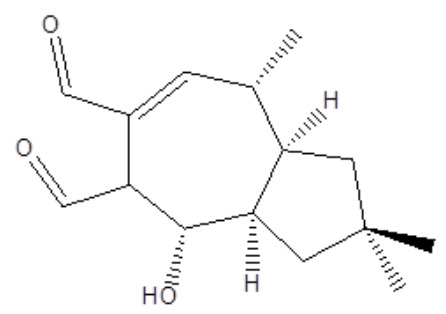

epi-Piperdial

Beyond the pungent sesquiterpenes, formed by injury, the fruit bodies of Ugly Milkcap contain a highly mutagenic alkaloidal pigment:

Mutagens: In 1982 Knuutinen and von Wright reported that an extract of Ugly Milkcap showed mutagenic activity in the Ames test, using the histidine requiring strains TA98 and TA100 of Salmonella typhimurium to detect the mutations. The investigators analysed for histidine in the mushroom extract and concluded that the levels of histidine did not influence the revertant frequencies in the assay (Knuutinen \& von Wright, 1982). Subsequently von Wright et al. (1982) confirmed the finding with an extended set of Salmonella strains TA1535, TA1537 and TA1538. The extract was positive regarding induction of mutations in Salmonella strains TA98, TA100, TA1535 and TA1537, but not in TA1538. Supplying the Salmonella assay with a metabolizing system from rat livers did not increase the mutation frequency. In this study, extracts of several Lactarius and other mushroom species, were tested in the Ames assay. The Ugly Milkcap extract was by far the most mutagenic mushroom extract in the study (Knuutinen \& von Wright, 1982; von Wright et al., 1982). There was no indication that the investigators had controlled for the presence of histidine in the mushroom extracts in this second study.

Also Sterner et al. (1982a) have tested extracts of the Ugly Milkcap in the Ames test using Salmonella strains TA98, TA100 and TA2637 as indicators of mutagenic activity. The extract was positive in the TA100 and TA2637 strains. The same investigators also compared the mutagenic activity of extracts of a Finnish pickled commercial Ugly Milkcap product with that of an extract of fresh Ugly Milkcap (Sterner et al., 1982b) in Salmonella typhimurium strains TA98, TA2637 and TA100. The comparison was done without including a metabolic activation system in the assay and there was no indication that the potential presence of histidine in the extract had been controlled for. Both extracts showed mutagenic activity, particularly in Salmonella strain TA2637. The high muta- 
genic activity of extracts of Ugly Milkcap was confirmed by Grüter et al. (1991) using a histidine-independent bacterial test system.

Alkaloidal pigments: Suortti and colleagues reported in 1983-1984 about the isolation, characterization and quantification of a highly mutagenic principle in Ugly Milkcap (Suortti, 1984a; 1984b; Suortti \& von Wright, 1983; Suortti et al., 1983; von Wright \& Suortti, 1983a, 1983b). The mutagen was isolated as bright red crystals with a molecular weight of 264 and was tentatively identified as the alkaloid 7-hydroxycoumaro[5,6-c]cinnoline, which was given the trivial name necatorin. Necatorin was shown to occur in amounts of 3-20 mg per $\mathrm{kg}$ fresh mushroom. Pure necatorin was shown to be highly mutagenic in the Ames test in all three of the Salmonella strains TA98, TA100 and TA1537. Addition of a metabolizing system (S9 fraction) reduced the mutagenic activity (von Wright \& Suortti, 1983a, b). The strong mutagenic activity of necatorin in the Ames test has later been confirmed (Hilger et al., 1985). However, necatorin was negative in the host-mediated assay and in the micronucleus test (von Wright \& Suortti, 1983a, b).

Boiling/blanching destroys about half of the necatorin in the mushroom leaving about $25 \%$ of the original content in the mushroom and about $25 \%$ in the water (Suoritti, 1984a, 1984b).

Subsequently, Fugmann et al. (1984) studied the pigments in Ugly Milkcap and isolated a pigment with the same molecular weight as the pigment, necatorin, isolated and tentatively identified as 7hydroxycoumaro[5,6-c]cinnoline by Suoritti et al. (1983). Fugmann et al. (1984) allocated the structure 5,10-dihydroxy-dibenzo[de,h][1,6] naphthyridin-6-one to the alkaloidal pigment and named it necatorone. The structure of necatorone was confirmed by total synthesis (Hilger et al., 1985). Direct comparison of necatorin, provided by Suortti, with necatorone by chromatographic and spectroscopic methods established that the two compounds were identical (Hilger et al., 1985).

Later, two other alkaloidal pigments, 4,4'-binecatorone and 10deoxy-4,4'-binecatorone, were isolated from Ugly Milkcap. There are no biological data available on these two alkaloids (Klamann et al., 1989).

The structure of necatorone (necatorin) and the two binecatorones are shown below. 


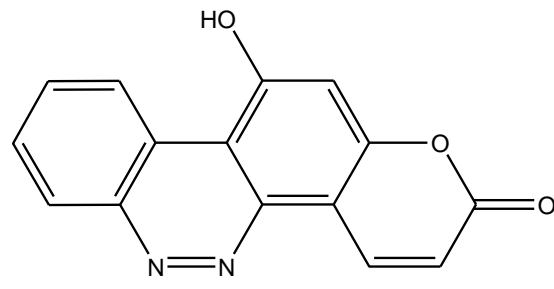

Necatorin<smiles></smiles>

4,4'-Binecatorone<smiles></smiles>

Necatorone<smiles></smiles>

10-Deoxy-4,4'-binecatorone

Overall, it is concluded, that Ugly Milkcap contains an alkaloidal pigment, necatorone (necatorin), which is highly mutagenic in the Ames test, and that pickling or boiling/blanching the mushroom only partly reduces its mutagenicity.

\section{Recommendation}

Ugly Milkcap contains the heat-stable necatorone (necatorin), which is suspected to be genotoxic. Therefore, Ugly Milkcap should not be used in commercial trade.

\section{Listing 4}




\section{Database search information}

SciFinder by September 2011. Keywords: Lactarius. PubMed: 2011-August 2012. Keywords: Lactarius necator, Lactarius plumbeus, Lactarius turpis.

\section{References}

Barceloux DG (2008): Medical Toxicology of Natural Substances: Foods, Fungi, Medicinal Herbs, Plants, and Venomous Animals. John Wiley \& Sons, Inc.: 1-1200.

Benjamin D (1995): Mushrooms: Poisons and panaceas. WH Freeman and company: 1-422.

Bresinsky A \& Besl H (1985): Giftpilze. Wissenschaftliche Verlagsgesellschaft mbH: 1-295.

Daniewski WM \& Vidari G (1999): Consituents of Lactarius (Mushroom). Progress in the Chemistry of Organic Natural Compounds 77: 69-171.

Fugman B, Steffan B \& Steglich W (1984): Necatorone, an alkaloidal pigment from the gilled toadstool Lactarius necator (Agaricales). Tetrahedron Letters 25: 3575-3578.

Grüter A, Friederich U \& Würgler FE (1991): The mutagenicity of edible mushrooms in a histidine-independent bacterial test system. Food and Chemical Toxicology 29: 159-165.

Hilger CS, Fugmann B \& Steglich W (1985): Synthesis of necatorone. Tetrahedron Letters 26: 5975-5978.

Klamann J-D, Fugmann B \& Steglich W (1989): Alkaloidal pigments from Lactarius necator and L. atroviridis. Phytochemistry 28: 3519-3522.

Knudsen H \& Vesterholt J (2012): Funga Nordica. Agaricoid, boletoid, clavarioid, cyphelloid and gastroid genera. Nordsvamp: 1-1083.

Knuutinen J \& von Wright A (1982): The mutagenicity of Lactarius mushrooms. Mutation Research 103: 115-118.

Roth L, Frank H \& Kormann K (1990): Giftpilze-Pilzgifte, Schimmelpilze-Mykotoxine: Ecomed Verlagsgesellschaft: 1-327.

Sterner 0 (1989): The co-formation of sesquiterpene aldehydes and lactones in injured fruit bodies of Lactarius necator and L. circellatus. The isolation of epipiperalol. Acta Chemica Scandinavia 43: 694-697.

Sterner O \& Anke H (1995): Toxic terpenoids isolated from higher fungi. Czech Mycology Journal 48: 39-52.

Sterner O, Bergman R, Kesler E, Magnusson L, Nilsson B, Wickberg B, Zimerson E \& Zetterberg G (1982a): Mutagens in larger fungi I. Forty-eight species screened for mutagenic activity in the Salmonella/microsome assay. Mutation Research 101: 269-281.

Sterner 0, Bergman R, Franzén C, Kesler E \& Nilsson L (1982b): Mutagens in larger fungi II. The mutagenicity of commercial picled Lactarius necator in the Salmonella assay. Mutation Research 104: 233-237.

Suortti T (1984a): Improved analytical and preparative methods for necatorin from Lactarius necator (Fr.) Karst. Mushroom. Journal of Chromotography 301: 303-307.

Suortti T (1984b): Stability of necatorin, a highly mutagenic compound from Lactarius necator mushroom. Food and Chemical Toxicology 22: 579-581.

Suortti T \& von Wright AV(1983): Isolation of a mutagenic fraction from aqueous extracts of the wild edible mushroom Lactarius necator (a preliminary note). Journal of Chromatography 255: 529-532. 
Suortti T, von Wright AV \& Koskinen A (1983): Necatorin, a highly mutagenic compound from Lactarius necator. Phyochemistry 22: 2873-2874.

von Wright A, Knuutinen J, Lindroth S \& Pellinen N (1982): The mutagenicity of some edible mushrooms in the Ames test. Food and Chemical Toxicology 20: 265-267.

von Wright A \& Suortti T (1983a): A potent mutagen isolated from a wild edible mushroom Lactarius necator. Mutation Research 113: 319.

von Wright A \& Suortti T (1983b): Preliminary characterization of the mutagenic properties of "necatorin", a strong mutagenic compound of the mushroom Lactarius necator. Mutation Research 121: 103-106. Erratum: Mutation Research 121: 308.

\section{Lactarius plumbeus s. auct.}

See Lactarius necator. 


\section{Lactarius rufus (Scop.) Fr.}

Rufous Milkcap, (Red Hot Milkcap) (DK: Rødbrun Mælkehat, FI: Kangasrousku, IS: No Icelandic name, NO: Rødbrun pepperriske, SE: Pepparriska).

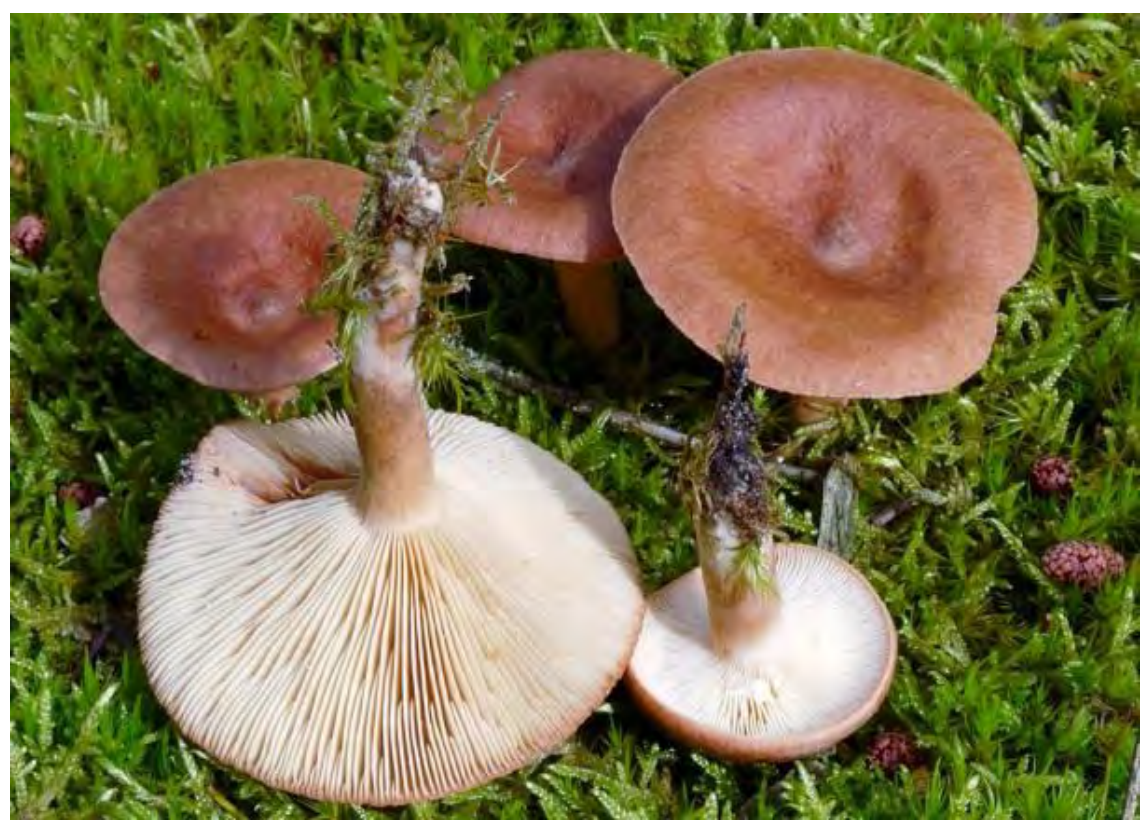

\section{Background and risk assessment}

Rufous Milkcap (Lactarius rufus) is, after appropriate pre-treatment, an edible mushroom.

It forms mycorrhiza with conifers, especially Spruce (Picea) and Pine (Pinus), but also with deciduous trees. It is very common in the Nordic countries in temperate to subarctic/subalpine zones, but rare in alpine/arctic zones (Knudsen \& Vesterholt, 2012).

Consumption of Rufous Milkcap has given rise to several cases of gastroenteritis, probably due to insufficient pre-treatment, e.g. salting and/or parboiling (Barceloux, 2008; Benjamin, 1995; Bresinsky \& Besl, 1985; Flammer \& Horak, 2003; Roth et al., 1990). Rufous Milkcap contains several potentially bioactive constituents:

\section{Bioactive constituents}

Sesquiterpenes: Rufous Milkcap contains stearoylvelutinal and 6ketostearoylvelutinal (Daniewski \& Vidary, 1999), which on physical injury of the fruit bodies (e.g. when cleaned and cut into pieces for food 
use) are both degraded within seconds or a few minutes to sesquiterpenes, including the pungent, unsaturated dialdehydes isovelleral and velleral (Sterner, 1989; Daniewski \& Vidary, 1999). By salting, pickling or parboiling, the pungent and gastroirritating isovelleral and velleral are further degraded to other sesquiterpenes, thereby abolishing the pungent and irritating activity.

The structural formulae of the two velutinal esters and the two dialdehydes are shown below:

Stearoylvelutinal
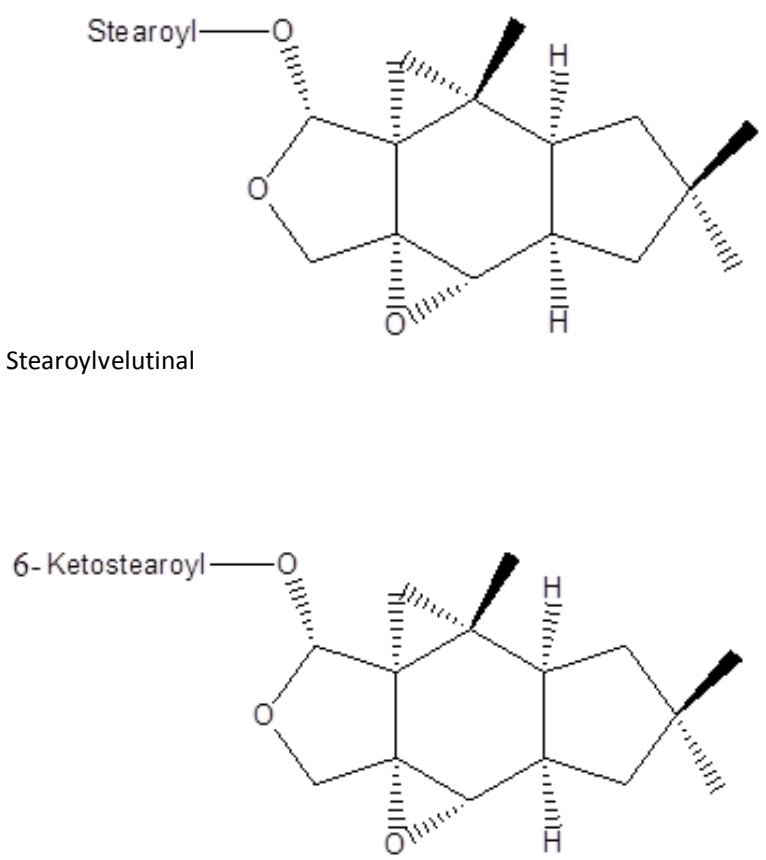

6-Ketostearoyl velutinal

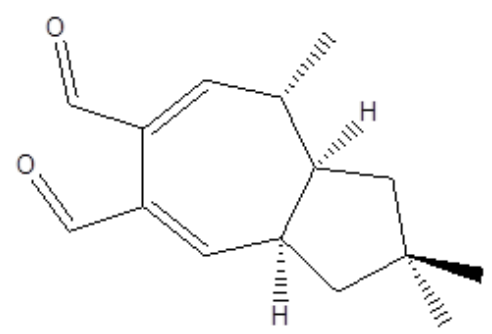

Velleral 


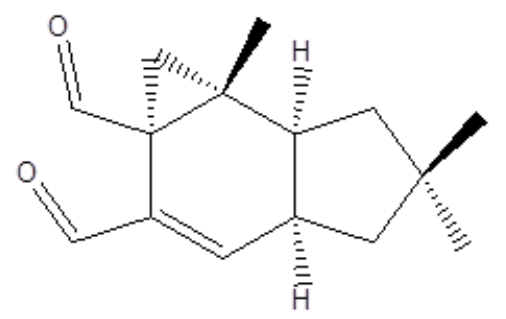

Isovelleral

Lectins: A lectin with six identical subunits has been characterized in Rufous Milkcap. Each subunit has a molecular weight of about $17 \mathrm{kDa}$. The lectin is quite stable, but $85 \%$ of the activity is lost by heating the mushroom at $65{ }^{\circ} \mathrm{C}$ (Panchak \& Antoniuk, 2007). Some lectins in foods, particularly in legumes (and possibly in mushrooms) are known to give rise to gastrointestinal distress (Liener, 1983), especially if the food is not sufficiently heat treated.

Muscarine: Rufous Milkcap has also been shown to contain trace amounts (totally less than $2 \mathrm{mg} / \mathrm{kg}$ fresh weight) of the toxicants L-(+)muscarine (approximately 40\%) and its stereoisomers (approximately $60 \%$ ) (Stadelmann et al., 1976). However, such low amounts of L-(+)muscarine and its stereoisomers are of no toxicological concern at normal consumption levels of Rufous Milkcap (Bresinsky \& Besl, 1985; Stadelmann et al., 1976). The structural formula of L-(+)-muscarine is shown below:

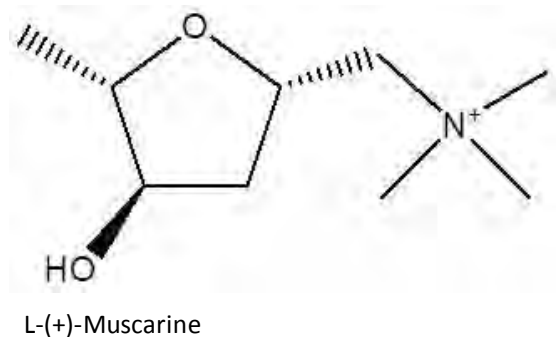

Mutagens: In 1982 Knuutinen and von Wright reported that extracts of Rufous Milkcap are weakly mutagenic in the Ames assay, using the histidine-requiring Salmonella typhimurium strains TA98 and TA100 to detect the activity. The finding was confirmed in studies with the Salmonella strains TA1535, TA1537 and TA1538 (von Wright et al., 1982). As the test system detects back-mutations from histidine requirement to histidine auxotrophy, presence of histidine or precursors of this amino acid (which may occur in mushrooms) in the test solution has the capability 
to induce false positives. It is unclear whether von Wright et al. (1982) controlled for the presence of histidine or histidine precursors in the mushroom extract.

Also Sterner et al. (1982) tested Rufous Milkcap extracts for mutagenic activity in the Ames test, using the Salmonella strains TA98, TA100 and TA2637 as indicators of mutagenic activity. The extract was reported to be positive in all three strains but inclusion of a metabolizing system from rat liver (S9) did not enhance the mutagenic activity. However, Sterner et al. (1982) gave no information whether they controlled for the potential presence of histidine in the extract and thereby induced false positives. In the same study, the pungent sesquiterpene velleral was negative whereas isovelleral was positive in two of the three Salmonella strains (TA100 and TA2637). However, isovelleral is likely to be destroyed during cooking. When Grüter et al. (1991) studied extracts of Rufous Milkcap in a histidine-independent bacterial test system, they could also demonstrate a weakly positive activity. Overall, it is likely that thoroughly cooked Rufous Milkcap has lost its mutagenic activity.

\section{Recommendation}

Before consumption, Rufous Milkcap needs to be pre-treated (salted/heattreated) to destroy the acrid substances in the mushroom and water from pre-treatment should be discarded.

Listing 2

\section{Database search information}

SciFinder by September 2011. Keywords: Lactarius. PubMed 2011 August 2012. Keywords: Lactarius rufus.

\section{References}

Barceloux DG (2008): Medical Toxicology of Natural Substances: Foods, Fungi, Medicinal Herbs, Plants, and Venomous Animals. John Wiley \& Sons, Inc.: 1-1200.

Benjamin D (1995): Mushrooms: Poisons and panaceas. WH Freeman and company: 1-422.

Bresinsky A \& Besl H (1985): Giftpilze. Wissenschaftliche Verlagsgesellschaft mbH: 1-295.

Daniewski WM \& Vidari G (1999): Consituents of Lactarius (Mushroom). Progress in the Chemistry of Organic Natural Compounds 77: 69-171.

Flammer R \& Horak E (2003): Giftpilze - Pilzgifte. Schwabe. Basel: 1-204.

Grüter A, Friederich U \& Würgler FE (1991): The mutagenicity of edible mushrooms in a histidine-independent bacteral test system. Food Chemical Toxicology 29: 159-165.

Knudsen H \& Vesterholt J (2012): Funga Nordica. Agaricoid, boletoid, clavarioid, cyphelloid and gastroid genera. Nordsvamp: 1-1083. 
Knuutinen J \& von Wright A (1982): The mutagenicity of Lactarius mushrooms. Mutation Research 103: 115-118.

Liener IE (1983): Naturally occurring toxicants in food and their significance in the human diet. Archives of Toxicology Supplements 6: 153-166.

Panchack LV \& Antoniuk VO (2007): Purification of lectin from fruiting bodies of Lactarius rufus (Scop.: Fr.) Fr. and its carbohydrate specificity. Ukrainskiĭ Biokhimicheskiĭ Zhurnal 79: 123-128. (Ukranian, English abstract available).

Roth L, Frank H \& Kormann K (1990): Giftpilze-Pilzgifte, Schimmelpilze-Mykotoxine: Ecomed Verlagsgesellschaft: 1-327.

Stadelmann RJ, Müller E \& Eugster CH (1976): Über die Verbreitung der stere omeren Muscarine innerhalb der Ordnung der Agaricales. Helvetica Chimica Acta 59: 2432-2436.

Sterner 0 (1989): The co-formation of sesquiterpene aldehydes and lactones in injured fruit bodies of Lactarius necator and L. circellatus. The isolation of epipiperalol. Acta Chemica Scandinavica 43: 694-697.

Sterner O, Bergman R, Kesler E, Magnusson L, Nilsson B, Wickberg B, Zimerson E \& Zetterberg G (1982): Mutagens in larger fungi I. Forty-eight species screened for mutagenic activity in the Salmonella/microsome assay. Mutation Research 101: 269-281.

von Wright A, Knuutinen J, Lindroth S \& Pellinen N (1982): The mutagenicity of some edible mushrooms in the Ames test. Food and Chemical Toxicology 20: 265-267. 


\section{Lactarius torminosus (Schaeff.) Gray}

Woolly Milkcap (DK: Skægget Mælkehat, FI: Karvarousku, IS: Loðlekta Loðglætingur, NO: Skjeggriske, SE: Skäggriska).

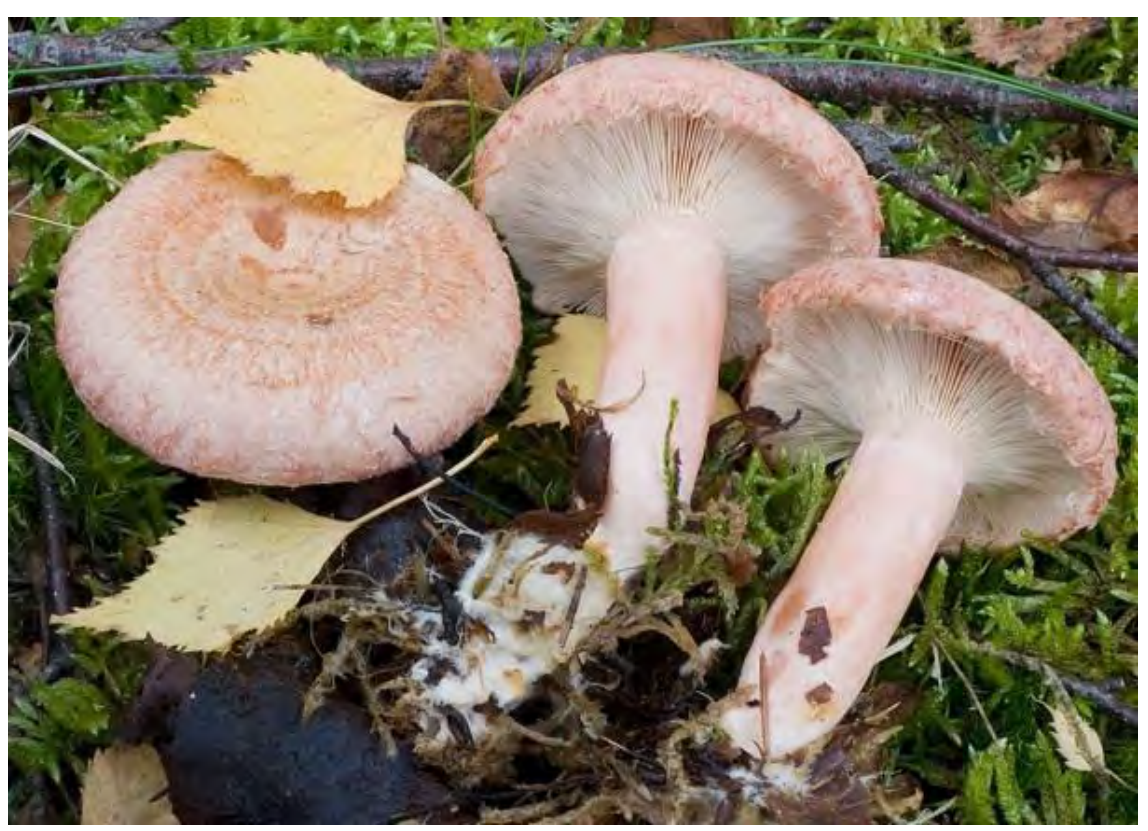

\section{Background and risk assessment}

Woolly Milkcap (Lactarius torminosus) is, after appropriate pretreatment, an edible mushroom.

It forms mycorrhiza with Birch (Betula) in forests, parks and gardens, in arctic habitats with Dwarf Birch (Betula nana). It is very common in the Nordic countries (Knudsen \& Vesterholt, 2012).

Woolly Milkcap is like certain other pungent species of Milkcap (Lactarius), such as Rufous Milkcap (L.rufus) consumed especially in central and eastern parts of Europe. Occasionally, the consumption gives rise to gastroenteritis, probably due to insufficiently pre-treated mushrooms (Barceloux, 2008; Benjamin, 1995; Bresinsky \& Besl, 1985; Flammer \& Horak, 2003; Roth et al., 1990). Some potentially bioactive constituents have been identified in Woolly Milkcap:

\section{Bioactive constituents}

Sesquiterpenes: As other pungent species of Milkcap, Woolly Milkcap contains stearoylvelutinal (Daniewski \& Vidary, 1999). Upon physical injury stearoylvelutinal is within seconds or minutes converted chemi- 
cally or enzymatically to the pungent sesquiterpenes piperdial and velleral (Sterner et al., 1985). According to Daniewsky \& Vidari (1999) also isovelleral has been detected in Woolly Milkcap. The pungent sesquiterpenes may be further degraded, for example by pre-treatment of the mushroom before cooking.

The structural formulae of stearoylvelutinal and the pungent velleral are shown below:

Stearoylvelutina
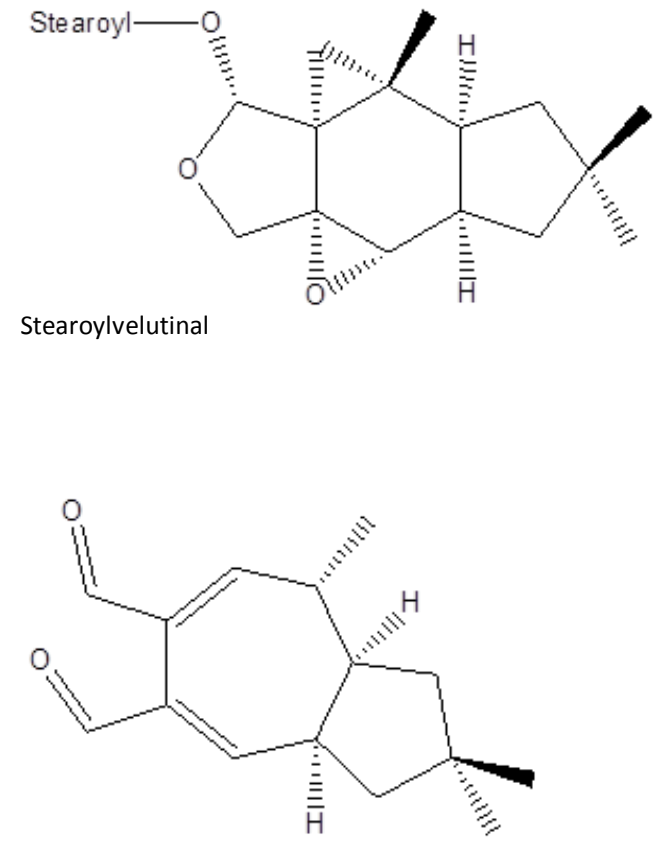

Velleral

Mutagens: In 1982 Knuutinen and von Wright reported that Woolly Milkcap extracts are weakly mutagenic as detected by the histidinerequiring Salmonella typhimurium strains TA 98 and TA 100 in the Ames assay. Subsequently, von Wright et al. (1982) confirmed the finding in three other indicator strains of Salmonella typhimurium, TA1535, TA1537 and TA1538.

Further confirmation on mutagenic activity in extracts of Woolly Milkcap was obtained by Sterner et al. (1982) who also used the Ames test with the Salmonella strains TA98, TA100 and TA2637 as indicators. The extract was positive in all three strains but was not enhanced when including a metabolizing system (S9 mix). Sterner et al. (1982) gave no information whether they controlled for the potential presence of histidine in the extract tested. The presence of histidine could have resulted in false positives. In the same study, the pungent sesquiterpene velleral 
was negative, whereas the pungent isovelleral was positive in two of the three Salmonella strains (TA100 and TA2637). However, isovelleral is likely to be destroyed during cooking.

Ergothioneine: Lee et al. (2009) have identified $820 \mathrm{mg} / \mathrm{kg}$ (dry weight; mean of tree samples) of ergothioneine in the fruit bodies of Wooly Milkcap. For further information on ergothioneine, see Lepista nuda.

\section{Recommendation}

Before consumption, Wooly Milkcap needs to be pre-treated (salted/heat treated) to destroy the acrid substances in the mushroom and water from pre-treatment should be discarded.

\section{Listing 2}

\section{Database search information}

SciFinder by September 2011. Keywords: Lactarius. PubMed: 2011August 2012. Keywords: Lactarius torminosus.

\section{References}

Barceloux DG (2008): Medical Toxicology of Natural Substances: Foods, Fungi, Medicinal Herbs, Plants, and Venomous Animals. John Wiley \& Sons, Inc.: 1-1200.

Benjamin D (1995): Mushrooms: Poisons and panaceas. WH Freeman and company: 1-422.

Bresinsky A \& Besl H (1985): Giftpilze. Wissenshaftliche Verlagsgesellschaft mbH: 1-295.

Daniewski WM \& Vidari G (1999): Consituents of Lactarius (Mushroom). Progress in the Chemistry of Organic Natural Compounds 77: 69-171.

Flammer R \& Horak E (2003): Giftpilze - Pilzgifte. Schwabe. Basel: 1-204.

Knudsen H \& Vesterholt J (2012): Funga Nordica. Agaricoid, boletoid, clavarioid, cyphelloid and gastroid genera. Nordsvamp: 1-1083.

Knuutinen J \& von Wright A (1982): The mutagenicity of Lactarius mushrooms. Mutation Research 103: 115-118.

Lee WY; Park E-J, Jin K \& Ka K-H (2009): Ergothioneine contents in fruiting bodies and their enhancement in mycelial cultures by addition of methionine. Mycobiology 37: 43-47.

Roth L, Frank H \& Kormann K (1990): Giftpilze-Pilzgifte, Schimmelpilze-Mykotoxine. Ecomed Verlagsgesellschaft: 1-327.

Sterner O, Bergman R, Franzén C \& Wickberg B (1985): New sesquiterpenes in a proposed Russulaceae chemical defense system. Tetrahedron Letters 26: 3136-3166.

Sterner 0 (1989): The co-formation of sesquiterpene aldehydes and lactones in injured fruit bodies of Lactarius necator and L. circellatus. The isolation of epipiperalol. Acta Chemica Scandinavica 43: 694-697. 
Sterner O, Bergman R, Kesler E, Magnusson L, Nilsson B, Wickberg B, Zimerson E \& Zetterberg G (1982): Mutagens in larger fungi I. Forty-eight species screened for mutagenic activity in the Salmonella/microsome assay. Mutation Research 101: 269-281.

von Wright A, Knuutinen J, Lindroth S \& Pellinen N (1982): The mutagenicity of some edible mushrooms in the Ames test. Food and Chemical Toxicology 20: 265-267. 


\section{Lactarius trivialis (Fr.) Fr. (L. utilis (Weinm.) Fr.)}

No UK name (DK: Nordisk Mælkehat (Slimet Mælkehat), FI: Haaparousku, Kalvashaaparousku, IS: No Icelandic name, NO: Hulriske (Blek hulriske), SE: Skogsriska).

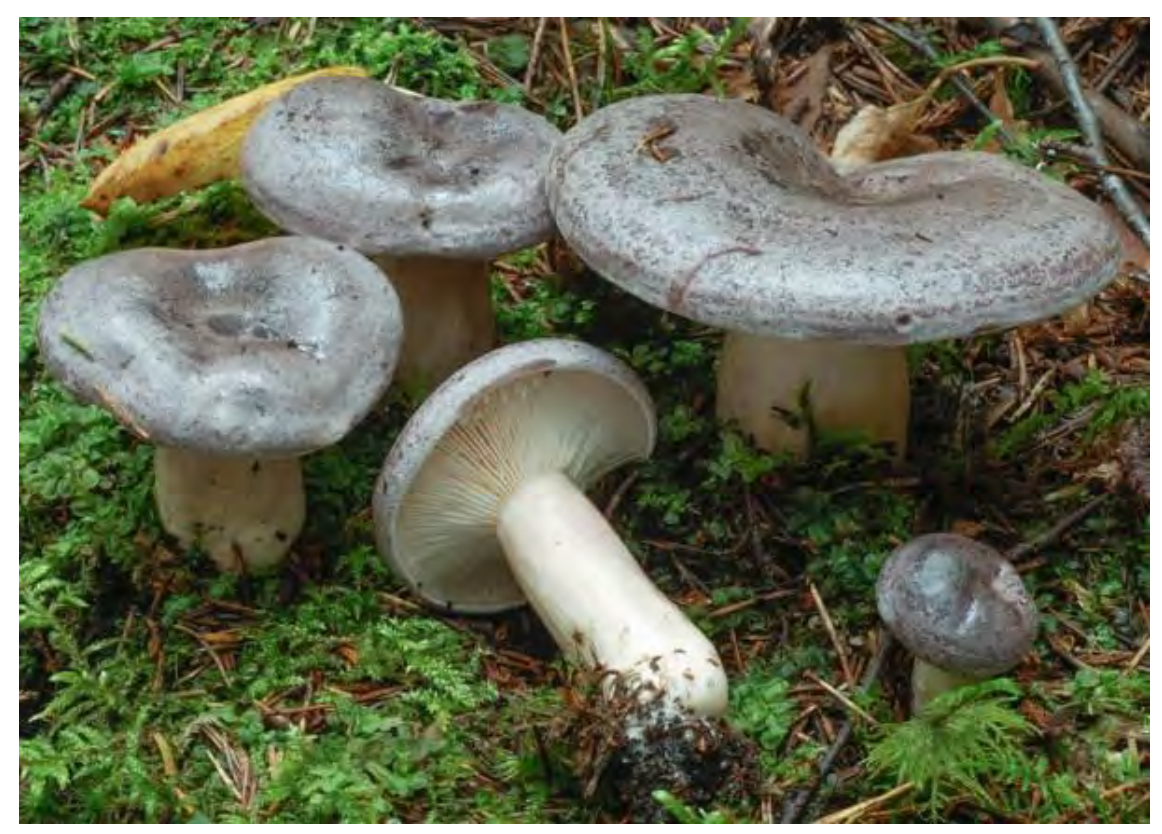

\section{Background and risk assessment}

Lactarius trivialis ${ }^{18}$ is, after appropriate pre-treatment, an appreciated, edible mushroom.

It forms mycorrhiza with Birch (Betula) and Spruce (Picea). It is occasional in the temperate zone, although rare in Denmark. Otherwise it is very common in the Nordic countries (Knudsen \& Vesterholt, 2012).

No intoxications have been reported after consumption of $L$. trivialis. However, some bioactive constituents have been identified in this mushroom.

${ }^{18}$ Lactarius utilis is considered as a separate species in the lists of commercial mushrooms in Finland, but it is considered as a synonym for L. trivialis by ArtDatabanken (2011), Danish Mycological Society (2012), Knudsen \& Vesterholt (2012) and Index Fungorum/Species Fungorum (2012). 


\section{Bioactive constituents}

Sesquiterpenes: L. trivialis contains both stearoylvelutinal and 6ketostearoylvelutinal (Daniewski \& Vidary, 1999). Upon injury of the mushroom fruit body, these compounds within a very short time are degraded chemically or enzymatically to pungent, unstable sesquiterpenes, which may be further degraded during pre-treatment and cooking of the mushroom.

The structural formulae of stearoylvelutinal and the pungent velleral are shown below:

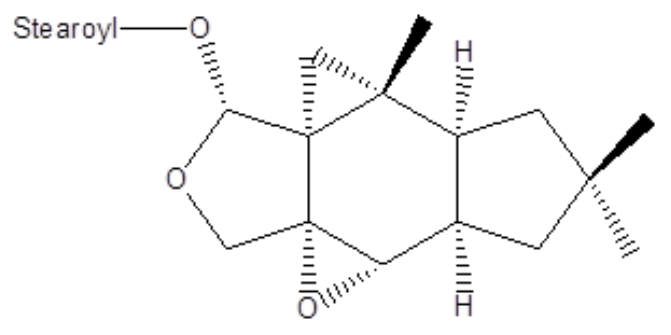

Stearoylvelutinal

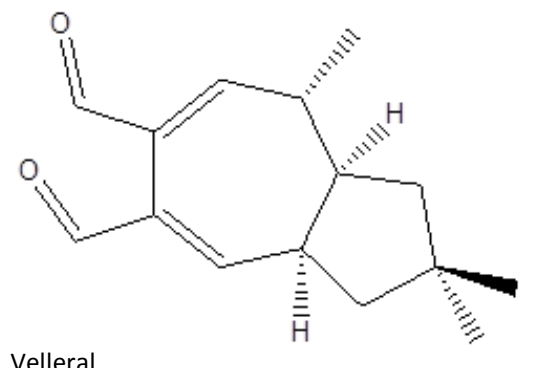

Muscarine: Trace amounts (totally less than $2 \mathrm{mg} / \mathrm{kg}$ fresh weight) of the toxicants L-(+)-muscarine (approximately $40 \%$ ) and its stereoisomers (approximately 60\%) have been detected in L. trivialis (Stadelmann et al., 1976). However, such low amounts of L-(+)-muscarine and its stereoisomers are of no toxicological concern at normal consumption levels of L. trivialis (Bresinsky \& Besl, 1985; Stadelmann et al., 1976). The structural formula of L-(+)-muscarine is shown below: 


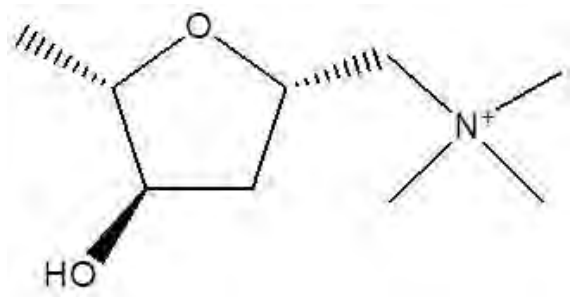

L-(+)-Muscarine

Mutagens: Sterner et al. (1982) tested an extract of L. trivialis in the Ames test using the Salmonella typhimurium strains TA98, TA100 and TA2637. The extract was found positive in all three strains. The activity was not enhanced in the presence of a metabolizing system prepared from rat liver (S9 mix). Unfortunately, Sterner et al. (1982) gave no information whether they had controlled for the potential presence of histidine in the extract. It is well known that false positives may be obtained in the presence of histidine.

\section{Recommendation}

Before consumption: Lactarius trivialis needs to be pre-treated (salted/heat-treated) to destroy the acrid substances in the mushroom and water from pre-treatment should be discarded.

The mushroom is red-listed as near threatened in Denmark. Should only be marketed in the Nordic countries, if it is from countries, where it is not red-listed.

\section{Listing 2}

\section{Database search information}

SciFinder by September 2011. Keywords: Lactarius. PubMed: 2011August 2012. Keywords: Lactarius trivialis, Lactarius utilis.

\section{References}

Bresinsky A \& Besl H (1985): Giftpilze. Wissenshaftliche Verlagsgesellschaft mbH: 1-295.

Daniewski WM \& Vidari G (1999): Consituents of Lactarius (mushroom). Progress in the Chemistry of Organic Natural Compounds 77: 69-171.

Knudsen H \& Vesterholt J (2012): Funga Nordica. Agaricoid, boletoid, clavarioid, cyphelloid and gastroid genera. Nordsvamp: 1-1083.

Stadelmann RJ, Müller E \& Eugster CH (1976): Über die Verbreitung der stereomeren Muscarine innerhalb der Ordnung der Agaricales. Helvetica Chimica Acta 59: 2432-2436. 
Sterner O, Bergman R, Kesler E, Magnusson L, Nilsson B, Wickberg B, Zimerson E \& Zetterberg G (1982): Mutagens in larger fungi I. Forty-eight species screened for mutagenic activity in the Salmonella/microsome assay. Mutation Research 101: 269-281.

\section{Lactarius turpis (Weinm.) Fr.}

See Lactarius necator.

Lactarius utilis (Weinm.) Fr.

See Lactarius trivialis. 


\section{Lactarius volemus (Fr.) Fr.}

Fishy Milkcap (DK: Spiselig Mælkehat, FI: Kultarousku, IS: No Icelandic name, NO: Mandelriske, SE: Mandelriska).

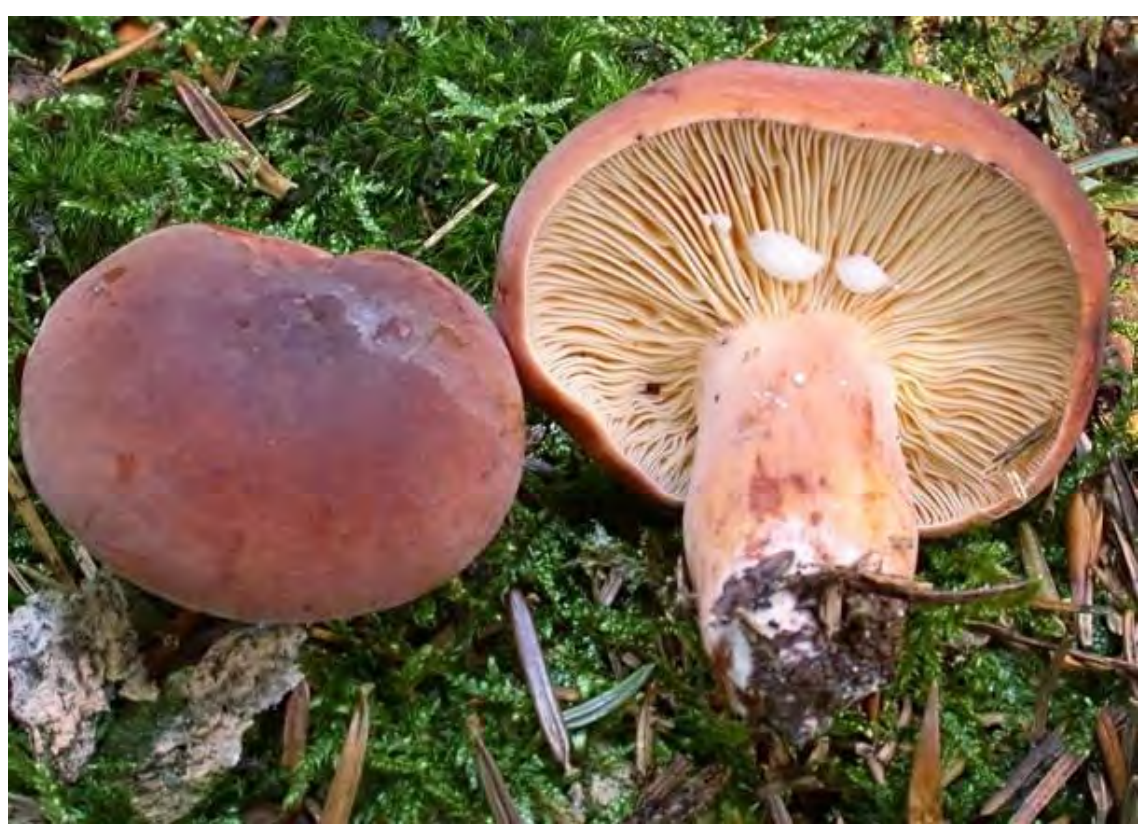

\section{Background and risk assessment}

Fishy Milkcap (Lactarius volemus) is an appreciated, edible mushroom.

It forms mycorrhiza in deciduous and coniferous forests. It is rare in temperate, hemiboreal and southern parts of boreal zones of the Nordic countries (Knudsen and Vesterholt, 2012).

Like all Milkcap (Lactarius) species, Fishy Milkcap exudes latex. The content of rubber (a relatively low molecular weight rubber composed of 160-300 cis-isoprene units) is very high in Fishy Milkcap, compared to other Milkcap species and, in fact, to other fungal species, as it is up to $7 \mathrm{~g}$ per $\mathrm{kg}$ fresh weight of the mushroom (Anderson et al., 1961; Stewart et al., 1965; Tanaka et al., 1994). It is not known whether the high content of cis-polyisoprene may influence the digestibility of Fishy Milkcap.

There are no intoxications reported after consumption of Fishy Milkcap, and no natural toxicant constituting a risk for humans has been identified in the mushroom. 


\section{Recommendation}

Fishy Milkcap is red-listed in Denmark. Should only be marketed in the Nordic countries, if it is from countries, where it is not red-listed.

\section{Listing 2}

\section{Database search information}

SciFinder by September 2011. Keywords: Lactarius. PubMed: 2011August 2012. Keywords: Lactarius volemus.

\section{References}

Anderson RF. Baker TI, Jayko LG \& Benedict RG (1961): Occurrence of polyisoprene in Lactarius species. Biochimica et Biophysica Acta 50: 374-375.

Knudsen H \& Vesterholt J (2012): Funga Nordica. Agaricoid, boletoid, clavarioid, cyphelloid and gastroid genera. Nordsvamp: 1-1083.

Stewart WD, Wachtel WL, Shipman JJ \& Yanko JA (1955): Synthesis of rubber by fungi. Science 122: 1271-1272.

Tanaka Y, Kawahara S, Eng A-H, Takei A \& Ohya N (1994): Structure of cispolyisoprene from Lactarius mushrooms. Acta Biochemica Polonica 41: 303-309.

\section{Leccinum albostipitatum den Bakker \& Noordel.}

See Leccinum aurantiacum. 
Leccinum aurantiacum s. lato

(L. albostipitatum den Bakker \& Noordel., L. quercinum (Pilát) E.E. Green \& Watling)

Orange Bolete (Orange Aspen Bolete, Orange Oak Bolete) (DK: Orange Aspe-Rørhat, Rustrød Ege-Rørhat, FI: Haavanpunikkitatti, IS: Asparlubbi, NO: Ospeskrubb, SE: Aspsopp).

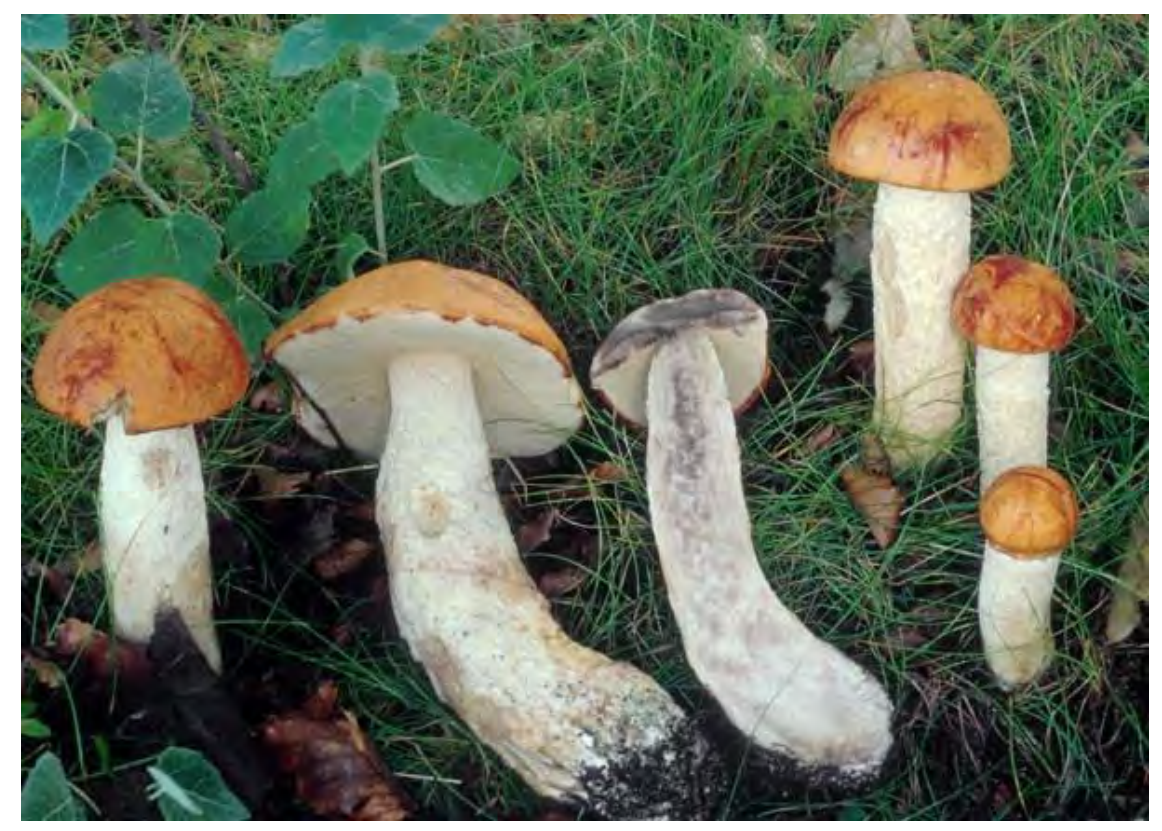

\section{Background and risk assessment}

Orange Bolete (Leccinum aurantiacum) ${ }^{19}$ is edible and good after thorough cooking.

It is mycorrhizal with Poplar (Populus), Oak (Quercus), Birch (Betula) and rarely with Willow (Salix), Lime (Tilia) and Beech (Fagus), in subalpine and arctic/alpine zones also with Bearberry (Arctostaphylos). It is occasional in Denmark and common in temperate-subalpine areas of the Nordic countries (Knudsen \& Vesterholt, 2012).

19 Index Fungorum/Species Fungorum (2012) and Knudsen \& Vesterholt (2012) have L. albostipitatum as preferred name but ArtDatabanken (2011) and Danish Mycological Society (2012) use L. aurantiacum s. lato as preferred name. Danish Mycological Society (2012) and Knudsen \& Vesterholt (2012) include L. quercinum in L. aurantiacum. 
No toxicants have been identified in Orange Bolete. However, there are many reports on mild intoxications with gastrointestinal symptoms after consumption of different Leccinum species (e.g., Beug 2007; 2009; 2010; 2011; 2012; Beug et al., 2006; Mattilsynet, 2012). Leccinum species have to be thoroughly cooked in order to destroy the unknown but rather heat-stable toxicant(s) giving rise to these symptoms.

Several phenolic and other hydroxylated pigments have been identified in this mushroom (Bresinsky et al., 1974; Massow \& Huber, 1977). However, no toxicological data were available on these potentially bioactive constituents.

Muszynska et al. (2011) have identified several indole compounds in Orange Bolete, but at low levels corresponding to approximately 1 $\mathrm{mg} / \mathrm{kg}$ (fresh weight) or lower, except for serotonin found at a level of approximately $32 \mathrm{mg} / \mathrm{kg}$ (fresh weight). However, seratonin is apparently completely destroyed during cooking (Muszynska et al., 2012).

\section{Recommendation}

Thorough heat-treatment is necessary as insufficiently cooked Leccinum mushrooms can give rise to intoxications.

\section{Listing 2}

\section{Database search information}

SciFinder by January 2012. Keywords: Leccinum.

\section{References}

Beug MW (2012): 2011 NAMA Toxicology Committee Report: North American mushroom poisonings: Mcllvainea 21: 1-14.

Beug MW (2011): 2010 NAMA Toxicology Committee Report for 2010: North American mushroom poisonings: McIlvainea 20: 1-11.

Beug MW (2010): NAMA Toxicology Committee Report for 2009: North American mushroom poisonings. Mcllvainea 19: 1-7.

Beug MW (2009): NAMAToxicology Committee Report for 2008: Recent mushroom poisonings in North America. Mcllvainea 18: 45-54.

Beug MW (2007): NAMA Toxicology Committee Report for 2006: Recent mushroom poisonings in North America. Mcllvainea 17: 63-72.

Beug MW, Shaw M \& Cochran KW (2006): Thirty-plus years of mushroom poisonings. Summary of the approximately 2,000 reports in the NAMA Case Registry. Mcllvainea 16: 47-67.

Bresinsky A, Besl H \& Steglich W (1974): Gyroporin and atromentic acid from Leccinum aurantiacum cultures. Phytochemistry 13: 271-272. 
Knudsen H \& Vesterholt J (2012): Funga Nordica. Agaricoid, boletoid, clavarioid, cyphelloid and gastroid genera. Nordsvamp: 1-1083.

Massow FV \& Huber D (1977): A new thin-layer chromatography system for the identification of moderately polar to lipophilic Boletales pigments. Journal of Chromatography 138: 232-237.

Mattilsynet (2012): Rødskrubb må varmebehandles godt. December 2012 (Norweigian Food Safety Authority). http://www.matportalen.no/ uonskedestoffer_i_mat/tema/biologiske_gifter/ rodskrubb_maa_varmebehandles_godt.

Muszynska B, Sulkowska-Ziaja K \& Ekert H (2011): Indole compounds in fruiting bodies of some edible Basidiomycota species. Food Chemistry 125: 1306-1308.

Muszyńska B \& Sułkowska-Ziaja K (2012): Analysis of indole compounds in edible Basidiomycota species after thermal processing. Food Chemistry 132: 455-459.

\section{Leccinum quercinum (Pilát) E.E. Green \& Watling)}

See Leccinum aurantiacum.

\section{Leccinum scabrum (Bull.) Gray}

See Leccinum species, other. 


\section{Leccinum species, other, e.g. L. scabrum (Bull.) Gray}

Other Leccinum species, e.g. Brown Birch Bolete (DK: Andre skælrørhatte fx Brun Birke-Rørhat, FI: Muut Leccinum lajin tatit, IS: Aðrir lubbarkúalubbi, NO: Andre skrubb arter - Brunskrubb, SE: Andra soppar av släktet Leccinum-Björksopp).

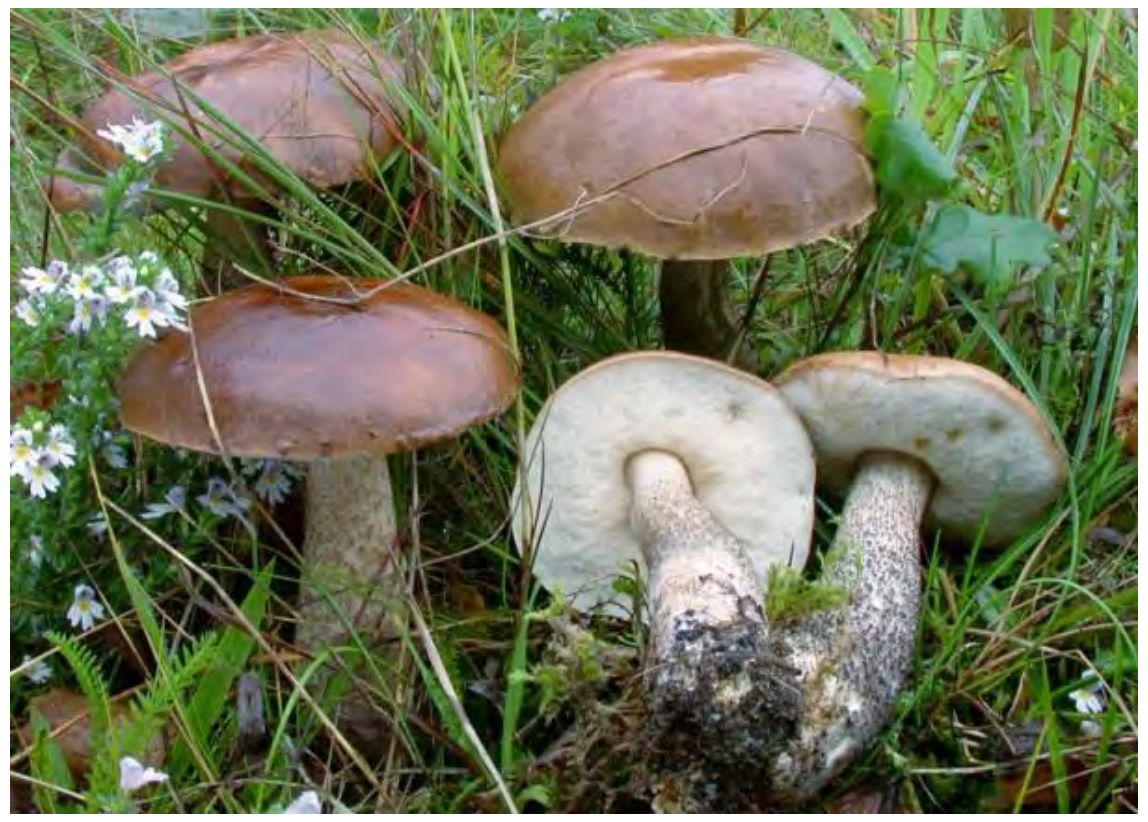

\section{Background and risk assessment}

Leccinum species growing in the Nordic countries e.g. Brown Birch Bolete (L. scabrum) are all edible after thorough cooking, but of varying culinaric quality.

They are myccorhizal, especially with Birch (Betula), but also with Poplar (Populus), Oak (Querqus), Hornbeam (Carpinus), Hazel (Corylus), Beech (Fagus) and some coniferous trees such as Pine (Pinus) and Spruce (Picea), often in moist habitats (Knudsen \& Vesterholt, 2012). Brown Birch Bolete is very common in the temperate-subalpine zone and occasional in arctic/alpine zone of the Nordic countries (Knudsen \& Vesterholt, 2012).

There are no intoxications reported after consumption of Brown Birch Bolete. However, other Leccinum species, and especially Orange Birch Bolete (Leccinum versipelle), have given rise to many intoxications with gastrointestinal symptoms due to insufficient heat-treatment (e.g., 
Beug 2007; 2009; 2010; 2011; 2012; Beug et al., 2006; Mattilsynet, 2012). Generally, Leccinum species have to be thoroughly cooked in order to destroy the unknown but rather heat-stable toxicant(s) giving rise to these symptoms.

Polyphenolic constituents with anticipated bioactive properties have been identified in Brown Birch Bolete, e.g. 3,4,5-hydroxybenzaldehyde (Edwards \& Elseworthy, 1967) as well as phenolic and other hydroxylated pigments (Besl \& Bresinsky, 1977).

\section{Recommendation}

Thorough heat treatment of Leccinum species is necessary as consumption of insufficiently cooked Leccinum species may give intoxications.

\section{Listing 2}

\section{Database search information}

SciFinder by January 2012. Keywords: Leccinum.

\section{References}

Besl H \& Bresinsky A (1977): Presence and systematic evaluation of pigments in higher fungi. Zeitschrift für Pilzkunde 43: 311-322.

Beug MW (2012): 2011 NAMA Toxicology Committee Report: North American mushroom poisonings: $1-14$.

Beug MW (2011): 2010 NAMA Toxicology Committee Report for 2010: North American mushroom poisonings: 1-11.

Beug MW (2010): NAMAToxicology Committee Report for 2009: North American mushroom poisonings. Mcllvainea 19: 1-7.

Beug MW (2009): NAMAToxicology Committee Report for 2008: Recent mushroom poisonings in North America. Mcllvainea 18: 45-54.

Beug MW (2007): NAMA Toxicology Committee Report for 2006: Recent mushroom poisonings in North America. Mcllvainea 17: 63-72.

Beug MW, Shaw M \& Cochran KW (2006): Thirty-plus years of mushroom poisonings. Summary of the approximately 2,000 reports in the NAMA Case Registry. Mcllvainea 16: 47-67.

Edwards RL \& Elseworthy GC (1967): Constituents of the higher fungi. Part. V. The phenolic constituents of Boletus (Leccinum) scaber (Bull ex Fr.) Gray. Journal of Chemical Society C 1967: 410-411.

Knudsen H \& Vesterholt J (2012): Funga Nordica. Agaricoid, boletoid, clavarioid, cyphelloid and gastroid genera. Nordsvamp: 1-1083.

Mattilsynet (2012): Rødskrubb må varmebehandles godt. December 2012 (Norweigian Food Safety Authority). http://www.matportalen.no/ uonskedestoffer_i_mat/tema/biologiske_gifter/ rodskrubb_maa_varmebehandles_godt 


\section{Leccinum versipelle (Fr. \& Hök) Snell}

Orange Birch Bolete (DK: Rød Birke-Rørhat, FI: Koivunpunikkitatti, IS: Reyðilubbi (Rauðhetta), NO: Rødskrubb, SE: Tegelsopp (Tegelröd björksopp)).

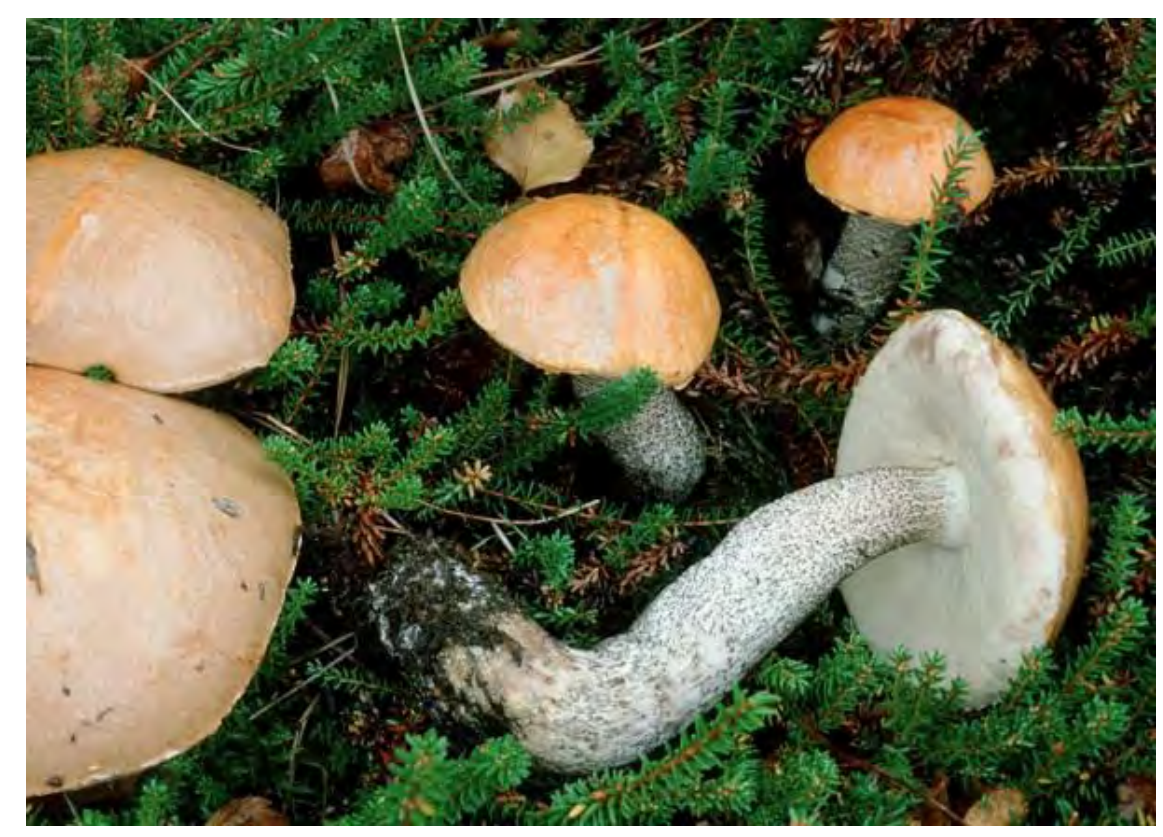

\section{Background and risk assessment}

Orange Birch Bolete (Leccinum versipelle) is edible and good when sufficiently cooked.

It grows mycorrhizal with Birch (Betula) and especially with Dwarf Birch (Betula nana) in arctic/alpine zone. It is common in Denmark and southern parts of Norway and Sweden, very common in hemiborealarctic/alpine zones, but rare in Iceland (Knudsen \& Vesterholt, 2012).

Consumption of Orange Birch Bolete has given rise to several intoxications with gastrointestinal symptoms. This mushroom needs very thorough cooking, in order to destroy some relatively heat-stable toxicant(s) of unknown chemical structure (e.g., Beug 2007; 2009; 2010; 2011; 2012; Beug et al., 2006; Matttilsynet, 2011).

Nieminen and co-workers (2006) have published a study on the potential myo- and hepatotoxic effects of different wild mushrooms in mice. The animals (six females per group) were for 5 days supplied large quantities of dried and powdered wild mushrooms in the feed. One of 
the mushrooms, Orange Birch Bolete, was given as $1.8 \%, 3.6 \%$ or $5.4 \%$ of the feed. The feeding resulted in exposures corresponding to 19,36 or $53 \mathrm{~g}$ per kg body weight of the mice per day, respectively, corresponding to $1.3,2.5$ or $3.2 \mathrm{~kg}$ mushroom per person $(70 \mathrm{~kg})$ per day of fresh mushroom. All mice were healthy at the end of the study. Of the many clinical-chemical parameters studied LDL cholesterol was significantly increased in a dose dependent manner. Creatine kinase was significantly increased at the two highest dose levels. No histological pathological changes in studied organs were found. Whether the observed increased creatine kinase (indicator of myopathy) in mice eating very high amounts of Orange Birch Bolete may be relevant for humans eating very large amount of the mushroom is difficult to evaluate.

\section{Recommendation}

Thorough heat treatment is necessary as consumption of insufficiently cooked Orange Birch Bolete may give intoxications.

Listing 2

\section{Database search information}

SciFinder by January 2012. Keywords: Leccinum.

\section{References}

Beug MW (2012): 2011 NAMA Toxicology Committee Report: North American mushroom poisonings: 1-14.

Beug MW (2011): 2010 NAMA Toxicology Committee Report for 2010: North American mushroom poisonings: 1-11.

Beug MW (2010): NAMAToxicology Committee Report for 2009: North American mushroom poisonings. Mcllvainea 19: 1-7.

Beug MW (2009): NAMAToxicology Committee Report for 2008: Recent mushroom poisonings in North America. Mcllvainea 18: 45-54.

Beug MW (2007): NAMA Toxicology Committee Report for 2006: Recent mushroom poisonings in North America. Mcllvainea 17: 63-72.

Beug MW, Shaw M \& Cochran KW (2006): Thirty-plus years of mushroom poisonings. Summary of the approximately 2,000 reports in the NAMA Case Registry. Mcllvainea 16: 47-67.

Knudsen H \& Vesterholt J (2012): Funga Nordica. Agaricoid, boletoid, clavarioid, cyphelloid and gastroid genera. Nordsvamp: 1-1083.

Mattilsynet (2012): Rødskrubb må varmebehandles godt. December 2012

(Norweigian Food Safety Authority). http://www.matportalen.no/ uonskedestoffer_i_mat/tema/biologiske_gifter/

rodskrubb_maa_varmebehandles_godt

Nieminen P, Kirsi M \& Mustonen A-M (2006): Suspected myotoxicity of edible wild mushrooms. Experimental Biology and Medicine 231: 221-228. 


\section{Leccinum vulpinum Watling}

Foxy Bolete (DK: Fyrre-Rørhat, FI: Männynpunikkitatti, IS: -lubbi, NO: Furuskrubb, SE: Tallsopp (Rävsopp)).

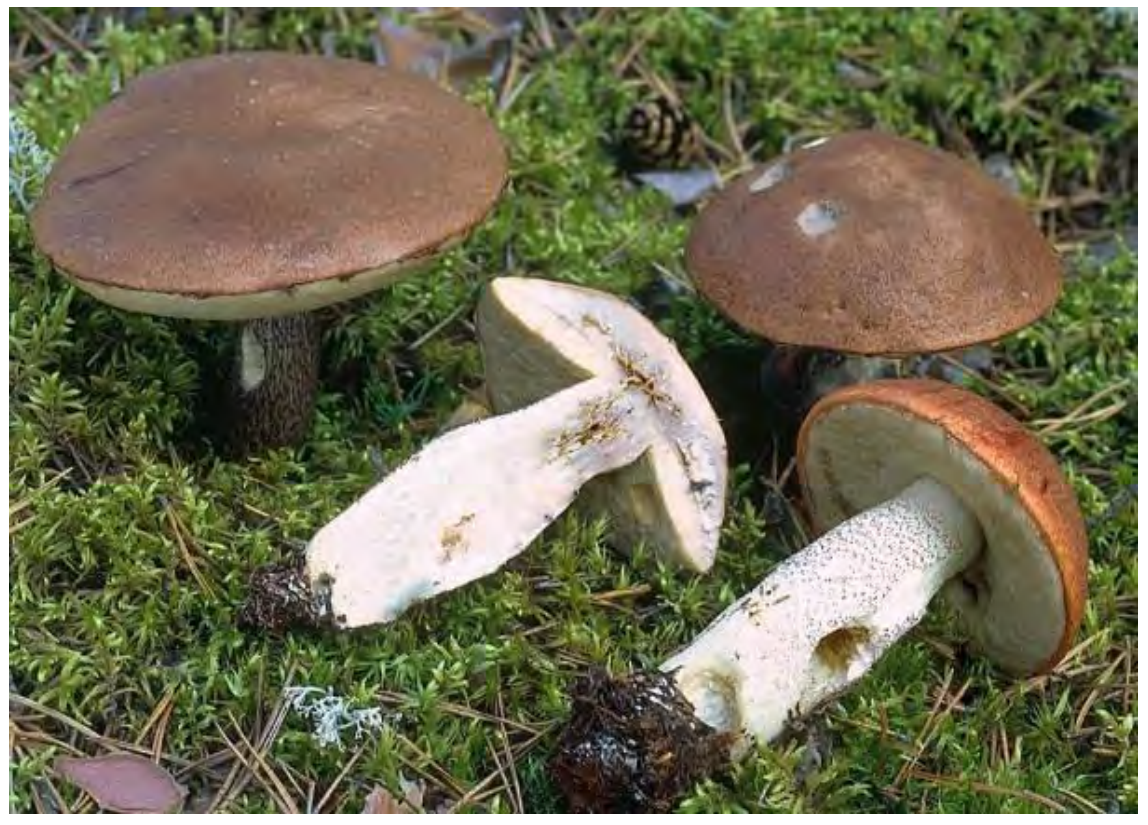

\section{Background and risk assessment}

Foxy Bolete (Leccinum vulpinum) is edible and good if sufficiently cooked.

It grows mycorrhizal with species of Pinaceae and Bearberry (Arctostophylos). It is occasional in Denmark and in southern temperate parts of Norway and Sweden and common in boreal regions of the Nordic countries (Knudsen \& Vesterholt, 2012).

There are no intoxications reported after consumption of Foxy Bolete, and no natural toxicant constituting a risk for humans has been identified in the mushroom.

However, other Leccinum species, and especially Orange Birch Bolete, have given rise to many intoxications with gastrointestinal symptoms due to insufficient heat treatment (e.g., Beug 2007; 2009; 2010; 2011; 2012; Beug et al., 2006; Mattilsynet, 2012). Generally, Leccinum species have to be thoroughly cooked in order to destroy the unknown but rather heat-stable toxicant(s) giving rise to these symptoms. 


\section{Recommendation}

Thorough heat treatment is necessary as insufficiently cooked Foxy Bolete can give intoxications.

\section{Listing 2}

\section{Database search information}

SciFinder by January 2012. Keywords: Leccinum.

\section{References}

Beug MW (2012): 2011 NAMA Toxicology Committee Report: North American mushroom poisonings: $1-14$.

Beug MW (2011): 2010 NAMA Toxicology Committee Report for 2010: North American mushroom poisonings: 1-11.

Beug MW (2010): NAMAToxicology Committee Report for 2009: North American mushroom poisonings. Mcllvainea 19: 1-7.

Beug MW (2009): NAMAToxicology Committee Report for 2008: Recent mushroom poisonings in North America. Mcllvainea 18: 45-54.

Beug MW (2007): NAMA Toxicology Committee Report for 2006: Recent mushroom poisonings in North America. Mcllvainea 17: 63-72.

Beug MW, Shaw M \& Cochran KW (2006): Thirty-plus years of mushroom poisonings. Summary of the approximately 2,000 reports in the NAMA Case Registry. Mcllvainea 16: 47-67.

Knudsen H \& Vesterholt J (2012): Funga Nordica. Agaricoid, boletoid, clavarioid, cyphelloid and gastroid genera. Nordsvamp: 1-1083.

Mattilsynet (2012): Rødskrubb må varmebehandles godt. December 2012 (Norweigian Food Safety Authority). http://www.matportalen.no/

uonskedestoffer_i_mat/tema/biologiske_gifter/

rodskrubb_maa_varmebehandles_godt 


\section{Lentinula edodes (Berk.) Pegler (L. edodes (Berk.) Singer)}

Shiitake (DK: Shiitake, FI: Siitake, IS: Shii-take sveppur, Tókasveppur, NO: Shiitake, SE: Shiitake (Ekmussling, Ekskivling)).

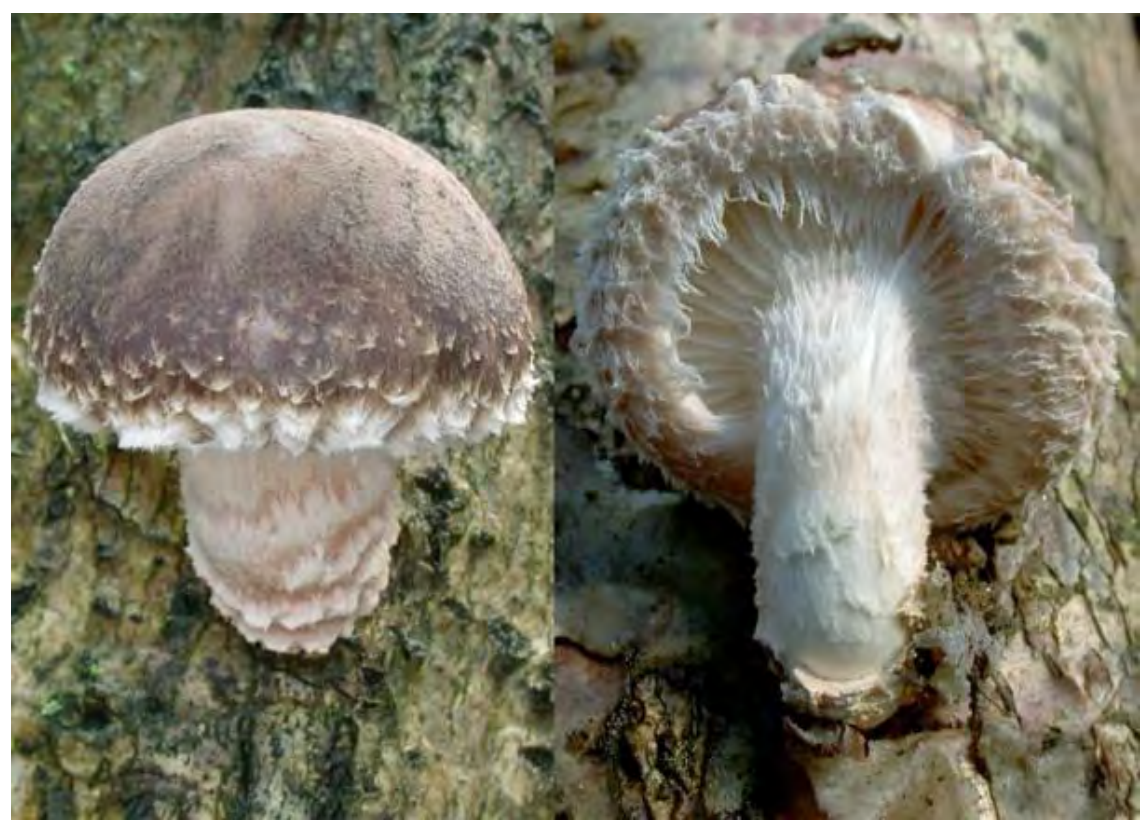

\section{Background and risk assessment}

Shiitake (Lentinula edodes) is an appreciated edible mushroom.

It is saprotrophic on branches, logs and trunks in deciduous forests with Oak (Quercus) and is native, especially in Japan and China (Hongo \& Izawa, 2006).

Shiitake is, next to Button Mushroom, the most cultivated and consumed mushroom in the world. In 1997, the year from which the latest world production figures were found, it was cultivated in 1.6 million tons (Chang \& Miles, 2004). However, more recently Chang \& Wasser (2012) reported that the total world production of cultivated mushrooms in 2009 has been estimated to be 24 million tons, of which more than 20 million tons have been produced in China. Approximately one quarter of this production comprises Shiitake. It was originally cultivated in East Asia (Japan, China and Korea), but is now also cultivated in e.g. Europe and the United States. Shiitake is commercially available as fresh, dried, canned or otherwise processed. Especially in Asia it is also widely 
used to promote health and supply medicinal effects. When included in products for health-beneficial uses also extracts and isolated fractions are used (Bisen et al., 2010; ; Chang, 1996; Chang \& Wasser, 2012; Lindequist et al., 2010; Mizuno et al., 1995).

Several intoxications have been reported after consumption of Shiitake, apparently in almost all cases after consumption of raw or insufficiently cooked mushrooms. The toxicant is supposed to be the thermolabile polysaccharide lentinan but the mushroom is also reported to contain other bioactive constituents.

\section{Bioactive constituents}

Lentinan: Consumption of Shiitake (Lentinula edodes) may result in a toxic or hypersensitivity reaction manifested as flagellate dermatitis (linear groups of erythematous papules, most frequently on the trunk) (Adler and Larsen, 2011; Adriano et al., 2013; Auth et al., 2005; Carlson et al., 2010; Chu et al., 2013; Diaz-Corpas et al., 2011; Garg \& Cockayne, 2008; Hanada \& Hashimoto, 1998; Hyry \& Kariniemi, 1998; Haas et al., 2001; Kopp et al., 2009; Hérault et al., 2010; Lapresta et al., 2011; Lippert et al., 2003; López-Núnez et al., 2011; Maier \& Herzinger, 2007; Mak \& Wakelin, 2006; Nakamura, 1977, 1992; Nakamura \& Kobayashi, 1985; Poppe et al., 2012; Ricar et al., 2012; Reefman et al., 2013; Schön, 2005; Soo et al., 2006; Tarvainen et al., 1991; Wagner and Sachse, 2011). In Japan, where most of these cases have appeared, it is quite common to consume the mushroom raw or half-cooked. The dermatitis has been described both after consumption of raw and half-cooked Shiitake, but apparently not after consumption of the thoroughly cooked mushroom.

Patch testing and skin prick test are inappropriate as this is not an allergic phenomenon. The exact pathogenesis of the dermatitis is unknown. However, it is speculated that the cause is a toxic reaction to lentinan, a thermolabile polysaccharide in Shiitake. Lentinan is indicated to have anti-tumour properties and the polysaccharide is used as adjuvant in cancer therapy in Japan. Some patients receiving lentinan have also developed a condition similar to flagellate dermatitis (Hanada \& Hashimoto, 1997).

The view that consumption of Shiitake may give health benefits to consumers is particularly strong in some areas of Asia. In this context a study on cholesterol-lowering effects of Shiitake consumption showed that 17 of 49 patients withdraw from the study because of rash or abdominal discomfort, and two had marked eosinophilia. One of the latter patients was subsequently challenged for 14 days with Shiitake and eosinophilia appeared again. Levy et al. (1998) studied 10 healthy subjects 
ingesting $4 \mathrm{~g}$ Shiitake powder for 10 weeks (study A) and later for 3-6 month (study B). Four of the subjects in each study (three being the same in both studies) responded with increased blood eosinophils, serum major basic protein, stool eosinophil-derived neurotoxin, and factors that enhanced eosinophil viability. Anti-Shiitake IgE was not found, and IgG was increased in two subjects. Gastrointestinal symptoms coincided with eosinophilia in two subjects. Stopping exposure resulted in symptoms disappearing. Thus, daily ingestion of Shiitake powder in five of 10 healthy persons provoked non-IgE-mediated systemic modulation of eosinophils (Levy et al., 1998).

Another type of hypersensitivity effect, an allergic reaction, to Shiitake was described by Goikoetxea et al. (2009) in a patient that showed oesophageal symptoms after mushroom ingestion. The allergenicity was confirmed by skin prick tests, basophile activation test, and histamine release test.

Formaldehyde: Formaldehyde occurs naturally in Shiitake (Mason et al., 2004). It is an essential metabolic intermediate in the biosynthesis of purines, thymidine and certain amino acids, and it is also produced via metabolism of some amino acids and xenobiotics. The generation of endogenous formaldehyde involves the two enzymes gamma-glutamyl transpeptidase and L-cysteine sulfoxide lyase (Liu et al., 2013). The background endogenous blood concentration is approximately $2-3 \mathrm{mg} / \mathrm{liter}$ in humans, monkeys and rats (Casanova et al., 1988; Heck et al., 1985).

Formaldehyde has been reported in concentrations of $3-23 \mathrm{mg} / \mathrm{kg}$ (IARC, 1982), $1-90 \mathrm{mg} / \mathrm{kg}$ (IPCS, 1989), 0.01-98 mg/kg (Clayes et al., 2009) and 1-140 mg/kg (Yau, 2007) in a variety of foods. The significance of ingestion of food as a source of formaldehyde exposure for the general population is questionable. Shiitake may contain higher amounts of formaldehyde than other foods. Mason et al. (2004) in a first part of a study reported levels ranging from $110-240 \mathrm{mg} / \mathrm{kg}$ (fresh weight, 7 samples) and in the second part of the study $100-320 \mathrm{mg} / \mathrm{kg}$ (fresh weight, 6 samples). In the second part of the study it was ensured that the mushroom had not been exposed to formaldehyde at any step of the production or later. The authors concluded that fresh Shiitake contains measurable concentrations in the region of $100-300 \mathrm{mg} / \mathrm{kg}$ (fresh weight), and that this formaldehyde is of natural origin in the mushroom. They also concluded that some, but not all of this formaldehyde may be derived from thermal, acidic or enzymatic breakdown of larger endogenous molecules in the mushroom during the analytical procedure. Storage at $4{ }^{\circ} \mathrm{C}$ for 10 days did not change the concentration, whereas frying in oil for 6 minutes reduced the content of formaldehyde 
significantly (Mason et al., 2004). Other studies have confirmed the presence of formaldehyde in Shiitake. Yamazaki et al. (1980) reported levels in the range $25-143 \mathrm{mg} / \mathrm{kg}$ (fresh weight, 46 samples) with no significant change of original content of formaldehyde after drying, but with a significant (less than 100\%) increase after acidic or enzymatic treatment of the fresh or dried mushroom. Yau (2007) reported 6-54 $\mathrm{mg}$ formaldehyde/kg in fresh Shiitake and 100-406 mg/kg in dried mushrooms (dry weight), and Liu et al. (2005) 119-494 mg/kg in dried mushrooms containing 11-13\% residual water.

The International Agency for Research on Cancer (IARC, 2006) has evaluated formaldehyde for carcinogenetic activity. They found that there is sufficient evidence for formaldehyde being carcinogenic in humans and in experimental animals. The conclusion that formaldehyde is carcinogenic in humans is mainly based on epidemiological studies suggesting a causal relationship between inhalation exposure to formaldehyde and cancer in humans. Support is obtained from animal carcinogenicity studies and mechanistic studies indicating that both genotoxicity and cytotoxicity play important roles in the carcinogenesis of formaldehyde in nasal tissues.

In the Twelfth Report on Carcinogens (NTP, 2011a, 2011b) formaldehyde is listed as "known to be a human carcinogen," virtually based on the same data as considered by IARC (2006). However, in the background document for development of the "WHO Guidelines for Drinkingwater Quality," it is stated that "There is little evidence that formaldehyde is carcinogenic by the oral route" (WHO, 2005). Similarly, the "European Food Safety Authority's Scientific Panel on food additives, flavourings, processing aids and materials in contact with food" has especially considered the safety in use of formaldehyde as a preservative during the manufacture of food additives. In its opinion the Panel concluded that there is no evidence indicating that formaldehyde is carcinogenic by the oral route (EFSA, 2006).

An exposure assessment under a worst case scenario characterized by consumption of $100 \mathrm{~g}$ fresh Shiitake with a formaldehyde content of $320 \mathrm{mg} / \mathrm{kg}$ fresh mushroom, once a week all the year, would result in an average daily intake of $0.08 \mathrm{mg}$ formaldehyde/ $\mathrm{kg}$ body weight, assuming a person weighing $60 \mathrm{~kg}$. This is a lower exposure than the Tolerable Daily Intake (TDI) calculated for formaldehyde $(0.15 \mathrm{mg} / \mathrm{kg}$ body weight) by the World Health Organisation for drinking water (WHO, 1996), and also lower than the oral Reference Dose (RfD) of $0.2 \mathrm{mg}$ formaldehyde/kg body weight/day set by the United States Environmental Protection Agency (IRIS, 1990). Both these values are based on a No 
Observed Adverse Effect Level (NOAEL) of $15 \mathrm{mg} / \mathrm{kg}$ body weight/day determined in a two-year oral toxicity study in rats (Til et al., 1989).

The structural formula for formaldehyde is shown below.

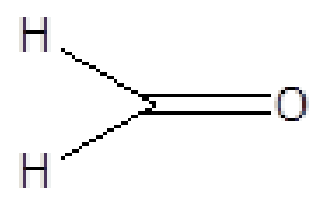

Formaldehyde

Statins: There is very different information on the occurrence of statins in fresh fruit bodies of Shiitake. Whereas Lo et al. (2012) reported relatively high amounts of lovastatin (317 $\mathrm{mg} / \mathrm{kg}$, mean of 3 samples), Lin et al. (2013) only found small amounts $(2.7 \mathrm{mg} / \mathrm{kg}, 3$ samples), Chen et al. (2012) at a level of $412 \mathrm{mg} / \mathrm{kg}$ (mean of 3 samples), and Chen et al. (2012) no lovastatin at all. For further information on statins, see Pleurotus ostreatus.

Ergothioneine: Lee et al. (2009) reported fresh fruit bodies of Shiitake to contain ergothioneine at a level of $1,860 \mathrm{mg} / \mathrm{kg}$ (mean of 3 samples), Chen et al. (2012) at a level of $412 \mathrm{mg} / \mathrm{kg}$ (mean of 3 samples), Nguyen et al. (2012) at a level of $123 \mathrm{mg} / \mathrm{kg}$ (mean of 3 samples) and Lo et al. (2012) at a level of $12 \mathrm{mg} / \mathrm{kg}$ (mean of 3 samples), whereas Ey et al. (2007) reported levels below the limit of detection. Dubost et al. (2006) reported a content of 2,090 mg/kg (mean of 4 samples) in dried Shiitake, which corresponds to approximately $200 \mathrm{mg} / \mathrm{kg}$ fresh mushroom. When grown in submerged culture Shiitake mycelia produced from 600 to 3,500 mg ergothioneine/kg of mycelia (dry weight), the quantity depending on the composition of the growth medium (Tepwong et al., 2012). For further information on ergothioneine, see Lepista nuda.

Agaritine: Agaritine has been detected in fresh Shiitake at the low level of $0.82 \mathrm{mg} / \mathrm{kg}$ (Hashida et al., 1990), but could not be demonstrated in dried Shiitake (limit of detection $300 \mathrm{mg} / \mathrm{kg}$, dry weight, corresponding to less than approximately $30 \mathrm{mg} / \mathrm{kg}$ fresh weight) (Stijve \& Pittet, 2000) and canned Shiitake (Andersson et al., 1999). For further information on agaritine, see Button Mushroom (Agaricus bisporus).

Cyanogenic compounds: Stijve \& de Meijer (1999) have detected small amounts of cyanogenic compounds in fresh Shiitake, corresponding to $6.5-12 \mathrm{mg} / \mathrm{kg}$ (duplicate analysis), whereas Shindo et al. (1999) were unable to detect any hydrogen cyanide in the two samples studied. It is estimated that the content of hydrogen cyanide in cooked Shiitake would be so low, that it is of no health concern (Stijve \& de Mejer, 1999). 
Polyisoprenoid alcohols: Shiitake contains approximately $20 \mathrm{mg} / \mathrm{kg}$ (fresh weight) of polyisoprenoid alcohols having 15-19 isoprene units (dolichols) with dolichol-17 dominating. Additionally, $\alpha$-unsaturated polyisoprenoid alcohols with corresponding chain lengths have also been detected. It is suggested that these polyisoprenoid alcohols, at adequate quantities, can modulate membrane properties (Wojtas et al., 2004).

Acelylenic compounds: The acetylenic compound octa-2,3-diene-5,7diyne-1-ol (named lentinamycin) has been isolated from the culture broth of Shiitake. Lentinamycin has been demonstrated to have antimicrobial effects against gram-negative bacteria (Komemushi et al., 1996). It is not known, whether lentinamycin is also produced in fruit bodies of Shiitake.

Lectins: A number of carbohydrate-binding lectins have been isolated from Shiitake mycelia and the broth in which the mushroom was cultivated (Tsivileva et al., 2001; Vetchinkina et al., 2008a; 2008b; 2008c). However, no data were given on the thermal and $\mathrm{pH}$ stability of the lectins.

A lectin with a molecular mass of $43 \mathrm{kDa}$ has been isolated from Shiitake fruit bodies. It had hemagglutinating activity, which was demonstrated with rabbit erythrocytes. This activity was specifically inhibited by $\mathrm{N}$-acetylgalactosamine, $\mathrm{N}$-acetylglucosamine and mannose. No information was given on the stability of the lectin at various $\mathrm{pH}$ conditions and at various temperatures. Eghianruwa et al. (2011) isolated a homotetrameric lectin with a molecular mass of $71 \mathrm{kDa}$ from Shiittake fruit bodies, with subunits of approximately $18 \mathrm{kDa}$. The lectin binds nonspecifically to $\mathrm{N}$-acetylglucosamine. The hemagglutinating activity is stable up to $70{ }^{\circ} \mathrm{C}$ but the activity is completely abolished at $90{ }^{\circ} \mathrm{C}$. The lectin is unchanged at pH 2-11 (Jeune et al., 1990; Wang et al., 1999).

Some lectins in foods are known to give rise to gastrointestinal distress, if the food is not sufficiently cooked (Liener, 1983). Whether any of the lectins in Shiitake could give rise to adverse effects after consumption of the mushroom is not known.

Purine alkaloids: Three adenine derivatives 4-(6-amino-9H-purin-9yl)-2R, 3R-dihydroxybutyric acid (eritadenine), deoxyeritadenine and 4(6-amino-9H-purin-9-yl)-propionic acid have been isolated from Shiitake (Chibata et al., 1969; Kamiya et al., 1969, 1972; Saito et al., 1970). As Shiitake mushrooms have been shown to have cholesterol reducing effects in both rats (Kaneda \& Tokuda, 1966; Yagishita et al., 1978; Yoon et al., 2011) and humans (Suzuki et al., 1976), and eritadenine has been found to have plasma cholesterol reducing effects in rats (e.g. Chibata et al., 1969; Rokujo et al., 1970; Takashima et al., 1974), considerable interest has been devoted to these compounds. Eritadenine has been reported to occur at fairly high levels in Shiitake - in the range 500-700 
$\mathrm{mg} / \mathrm{kg}$ in the cap and in the range 300-400 $\mathrm{mg} / \mathrm{kg}$ in the stem (dry weight) (Saito et al., 1975; Vitanyi et al., 1998). In more recent studies, up to ten times higher levels have been reported in Shiitake fruit bodies, about 3,200 to $6,300 \mathrm{mg} / \mathrm{kg}$ dry weight (Enman et al., 2007), corresponding to approximately $320-630 \mathrm{mg} / \mathrm{kg}$ fruit body (fresh weight). In submerged culture, eritadenine was detected at similar levels in mycelia and broth (Enman et al., 2008). The level in the mycelia was in the range $160-1100 \mathrm{mg} / \mathrm{kg}$ (dried biomass) (Enman et al., 2008; Lelik et al., 1997). Whether eritadenine could have any adverse effects in humans is not known.

The structural formula for eritadenine is shown below:<smiles>Nc1ncnc2c1ncn2C[C@H](O)[C@H](O)C(=O)O</smiles>

Eritadenine

Sulfur-containing volatile constituents: Fresh fruit bodies of Shiitake are almost odourless (Wu \& Wang, 2000). However, after cutting/crushing, drying and then soaking and heating some 20 sulfur-containing, organic, volatile substances may be formed (Chen \& Ho, 1986; Chiron \& Michelot, 2005; Morita \& Kobayashi, 1967). Fresh Shiitake contains a tetrathiodipeptide, lentinic acid, which after sequential enzymatic reactions by $\gamma$-glutamyl transpeptidase and C/S-lyase, and subsequent thermochemical reactions may give rise to several sulfur-containing flavouring substances (Höfle et al., 1976; Sneeden et al., 2004). According to Chen \& Ho (1986) the quantitatively most important sulfur-containing compounds in fresh homogenates of Shiitake fruit bodies are 1,2,4-trithiolane, 1,2,4,5-tetrathiane and lenthionine (1,2,3,5,6-pentathiepane), occurring at levels of approximately 3,9 and $9 \mathrm{mg} / \mathrm{kg}$, respectively.

The major volatile flavouring substances identified in Shiitake have been risk assessed by the European Food Safety Authority (EFSA, 2012). They were found to be of no safety concern at estimated levels of intake. However, most of the sulfur-containing volatiles could not be predicted to be metabolized to innocuous products. Therefore animal studies were considered and No Observed Adverse Effect Levels (NOAEL's) were de- 
termined in order to establish safety margins for the food use (EFSA 2012). Lenthionine, the characteristic flavouring substance in Shiitake, is reported at a level of approximately $9 \mathrm{mg} / \mathrm{kg}$ of fresh, homogenised Shiitake fruit bodies (Chen \& Ho, 1986). With a human intake of $100 \mathrm{~g}$ Shiitake once a week for life-time, an average daily intake of $0.02 \mathrm{mg}$ lenthionine/kg body weight/day would result, assuming a body weight of 60 $\mathrm{kg}$. When comparing this estimated level of intake with the NOAELs estimated in the 5 animal studies $(0.2-7 \mathrm{mg} / \mathrm{kg}$ body weight/day) used for the evaluation of these flavourings by EFSA (2012), a safety margin between 100 and 3,500 was established. For other major cyclic sulfurcontaining flavourings the safety margins would be the same or higher.

The structural formula for lenthionine is shown below:

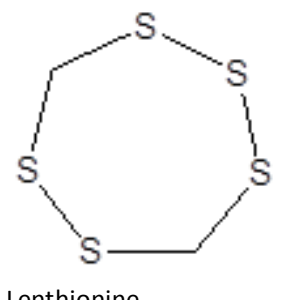

\section{Toxicity studies}

Mutagenicity studies: von Wright et al. (1982) reported that extracts of Shiitake are weakly mutagenic in the Ames assay, using the histidinerequiring Salmonella typhimurium strains TA1535, TA1537 and TA1538. As the test system detects back-mutations from histidine requirement to histidine auxotrophy, presence of histidine or precursors of this amino acid (which may occur in mushrooms) in the test solution has the capability to induce false positives. It is unclear whether von Wright et al. (1982) controlled for the presence of histidine or histidine precursors in the mushroom extract. However, Grüter et al. (1991), using a histidineindependent bacterial test system, identified no mutagenic activity in extracts of Shiitake. Altogether, it is not likely that extracts of Shiitake are mutagenic.

Short-term oral mouse study: Nieminen and co-workers (2009) have published a study on the potential myo- and hepatotoxic effects of different cultivated mushrooms in mice. The animals (six females per group) were for 5 days supplied large quantities of dried and powdered cultivated mushrooms in the feed. One of the cultivated mushrooms, Shiitake, was given as $1.8 \%, 3.6 \%$ or $5.4 \%$ of the feed. The feeding resulted in mice being exposed to 19,42 and $61 \mathrm{~g} / \mathrm{kg}$ body weight per day, respectively, which is equivalent to humans ingesting $1.4,2.9$ and $4.3 \mathrm{~kg}$ 
Shiitake per person (70 kg), or when corrected for body surface constant, 113, 244 and $358 \mathrm{~g}$ fresh Shiitake per person $(70 \mathrm{~kg})$ per day, respectively. Of the many clinical parameters studied, plasma bilirubin and creatine kinase levels were significantly increased, but not in a doserelated manner. Plasma HDL/total cholesterol was significantly reduced, reaching statistical significance at the two highest doses of Shiitake intake (Nieminen et al., 2009). The HDL/total cholesterol lowering effect might be due to the mushroom containing eritadenine.

Oral 28-day rat study: Two groups, each of 10 male and 10 female rats, received by gavage either an aqueous suspension of $2 \mathrm{~g} / \mathrm{kg}$ body weight/day of an extract of cultivated Shiitake mycelium or distilled water (control group) for 28 days. Body weight and food consumption were significantly reduced in the group administrated Shiitake extract, especially in males, but the weight reduction was less than $10 \%$ at the end of the study, when comparing with the control group. Of the many clinical-biochemical parameters measured serum total cholesterol was significantly reduced in dosed animals. No toxicologically relevant effect was observed on hematological and biochemical examinations, absolute and relative organ weights, macroscopic findings and histological findings at the end of the administration (Yoshioka et al., 2010).

\section{Recommendation}

Shiitake should be thoroughly cooked, as consumption of the raw or insufficiently cooked mushroom may cause dermatitis.

Listing 1

\section{Database search information}

SciFinder by January 2012. Keywords: Lentinula or Lentinus or Shiitake. PubMed by December 2012. Keywords: Lentinula or Lentinus or Shiitake.

\section{References}

Adler MJ \& Larsen WG (2012): Clinical variability of Shiitake dermatitis. Journal of the American Academy of Dermatology 67: e140-e141.

Adriano AR, Acosta ML, Azulay DR, Quiroz CD \& Talarico SR (2013): Shiitake dermatitis: the first case reported in Brazil. Anais Brasileiros de Dermatologia 88: 417-419.

Andersson HC, Hajslova J, Schulzova V, Panovska Z, Hajkova L \& Gry J (1999): Agaritine content in processed foods containing the cultivated mushroom (Agaricus bisporus) on the Nordic and Czech market. Food Additives and Contaminants 16: 439-446.

Auth M, Wienrich BG, Bauer B, Seitz CS, Bröcker EB \& Schön MP (2005): Striate urticarial erythemas on trunk and extremities. Journal der Deutsche Dermatologische Gesellschaft 3: 812-814. 
Bisen PS, Baghel RK, Sanodiya BS, Thakur GS \& Prasad GBKS (2010): Lentinus edodes: A macrofungus with pharmacological activities. Current Medicinal Chemistry 17: 2419-2430.

Carlson S, Stuckert J \& Nedorost S, 2010: Shiitake mushroom dermatitis. Dermatitis 21: 290-291.

Casanova M, Heck HD, Everitt JI, Harrington WW Jr \& Popp JA (1988): Formaldehyde concentrations in the blood of rhesus monkeys after inhalation exposure. Food and Chemical Toxicology 26: 715-716.

Chang FACP (1996): Functional properties of edible mushrooms. Nutrition Reviews 54: S91-S93.

Chang S-T \& Miles PG (2004): Mushrooms. Cultivation, nutritional value, medicinal effect, and environmental Impact. CRC Press, Boca Raton: 1-351.

Chang ST \& Wasser SP (2012): The role of culinary-medicinal mushrooms on human welfare with pyramid model for human health. International Journal of Medicinal Mushrooms 14: 95-134.

Chen C-C \& Ho C-T (1986): Identification of sulfuruos compounds of Shiitake mushroom (Lentinus edodes Sing.). Journal of Agricultural and Food Chemistry 34: 830-833.

Chen S-Y, Ho K-J, Hsieh Y-J, Wang L-T \& Mau J-L (2012): Contents of lovastatin, $\gamma$ aminobutyric acid and ergothioneine in mushroom fruiting bodies and mycelia. IWT - Food Science and Technology 47: 274-278.

Chibata I, Okumura K, Takeyama S \& Kotera K (1969): Lentinacin: a new hypocholesterolemic substance in Lentinus edodes. Experientia 25: 1237-1238.

Chiron N \& Michelot D (2005): Odeurs des Champignons: Chimie et role dans les interactions biotiques - une revue. Cryptogamie, Mycologie 26: 299-364.

Chu EY, Anand D, Dawn A, Elenitsas R \& Adler DJ (2013): Shiitake dermatitis: a report of 3 cases and review of the literature. Cutis 91: 287-290.

Claeys W, Vleminckx C, Dubois A, Huyghebaert A, Höfte M, Daenens P \& Schiffers B (2009): Formaldehyde in cultivated mushrooms: a negligible risk for the consumer. Food Additives and Contaminats 9: 1265-1272.

Diaz-Corpas T, Mateu-Puchades A, Coll-Puigserver MN \& Marquina-Vila A (2011): Flagellate dermatitis after eating shiitake mushrooms. Actas Dermosifiliográficas 102: 830-832.

Dubost NJ, Beelman RB, Petersson D \& Royse DJ, (2006): Identification and quantification of ergothioneine in cultivated mushrooms by liquid chromotography-mass spectroscopy. International Journal of Medicinal Mushrooms 8: 215-222.

EFSA (2006): European Food Safety Authority. Opinion of the Scientific Panel on food additives, flavourings, processing aids and materials in contact with food (AFC) on a request from the Commission related to "Use of formaldehyde as a preservative during the manufacturing and preparation of food additives". The EFSA Journal 415: 1-10.

EFSA (2012): European Food Safety Authority. Scientific opinion on flavouring group evaluation 08, revision 5 (FGE.08Rev5): Aliphatic and alicyclic mono-, di-, tri-, and polysulphides with or without additional oxygenated groups from chemical groups 20 and 30. The EFSA Journal 10: 1-139.

Eghianruwa Q, Odekanyin O \& Kuku A (2011): Physicochemical properties and acute toxicity studies of a lectin from the saline extract of the fruiting bodies of the shiitake mushroom, Lentinula edodes (Berk). International Journal of Biochemistry \& Molacular Biology 2: 309-317. 
Enman J, Rova U \& Berglund KA (2007): Quantification of the bioactive compound eritadenine in selected strains of Shiitake mushoom (Lentinus edodes). Journal of Agricultural and Food Chemistry 55: 1177-1180.

Enman J, Hodge D, Berglund KA \& Rova U (2008): Production of the bioactive compound eritadenine by submerged cultivation of Shiitake (Lentinus edodes) mycelia. Journal of Agricultural and Food Chemistry 56: 2609-2612.

Ey J, Schömig E \& Taubert D (2007): Dietary sources and antioxidant effects of ergothioneine. Journal of Agricultural and Food Chemistry 55: 6466-6474.

Garg S \& Cockayne SE (2008): Shiitake dermatitis diagnosed after 16 years. Archives of Dermatology 144: 1241-1242.

Goikoetxea MJ, Fernández-Benítez M \& Sanz ML (2009): Food allergy to Shiitake (Lentinus edodes) manifested as oesophageal symptoms in a patient with probable eosinophilic oesophagitis. Allergologia et Immunopatholia 37: 333-334.

Grüter A, Friederich U \& Würgler FE (1991): The mutagenicity of edible mushrooms in a histidine-independent bacterial test system. Food and Chemical Toxicology 29: 159-165.

Haas N, Vogt R \& Sterry W (2001): Shiitake-Dermatitis. Flagella(n)ten-Dermatitis nach Pilzgenuss. Der Hautarzt 52: 132-135.

Hanada K \& Hashimoto I. (1998): Flagellate mushroom (Shiitake) dermatitis and photosensitivity. Dermatology 197: 255-257,

Hashida C, Hayashi K, Haga S, Sakurai M \& Shimizu H (1990): Quanitities of agaritine in mushroom (Agaricus bisporus) and the carcinogenicity of mushroom methanol extracts on the mouse bladder epithelium. Nippon-Koshu-Eisei-Zasshi 37: 400405. (Japanese, English abstract available).

Heck HD, Casanova-Schmitz M, Dodd PB, Schachter EN, Witek TJ \& Tosun T (1985): Formaldehyde $\left(\mathrm{CH}_{2} \mathrm{O}\right)$ concentraions in the blood of humans and Fischer-344 rats exposed to $\mathrm{CH}_{2} \mathrm{O}$ under controlled conditions. American Industrial Hygiene Association Journal 46: 1-3.

Hérault M, Waton J, Bursztejn AC, Schmutz JL \& Barbaud A. (2010): La shiitake dermatitis (dermatose toxique au lentin) est arrive en France. Annales de Dermatologie et de Venereologie 137: 290-293.

Hongo T \& Izawa M (2006): Kinoko (Fungi) 1-383 (Japanese).

Höfle G, Gmelin R, Luxa H-H, N'Galamulume-Treves M \& Hatanaka SI (1976): Struktur der Lentinsäure: 2-( $\gamma$-glutamylamino)-4,6,8,10, 10-pentaoxo-4,6,8,10tetrathiaundecansäure. Tetrahedron Letters 17: 3129-3132.

Hyry H \& Kariniemi AL (1998): Siitakedermatiitti: siitakesienet kypsennettävä ennen käyttöä. Duodecim 114: 555-557. (Finnish, English abstract available).

IARC (1982): International Agency for Research on Cancer. IARC Monographs on the Carcinogenic Risk of Chemicals to Humans. Some industrial chemicals and dyestuffs. Volume 29: 345-389.

IARC (2006): International Agency for Research on Cancer. Monographs on the Evaluation of Carcinogenic Risk to Humans. IARC Monographs on the Carcinogenic Risk of Chemicals to Humans. Formaldehyde, 2-butoxyethanol and 1-tert.butoxypropan2-ol. Volume 88: 401-435.

IPCS (1989): International Programme on Chemical Safety. Environmental Health Criteria. Formaldehyde: 9. http://www.inchem.org/documents/ehc/ehc/ehc89.htm

IRIS (1990): Integrated Risk Information System. Formaldehyde. United States Environmental Protection Agency. Last revised 09/01/1990. http://www.epa.gov/ iris/subst/0419.htm 
Jeune KH, Moon IJ, Kim MK \& Chung SR (1990): Studies on lectins from Korean higher fungi; IV A Mitogenic lectin from the mushroom Lentinus edodes. Planta Medica 56: 592.

Kamiya T, Saito Y, Hashimoto M \& Seki H (1969): Structure and synthesis of lentysine, a new hypocholesterolemic substance. Tetrahedron 10: 4729-4732.

Kamiya T, Saito Y, Hashimoto M \& Seki H (1972): Hypocholesterolemic alkaloids of Lentinus edodes (Berk.) Sing. - I. Structure and synthesis of eritadenine. Tetrahedron 28: 899-906.

Kaneda T \& Tokuda S (1966): Effect of various mushroom preparations on cholesterol levels in rats. Journal of Nutrition 90: 371-376.

Komemushi S, Yamamoto Y \& Fujita T (1996): Purification and identification of antimicrobial substances produced by Lentinus edodes. Journal of Antibacterial and Antifungal Agents 1: 21-25. (Japanese, English abstract available).

Kopp T, Mastan P, Mothes N, Taneva S, Stingl G \& Tanew A (2009): Systemic allergic contact dermatitis due to consumption of raw shiitake mushroom. Clinical dermatology 34: e910-e913.

Lapresta A, de Miguel R, Sánchez-Moya AI, Robuschi F \& Cardona C (2011): Letter: Dermatitis shiitake en una paciente espanola. Dermatology Online Journal 17(12): 16.

Lee WY; Park E-J, Jin K \& Ka K-H (2009): Ergothioneine contents in fruiting bodies and their enhancement in mycelial cultures by addition of methionine. Mycobiology 37: 43-47.

Lelik L, Vitanyi G, Lefler J, Hegoczky J. Nagy-Gasztonyi M \& Vererzkey G (1997): Production of the mycelium of shiitake (Lentinus edodes) mushroom and investigation of its bioactive compounds. Acta Alimentarius 26: 271-277.

Levy AM, Kita H, Phillips SF, Schkade PA, Dyer PD, Gleich GJ \& Dubravec VA (1998): Eosinophilia and gastrointestinal symptoms after ingestion of shiitake mushrooms. Journal of Allergy and Clinical Immunology 101: 613-620.

Liener IE (1983): Naturally occurring toxicants in food and their significance in the human diet. Archives of Toxicology Supplements 6: 153-166.

Lin S-Y, Chen Y-K, Yu H-T, Barseghyan GS, Asatiani MD, Wasser SD \& Mau J-L (2013): Comparative study of contents of several bioactive component in fruiting bodies and mycelia of culinary-medicinal mushrooms. International Journal of Medicinal Mushrooms 15: 313-327.

Lindequist U, Rausch R, Füssel A \& Hanssen HP (2010): Höhere Pilze in der traditionellen Heilkunde und Medizin. Medizinische Monatsheft für Pharmazeuten 33: 40-48.

Lippert U, Martin V, Schwertfeger C, Junghans V, Ellinghaus B \& Fuchs T (2003): Shiitake dermatitis. British Journal of Dermatology 148: 178-179.

Liu J-f, Peng J-f, Chi Y-g \& Jiang G-b (2005): Determination of formaldehyde in shiitake mushroom by ionic liquid-based liquid-phase microextraction coupled with liquid chromatography. Talanta 65: 705-709.

Liu Y, Yuan Y, Lei X-y, Yang H, Ibrahim SA \& Huang W (2013): Purification and characterisation of two enzymes related to endogenous formaldehyde in Lentinula edodes. Food Chemistry 138: 2174-2179.

Lo Y-C, Lin S-Y, Ulziijargal E, Chen S-Y, Chien R-C, Tzou Y-J \& Mau J-L (2012): Comparative study of contents of several bioactive components in fruiting bodies and mycelia of culinary-medicinal mushrooms. International Journal of Medicinal Mushrooms 14: 357-363.

López-Núnez M, Jaka-Moreno A \& Tuneu-Valls A (2012): Pregnant woman with flagellate erythema. Actas Dermosifiliográficas 103: 155-156.

Maier T \& Herzinger T (2007): Linear dermatitis due to shiitake mushrooms. Der Hautarzt 58: 1021-1022. 
Mak RK \& Wakelin SH (2006): Shiitake dermatitis: the first case reported from a European country. British Journal of Dermatology 154: 800-801.

Mason DJ, Sykes MD, Panton SW \& Rippon EH (2004): Determination of naturallyoccuring formaldehyde in raw and cooked Shiitake mushrooms by spectrophotometry and liquid chromatography-mass spectrometry. Food Additives and Contaminants 21: 1071-1082.

Mizuno T, Sakai T \& Chihara G (1995): Health foods and medicinal usages of mushrooms. Food Reviews International 11: 69-81.

Morita K \& Kobayashi S (1967): Isolation, structure and synthesis of lenthionine and its analogs. Chemical and Pharmaceutical Bulletin 15: 988-993.

Nakamura T (1977): Toxicoderma caused by shiitake (Lentinus edodes). Japanese Journal of Clinical Dermatology 31: 65-68 (Japanese, English abstract available).

Nakamura T (1992): Shiitake (Lentinus edodes) dermatitis. Contact Dermatitis 27: 65-70 (Japanese, English text avaiable).

Nakamura T \& Kobayashi A (1985): Toxikodermie durch den Speisepilz Shiitake (Lentinus edodes). Der Hautarzt 36: 591-593.

Nguyen H, Giri A \& Ohshima T (2012): A rapid HPLC post column reaction analysis for quantification of ergothioneine in edible mushrooms and in animals fed a diet supplemented with extracts from the processing waste of cultivated mushrooms. Food Chemistry 133: 585-591.

Nieminen P, Kärjä V \& Mustonen A-M (2009): Myo- and hepatotoxic effects of cultivated mushrooms in mice. Food and Chemical Toxicology 47: 70-74.

NTP (2011a): National Toxicology Program. US Departement of Health and Human Services. Formaldehyde. Report on Carcinogens, Twelfth Edition: 195-206.

NTP (2011b): National Toxicology Program. US Departement of Health and Human Services. Addendum to the 12 th Report on Carcinogens: 1-6.

Poppe LM, Kneitz H, Benoit S, Anders D \& Bröcker E-B (2012): Flagellate dermatitis caused by shiitake mushrooms. Anais Brasileiros de Dermatologia 87: 463-466.

Reefman K, Galvis Martinez J-G \& Daelmans HEM (2013): Een vrouw met streepvormige huidafwijkingen. Nederlands Tijdschrift voor Geneeskunde 157: A5964.

Ricar J, Pizinger K \& Cetkovska P (2013): Shiitake dermatitis: a distinctive clinical entity. International Journal of Dermatology 52: 1567-1624.

Rokujo T, Kikuchi H, Tensho A, Tsukitani Y, Takenawa T, Yoshida K \& Kamiya T (1970): Lentysine: a new hypolipidemic agent from a mushroom. Life Sciences 9 (part II): 379-385.

Saito Y, Hashimoto M, Seki H \& Kamiya T (1970): Two new constituents from Lentinus edodes. Tetrahedron Letters 11: 4863-4866.

Saito M, Yasumoto T \& Kaneda T (1975): Quantitative analysis of eritadenine in "Shii-ta-ke" mushroom and other edible fungi. Journal of Janpanese Society of Food and Nutrition 28: 503-513 (Japanese, English abstract available).

Schön MP (2005): Diagnose: Flagella(n)tendermatitis. Flagellate dermatitis. Journal der Deutschen Dermatologiscken Gesellschaft 3: 814.

Shindo T, Ushiyama H, Kan K \& Yasuda K (1999): Study on content of cyanide in Basidiomycetes and the effect of cooking. Journal of Food Hygienic Society of Japan 40: 29-35. (Japanese, English abstract available).

Sneeden EY, Harris HH, Pickering IJ, Prince RC, Johnson S, Li X, Block E \& George GN (2004): The sulfur chemistry of Shiitake mushroom. Journal of American Chemical Society 126: 458-459. 
Soo JK, Pearson IC \& Misch KJ (2007): A case of flagellation. Clinical and Experimental Dermatology 32: 339-340.

Stijve T \& de Meijer AAR (1999): Hydrocyanic acid in mushrooms, with special reference to wildgrowing and cultivated species. Deutsche Lebensmittel Rundschau 95: 366-373.

Stijve T \& Pittet A (2000): Absence of agaritine in Pleurotus species and in other cultivated and wild-growing mushrooms not belonging to the genus Agaricus. Deutsche Lebensmittel-Rundschau 96: 251-254.

Suzuki S \& Ohshima S (1976): Influence of Shiitake (Lentinus edodes) on human serum cholesterol. Annual Report of the National Institute of Nutrition, No 25, Tokyo, Japan: 89-94.

Takashima K, Sato C, Sasaki Y, Morita T \& Takeyama S (1974): Effect of eritadenine on cholesterol metabolism in the rat. Biochemical Pharmacology 23: 433-438.

Tarvainen K, Salonen JP, Kanerva L, Estlander T, Keskinen H \& Rantanen T (1991): Allergy and toxicodermia from shiitake mushrooms. Journal of the American Academy of Dermatology 24: 64-66.

Tepwong P, Giri A, Sasaki F, Fukui R \& Ohshima T (2012): Mycobial enhancement of ergothioneine by submerged cultivation of edible mushroom mycelia and its application as an antioxidative compound. Food Chemistry 131: 247-258.

Til HP, Woutersen RA, Feron VJ, Hollanders VHM \& Falke HE (1989): Two-year drinking water study of formaldehyde in rats. Food and Chemical Toxicology 56: 79-86.

Tsivileva OM, Nikitina VE, Garibova LV, Zav'yalova LA \& Ignatov VV (2000): Hemagglutinating activity of the fungus Lentinus edodes (Berk.) Sing [Lentinus edodes (Berk.) Pegler]. Microbiology 69: 30-35.

Tsivileva OM, Nikitina VE \& Loshchinina EA (2008): Isolation and characterization of Lentinus edodes (Berk.) Singer extracellular lectins. Biochemistry (Moscow) 73: 1154-1161.

Vetchinkina EP, Pozdnyakova NN \& Nikitina VE (2008a): Laccase and lectin activities of intracellular protein produced in a submerged culture of the xylotrophic basidiomycete Lentinus edodes. Current Microbiology 57: 381-385.

Vetchinkina EP, Nikitina VE, Tsivileva OM \& Garibova LV (2008b): Activity of Lentinus edodes intracellular lectins at various developmental stages of the fungus. Applied Biochemistry and Microbiology 44: 66-72.

Vetchinkina EP, Sokolov OI \& Nikitina VE (2008c): Intracelluar lectins of Lentinus edodes at various developmental stages of the fungus. Mikrobiologiia 77: 496-501 (Russian, English abstract available).

Vitanyi G, Lelik L, Bihatsi-Karsai E, Lefler J, Nagy-Gasztonyi M \& Vereczkey G (1998): Detection of eritadenine in extracts from shiitake mushroom by gas chromatography/mass spectrometry. Rapid Communication in Mass Spectrometry 12: 120-122.

Wagner G \& Sachse MM (2011): Parallel angeordnete streifenförmige Erytheme am Nacken, and den Schultern und am vorderen Dekolleté. Journal of the German Society of Dermatology 9(7): 555-557.

Wang HX, Ng TB \& Ooi VEC (1999): Studies on purification of a lectin from fruiting bodies of the edible shiitake mushroom Lentinus edodes. The International Journal of Biochemistry \& Cell Biology 31: 595-599.

WHO (2005): World Health Organisation. Formaldehyde in drinking water. Background document for development of WHO guidelines for drinking-water quality: 1-10.

Wojtas M, Bienkowski T, Tateyama S, Sagami H, Chojnacki T, Danikiewicz W \& Swiezewska E (2004): Polyisoprenoid alcohols from the mushroom Lentinus edodes. Chemistry and Physics of Lipids 130: 109-115. 
Wu C-M \& Wang Z (2000): Volatile compounds in fresh and processed Shiitake mushrooms (Lentinus edodes Sing.). Food Science and Technology Research 6: 66-170.

Yamazaki H, Ogasawara Y, Sakai C, Yoshiki M, Makino K, Kishi T \& Kakiuchi Y (1980): Studies on formaldehyde in Lentinus edodes. Journal of the Food Hygiene Society of Japan 21: 165-170 (Japanese, English abstract available).

Yau A (2007): Formaldehyde in food. Centre for Food Safety. Hong Kong. http://www.cfs.gov.hk/english/multimedia/multimedia_pub/ multimedia_pub_fsf_06_01.html

Yoon KN, Alam N, Lee JS, Cho HJ, Kim HY, Shim MJ, Lee MW \& Lee TS (2011): Antihyperlipidemic effect of dietary Lentinus edodes on plasma, feces and hepatic tissues in hypercholesterolemic rats. Mycobiology 39: 96-102.

Yoshioka Y, Tamesada M \& Tomi H (2010): A repeated dose 28-day toxicity study of extract from cultured Lentinula edodes mycelia in Wistar rats. The Journal of Toxicological Sciences 35: 785-791.

\section{Lentinus edodes (Berk.) Singer}

See Lentinula edodes.

\section{Lepiota olivieri Barla}

See Chlorophyllum olivieri.

\section{Lepiota rhacodes (Vittad.) Quél.}

See Chlorophyllum rachodes.

\section{Lepista nebularis (Batsch) Harmaja}

See Clitocybe nebularis. 


\section{Lepista nuda (Bull.) Cooke (Tricholoma nudum (Bull.) P. Kumm.)}

Wood Blewit (DK: Violet Hekseringshat ("Blåfod"), FI: Sinivalmuska, IS: Fjólujússa, NO: Blå ridderhat, SE: Blåmusseron).

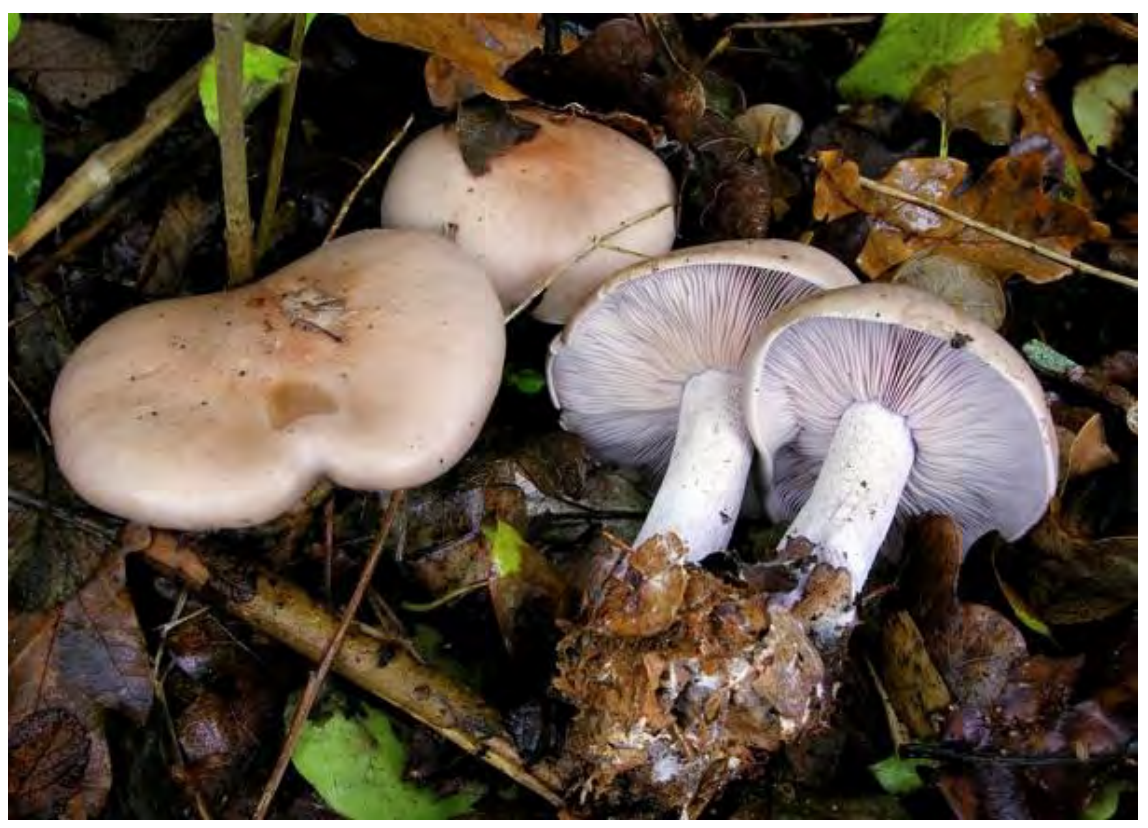

\section{Background and risk assessment}

Wood Blewit (Lepista nuda) is an edible mushroom. However, Wood Blewit may give rise to gastrointestinal symptoms, sometimes severe, if eaten raw - or insufficiently cooked (Beug et al., 2006; Bresinsky \& Besl, 1985; Roth et al., 1990).

Wood Blewit is a saprotrophic mushroom. It grows in gardens, parks and forests in nitrogen rich soil, e.g. deep needle beds, heaps of leaves and compost, often in fairy rings. It is very common in temperate/hemiboreal/boreal zones and occasional in subalpine/subarctic zones of the Nordic countries (Knudsen \& Vesterholt, 2012). Wood Blewit may also be cultivated.

No intoxications have been reported after consumption of thoroughly cooked Wood Blewit. However, it contains several potentially bioactive constituents. 


\section{Bioactive constituents}

Hydrogen cyanide: Wood Blewit may contain small amounts of cyanogenic compounds corresponding to 15-29 mg hydrogen cyanide per $\mathrm{kg}$ fresh mushroom (Stijve \& de Meijer, 1999). During cooking, most of the hydrogen cyanide disappears and the precursors are apparently destroyed. Therefore, consumption of cooked Wood Blewit does not pose any hazard with respect to hydrogen cyanide.

Lectins: Like many other mushrooms the Wood Blewit contains lectin(s). Zaremba (1973) isolated and partially purified a lectin from Wood Blewit and demonstrated that it has hemagglutinating activity on different animal erythrocytes. Also Mikiashvili et al. (2006) have demonstrated lectin activity in extracts from fruit bodies of the mushroom (on rabbit erythrocytes). However, the lectin(s) is(are) not well characterised, neither with respect to binding capacity and stability nor to molecular weight.

Ergothioneine: Wood Blewit may contain 5.5 g per kg (dry weight) in the fruit bodies of the non-protein amino acid ergothioneine as shown by Lee et al. (2009). Ergothioneine is biosynthesized by mycobacteria, cyanobacteria and non-yeast-like fungi, including many edible mushrooms. For instance, dried fruit bodies of edible Pleurotus species, Shiitake (Lentinula edodes) and Button Mushroom (Agaricus bisporus) may contain in the range of 0.1-2.9 g ergothioneine per $\mathrm{kg}$ (Chen et al., 2012a; Dubost et al., 2006; Ey et al., 2007; Lee et al., 2009; Lin et al., 2013; Lo et al., 2012). Generally ergothioneine has been found in somewhat lower amounts in other edible mushrooms (Chen et al., 2012a; Dubost et al., 2006; Ey et al., 2007; Lee et al., 2009; Lin et al., 2013; Lo et al., 2012). Whereas food processing destroys some bioactive constituents, a considerable proportion of the ergothioneine remains unchanged (Ulziijargal et al., 2013).

Ergothioneine has in numerous in vitro and in a few in vivo studies been shown to have antioxidative and cytoprotective properties against a wide range of cellular stressors and it is anticipated to have a potential as a physiological antioxidant (e.g. Song et al., 2010). It has been shown that ergothioneine can be absorbed from food and accumulate in specific tissues of mammals (including humans) via the highly specific ergothioneine transporter (Cheah and Halliwell, 2012; Gründemann, 2012). However, the physiological role of ergothioneine is not well understood and the consequence of ergothioneine deficiency is unclear. Ergothioneine transporter has been suggested as a possible factor in the autoimmune diseases rheumatoid arthritis and Crohn's disease and patients with rheumatoid arthritis have high levels of ergothioneine (Cheah \& Halliwell, 2012; Ey et al., 2007; Gründemann, 2012; Seebeck, 2013; 
Weigand-Heller et al., 2012). No adverse effects have been related to even high intakes of the compound. The structural formula of ergothioneine is shown below.<smiles>C=C(O)C(Cc1c[nH]c(=S)[nH]1)[N+](C)(C)C</smiles>

Ergothioneine

Tryptophan metabolites: Fruit bodies of Wood Blewit have been shown to contain several metabolites of tryptophan: 3-indole acetic acid, 3-indole propionic acid, kynurenine and 3-hydroxykynurenine (Kohlmunzer \& Wegiel, 2001). As no quantitative data were available, it is not possible to estimate the potential risk from these bioactive constituents.

Acetylenic compounds: Two acetylenic compounds, diatretyne 2 and 3 , have been isolated from the culture liquid of Wood Blewitt and their structures elucidated as (2E)-7-cyano-2-heptene-4,6-diynoic acid and (2E)-10-hydroxy-2-decene-4,6,8-triynoic acid, respectively (Anchel, 1953; 1955; 1958; 1959; Anchel et al., 1962; Heatley \& Stephenson, 1957; Silverman \& Anchel, 1958). Diatretyne 2 was studied for its antibiotic properties and was shown to inhibit the growth of several different bacteria and fungi (Anchel, 1958). More recently, Dighe \& Agathe (2000) demonstrated the presence of an antibacterial polyacetylenic compound in a culture filtrate from Wood Blewit. The compound was not well characterized, but as it was water soluble, it is unlikely to be one of the more lipophilic diatrynes. It is not known whether the abovementioned acetylenic compounds also can be found in the fruit bodies.

The structural formula for one of these diatretynes, diatretyne 2 is shown below.

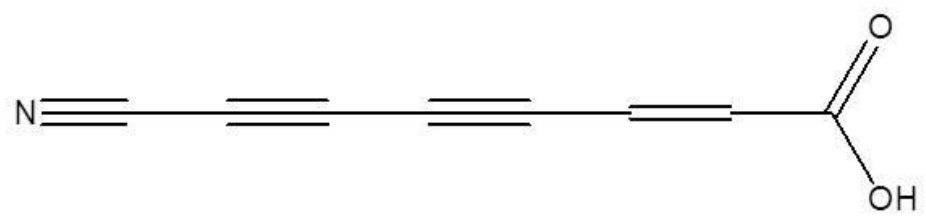

2(E)-7-Cyano-2-heptene-4,6-diynoic acid (Diatretyne 2) 
Other metabolites: Extracts from the fruit body or mycelia from Wood Blewit have been shown to have antimicrobial activity, e.g. against certain human pathogenic bacteria and certain plant pathogenic fungi (Chen et al., 2012a; Chen \& Huang, 2009). Chen et al. (2012b) isolated and identified three bioactive constituents inhibiting the zoospore germination of Phytophthora capsici from the fluid of Wood Blewit grown in culture: 2-methoxy-5-methyl-6-methoxy-p-benzoquinone, 6-hydroxy$2 \mathrm{H}$-pyran-3-carbaldehyde and indole-3-carbaldehyde. There are no data available demonstrating the potential occurrence of these bioactive compounds in the fruit bodies of Wood Blewit.

Recommendation

No special recommendation.

Listing 1 (as cultivated); 2 (as wild)

\section{Database search information}

SciFinder by December 2012. Keywords: Lepista nuda or Clitocybe nuda or Tricholoma nudum. PubMed by December 2012. Keywords: Lepista or Clitocybe or Tricholoma.

\section{References}

Anchel M (1953): Identification of an antibiotic polyacetylene from Clitocybe diatreta as a suberamic acid ene-diyne. Journal of American Chemical Society 75: 4621-4622.

Anchel M (1955): Structure of diatretyne 2, an antibiotic polyacetylenic nitrile from Clitocybe diatreta. Science 121: 607-608.

Anchel M (1958): Metabolic products of Clitocybe diatreta. I. Diatretyne amide and diaretyne nitrile. Archives of Biochemistry and Biophysics 78: 100-110.

Anchel M (1959): Metabolic products of Clitocybe diatreta. III. Characterization of diatretyne 3 as trans-10-hydroxy-dec-2-en-4,6,8-trynoic acid. Archives of Biochemistry and Biophysics 78: 569-571.

Anchel M, Silverman WB, Valanju N \& Rogerson CT (1962): Patterns of polyacetylene production I. The diatretynes. Mycologia 54: 249-257.

Beug MW, Shaw M \& Cochran KW (2006): Thirty-plus years of mushroom poisoning: Summary of the approximately 2,000 reports in the NAMA Case Registry, Mcllvainea 16: 47-67.

Bresinsky A \& Besl H (1985): Giftpilze. Wissenschaftliche Verlagsgesellschaft mbH: 1-295.

Cheah IK \& Halliwell B (2012): Ergothioneine; antioxidant potential, physiological function and role in disease. Biochimica et Biophysica Acta 1822: 784-793.

Chen J-T \& Huang J-W (2009): Control of plant diseases with secondary metabolite of Clitocybe nuda. New Biotechnology 26: 193-198. 
Chen S-Y, Ho K-J, Hsieh Y-J, Wang L-T \& Mau J-L (2012a): Contents of lovastatin, $\gamma$ aminobutyric acid and ergothioneine in mushroom fruiting bodies and mycelia. Food Science and Technology 47: 274-278.

Chen J-A, Su H-J \& Huang J-W (2012b): Isolation and identification of secondary metabolites of Clitocybe nuda responsible for inhibition of zoospore germination of Phytophthora capsici. Journal of Agricultural and Food Chemistry 60: 7341-7344.

Dighe S \& Agate AD (2000): Antibacterial activity of some Indian mushrooms. International Journal of Medicinal Mushrooms 2: 141-150.

Dubost NJ, Beelman RB, Petersson D \& Royse DJ, (2006): Identification and quantification of ergothioneine in cultivated mushrooms by liquid chromotography-mass spectroscopy. International Journal of Medicinal Mushrooms 8: 215-222.

Ey J, Schömig E \& Taubert D (2007): Dietary sources and antioxidant effects of ergothioneine. Journal of Agricultural and Food Chemistry 55: 6466-6474.

Gründemann D (2012): The ergothioneine transporter controls and indicates ergothioneine activity - a review. Preventive Medicine 54: S71-S74.

Heatley NG \& Stephenson JS (1957): Identity of "nudic acid B" and "diatretyne II". Nature 179: 1078.

Knudsen H \& Vesterholt J (2012): Funga Nordica. Agaricoid, boletoid, clavarioid, cyphelloid and gastroid genera. Nordsvamp: 1-1083.

Kohlmunzer S \& Wegiel J (2001): Indole metabolites of the edible mushroom Lepista nuda. Bromatologia i Chemia Toksykologiczna 34: 85-90 (Polish, English abstract available).

Lee WY; Park E-J, Jin K \& Ka K-H (2009): Ergothioneine contents in fruiting bodies and their enhancement in mycelial cultures by addition of methionine. Mycobiology 37: 43-47.

Lin S-Y, Chen Y-K, Yu H-T, Barseghyan GS, Asatiani MD, Wasser SD \& Mau J-L (2013): Comparative study of contents of several bioactive component in fruiting bodies and mycelia of culinary-medicinal mushrooms. International Journal of Medicinal Mushrooms 15: 313-327.

Lo Y-C, Lin S-Y, Ulziijargal E, Chen S-Y, Chien R-C, Tzou Y-J \& Mau J-L (2012): Comparative study of contents of several bioactive components in fruiting bodies and mycella of culinary-medicinal mushrooms. International Journal of Medicinal Mushrooms 14: 357-363.

Mikiashivili N, Elisashvili V, Wasser SP \& Nevo E (2006): Comparative study of lectin activity of higher basidiomycetes. International Journal of Medicinal Mushrooms 8: 31-33.

Roth L, Frank H \& Kormann K (1990): Giftpilze-Pilzgifte, Schimmelpilze-Mykotoxine. Ecomed Verlagsgesellschaft: 1-327.

Seebeck FP (2013): Thiohistidine biosynthesis. Chimia 67: 333-336.

Silverman WB \& Anchel M (1958): Similar polyacetylenes produced by spores of Clitocybe and related genera. Federation Proceedings 324.

Song T-Y, Chen C-L, Liao J-W, Ou H-C \& Tsai M-S (2010): Ergothioneine protects against neuronal injury induced by cisplatin both in vitro and in vivo. Food and Chemical Toxicology 48: 3492-3499.

Stijve T \& de Meijer AAR (1999): Hydrocyanic acid in mushrooms, with special reference to wild-growing and cultivated species. Deutsche Lebensmittel Rundschau 95: 366-373. 
Ulziijargal E, Yang J-H, Lin L-Y, Chen C-P \& Mau J-L (2013): Quality of bread supplemented with mushroom mycelia. Food Chemistry 138: 70-76.

Zaremba S (1973): Influence of a specific type of factors on agglutination of erythrocytes of selected species of animals. I Activity of phytohemagglutinins (PHA)

against erythrocytes of different species of animals. Folia Biologica 21: 391-410.

\section{Lepista personata s. auct. non (Fr.) Cooke,}

See Lepista saeva. 


\section{Lepista saeva (Fr.) P.D. Orton}

(L. personata s. auct. non (Fr.) Cooke, Tricholoma personatum s. auct. non (Fr.) P. Kumm.)

Field Blewit (DK: Bleg Hekseringshat, FI: Syysvalmuska, IS: Blásveppur, NO: Lillastilket ridderhatt, SE: Höstmusseron).

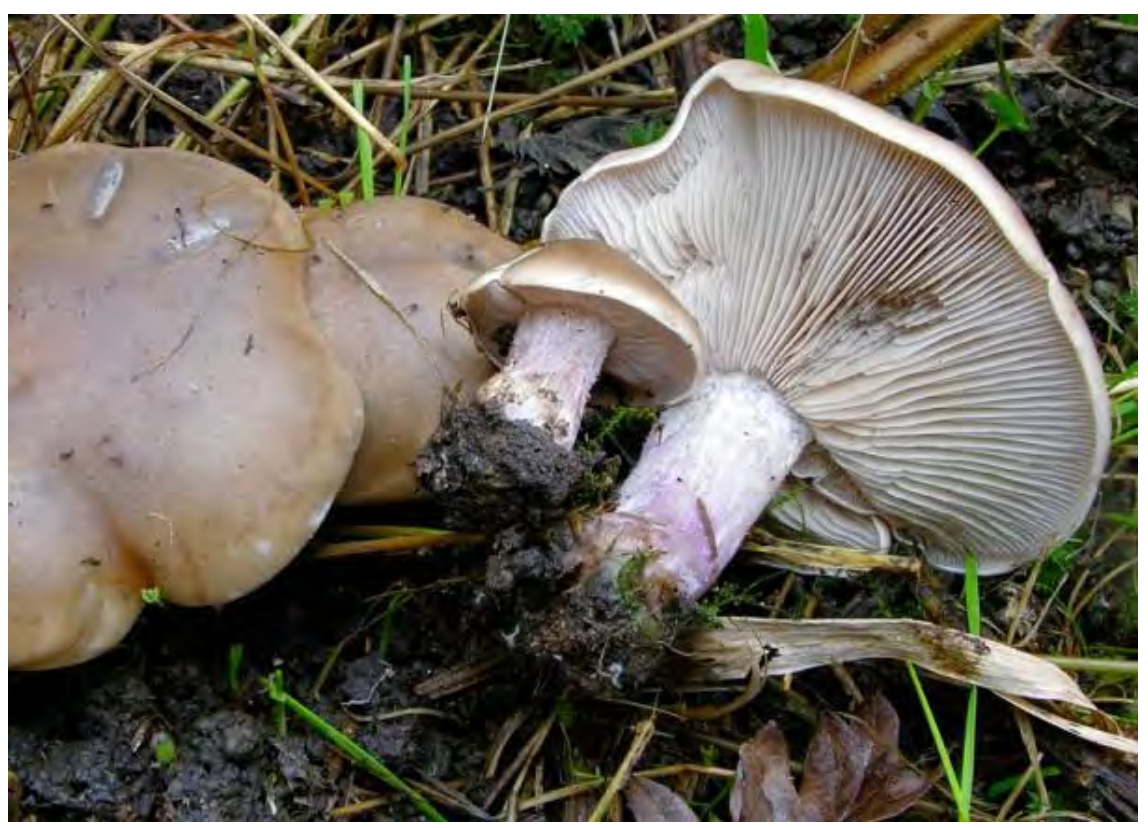

\section{Background and risk assessment}

Field Blewit (Lepista saeva) ${ }^{20}$ is an edible mushroom.

It is saprotrophic, growing in gardens, parks, roadsides and deciduous woods. It is common in temperate, occasional in hemiboreal/boreal zones of the Nordic countries (Knudsen \& Vesterholt, 2012). Occasionally, it is cultivated.

There are no intoxications reported after consumption of Field Blewit, and no natural toxicant constituting a risk for humans has been identified in the mushroom, except that trace amounts of cyanide have been detect-

20 Index Fungorum/Species Fungorum (2012) uses L. personata as preferred name but this is wrongly applied for L. saeva according to Knudsen \& Vesterholt (2012), ArtDatabanken (2011) and Danish Mycological Society (2012). 
ed. As the cyanide percursors apparently are effectively destroyed during cooking, the prepared meals will be exempt of cyanide (less than 0.5 $\mathrm{mg} / \mathrm{kg}$ of prepared meal) and therefore do not pose any hazard in relation to consumtion of the cooked mushroom (Stijve \& de Meijer, 1999).

Sterner et al. (1982) tested an extract of Field Blewit in the Ames test using the Salmonella typhimurium strains TA98, TA100 and TA2637. The extract was positive in the Salmonella strain TA100. The activity was not enhanced in the presence of microsomal enzymes. Unfortunately, Sterner et al. (1982) give no information, whether they had controlled for the potential presence of histidine in the extract. It is well known that false positives may be obtained in the presence of histidine. Also Morales et al. (1990) studied mushroom extracts in the Ames test. Extracts of Field Blewit mushrooms were reported to be weakly mutagenic in the Salmonella strains TA98 and TA100. The activity was not enhanced by addition of microsomal enzymes. Apparently, Morales et al. (1990) did not control for possible histidine in the extracts for the Ames test. Thus, there is no strong indication that extracts of Field Blewit are mutagenic.

\section{Recommendation}

No special recommendation.

\section{Listing 2}

\section{Database search information}

SciFinder by December 2012. Keywords: Lepista saeva or Lepista personata or Tricholoma personata. PubMed by December 2012. Keywords: Lepista or Clitocybe or Tricholoma.

\section{References}

ArtDatabanken (2011): http://www.artdata.slu.se/default.asp

Danish Mycological Society (2012): Danish-Latin database on names for fungi. www. http://www.svampe.dk/

Index Fungorum/Species Fungorum (2012): http://www.indexfungorum.org/ Knudsen H \& Vesterholt J (2012): Funga Nordica. Agaricoid, boletoid, clavarioid, cyphelloid and gastroid genera. Nordsvamp: 1-1083.

Morales P, Bermudez E, Hernandez PE \& Sanz B (1990): The mutagenicity of some Spanish edible mushrooms in the Ames test. Food Chemistry 38: 279-288.

Sterner O, Bergman R, Kesler E, Magnusson L, Nilsson B, Wickberg B, Zimerson E \& Zetterberg G (1982): Mutagens in larger fungi I. Forty-eight species screened for mutagenic activity in the Salmonella/microsome assay. Mutation Research 101: 269-281.

Stijve T \& de Meijer AAR (1999): Hydrocyanic acid in mushrooms, with special reference to wildgrowing and cultivated species. Deutsche Lebensmittel Rundschau 95: 366-373. 


\section{Lyophyllum connatum (Schumach.) Singer}

See Clitocybe connata.

Lyophyllum gambosum (Fr.) Singer

See Calocybe gambosa.

Macrolepiota olivieri (Barla) Wasser

See Chlorophyllum olivieri. 


\section{Macrolepiota procera (Scop.) Singer}

Parasol (DK: Stor Parasolhat, FI: Ukonsieni, IS: Sólhlífarskermill, NO: Stor parasollsopp, SE: Stolt fjällskivling).

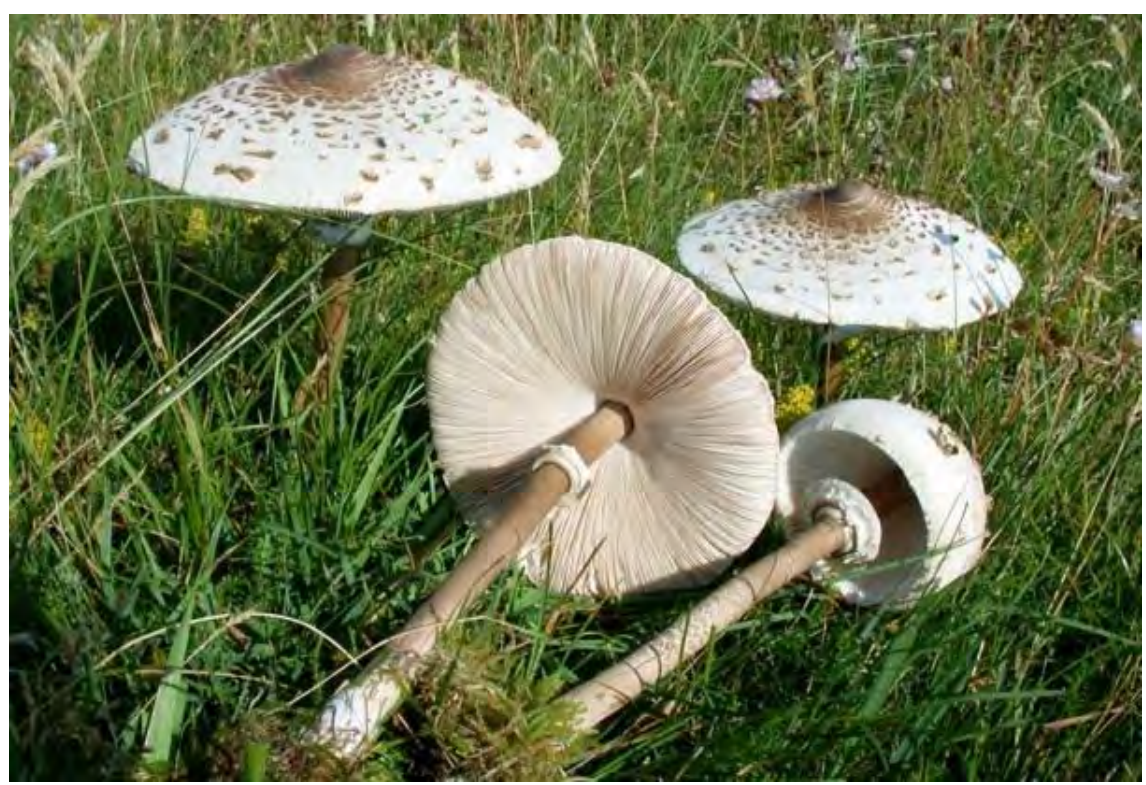

\section{Background and risk assessment}

Parasol (Macrolepiota procera) is an excellent edible mushroom, but it should be thoroughly cooked, as it is slightly toxic when eaten raw (Roth et al., 1990).

It grows in grassland, dunes, roadsides and open wood. It is common in temperate and occasional in hemiboreal/boreal zones of the Nordic countries, in Norway only in hemiboreal zones (Knudsen \& Vesterholt, 2012).

There are no intoxications reported after consumption of Parasol, and no natural toxicant constituting a risk for humans has been identified in the mushroom. However, two potentially bioactive protease inhibitors have been isolated from Parasol.

Protease inhibitors: Sabotič et al. (2009) isolated several similar cysteine proteinase inhibitors with apparent molecular mass around 19 $\mathrm{kDa}$ from fruit bodies of Parasol and called the proteinase inhibitors macrocypins. The amino acid sequence identity between the five macrocypin varieties was $75-86 \%$. Characterization of the macrocypins revealed considerable stability at high temperatures and extremes of $\mathrm{pH}$. Macrocypins were demonstrated to be effective inhibitors of papain and 
cysteine cathepsin endopeptidases, and also to inhibit cathepsins B and $\mathrm{H}$, which exhibit both exopeptidase and endopeptidase activities but have low efficiency for others (Sabotič et al., 2009). The same research team also identified another cysteine proteinase inhibitor, clitocypin, in the mushroom (Sabotič et al. (2011). The binding of the mycocypin proteinase inhibitors with papain-like cysteine proteases have been studied in crystalized material (Renko et al., 2010). Analysis of mycocypin expression in mature fruiting bodies of Parasol revealed that clitocypin is expressed evenly throughout the fruiting body, while the level of expression of macrocypins varies between tissues, the highest amounts occurring in veil fragments and the ring (Sabotič et al., 2011).

By inhibiting protein degradation, proteinase inhibitors have antinutritional effects. The clitocypin retained its activity and dimer composition after boiling in water. It is not known if this is the case also for macrocypin.

However, the potential presence of these protease inhibitors has not been reported to give any discomfort after consumption of Parasol.

\section{Recommendation}

No special recommendation.

\section{Listing 1}

\section{Database search information}

SciFinder by January 2012. Keywords: Lepiota or Macrolepiota. PubMed by December 2012. Keywords: Lepiota or Macrolepiota.

\section{References}

Knudsen H \& Vesterholt J (2012): Funga Nordica. Agaricoid, boletoid, clavarioid, cyphelloid and gastroid genera. Nordsvamp: 1-1083.

Renko M, Sabotič J, Mihelič M, Brzin J, Kos J \& Turk D (2009): Versatile loops in mycocypins inhibit three protease families. The Journal of Biological Chemistry 285: 308-316.

Sabotič J, Popovič T, Puizdar V \& Brzin J (2009): Macrocypins, a family of cysteine protease inhibitors from the basidiomycete Macrolepiota procera. FEBS Journal 276: 4334-4345.

Sabotič J, Kilaru S, Budič M, Gašparič MB, Gruden K, Bailey AM, Foster GD \& Kos J (2011): Protease inhibitors clitocypin and macrocypin are differentially expressed within basidiomycete fruiting bodies. Biochimie 93: 1685-1693. 


\section{Macrolepiota rachodes (Vittad.) Singer}

See Chlorophyllum rachodes. 


\section{Morchella conica Pers. (M. elata Fr.)}

Black Morel ("Morel”, "Pointed Morel”, "Ribbed Morel") (DK: Kegle-Morkel ("Morkel"), FI: Kartiohuhtasieni, IS: Keilumyrkill, NO: Spissmorkel, SE: Toppmurkla).

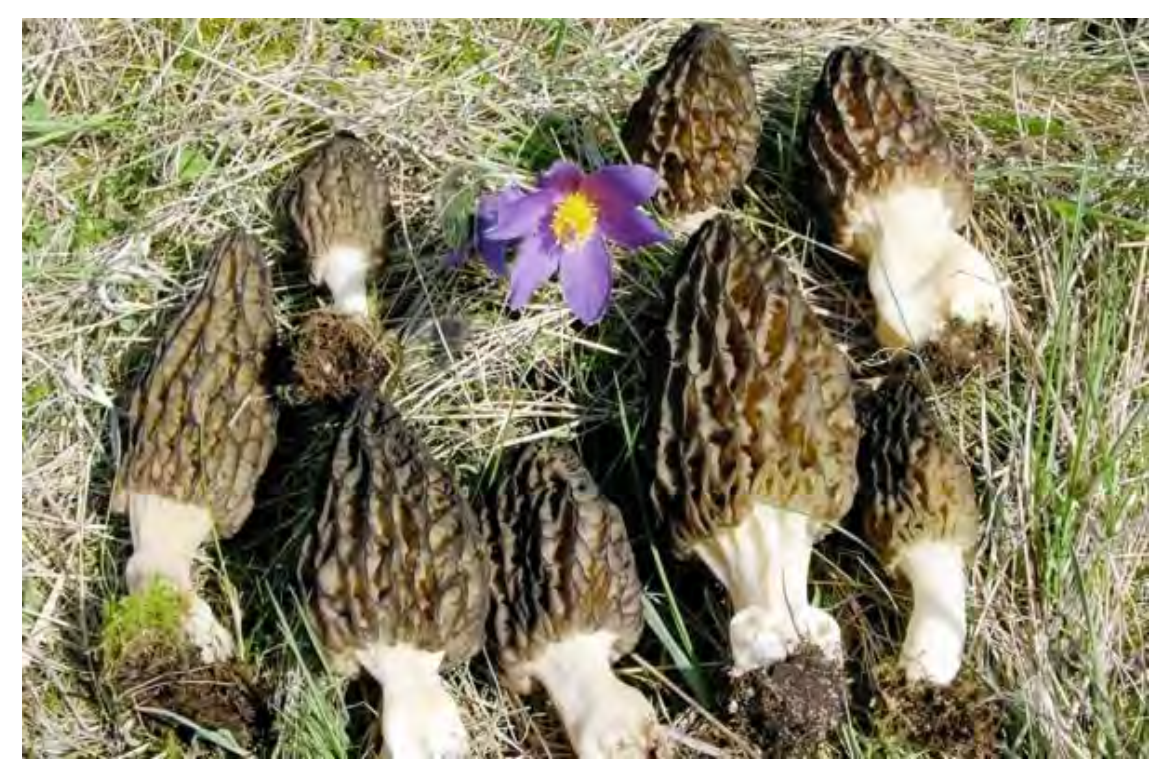

\section{Background and risk assessment}

Black Morel (Morchella conica) is, like Morel (M. esculenta), a very delicious fungus.

Black Morel and the closely related Morel (M. esculenta) are generally referred to as "morels" and evaluated together (see risk assessment of M. esculenta). Based on molecular studies these two species can be divided into several more species, which cannot be distinguished morphologically (O’Donnell et al., 2011).

It is not common in the Nordic countries. It can be found in spring. It grows both in deciduous and coniferous forests (Hansen \& Knudsen, 2000). Occasionally, it may be found in great amounts on bark chips from coniferous trees. Until now Black Morel has not been very successfully cultivated.

A thorough risk assessment of the consumption of Black Morel is not possible, as the toxicants responsible for the gastrointestinal and/or the neurological effects are unknown. However, based on estimated exposure and human observations on consumption of Black Morel and the closely related Morel it is concluded that Black Morel may give rise to 
gastrointestinal effects when eaten raw or insufficiently cooked, with an onset time between less than 1 and up to 6 hours. Intake of higher amounts (more than $100 \mathrm{~g}$ per meal) of even well-cooked, fresh morels, or probably also of corresponding amounts of dried morels may in addition give rise to neurologic effects after 6-12 hours latency with ataxia, dizziness and visual disturbances. All symptoms resolve within one day.

Lin et al. (2013) have isolated small amounts, up to $35 \mathrm{mg} / \mathrm{kg}$ (dry weight, 12 samples) of ergothioneine and of lovastatin, up to $29 \mathrm{mg} / \mathrm{kg}$ (dry weight, 12 samples) in mycelia of Black Morel. It is not known, whether these two compounds also may occur in the fruit bodies. For further data on ergothioneine and lovastatin: See Lepista nuda and Pleurotus ostreatus, respectively.

For a more thorough risk assessment of Black Morel (together with M. esculenta), see M. esculenta.

\section{Recommendations}

Black Morel (Morchella conica) and the closely related Morel (M. esculenta):

- Should never be eaten raw

- Should be cooked for at least 10 minutes

- Intake of higher amounts (more than $100 \mathrm{~g}$ per meal) of cooked, fresh - or corresponding amounts of dried morels - may occasionally, beyond gastrointestinal disturbances, give rise to neurological effects like ataxia, dizziness and visual disturbances and should accordingly be avoided.

\section{Database search information}

SciFinder by December 2012. Keywords: Morchella.

\section{Listing 1}




\section{References}

Hansen L \& Knudsen H (2000): Nordic Macromycetes, Volume 1. Ascomycetes. Nordsvamp: 1-309.

Lin S-Y, Chen Y-K, Yu H-T, Barseghyan GS, Asatiani MD, Wasser SD \& Mau J-L (2013): Comparative study of contents of several bioactive components in fruiting bodies and mycelia of culinary-medicinal mushrooms. International Journal of Medicinal Mushrooms 15: 313-327.

O’Donnel K, Rooney AP, Milles GL, Kuo M, Weber NS \& Rehner SA (2011): Phylogeni and historical biogeography of true morels (Morchella) reveals an early Cretaceous origin and high continental endemism and provincialism in the Holarctic. Fungal Genetics and Biology 48: 252-265.

\section{Morchella elata Fr.}

See Morchella conica. 


\section{Morchella esculenta (L.) Pers.}

Morel (DK: Spiselig Morkel ("Morkel"), FI: Pallohuhtasieni, IS: Steinmyrkill, NO: Rundmorkel, SE: Rund toppmurkla).

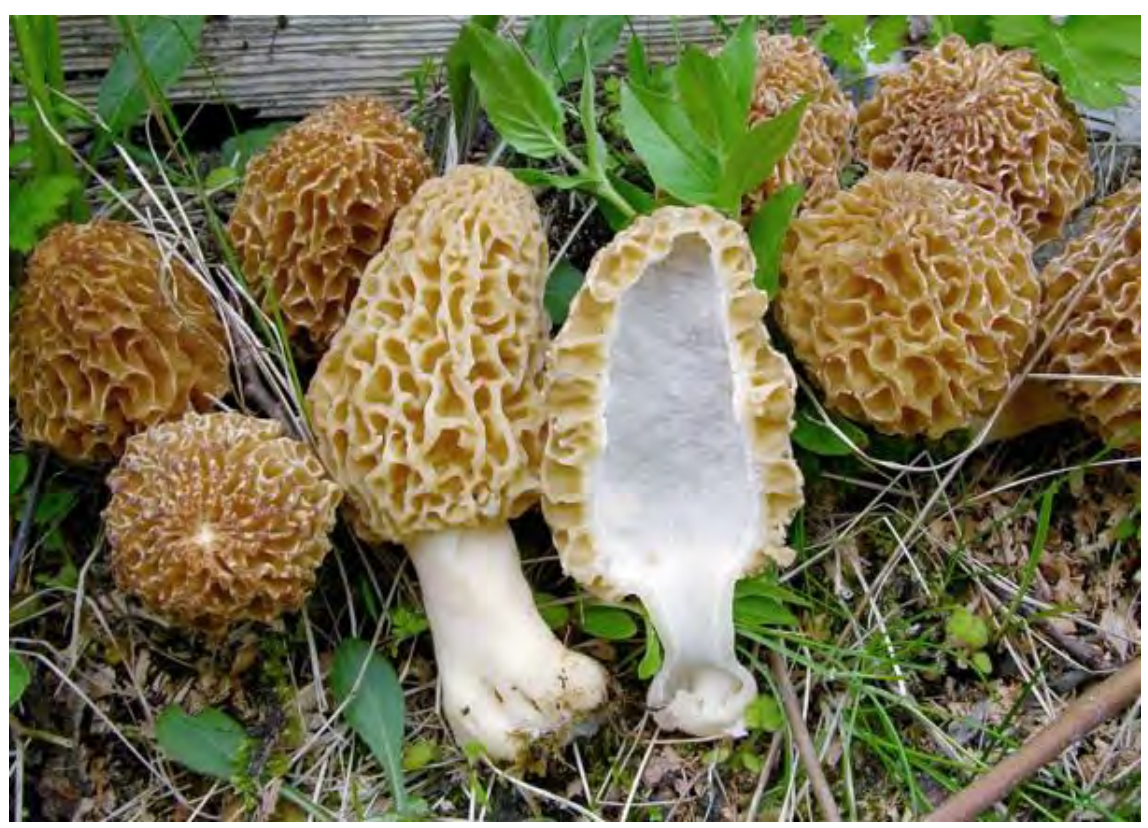

\section{Background and hazard identification}

Morel is prized as one of the most delicious edible fungi.

Morel (Morchella esculenta) and the closely related Black Morel (M. conica) are generally referred to as "morels". Based on molecular studies these two species can be divided into several more species, which cannot be distinguished morphologically (O'Donnell et al., 2011).

It is an uncommon wild mushroom, which can be found in spring in rich deciduous forests, parks and gardens, often on chalky soils (Hansen \& Knudsen, 2000). Until now morels have not been cultivated very successfully.

Both the fresh and the dried morels are commercially available on the market.

Old publications did report more serious intoxications after eating Morel. This gave rise to the recommendation, that the mushroom should only be eaten after parboiling and removal of the boiling water (Krause, 1918; Aufrecht, 1927). Afterwards, intoxications with gastrointestinal symptoms have been reported occasionally. Newer mushroom books 
and other references do not recommend parboiling, but indicate that intake of raw or insufficiently cooked fresh morels may give intoxications (Flammer \& Schenk-Jäger, 2009).

Recently, case reports (Pfab et al., 2008) and a 20 years' summary of poisonings with morels collected in French poison control centres (Saviuc et al., 2010) have described a series of well-documented cases with neurological effects after consumption of morels.

\section{Hazard characterisation}

Animal, in vitro, genotoxicity and metabolism studies

No experimental toxicity data were available for Morel or its constituents.

\section{Human observations}

Already in 1889 Roumeguère reported intoxications with morels. Later Krause referred to poisonings after intake of morels, especially if they had not been parboiled before cooking (Krause, 1918; Roumeguerè, 1889). In 1927 a serious case of poisoning with canned Morel (M. esculenta) was reported, but this intoxication was traced back to the presence of "Helvella suspecta" (Aurecht, 1927). Saviuc and colleagues (Saviuc et al., 2010) have reviewed several older reports on morel poisonings (Jaccottet, 1925; Maublanc, 1941; Alder, 1956; Nothnagel, 1962 and Fuste et al., 1979) which all suffer from lack of important data like identification of the consumed mushrooms, cooking conditions and amounts consumed.

A few publications deal with the possible association with alcohol in poisonings with morels (Groves, 1964; Piqueras, 2003 and Beug, 2006; Beug et al., 2006). Whether there is a connection is still an open question.

Recently thorough descriptions of intoxications after consumption of Morel and Black Morel (M. conica) have been reported by Pfab and colleagues (Pfab et al., 2008). In six cases people had eaten freshly collected, cooked Morel often in high amounts, up to 250 gram and in one case up to 600 gram and after 6-12 hours latency experienced different neurological effects, typically ataxia and visual disturbances. The effects disappeared within one day after consumption. On request, none of the six persons had eaten any drugs or sedatives, and only two persons had consumed alcohol, one or two glass of beer. In five of the six cases the mushrooms were identified as Morel and in one case as Black Morel, based on macroscopic observations and microscopical identification of the spores. Pfab and coworkers, Department of Toxicology, Klinikum rechts der Isar, Munich also referred to ten similar cases reported from their Poison Control Center 
with neurologic effects like dizziness ataxic gait and blurred vision after intake of either Morel or Black Morel (Pfab et al., 2008).

Several morel intoxications with neurological syndrome have been reported by poison control centres in North America (Beug et al., 2006), and in France (Saviuc \& Harry, 2008; Saviuc et al., 2010). When detailed information was available, the neurological syndrome was apparently only observed after intake of large amounts of morels, also if they had been well cooked. Most intoxications with morels have gastrointestinal symptoms as their main toxic effect and no neurological symptoms. Poisonings with mainly gastrointestinal symptoms are generally observed after intake of raw or insufficiently cooked morels, even after intake of small amounts (Beug et al., 2006b; Saviuc et al., 2010).

The toxicants responsible for the reported gastrointestinal and neurologic effects are not known, but those responsible for gastrointestinal effects without neurological symptoms are at least partially destroyed or eliminated by cooking (Saviuc \& Harry, 2008; Flammer \& Schenk-Jäger, 2009). Based on information available, it is anticipated that consumption of dried morels do not give rise to intoxications (Flammer \& SchenkJäger, 2009), but this is at least not always the case as reported by Beug (2006a) and by Saviuc et al. (2010).

In studies on mycelia of Morel, small amounts of ergothioneine have been identified, $19 \mathrm{mg} / \mathrm{kg}$ (dry weight, mean of 3 samples) by Lo et al. (2012) and up to $35 \mathrm{mg} / \mathrm{kg}$ (dry weight, mean of 3 samples) by Lin et al. (2013). For further data on ergothioneine: see Lepista nuda. Also small amounts of lovastatin, 8-21 mg/kg (dry weight) have been shown in the mycelia (Lin et al., 2013), whereas, Lo et al. (2012) identified 1440 $\mathrm{mg} / \mathrm{kg}$ (dry weight, mean of 3 samples) of lovastatin. For further data on lovastatin: see Pleurotus ostreatus. It is not known, whether these bioactive compounds also occur in the fruit bodies of Morel.

\section{Exposure assessment}

Morel is a costly mushroom, usually only consumed in small amounts. Generally, intakes are estimated to be less than $50 \mathrm{~g}$ fresh or correspondingly smaller amounts of dried mushrooms per meal, but occasionally, it may be consumed in large amounts (about 200-600 g per meal: Pfab et al., 2008) or as "several successive platefuls or meals" (Saviuc et al., 2010). 


\section{Risk characterisation}

A thorough risk assessment of the consumption of Morel is not possible, as the toxicants responsible for the gastrointestinal and/or the neurological effects are unknown. However, based on estimated exposure and human observations on consumption of Morel (M. esculenta) and the closely related Black Morel (M. conica), it is concluded that morels may give rise to gastrointestinal effects when eaten raw or insufficiently cooked with an onset time between less than 1 and up to 6 hours. Intake of higher amounts (more than $100 \mathrm{~g}$ per meal) of even well-cooked, fresh morels, or probably also of corresponding amounts of dried morels may in addition give rise to neurologic effects after 6-12 hours latency with ataxia, dizziness and visual disturbances. All symptoms resolve within one day.

\section{Recommendations}

Morel (M. esculenta) and the closely related morel Black Morel (M. conica).

- Should never be eaten raw

- Should be cooked for at least 10 minutes

- Intake of higher amounts (more than $100 \mathrm{~g}$ per meal) of cooked, fresh - or corresponding amounts of dried morel - may occasionally, beyond gastrointestinal disturbances, give rise to neurological effects like ataxia, dizziness and visual disturbances and should accordingly be avoided.

\section{Database search information}

SciFinder by December 2012. Keywords: Morchella.

\section{Listing 1}

\section{References}

Alder AE (1956): Die Pilzvergiftungen in der Schweiz in den Jahren 1952 und 1953, Schweizerische Zeitschrift für Pilzkunde 34: 4-11.

Aufrecht (1927): Methods to identify the poison of the morel. Chemiker-Zeitung 51: 130.

Beug MW (2006): Mushroom poisonings reported in 2001, 2002, 2003 and 2004. McIlvainea 16: 56-69.

Beug MW, Shaw M \& Cochran KW (2006): Thirty-plus years of mushroom poisoning: Summary of the approximately 2,000 reports in the NAMA Case Registry. Mcllvainea 16: 47-67. 
Flammer RJ \& Schenk-Jäger M (2009): Pilzvergiftung - die Schattenseiten des Myzetismus. Therapeutische Umschau 66: 357-364.

Fuste L, Casais L \& Vilardell F (1979): Poisoning caused by Morchella esculenta. Medicina Clinica 73: 247-249.

Groves JW (1964): Poisoning by morels when taken with alcohol. Mycologia 56: 779-780.

Hansen L \& Knudsen H (2000): Nordic Macromycetes, Volume 1. Ascomycetes. Nordsvamp: 1-309.

Harry P, Pulce C \& Saviuc P (2008): Toxidrome neurologique et ingestion de morilles (Morchella sp.) J. Electron. Toxicol., 1: 8-9.

Jaccottet J \& Robert P (1925): Les champignons dans la nature Delachaux \& Niestlé, Neuchâtel, Switzerland: 205 (Referred by Saviuc et al., 2010).

Krause F (1918): Toxicity of morels and lorchels (fungi), Apoth. Ztg. 33: 279-280.

Lin S-Y, Chen Y-K, Yu H-T, Barseghyan GS, Asatiani MD, Wasser SD \& Mau J-L (2013): Comparative study of contents of several bioactive components in fruiting bodies and mycelia of culinary-medicinal mushrooms. International Journal of Medicinal Mushrooms 15: 313-327.

Lo Y-C, Lin S-Y, Ulziijargal E, Chen S-Y, Chien R-C, Tzou Y-J \& Mau J-L (2012): Comparative study of contents of several bioactive components in fruiting bodies and mycelia of culinary-medicinal mushrooms. International Journal of Medicinal Mushrooms 14: 357-363.

Maublanc A (1941): Séance de 6 mai 1941. Bulletin de la Societe Mycologique de France 57: 1-4.

Nothnagel P (1926): Gesundheitliche Störungen nach Morchelgenuss. Mykologisches Mitteilungsblatt, Halle, S 6: 32-33.

O’Donnel K, Rooney AP, Milles GL, Kuo M, Weber NS \& Rehner SA (2011): Phylogeny and historical biogeography of true morels (Morchella) reveals an early Cretaceous origin and high continental endemism and provincialism in the Holarctic. Fungal Genetics and Biology 48: 252-265.

Pfab R, Haberl B, Kleber J \& Zilker T (2008): Cerebellar effects after consumption of edible morels, Morchella conica and Morcella esculenta. Clinical Toxicology 46: 249-260.

Piqueres J (2003): La toxicide de las colmenillas (Morchella sp.). Lactarius 12: 83-87. Roumeguère C (1889): Un cas - d'empoisonnement par les morilles, Rev. Mycol. 11: 9-14 (Referred by Saviuc et al., 2010).

Saviuc P \& Harry P (2008): Existe-t-il-une toxicité neurologique des Morils? Bull. Assoc. Entreval. Mycol. Bot. Appl. 49: 8-13.

Saviuc P, Harry P, Pulce C, Garnier R \& Cochet A (2010): Can morels (Morchella sp.) induce a toxic neurological syndrome? Clinical Toxicology 48: 365-370. 


\section{Paxillus involutus (Batsch.) Fr.}

Brown Rollrim (Common Roll-rim, Poison Pax) (DK: Almindelig Netbladhat, FI: Pulkkosieni, IS: Garðlumma Lummusveppur, NO: Pluggsopp, SE: Pluggskivling).

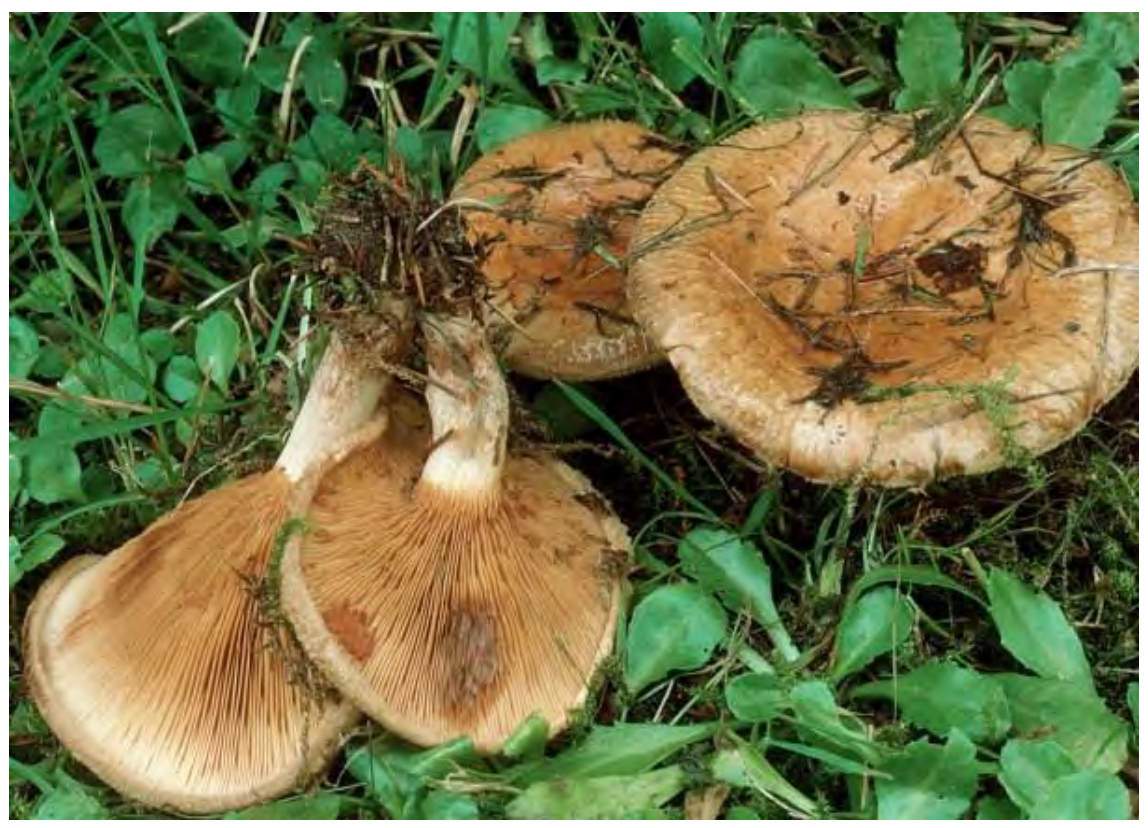

\section{Background and hazard identification}

Brown Rollrim (Paxillus involutus) has earlier been regarded as an edible mushroom (e.g. Ferdinansen \& Winge, 1978; Joly, 1973; Lange, 1970), but is now considered as a poisonous mushroom (Barceloux., 2008; Benjamin, 1995; Breskinsky \& Besl, 1985; Flammer, 1983; Roth et al., 1990).

Brown Rollrim grows mycorrhizal with different hosts, especially with Spruce (Picea) and Birch (Betula), in the north with Dwarf Birch (Betula nana). It is very common in temperate and up to boreal zones, and occasional, but locally common, in subarctic to alpine zones of the Nordic countries (Knudsen \& Vesterholt, 2012). 


\section{Hazard characterisation}

\section{Human intoxications}

The earliest reports that consumption of Brown Rollrim may give rise to intoxications were published in the mid 1900s and described case reports where the poisoned persons had consumed raw or not sufficiently cooked mushrooms (Grzymala, 1958; Rauschert, 1962; Straus, 1949). In one of these reports, Grzymala (1958) stated that around one third of the intoxications in Poland were due to this mushroom. These intoxications occurred 15 minutes- 4 hours after mushroom consumption and gave gastrointestinal symptoms. Subsequently, in the early 1960s, Bschor and colleagues described four intoxications with cooked Brown Rollrim, of which three were fatal. The intoxications occurred shortly after the mushroom consumption and resulted in non-localized abdominal pain, circulatory disturbance, parenchymal damage and fat deposition in blood (Bschor \& Mallach, 1963; Bschor et al., 1963). Cochet (1974) and Kubicka \& Veselsky (1975) have reviewed a series of intoxications, mainly cases with raw or insufficiently cooked Brown Rollrim. Further insight into the Brown Rollrim intoxications was given by Schmidt et al. (1971) who described two cases that developed acute hemolytic anemia after eating the mushroom. In both instances massive hemolysis with subsequent shock and acute renal failure occurred. Specific antibodies were demonstrated in the serum of both patients which, in the presence of Brown Rollrim extracts, caused an immune reaction resulting in agglutination and hemolysis of red blood cells. ${ }^{21} \mathrm{~A}$ few years later, the same research team presented four new cases that within $1 \frac{1 / 2}{2}$ hours after consumption of cooked Brown Rollrim experienced urticaria, difficulties to breathe, stomach pain, vomiting and diarrhoea, and hemolysis followed by jaundice. At the time it was already known that extracts of raw Brown Rollrim agglutinates erythrocytes (Krüpe, 1956). When the investigators tested extracts from well-cooked and lyophilized Brown Rollrim on the sera of these individuals, they noted agglutination of erythrocytes and in two cases hemolysis. The antibodies in the patient's sera were identified as IgG. It was hypothesized that a mushroom component forms a hapten-like structure in the serum which subsequently forms a complex with erythrocytes that has the potential to act as antigen. The fatal cases that had been reported earlier were suggested

\footnotetext{
${ }^{21}$ In the discussion of the immunological observations, Schmidt et al. (1971) mentioned allergic reactions. This reference could have been uncritically transmitted into several publications on Brown Rollrim intoxications.
} 
to have resulted in an immunologic cytotoxic reaction similar to those found in their study.

Okonek (1977) described a further patient suffering from hemolytic syndrome and acute failure to produce urine (anuresis) due to ingestion of cooked Brown Rollrim. The patient recovered completely after treatment of combined hemodialysis and hemoperfusion. Winkelmann et al. (1982) reported the death of a previously healthy 49-year old man that fell gravely ill and died $3 \frac{1}{2}$ days after repeatedly having eaten Brown Rollrim. The consumption resulted in hemolysis and circulatory shock, leading to acute renal failure, acute respiratory failure and disseminated intravascular coagulation in lungs, kidneys, adrenals, myocardium, liver and spleen. Extensive fat emboli were observed in both lungs. An IgG antibody against the mushroom was demonstrated in the patients serum. Olesen (1991) described a Danish case of Brown Rollrim intoxication. Two hours after having consumed a dish with three fruit bodies the person experienced diffuse abdominal pain, vomiting, diarrhoea, dizziness and powerlessness. Although free hemoglobin could be identified in plasma and urine over the following two days, no organ damage was demonstrated. Both serum creatinine and liver enzymes were normal.

A further case that experienced back pain, general weakness, dizziness, nausea and vomiting following a dinner including sufficiently cooked Brown Rollrim was described by Winkelmann et al. (1986). Other family members who ate the same meal had no symptoms. Immunological studies using serum from the patient, Brown Rollrim extracts and various reagents identified IgG specific antibodies, probably occurring in immune complexes. To form such complexes, penetration of intact mushroom antigen through intestinal mucosa into blood or lymph vessels has to be postulated. Such penetration without loss of activity has been demonstrated for other agents. Any further mechanism of the immune reaction must be a speculation but the formation of immune complexes bound to erythrocyte membranes is suggestive (Winkelmann et al., 1982, 1986). Adverse reactions subsequently occur when presensitized persons consume the mushroom. Binding of an immune complex to erythrocytes could then cause intravascular hemolysis by activation of the complement chain. Such a mechanism would explain the short latency between consumption and development of clinical symptoms of shock.

More recently, a Russian report refers to thirty-eight intoxications after consumption of Brown Rollrim and/or another Paxillus species, Paxillus atrotomentosus. Slight intoxication (acute gastroenteritis) was diagnosed in 17 patients, medium-severe in 13 cases, severe in 6 cases, and 
extremely severe in two cases. The mushrooms induced functional disorders in the small intestine, as well as acute renal failure. Two patients died (Musselius et al., 2002).

Paxillus syndrome: In his review of hemolytic mushrooms, Flammer (1983) summarized the immune-hemolytic activity of well-cooked Brown Rollrim in sensitized persons. After many years of being able to consume Brown Rollrim, an intoxication suddenly appears 15 minutes-2 hours after mushroom ingestion and results in symptoms such as collapse, weakness, dizziness, stomach pain, nausea, vomiting, diarrhoea, hemolysis, jaundice, reduced or no urine production, kidney pain and red urine. Erythrocyte hemolysis leads to hemoglobinuria that might require plasma exchange and dialysis. Thus, a prerequisite for the immune-hemolytic anemia, the Paxillus syndrome, is the sensitization to a mushroom-antigen that subsequently may lead to hemolysis. The effect is unrelated to that of hemolysing proteins which may be found in raw mushrooms but which are inactivated by cooking. The nature of the mushroom-antigen has not been established. However, it seems as an antigen-antibody complex located on the surface of erythrocyte leads to hemolysis after consumption of Brown Rollrim for a minimum number of times to result in sensitization (Schmidt et al., 1971). Deicher and Stangel (1977), and Winkelmann et al., (1982) have identified the antibody as IgG. However, Lefévre (1982) were unable to inhibit the IgGmediated reaction by anti-IgG antibodies.

\section{Experimental studies}

Although several studies have been performed with Brown Rollrim or extracts from the mushroom in vitro (Habtemariam, 1996), or in vivo, (Gilot-Delhalle et al., 1991; Lasota, 1970; Lasota \& Fortak, 1965; 1966; 1968; Lasota et al., 1967; Nieminen et al., 1977), these have not been able to explain the mechanism for the Paxillus syndrome.

Habtemariam (1996) studied the cytotoxicity of water-, butanol- and ethyl acetate-extracts of Brown Rollrim against cells of murine (L929 and RAW 264.7) and human (HeLa and EAhy926) origin. Whereas water extracts had no influence on cell viability, and the butanol extract had some activity at the highest dose tested $(1 \mathrm{mg} / \mathrm{ml})$, the ethyl acetate extract was cytotoxic in a concentration-dependent manner (IC50 values between 125 and $250 \mu \mathrm{g} / \mathrm{ml}$ ). Extracts that had been exposed to heat or low $\mathrm{pH}$ for four hours had the same effects. Lasota and co-workers published four papers describing the toxicity of dried Brown Rollrim in rats. Subsequently, Nieminen et al. (1977) administered to male rats 50 or $250 \mathrm{mg}$ dried homogenized Brown Rollrim in aqueous suspension per kg body weight by gastric intubation for 40 days. In these studies on 
non-sensitized rats, no toxic symptoms were observed, and no difference in general behavior, body-weight-gain, relative organ weights, gross appearance, and histopathology of major organs was observed between exposed and control rats.

\section{Causative agents}

Possibly, Brown Rollrim contains two types of toxicants. One thermolabile toxicant(s), which give(s) rise to relatively harmless intoxications with gastrointestinal effects after consumption of raw or insufficiently cooked mushrooms and another more thermostabile toxicant(s), which after repeated consumption of the mushroom may give rise to serious intoxications with immune-hemolytic anemia and renal failure, which in some cases have led to shock and death after consumption of even thoroughly cooked mushrooms. However, neither the thermolabile nor thermostabile toxicants have been identified (Antkowak, 2001; Barceloux, 2008) and only few bioactive constituents are known to occur in Brown Rollrim.

\section{Bioactive constituents}

Polyphenols: Two polyphenols, involutin and involutone have been identified in the mushroom (Antkowiak et al., 2003; Edwards et al., 1967; Mikolajczyk \& Antkowiak, 2009). Gilot-Delhalle et al. (1991) linked the Paxillus syndrome to the presence in the mushroom of involutin, the chemical and pharmacological properties of which were demonstrated in the 1960s (Edwards et al., 1967). In order to confirm their hypothesis, these investigators studied the chromosome-breaking activity of extracts of Brown Rollrim in early root tips of the plant Nigella damascena. These studies identified chromosome type aberrations both in root tips exposed to non-heated and heated mushroom extracts (Gilot-Dehalle et al., 1991). As both involutin and involutone are heatlabile, they are unlikely to be responsible for the clastogenic effects observed and the Paxillus syndrome. The structure of involutin is shown below.<smiles>O=C1C(c2ccc(O)cc2)=C(O)C(O)C1c1ccc(O)c(O)c1</smiles>

Inovolutin 
Muscarine alkaloids: Trace amounts (totally less than $2 \mathrm{mg} / \mathrm{kg}$ fresh weight) of the toxicants L-(+)-muscarine (approximately 4\%) and its stereoisomer epi-muscarine (96\%) have been detected in Brown Rollrim (Stadelmann et al., 1976). However, such low amounts of L-(+)muscarine and its stereoisomer are per se of no toxicological concern in relation to consumption of mushrooms (Bresinsky \& Besl, 1985; Stadelmann et al., 1976). The structural formula of L-(+)-muscarine is shown below:

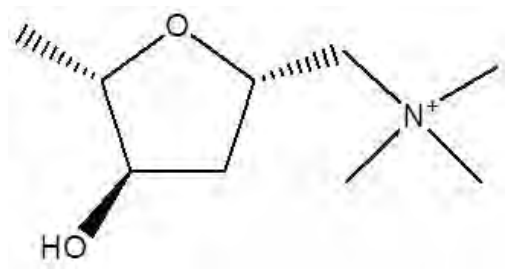

L-(+)-Muscarine

\section{Exposure assessment}

There are no intake data available on Brown Rollrim. As neither the thermolabile, nor the thermostabile toxicants are known, it is not either possible to indicate the exposure to the toxicants in a meal. It is, however, observed that consumption of even a few finger-thick pieces of the mushroom may give rise to significant gastrointestinal symptoms (Bschor et al., 1963). Repeated intake of even parboiled and sufficiently cooked Brown Rollrim may cause serious, possibly fatal, poisonings in sensitized persons (Bresinsky \& Besl, 1985). In these cases also intake of small amounts could lead to severe hemolytic reactions.

\section{Risk characterisation}

Consumption of raw or insufficiently cooked Brown Rollrim has given rise to many intoxications with gastrointestinal symptoms. Apparently, repeated consumption of meals even with thoroughly cooked mushrooms may occasionally give rise to more serious intoxications with immune-hemolytic anemia, possibly with subsequent renal damage, shock and even death. Neither heatlabile nor heatstable toxicants have been identified. 


\section{Recommendation}

Brown Rollrim contains potent, but unknown toxicant(s), which is (are) not efficiently destroyed by cooking, and which after repeated meals may give severe adverse reactions, in some cases deadly.

Listing 4

\section{Database search information}

SciFinder by January 2012. Keywords: Paxillus and toxicity. Paxillus and constituents. PubMed by December 2012. Keywords: Paxillus involutus.

\section{References}

Antkowiak WZ (2001): Paxillus involutus, a popular mushroom of controversial physiological properties. Wiadomosci Chemiczne Volumen 55: 245-261 (Polish, English abstract available).

Antkowiak R, Antkowiak WZ, Banczyk I \& Mikolayczyk L (2003): A new phenolic metabolite, involutone, isolated from the mushroom Paxillus involutus. Canadian Journal of Chemistry 81: 118-124.

Barceloux DG (2008): Medical Toxicology of Natural Substances: Foods, Fungi, Medicinal Herbs, Plants, and Venomous Animals. John Wiley \& Sons, Inc.: 1-1200.

Benjamin D (1995): Mushrooms: Poisons and panaceas. WH Freeman and company: 1-422.

Bresinsky A \& Besl H (1985): Giftpilze. Ein Handbuch für Apotheker, Ärzte und Biologen. Wissenschaftliche Verlagsgesellschaft mbH Stuttgart: 1-295.

Bschor F \& Mallach HJ (1963): Poisonings caused by Paxillus involutus, an edible mushroom. Archiv für Toxikologie 20: 82-95.

Bschor F, Kohlmeyer J \& Mallach HJ (1963): Neue Vergiftungsfälle durch Paxillus involutus (Batsch) Fr. Zeitschrift für Pilzkunde 29: 1-3.

Cochet S (1974): Notes sur divers cas d'empoisonnements mortels par le Paxillus involutus (Batsch) Fr. Bulletin de Société mycologique de France 90: 67-68. (Referred to by Bresinsky \& Besl, 1985).

Deicher H \& Stangel W (1977): Acute immunohemolytic anemia following eating of Paxillus involutus. Verhandlungen der Deutschen Gesellschaft für Innere Medizin 83: 1606-1609.

Edwards RL, Elsworthy GC \& Kale N (1964): Constituents of the higher fungi. Part IV. Involutin, a diphenylcyclopenteneone from Paxillus involutus (Oeder ex Fries). Journal of the Chemical Society: 405-409.

Ferdinandsen C \& Winge Ø (1978): Mykologisk Ekskursionsflora. Foreningen til Svampekundskabens Fremme: 1-434.

Flammer R (1983): Hämolyse bei Pilzvergiftungen: Fakten und Hypothesen. Hemolysis in mushroom poisoning: facts and hypothesis. Schweizerische Medizinische Wochenschrift 113: 1555-1561.

Gilot-Delhalle J, Moutschen J \& Moutschen-Dahmen M (1991): Chromosomebreaking activity of extracts of the mushroom Paxillus involutus Fries ex Batsch. Experientia 47: 282-284. 
Grzymala S (1958): Vergiftungen durch Paxillus involutus (Batsch) Fr., Zeitschrift für Pilzkunde 24: 19-21.

Habtemariam S (1996): Cytotoxicity of extracts from the mushroom Paxillus involutus. Toxicon 34: 711-713.

Knudsen H \& Vesterholt J (2012): Funga Nordica. Agaricoid, boletoid, clavarioid, cyphelloid and gastroid genera. Nordsvamp: 1-1083.

Krüpe (1956): Blutgruppenspezifische pflanzliche Eiweisskörper (Phytagglutinine). Ferdinand Enke Verlag, Stuttgart: 1-132. (Referred to by Deicher \& Stangel, 1977).

Kubicka J \& Veselský J (1975): Die Schädlichkeit des Kahlen Kremplings Paxillus involutus (Batsch ex Fr.) Fr. historisch betrachtet. Mykologisches Mitteilungsblatt 19: 1-5. (Referred to by Bresinsky \& Besl, 1985.).

Lange JE \& Lange M (1973): Illustreret svampeflora. GEC Gads Forlag: 1-242.

Lasota W (1970): Studies on the mushroom Paxillus involutus in connection with its evaluation in feeding. Farmcja Polska 26: 317-323. (Polish).

Lasota W \& Fortak W (1965): Studies on Paxillus involutus I. Changes in alimentary canal of young white rats fed on dried Paxillus involutus. Acta Poloniae Pharmaceutica 22: 619-626.

Lasota W \& Fortak W (1966): Studies on Paxillus involutus. II. Changes in some parenchymal organs of young white rats fed with dried Paxillus involutus. Acta Poloniae Pharmaceutica 23: 81-86.

Lasota W \& Fortak W (1968): Studies on Paxillus involutus Batsch, Fr. IV. Studies of acute toxicity of the extract and the extracted residue. Acta Poloniae Pharmaceutica 25: 339-345. (Polish, English abstract available).

Lasota W, Rybarkiewicz G \& Mlodecki H (1967): Studies on Paxillus involutus Batsch, Fr. III. Peripheral blood picture of young white rats poisoned with dried Paxillus involutus. Acta Poloniae Pharmaceutica 24: 76-82.

Lefèvre H (1982): Immunhämolytische Anämie nach Genuss des Kahlen Krempling (Paxillus involutus). Deutsche Medizinische Wochenschrift 107: 1374.

Joly P (1973): Svampe. Wøldike: 1-256.

Micolajczyk L \& Antkowiak WZ (2009): Structure studies of the metabolites of Paxillus involutus. Heterocycles 79: 423-426.

Musselius SG, Ryk AA, Lebedev AG, Pakhomova GV, Golikov PP, Davydov BV, Donova LV, Zimina LN, Platonova GA, Selina IE\& Skvortsova AV (2002): Toxicity of mushrooms Paxillus involutus and Paxillus atrotomentosus. Anesteziologiya i Reanimatologiya Mar-Apr;(2): 30-35 (Russian, English abstract available).

Nieminen L, Bjondahl K, Ojanen H \& Ohenoja E (1977): Short-term toxicity study of Paxillus involutus in the rat. Food and Cosmetics Toxicology 15: 445-446.

Okonek S (1977): Hemoperfusion with coated activated charcoal for treating acute poisoning by remedies, plant protectants, and fungi. III. Fungi. Medizinische Klinik 72: 1917-1921.

Olesen LL (1991): Poisoning with the Brown Roll-Rim mushroom, Paxillus involutus. Ugeskrift for Laeger 153: 445.

Rauschert W (1962): Bericht über die Pilzberatungs- und Aufklärungstätigkeit in der DDR 1961. Mykologisches Mitteilungsblatt 6: 40-41. (Referred to by Bresinsky \& Besl, 1985).

Roth L, Frank H \& Kormann K (1990): Giftpilze-Pilzgifte, Schimmelpilze-Mykotoxine. Ecomed Verlagsgesellschaft: 1-327. 
Schmidt J, Hartmann W, Würstlin A \& Deicher H (1971): Akutes Nierenversagen durch immunhämolytische Anämie nach Genuss des Kahlen Kremplings (Paxillus involutus). Deutsche Medizinische Wochenschrift 96: 1188-1191.

Stadelmann RJ, Müller E \& Eugster CH (1976): Über die Verbreitung der stere omeren Muscarine innerhalb der Ordnung der Agaricales. Helvetica Chimica Acta 59: 2432-2436.

Straus A (1.949): Pilzvergiftungen 1946 in Berlin und Brandenburg. Zeitschrift für Pilzkunde 21: 37-41.

Winkelmann M, Stangel W, Schedel I \& Grabensee B (1986): Severe hemolysis caused by antibodies against the mushroom Paxillus involutus and its therapy by plasma exchange. Klinische Wochenschrift 64: 935-938.

Winkelmann M, Borchard F, Stangel W \& Grabensee B (1982): Todlich verlaufene immunhamolytische Anamie nach Genuss des Kahlen Kremplings (Paxillus involutus). Fatal immunohaemolytic anaemia after eating the mushroom Paxillus involutus. Deutsche Medizinische Wochenschrift 107: 1190-1194.

\section{Pholiota mutabilis (Schaeff.) P. Kumm.}

See Kuehneromyces mutabilis. 


\section{Pholiota nameko (T. Itô) S. Ito \& S. Imai}

(Nameko) "Pholiote" (DK: Nameko-Skælhat, FI: No Finnish name, IS: Namekoskrýfa, NO: (Nameko), SE: Namekotofsskivling).

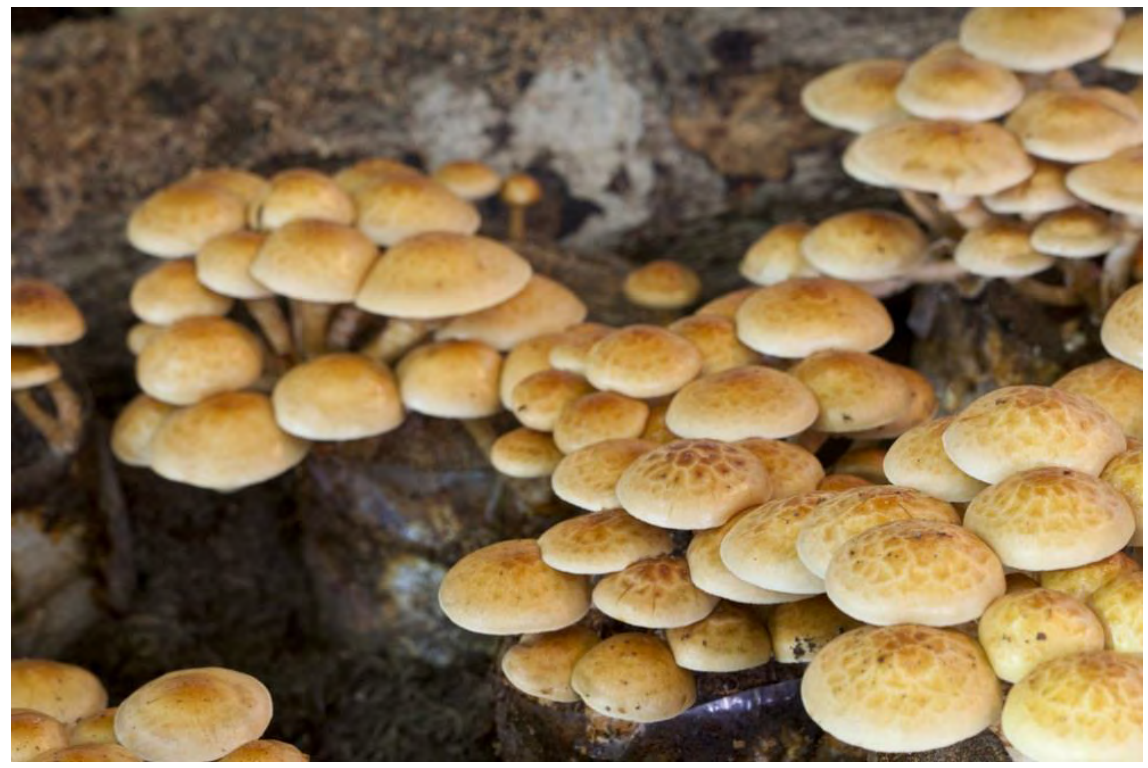

\section{Background and risk assessment}

Pholiota nameko is an edible mushroom.

It is a saprotrophic mushroom and grows wild in deciduous forests in south-eastern Asia, especially Japan (Hongo \& Izawa, 2006). It is also widely cultivated, especially in China and Japan.

There are no intoxications reported after consumption of Pholiota nameko, and no natural toxicants constituting a risk for humans have been identified in the mushroom. However, two bioactive constituents may occur in P. nameko:

Statins: Chen et al. (2012) found $186 \mathrm{mg} / \mathrm{kg}$ (dry weight, mean of 3 samples) of lovastatin in fruit bodies of $P$. nameko. For further information on statins: see Pleurotus ostreatus.

Ergothioneine: Furthermore, Chen et al. (2012) found $229 \mathrm{mg} / \mathrm{kg}$ (dry weight, mean of 3 samples) of ergothioneine in the fruit bodies of $P$. nameko. For further information on ergothioneine: see Lepista nuda. 


\section{Recommendation}

No special recommendation.

\section{Listing 1}

\section{Database search information}

SciFinder by January 2012. Keywords: Pholiota. PubMed by December 2012. Keywords: Pholiota.

\section{References}

Chen S-Y, Ho K-J, Hsieh Y-J, Wang L-T \& Mau J-L (2012): Contents of lovastatin, $\gamma$ aminobutyric acid and ergothioneine in mushroom fruiting bodies and mycelia. IWT - Food Science and Technology 47: 274-278.

Hongo T \& Izawa M (2006): Kinoko (Fungi) 1-383 (Japanese). 


\section{Pholiota squarrosa (Vahl) P. Kumm.}

Shaggy Scalycap (DK: Krumskællet skælhat, FI: Pörhösuomuhelokka, IS: Ígulskrýfa, NO: No Norwegian name, SE: Fjällig tofsskivling).

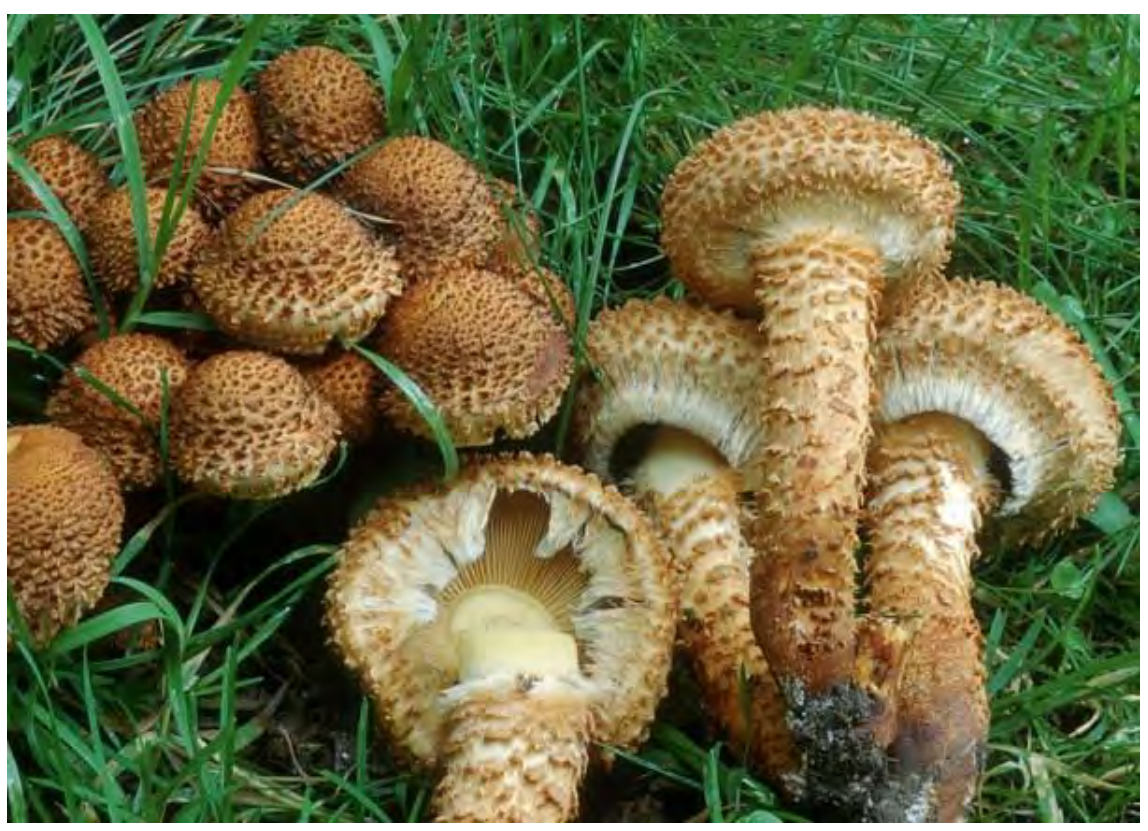

\section{Background and risk assessment}

Shaggy Scalycap (Pholiota squarrosa) is no longer considered as an edible mushroom, although it is indicated to be edible in some mushroom textbooks (e.g. Egeland \& Myhr, 2003; Gerhardt, 1997; Gulden et al., 1999; Knudsen \& Petersen, 2007).

Shaggy Scalycap grows in large clusters at the base of living or recently dead deciduous trees, often on cultivated trees and rather frequently also on Spruce (Picea). It is common in temperate and up to middle boreal zones and occasional up to subalpine/subarctic zones of the Nordic countries (Knudsen \& Vesterholt, 2012).

Poisonings have been reported after consumption of Shaggy Scalycap (Benjamin, 1995; Beug et al., 2006; Beug, 2009; Danish Veterinary and Food Administration, 2012; Hirohisa, 2000; Shaffer, 1965). Although some people eat this mushroom regularly without discomfort others may have gastrointestinal distress, sometimes severe, with vomiting and diarrhoea, one or more hours after consumption of the mushroom (Aurora, 1986; Benjamin, 1995; Bresinsky \& Besl, 1985; Lincoff \& Mitchel, 
1977; Roth, 1990). Some of the poisonings are associated with alcohol intake along with the mushroom, but others are poisoned without concomitant alcohol consumption (Benjamin, 1995; Bresinsky \& Besl, 1985; Haberl et al., 2011; Lincoff \& Mitchel, 1977).

No toxicants have been identified in Shaggy Scalycap. However, it contains a lectin with a molecular weight of $4.5 \mathrm{kDa}$ which is stable between $\mathrm{pH} 2$ and 11 and at temperatures ranging from 0 to $100{ }^{\circ} \mathrm{C}$. The lectin binds specifically to $\alpha 1-6$ fucosylated glycans and agglutinates intact erythrocytes from many animals (Kobayashi et al., 2012). Earlier, Furukawa and colleagues (1995) had shown that a partially purified lectin from the mushroom strongly inhibited human erythrocytes. Some lectins, especially the thermostabile ones, may give rise to gastrointestinal discomfort (Liener, 1983).

\section{Recommendation}

Shaggy Scalycap may occasionally give rise to intoxications. The toxicant(s) is(are) unknown. Therefore, the mushroom should not be traded commercially.

\section{Listing 4}

\section{Database search information}

SciFinder by January 2012. Keywords: Pholiota. PubMed by December 2012. Keywords: Pholiota.

\section{References}

Aurora D (1986): Mushrooms demystified. Ten Speed Press: 1-958.

Benjamin D (1995): Mushrooms: Poisons and panaceas. WH Freeman and company: $1-422$.

Beug MW (2009): NAMA Toxicology Committee Report for 2007: Recent mushroom poisonings in North America. Mcllvainea 18: 40-44.

Beug MW, Shawn M \& Cochran KW (2006): Thirty-plus years of mushroom poisoning: Summary of approximately 2,000 reports in the NAMA case registry. McIllvainea 16: 47-68.

Bresinsky A \& Besl H (1985): Giftpilze. Wissenschaftliche Verlagsgesellschaft mbH: 1-295.

Danish Veterinary and Food Administration (2012): Unpublished data.

Egeland IL \& Myhr S (2003): Norske sopper. Gyldendal: 1-296.

Furukawa K, Ying R, Nakajima T \& Matsuki T (1995): Hemagglutinins in fungus extracts and their blood group specificity. Experimental and Clinical Immunogenetics 12: 223-231.

Gerhardt E (1997): Der grosse BLV Pilzführer für Unterwegs. BLV München: 1-718. 
Gulden G, Jenssen KM \& Stordal J (1999): Norsk lommesoppbok. Tiden Norsk Forlag: 1-298.

Haberl B, Pfab R, Berndt S, Greifenhagen C \& Zilker T (2011): Case series: Alcohol intolerance with Coprine-like syndrome after consumption of the mushroom Lepiota aspera (Pers.: Fr.) Quél., 1886 (Freckled Dapperling). Clinical Toxicology 49: 113-114.

Hirohisa Y, Nobuaki K, Etsuko F, Haruo T, Ikuo K, Masaichi T \& Toshimitsu F (2000): Incidents of mushroom poisoning in Chiba Prefecture. Bulletin of the Public Heath of Chiba Prefecture 24: 5-9 (Japanese, English abstract available).

Knudsen H \& Petersen J H (2007): Politikens svampebog, Politikens forlag: 1-313.

Knudsen H \& Vesterholt J (2012): Funga Nordica. Agaricoid, boletoid, clavarioid, cyphelloid and gastroid genera. Nordsvamp: 1-1083.

Kobayashi Y, Tateno H, Dohra H, Moriwaki K, Miyoshi E, Hirabayashi J \& Kawagishi H (2012): A novel core fucose-specific lectin from the mushroom Pholiota squarrosa. The Journal of Biological Chemistry 287: 33973-33982.

Liener IE (1983): Naturally occurring toxicants in food and their significance in the human diet. Archives of Toxicology Supplements 6: 153-166.

Lincoff G \& Mitchel DH (1977): Toxic and hallucinogenic mushroom poisoning. Van Nostrand Reinhold Company: 1-267.

Roth L, Frank H \& Kormann K (1990): Giftpilze-Pilzgifte, Schimmelpilze-Mykotoxine. Ecomed Verlagsgesellschaft: 1-327.

Shaffer RL (1965): Poisoning by Pholiota squarrosa. Mycologia 57: 318-319. 


\section{Pleurocybella porrigens (Pers.) Singer}

Angel's Wings (DK: Kridthat, FI: No Finnish name, IS: No Icelandic name, NO: Krittøstersopp, SE: Öronmussling).

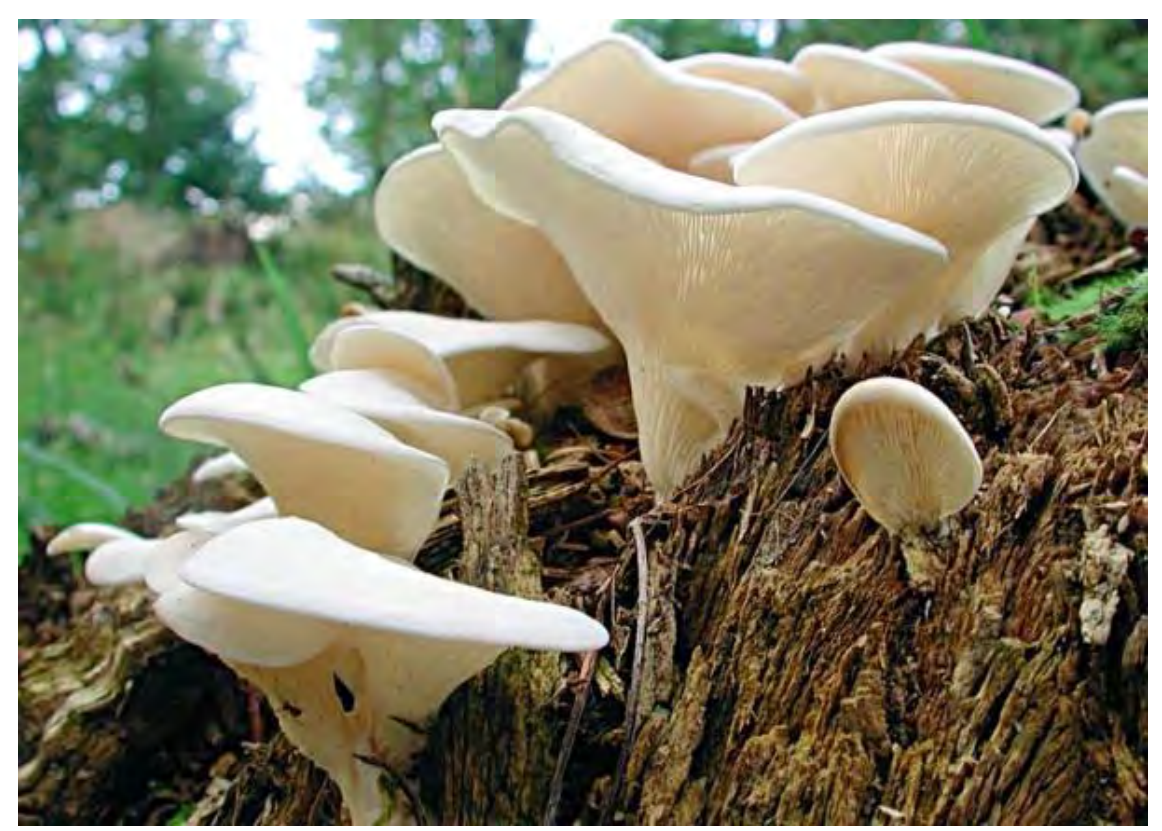

\section{Background and hazard identification}

Angel's Wings (Pleurocybella porrigens) has generally been considered as an edible mushroom in Europe, North America and Asia (Holmberg \& Marklund, 1996; Lincoff, 2000; Læssøe, 1998; Philips, 1991; Philips \& Jacobsson, 1996; Sasaki et al., 2006). Especially in Japan, it has been highly appreciated and was widely consumed without any reports on adverse effects (Gejyo et al., 2005; Sasaki et al., 2006; Wakimoto et al., 2011) until an acute outbreak of encephalopathy with several fatalities occurred in northern Japan in 2004 (Gonmori et al., 2011). In Europe, it has been commercialized in the UK for more than ten years. After the reports on encephalopathy with associated fatalities, the sale in UK was suspended (Peebles, 2012). However, the poisonings of Angel's Wings consumers in Japan in 2004 and apparently also a few years later (Takata et al., 2009) have given rise to serious concern about the edibility of this mushroom.

Angel's Wings is a saprotrophic mushroom growing on stumps or logs of coniferous wood. It is occasional in southern parts of Finland, parts of Jutland in Denmark and very common in south-western parts of Sweden 
and found in costal parts up to the boreal zone of Norway, but otherwise rare or lacking in the Nordic countries (Knudsen \& Vesterholt, 2012).

Chemical investigations have demonstrated several biologically active constituents in Angel's Wings which alone or in combination could be the potential causative agents for the poisonings described. The bioactive constituents include vitamin D analogues (Sasaki et al., 2006), unusual long-chain fatty acids (Amakura et al., 2006a, 2006b; Hasegawa et al., 2007), sialic acids (Takata et al., 2009), lectin (Furukawa et al., 1995; Suzuki et al., 2007), hirsutane-type sesquiterpenoids (Liermann et al., 2011) and $\beta$-hydroxyvaline related amino acids (Aoyagi \& Sugaharra, 1988; Kawaguchi et al., 2010). In addition, small amounts of cyanogenic compounds occur in the mushroom (corresponding to up to $11 \mathrm{mg}$ hydrogen cyanide per kg fresh weight) has been proposed to be the cause for the encephalopathy (Akiyama \& Sasaki, 2007; Akiyama et al., 2006; Gonmori \& Yokoyama, 2009), but such low exposures to hydrogen cyanide via consumption of Angel's Wings is unlikely to be of any concern (Stijive \& de Meijer, 1999). The most likely causative agent is an unstable aziridine carboxylic acid, isolated in high amounts from Angel's Wings and named pleurocybellaziridine (Wakimoto et al., 2011). It seems probable that this compound may be an unstable common precursor for the $\beta$-hydroxyvaline related amino acids isolated from Angel's Wings by Kawaguchi et al. (2010). In vitro studies exposing rat oligodendrocytes to pleurocybellaziridine showed that that the compound significantly reduced the viability of the cultivated cells, whereas the $\beta$ hydroxyvaline carboxylic acids formed from pleurocybellaziridine were significantly less cytotoxic (Wakimoto et al., 2011).

The chemical structures of pleurocybellaziridine and one of the $\beta$ hydroxyvaline related amino acids are shown below.

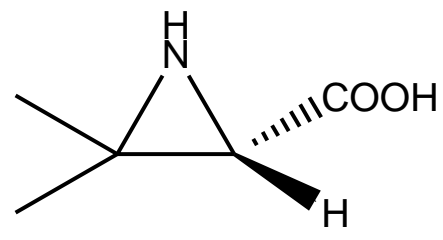

Pleurocybellaziridine

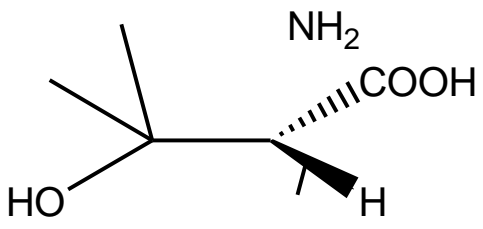

2-Amino-3-hydroxy-3-methylbutanoic acid 


\section{Hazard characterisation}

\section{Human observations}

At least 55 cases with encephalopathy including at least 19 deaths, most due to respiratory failure, have been reported after consumption of Angel's Wings in Japan in 2004 (Gejyo et al., Gonmori \& Yokoyama, 2009; Kawaguchi et al., 2010; Kato et al., 2004; Obara et al., 2005; Saviuc \& Danel, 2006; Takata et al., 2009) and apparently also in 2007 (Takata et al., 2009). Nearly all of the poisoned persons already experienced chronic renal failure and many were undergoing hemodialysis treatment.

The onset of symptoms varied from one to 31 days (mean 9 days) (Gejyo et al., 2009) or 2-3 weeks (Kato et al., 2004; Kurakawa et al., 2005) after consumption of the mushroom. The symptoms were not gastrointestinal or hepatic symptoms commonly seen in mushroom poisonings. Instead a number of neurological symptoms were reported, such as disturbed consciousness, weakness of extremities, convulsions, myoclonus, dysarthia, ataxia and paresis/paralysis (Gejyo et al., 2005; Kato et al., 2004; Kurokuwa et al., 2005). CT and MR brain scans were normal the first days after onset of symptoms, but later different brain lesions were observed. Approximately $30 \%$ of the patients who had presented with encephalopathy after ingestion of Angel's Wings died, in most cases after respiratory failure (Gejyo et al., 2005; Kato et al., 2004; Obara et al., 2008; Saviuc \& Danel, 2006).

Based on the data available, it has not been possible to establish a dose-response relationship between the amount of mushrooms consumed and the severities of the encephalopathy. However, the degree of renal failure is apparently essential for the prognosis of this type of encephalopathy (Kato et al., 2004; Saviuc \& Danel, 2006).

Histological examination of the brain of patients affected by encephalopathy show symptoms of demyelination (Wakimoto et al., 2011). This indicates that toxic constituent(s) in the mushroom has (have) damaged oligodendrocytes in the brain. Therefore, Wakimoto and colleagues (2011) studied the toxicity of the suspected causative agent pleurocybellaziridine against rat CG4-oligodendrocytes cultured in vitro. The cell viability was significantly reduced at concentrations of $10 \mathrm{mg} / \mathrm{ml}$ pleurocybellaziridine. At a concentration of $30 \mathrm{mg} / \mathrm{ml}$ most of the cells died. Pleurocybellaziridine seems to be a precursor for at least five unusual amino acids which all contain a 2-hydroxyvaline moiety. These unusual amino acids have been shown to be cytotoxic against mouse cerebrum glial cells (Kawaguchi et al., 2010), but they exhibited much less toxicity than pleurocybellaziridine against rat CG4-16 oligodendrocytes. It is therefore indicated that pleurocybellaziridine is the causative constituent or at least contributes to the observed encephalopathy after consumption of Angel's Wings. 


\section{Animal studies}

In an in vivo study with two strains of mouse, oral administration of 5 $\mathrm{g} / \mathrm{kg}$ body weight/day of an aqueous extract of Angel's Wings (extracted by $90^{\circ} \mathrm{C}$ for 30 minutes) showed no toxicity. However, an intraperitoneal injection of $1 \mathrm{~g} / \mathrm{kg}$ bodyweight of the same extract caused anemia, shock and death, whereas an intraperitoneal injection of an aqueous extract that had been prepared at $100{ }^{\circ} \mathrm{C}$ for 30 minutes had no significant toxic effects. These data indicate that the toxicant(s) in the mushroom might be thermolabile (Takano et al., 2005).

\section{Exposure assessment}

Mushroom consumption: Although Angel's Wings is common in Finland, Norway and Sweden (rare in Denmark and not found in Iceland) and indicated to be edible in some Nordic mushroom textbooks (Holmberg \& Marklund, 1996; Læssøe, 1995; Philips \& Jacobsson, 1996), it has not been included in earlier Nordic guidance lists on mushrooms for consumption, and it has not been marketed in the Nordic countries. Therefore, it is estimated that the Nordic consumption of this mushroom is very modest, if occurring at all. However, in other countries, especially in Japan, it is a popular mushroom considered to be edible. In the autumn of 2004, when most of the intoxications due to Angel's Wings consumption in Japan took place, the mushroom was extraordinary abundant due to special weather conditions and it is possible that it was eaten in high amounts. However, there are no specific data available on consumption.

Content of anticipated causative agent: As mentioned above, Wakimoto and colleagues have recently isolated an aziridine carboxylic acid ester from an esterified extract of Angel's Wings in amounts corresponding to $2.3 \mathrm{~g}$ pleurocybellaziridine per $\mathrm{kg}$ fresh mushroom. It was necessary to esterify the mushroom sample as the free pleurocybellaziridine otherwise will be destroyed during the isolation process. It was also mentioned above, that in vitro studies indicate that this compound is the causative agent for the encephalopathy after consumption of Angel's Wings in Japan.

It is not possible to estimate the content of pleurocybellaziridine in the Angel's Wings samples consumed and giving rise to the intoxications in 2004. The content has been determined only once, in mushrooms, apparently collected several years after the outbreak of poisonings in 2004 (Wakimoto et al., 2011). It has been proposed that there are different varieties of Angel's Wings in Japan, and it is conceivable that these contain different amounts of the causative agent (Matsumoto et al., 
2005). As the toxicant seems to be destroyed by heat (Takano et al., 2005; Wakimoto et al., 2011), the cooking of Angel's Wings, although traditionally for a very short period (Wakimoto et al., 2005), could lead to a reduction in the content of the toxic compound.

\section{Risk characterisation}

Based on human observations it is highly likely that consumption of Angel's Wings has given rise to at least 55 cases of encephalopathy. At least 19 of the affected persons died. Most of the patients had a history of chronic renal failure and many underwent hemodialysis.

The anticipated causative agent is an unstable aziridine carboxylic acid, pleurocybellaziridine, which may occur at high levels in the mushroom. However, neither the amounts of mushrooms consumed by the poisoned persons, nor the level of pleurocybellazeridine in the consumed mushrooms are known.

Uncertainties: As Angel's Wings has been consumed for many years in Europe, Asia and North America without any intoxications having been reported before the epidemic outbreak of encephalopathy in Japan in 2004 (and apparently also some in 2007), the Asian cases have raised several questions and resulted in uncertainties whether it is appropriate to consume the mushroom (Beug, 2011; Gejyo et al., 2005; Saviuc \& Danel, 2006):

- Was the content of toxicants in the mushroom extraordinary high in 2004 due to the extraordinary hot and humid weather conditions this year?

- Was the consumption exceptionally high in 2004, as the Angel's Wings could be collected in large quantities this year?

- Is pleurocybellaziridine the causative agent (the anticipation is mainly based on cell culture studies and data from very limited studies in mice)?

- Do all collections of Angel's Wings contain the agent (pleurocybellaziridine) that caused the outbreak of intoxications in 2004 or are there various forms of the mushroom?

- What is the mechanism of the acute encephalopathy after consumption of Angel's Wings? 


\section{Recommendation}

Consumption of Angel's Wings has given rise to several serious and sometimes fatal intoxications, most likely due to its content of pleurocybellaziridine. With the present knowledge, Angel's Wings should not be marketed as an edible mushroom.

\section{Listing 4}

\section{Database search information}

PubMed by December 2012. Keywords: Pleurocybella. SciFinder 20112012. Keywords: Pleurocybella.

\section{References}

Akiyama H \& Sasaki H (2007): Relationship between the acute encephalopathy and Sugihiratake mushroom intake. Japanese Journal of Food Chemistry 14: 43-50 (Japanese, English abstract available).

Akiyama H, Toida T, Sakai S, Amakura Y, Kondo K, Sugita-Konishi Y \& Maitani T (2006): Determination of cyanide and thiocyanate in Sugihiratake mushroom using HPLC method with fluorometric detection. Journal of Health Science 52: 73-77.

Amakura Y, Kondo K, Akiyama H, Ito H, Hatano T, Yoshida T \& Maitani T (2006a): Characteristic long-chain fatty acid of Pleurocybella porrigens. Journal of Food Hygienic Society of Japan 47: 178-181.

Amakura Y, Kondo K, Akiyama H, Ito H, Hatano T, Yoshida T \& Maitani T (2006b): Conjugated ketonic fatty acids from Pleurocybella porrigens. Chemical and Pharmaceutical Bulletin 54: 1213-1215.

Aoyagi Y \& Sugahara T (1988): $\beta$-Hydroxy-L-valine from Pleurocybella porrigens. Phytochemistry 27: 3306-3307.

Furukawa K, Ying R, Nakajima T \& Matsuki T (1995): Hemagglutinins in fungus extracts and their blood group specificity. Experimental and Clinical Immunogenetics 12: 223-231.

Gejyo F, Homma N, Higuchi N, Ataka K, Teramura T, Alchi B, Suzuki Y, Nishi S \& Narita I (2005): A novel type of encephalopathy associated with mushroom Sugihiratake ingestion in patients with chronic kidney diseases. Kidney International 68: 188-192.

Gonmori K \& Yokoyama K (2009): Acute encephalopathy caused by cyanogenic fungi in 2004, and magic mushroom regulation in Japan. Chudoku Kenkyu 22: 61-69 (Japanese, English abstract available.

Gonmori K, Fujita H, Yokoyama K, Watanabe K \& Suzuki O (2011): Mushroom toxins: a forensic toxicological review. Forensic Toxicology 29: 85-94.

Hasegawa T, Ishibashi M, Takata T, Takano F \& Ohta T (2007): Cytotoxic fatty acid from Pleurocybella porrigens. Chemical and Pharmaceutical Bulletin 55: 1748-1749.

Holmberg P \& Marklund H (1996): Nya Svampbooken. Rabén risam. Stockholm: 1-251. 
Kato T, Kawanami T, Shimuzu H, Kurokawa K, Sato H, Nakajima K, Nomoto T, Seta T, Kamei T, Yoshino H, Sasagawa S, Karasawa S, Kimura H, Ito M, Suzuki Y, Degawa N, Tagawa A, Ataka K, Ando S, Omae T \& Shikama Y (2004): An outbreak of encephalopathy after eating autumn mushroom (Sugihiratake; Pleurocybella porrigens) in patients with renal failure: a clinical analysis of ten cases in Yamagata, Japan. No To Shinkei 56: 999-1007 (Japanese, English abstract available).

Kawaguchi T, Suzuki T, Kobayashi Y, Kodani S, Hirai H, Nagai K \& Kawagishi H (2010): Unsual amino acid derivatives from the mushroom Pleurocybella porrigens. Tetrahedron 66: 504-507.

Knudsen H \& Vesterholt J (2012): Funga Nordica. Agaricoid, boletoid, clavarioid, cyphelloid and gastroid genera. Nordsvamp: 1-1083.

Kurokawa K, Sato H, Nakajima K \& Kato T (2005): Clinical, neuroimaging and electroencephalografic findings after the ingestion of "Sugihiratake" (Pleurocybella porrigens), an autumn mushroom: a report of two cases. Rinsho Shinkeigaku 45: 111116 (Japanese, English abstract available).

Kuwabara T, Arai A, Honma N \& Nishizawa M (2005): Acute encephalopathy among patients with renal dysfunction after ingestion of "Sugihiratake", Angel's Wing mushroom - study on the incipient cases in the northern area of Nigata Prefecture. Rinsho Shinkeigaku 45: 239-245 (Japanese, English abstract available).

Liermann JC, Schüffler A, Wollinsky B, Birnbacher J, Kolshorn H, Anke T \& Opatz T (2010): Hirsutane-type sesquiterpenes with uncommon modifications from three basidiomycetes. Journal of Organic Chemistry 75: 2955-2961.

Lincoff G (2000): National Audubon Society Field guide to North American mushrooms. Alfred A. Knopf: 1-927.

Læssøe T (1998): Politikens Store Svampebog. Politikens Forlag: 1-304.

Matsumoto T, Nagasawa E \& Fukumasa-Nakai Y (2005): Variation of ITS sequences in a natural Japanese population of Pleurocybella porrigens. Mycoscience 46: 370-375.

Nishizawa M (2005): Acute encephalopathy after ingestion of "Sugihiratake" mushroom. Rinsho Shinkeigaku 45: 818-820 (Japanese, English abstract available).

Obara K, Okawa S, Kobayashi M, Takahishi S, Watanabe S, Toyoshima I (2005): A case of encephalopathy related to Pleurocybella porringens (Sugihiratake). Rinsho Skinkeigaku 45: 253-256 (Japanese, English abstract available).

Obara K, Wada C, Yoshioka T, Enomoto K, Yagishita S \& Toyoshima I (2008): Acute encephalopathy associated with ingestion of a mushroom, Pleurocybella porrigens (Angel's Wing), in a patient with chronic renal failure. Neuropathology 28: 151-156.

Peebles R (2012): Richard Peebles, wild food consultant to the British Catering Industry. Personal communication to the authors.

Philips R (1991): Mushrooms of North America. Little, Brown and Company: 1-319.

Philips R \& Jacobsson S (1996): Norstedts Stora Svampbok. Norstedts Förlag: 1-288.

Sasaki H, Akiyama H, Yoshida Y, Kondo K, Amakura Y, Kasahara Y \& Maitani T (2006): Sugihiratake mushroom (Angel's Wing mushroom) - Induced cryptogenic encephalopathy may involve vitamin D analogues. Biological \& Pharmaceutical Bulletin 29: 2514-2518.

Saviuc P \& Danel V (2006): New syndromes in mushroom poisoning. Toxicological Reviews 25: 199-209.

Stijve T \& de Meijer AAR (1999): Hydrocyanic acid in mushrooms, with special reference to wildgrowing and cultivated species. Deutsche Lebensmittel Rundschau 95: 366-373. 
Suzuki T, Amano Y, Motohiro F, Kobayashi Y, Dohra H, Hirai H, Murata T, Usui T, Morita T \& Kawagishi H (2009): Purification, characterization, and cDNA cloning of a lectin from the mushroom Pleurocybella porrigens. Bioscience Biotechnology Biochemistry 73: 702-709.

Takano F, Yamaguchi M, Shoda S, Zi-Dong F \& Ohta T (2005): Toxicological studies on hot water extracts of Pleurocybella porrigens (Pers.: Fr.) in mice. Natural Medicines 59: 151-156 (Japanese, English abstract available).

Takata T, Hasegawa T, Tatsuno T, Date J, Ishigaki Y, Nakamura Y, Tomosugi N, Takano F \& Ohta T (2009): Isolation of $N$-acetylneuraminic acid and $N$ -

glycolylneuraminic acid from Pleurocybella porrigens. Journal of Health Science 55: 373-379.

Wakimoto T, Asakawa T, Akahoshi S, Suzuki T, Nagai K, Kawagishi H \& Kan T (2011): Proof of the existence of an unstable amino acid: Pleurocybellaziridine in Pleurocybella porrigens. Angewandte Chemie International Edition 50: 1168-1170 (Supporting Information: S1-45). 


\section{Pleurotus citrinopileatus Singer}

Golden Oyster (DK: Gul Østershat, FI: Sitruunavinokas, IS: Gulvængu, NO: Sitronøsterssopp, SE: Citronmussling).

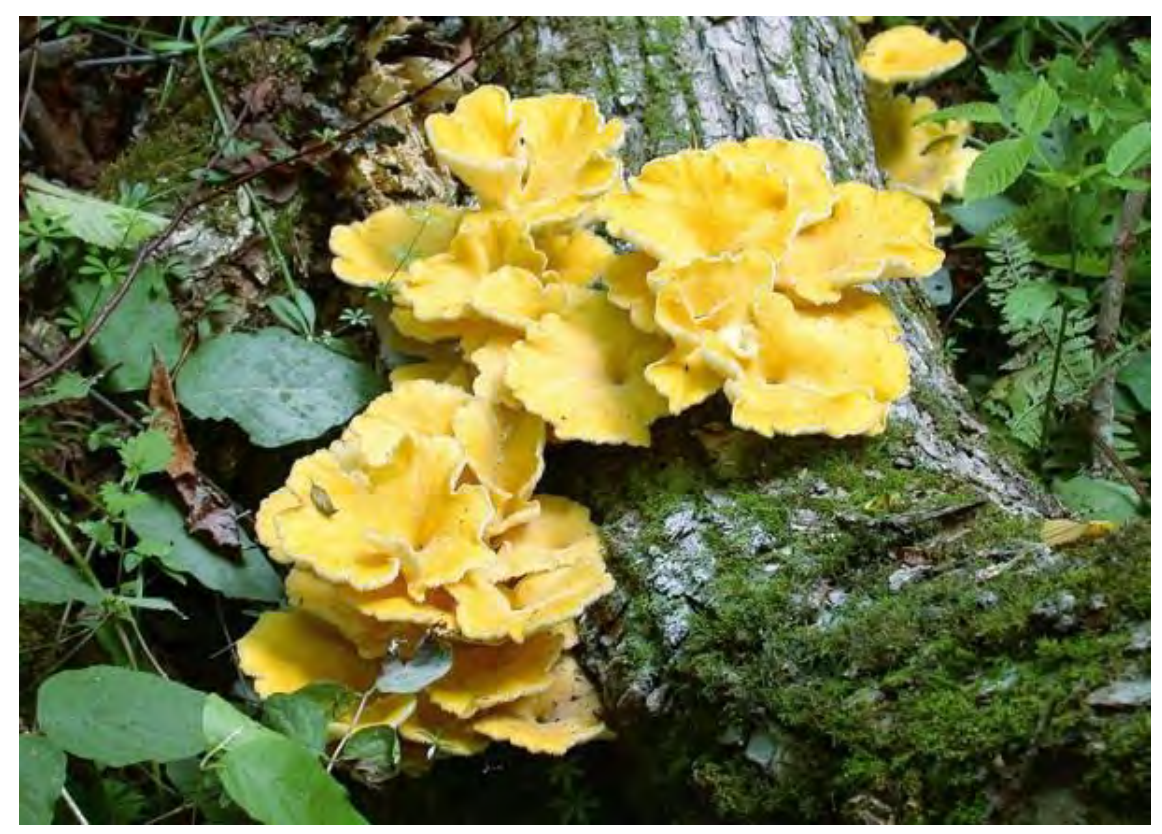

\section{Background and risk assessment}

Golden Oyster (Pleurotus citrinopileatus) is an edible mushroom, which is commonly cultivated and consumed.

It is a saprotrophic mushroom, growing wild in deciduous forests in Japan and far-east Russia (Hongo \& Izawa, 2006). It is mainly the cultivated form, which is commercially available.

There are no intoxications reported after consumption of Golden Oyster, and no natural toxicants constituting a risk for humans have been identified in the mushroom. However, Golden Oyster contains different bioactive constituents:

\section{Bioactive constituents}

Statins: Chen et al. (2012) have found $120 \mathrm{mg} / \mathrm{kg}$ (dry weight) of lovastatin in fruit bodies of Golden Oyster. Lovastatin has also been identified in an amount of $930 \mathrm{mg}$ per kg (dry weight) in mycelia (Lo et al., 2012), whereas Lin et al. (2013) could not detect any lovastatin in mycelia from this mushroom. When statins like lovastatin are used as a cholesterollowering drug, it has in rare cases given rise to adverse effects with my- 
opathy, characterised by muscular weakness and/or pain, and in very rare cases rhabdomyolysis. ${ }^{22}$ These serious adverse effects have not been reported after consumption of Golden Oyster. For further data on lovastatin, see $P$. ostreatus.

Hydrogen cyanide: Golden Oyster has been demonstrated to produce low amounts of hydrogen cyanide. However, during cooking the cyanogenic compound is completely destroyed and accordingly does not pose any health hazards to the consumers (Stijve \& de Meijer, 1999).

Lectins: Li et al. (2008) have isolated a dimeric lectin with a molecular weight of $32.4 \mathrm{kDa}$ from the mushroom. The lectin has high hemagglutinating activity and is stable up to $60{ }^{\circ} \mathrm{C}$. Whether this lectin could give rise to discomfort in people eating Golden Oyster raw or insufficiently cooked is not reported. It is well-known that some other lectins in certain foods may cause gastrointestinal effects (Liener, 1983).

Ergothioneine: It has been shown that Golden Oyster contains $2,850 \mathrm{mg} / \mathrm{kg}$ (dry weight) of ergothioneine in the fruit bodies (Chen et al., 2012) and $1,000 \mathrm{mg} / \mathrm{kg}$ (dry weight) in the mycelia (Lin et al., 2013) or $26 \mathrm{mg} / \mathrm{kg}$ (dry weight) in the mycelia (Lo et al., 2012). For further information on ergothioneine, see Lepista nuda.

Experimental studies: Fractions of aqueous extracts from fruit bodies of Golden Oyster significantly lowered serum triglycerides and total cholesterol when fed as a supplement to high-fat diets to hyperlipidemic rats. Furthermore, high-density lipoprotein levels were significantly higher than in the control groups (Hu et al., 2006). There was no information on possible content of statins in the diets used.

\section{Recommendation}

No special recommendation.

\section{Listing 1}

Database search information

PubMed by 1 December 2012. Keywords: Pleurotus citrinopileatus.

22 Rhabdomyolysis is the breakdown of muscle fibers that leads to the release of muscle fiber contents (myoglobin) into the blood stream. Myoglobin is harmful to the kidney and often causes kidney damage (MedlinePlus Medical Enclyclopedia, 2012). 


\section{References}

Chen S-Y, Ho K-J, Hsieh Y-J, Wang L-T \& Mau J-L (2012): Contents of lovastatin, $\gamma$ aminobutyric acid and ergothioneine in mushroom fruiting bodies and mycelia. Food Science and Technology 47: 274-278.

Hongo T \& Izawa M (2006): Kinoko (Fungi) 1-383 (Japanese).

Hu SH, Liang ZC, Chia YC, Lien JL, Chen KS, Lee MY \& Wang JC (2006): Antihyperlipidemic and antioxidant effects of extracts from Pleurotus citrinopileatus. Journal of Agricultural and Food Chemistry 54: 2103-2110.

Li YR, Liu QH, Wang HX \& Ng TB (2008): A novel lectin with potent antitumor, mitogenic and HIV-1 reverse transcriptase inhibitory activities from the edible mushroom Pleurotus citrinopileatus. Biochimica et Biophysica Acta 51-57.

Liener IE (1983): Naturally occurring toxicants in food and their significance in the human diet. Archives of Toxicology Supplements 6: 153-166.

Lin S-Y, Chen Y-K, Yu H-T, Barseghyan GS, Asatiani MD, Wasser SP \& Mau JL (2013): Comparative study of contents of several bioactive components in fruiting bodies and mycelia of culinary-medicinal mushrooms. International Journal of Medical Mushrooms 15: 315-323.

Lo Y-C, Lin S-Y, Ulziijargal E, Chen S-Y, Chien R-C, Tzou Y-J \& Mau J-L (2012): Comparative study of contents of several bioactive components in fruiting bodies and mycelia of culinary-medicinal mushrooms. International Journal of Medicinal Mushrooms 14: 357-363.

MedLine Plus Medical Encyclopedia (2012): U.S. National Library of Medicin. National Institutes of Health.

Stijve T \& de Meijer AAR (1999): Hydrocyanic acid in mushrooms, with special reference to wild-growing and cultivated edible species. Deutsche LebenmittelsRundschau 95: 366-373. 


\section{Pleurotus djamor (Rumph. ex. Fr.) Boedijn (P. salmoneostramineus Lj. N. Vassiljeva)}

Tropical Oyster (DK: Rød Østershat, FI: No Finnish name, IS: Rodavængur, NO: Flamingoøsterssopp, SE: (Rosa ostronmussling)).

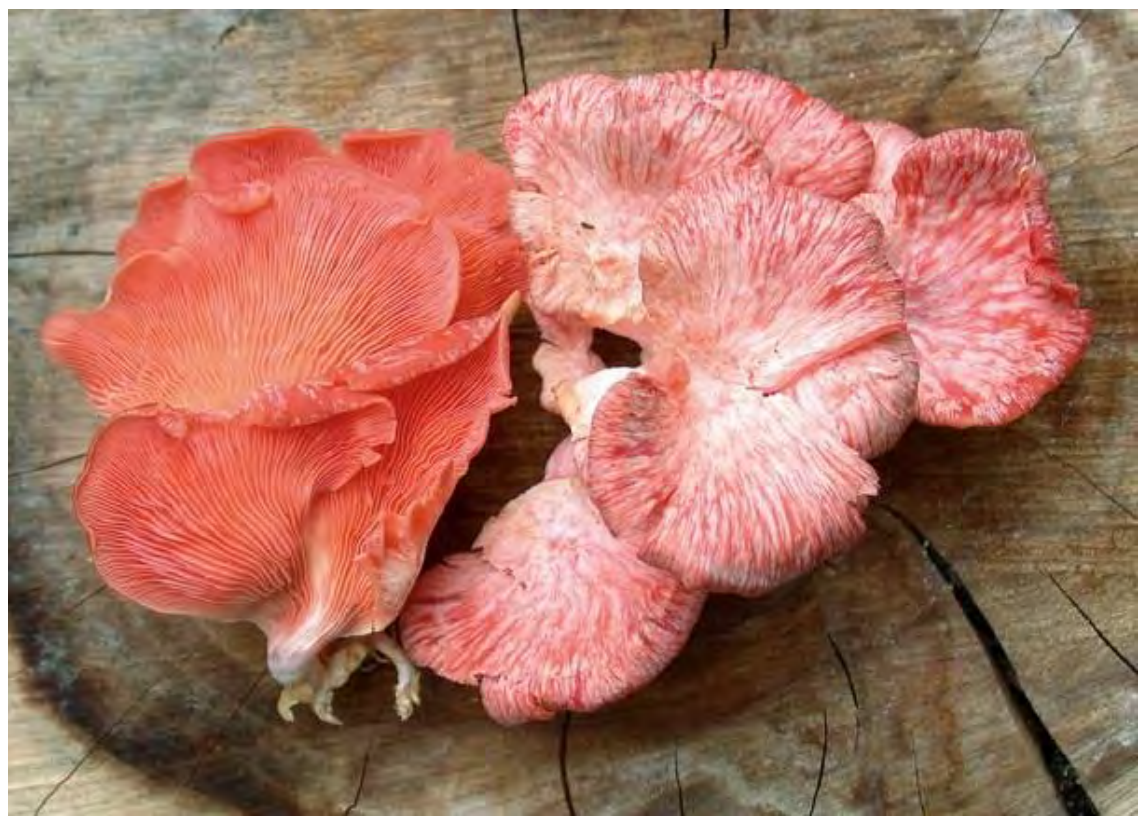

\section{Background and risk assessment}

Tropical Oyster (Pleurotus djamor) is an edible mushroom, which is commonly cultivated and consumed.

It is a saprotrophic mushroom, growing wild, on wood, in China, Sri Lanka and Japan (Anonymous, 1986; Pegler, 1986).

There are no intoxications reported after consumption of Tropical Oyster, and no natural toxicants constituting a risk for humans have been identified in the mushroom. There are only few studies on bioactive constituents in Tropical Oyster:

\section{Bioactive constituents}

Ergothioneine: Chen et al. (2012) detected 1,250 mg/kg of ergothioneine in the fruit bodies (dry weight) and Lo et al. (2012) $220 \mathrm{mg} / \mathrm{kg}$ in the mycelia (dry weight). For further information on ergothioneine, see Lepista nuda.

Statins: Neither Chen et al. (2012) analysing fruit bodies, nor Lo et al. (2012) and Chegwin-Angarita et al. (2013) analysing cultured mycelia 
could detect any lovastatin in Tropical Oyster. Most other Pleurotus species studied contain lovastatin (Lin et al., 2013).

Experimental studies: In a study on hypolipidemic (and antiatherogenetic) effects of Tropical Oyster, hypercholesterolemic rats were fed $5 \%$ dried, powdered fruit bodies of the mushroom. Plasma total cholesterol, triglycerides and cholesterol in low-density-lipoprotein (LDL) were significantly reduced when compared with rats fed a control diet. The authors did not analyse for lovastatin in the mushrooms used for the rat study (Yoon et al., 2012).

\section{Recommendation}

No special recommendation.

\section{Listing 1}

\section{Database search information}

PubMed by 1 December 2012. Keywords: Pleurotus djamor, Pleurotus salmoneostraminineus.

\section{References}

Anonymous (1986): Illustrated pocket book of mushrooms in colour: 1-358 (Japanese). Chegwin-Angarita C, Nieto-Ramirez IJ, Diaz GJ, Rojas LJR, Sepulveda L \& Atehortua L (2013): Evaluation of a method using high performance liquid chromatography with ultraviolet detection for the determination of statins in macromycetes of the genus Pleurotus cultivated by fermentation processes. Talanta 116: 56-64.

Chen S-Y, Ho K-J, Hsieh Y-J, Wang L-T \& Mau J-L (2012): Contents of lovastatin, $\gamma$ aminobutyric acid and ergothioneine in mushroom fruiting bodies and mycelia. Food Science and Technology 47: 274-278.

Lo Y-C, Lin S-Y, Ulziijargal E, Chen S-Y, Chien R-C, Tzou Y-J \& Mau J-L (2012): Comparative study of contents of several bioactive components in fruiting bodies and mycelia of culinary-medicinal mushrooms. International Journal of Medicinal Mushrooms 14: 357-363.

Pegler DN (1986): Agaric flora of Sri Lanka. HMSO, Kew: 1-519.

Yoon KN, Alam N, Shim MJ \& Lee TS (2012): Hypolipidemic and antiatherogenesis effect of culinary-medicinal Pink Oyster Mushroom, Pleurotus salmoneostramineus L. Vass (higher Basidiomycetes), in hypercholesterolemic rats. International Journal of Medicinal Mushrooms 14: 27-36. 


\section{Pleurotus eryngii (DC.) Quél. (P. eryngii var. ferulae (Lanzi) Sacc.)}

King Oyster (French Horn Mushroom, King Trumpet Mushroom) (DK: Kejser-Østershat (Mandstro-Østershat, "Kejserhat"), FI: Kuningasosterivinokas (Kuningasvinokas), IS: Istruvængur, NO: Kongeøsterssopp, SE: ("Kungsmussling")).

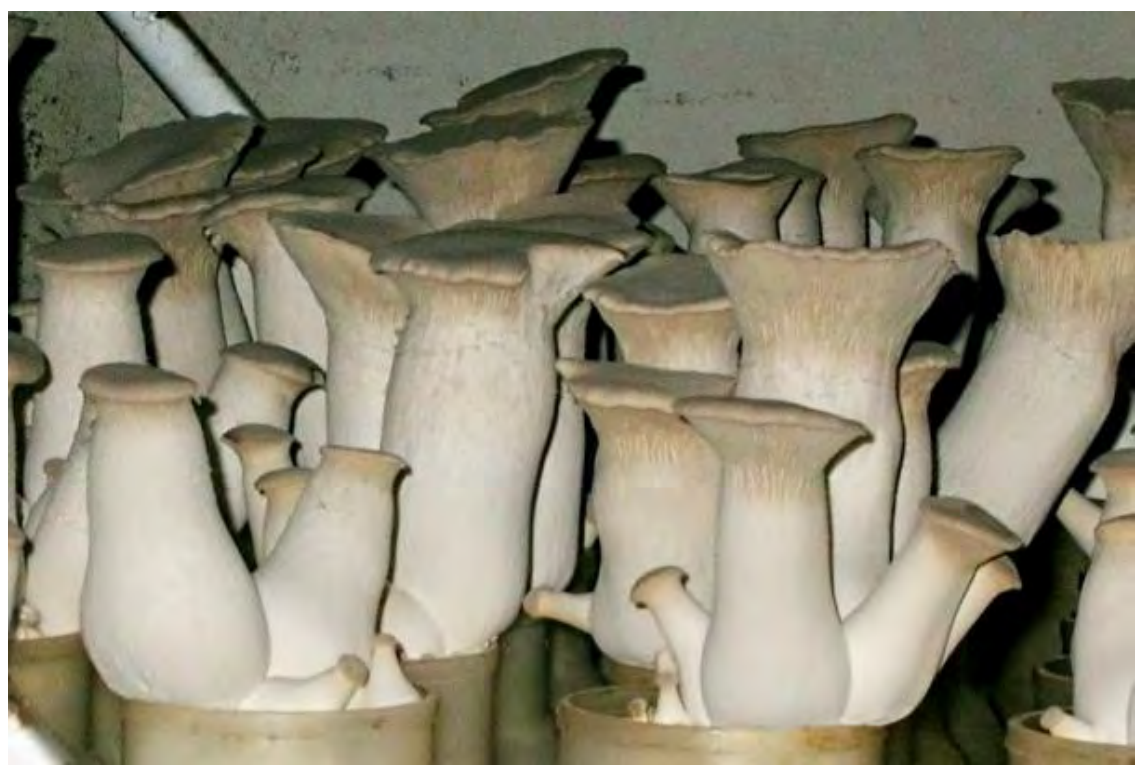

\section{Background and risk assessment}

King Oyster (Pleurotus eryngii) is an edible mushroom, which is commonly cultivated and consumed.

It is a saprotrophic mushroom growing on dead (apparently also on living/dying) tall umbelliferous herbs, e.g. on species of the genera Eryngium and Ferula in open steppe-like areas. The mushroom grows wild in the Mediterranean area and eastwards into China and Central Asia (Hongo \& Izawa, 2006).

King Oyster is a complex of varieties or possibly species, including $P$. eryngii var. eryngii and P. eryngii var. ferulae, but classification is still under discussion (Stajic et al., 2009).

There are no intoxications reported after consumption of King Oyster, and no natural toxicants constituting a risk for humans have been identified in the mushroom. However, different bioactive constituents have been identified in King Oyster. 


\section{Bioactive constituents}

Statins: Between 120 and 150 mg lovastatin per kg (dry weight, 9 samples) have been detected in dried fruit bodies of King Oyster by Chen et al. (2012), whereas these investigators found lower levels in the mycelium $45 \mathrm{mg}$ per kg (dry weight, 3 samples) in mycelia. Lo et al. (2012) and Lin et al. (2013) have confirmed the presence of lovastatin in mycelia from King Oyster, the levels being 67 and $42 \mathrm{mg}$ per kg (dry weight, 3 samples) in mycelium, respectively. For further information on statins: see Pleurotus ostreatus.

Alam et al. (2011) studied the antihyperlipidemic effects of King Oyster in hypercholesterolemic rats and noted that feeding a diet containing $5 \%$ dried powdered fruit bodies of the mushroom, reduced significantly plasma total cholesterol, triglycerides, low-density-lipoprotein (LDL) and other lipid parameters. It was hypothesized whether these effects could partly be explained by the content of lovastatin.

The structural formula of lovastatin is shown below.<smiles>CCC(C)C(=O)O[C@H]1C[C@@H](C)C=C2C=C[C@H](C)[C@H](CC[C@H]3C[C@@H](O)CC(=O)O3)C21</smiles>

Lovastatin

Ergothioneine: In one study Chen et al. (2012) identified $460-840 \mathrm{mg} / \mathrm{kg}$ (dry weight, 9 samples) of ergothioneine in the fruit bodies and 1,500 $\mathrm{mg} / \mathrm{kg}$ (dry weight, 3 samples) in mycelia of King Oyster. Lo et al. (2012) and Lin et al. (2013) found somewhat less, 250 and $240 \mathrm{mg} / \mathrm{kg}$ (dry weight) in the mycelia, respectively.

Cytolysins: A monomeric hemolysin, designated eryngeolysin, with a molecular weight of $17 \mathrm{kDa}$ has been isolated from King Oyster fruit bodies. It has structural similarities with the hemolysin, ostreolysin, from $P$. ostreatus. It is stable in the $\mathrm{pH}$ range 4.0-12.0, but only stable up to $30{ }^{\circ} \mathrm{C}$ (Ngai \& $\mathrm{Ng}$, 2006). More recently, Shibata et al. (2010) isolated and characterized a thermostable two-component hemolysin constituted by erylysin A (molecular weight $15 \mathrm{kDa}$ ) and erylysin B (molecular weight $52 \mathrm{kDa}$ ). Erylysin A was a homodimer, whereas erylysin B was a 
heterodimer of the $\mathrm{B}_{1}$ (molecular weight $15 \mathrm{kDa}$ ) and $\mathrm{B}_{2}$, (molecular weight $37 \mathrm{kDa}$ ) components. Erylysin (A and $\mathrm{B}$ ) is similar to the hemolysin, pleurotolysin (A and B) isolated and characterized by Tomita el al. (2004) in P. ostreatus. Both hemolysins require coexistence of the A and $B$ units to exhibit strong activity.

There are no intoxications reported after consumption of thoroughly cooked King Oyster. This indicates that any potential effects of the cytolysins are eliminated during heating and/or digestion.

$\alpha, \beta$-Unsaturated lactones: Three $\alpha, \beta$-unsaturated lactones have been isolated and identified from a solid culture of King Oyster, eryngiolide A, 1,2dihydroxymintlactone and 5-hydroxy-3,4,5-trimethylfuran-2(5H)-one. An $\alpha, \beta$-unsaturated lactone moiety is regarded as a significant structural characteristic for many naturally occurring bioactive compounds. EFSA (2007) considers the $\alpha, \beta$-unsaturated ketone structure as a structural alert for genotoxicity. The three lactones were tested for cytotoxic activity against the two human cancer cell lines HeLa and HepG2. Only eryngiolide A showed toxicity against the cell lines (Wang et al., 2012). Eryngiolide A is a diterpenoid with a cyclodecane skeleton, substituted with several functional groups and fused with two lactone groups. The structural formula for eryngiolide $\mathrm{A}$ is shown below.

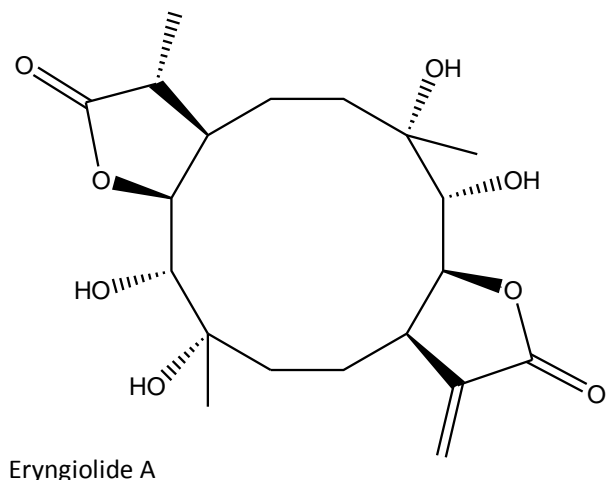

A further $\alpha, \beta$-unsaturated lactone (4H-1,3-dioxine-2,4-dione), designated pleurone, has been isolated from fruit bodies of $P$. eryngii var. ferulae (King Oyster). Pleurone was shown in vitro to be a moderate human neutrophil elastase inhibitor (Lee et al., 20111). As none of these four $\alpha, \beta$ unsaturated lactones have been studied in vivo, it is difficult to estimate if these compounds could be of health concern for humans.

Cyanogenic compounds: Shindo and colleagues examimed the content of cyanide in different Basidiomycetes. The content of cyanide in King Oyster was in average $14 \mathrm{mg}$ per $\mathrm{kg}$ of fresh mushroom $(7$ samples, 
range $1-26 \mathrm{mg} / \mathrm{kg}$ ). The chemical form was probably as free cyanide, because there was no significant difference in quantities of cyanide before and after incubation with glucosidases (Shindo et al., 1999). Subsequent studies by Chou et al. (2006) in 52 samples of fresh King Oyster mushrooms collected from the local market in Taiwan or mushroom farms, showed that most (67\%) products contained hydrogen cyanide concentrations below $1 \mathrm{mg} / \mathrm{kg}, 17 \%$ of the samples levels between 1.0 and $2.0 \mathrm{mg} / \mathrm{kg}$, and only $15 \%$ of samples more than $2.0 \mathrm{mg} / \mathrm{kg}$. When the mushroom was sliced and cooked in water at $95{ }^{\circ} \mathrm{C}$ for 6 minutes, $89 \%$ of the original hydrogen cyanide was lost (Chou et al., 2006). Thus, it is estimated that the exposure to hydrogen cyanide after consumption of King Oyster, especially after cooking, would be so low that it is of no health concern.

Mutagens: Morales et al. (1990a, 1990b) studied mushroom extracts in the Ames test. Extracts of freshly harvested and frozen King Oyster were reported to be weakly mutagenic in the Salmonella strains TA98 and TA100. Extracts of canned King Oyster were negative in the Ames test but weakly mutagenic, however only after addition of microsomal enzymes, in the Chinese Hamster Ovary (CHO/HPRT) cell mutation assay. Apparently, Morales et al. (1990a, 1990b) did not control for possible histidine in the extracts for the Ames test. Thus, there is no strong indication that extracts of King Oyster are mutagenic.

\section{Recommendation}

No special recommendation.

Listing 1

\section{Database search information}

PubMed by 1 December 2012. Keywords: Pleurotus eryngii, Pleurotus ferulae.

\section{References}

Alam N, Yoon KN \& Lee TS (2011): Antihyperlipidemic activities of Pleurotus ferulae on biochemical and histological function in hypercholesterolemic rats. Journal of Research in Medical Sciences 16: 776-786.

Chen S-Y, Ho K-J, Hsieh Y-J, Wang L-T \& Mau J-L (2012): Contents of lovastatin, $\gamma$ aminobutyric acid and ergothioneine in mushroom fruiting bodies and mycelia. Food Science and Technology 47: 274-278.

Chou P-Y, Hong C-H, Chen W, Li Y-J, Chen Y-S \& Chiou Y-Y (2006): Glass distilling collector applied for HCN recovery from submerged culture broth and fruiting body of Pleurotus eryngii for identification and quantification. Journal of Agricultural and Food Chemistry 54: 1551-1556. 
EFSA (2007): European Food Safety Authority. Minutes of the $26^{\text {th }}$ plenary meeting of the scientific panel on food additives, flavourings, processing aids and materials in contact with food. Held in Parma on 27-29 November 2007: 1-32 (EFSA/AFC/P_M26/min).

Hongo T \& Izawa M (2006): Kinoko (Fungi) 1-383 (Japanese).

Lee I-S, Ryoo I-J, Kwon K-Y, Ahn JS \& Yoo I-D (2011): Pleurone, a novel human neutrophil elastase inhibitor from fruiting bodies of the mushroom Pleurotus eryngii var. ferulae. Journal of Antibiotics 64: 587-589.

Lin S-Y, Chen Y-K, Yu H-T, Barseghyan GS, Asatiani MD, Wasser SP \& Mau JL (2013): Comparative study of contents of several bioactive components in fruiting bodies and mycelia of culinary-medicinal mushrooms. International Journal of Medical Mushrooms 15: 315-323.

Lo Y-C, Lin S-Y, Ulziijargal E, Chen S-Y, Chien R-C, Tzou Y-J \& Mau J-L (2012): Comparative study of contents of several bioactive components in fruiting bodies and mycelia of culinary-medicinal mushrooms. International Journal of Medicinal Mushrooms 14: 357-363.

Ngai PHK \& Ng TB (2006): A hemolysin from the mushroom Pleurotus eryngii. Applied Microbiology and Biotechnology 72: 1185-1191.

ShibataT, Kuduo M, Hoshi Y, Kudo A, Nanashima N \& Miyairi K (2010): Isolation and characterization of a novel two-component hemolysin erylysin A and B, from an edible mushroom, Pleurotus eryngii. Toxicon 56: 1436-1442.

Shindo T, Ushiyama H, Kan K \& Yasuda K (1999): Study on content of cyanide in Basidiomycetes and the effect of cooking. Journal of Food Hygienic Society of Japan 40: 29-35.

Stajić M, Vukojević J \& Duletić-Laušević S (2009): Biology of Pleurotus eryngii and role in biotechnological processes: a review. Critical Reviews in Biotechnology 29: $55-66$.

Tomita T, Noguchi K, Mimuro H, Ukaji F, Ito K, Sugawara-Tomita N \& Hashimoto Y (2004): Pleurotolysin, a novel sphingomyelin-specific two-component cytolysin from the edible mushroom Pleurotus ostreatus, assembles into a transmembrane pore complex. Journal of Biological Chemistry 279: 26975-26982.

Wang S-J, Li Y-X, Bao L, Han J-J, Yang X-L, Li H-R, Wang Y-Q, Li S-J \& Liu H-W (2012): Eryngiolide A, a cytotoxic macrocyclic diterpenoid with an unusual cyclododecane core skeleton produced by the edible mushroom Pleurotus eryngii. Organic Letters 14: 3672-3675.

\section{P. eryngii var. ferulae (Lanzi) Sacc.}

See P. eryngii 


\section{Pleurotus ostreatus (Jacq.) P. Kumm.}

Oyster Mushroom (DK: Almindelig Østershat, FI: Osterivinokas, IS: Ostruvængur, NO: Blågrå østerssopp, SE: Ostronmussling (Ostronskivling)).

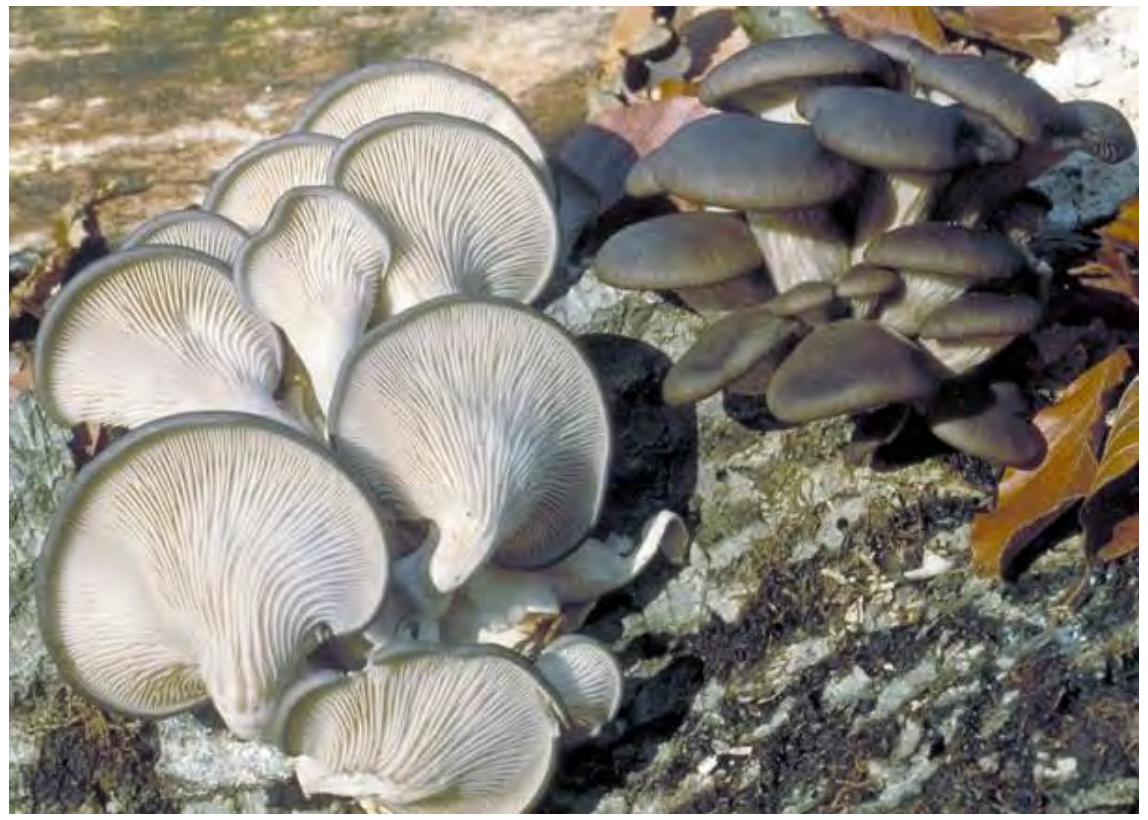

\section{Background and risk assessment}

Oyster Mushroom (Pleurotus ostreatus) is an edible mushroom. It is one of the most commonly cultivated and consumed mushrooms. In 1997, the year from which the latest world production figures were available, it was cultivated in 875,000 tons (Chang \& Miles, 2004).

It is a saprotrophic or weakly parasitic mushroom, which grows imbricate in groups on trunks of living and dead deciduous woods, rarely on conifers. It is common in temperate, up to southern boreal zones and is occasional in middle boreal up to subarctic/subalpine zones of the Nordic countries (Knudsen \& Vesterholt, 2012).

There are no intoxications reported after consumption of cooked Oyster Mushroom. However, there are some indications that consumption of large amounts of raw Oyster Mushroom may give adverse effects (Al-Deen et al., 1987; Juntes et al., 2009). Several bioactive constituents have been identified in the mushroom: 


\section{Bioactive constituents}

Cyanogenic compounds: Traces of hydrogen cyanide (less than $1 \mathrm{mg} / \mathrm{kg}$ ) have been identified in fresh Oyster Mushroom (Shindo et al., 1999). Such low levels are of no health concern in relation to consumption of the mushroom.

Ergothioneine: Ergothioneine has been demonstrated in Oyster Mushroom fruit bodies at levels in the range 940-2200 mg/kg (dry weight) corresponding to approximately $90-220 \mathrm{mg} / \mathrm{kg}$ in the raw mushroom (Chen et al., 2012; Dubost et al., 2006; Lee et al., 2009) which agree with the finding $119 \mathrm{mg} / \mathrm{kg}$ in raw fruit bodies (Ey et al., 2007). Much less could be found in the dried mycelia, 78-120 mg/kg (Lo et al., 2012) and $220 \mathrm{mg} / \mathrm{kg}$ (Lin et al., 2013), respectively. For further information on ergothioneine, see Lepista nuda.

Cytolysins: As mentioned above, there are some indications that intake of large quantities of raw or insufficiently cooked Oyster Mushroom may give rise to intoxications (Al-Deen et al., 1987; Juntes et al., 2009). After oral or intraperitoneal administration of an Oyster Mushroom extract, the $\mathrm{LD}_{50}$ in both cases exceeded $3,000 \mathrm{mg} / \mathrm{kg}$ body weight. The extract was prepared at room temperature in order not to denaturate suspected proteinaceous toxins. Oral or intraperitoneal administration of up to 1,000 mg mushroom extract/kg body weight/day to mice for 30 days resulted in hemorrhages in the intestine and in other tissues. The main histological findings were pathological hepatic changes, but apparently not in a dose-dependent manner (Al-Deen et al., 1987).

Berne et al. (2002) have isolated and characterized a thermolabile protein, ostreolysin, having a molecular weight of $15 \mathrm{kDa}$. It is a cytolysin which lyses bovine, sheep and human erythrocytes in vitro and probably also have similar effects in vivo as indicated by increased serum potassium (Zuzek et al., 2006). After parenteral application of ostreolysin to rats endothelial injury with oedema in the heart and lungs, as well as myocardial hemorrhages could be demonstrated (Juntes et al., 2009). In 2004, Tomita and colleagues isolated and characterized a twocomponent, pore-forming cytolysin, pleurotolysin, which consists of two, non-associated components, pleurolysin A (molecular weight $17 \mathrm{kDa}$ ) and pleurolysin B (molecular weight $52 \mathrm{kDa}$ ). Cooperatively, these two components cause leakage of potassium ions from human erythrocytes and swelling, leading to hemolysis (Tomita et al., 2004). A hemolysin (pleurotolysin) isolated from Oyster Mushroom by Bernheimer \& Avigad (1979) is anticipated to be a proteolytic product of the pleurotolysin characterized by Tomita et al. (2004). There are no intoxications reported after consumption of thoroughly cooked Oyster Mushroom. This indi- 
cates, that any potential effects of the cytolysins are eliminated during heating and/or digestion.

Indole constituents: Oyster Mushroom contains a series of simple biologically active indole compounds (5-hydroxytryptophan, serotonin and tryptamine) (Muszynska et al., 2011, 2012). It was demonstrated that boiling of Oyster Mushroom fruit bodies significantly changed the content of these indoles. 5-Hydroxytryptophan and serotonin were completely decomposed and tryptophan and 5-methyltryptophan had been formed in amounts of $81 \mathrm{mg}$ and $38 \mathrm{mg} / \mathrm{kg}$ (dry weight) corresponding to approximately 8 and $4 \mathrm{mg} / \mathrm{kg}$ (fresh weight), respectively. Some of these constituents are tissue hormones and neurotransmitters and high intakes of tryptophan can damage the nervous system (Stone et al., 2003).

Mutagens: Morales et al. (1990a, 1990b) studied mushroom extracts for mutagenic activity in the Ames test, which detects revertants from histidine dependence to histidine auxotrophy. Extracts of freshly harvested and frozen Oyster Mushroom were reported to be mutagenic in Salmonella test strains TA98 and TA100. Extracts of canned Oyster Mushroom were negative in the Ames assay, but weakly positive in the Chinese Hamster Ovary (CHO/HPRT) cell mutation assay. The authors indicate, it is possible that the weak positive response obtained in the test assay may be an artefact. Apparently, Morales et al. (1990a, 1990b) did not control for possible presence of histidine in the extracts tested in the Ames test. Therefore, the positive response could be due to histidine in the test solution allowing the detector strain of Salmonella bacteria to grow and form colonies. Grüter et al., (1991), using a histidineindependent bacterial test system, identified no mutagenic activity in extracts of Oyster Mushroom. It is concluded that extracts of Oyster Mushroom are probably not mutagenic.

Statins: Oyster Mushroom may contain relatively high amounts of the statin lovastatin. Natural statins are hexahydronaphthalene derivatives, substituted with a $\beta$-hydroxylactone. Statins are widely used as hypolipidemic drugs for lowering cholesterol. Lovastatin and simvastatin are examples of statins and are used in daily doses in the range 10 to $80 \mathrm{mg}$. In certain cases statins may give rise to myopathy, characterised by muscular weakness and/or pain and in very rare cases rhabdomyoly$\operatorname{sis}^{23}$ (e.g., FDA, 2011a, 2011b, 2013; Floyd et al., 2012; Mastaglia \&

${ }^{23}$ Rhabdomyolysis is the breakdown of muscle fibers that leads to the release of muscle fiber contents (myoglobin) into the blood stream. Myoglobin is harmful to the kidney and often causes kidney damage (MedlinePlus Medical Enclyclopedia, 2012). 
Needham, 2012). These serious adverse effects have not been reported after consumption of Oyster Mushroom.

Lovastatin was originally isolated from Penicillium citrinum by Endo et al. (1976). Later, it has also been identified in other microorganisms and in 1993-95 Gunde-Cimerman et al., (1993a; 1993b) and GundeCimerman \& Cimerman (1995) reported on the isolation of lovastatin from different Pleurotus species, including Oyster Mushroom. They detected 2,000 to $3,000 \mathrm{mg} / \mathrm{kg}$ (dry weight) in the pileus without lamellae and between 2,500 and $6,000 \mathrm{mg} / \mathrm{kg}$ (dry weight) in the lamellae. Levels were lower in the stipe; up to $1,000 \mathrm{mg} / \mathrm{kg}$ (dry weight) in the lowest part (Gunde-Cimerman et al., 1995). These figures indicate that the fresh fruit bodies would contain approximately 200-300 mg lovastatin/kg. In another study, Alarcon et al. (2003) detected $0.40-2.1 \%$ of the dry matter of Oyster Mushrooms cultivated on straw to be lovastatin. The corresponding amounts of lovastatin in Oyster mushrooms collected from the forest was $0.7-2.8 \%$ of dry mater. These contents correspond to approximately 400-2800 mg lovastatin/kg fresh mushroom. Lower lovastatin levels were found in dried samples of cultivated Oyster Mushroom by Chen et al. (2012), $165 \mathrm{mg} / \mathrm{kg}$ mushroom in a Korean strain, $607 \mathrm{mg} / \mathrm{kg}$ mushroom in a Japanese strain, and $216 \mathrm{mg}$ in a Taiwanese strain, corresponding to approximately 17,61 and $22 \mathrm{mg} / \mathrm{kg}$ in the fresh mushroom, respectively. Lo et al. (2012) examined the mycelia of cultivated Korean and Taiwanese strains of Oyster Mushroom, and showed these to contain 60 and $147 \mathrm{mg}$ lovastatin/kg dry weight, respectively, and Lin et al. (2013) mycelia from an Israelian strain to contain $222 \mathrm{mg} / \mathrm{kg}$ (dry weight). However, Chegwin-Angarita et al. (2013) were unable to detect any statin in another strain of Oyster Mushroom. They could neither find it in the cultivated mycelia nor in broth. In a study on lipid lowering effects of Oyster Mushroom in humans, Schneider et al. (2011) were unable to detect lovastatin in lyophilized fruit bodies of Oyster Mushroom used in the study diet. Altogether, it seems that some cultivars of Oyster mushroom do not produce lovastatin, whereas others produce quite high amounts.

Food processing may destroy biologically active constituents in mushrooms, e.g., many lectins and other bioactive proteins. Ulziijargal et al. (2013) did not find any or very little lovastatin $(0.05 \mathrm{mg} / \mathrm{kg})$ in bread added $0.7-0.9 \mathrm{mg} /$ lovastatin per $\mathrm{kg}$ bread before baking. However, it is difficult, based on this study, to predict to what extent the much higher amounts of lovastatin, e.g., 400-2,800 mg/kg in fresh Oyster Mushroom (Gunde-Cimerman \& Cimerman, 1995; Alarcon et al., 2003) will be chemically changed or extracted during cooking of the mushroom. Furthermore, 
the analytical method used by Ulziijargal et al. (2013) does not take into account, that the lactone lovastatin during baking processes may be hydrolysed to the corresponding hydroxycarboxylic acid, the active cholesterol lowering form of the statin. Lovastatin is stable in aqueous neutral or acidic solutions at room temperature (Piecha et al., 2010), but $25 \%$ is hydrolysed after one hour's heating at $100{ }^{\circ} \mathrm{C}$ (Yang et al., 2007). In a thermal and kinetic study on statins, lovastatin was shown to be stable up to $190^{\circ} \mathrm{C}$ under solvent-free conditions (Souza et al., 2007).

Altogether, it is likely that a considerable proportion of lovastatin in the mushroom is stable during cooking or possibly to some extent hydrolysed to the hydroxycarboxylic acid, which is the biologically active form of lovastatin.

Human observations: Schneider et al. (2011) studied the lipid lowering effects of Oyster Mushroom in humans. Twenty adults (20-34 years) were randomized to consume tomato soup with or without $30 \mathrm{~g}$ dried Oyster Mushroom (corresponding to $300 \mathrm{~g}$ fresh mushrooms) on a daily basis for 21 days. In the group receiving Oyster Mushroom serum triglycerides, oxidized low density lipoprotein and total cholesterol values were significantly lower, than in the control group. It is remarkable, that the Oyster Mushroom cultivar used for the study did not contain any detectable level of lovastatin. The described effects on the serum lipid parameters must therefore be attributed to other constituents in the Oyster Mushroom diet.

Experimental studies: Several experimental studies in rats and rabbits (Alam et al., 2011; Anandhi et al., 2013; Bobek \& Galbavy, 1999; Bobek et al., 1998; Hossain et al., 2003)) indicate that supplying Oyster Mushrooms in the diet may alter the serum lipid profile, including lowering of serum total cholesterol, very-low-density-lipoprotein (VLDL) cholesterol and lowdensity-lipoprotein (LDL) cholesterol. This effect can, at least partly, be explained by the usually high content of lovastatin in Oyster Mushroom.

Nieminen and co-workers (2009) have published a study on the potential myo- and hepatotoxic effects of different cultivated mushrooms in mice. The animals (six females per group) were for 5 days supplied large quantities of dried and powdered cultivated mushrooms in the feed. One of the cultivated mushrooms, Oyster Mushroom, was given as $1.8 \%, 3.6 \%$ or $5.4 \%$ of the feed. The feeding resulted in mice being exposed to 18,28 and $38 \mathrm{~g}$, respectively, which is equivalent to humans ingesting 1.2, 2.0 or $2.7 \mathrm{~kg}$ Oyster Mushroom per person (70 kg) per day or when corrected for body surface constant 102, 164 or 224 g per person $(70 \mathrm{~kg}$ ) per day of fresh Oyster Mushroom, respectively. All mice were healthy at the end of the study and no pathological changes were observed in the histological studies of organs. Of the many clinical pa- 
rameters studied, plasma total cholesterol was reduced, reaching statistical significance at the highest dose. The cholesterol lowering effect was possibly due to content of the statin, lovastatin (Nieminen et al., 2009).

The structural formula of lovastatin is shown below.<smiles>CCC(C)C(=O)O[C@H]1C[C@H](C)C=C2C=C[C@H](C)[C@H](CC[C@H]3C[C@@H](O)CC(=O)O3)C21</smiles>

Recommendation

No special recommendation.

\section{Listing 1}

\section{Database search information}

OECD database search by June 2010 (OECD, 2012). PubMed: 2010-2012. Keywords: Pleurotus ostreatus.

\section{References}

Alam H, Yoon KN, Lee TS \& Lee UY (2011): Hypolipidemic activities of dietary Pleurotus ostreatus in hypercholesterolemic rats. Mycobiology 39: 45-51.

Alarcón J, Águila S, Arancibia-Avila P, Fuentes 0, Zamorano-Ponce E \& Hernández M (2003): Production and purification of statins from Pleurotus ostreatus (Basidiomycetes) strains. Zeitschrift für Naturforschung 58c: 62-64.

Al-Deen IHS, Twaij HAA, Al-Badr AA \& Istarabadi TAW (1987): Toxicologic and histopathologic studies of Pleurotus ostreatus in mice. Journal of Ethnopharmacology 21: 297-305.

Anandi R, Anadurai T, Anitha TS, Muralidharan AR, Najmunnisha K, Nachiappan V, Thomas PA \& Geraldine P (2013): Antihypercholesterolemic and antioxidative effects of an extract of the Oyster Mushroom, Pleurotus ostreatus, and its major constituent, chrysin, in Triton WR-1339-induced hypercholesterolemic rats. Journal of Physiological Biochemistry 69: 313-323.

Berne S, Krizaj I, Pohleven F, Turk T, Macek P \& Sepčic K (2002): Pleurotus and Agrocybe hemolysins, new proteins hypothetically involved in fungal fruiting. Biochemical and Biophysical Acta 1570: 153-159.

Bernheimer AW \& Avigard LS (1979): A cytolytic protein from the edible mushroom, Pleurotus ostreatus. Biochimica et Biophysica Acta 585: 451-461. 
Bobek P \& Galbavy S (1999): Hypocholesterolemic and antiatherogenic effect of Oyster Mushroom (Pleurotus ostreatus) in rabbits. Nahrung 43: 339-342.

Bobek P, Ozdin L \& Galbavy S (1998): Dose- and time-dependent hypocholesterolemic effect of Oyster Mushroom (Pleurotus ostreatus) in rats. Nutrition 14: 282-286.

Chang S-T \& Miles PG (2004): Mushrooms. Cultivation, nutritional value, medicinal effect, and environmental impact. CRC Press, Boca Raton: 1-351.

Chegwin-Angarita C, Nieto-Ramirez IJ, Diaz GJ, Rojas LJR, Sepulveda L \& Atehortua L (2013): Evaluation of a method using high performance liquid chromatography with ultraviolet detection for the determination of statins in macromycetes of the genus Pleurotus cultivated by fermentation processes. Talanta 116: 56-64.

Chen S-Y, Ho K-J, Hsieh Y-J, Wang L-T \& Mau J-L (2012): Contents of lovastatin, $\gamma$ aminobutyric acid and ergothioneine in mushroom fruiting bodies and mycelia. Food Science and Technology 47: 274-278.

Endo A, Kuroda M \& Tanzawa K (1976): Competitive inhibition of 3-hydroxy-3methyl glutaryl coenzyme A reductase by ML-236A and ML-236B fungal metabolites, having hypocholesterolemic activity. Federation of the European Biochemical Societies Letters 72: 323-326.

FDA (2011a): FDA announces new safety recommendations for high-dose simvastatin. June 8, 2011. Last updated August 6, 2011.

FDA (2011b(: FDA restricts use of high doses of cholesterol-lowering drug Zocor. June 9, 2011.

FDA (2013): FDA expands advice on statin risks. February 27, 2011. Last updated April 4, 2013.

Floyd JS, Heckbert SR, Weiss NS, Carrell DS \& Psaty BM (2012): Use of administrative data to estimate the incidence of statin-related rhabdomyolysis. Journal of the American Medical Association 307: 1580-1582.

Grüter A, Friederich U \& Würgler FE (1991): The mutagenicity of edible mushrooms in a histidine-independent bacterial test system. Food and Chemical Toxicology 29: 159-165.

Gunde-Cimerman N \& Cimerman A (1995): Pleurotus fruiting bodies contain the inhibitor of 3-hydroxy-3-methylglutaryl-coenzyme A reductase - lovastatin. Experimental Mycology 19: 1-6.

Gunde-Cimerman N, Friedrich J, Cimerman A \& Benički N (1993a): Screening fungi for the production of an inhibitor of HMG CoA reductase: Production of mevinolin by the fungi of the genus Pleurotus. Federation of European Microbiological Societies Letters 111: 203-206.

Gunde-Cimerman N, Plemenitaš A \& Cimerman A (1993b): Pleurotus fungi produce mevinolin, an inhibitor of HMG CoA reductase. Federation of European Microbiological Societies Letters 113: 333-338.

Hossain S, Hashimoto M, Choudhury EK, Alam N, Hussain S, Hassan M, Choudhury SK \& Mahmud I (2003): Dietary mushroom (Pleurotus ostreatus) ameliorates atherogenic lipid in hypercholesterolaemic rats. Clinical and Experimental Pharmacology and Physiology 30: 470-475.

Juntes P, Rebolj K, Sepcic K, Macek P, Zuzek MC, Cestnik V \& Frangez R (2009): Ostreolysin induces sustained contraction of porcine coronary arteries and endothelial dysfunction in middle- and large-size vessels. Toxicon 54: 784-792.

Knudsen H \& Vesterholt J (2012): Funga Nordica. Agaricoid, boletoid, clavarioid, cyphelloid and gastroid genera. Nordsvamp: 1-1083. 
Lin S-Y, Chen Y-K, Yu H-T, Barseghyan GS, Asatiani MD, Wasser SP \& Mau JL (2013): Comparative study of contents of several bioactive components in fruiting bodies and mycelia of culinary-medicinal mushrooms. International Journal of Medical Mushrooms 15: 315-323.

Lo Y-C, Lin S-Y, Ulziijargal E, Chen S-Y, Chien R-C, Tzou Y-J \& Mau J-L (2012): Comparative study of contents of several bioactive components in fruiting bodies and mycella of culinary-medicinal mushrooms. International Journal of Medicinal Mushrooms 14: 357-363.

Mastaglia FL \& Needham M (2012): Update on toxic myopathies. Current Neurology and Neuroscience Reports 12: 54-61.

MedLine Plus Medical Encyclopedia (2012): U.S. National Library of Medicine.. National Institutes of Health.

Morales P, Bermúdez E, Sanz B \& Hernández PE (1990a): A study of the mutagenicity of some commercially canned Spanish mushrooms. Food and Chemical Toxicology 28: 607-611.

Morales P, Bermúdez E, Hernández PE \& Sanz B (1990b): The mutagenicity of some Spanish edible mushrooms in the Ames test. Food Chemistry 38: 279-288.

Muszyńska B, Sułkowska-Ziaja K \& Ekiert H (2011): Indole compounds in some culinary-medicinal higher Basidiomycetes from Poland. International Journal of Medicinal Mushrooms 13: 449-454.

Muszyńska B \& Sułkowska-Ziaja K (2012): Analysis of indole compounds in edible Basidiomycota species after thermal processing. Food chemistry 132: 455-459.

Nieminen P, Kärjä V \& Mustonen A-M (2009): Myo- and hepatotoxic effects of cultivated mushrooms in mice. Food and Chemical Toxicology 47: 70-74.

OECD (2013): Consensus Document on Compositional Considerations for New Varieties of Oyster Mushroom (Pleurotus ostreatus): Key food and feed nutrients, antinutrients and toxicants. Series on the Safety of Novel Foods and Feeds, No. 25: 1-39 (accepted for publication).

Piecha M, Sarakha M, Trebse P \& Kocar D (2010): Stability studies of cholesterol lowering statin drugs in aqueous samples using HPLC and LC-MS. Environmental Chemical Letters 8: 185-191.

Schneider I, Kressel G, Meyer A, Krings U, Berger RG \& Hahn A (2011): Lipid lowering effects of Oyster Mushroom (Pleurotus ostreatus) in humans. Journal of Functional Foods 3: 17-24.

Shindo T, Ushiyama H, Kan K \& Yasuda K (1999): Study on content of cyanide in Basidiomycetes and the effect of cooking. Journal of Food Hygiene Society of Japan 40: 29-35 (Japanese, English Abstract available).

Stone TW, Mackay GM, Forrest CM, Clark CJ, Darlington LG (2003): Tryptophan metabolites and brain disorders. Clinical Chemistry and Laboratory Medicine 41: 852-859.

Souza MAF, Conceicao MM, Silva MCD, Soledade LEB \& Souza AG (2007): Thermal and kinetic study of statins: simvastatin and lovastatin. Journal of Thermal Analysis and Calorimetry 87: 859-863.

Tomita T, Noguchi K, Mimuro H, Ukaji F, Ito K, Sugawara-Tomita N \& Hashimoto Y (2004): Pleurotolysin, a novel sphingomyelin-specific two-component cytolysin from the edible mushroom Pleurotus ostreatus, assembles into a transmembrane pore complex. The Journal of Biological Chemistry 279: 26975-26982.

Ulziijargal E, Yang J-H, Lin L-Y, Chen C-P \& Mau J-L (2013): Quality of bread supplemented with mushroom mycelia. Food Chemistry 138: 70-76. 
Yang D-J \& Hwang LS (2006): Study on the conversion of three natural strains from lactone forms to their corresponding hydroxy acid forms and their determination in Pu-Erh tea. Journal of Chromatography A 1119: 277-284.

Zuzek MC, Macek P, Sepcic K, Cestnik V \& Frangez R (2006): Toxic and lethal effects of ostreolysin, a cytolytic protein from edible oyster mushroom (Pleurotus ostreatus), in rodents. Toxicon 48: 264-271.

\section{Pleurotus salmoneostramineus Lj. N. Vassiljeva}

See Pleurotus djamor.

\section{Rozites caperatus (Pers.) P. Karst.}

See Cortinarius caperatus. 


\section{Russula Pers.}

Brittlegill (DK: Skørhat, FI: Hapero, IS: Hnefla, NO: Kremle, SE: Kremla).

The genus Brittlegill (Russula) comprises 152 species in the Nordic countries. They form mycorrhiza with the coniferous trees Spruce (Picea) and Pine (Pinus) and with many deciduous trees, especially with Beech (Fagus), Birch (Betula) and Oak (Quercus). The Brittlegill (Russula) and Milkcap (Lactarius) genera are related and belong to the same family Russulaceae. The fruit bodies of the Brittlegill genus are characterized by their crumbling texture, but contrary to the Milkcap species, they do not exude milky juice (latex) after injury. The taste of the different species varies from mild to very pungent/acrid, rarely bitter or oily (Knudsen \& Vesterholt, 2012). Furthermore, the Brittlegill genus contains pteridine derivatives (russupteridines) as some of the major colouring matters. These nitrogen containing pigments have not been found in the Milkcap genus (Eugster, 1973; Gluchoff \& Lebreton, 1970; Iten et al., 1973; 1984).

The structural formulae of one of the yellow pteridines, riboflavin, and a part of the dimeric structure of a red pteridine, a lumazine derivative, are shown below.<smiles>CCCCOn1c2nc(=O)[nH]c(=O)c-2nc2cc(C)c(C)cc21</smiles><smiles>CCCCCOn1c2c(nc(=C(C)C)c1=O)C(=O)NC(=O)N=2</smiles> 
Generally, mild tasting raw Brittlegill species are considered as edible. However, there are some exceptions. Thus, the mild tasting Russula subnigricans Hongo, which is widely distributed in Asia, and also found in North America, but not in Europe, has given rise to many severe intoxications in Japan and Taiwan. It looks very much like Blackening Brittlegill ( $R$. nigricans), but $R$. subnigricans is only reddening not blackening as Blackening Brittlegill, when bruised (Gonmori et al., 2011). The intoxications have included gastrointestinal symptoms within 2 hours and in several cases also rhabdomyolysis ${ }^{24}$ within 6 hours after ingestion of the mushroom (Lee et al., 2001, Matsuura et al., 2009). Eight of 20 rhabdomyolysis cases described in Japan between 1955 and 2007 after consumption of $R$. subnigricans were fatal (Gonmori et al., 2011). The rhabdomyolysis occurring after $R$. subnigricans consumption was apparently induced by a different mechanism than rhabdomyolysis observed after Yellow Knight (Tricholoma equestre) consumption (Saviuc \& Danel, 2006). Based on studies in mice, the causative toxicant in $R$. subnigricans has been identified as cycloprop-2-ene carboxylic acid (the structural formula is shown below). The authors estimate that consumption of 2-3 fruit bodies may be fatal for humans (Matsuura et al., 2009).

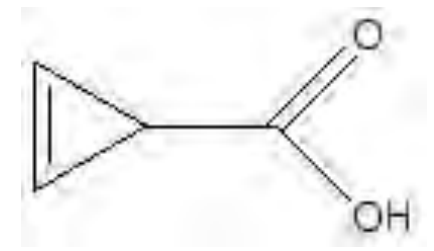

Cycloprop-2-ene carboxylic acid

R. subnigricans belongs to the section Compactae Fr. of the genus Russula Pers., and this group is characterized by firm flesh which is reddening and then usually blackening, when cut or bruised. The section comprises 6 species in the Nordic countries (Knudsen \& Vesterholt, 2012). Three of these 6 species ( $R$. adusta, $R$. densifolia, $R$. nigricans and some varieties of $R$. anthracina are described as mild tasting (Knudsen \& Vesterholt, 2012). The most common of them in the Nordic countries is Blackening Brittlegill (R. nigricans) which is indicated as edible but poor, or inedible

${ }^{24}$ Rhabdomyolysis is the breakdown of muscle fibers that leads to the release of muscle fiber contents (myoglobin) into the blood stream. Myoglobin is harmful to the kidney and often causes kidney damage (MedlinePlus Medical Enclyclopedia, 2012). 
(Egeland \& Myhr, 2005; Knudsen \& Petersen 2007; Læssøe, 1998; Philips, 2006) or even toxic (Shawn, 1994).

The mild tasting Olive Brittlegill ( $R$. olivacea (Schaeff.) Fr.) is generally considered as edible, but some authors warn against this mushroom (Lohmeyer \& Künkele, 2006), especially if eaten raw or insufficiently cooked (e.g., Mazza, 2000; Bresinsky \& Besl, 1985; Alder, 1954; Pieschl, 1964). However, there are no publications available demonstrating that consumption of thoroughly cooked Olive Brittlegill may give rise to any discomfort.

Pungent/acrid/bitter Brittlegill species are generally considered as inedible or even toxic (Benjamin, 1995; Bresinsky \& Besl, 1985; Flammer \& Horak, 2003; Roth et al., 1990). There are several intoxication reports describing more or less severe gastrointestinal symptoms after intake of raw or insufficiently cooked pungent species (Beug, 2012; Beug et al., 2006; Flammer \& Horak, 2003). The pungent, acrid or bitter constituents are not so well studied as in the related genus Milkcap (Lactarius). However, Clericuzio and colleagues have shown, that tasteless velutinal esters, like those occurring in the Milkcap genus, are found in 13 more or less pungent Brittlegill species, also growing in the Nordic countries. Some of these mushrooms were also studied after physical injury, and in several cases formation of the pungent sesquiterpene dialdehydes, velleral and isovelleral, as well as sesquiterpene metabolites of these could be demonstrated (Clericuzio et al., 2008). It is not clear, to what extent pre-treatment before cooking, e.g., parboiling and/or salting destroys the toxicants in pungent Brittlegill species (Benjamin, 1995; Beug, 2012; Bresinsky \& Besl, 1985).

The structures of one of the precursor velutinal esters and of the two pungent dialdehydes are shown below:

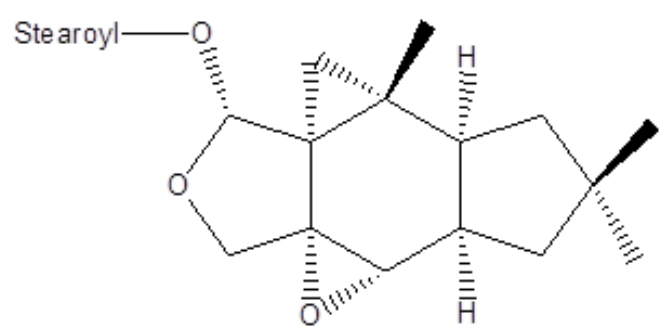

Stearoylvelutinal 


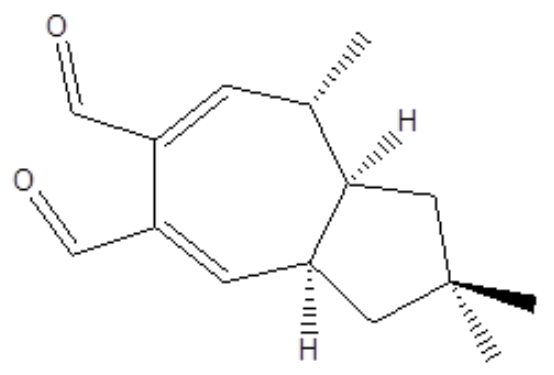

Velleral

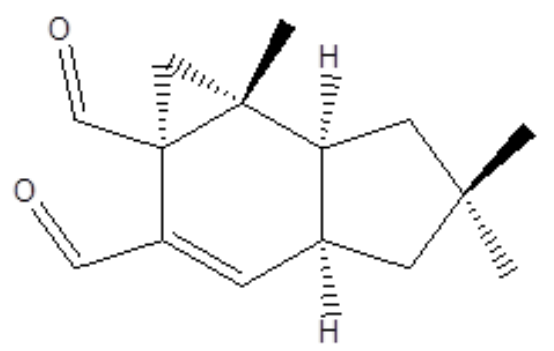

Isovelleral

The colouring matters of Brittlegill species are of very different chemical composition. Some of these pigments contain nitrogen, which is the case for the pteridine derivatives riboflavin and the russupteridines, whereas other pigments in this genus, the carotenoids and the sesquiterpenoids do not contain nitrogen. The Russula-pigments are not so well studied, especially the blue and violet colours remain to be chemically characterized (for reviews see Eugster, 1973; Gill and Steglich, 1987; Iten et al., 1984; Velisek \& Cejpek, 2011). Except for riboflavin and some of the carotenoids, little is known about the biological activity of these pigments.

Green Brittlegill (Russula aeruginea) and other glaucous green Brittlegill species are all edible, but can be mistaken for Deathcap (Amanita phalloides) which is deadly poisonous and they are therefore not suitable for commercial use. These Brittelgill species are described below under $R$. aeruginea, $R$ cyanoxantha, $R$. grisea, $R$. ionochlora, $R$ parazurea and $R$. virescens.

\section{Database search information}

SciFinder by September 2011. Keywords: Russula. PubMed by October 2012. Keywords: Russula. 


\section{References}

Alder AE (1954): Vergiftungen duch roh genossene Pilze. Schweizerische Zeitschrift für Pilzkunde 32: 174-177.

Benjamin D (1995): Mushrooms: Poisons and panaceas. WH Freeman and company: $1-422$.

Beug MW (2004): An overview of mushroom poisonings in North America. The Mycophile 45: 4-5.

Beug MW (2012): 2011 NAMA toxicology committee report North American mushroom poisonings. McIllvainea 21: 1-14.

Beug MW, Shawn M \& Cochran KW (2006): Thirty-plus years of mushroom poisoning: Summary of approximately 2,000 reports in the NAMA case registry. Mclllvainea 16: 47-68.

Bresinsky A \& Besl H (1985): Giftpilze. Wissenschaftliche Verlagsgesellschaft mbH: 1-295.

Clericuzio M, Gillardoni G, Malagòn O, Vidari G \& Finzi PV (2008): Sesquiterpenes of Lactarius and Russula (Mushrooms): An update. Natural Product Communications 3: 951-974.

Egeland IL \& Myhr S (2003): Norske sopper. Gyldendal: 1-296.

Eugster CH (1973): Pilzfarbstoffe, ein Überblick aus chemischer Sicht mit besonderer Berücksichtigung der Russulae. Zeitschrift für Pilzkunde 39: 45-96.

Flammer R \& Horak E (2003): Giftpilze - Pilzgifte. Schwabe. Basel: 1-204.

Gill M \& Steglich W (1987): Pigments of fungi (Macromycetes). Progress in the Chemistry of Organic Natural Products 51: 1-317.

Gluchoff K \& Lebreton P (1970): Biochimie végétale - Recherches chimiotaxinomiques sur le champignon. Premiers resultats sur les proprietes et la structure du pigment majeur rouge des russules (Basidiomycetes). Comptes Rendus de Sciences Serie D 270: 213-216.

Gonmori K, Fujita H, Yokoyama K, Watanabe K \& Suzuki O (2011): Mushroom toxins: a forenisic toxicological review. Forensic Toxicology 29: 85-94.

Iten PX, Arihara S \& Eugster CH (1973): Russula-Farbstoffe: zur Struktur von Russupteridin-s-III. Helvetica Chimica Acta 56: 20, 302-310.

Iten PX, Märki-Danzer H, Kock H \& Eugster CH (1984): Isolierung und Struktur von pteridinen (Lumazinen) aus Russula sp. (Täublinge: Basidiomycetes). Helvetica Chimica Acta 67: 550-569.

Knudsen H \& Petersen J H (2007): Politikens svampebog, Politikens forlag: 1-313.

Knudsen H \& Vesterholt J (2012): Funga Nordica. Agaricoid, boletoid, clavarioid, cyphelloid and gastroid genera. Nordsvamp: 1-1083.

Lee P-T, Wu M-L, Tsai W-J, Ger J, Deng J-F \& Chung H-M (2001): Rhabdomyolysis: An unusual feature with mushroom poisoning. American Journal of Kidney Diseases 38: $1-5$.

Lohmeyer TR \& Künkele U (2006): Svampe: Parragon Books Ltd.: 1-256.

Læssøe T (1998): Politikens store svampebog. Politikens forlag: 1-304.

Matsuura M, Saikawa Y, Inui K, Nakae K, Igarashi M, Hashimoto K \& Nakata M (2009): Identification of the toxic trigger in the mushroom poisoning. Nature Chemical Biology 5: 465-467.

Mazza R (2000): Funghi commestibili e velenosi a confronto. Fabbri Editori: 1-320.

MedLine Plus Medical Encyclopedia (2012): U.S. National Library of Medicin. National Institutes of Health. 
Philips R (2006): Mushrooms. MacMillan: 1-384.

Pieschl E (1964): Die Rohgiftfkeit einiger Lebensmittel und Pilze. Mykologische Mitteilungsblatt 8: 69-77.

Roth L, Frank H \& Kormann K (1990): Giftpilze-Pilzgifte, Schimmelpilze-Mykotoxine. Ecomed Verlagsgesellschaft: 1-327.

Saviuc P \& Danel V (2006): New syndromes in mushroom poisoning. Toxicology Review 25: 199-209.

Shawn M (1994): In: Handbook of Mushroom Poisoning. Diagnosis and Treatment. Eds. Spoerke DG \& Rumack BM. CRC Press: 9-38.

Velisek J \& Cejpek K (2011): Pigments of higher fungi: A review. Czech Journal of Food Science 29: 87-102. 


\section{Russula aeruginea Lindblad.}

Green Brittlegill (DK: Græsgrøn Skørhat FI: Koivuhapero, IS: Grænhnefla, NO: Grønkremle, SE: Grönkremla).

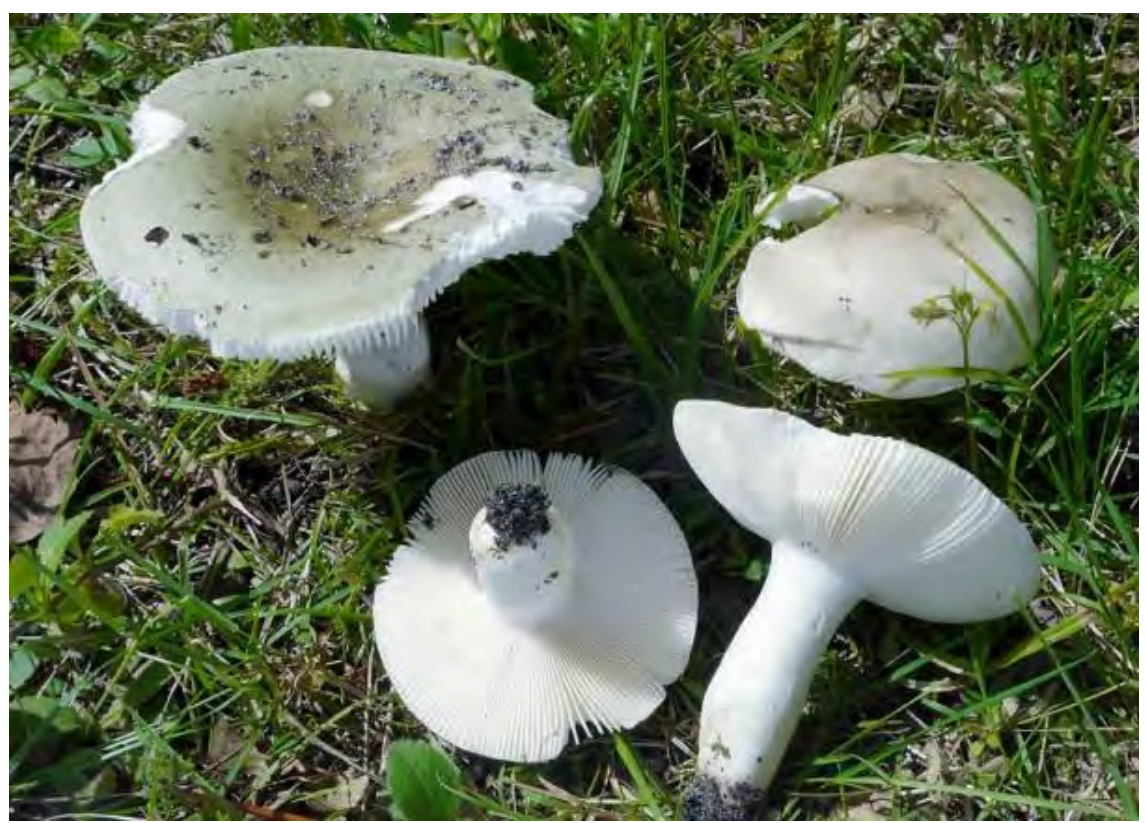

\section{Background and risk assessment}

Green Brittlegill (Russula aeruginea) is, as other mild-tasting Brittlegill (Russula) species of the section Heterophyllae Fr., an edible mushroom. The taste of the young fruit bodies is often slightly acrid (Knudsen \& Vesterholt, 2012; Egeland \& Myhr, 2003), probably due to the content of certain sesquiterpenes (see Russula Pers.).

It forms mycorrhiza with Birch (Betula) on acid, sandy or peaty soil and more rarely with Spruce (Picea) on more rich soil. It is occasional in the arctic/alpine zone, but otherwise common in the Nordic countries (Knudsen \& Vesterholt, 2012).

There are no intoxications reported after consumption of Green Brittlegill.

Sterner et al. (1982) tested an extract of Green Brittlegill in the Ames test using the Salmonella typhimurium strains TA98, TA100 and TA2637. The extract was positive in all three strains. The activity was not enhanced in the presence of microsomal enzymes. Unfortunately, Sterner et al (1982) give no information, whether they had controlled for the potential presence of histidine in the extracts. It is well known that false 
positives may be obtained in the presence of histidine. Thus, there is no strong indication that extracts of Green Brittlegill are mutagenic.

\section{Recommendation}

Green Brittlegill (Russula aeruginea) may be mistaken for Deathcap (Amanita phalloides), which is deadly poisonous (see Chapter 4). It is therefore not suitable for commercial marketing.

\section{Database search information}

SciFinder by September 2011. Keywords: Russula. PubMed by October 2012. Keywords: Russula.

Listing 3

\section{References}

Egeland IL \& Myhr S (2003): Norske sopper. Gyldendal: 1-296.

Knudsen H \& Vesterholt J (2012): Funga Nordica. Agaricoid, boletoid, clavarioid, cyphelloid and gastroid genera. Nordsvamp: 1-1083.

Sterner O, Bergman R, Kesler E, Magnusson L, Nilsson B, Wickberg B, Zimerson E \& Zetterberg G (1982): Mutagens in larger fungi I. Forty-eight species screened for mutagenic activity in the Salmonella/microsome assay. Mutation Research 101: 269-281. 


\section{Russula claroflava Grove (R. flava (Romell) Romell)}

Yellow Swamp Brittlegill (DK: Birke-Skørhat FI: Keltahapero, IS: Glóhnefla, NO: Mild gulkremle, SE: Gulkremla).

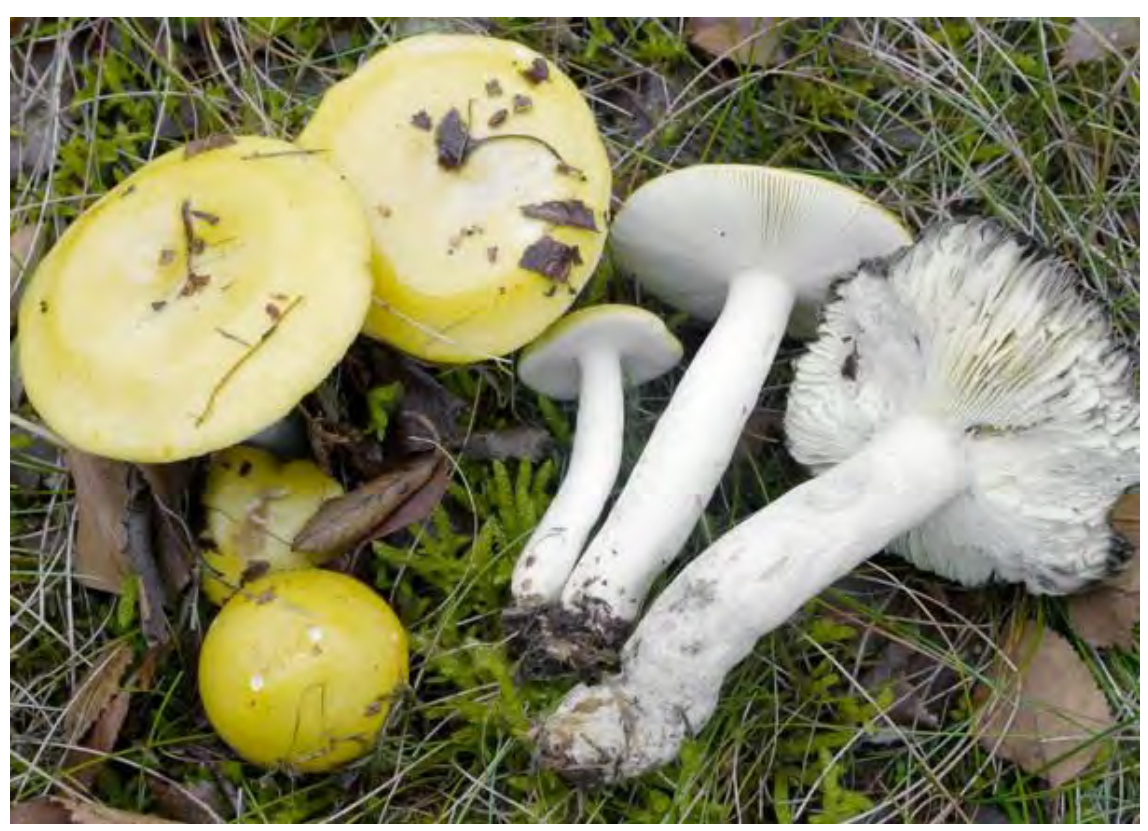

\section{Background and risk assessment}

Yellow Swamp Brittlegill (Russula claroflava) is, as other mild-tasting Brittlegill (Russula) species of the section Polychromae Maire, subsection Integroidinae (Romagn.) Bon, an edible species (see Russula Pers.).

It forms mycorrhiza with Birch (Betula) and is rare in Iceland, but otherwise common in the Nordic countries except in the arctic/alpine zone (Knudsen \& Vesterholt, 2012).

There are no intoxications reported after consumption of Yellow Swamp Brittlegill.

\section{Recommendation}

No special recommendation. 


\section{Database search information}

SciFinder by September 2011. Keywords: Russula. PubMed by October 2012. Keywords: Russula.

\section{References}

Knudsen H \& Vesterholt J (2012): Funga Nordica. Agaricoid, boletoid, clavarioid, cyphelloid and gastroid genera. Nordsvamp: 1-1083. 


\section{Russula cyanoxantha (Schaeff.) Fr.}

Charcoal Burner (DK: Broget Skørhat FI: No Finnish name, IS: No Icelandic name, NO: Broket kremle, SE: Brokkremla).

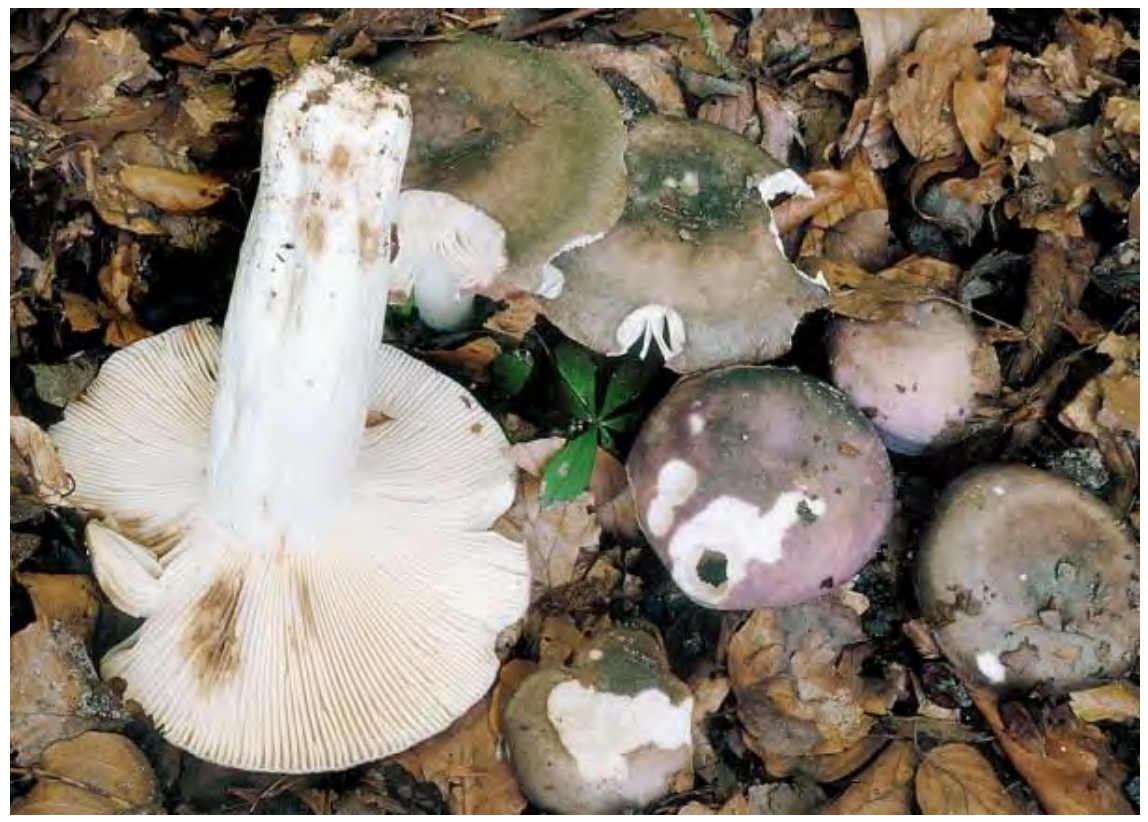

\section{Background and risk assessment}

Charcoal Burner (Russula cyanoxantha) is, as other mild-tasting Brittlegill (Russula) species of the section Heterophyllae Fr., an edible mushroom (see Russula Pers.).

It forms mycorrhiza in deciduous woods. It is very common in the temperate and hemiboreal zones of the Nordic countries (Knudsen \& Vesterholt, 2012).

There are no intoxications reported after consumption of Charcoal Burner.

\section{Recommendation}

Green forms of Charcoal Burner (Russula cyanoxantha) may be mistaken for Deathcap (Amanita phalloides) which is deadly poisonous (see Chapter 4.). Charcoal Burner is therefore not suitable for commercial marketing. 


\section{Database search information}

SciFinder by September 2011. Keywords: Russula. PubMed by October 2012. Keywords: Russula.

\section{Listing 3}

\section{References}

Knudsen H \& Vesterholt J (2012): Funga Nordica. Agaricoid, boletoid, clavarioid, cyphelloid and gastroid genera. Nordsvamp: 1-1083. 


\section{Russula decolorans (Fr.) Fr.}

Copper Brittlegill (DK: Afblegende Skørhat FI: Kangashapero, IS: No Icelandic name, NO: Gulrød Kremle, SE: Tegelkremla).

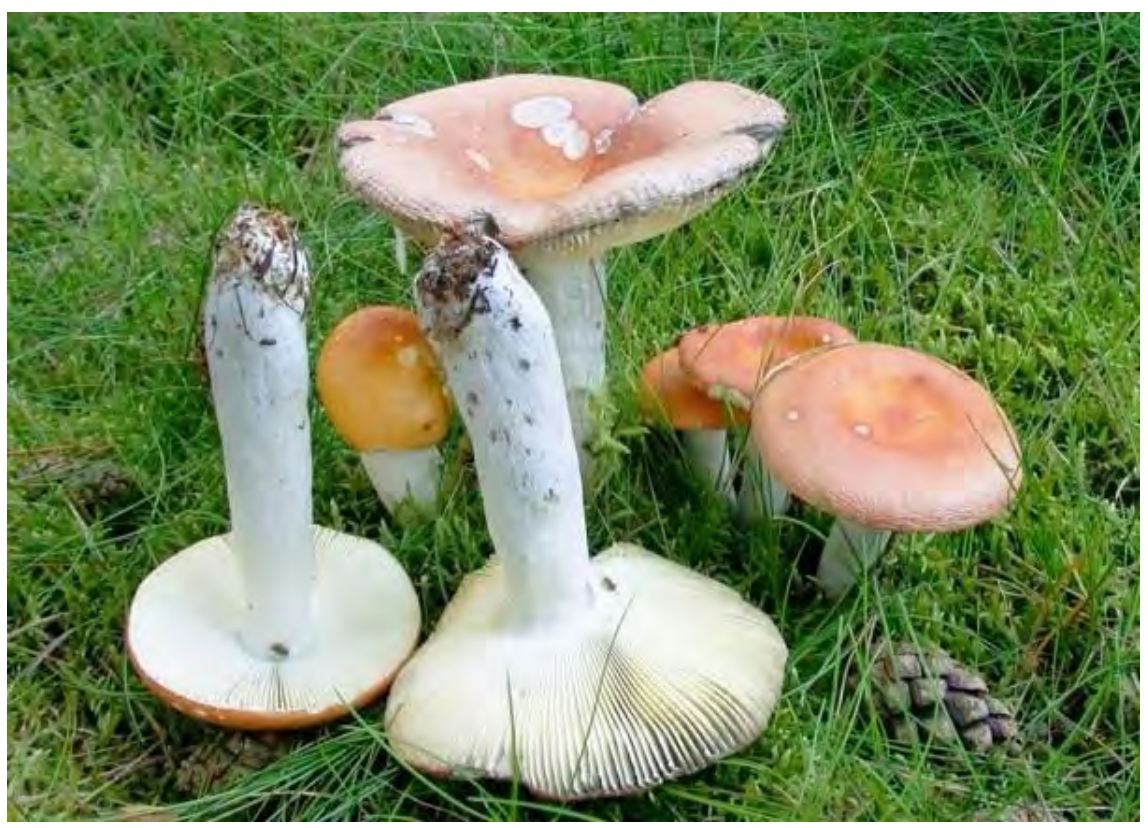

\section{Background and risk assessment}

Copper Brittlegill (Russula decolorans) is, as other mild-tasting Brittlegill (Russula) species of the section Polychromae Maire, subsection Integriforminae Bon and Melliolentinae Singer, an edible mushroom (see Russula Pers.).

It forms mycorrhiza in coniferous woods, especially with Pine (Pi$n u s$ ), but in the subarctic/subalpine zone with Birch (Betula). It is rare in Denmark (occasional in Western Jutland), but common in the other Nordic countries (Knudsen \& Vesterholt, 2012).

There are no intoxications reported after consumption of Copper Brittlegill.

\section{Recommendation}

No special recommendation.

\section{Database search information}

SciFinder by September 2011. Keywords: Russula. PubMed by October 2012. Keywords: Russula. 
Listing 2

\section{References}

Knudsen H \& Vesterholt J (2012): Funga Nordica. Agaricoid, boletoid, clavarioid, cyphelloid and gastroid genera. Nordsvamp: 1-1083.

\section{Russula elatior Lindblad}

See Russula paludosa.

\section{Russula flava (Romell) Romell).}

See Russula claroflava. 


\section{Russula grisea Fr. s. Gillet}

No English name (DK: Grålig Skørhat FI: No Finnish name, IS: No Icelandic name, NO: Gråfiolett kremle, SE: Duvkremla).

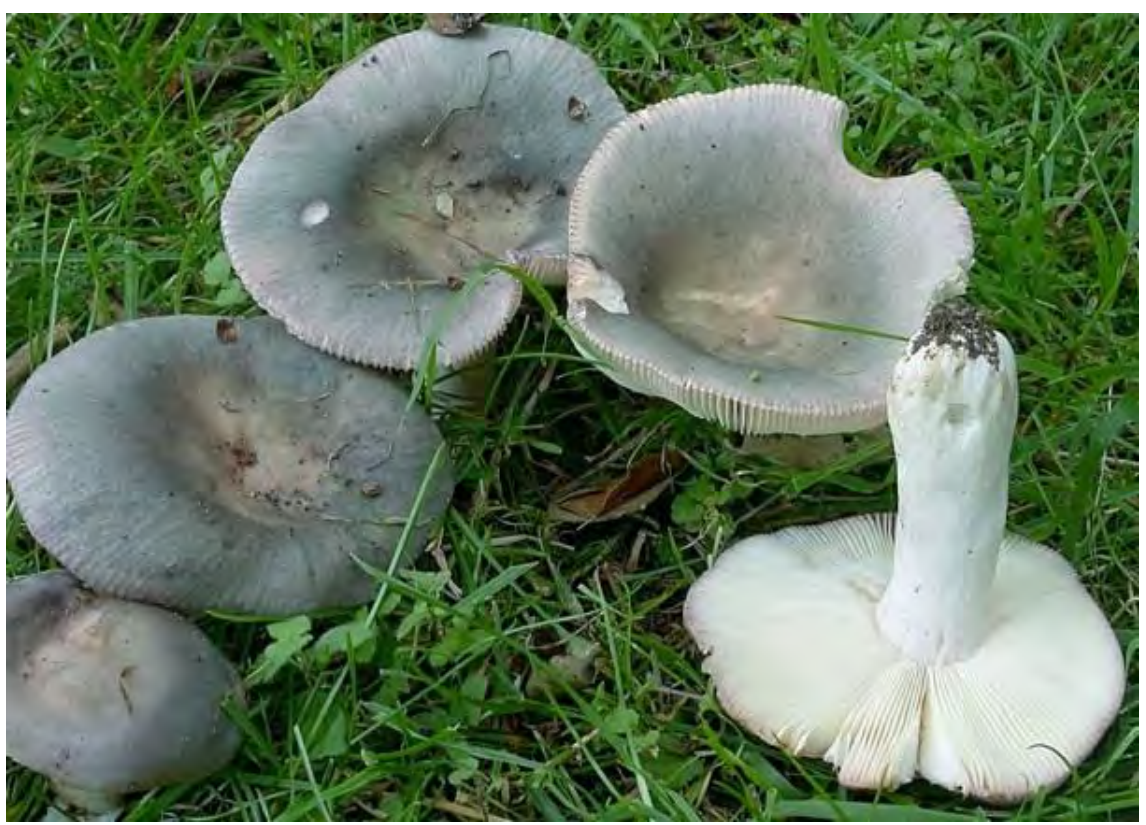

\section{Background and risk assessment}

Russula grisea is, as other mild-tasting Brittlegill (Russula) species of the section Heterophyllae Fr., an edible mushroom (see Russula Pers.)

It forms mycorrhiza in deciduous forests with Beech (Fagus) and Oak (Quercus). Its distribution in the Nordic countries is unclear due to confusion with related species (Knudsen \& Vesterholt, 2012).

There are no intoxications reported after consumption of $R$. grisea

\section{Recommendation}

Russula grisea may be mistaken for Deathcap (Amanita phalloides) which is deadly poisonous (see Chapter 4). It is therefore not suitable for commercial marketing.

\section{Database search information}

SciFinder by September 2011. Keywords: Russula. PubMed by October 2012. Keywords: Russula. 


\section{Listing 3}

\section{References}

Knudsen H \& Vesterholt J (2012): Funga Nordica. Agaricoid, boletoid, clavarioid, cyphelloid and gastroid genera. Nordsvamp: 1-1083. 


\section{Russula integra (L.) Fr. s. Maire (R. polychromae Hora)}

Nutty Brittlegill (DK: Mandel-Skørhat, FI: Keltahapero, IS: No Icelandic name, NO: Mandelkremle, SE: Mandelkremla).

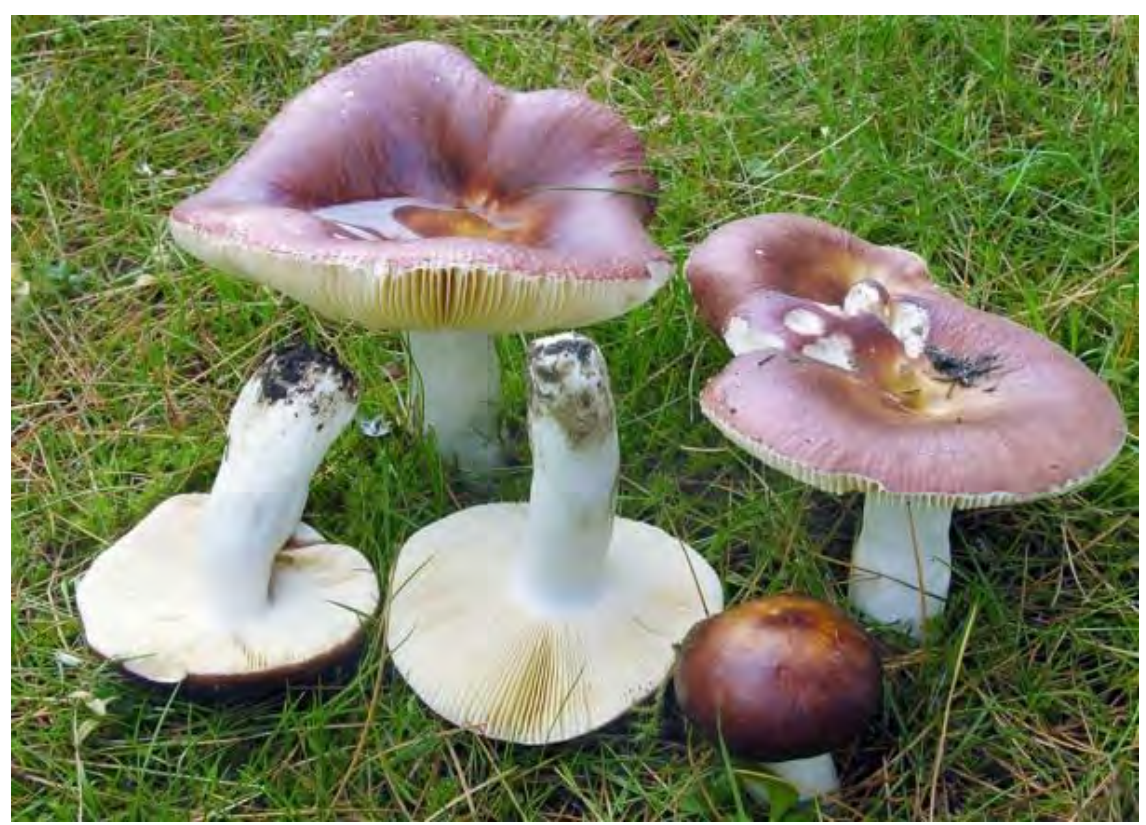

\section{Background and risk assessment}

Nutty Brittlegill (Russula integra) is, as other mild-tasting Brittlegill (Russula) species of the section Polychromae Maire, subsection Integroidinae (Romagn.) Bon, an edible mushroom (see Russula Pers.).

It forms mycorrhiza on rich soil in coniferous woods with Spruce (Picea) and Pine (Pinus) and more rarely in deciduous forests. It is rare in Denmark, but common in hemiboreal and boreal zones of the Nordic countries (Knudsen \& Vesterholt, 2012).

There are no intoxications reported after consumption of Nutty Brittlegill.

\section{Recommendation}

No special recommendation.

\section{Database search information}

SciFinder by September 2011. Keywords: Russula. PubMed by October 2012. Keywords: Russula. 


\section{Listing 2}

\section{References}

Knudsen H \& Vesterholt J (2012): Funga Nordica. Agaricoid, boletoid, clavarioid, cyphelloid and gastroid genera. Nordsvamp: 1-1083. 


\section{Russula ionochlora Romagn.}

Oilslick Brittlegill (DK: Violetgrøn Skørhat, FI: Patihapero, IS: No Icelandic name, NO: Iriskremle, SE: Iriskremla).

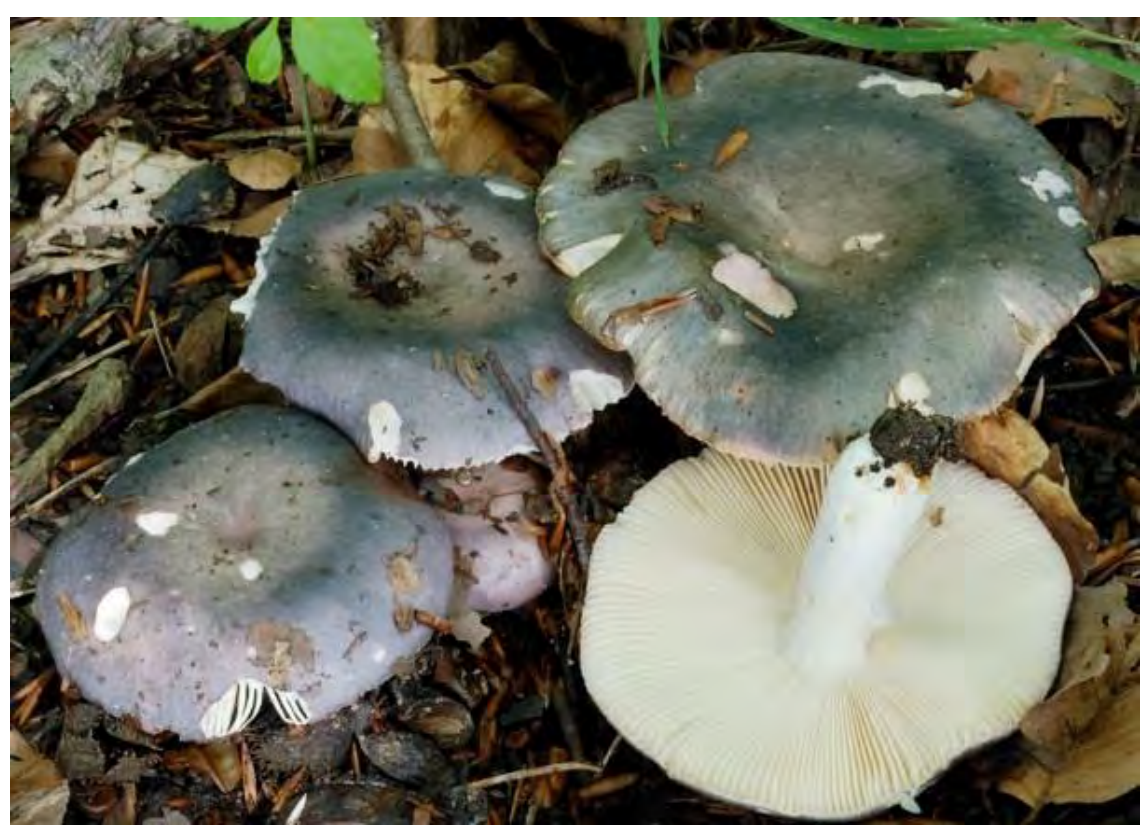

\section{Background and risk assessment}

Oilslick Brittlegill (Russula ionochlora) is, as other mild-tasting Brittlegill (Russula) species of the section Heterophyllae Fr. an edible mushroom. The taste of the gills may be slightly acrid (Knudsen \& Vesterholt, 2012), probably due to the content of certain sesquiterpenes (see Russula Pers.).

It forms mycorrhiza, mainly with Beech (Fagus). It is occasional in temperate and hemiboreal zones of the Nordic countries (Knudsen \& Vesterholt, 2012).

There are no intoxications reported after consumption of Oilslick Brittlegill.

\section{Recommendation}

Oilslick Brittlegill (Russula ionochlora) may be mistaken for Deathcap (Amanita phalloides), which is deadly poisonous (see Chapter 4). It is therefore not suitable for commercial marketing. 
Database search information

SciFinder by September 2011. Keywords: Russula. PubMed by October 2012. Keywords: Russula.

\section{Listing 3}

\section{References}

Knudsen H \& Vesterholt J (2012): Funga Nordica. Agaricoid, boletoid, clavarioid, cyphelloid and gastroid genera. Nordsvamp: 1-1083.

\section{Russula obscura (Romell) Peck}

See Russula vinosa. 


\section{Russula paludosa Britzelm. (R. elatior Lindblad)}

("Tall Brittlegill”) (DK: Prægtig Skørhat, FI: Isohapero, IS: Myrahefla, NO: Storkremle, SE: Storkremla).

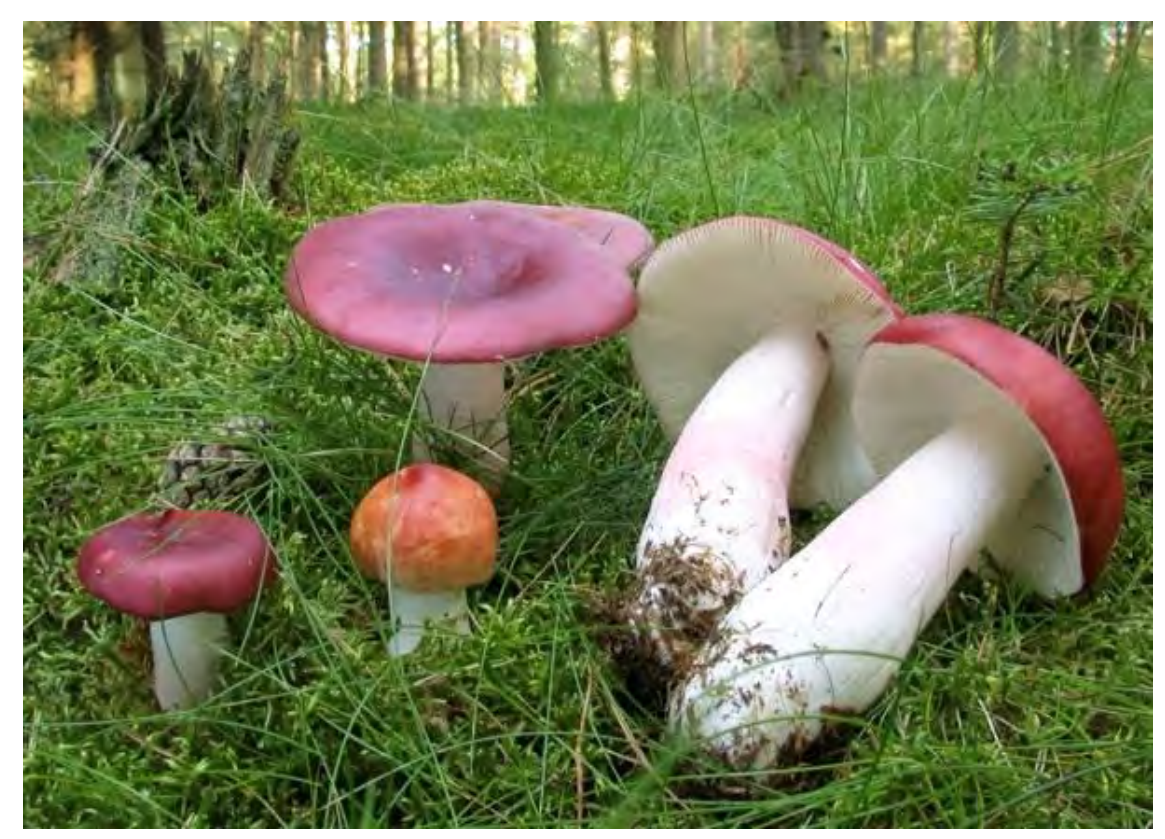

\section{Background and risk assessment}

Russula paludosa is, as other mild-tasting Brittlegill (Russula) species of the section Polychromae Maire, subsection Integroidinae (Romagn.) Bon, an edible mushroom. The taste of the young fruit bodies is often slightly acrid (Knudsen \& Vesterhold, 2012; Egeland \& Myhr, 2003) probably due to its content of velutinal esters (Clericuzio et al., 2008), which by physical injury of the fruit body can be converted to pungent sesquiterpenes (see Russula Pers.).

It forms mycorrhiza in coniferous woods on poor soil, especially with Pine (Pinus) and in the arctic/alpine zone with Birch (Betula). It is common in the Nordic countries (Knudsen \& Vesterholt, 2012).

There are no intoxications reported after consumption of $R$. paludosa.

\section{Recommendation}

No special recommendation. 


\section{Database search information}

SciFinder by September 2011. Keywords: Russula. PubMed by October 2012. Keywords: Russula.

\section{Listing 2}

\section{References}

Clericuzio M, Gillardoni G, Malagòn O, Vidari G \& Finzi PV (2008): Sesquiterpenes of Lactarius and Russula (Mushrooms): An update. Natural Product Communications 3: 951-974.

Egeland IL \& Myhr S (2003): Norske sopper. Gyldendal: 1-296.

Knudsen H \& Vesterholt J (2012): Funga Nordica. Agaricoid, boletoid, clavarioid, cyphelloid and gastroid genera. Nordsvamp: 1-1083. 


\section{Russula parazurea Jul. Schäff.}

Powdery Brittlegill (DK: Blågrå Skørhat, FI: No Finnish name, IS: No Icelandich name, NO: Blågrønn kremle, SE: Blågrön kremla).

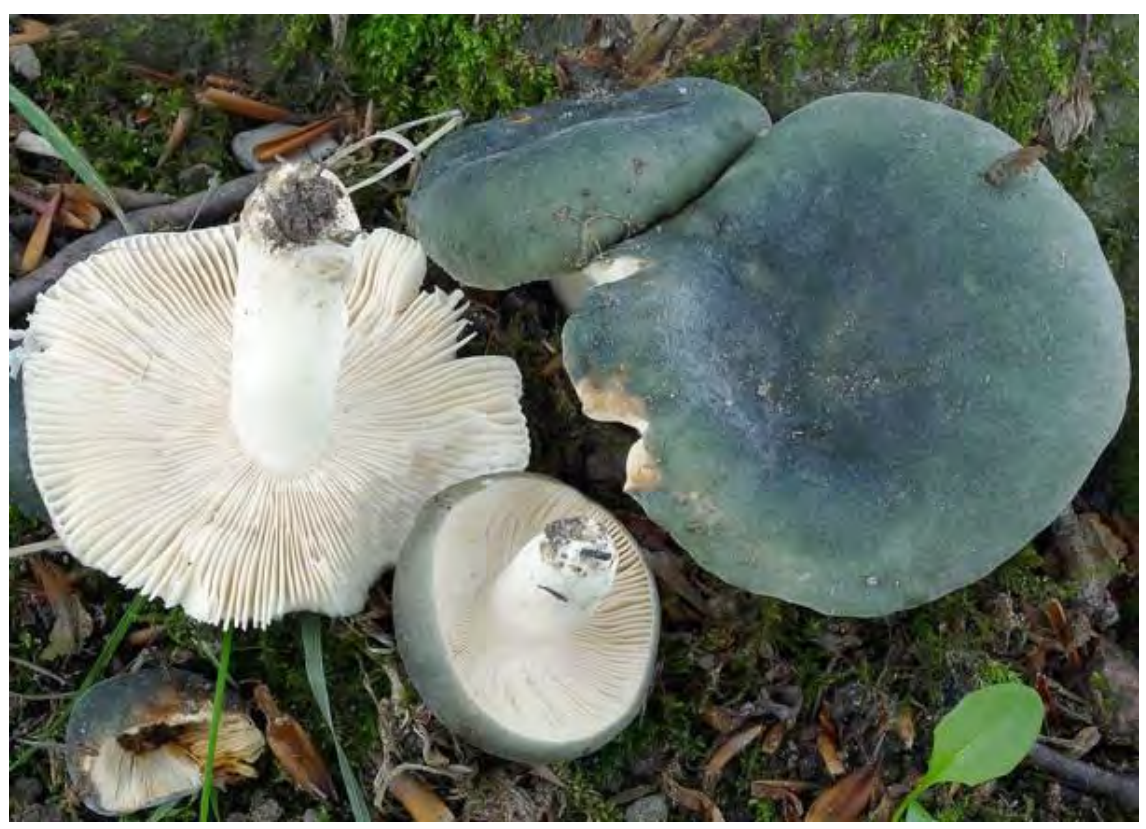

\section{Background and risk assessment}

Powdery Brittlegill (Russula parazurea) is, as other mild-tasting Russula species of the section Heterophyllae Fr., an edible mushroom.

Although Powdery Brittlegill may contain velutinal esters (Clericuzio et al., 2008), this does apparently not influence the mild taste of the mushroom (see Russula Pers.).

It forms mycorrhiza with various deciduous and coniferous trees on acid soil. It is occasional in Iceland and in the temperate and hemiboreal zones of the other Nordic countries (Knudsen \& Vesterholt, 2012).

There are no intoxications reported after consumption of Powdery Brittlegill.

\section{Recommendation}

Powdery Brittlegill (Russula parazurea) may be mistaken for Deathcap (Amanita phalloides) which is deadly poisonous (see Chapter 4). It is therefore not suitable for commercial marketing. 


\section{Database search information}

SciFinder by September 2011. Keywords: Russula. PubMed by October 2012. Keywords: Russula.

\section{Listing 3}

\section{References}

Clericuzio M, Gillardoni G, Malagòn 0, Vidari G \& Finzi PV (2008): Sesquiterpenes of Lactarius and Russula (Mushrooms): An update. Natural Product Communications 3: 951-974.

Knudsen H \& Vesterholt J (2012): Funga Nordica. Agaricoid, boletoid and cyphelloid genera. Nordsvamp: 1-965.

\section{Russula polychromae Hora}

See Russula integra. 


\section{Russula vesca Fr.}

The Flirt (Bare-toothed Russula) (DK: Blågrå Skørhat, FI: Palterohapero, IS: Garðhnefla, NO: Nøttekremle, SE: Kantkremle).

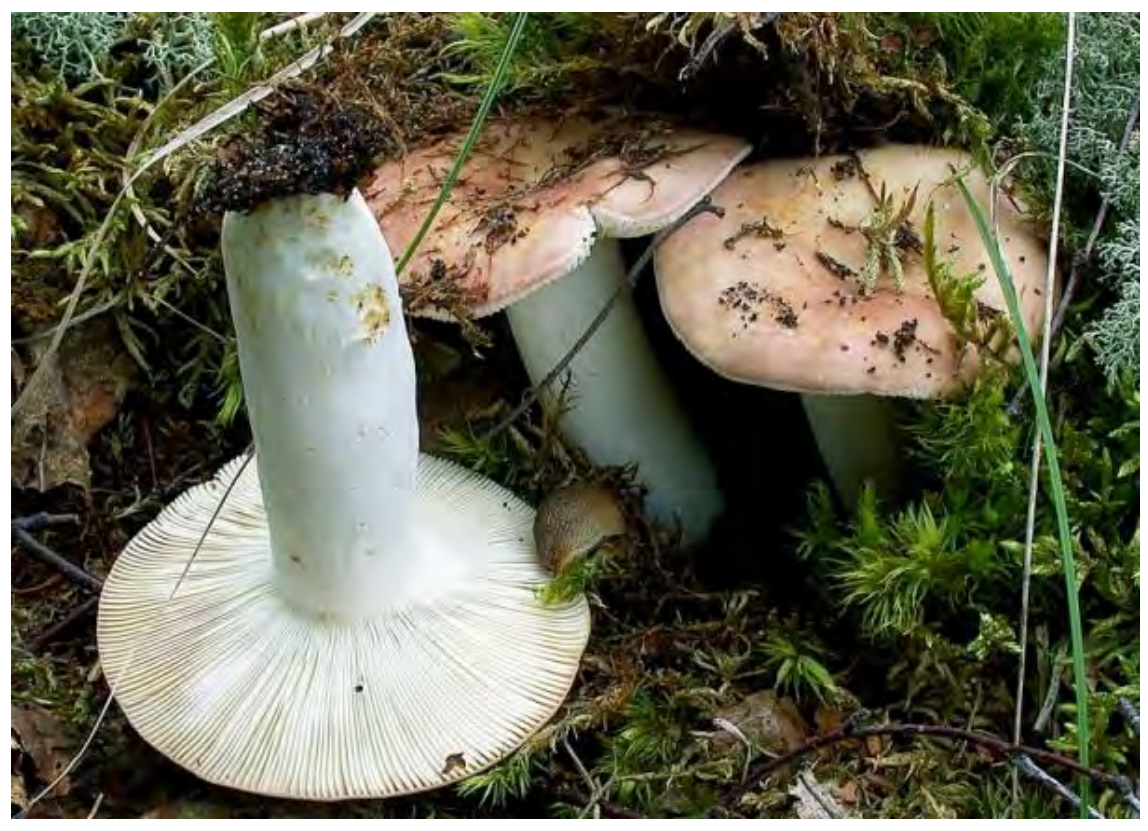

\section{Background and risk assessment}

The Flirt (Russula vesca) is, as other mild-tasting Brittlegill (Russula) species of the section Heterophyllae Fr., an edible mushroom (see Russula Pers.).

It forms mycorrhiza with various deciduous and coniferous trees on acid soil. It is rare in Iceland, but common in temperate and hemiboreal zones and otherwise occasional in the Nordic countries (Knudsen \& Vesterholt, 2012).

There are no intoxications reported after consumption of The Flirt.

\section{Recommendation}

No special recommendation. 


\section{Database search information}

SciFinder by September 2011. Keywords: Russula. PubMed by October 2012. Keywords: Russula.

Listing 2

\section{References}

Knudsen H \& Vesterholt J (2012): Funga Nordica. Agaricoid, boletoid, clavarioid, cyphelloid and gastroid genera. Nordsvamp: 1-1083. 


\section{Russula vinosa Lindblad (R. obscura (Romell) Peck)}

Darkening Brittlegill (DK: Vinrød Skørhat, FI: Viinihapero, IS: No Icelandic name, NO: Vinrød kremle, SE: Vinkremla).

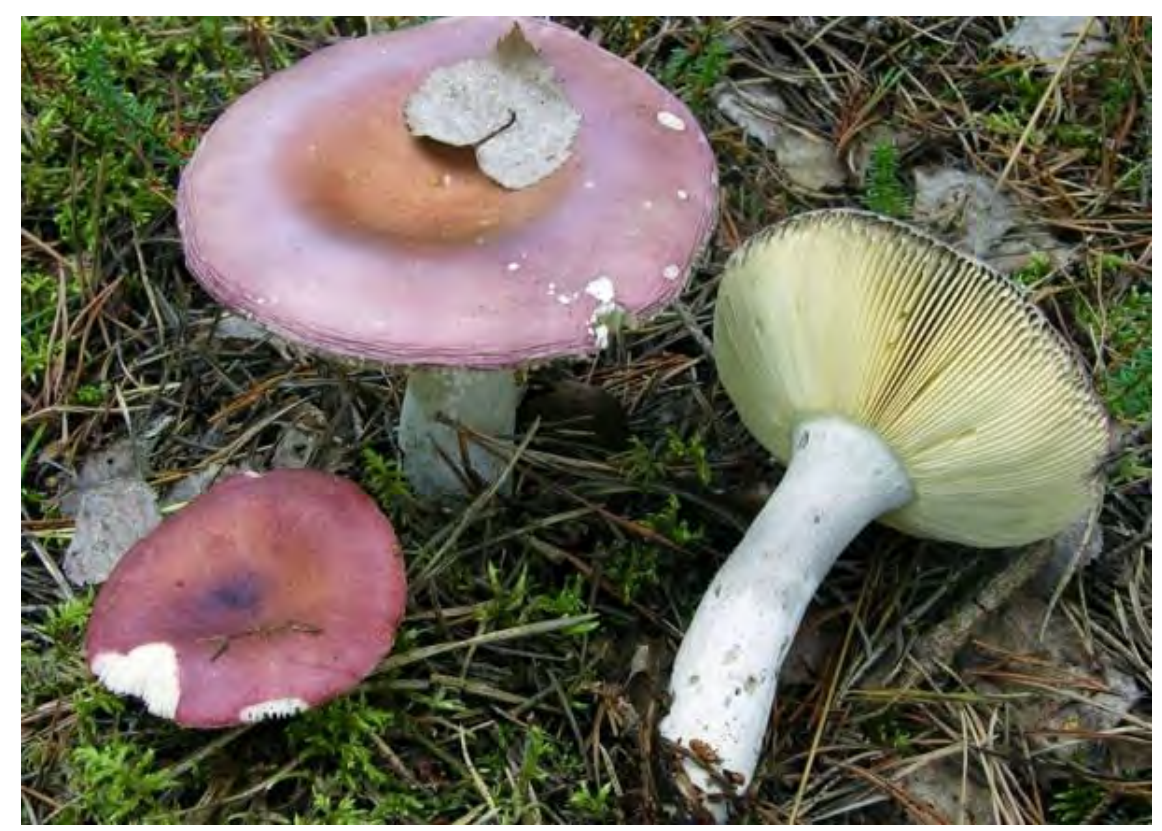

\section{Background and risk assessment}

Darkening Brittlegill is, as other mild-tasting Brittlegill (Russula) species of the section Heterophyllae Fr., an edible mushroom (see Russula Pers.).

It forms mycorrhiza with conifers and in mountains also with Birch (Betula). It is occasional in Denmark, but common in the other Nordic countries (Knudsen \& Vesterholt, 2012).

There are no intoxications reported after consumption of Darkening Brittlegill.

Sterner et al. (1982) tested an extract of Darkening Brittlegill in the Ames test using the Salmonella typhimurium strains TA98, TA100 and TA2637. The extract was only positive in the strain TA2637. The activity was not enhanced in the presence of microsomal enzymes. Unfortunately, Sterner et al (1982) give no information, whether they had controlled for the potential presence of histidine in the extract. It is well known that false positives may be obtained in the presence of histidine. Thus, there is no strong indication that extracts of Darkening Brittlegill are mutagenic. 


\section{Recommendation}

No special recommendation.

\section{Database search information}

SciFinder by September 2011. Keywords: Russula. PubMed by October 2012. Keywords: Russula.

Listing 2

\section{References}

Knudsen H \& Vesterholt J (2012): Funga Nordica. Agaricoid, boletoid, clavarioid, cyphelloid and gastroid genera. Nordsvamp: 1-1083.

Sterner O, Bergman R, Kesler E, Magnusson L, Nilsson B, Wickberg B, Zimerson E \& Zetterberg G (1982): Mutagens in larger fungi I. Forty-eight species screened for mutagenic activity in the Salmonella/microsome assay. Mutation Research 101: 269-281. 


\section{Russula virescens (Schaeff.) Fr.}

Greencracked Brittlegill (DK: Spanskgrøn Skørhat, FI: No Finnish name, IS: Bláhnefla, NO: Rutekremle, SE: Rutkremla).

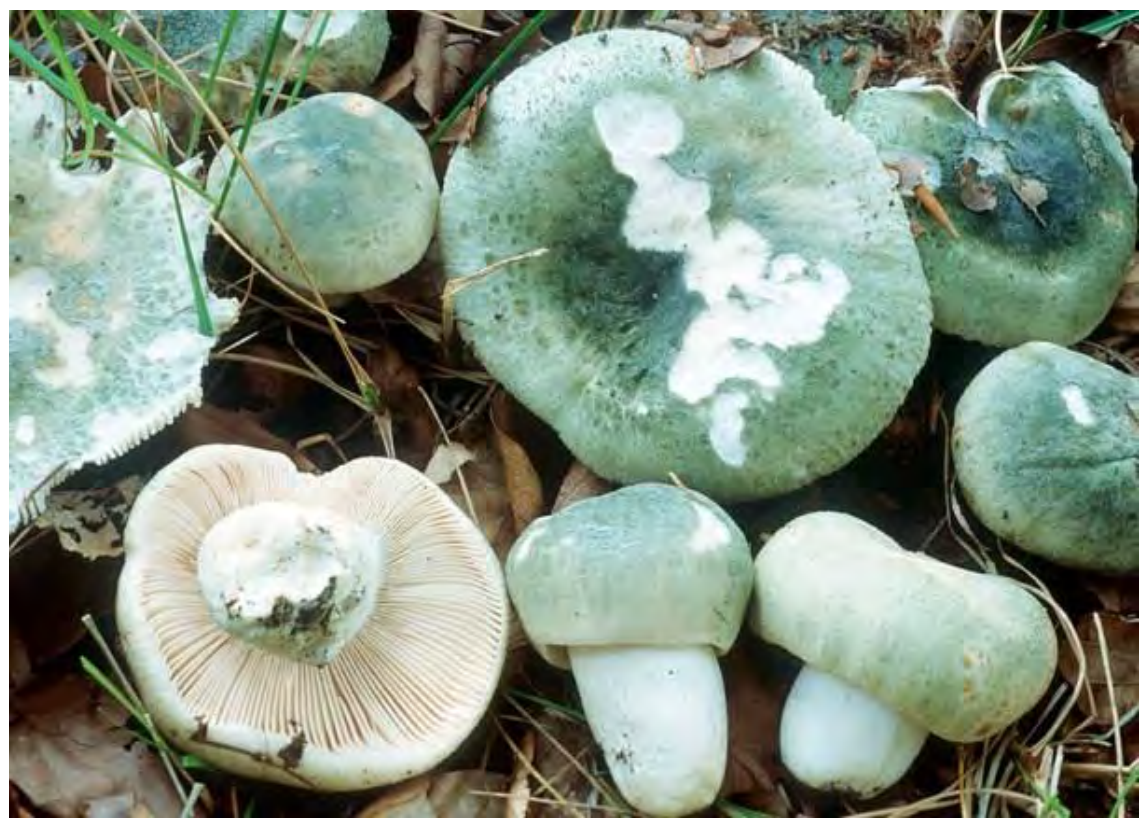

\section{Background and risk assessment}

Greencracked Brittlegill is, as other mild-tasting Brittlegill (Russula) species of the section Heterophyllae Fr., an edible mushroom (see Russula Pers.).

It forms mycorrhiza in deciduous and coniferous woods, especially with Beech (Fagus). It is rare in Norway, otherwise occasional in temperate and rare in hemiboreal zones of the Nordic countries (Knudsen \& Vesterholt, 2012).

There are no intoxications reported after consumption of Greencracked Brittlegill.

Greencracked Brittlegill has been reported to contain $680 \mathrm{mg} / \mathrm{kg}$ (dry weight, 3 samples) of ergothioneine in the fruit bodies (Lee et al., 2009). For further information on ergothioneine: see Lepista nuda.

\section{Recommendation}

Greencracked Brittlegill (Russula virescens) may be mistaken for Deathcap (Amanita phalloides) which is deadly poisonous (see Chapter 4). It is therefore not suitable for commercial marketing. 


\section{Database search information}

SciFinder by September 2011. Keywords: Russula. PubMed by October 2012. Keywords: Russula.

\section{Listing 3}

\section{References}

Knudsen H \& Vesterholt J (2012): Funga Nordica. Agaricoid, boletoid and cyphelloid genera. Nordsvamp: 1-965.

Lee WY; Park E-J, Jin K \& Ka K-H (2009): Ergothioneine contents in fruiting bodies and their enhancement in mycelial cultures by addition of methionine. Mycobiology 37: 43-47. 


\section{Russula xerampelina (Schaeff.) Fr. s. str}

Crab Brittlegill (Shrimp Mushroom) (DK: Hummer-Skørhat, FI: Sillihapero, IS: Móhneflur, NO: Rød Sildekremle, SE: Sillkremla).

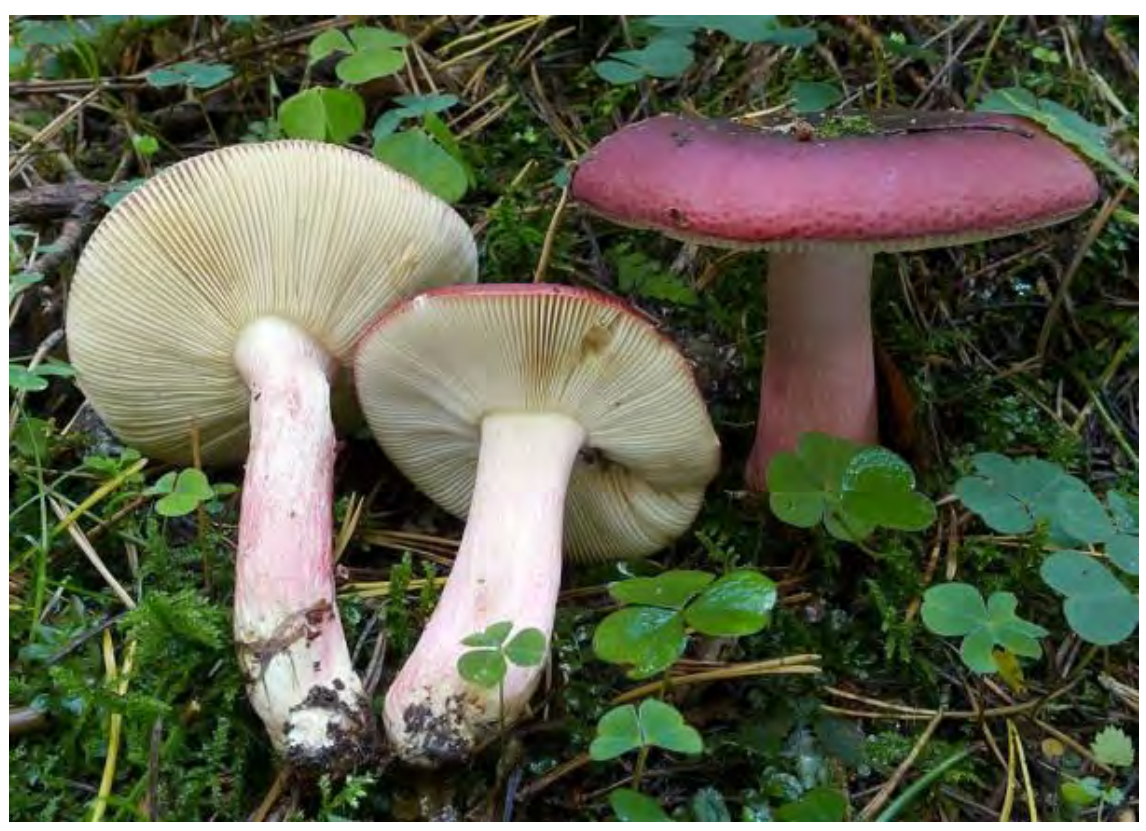

\section{Background and risk assessment}

Crab Brittlegill (Russula xerampelina) is, as other mild-tasting Brittlegill (Russula) species of the section Polychromae Maire, subsection Xerampelinae Singer, an edible mushroom. Although Crab Brittlegill may contain velutinal esters (Clericuzio et al., 2008), this does apparently not influence the mild taste of the mushroom (see Russula Pers.).

It forms mycorrhiza with Pine (Pinus) and more rarely with Spruce (Picea). It is common in Denmark and the southern parts of the other Nordic countries, but only occasional in the subarctic/subalpine zones (Knudsen \& Vesterholt, 2012).

There is a group of 7 closely related and similar Brittlegill species in the Nordic countries, all belonging to the section Polychromae Maire, Subsection Xerampelinae Singer ( $R$. clavipes Velen, $R$. faginea Romagn., $R$. favrei M.M. Moser, R. graveolens Romell, R. pascua (F. H. Møller \& Jul. Schäff.) Kühner, $R$. subrubens (J.E. Lange) Bon, and R. xerampelina (Schaeff.) Fr. s. str. They are very changeable in the colours of the cap, but usually with elements of red or brown colour. The mature fruit bod- 
ies have a smell of cooked shellfish, and they are all edible with a mild taste (Knudsen \& Vesterholt, 2012).

Only $R$. xerampelina (Schaeff.) Fr. s. str (Crab Brittlegill), which is common in parts of the Nordic countries and sometimes is traded, is dealt with in the following. The other 6 species are less common in the Nordic countries and not of interest for trade.

There are no intoxications reported after consumption of $R$. xerampelina (Schaeff.) Fr. s. str (Crab Brittlegill) or the other six related species mentioned above.

Sterner et al. (1982) tested an extract of Crab Brittlegill in the Ames test using the Salmonella typhimurium strains TA98, TA100 and TA2637. The extract was positive in the strain TA100. The activity was not enhanced in the presence of microsomal enzymes. Unfortunately, Sterner et al (1982) give no information, whether they had controlled for the potential presence of histidine in the extract. It is well known that false positives may be obtained in the presence of histidine. Thus, there is no strong indication that extracts of the Crab Brittlegill are mutagenic.

\section{Recommendation}

No special recommendation.

\section{Database search information}

SciFinder by September 2011. Keywords: Russula. PubMed by October 2012. Keywords: Russula.

\section{Listing 2}

\section{References}

Clericuzio M, Gillardoni G, Malagòn O, Vidari G \& Finzi PV (2008): Sesquiterpenes of Lactarius and Russula (Mushrooms): An update. Natural Product Communications 3: 951-974.

Knudsen H \& Vesterholt J (2012): Funga Nordica. Agaricoid, boletoid, clavarioid, cyphelloid and gastroid genera. Nordsvamp: 1-1083.

Sterner O, Bergman R, Kesler E, Magnusson L, Nilsson B, Wickberg B, Zimerson E \& Zetterberg G (1982): Mutagens in larger fungi I. Forty-eight species screened for mutagenic activity in the Salmonella/microsome assay. Mutation Research 101: 269-281. 


\section{Sparassis crispa (Wulfen) Fr.}

Wood Cauliflower (DK: Blomkålssvamp, FI: Kurttusieni, IS: Blómkálssveppur, NO: Blomkålsopp, SE: Blomkålssvamp).

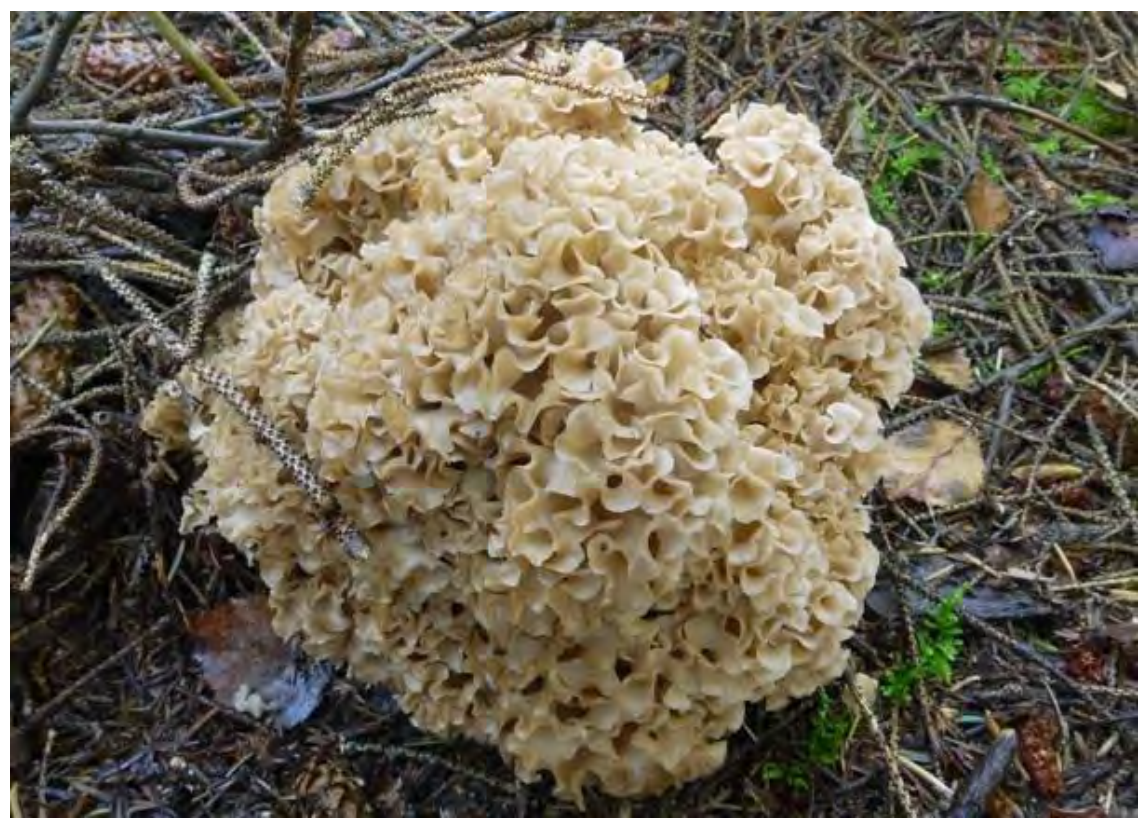

\section{Background and risk assessment}

Wood Cauliflower (Sparassis crispa) is an edible mushroom.

It is parasitic on roots of conifers, especially Pine (Pinus) or saprotrophic on dead and dying coniferous stumps and standing trees. It is occasional in Denmark and in southern parts of Finland, Norway and Sweden but more rare in northern parts, especially in the boreal areas of the Nordic countries (Hansen \& Knudsen, 1997). Wood Cauliflower is also cultivated, especially in South-East Asia.

There are no intoxications reported after consumption of Wood Cauliflower, and no natural toxicant constituting a risk for humans has been identified in the mushroom.

Wood Cauliflower contains, besides $\beta$-glucans, several types of potentially bioactive constituents, such as phenylpyrrolidines, chalcones, sesquiterpenoids, substituted benzoates and tetrahydrofurans (Chandrasekaran et al., 2011; Jiang et al., 2009; Kawagishi et al., 2007, 2008; Kodani et al., 2009), and ergothioneine (Lee et al., 2009). Compounds of these types have often been shown to have biological activity in experimental studies: 


\section{Bioactive constituents}

Substituted benzoates: Three substituted benzoates have been isolated from fruit bodies harvested from submerged cultures of the mushroom (Woodward et al., 1993) and they have all been shown to have antifungal activity in in vitro studies (Chandrasekaran et al., 2011). The structural formula of one of these benzoates, sparassol, is shown below.<smiles>COC(=O)c1c(C)cc(OC)cc1O</smiles>

Sparassol

Phenylpyrrolidines: Kawagashi et al. $(2007,2008)$ have isolated a phenylpyrrolidindione derivative and an $\alpha, \beta$-unsaturated ketone tautomer of this dione from fruit bodies of Wood Cauliflower in small amounts, 0.8 and $0.4 \mathrm{mg}$ per kg dry weight, respectively. At appropriate concentrations both compounds inhibited melanin synthesis in B16 mouse melanoma cells and growth of methilin-resistant Staphylococcus aureus. The $\alpha, \beta$-unsaturated ketone-structure is considered to be a structural alert for genotoxicity (EFSA, 2007). The structural formula of the $\alpha, \beta$ unsaturated ketone is shown below.<smiles>CC(C)=CCOc1ccc(C2=C(CC(C)C)C(=O)N(O)C2O)cc1</smiles>

Phenylpyrrolidinedione derivative (enol tautomer)

Flavonoids: Small quantities of the chalcones xanthoangelol and 4hydroxyderricin have been isolated from Wood Cauliflower (0.1-0.2 mg per kg dried fruit bodies). Both compounds have been demonstrated to be cytotoxic at low doses in human neuroblastoma cell lines cultured in vitro (Nishimura et al., 2007). 
When given in high concentrations (daily doses of 50 and $100 \mathrm{mg} / \mathrm{kg}$ ) both compounds inhibit tumour growth in tumour-bearing mice (Kimura \& Baba, 2003; Kimura et al., 2004) and growth of methilin-resistant Staphylococcus aureus in vitro (Kodani et al., 2008). In addition the flavanone naringenin has been isolated from the mushroom at $35 \mathrm{mg} / \mathrm{kg}$ dry weight, corresponding to approximately $4 \mathrm{mg} / \mathrm{kg}$ fresh weight (Kim et al., 2008). Naringenin is weakly estrogenic in vitro, but this activity has not been confirmed in in vivo studies (EFSA, 2010). The structural formula of one of the chalcones, xanthoangelol, is shown below.<smiles>CC(C)=CCC/C(C)=C/Cc1c(O)ccc(C(=O)/C=C/c2ccc(O)cc2)c1O</smiles>

Xanthoangelol

Ergothioneine: Lee et al. (2009) reported relatively high amounts, 2370 $\mathrm{mg} / \mathrm{kg}$ (dry weight, 3 samples), of ergothioneine in fruit bodies of Wood Cauliflower. For further information on ergothioneine: see Lepista nuda.

Mutagens: Sterner et al. (1982) tested an extract of Wood Cauliflower in the Ames test using the Salmonella typhimurium strains TA98, TA100 and TA2637. The extract was positive in all three strains. The activity was not enhanced in the presence of microsomal enzymes. Unfortunately, Sterner et al (1982) give no information, whether they had controlled for the potential presence of histidine in the extract. It is well known that false positives may be obtained in the presence of histidine. Thus, there is no strong indication that extracts of Wood Cauliflower are mutagenic.

\section{Recommendation}

No special recommendation.

\section{Listing 2}




\section{Database search information}

SciFinder by September 2011. Keywords: Sparassis. PubMed by December 2012. Keywords: Sparassis.

\section{References}

Chandrasekaran G, Oh D-S \& Shin H-J (2011): Properties and potential applications of the culinary-medicinal Cauliflower Mushroom, Sparassis crispa Wulf.: Fr. (Aphyllophoromycetidae): A review. International Journal of Medicinal Mushrooms 13: 177-183.

EFSA (2007): Minutes of the 26th Plenary Meeting of the Scientific Panel on Food Additives, Flavourings, Processing Aids and Materials in Contact with Food. Section 9 Flavourings. 9.1.1 FGE 19 (EFSA- Q-2003-162). (Q)SAR predictions on alpha, beta-unsaturated substances including predicted metabolism products of flavouring precursors for alpha, beta-unsaturated aldehydes and ketones. Status of the predictions and outcome of the validation of the genotoxicity studies: 6-9.

EFSA (2010): Flavouring group evaluation 32 (FGE.32): Flavonoids (flavanones and dihydrochalcones) from chemical groups 25 and 30. EFSA Journal 8: 1065 (1-61).

Hansen L \& Knudsen H (1997): Nordic Macromycetes, Volume 3. Heterobasidiod, aphyllophoroid and gastromycetoid basidiomycetes. Nordsvamp: 1-444.

Jiang M-Y, Zhang L, Dong Z-J \& Liu J-K (2009): Two new metabolites from basidiomycete Sparassis crispa. Zeitschrift für Naturforschung 64b: 1087-1089.

Kawagishi H, Hayashi K, Tokuyama S, Hashimoto N, Kimura T \& Dombo M (2007): Novel bioactive compounds from the Sparassis crispa mushroom. Bioscience, Biotechnology and Biochemistry 71: 1804-1806.

Kawagishi H, Tokuyama S, Hashimoto N, Kimura T, Yuki M \& Donho M (2008): Antibacterial agents containing phenylpyrrolone deritative or phenylpyrrolidinedione derivative. Japanese Kokai Tokkyo Koho (Japanese, English abstract available).

Kim M-Y, Seguin P, Ahn J-K, Kim J-J, Chun S-C, Kim E-H, Seo S-H, Kang E-Y, Kim S-L, Park Y-J, Ro H-M \& Chung I-M (2008): Phenolic compound concentration and antioxidant activities of edible and medicinal mushrooms from Korea. Journal of Agricultural and Food Chemistry 56: 7265-7270.

Kimura Y \& Baba K (2003): Antitumor and antimetastatic activities of Angelica keiskei roots, part 1: Isolation of an active substance, xanthoangelol. International Journal of Cancer 106: 429-437.

Kimura Y, Taniguchi M \& Baba K (2004): Antitumor and antimetastatic activities of 4-hydroxyderricin isolated from Angelica keiskei roots. Planta Medica 70: 211-219.

Kodani S, Hayashi K, Hashimoto M, Kimura T, Dombo M \& Kawagishi H (2009): New sesquiterpenoid from the mushroom Sparassis crispa. Bioscience, Biotechnology and Biochemistry 73: 228-229.

Kodani S, Hayashi K, Tokuyama S, Hashimoto M, Kimura T, Dombo M \& Kawagishi H (2008): Occurrence and identification of chalcones from the culinary-medicinal Cauliflower Mushroom Sparassis crispa (Wuld.) Fr. (Aphyllophoromycetideae). International Journal of Medicinal Mushrooms 10: 331-336.

Lee WY; Park E-J, Jin K \& Ka K-H (2009): Ergothioneine contents in fruiting bodies and their enhancement in mycelial cultures by addition of methionine. Mycobiology 37: 43-47.

Nishimura R, Tabata K, Arakawa M, Ito Y, Kimura Y, Akihisa T, Nagai H, Sakuma A, Kohno H \& Suzuki T (2007): Isobavachalcone, a chalcone constituent of Angelica keiskei, induces apoptosis in neublastoma. Biological and Phamacological Bulletin 30: 1878-1883. 
Sterner O, Bergman R, Kesler E, Magnusson L, Nilsson B, Wickberg B, Zimerson E \& Zetterberg G (1982): Mutagens in larger fungi I. Forty-eight species screened for mutagenic activity in the Salmonella/microsome assay. Mutation Research 101: 269-281.

Woodward S, Sultan HY, Barret DK \& Pearce RB (1993): Two new antifungal metabolites produced by Sparassis crispa in culture and in decayed trees. Journal of General Microbiology 139: 153-159. 


\section{Suillus granulatus (L.) Roussel}

Weeping Bolete (Granulated Bolete) (DK: Kornet Rørhat, FI: Jyvästatti, IS: Kornasúlungur, NO: Ringløs smørsopp, SE: Grynsopp).

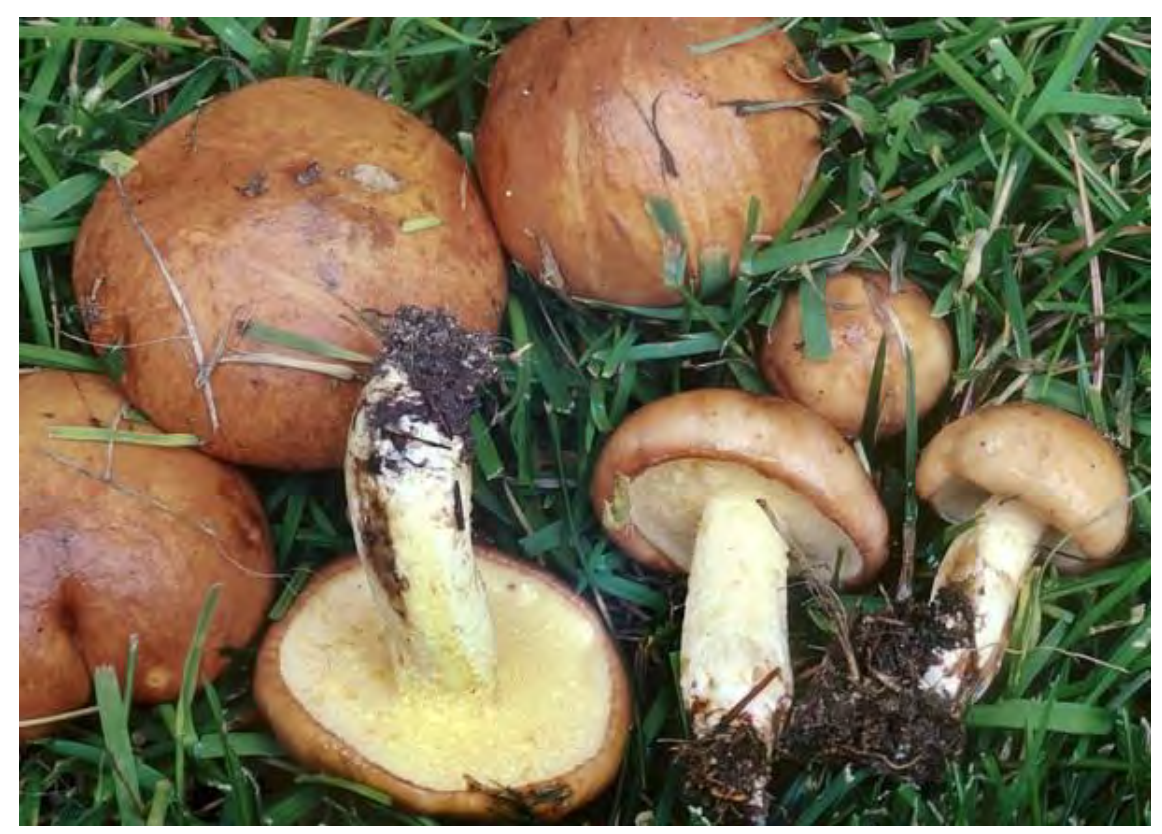

\section{Background and risk assessment}

Weeping Bolete (Suillus granulatus) is an edible mushroom.

It grows mycorrhizal with Pine (Pinus) in forests and gardens. It is occasional in Denmark and also occasional in temperate-boreal zones, but rare in subalpine zones of the Nordic countries (Knudsen \& Vesterholt, 2012).

There are no intoxications reported after consumption of Weeping Bolete, and no natural toxicant constituting a risk for humans has been identified in the mushroom.

Most Suillus species contain colouring matters and precursors for these, which mainly belong to three groups of phenolic compounds: the pulvinic acid group (e.g. variegatic acid), the grevillins/pyrandiones (e.g. grevillin D) and the prenylated phenols (e.g. suillin) (Besl \& Bresinsky, 1997). Several compounds from these chemical groups have been shown to have antioxidative, antibacterial and antiviral activity or to have inhibitory effects on cytochrome P450 activity, but mainly in in vitro stud- 
ies (e.g. Geraci et al., 1992; Hayashi et al., 1979; Huang et al., 2009; Liu et al., 2007; Tringali et al., 1989a; 1989b).

Thus, tetraprenylated phenolic constituents have been identified in Weeping Bolete, collected in Germany and Italy, with suillin as the most abundant compound (Jägers et al., 1986, Tringali et al., 1989a). Suillin is mainly found in the viscid skin of the cap and corresponds to about $0.1 \%$ of the skin, but the content may vary between 0.01 and $0.5 \%$ depending on age and condition of the mushroom (Jägers et al., 1989). Also phenolic pyrandiones (grevillin B, C and D) have been identified in the mushroom, collected in Austria and Germany (Besl et al., 1974; Besl \& Bresinsky, 1997). The structural formulae of representatives for these phenols, suillin and grevillin B are shown below.<smiles>CC(=O)Oc1ccc(O)c(O)c1C/C=C(\C)CC/C=C(\C)CC/C=C(\C)CCC=C(C)C</smiles>

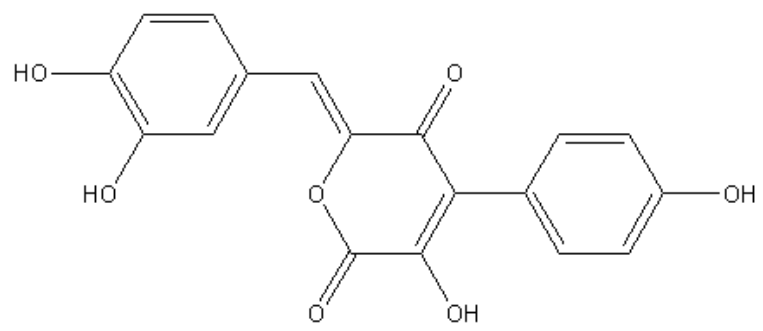

Grevillin B

According to Dong et al. (2007) Weeping Bolete (probably collected in China) does also contain the hydroxymethylfuryl- $\beta$-carboline-carboxylic acid, flazin, an alkaloid with antiviral properties indicated in in vitro studies (Wang et al., 2007; Dong et al., 2007). Moreover, Kang et al. (2001) have isolated 1,3,5-trihydroxy-7-methyl-antraquinone from the mushroom (probably collected in Korea).

Ergothioneine: Lee et al. (2009) reported relatively small amounts, 90 $\mathrm{mg} / \mathrm{kg}$ (dry weight, 3 samples), of ergothioneine in fruit bodies of Weeping Bolete. For further information on ergothioneine: see Lepista nuda. 
It is not possible to evaluate whether the above-mentioned bioactive compounds in Weeping Bolete may have any beneficial or adverse effect in humans consuming this mushroom, as representatives of these constituents have mainly been studied in vitro, and as the quantitative occurrence of these constituents is generally not well described.

\section{Recommendation}

No special recommendation.

Listing 2

\section{Database search information}

SciFinder by July 2012. Keywords: Suillus. PubMed by January 2012. Keyword: Suillus.

\section{References}

Besl H \& Bresinsky A (1997): Chemosystematics of Suillaceae and Gomphidiaceae (suborder Suillineae). Plant Systemtics and Evolution 206: 223-242.

Besl H, Michler I, Preuss R \& Steglich W (1974): Pigments of fungi. XXII. Grevillin D, the main pigment of Suillus granulatus, S. luteus and S. placidus (Boletales). Zeitschrift für Naturforschung 29c: 784-786.

Dong Z, Wang F, Wang R, Yang L, Zeng Y \& Liu J (2007): Chemical constituents of fruiting bodies from Basidionmycete Suillus granulatus and their anti-HIV-1 activity. Zhoncaoyao 38: 337-339 (Chinese, English abstract available).

Geraci C, Piattelli M, Trigali C, Verbist JF \& Roussakis C (2007): Cytotoxic activity of tetraprenylphenols related to suillin, an antitumor principle from Suillus granulatus. Journal of Natural Products 55: 1772-1775.

Hayashi T, Kanetoshi A, Ikura M \& Shirahama H (1989): Bolegreviol, a new lipid peroxidation inhibitor from the edible mushroom Suillus grevillei. Chemical and Pharmaceutical Bulletin 37: 1424-1427.

Huang Y-T, Onose J-i, Abe N \& Yoshikawa K (2009): In vitro inhibitory effects of pulvinic acid derivatives isolated from Chinese edible mushrooms, Boletus calopus and Suillus bovinus, on cytochrome P450 activity. Bioscience, Biotechnology and Biochemistry 73: 855-860.

Jägers E, Vinayagar P, Anke H \& Steglich W (1986): Suillin, ein characteristischer Inhaltsstoff von Rörhlingen der Gattung Suillus (Boletales). Zeitschrift für Naturforschung 41b: 645-648.

Kang H-C, Yun B-S, Yu H \& Yoo I-D (2001): Chemical structures of compounds isolated from the mushroom Suillus granulatus. Sanop Misaengmul Hakhoechi (Korean, English abstract available).

Knudsen H \& Vesterholt J (2012): Funga Nordica. Agaricoid, boletoid, clavarioid, cyphelloid and gastroid genera. Nordsvamp: 1-1083.

Lee WY; Park E-J, Jin K \& Ka K-H (2009): Ergothioneine contents in fruiting bodies and their enhancement in mycelial cultures by addition of methionine. Mycobiology 37: 43-47. 
Liu F, Wu P, Wu S; Chen Y, Liu X \& Zhao Y (2007): Method for preparing suillin (niangainiganjunsu) and its application. Faming Zhuanli Shenqing, CN 1923791 A 20070307 (Chinese, English abstract available).

Tringali C, Geraci C, Nicolosi G, Verbisi JF \& Roussakis C (1989a): An antitumor principle from Suillus granulatus. Journal of Natural Products 52: 844-845.

Tringali C, Piatteli M, Geraci C \& Nicolosi G (1989b): Antimicrobial tetraprenylphenols from Suillus granulatus. Journal of Natural Products 52: 941-947.

Wang Y-H, Tang J-G, Wang R-R, Yang L-M, Dong Z-J, Du L, Shen X, Liu J-K \& Zheng Y-T (2007): Flazinamide, a novel $\beta$-carboline compound with anti-HIV actions. Biochemical and Biophysical Research Communitation 355: 1091-1095. 


\section{Suillus grevillei (Klotzsch) Singer}

Larch Bolete (Greville's Bolete) (DK: Lærke-Rørhat, FI: Lehtikuusentatti, IS: Lerkisúlungur, Lerkisveppur, NO: Lerkesopp, SE: Lärksopp).

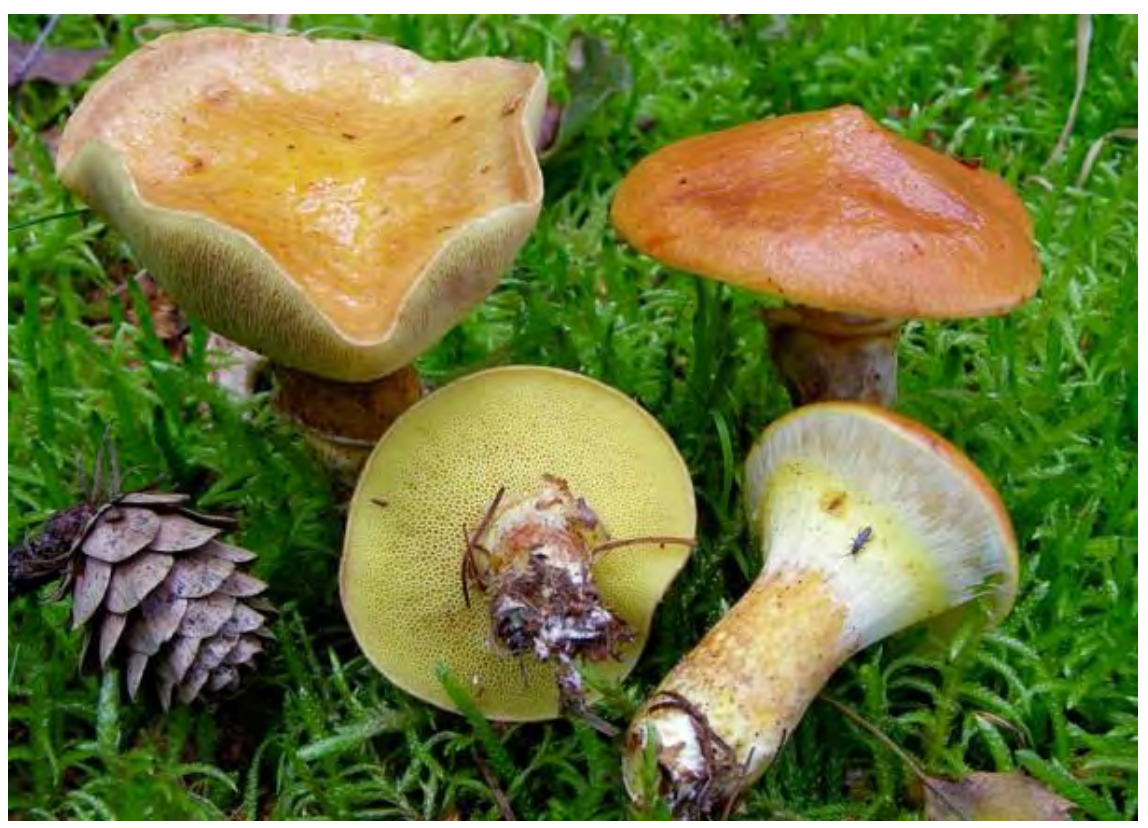

\section{Background and risk assessment}

Larch Bolete (Suillus grevillei) is an edible mushroom.

It is mycorrhizal with Larch (Larix) in plantations, gardens and parks. It is very rarely associated with Psedotsuga. It is common in Denmark and southern parts of the Nordic countries and occasional in middle boreal-subalpine areas (Knudsen \& Vesterholt, 2012).

There are no intoxications reported after consumption of Larch Bolete, and no natural toxicant constituting a risk for humans has been identified in the mushroom.

Most Suillus species contain colouring matters and precursors for these, which mainly belong to three groups of phenolic compounds: the pulvinic acid group (e.g. variegatic acid), the grevillins/pyrandiones (e.g. grevillin D) and the prenylated phenols (e.g. suillin) (Besl \& Bresinsky, 1997). Several compounds from these chemical groups have been shown to have antioxidative, antibacterial and antiviral activity or to have inhibitory effects on cytochrome P450 activity, but mainly in in vitro stud- 
ies (e.g. Geraci et al., 1992; Hayashi et al., 1979; Huang et al., 2009; Liu et al., 2007; Tringali et al., 1989a; 1989b).

Thus, Larch Bolete contains representatives from all these phenolic groups; from the grevillin/pyrandione group, grevillin A, B and C (Gill \& Kiefel, 1988; Massow \& Huber, 1977; Steglich et al., 1972), from the tetraprenylated phenol group, e.g. bolegreviol, an isomer of suillin (Hayashi et al., 1989) and from the pulvinic acid group, varieagatic acid (Besl \& Bresensky, 1997). Additionally, some terphenylquinones, thelephoric acid and cyclovariegatin have been identified in Larch Bolete (Edwards \& Gill, 1973; 1975). The structural formulae of representatives of these phenols, grevillin B, bolegreviol, variegatic acid and the terphenyl quinone, thelephoric acid, are shown below.

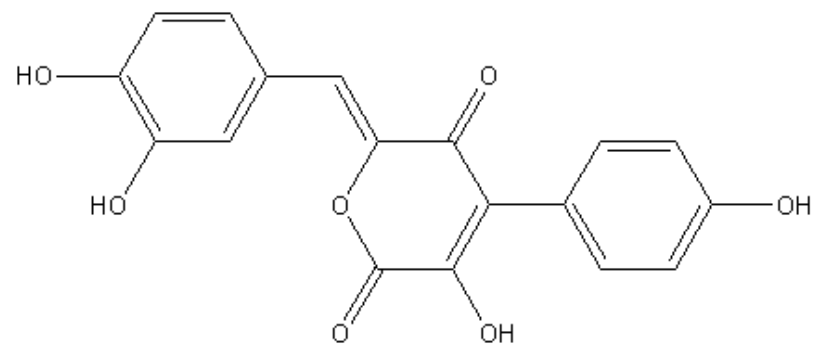

Grevillin B<smiles>CC(=O)Oc1c(O)cc(O)cc1C/C=C(\C)CC/C=C(\C)CC/C=C(\C)CCC=C(C)C</smiles><smiles>O=C1c2oc3cc(O)c(O)cc3c2C(=O)c2oc3cc(O)c(O)cc3c21</smiles>

Thelephoric acid 
<smiles>O=C(O)C(=C1OC(=O)C(c2ccc(O)c(O)c2)=C1O)c1ccc(O)c(O)c1</smiles>

It is not possible to evaluate whether the above-mentioned bioactive compounds in Larch Bolete may have any beneficial or adverse effect in humans consuming this mushroom, as representatives of these constituents have mainly been studied in vitro, and as the quantitative occurrence of these constituents is generally not well described.

\section{Recommendation}

No special recommendation.

\section{Listing 2}

\section{Database search information}

SciFinder by July 2012. Keywords: Suillus. PubMed by January 2012. Keywords: Suillus.

\section{References}

Besl H \& Bresinsky A (1997): Chemosystematics of Suillaceae and Gomphidiaceae (suborder Suillineae). Plant Systemtics and Evolution 206: 223-242.

Besl H, Michler I, Preuss R \& Steglich W (1974): Pigments of fungi. XXII. Grevillin D, the main pigment of Suillus granulatus, S. luteus and S. placidus (Boletales).

Zeitschrift für Naturforschung 29c: 784-786.

Edwards RL \& Melvyn G (1973): Constituents of higher fungi. Part XIV. 3,4,4-trihydroxypulvinone, thelephoric acid and novel pyrandione and furanone pigments from Suillus grevillei (Klotsch) Sing. [Boletus elegans (Schum. per Fries)]. Journal of the Chemical Society, Perkin I: 1921-1928.

Edwards RL \& Melvyn G (1975): Constituents of higher fungi. Part XV.

3-(3,4-dihydroxyphenyl)-2,7,8-trihydroxydibenzofuran-1,4-dione, a precursor of thelephoric acid from the fungus Suillus grevillei (Klotsch) Sing. [Boletus elegans (Schum. per Fries)]. Journal of the Chemical Society, Perkin I: 351-354.

Geraci C, Piattelli M, Trigali C, Verbist JF \& Roussakis C (2007): Cytotoxic activity of tetraprenylphenols related to suillin, an antitumor principle from Suillus granulatus. Journal of Natural Products 55: 1772-1775.

Gill M \& Kiefel MJ (1988): Pigments of fungi. Part 9. Synthesis of fungus pigments of the grevillin and pulvinone types from benzylacyloins. Tetrahedron Letters 29: 2085-2088. 
Hayashi T, Kanetoshi A, Ikura M \& Shirahama H (1989): Bolegreviol, a new lipid peroxidation inhibitor from the edible mushroom Suillus grevillei. Chemical and Pharmaceutical Bulletin 37: 1424-1427.

Huang Y-T, Onose J-i, Abe N \& Yoshikawa K (2009): In vitro inhibitory effects of pulvinic acid derivatives isolated from Chinese edible mushrooms, Boletus calopus and Suillus bovinus, on cytochrome P450 activity. Bioscience, Biotechnology and Biochemistry 73: 855-860.

Jägers E, Vinayagar P, Anke H \& Steglich W (1986): Suillin, ein characteristischer Inhaltsstoff von Rörhlingen der Gattung Suillus (Boletales). Zeitschrift für Naturforschung 41b: 645-648.

Knudsen H \& Vesterholt J (2012): Funga Nordica. Agaricoid, boletoid, clavarioid, cyphelloid and gastroid genera. Nordsvamp: 1-1083.

Liu F, Wu P, Wu S; Chen Y, Liu X \& Zhao Y (2007): Method for preparing suillin (niangainiganjunsu) and its application. Faming Zhuanli Shenqing, CN $1923791 \mathrm{~A}$ 20070307 (Chinese, English abstract available).

Massow FV \& Huber D (1977): A new thin-layer chromatography system for the identification of moderately polar to lipophilic Boletales pigments. Journal of Chromatography 138: 232-237.

Steglich W, Besl H \& Prox A (1972): Fungus pigments 13. Structure of grevilins, new pigments from Suillus grevillei (Boletaceae). Tetrahedron Letters: 4895-4898.

Tringali C, Geraci C, Nicolosi G, Verbisi JF \& Roussakis C (1989a): An antitumor principle from Suillus granulatus. Journal of Natural Products 52: 844-845.

Tringali C, Piatteli M, Geraci C \& Nicolosi G (1989b): Antimicrobial tetraprenylphenols from Suillus granulatus. Journal of Natural Products 52: 941-947. 


\section{Suillus luteus (L.) Roussel}

Slippery Jack (DK: Brungul Rørhat, FI: Voitatti, IS: Furusúlungur, Furusveppur, NO: Smørsopp, SE: Smörsopp).

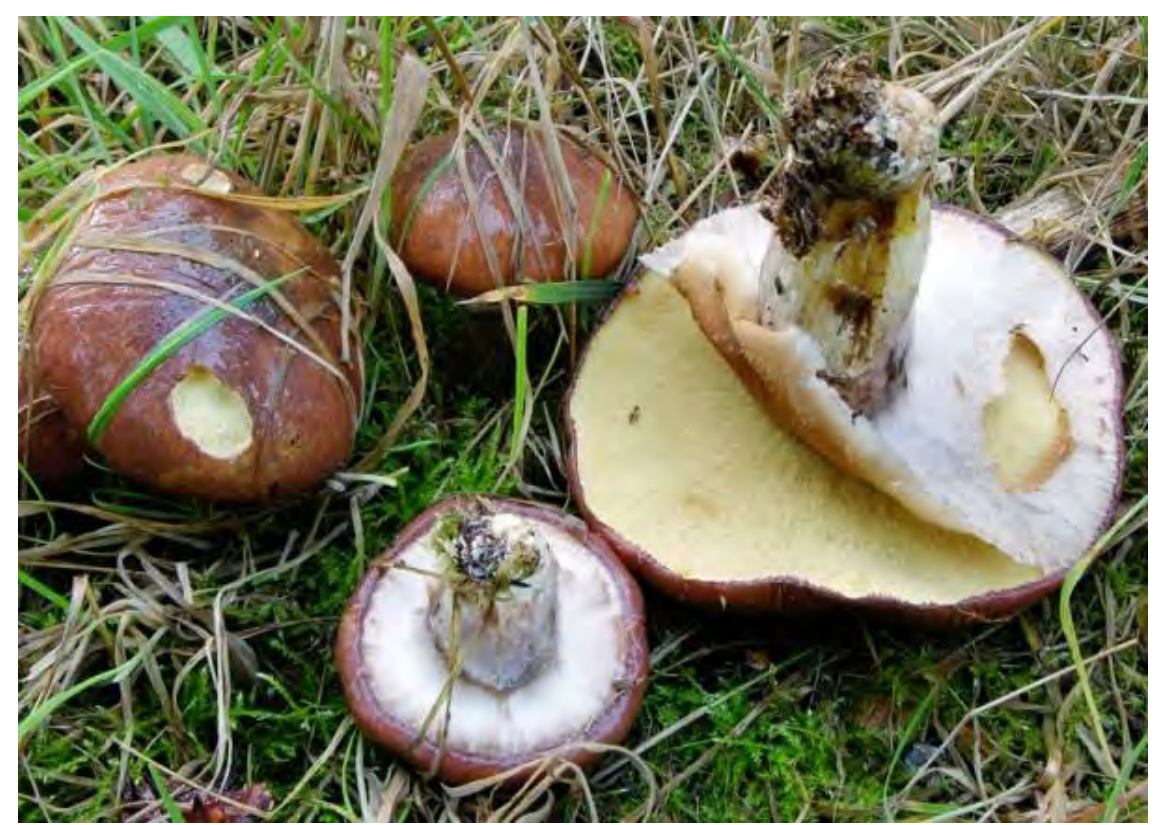

\section{Background and risk assessment}

Slippery Jack (Suillus luteus) is an edible mushroom. It is mostly used as fresh, but is also commonly traded, especially dried, often in mixtures of mushrooms.

It is mycorrhizal with pine (Pinus) and is very common in the Nordic countries in temperate-coniferous subalpine areas (Knudsen \& Vesterholt, 2012).

Although Slippery Jack generally is regarded as safe to eat and is commonly traded, it has given rise to some intoxications and e.g., Lincoff (2010) recommends to remove the slime (the glutinous skin of the cap) before its use for consumption.

\section{Human observations}

Bobrowski (1966) described a person who experienced intoxications in 1958 and 1964 with fatigue, feeling unwell and with temporary icterus after consumption of Slippery Jack. The symptoms disappeared spontaneously after a short time. In 1965, the same person (30 years old woman) had a third intoxication after consumption of the same mushroom 
species. The poisoning was diagnosed as severe acute haemolysis with kidney insufficiency. After one month of hospitalization, the patient was discharged without symptoms. Other family members did eat the same mushroom dish without any adverse reactions.

In 1984, a case of mild poisoning after consumption of Slippery Jack was reported (Prager \& Goos, 1984). The involved person, a 31 year old, healthy man had eaten the mushroom before, after peeling of the glutinous cuticle, without illness. This time he had eaten newly-emerged fruit bodies which were in excellent condition, and the cuticle of the caps was not at all slimy and therefore not removed. He ate about $300 \mathrm{~mL}$ of the mushroom, which was sliced and cooked with butter and lemon. The remaining mushrooms were sliced and dried. Watery diarrhoea commenced 15 minutes after consumption of the dish. After five days, he had totally recovered. He had no nausea, pain or other symptoms except for accompanying fatigue. Six days later he made a soup with about $3 \mathrm{~g}$ of the sliced, dried mushrooms. He ate about 3 slices of the mushroom with the soup. About 15 minutes later diarrhoea sets in and lasted for 5 days. The remaining soup was refrigerated. Eight days after the meal with the soup as an experiment, he heated the frozen soup and ate some of it, but without mushroom slices and had no symptoms. Next day he ate 2 slices of the mushroom from the soup, and again experienced the symptoms he had obtained earlier. Apparently, the cuticle contained non-volatile toxicant(s) stable to heating and drying and not readily extracted from the mushroom slices by boiling, and seems rather potent in this individual (Prager \& Groos, 1984). The identity of the consumed Slippery Jack was confirmed by field characteristics and microscopy.

Beug et al. (2006) have summarized thirty-plus years of mushroom poisonings in the USA from approximately 2,000 reports, covering data until the end of 2005 . In this period totally 8 cases $(6$ adults and 2 children) from North America are registered in the summary. Seven of the cases with symptoms after consumption of Slippery Jack included gastrointestinal distress.

Since the report by Bobrowski in 1966, there are no published data available on poisonings in Europe with this commonly consumed mushroom.

Although the potential toxicant is unknown, several anticipated bioactive constituents occur in Slippery Jack.

\section{Bioactive constituents}

Colouring matters: It contains colouring matters and precursors for these, which mainly belong to three groups of phenolic compounds: the pulvinic acid group (e.g. variegatic acid), the grevillins/pyrandiones (e.g. 
grevillin D) and the prenylated phenols (e.g. suillin) (Besl \& Bresinsky, 1997). Several compounds from these chemical groups have been shown to have antioxidative, antibacterial and antiviral activity or to have inhibitory effects on cytochrome P450 activity, but almost only in in vitro studies (e.g. Geraci et al., 1992; Hayashi et al., 1979; Huang et al., 2009; Liu et al., 2007; Tringali et al., 1989a; 1989b).

At least three different pulvinic acid derivatives have been identified in Slippery Jack, atromentic acid, variegatic acid and xerocomic acid (Besl \& Bresinsky, 1997), four grevillins, grevillin A, B C and D (Besl et al., 1974; Besl \& Bresinsky, 1997) and the tetraprenylated phenol suillin (Jägers et al., 1986).

The structural formulae of variegatic acid, grevillin B and suillin, representatives for the three groups of phenols in Slippery Jack, are shown below.

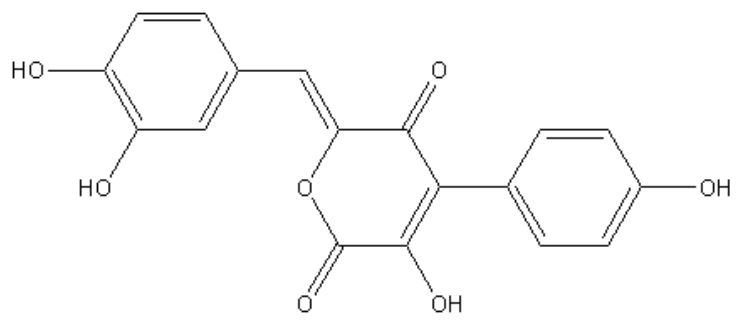

Grevillin B<smiles>CC(=O)Oc1ccc(O)c(O)c1C/C=C(\C)CC/C=C(\C)CC/C=C(\C)CCC=C(C)C</smiles><smiles>O=C(O)C(=C1OC(=O)C(c2ccc(O)c(O)c2)=C1O)c1ccc(O)c(O)c1</smiles>

Variegatic acid 
Indole compounds: Muszynska et al. (2011) have identified several indole compounds in Slippery Jack, but at low levels corresponding to approximately $1 \mathrm{mg} / \mathrm{kg}$ (fresh weight) or lower, except for serotonin found at a level of approximately $34 \mathrm{mg} / \mathrm{kg}$ (fresh weight). However, serotonin is apparently completely destroyed during cooking (Muszynska et al., 2012).

Ergothioneine: Lee et al. (2009) reported relatively high amounts, 2270 $\mathrm{mg} / \mathrm{kg}$ (dry weight, 3 samples), of ergothioneine in fruit bodies of Slippery Jack. For further information on ergothioneine: see Lepista nuda.

Mutagens: Morales et al. (1990a; 1990b) studied mushroom extracts in the Ames test. Extracts of freshly harvested and frozen Slippery Jack mushrooms were reported to be weakly mutagenic in the Salmonella strains TA98 and TA100 (for the fresh mushroom less than doubling in mutation frequency). Extracts of canned Slippery Jack were negative both in the Ames test and in the Chinese Hamster Ovary (CHO/HPRT) cell mutation assay. Apparently, Morales et al. (1990a, 1990b) did not control for possible histidine in the extracts for the Ames test. Thus, there is no strong indication that extracts of the Slippery Jack are mutagenic.

It is not possible to evaluate whether the above-mentioned bioactive compounds in Weeping Bolete may have any beneficial or adverse effect in humans consuming this mushroom, as representatives of these constituents have mainly been studied in vitro, and as the quantitative occurrence of these constituents is generally not well described.

\section{Recommendation}

No special recommendation.

Listing 1

\section{Database search information}

SciFinder by July 2012. Keywords: Suillus. PubMed January 2012. Keywords: Suillus.

\section{References}

Besl H \& Bresinsky A (1997): Chemosystematics of Suillaceae and Gomphidiaceae (suborder Suillineae). Plant Systemtics and Evolution 206: 223-242.

Besl H, Michler I, Preuss R \& Steglich W (1974): Pigments of fungi. XXII. Grevillin D, the main pigment of Suillus granulatus, S. luteus and S. placidus (Boletales). Zeitschrift für Naturforschung. 29c: 784-786.

Beug MW, Shaw M \& Cochran KW (2006): Thirty-plus years of mushroom poisoning: Summary of the approximately 2,000 reports in the NAMA Case Registry. Mcllvainea 16: 47-67. 
Bobrowski, H. (1966): Ostra niewydolność nerek w przebiegu ostrego nabytego zespolu hemolitycznego u osoby uczulonej na grzyb maslak (Boletus luteus). Polski Tygodnik Lekarski. 21: 1864-1870 (Polish).

Geraci C, Piattelli M, Trigali C, Verbist JF \& Roussakis C (2007): Cytotoxic activity of tetraprenylphenols related to suillin, an antitumor principle from Suillus granulatus. Journal of Natural Products 55: 1772-1775.

Hayashy T, Kanetoshi A, Ikura M \& Shirahama H (1989): Bolegreviol, a new lipid peroxidation inhibitor from the edible mushroom Suillus grevillei. Chemical and Pharmaceutical Bulletin 37: 1424-1427.

Huang Y-T, Onose J-i, Abe N \& Yoshikawa K (2009): In vitro inhibitory effects of pulvinic acid derivatives isolated from Chinese edible mushrooms, Boletus calopus and Suillus bovinus, on cytochrome P450 activity. Bioscience, Biotechnology and Biochemistry 73: 855-860.

Jägers E, Vinayagar P, Anke H \& Steglich W (1986): Suillin, ein characteristischer Inhaltsstoff von Rörhlingen der Gattung Suillus (Boletales). Zeitscrift für Naturforshung 41b: 645-648.

Knudsen H \& Vesterholt J (2012): Funga Nordica. Boletoid, clavarioid, cyphelloid and gastroid genera. Nordsvamp: 1-1083.

Lee WY; Park E-J, Jin K \& Ka K-H (2009): Ergothioneine contents in fruiting bodies and their enhancement in mycelial cultures by addition of methionine. Mycobiology 37: 43-47.

Lincoff GH (2010): National Audubon Society. Field Guide to North American Mushrooms. Alfred Knopf. New York: 1-926.

Liu F, Wu P, Wu S; Chen Y, Liu X \& Zhao Y (2007): Method for preparing suillin (niangainiganjunsu) and its application. Faming Zhuanli Shenqing, CN 1923791 A 20070307 (Chinese, English abstract available).

Morales P, Bermudez E, Sanz B \& Hernandez PE (1990a): A study of the mutagenicity of some commercially canned Spanish mushrooms. Food and Chemical Toxicology 28: 607-611.

Morales P, Bermudez E, Hernandez PE \& Sanz B (1990b): The mutagenicity of some Spanish edible mushrooms in the Ames test. Food Chemistry 38: 279-288.

Muszyńska B, Sułkowska-Ziaja K \& Ekiert H (2011): Indole compounds in some culinary-medicinal higher basidiomycetes from Poland. International Journal of Medicinal Mushrooms 13: 449-454.

Muszyńska B \& Sułkowska-Ziaja K (2012): Analysis of indole compounds in edible Basidiomycota species after thermal processing. Food chemistry 132: 455-459.

Prager MH \& Goos RD (1984): A case of mushroom poisoning from Suillus luteus. Mycopathologia 85: 175-176.

Tringali C, Geraci C, Nicolosi G, Verbisi JF \& Roussakis C (1989a): An antitumor principle from Suillus granulatus. Journal of Natural Products 52: 844-845.

Tringali C, Piatteli M, Geraci C \& Nicolosi G (1989b): Antimicrobial tetraprenylphenols from Suillus granulatus. Journal of Natural Products 52: 941-947. 


\section{Suillus variegatus (Sw.) Kuntze}

Velvet Bolete (Variegated Bolete) "Swedish Jack" (DK: Broget Rørhat, FI: Kangastatti, IS: Sandsúlungur, NO: Sandsopp, SE: Sandsopp).

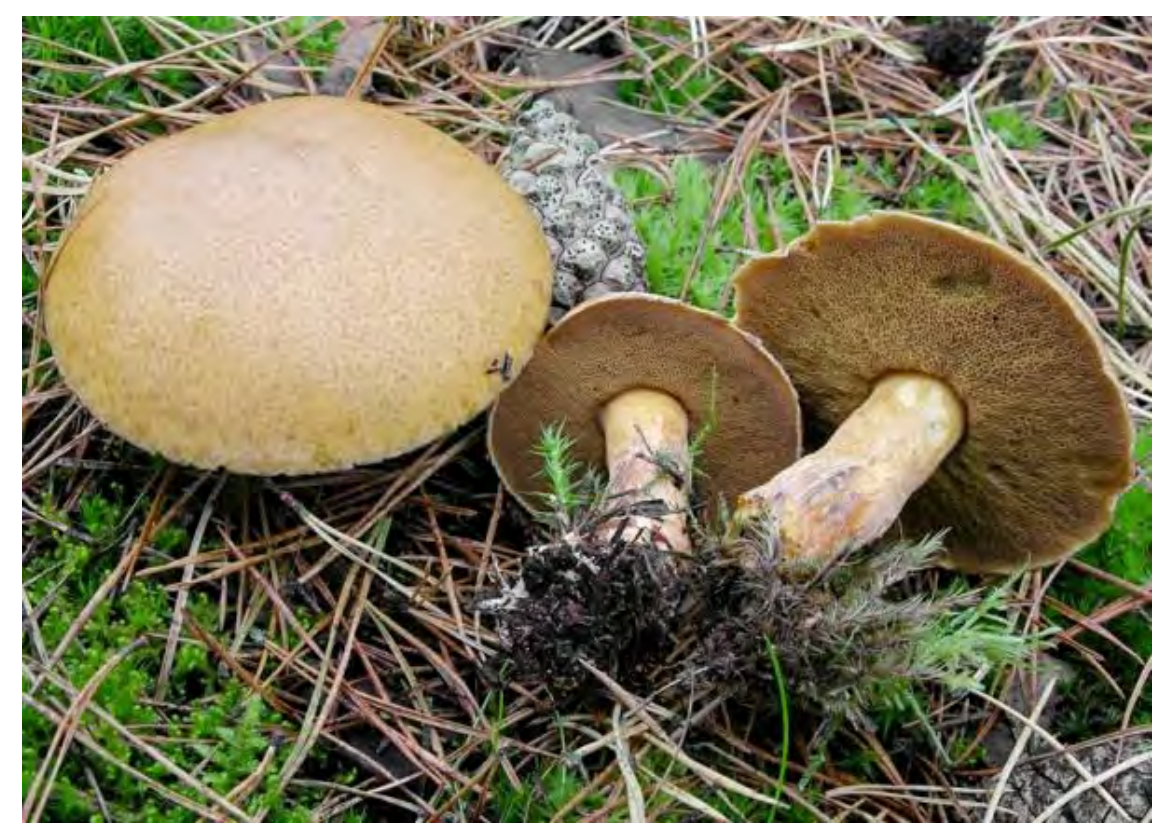

\section{Background and risk assessment}

Velvet Bolete (Suillus variegatus) is an edible mushroom.

It is mycorrhizal with pine (Pinus) in forests and plantations. It is very common in Denmark and in temperate-coniferous subalpine areas of the Nordic countries (Knudsen \& Vesterholt, 2012).

There are no intoxications reported after consumption of Velvet Bolete, and no natural toxicant constituting a risk for humans has been identified in the mushroom.

Most Suillus species contain colouring matters and precursors for these, which mainly belong to three groups of phenolic compounds: the pulvinic acid group (e.g. variegatic acid), the grevillins/pyrandiones (e.g. grevillin D) and the prenylated phenols (e.g. suillin) (Besl \& Bresinsky, 1997). Several compounds from these chemical groups have been shown to have antioxidative, antibacterial and antiviral activity or to have inhibitory effects on cytochrome P450 activity, but mainly in in vitro studies (e.g. Geraci et al., 1992; Hayashi et al., 1979; Huang et al., 2009; Liu et al., 2007; Tringali et al., 1989a; 1989b). 
Thus, Velvet Bolete contains the two pulvinic acid derivatives: variegatic acid and atromentic acid and the related lactone variegatorubin (Edwards and Elseworthy, 1967; Beaumont et al., 1968; Bresinsky \& Orendi, 1970) and the prenylated phenol suillin (Jägers et al., 1986), but apparently no grevillins.

The structural formulae of suillin and variegatic acid, as representatives for the two groups of phenolic constituents in the mushroom are shown below.<smiles>O=C(O)C(=C1OC(=O)C(c2ccc(O)c(O)c2)=C1O)c1ccc(O)c(O)c1</smiles><smiles>CC(=O)Oc1ccc(O)c(O)c1C/C=C(\C)CC/C=C(\C)CCC=C(C)CCC=C(C)C</smiles>

It is not possible to evaluate whether the above-mentioned bioactive compounds in Velvet Bolete may have any beneficial or adverse effect in humans consuming this mushroom, as representatives of these constituents have mainly been studied in vitro, and as the quantitative occurrence of these constituents is generally not well described.

\section{Recommendation}

No special recommendation.

\section{Listing 2}




\section{Database search information}

SciFinder by July 2012. Keywords: Suillus. PubMed January 2012. Keywords: Suillus.

\section{References}

Beaumont PC, Edwards RL \& Elsworthy GC (1968): Constituents of the higher fungi. Part VIII. The blueing of Boletus species. Variegatic acid, a hydroxytetronic acid from Boletus species and a reassessment of the structure of boletol. Journal of Chemical Society (C): 2968-2974.

Bresinsky A \& Orendi P (1970): Chromatografische Analyse von Farbmerkmalen der Boletales und anderer Makromyzeten auf Dünnschichten. Zeitschrift für Pilzkunde 36: 135-169.

Besl H \& Bresinsky A (1997): Chemosystematics of Suillaceae and Gomphidiaceae (suborder Suillineae). Plant Systemtics and Evolution 206: 223-242.

Edwards RL \& Elsworthy GC (1967): Variegatic acid, a new tetronic acid responsible for the blueing reaction in the fungus Suillus variegatus. Chemical Communications 8: 373-374.

Geraci C, Piattelli M, Trigali C, Verbist JF \& Roussakis C (2007): Cytotoxic activity of tetraprenylphenols related to suillin, an antitumor principle from Suillus granulatus. Journal of Natural Products 55: 1772-1775.

Hayashi T, Kanetoshi A, Ikura M \& Shirahama H (1989): Bolegreviol, a new lipid peroxidation inhibitor from the edible mushroom Suillus grevillei. Chemical and Pharmaceutical Bulletin 37: 1424-1427.

Huang Y-T, Onose J-i, Abe N \& Yoshikawa K (2009): In vitro inhibitory effects of pulvinic acid derivatives isolated from Chinese edible mushrooms, Boletus calopus and Suillus bovinus, on cytochrome P450 activity. Bioscience, Biotechnology and Biochemistry 73: 855-860.

Jägers E, Vinayagar P, Anke H \& Steglich W (1986): Suillin, ein characteristischer Inhaltsstoff von Rörhlingen der Gattung Suillus (Boletales). Zeitscrift für Naturforshung 41b: 645-648.

Knudsen H \& Vesterholt J (2012): Funga Nordica. Agaricoid, boletoid, clavarioid, cyphelloid and gastroid genera. Nordsvamp: 1-1083.

Liu F, Wu P, Wu S; Chen Y, Liu X \& Zhao Y (2007): Method for preparing suillin (niangainiganjunsu) and its application. Faming Zhuanli Shenqing, CN 1923791 A 20070307 (Chinese, English abstract available).

Tringali C, Geraci C, Nicolosi G, Verbisi JF \& Roussakis C (1989a): An antitumor principle from Suillus granulatus. Journal of Natural Products 52: 844-845.

Tringali C, Piatteli M, Geraci C \& Nicolosi G (1989b): Antimicrobial tetraprenylphenols from Suillus granulatus. Journal of Natural Products 52: 941-947.

\section{Tricholoma auratum (Paulet) Gillet}

\section{See Tricholoma equestre.}




\section{Tricholoma equestre (L.) P. Kumm. (T. flavovirens (Pers.) S. Lundell, T. auratum (Paulet) Gillet)}

Yellow Knight (Man on Horseback, "Canary Mushroom") (DK: Ægte Ridderhat, FI: Kangaskeltavalmuska, IS: Riddaraskjalda, NO: Riddermusserong, SE: Riddarmusseron).

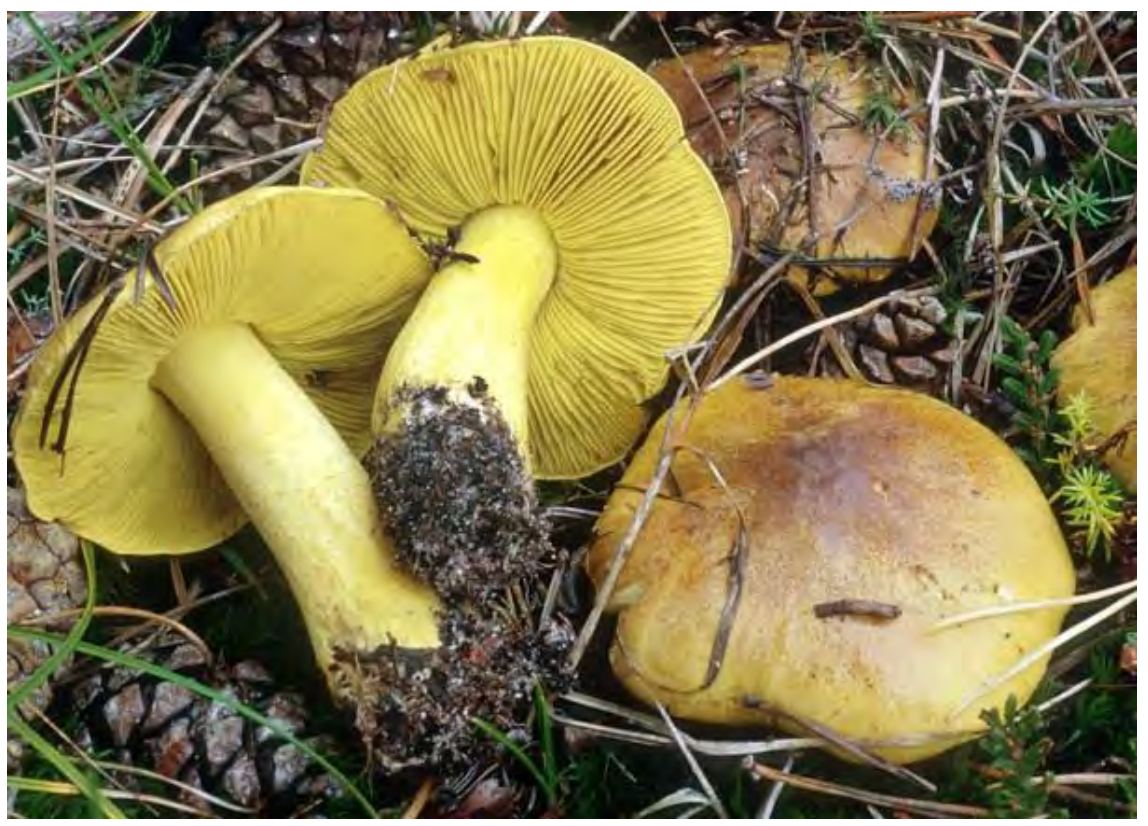

\section{Background and hazard identification}

Worldwide, Yellow Knight has for many years been regarded as a very good edible mushroom. However, after Bedry et al. (2001) in France, and Chodorowski et al. (2002; 2003), Sein Anand et al. (2009), and Sein Anand \& Chwaluk $(2001 ; 2010)$ in Poland, reported on serious intoxications after consumption of this mushroom, its edibility has been questioned. However, Nylén (2012) has recently claimed that T. equestre is an excellent food mushroom, and that it is the related look-alike T. auratum which previously has been considered edible, which has been responsible for the intoxications reported in France and Poland.

Yellow Knight (Tricholoma equestre) forms commonly mycorrhiza with Pine (Pinus) in sandy, poor nutrient soil or more rarely on calcareous soil in the temperate - boreal zones of the Nordic countries (Knudsen \& Vesterholt, 2012). Other forms (or possibly species) of Yellow Knight grow under deciduous trees, especially Aspen (Populus tremula) 
and Poplar (Populus) or under Spruce (Picea). Taxonomically, Yellow Knight (T. equestre/T. flavovirens/T. auratum) is apparently a group of related species, which requires genetic analysis to be distinguished. Hitherto, some authors have treated the Yellow Knight complex as one species, e.g. Knudsen \& Vesterholt (2008), other authors as more than one species, e.g. Nylén (2012).

\section{Hazard characterisation}

Human intoxications: Since 1992, 12 cases of delayed rhabdomyolysis ${ }^{25}$ have been documented in France after ingestion of several consecutive meals including large quantities of Yellow Knight. Three of the 12 cases were fatal. The 12 cases clearly implicated Yellow Knight as the cause of rhabdomyolysis. No other potential cause of rhabdomyolysis like direct injury, very hard exercise, infections, certain medications, immunotoxicity or toxin exposure were found. The consumed Yellow Knight leading to the intoxications was collected under Pine on a sandy coast in southwestern France and had been positively identified (Bedry et al., 2001; Bedry \& Gromb, 2009).

Five Polish cases, including one boy ( 5 years) and 4 adults ( 2 men, aged 20 and 72 years and two women, aged 42 and 45 years) were hospitalized after having consumed large quantities of Yellow Knight (100400 g) daily for several (3-10) consecutive meals.

The child was admitted to hospital in deep coma with cyanosis and convulsions, 4 hours after the last meal (300-400 g of the mushroom daily during 4 consecutive days). After 2-3 weeks of supportive treatment at the hospital, all his rhabdomyolysis symptoms with complications had disappeared (Chodorowski et al., 2003; Sein Anand et al., 2009)

The 72 years old man was admitted to hospital with muscle weakness and myalgia one day after the last of ten consecutive mushroom meals (300-400 g mushroom). He complained about dyspnoea and breathing problems the second day of hospitalisation, and shortly after, irrespective of intubation and connection to respirator, he died by cardiac arrest (Sein Anand et al., 2009; Sein Anand \& Chwaluk, 2010).

The 42-years old mother and her 20 years old son were admitted to hospital two days after the last of 9 consecutive meals with Yellow

25 Rhabdomyolysis is the breakdown of muscle fibers that leads to the release of muscle fiber contents (myoglobin) into the blood stream. Myoglobin is harmful to the kidney and often causes kidney damage (MedlinePlus Medical Enclyclopedia, 2012). 
Knight, each with about 100-300 g mushroom. Their symptoms included fatigue, muscle weakness, myalgia, loss of appetite, nausea and sweating. All symptoms disappeared within 3 weeks of supportive treatment, but the muscle weakness lasted for another 2-3 months (Chorodowski et al., 2002; Sein Anand et al., 2009; Sein Anand \& Chwaluk, 2010).

The 45 years old woman was admitted to hospital approximately 5 days after the last of three meals consumed on three consecutive days, each meal with about 2-300 g of the mushroom, because of fatigue, myalgia and profuse sweating. All symptoms had disappeared after 10 days, except that the serum creatine kinase was still increased when she left hospital the eleventh day.

There was no indication that any of the Polish patients were exposed to parasites, microorganisms or systemic disease (Chodorowski et al., 2002; 2003; Sein Anand et al., 2009; Sein Anand \& Chwaluk, 2010).

Sein Anand \& Chwaluk (2010) reviewed the information on all patients above admitted to the poison centres in Gdansk and Bila Podlaska in the years from 2001 to 2010, who had been poisoned with Yellow Knight. The symptoms included muscle weakness, nausea (without vomiting), diaphoresis (without fever) and in most serious cases acute respiratory failure. There was a marked increase in serum/plasma levels of creatine kinase, and aspartate and alanine aminotransferase. The mortality rate was $20 \%$. Apparently, the severity of the intoxications was correlated with the amounts of Yellow Knight consumed. The most serious effects were acute respiratory failure, myocarditis with cardiac arrhythmia and cardiovascular collapse. It was emphasized that the clinical picture might be different for children, e.g. the creatine kinase and alanine aminotransferase were much less increased compared to the adults and did not correspond well with the grave clinical conditions (Sein Anand \& Chwaluk, 2010).

It has also been speculated, whether an intoxication in Finland was caused by Yellow Knight (Nieminen et al., 2009).

Horn et al. (2005) described in a poster a 71 years old man in Germany, who had eaten Yellow Knight in large quantities for many years. He was admitted to hospital six days after having consumed Yellow Knight meals twice daily on six consecutive days and showed typical symptoms of rhabdomyolysis, myalgia, fatigue, muscle weakness and profuse sweating. The first day after admission to the hospital the patient's creatine kinase, myoglobin,, and aspartate and alanine aminotransferase were significantly increased. However, simvastatin treatment for hyperlipidemia had been initiated 6 months before the admission to hospital. The treatment at the hospital was supportive and the 
simvastatin treatment was discontinued. As a result the symptoms disappeared and the laboratory findings decreased, but they were not fully normalised 10 days later.

It is not clear in this case, whether the cause of the rhabdomyolysis was the simvastatin exposure alone (less than $0.1 \%$ of patients treated with simvastatin may get myopathy and/or rhabdomyolysis), Yellow Knight alone, or a combination of both (Horn et al., 2005).

Although a study by Chodorowsky et al. (2005) could not demonstrate toxic effects in patients taking statins and consuming large quantities of Yellow Knight (between 300 and 1,200 g for 4 consecutive days), Horn et al. (2005) discourage patients receiving statins to consume Yellow Knight.

Recently Chwaluk (2013) reported a case where a 57-year old man was hospitalized with severe pain and weakness of thigh muscles and high serum creatine kinase activity. Within two days before hospitalisation he had repeatedly consumed large amounts of stewed Leccinum and Boletus mushrooms. The man recovered after several days of hospitalisation.

There are no information on which quantities and species of Leccinum and Boletus the man had consumed. This is apparently the first report, where consumption of Leccinum and/or Boletus mushrooms have given rise to clinical signs of toxicity and biochemical changes, indicating rhabdomyolysis.

These cases highlight the problem of identifying the cause of the rhabdomyolysis after consumption of Yellow Knight and possibly other mushrooms.

\section{Experimental studies}

In order to demonstrate, that Yellow Knight is likely to be the cause of the rhabdomyolysis observed in consumers of the mushroom, three research teams have tested the hypothesis by supplying mice for several days with different preparations of Yellow Knight: in water, by gavage or mixed into their feed.

In the first of two studies described by Bedry et al. (2001), 3 groups of 3 mice were during three days given a total dose of 2, 4 or $6 \mathrm{~g}$ Yellow Knight per kg body weight as a powder in water by gavage. The highest total dose given to mice ( $6 \mathrm{~g}$ per kg body weight) corresponds to a $60 \mathrm{~kg}$ person consuming totally $3 \mathrm{~kg}$ fresh mushroom over the course of 6 meals in a period of 3 days. The treated mice had a dose dependent increase in the serum creatine kinase level measured 2 days after the final Yellow Knight dose. The increase was statistically significant at the two highest total doses ( 4 and $6 \mathrm{~g}$ per kg body weight). 
In a second study, Bedry et al. (2001) used 5 groups of 5 mice each; four groups being gavaged for 3 days with two different extracts (aqueous or chloroform-methanol extracts) of Yellow Knight or the Oyster Mushroom (Pleurotus ostreatus), whereas the fifth group was gavaged with the positive control p-phenylendiamine - a potent myotoxin in mice - (70 mg per kg body weight per day), for 3 days. The total dose of Yellow Knight extract corresponded to a total dose of $6 \mathrm{~g}$ per kg mouse. The serum creatine kinase levels were determined 4 days after the final mushroom dose and were significantly increased in the two groups given Yellow Knight, as well as in the p-phenylendiamine group. The Oyster Mushroom extracts had no influence on the serum creatine kinase activity. Thus the results of the two studies in mice supported the involvement of Yellow Knight in the etiology of rhabdomyolysis in humans (Bedry et al., 2001).

In a similar animal feeding study by Chodorowski et al. (2004) thirty male mice were divided into 6 groups of 5 males and supplied aqueous or chloroform/methanol extracts of Yellow Knight, the respective solvents, a powder of Yellow Knight, or the positive control pphenylendiamine. Contrary to the findings of Bedry et al. (2001), the Polish investigators observed no effect of the mushroom on the level of creatine kinase. However, as the sample of Yellow Knight mushrooms had been stored for 12 months at $-20^{\circ} \mathrm{C}$ ), the authors concluded that extracts of Yellow Knight stored for 12 months at $-20{ }^{\circ} \mathrm{C}$ do not cause rhabdomyolysis in mice (Chodorowski et al., 2004).

Also Nieminen and colleagues have fed Yellow Knight (and several other edible mushroom species) to mice (Nieminen et al., 2005, 2006, 2008). In their first study, 42 mice were divided into 7 groups of 6 mice each (Nieminen et al., 2005). Three groups received 3, 6 and $9 \mathrm{~g}$ per $\mathrm{kg}$ body weight per day of dried, powdered Yellow Knight mixed into pelleted feed, one group received $9 \mathrm{~g}$ per kg body weight freshly frozen, then thawed and homogenized Yellow Knight mixed into the feed, one group received $9 \mathrm{~g}$ per kg body weight per day of dried powdered Cep (Boletus edulis) mixed into feed, one group (positive control) received $75 \mathrm{mg}$ per kg body weight per day of p-phenylendiamine, and one group (control) received the regular mouse feed. Animals were sacrificed after 5 days feeding, blood and muscle samples were taken, and livers and kidneys were dissected and weighed. Body mass, feed and water intake, organ weights and biochemical parameters were measured. In the high dose dried Yellow Knight group the feed intake was reduced, the plasma cholesterol increased (dose-dependently) and the plasma creatine kinase activity significantly increased (the increase was dose dependent) but 
plasma creatine kinase was not affected in the group receiving the same amount of frozen/thawed Yellow Knight. However, and surprisingly, creatine kinase was increased also in the group receiving $9 \mathrm{~g}$ per kg body weight per day of dried Cep. The plasma aspartate and alanine aminotranferases were unaffected by the exposure (Nieminen et al., 2005).

Together with the initial animal feeding study, the investigators reported a study on 4 healthy human volunteers $(2$ males and 2 females, age 29-33 years) who consumed $0.15 \mathrm{~g}$ dried Yellow Knight in a rice dish. Blood samples were taken before the experiment and 3 and 7 days later. There were no significant changes in the plasma creatine kinase, aspartate or alanine amminotranferase activities (Nieminen et al., 2005).

Overall, the authors concluded that the results confirm that consumption of Yellow Knight may cause elevated creatine kinase activity and that the effect most probably requires high amounts of ingested mushroom, individual susceptibility and repeated meals for many days (Nieminen et al., 2005).

In a second investigation on Yellow Knight, Niemenen et al. (2008) focused more on the mechanism of Yellow Knight poisoning by studying subchronic effects of the mushroom on mice at a dose level relevant to human consumption in a 28-day repeated dose toxicity study. Parameters studied included effects on biochemical markers of toxicity and histological findings related to the exposure. The study had two groups of six male mice. The control group received regular mouse feed and the treatment group $12 \mathrm{~g}$ per kg body weight per day of Yellow Knight (freshly frozen at $-80^{\circ} \mathrm{C}$, thawed, homogenized and mixed into standard feed). After 28 days of treatment, animals were sacrificed and blood and muscle samples taken for analysis, and livers, hearts and kidneys dissected and weighed. There was no effect of the treatment on body mass change and food intake, and absolute relative organ weights. Regarding plasma clinical chemistry, bilirubin was increased, while the concentration of uric acid and protein was reduced. The activities of plasma creatine kinase and plasma creatine kinase-MB (a creatine kinase isoenzyme more specifically related to myocardial injury than creatine kinase) were increased. The histological analysis revealed a higher incidence of inflammation in the pericardial fat of mice supplied Yellow Knight (Nieminen et al., 2008). The investigators concluded that: "Regular consumption of Yellow Knight should not be recommended and that the results support previous findings that the harmful effects probably require prolonged exposure and high amounts of Yellow Knight" (Niemenen et al., 2008; 2009).

As a follow-up on the study by Nieminen et al. (2005) showing that not only feeding mice with Yellow Knight but also with Cep (Boletus edu- 
lis) could give rise to elevated levels of plasma creatine kinase activities and thereby suspected myotoxicity, Nieminen et al. (2006) tested several edible wild mushrooms representing four genera (Brittlegill species (Russula spp.), Chanterelle (Cantharellus cibarius), Forest Lamb (Albatrellus ovinus) and Orange Birch Bolete (Leccinum versipelle)) in mice. The plasma creatine kinase activity increased with all studied mushrooms at the highest dose of $9 \mathrm{~g}$ per kg body weight per day (for Russula spp. even at $3 \mathrm{~g}$ ) in the mice. The results support the hypothesis that the previous observed toxic effects with Yellow Knight are not specific to this mushroom, but probably represent a non-specific response requiring individual sensitivity and a significant amount of ingested mushroom to manifest itself (Nieminen et al., 2006). A similar conclusion was drawn by Chwaluk (2013) based on his abovementioned case report on intoxication after consumption of Leccinum and Boletus mushrooms.

Some scepticism with respect to the toxicity of T. equestre/Yellow Knight has been expressed by the American mycological/toxicological expert Benjamin (2003), and he raises numerous questions to the publication by Bedry et al. (2001), e.g., he asks for more complete clinical history, if all who ate the same mushroom meals develop symptoms, did the parents have predispositions to muscle disease, are there geographical/environmental differences and could there be a taxonomical problem? He also raised questions about the experimental data (Benjamin, 2003).

More recent toxicological reviews on mushrooms also include $T$. equestre/Yellow Knight intoxications, which should be interpreted with caution, but with the present knowledge one should refrain from consuming this mushroom (Diaz, 2005; Flammer \& Schenk-Jäger, 200; Karlson-Stiber \& Persson, 2003; Saviuc \& Danel, 2006).

\section{Causative inherent toxicant}

The causative toxicant has not been identified. It is indicated that drying of the mushroom does not influence the effect of the toxicant and that the toxicant is soluble both in water and in chloroform-methanol (Nieminen et al., 2005). It is also shown that storage of extracts of Yellow Knight at $-20{ }^{\circ} \mathrm{C}$ for 12 months apparently reduces the activity of the toxicant(s) as such extracts have been shown to be harmless to mice (Chodorowsky et al., 2004). Some potential bioactive constituents have been identified in Yellow Knight, e.g. Muszynska et al. (2009) isolated a series of simple biologically active indole compounds (tryptophan, 5hydroxytryptophan, serotonin, thryptamine and melatonin). Some of these constituents are tissue hormones and neurotransmitters and high intakes of tryptophan can damage the nervous system (Stone et al., 2003).The yellow pigment flavomannin-6,6-dimethylether (Steglich et 
al., 1972; Pachón-Peña et al., 2009) is also biologically active, but it is not known to have myotoxic properties.

Few other mushrooms or mushroom constituents are known to have been involved in myopathy and possibly rhabdomyolysis. Lovastatin, which occurs in Oyster Mushroom (Pleurotus oestreatus) and other edible mushrooms, has as side effects in a little fraction of humans using lovastatin as a drug developed myopathy and possibly rhabdomyolysis. For further information on statins: see Pleurotus oestratus.

The Asian Brittlegill Russula subnigricans has given rise to several cases of rhabdomyolysis, some with fatal outcome (Lee et al., 2001; Matsuura et al., 2009). In this mushroom the causative inherent toxicant has recently been identified as cycloprop-2-ene carboxylic acid (Matsuura et al., 2009). In order to better understand the mechanism of the rhabdomyolysis after consumption of Yellow Knight, it would be important to identify the toxicant(s) in this mushroom.

\section{Exposure assessment}

There are no data on the general consumption of Yellow Knight. However, all reported intoxications have been observed after recent intake of several, consecutive meals with large quantities of Yellow Knight, and where more specified, between 100 and $400 \mathrm{~g}$ per meal for 3 to 10 consecutive days (Bedry et al., 2001; Chodorowski et al., 2002; 2003; Sein Anand \& Chwaluk, 2010; Sein Anand et al., 2009).

\section{Risk characterisation}

Yellow Knight (T. equestre) has been involved in at least 17 cases of myopathy/rhabdomyolysis, of which four were fatal. Five studies in mice have supported that Yellow Knight can be the cause, as feeding with Yellow Knight could give rise to dose-dependent increase in creatine kinase activities in these animals.

Uncertainties: It should be emphasized that the rhabdomyolysis in humans are only reported after consumption of high amounts of Yellow Knight in several consecutive meals. It should also be noted that the number of animals in each group in the experimental studies was low 36 animals per group and only one sex in each study.

The causative inherent toxicant(s) is(are) not identified and the taxonomy of the Yellow Knight complex T.equstre/T. flavovirens/T. auratum needs to be clarified. 


\section{Recommendation}

Severe, also some fatal intoxications have been reported after consumption of repeated meals with substantial amounts of Yellow Knight (Tricholoma equestre).

Yellow Knight should not be marketed before a safe level of use can be established. This requires identification of the toxicant(s), knowledge of its concentration in the mushroom and clarification of the mechanism of toxicity.

Due to the intoxications, some European countries have forbidden trade with Yellow Knight and other countries have given warnings.

\section{Listing 4}

\section{Database search information}

SciFinder by February 2012. Keywords: Tricholoma equestre or flavovirens or auratum. Rhabdomyolysis and mushrooms.

\section{References}

Bedry R \& Gromb S (2009): Intoxications specific to the Aquitaine region. La Revue de Médicine Interne 30: 640-645.

Bedry D, Baudrimont, I, Defieux G, Creppy EE, Pomies J P, Ragnaud JM, Dupon M, Neau D, Gabinski C, Witte SD, Chapalain JC \& Godeau P (2001): Wild mushroom intoxication as a cause of rhabdomyolysis. The New England Journal of Medicine 345: 798-802.

Benjamin DR (2003): The toxicity of Tricholoma equestre. Spore Prints 388: 2-3.

Chodorowski Z, Waldman W \& Sein Anand J (2002): Acute poisoning with Tricholoma equestre. Przeglad Lekarski 59: 386-387.

Chodorowski Z, Sein Anand J \& Grass M (2003): Acute poisoning with Tricholoma equestre. Przeglad Lekarski 60: 309-310.

Chodorowski Z, Sznitowska M, Wisniewski M, Sein Anand J, Waldman W \& Ronkier A (2004): Tricholoma equestre - Animal toxicity study. Przeglad Lekarski 61: 351-352.

Chodorowski Z, Sein Anand J, Madalinski M, Rutkowski B, Cylkowska B, Rutkowski P, Wisniewski M \& Hajduk A (2005): Enzymatic examination of potential interaction between statins or fibrates and consumed Tricholoma equstre. Przeglad Lekarski 62: 468-470.

Chwaluk P (2013): Rhabdomyolysis as an unspecific symptom of mushroom poisoning - a case report. Przeglad Lekarski 70: 684-686 (Polish, English abstract available).

Diaz JH (2005): Syndromic diagnosis and management of confirmed mushroom poisonings. Critical Care Medicine 33: 427-436.

Flammer R \& Schenk-Jäger KM (2009): Pilzvergiftungen - die Schattenseiten des Myzetismus. Therapeutische Umschau 66: 357-364.

Horn U, Prasa D, Rothvinchow C \& Hentschek H (2005): Acute poisoning with Tricholoma equestre as consequence of simvastatin-mushroom interaction. Poison Information Centre, Erfurt \& Rudolf Virchow Hospital, Glauchau, Germany. (Poster). 
Karlson-Stiber C \& Persson H (2003): Cytotoxic fungi - an overview. Toxicon 42: 339-349.

Knudsen H \& Vesterholt J (2012): Funga Nordica. Agaricoid, boletoid, clavarioid, cyphelloid and gastroid genera. Nordsvamp: 1-1083.

Lee P-T, Wu M-L, Tsai W-J, Ger J, Deng J-F \& Chung H-M (2001): Rhabdomyolysis: An unusual feature with mushroom poisoning. American Journal of Kidney Diseases 38:E17/1-5.

Matsuura M, Saikawa Y, Inui K, Nakae K, Igarashi M, Hashimoto K \& Nakata M (2012): Identification of the toxic trigger in mushroom poisoning. Nature Chemical Biology 5: 465-467.

Muszynska B, Sulkowska K \& Ekiert H (2009): Indole compounds in fruiting bodies of some selected Macromycetes species and their mycelia cultured in vitro. Pharmazie 64: 479-480.

Nieminen, P, Mustonen A-M \& Kirsi M (2005): Increased plasma creatine kinase activities triggered by edible wild mushroom. Food and Chemical Toxicology 43: 133-138.

Nieminen P, Kirsi M \& Mustonen A-M (2006): Suspected myotoxicity of edible wild mushrooms. Experimental Biology and Medicine 231: 221-228.

Nieminen P, Kärjä V \& Mustonen A-M (2008): Indications of hepatic and cardiac toxicity caused by subchronic Tricholoma flavovirens consumption. Food and Chemical Toxicology 46: 781-786.

Nieminen P, Mustonen A-M, Kirsi M \& Kärjä V (2009): Toxicity of the Tricholoma equestre complex and similar effects by other mushroom genera. 4 Convegno Internazionale di Micotossicologia, 6-7 Dicembre 2007, Trento. Pagine di Micologia, 32: 113-118.

Nylén B (2012): Svampar I skog og mark. Norstedts. Stokholm: 1-448.

Pachón-Peña G, Reyes-Zurita FJ, Deffieux G, Azqueta A, Cerain ALD, Centelles JJ, Creppy EE \& Cascante M (2009): Antiproliferative effect of flavomannin-6,6dimethylether from Tricholoma equestre on Caco-2 cells. Toxicology 264: 192-197.

Saviuc P \& Danel V (2006): New syndromes in mushroom poisoning. Toxicological Review 25: 199-209.

Sein Anand J, Chwaluk P \& Sut M (2009): Acute poisoning with Tricholoma equestre, Przeglad Lekarski 66: 339-340.

Sein Anand J \& Chwaluk M (2010): Acute intoxication with Tricholoma equestreclinical course. Przeglad Lekarski 67: 617-618.

Steglich W, Toepfer-Petersen E, Reininger W, Gluchoff K \& Arpin N (1972): Chemotaxonomic studies on mushrooms. XX. Pigments of fungi. VIII. Isolation of mannin6,6-dimethylether and one of its racemates from higher fungi. Phytochemistry 11: 3299-304.

Stone TW, Mackay GM, Forrest CM, Clark CJ, Darlington LG (2003): Tryptophan metabolites and brain disorders. Clinical Chemistry and Laboratory Medicine 41: 852-859.

\title{
Tricholoma flavovirens (Pers.) S. Lundell
}

\author{
See Tricholoma equestre.
}


Tricholoma gambosum (Fr.) P. Kumm.

See Calocybe gambosa.

Tricholoma georgii (L.) Quél.

See Calocybe gambosa. 


\section{Tricholoma matsutake (S. Ito \& S. Imai) Singer (T. nauseosum (A. Blytt) Kytöv)}

Matsutake (DK: Duft-Ridderhat ("Matsutake"), FI: Tuoksuvalmuska, IS: No Icelandic name, NO: Kransmusserong, SE: Goliatmusseron ("Matsutake”)).

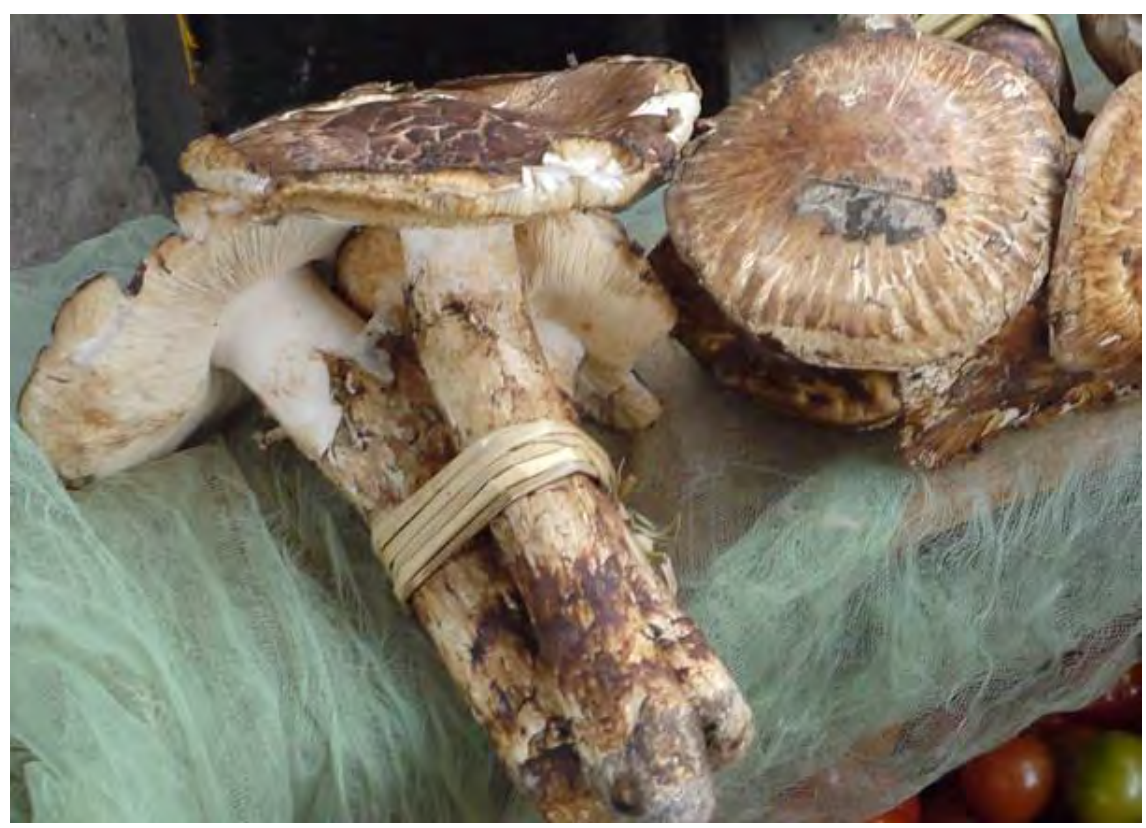

\section{Background and risk assessment}

Matsutake (Tricholoma matsutake) is a highly appreciated edible mushroom, which is especially consumed in parts of Asia.

Matsutake grows mycorrhizal with Pine (Pinus) on sandy soils and rocky habitats. It is rare, but locally occasional in hemiboreal/boreal/subalpine/subarctic zones of the Nordic countries. It is very rare in the temperate zone (Knudsen \& Vesterholt, 2012).

There are no intoxications reported after consumption of Matsutake, except for some cases of allergenicity and possibly other types of hypersensitivity. Allergens and other bioactive constituents are described below.

\section{Bioactive constituents}

Allergens: In some of the cases described below the allergens are not characterized.

The first report, that ingestion of Matsutake may lead to anaphylaxis, appeared at the end of the 1990s. Okano and Sakuma (1997) reported a 
case of food-dependent exercise-induced anaphylaxis (pruritus, diffuse erythematous rashes, weals and oedema, abdominal distress, diarrhoea and extreme weakness) in a 17-year old healthy male high-school basketball player who had ingested Matsutake mushrooms a few hours before athletic exercise. The requirement of both components was confirmed in provocation tests. The observation of allergic reactions may be dependent on physical exercise had previously been observed after intake of shellfish, squid and octopus, celery and wheat, peach, grape, kiwi, hazelnut, egg and milk, but not with a mushroom.

It has subsequently become clear that physical exercise is not a prerequisite for anaphylactic reaction after ingestion of Matsutake. For example an 8-year old girl was taken to hospital one hour after consuming around $14 \mathrm{~g}$ of the mushroom in a restaurant. She experienced nausea, swelling of her face and dyspnea, difficulties to breathe and severe stridor. Angioderma of her face, eyelids and fingers, and skin erythema were also evident (Ichikawa et al., 2006). Skin-prick tests were positive against a Matsutake extract and IgE antibodies were detected in the patient's serum but not in sera from healthy controls. Cytokines and chemical mediators of immunological reactions were significantly higher at the time of the anaphylaxis.

Another case showing anaphylactic reactions to Matsutake was challenged with about $100 \mathrm{~g}$ grilled Matsutake to confirm the allergic reaction. Within half an hour the provocation resulted in throat irritation, dyspnea and reduced peak flow rate. All these symptoms disappeared spontaneously 4 hours later but after another hour the patient suffered from dyspnea and general cutaneous erythema, with urticaria of his face and body. Medical treatment had to be initiated. Whereas a skin prick test was positive for Matsutake, no mushroom specific IgE could be identified in the patient serum (Komase et al., 1999). This is not the only case in which anaphylaxis has occurred, but no IgE has been identified.

A patient with a history of atopic asthma but no history of food allergic reactions experienced anaphylactic reactions consisting of systemic urticaria, dyspnea and consciousness disturbances 10 minutes after ingesting a soup containing several vegetables and Matsutake (Toda et al., 2010). One year after recovery, the woman had another anaphylactic reaction consisting of systemic urticaria and abdominal pain after consuming baked Matsutake. It was not until after this episode, the mushroom was incriminated as the cause. The suspicion was confirmed by a positive skin prick test with Matsutake extract and a positive basophil histamine release test. 
At the end of 2010 about 13 cases of anaphylaxis caused by Matsutake have been described in Japan (Amano et al., 2003; Ishikawa et al., 2002, 2006; Komase et al., 1999; Okano \& Sakuma, 1997; Takamasu et al., 2000; Terao et al., 1984; Toda et al., 2010).

A Japanese study analysed the association between allergic reactions to one type of food and allergic reactions to other types of food (Kanagawa et al., 2009). This study was based on 878 families with 1,383 allergic patients, including 402 with anaphylaxis. In total these patients described 6,549 food allergies. The analysis showed that the occurrence probability of an allergy combination Matsutake - milk was high. Based on this finding, the investigators speculated that Matsutake does not independently induce food allergies. However, there is no experimental support for this hypothesis.

Cyanogenic compounds: Matsutake may contain small amounts of cyanogenic compounds. In seven samples of the raw mushroom from Korea, Japan and Canada, levels up to $0.8 \mathrm{mg} / \mathrm{kg}$ (average $0.2 \mathrm{mg}$ ) of hydrogen cyanide have been demonstrated (Shindo et al., 1999). Such low levels are of no health concern in relation to consumption of Matsutake.

Sesquiterpenoids: The sesquiterpene farnesa-1,6-diene-3,10,11-triol, an $\alpha, \beta$-unsaturated secondary alcohol, has been isolated from the fruit bodies of Matsutake (Ohnuma et al., 2000). When the mushroom is consumed, this compound may be oxidized to a potential bioactive $\alpha, \beta$-unsaturated ketone. The $\alpha, \beta$-unsaturated aldehyde and ketone structures are generally considered as structural alerts for genotoxicity (EFSA, 2007).

Ergothioneine: Matsutake has been reported to contain $740 \mathrm{mg} / \mathrm{kg}$ (dry weight, 3 samples) of ergothioneine in the fruit bodies (Lee et al., 2009). For further information on ergothioneine: see Lepista nuda.

Experimental studies: A preparation derived from cultured mycelia of Matsutake was studied for mutagenic activity in bacterial bioassays. The preparation neither induced gene mutations in four different strains of Salmonella typhimurium (TA98, TA100, TA1535 and TA1537) and one strain of Escherichia coli in the absence of a metabolic activation system, nor in the presence of such a system (Torigoe et al., 2003). The same preparation used for the mutagenicity tests was used for three experimental studies on rats, one acute toxicity study, one 28-day toxicity study and one 90-day sub-chronic feeding study.

The acute rat study identified the oral $L_{50}$ to be higher than $2,000 \mathrm{mg} / \mathrm{kg}$ body weight in both male and female animals (Yamamoto et al., 2003a). Neither in the 28-day toxicity study, nor in the 90-day subchronic study, oral administration of the preparation had any doserelated effects on studied parameters (e.g. body weight, clinical chemis- 
try, organ weights and histopathology). The no observed adverse effect level (NOAEL) in both males and females were thus higher than the highest dose tested in the studies, that is higher than 5,000 $\mathrm{mg}$ of the preparation/kg body weight in the 28-day study, and higher that 10,000 $\mathrm{mg}$ of the preparation/kg body weight in the 90-day study (Omori et al., 2003; Yamamoto et al., 2003b).

All the experimental studies have been performed with a preparation from cultivated mycelia of Matsutake. As there is no information on composition or concentration/fractionation of the preparation, it is not possible to conclude very much from these studies in relation to consumption of the Matsutake mushroom.

\section{Recommendation}

Matsutake is red-listed in Denmark and Norway as near threatened.

Should only be marketed in the Nordic countries, if it is from countries, where it is not red-listed.

Listing 1

\section{Database search information}

SciFinder by February 2012. Keywords: Tricholoma. PubMed by December 2012. Keywords: Tricholoma.

\section{References}

Amano A, Yamanishi T, Fujimoto K, Kawana S (2003): A case of anaphylaxis due to Matsutake mushroom. Arerugi 52: 444-446. (Japanese, English abstract available).

Ichikawa K, Ito R, Kobayashi Y, Aihara M, Osuna H, Aihara Y (2006): A pediatric case of anaphylaxis caused by matsutake mushroom (Tricholoma matsutake) ingestion. Allergology International 55: 85-88.

Ishikawa T, Kouno M, Osuna H, Aihara M, Ikezawa Z (2002): A case report of anaphylaxis after ingestion of Matsutake mushroom. Allergy in Practice 2002: 66-69 (Japanese, English abstract available).

Kanagawa Y, Matsumoto S, Koike S, Imamura T (2009): Association analysis of food allergens. Pediatric Allergy and Immunology 20: 347-352.

Knudsen H \& Vesterholt J (2012): Funga Nordica. Agaricoid, boletoid, clavarioid, cyphelloid and gastroid genera. Nordsvamp: 1-1083.

Komase Y, Ito S, Kobayashi M, Nakagawa T (1999): A case of anaphylactoid reaction due to Matsutake mushroom ( Tricoloma matsutake) ingestion. Allergology International 48: 297-301.

Lee WY; Park E-J, Jin K \& Ka K-H (2009): Ergothioneine contents in fruiting bodies and their enhancement in mycelial cultures by addition of methionine. Mycobiology 37: 43-47.

Ohnuma N, Yoita Y, Kakuda R, Machida K \& Kikuchi M (2000): Studies on the constituents of mushrooms. XI. Chemical constituents from the fruiting bodies of Trichlo- 
ma matusutake. Journal of Tohoku Pharmaceutical University 47: 67-70 (Japanese, English abstract available).

Okano, M. and Sakuma, Y (1997): Food-dependent exercise-induced anaphylaxis due to Matsutake mushrooms. British Journal of Dermatology 136: 792-806.

Omori M, Baba S, Yamashita R, Nakama K, Kamimura Y, Sameshima H, Tanaka H \& Iwata M (2003): A 28-day repeated dietary dose toxicity study of a preparation derived from cultured mycelia of Tricholoma matsutake BP-7304 strain (Kureha M6271) in rats followed by a 14-day recovery study. Pharmacometrics 64: 95-108 (Japanese, English abstract available).

Shindo T, Ushiyama H, Kan K \& Yasuda K (1999): Study on content of cyanide in Basidiomycetes and the effect of cooking. Journal of Food Hygiene Society of Japan 40: 29-35 (Japanese, English abstract available).

Takamasu T, Nakazawa M, Kurihara K (2000): A case of anaphylaxis after ingestion of Matsutake Mushroom. Japan Journal of Chest Disease 59: 328-333 (Japanese, English abstract available).

Terao A, Kawabata I, Katsuhata A (1984): A case of anaphylaxis due to Matsutake mushroom. Allergy in Practise 4: 216-219 (Japanese, English abstract available).

Toda T, Yamaguchi M, Nakase Y, Sugimoto N, Suzukawa M, Nagase H, Ohta K (2010): A case of anaphylactic reaction following Matsutake mushroom ingestion: demonstration of histamine release reaction of basophils. Allergology International 59: 417-419.

Torigoe N, Ukezono T, Saigo K, Omori M, Sameshima H, Tanake H, Iwata M \& Matsunaga $K$ (2003): A bacterial reverse mutation test of a preparation derived from cultured mycelia of Tricholoma matsutake BP-7304 strain (Kureha M6271). Pharmacometrics 64: 89-94 (Japanese, English abstract available).

Yamamoto H, Kawazoe M, Baba S, Yamashita R, Kamimura Y, Omori M, Sameshima H, Tanaka H \& Iwata M (2003a): An acute single oral dose toxicity study of a preparation derived from cultured mycelia of Tricholoma matsutake BP-7304 (Kureha M6271) in rats. Pharmacometrics 64: 85-87 (Japanese, English abstract available).

Yamamoto H, Kawazoe M, Yamashita R, Nakama K, Kamimura Y, Omori M, Sameshima H, Tanaka H \& Iwata M (2003b): A 90-day repeated dose toxicity study of a preparation derived from cultured mycelia of Tricholoma matsutake BP-7304 (Kureha M6271) in rats. Pharmacometrics 65: 61-72 (Japanese, English abstract available).

\section{Tricholoma nauseosum (A. Blytt) Kytöv.}

See Tricholoma matsutake.

\section{Tricholoma nudum (Bull.) P. Kumm.}

See Lepista nuda. 
Tricholoma personatum s. auct. non (Fr.) P. Kumm.

See Lepista saeva. 


\section{Tricholoma portentosum (Fr.) Quél.}

Charbonnier ("The Coalman”) (DK: Grå Ridderhat, FI: Viiruvalmuska, IS: No Icelandic name, NO: Gråmusserong, SE: Streckmusseron.

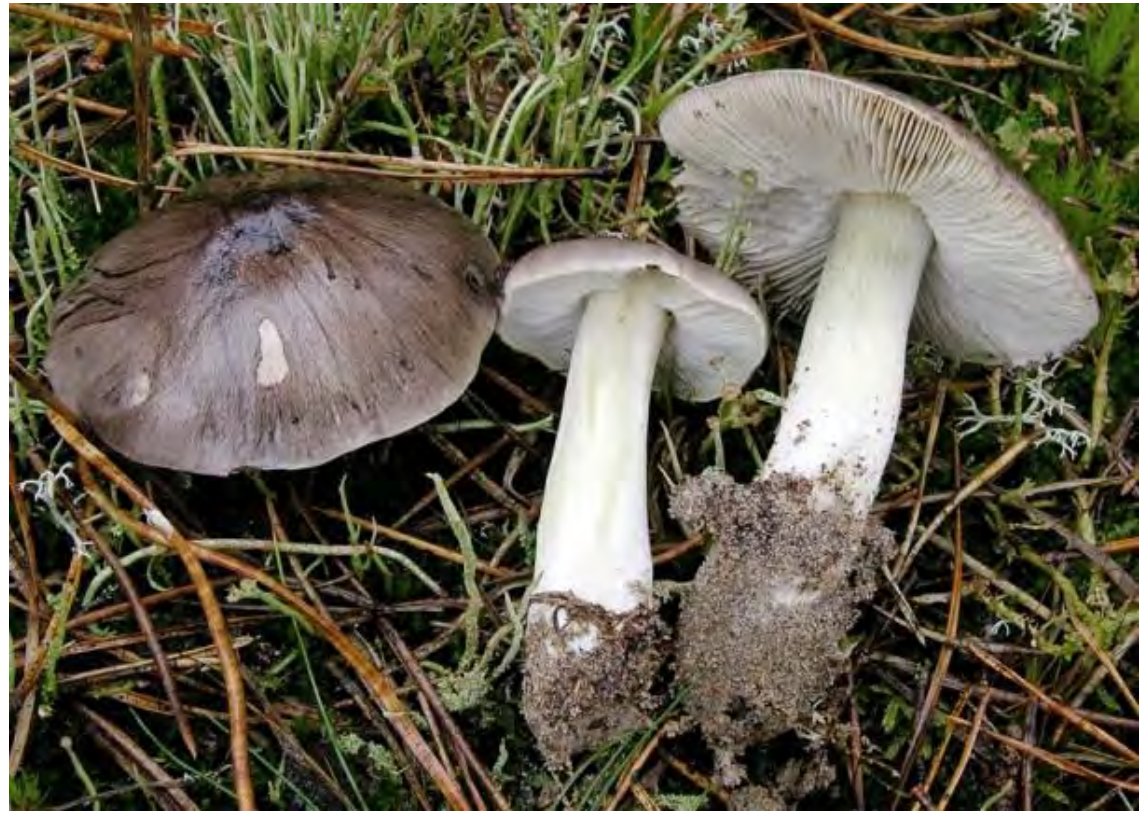

\section{Background and risk assessment}

Charbonnier (Tricholoma portentosum) is an edible mushroom.

It forms mycorrhiza with Pine (Pinus) and Spruce (Picea), more rarely with Beech (Fagus), Lime (Tilia) and Poplar (Populus). It is common in boreal, occasional, but locally common in temperate and hemiboreal and in subalpine/subarctic zones of the Nordic countries (Knudsen \& Vesterholt, 2012).

There are no intoxications reported after consumption of Charbonnier, and no natural toxicant constituting a risk for humans has been identified in the mushroom.

\section{Recommendation}

No special recommendation. 


\section{Database search information}

SciFinder by January 2012. Keywords: Tricholoma. PubMed by December 2012. Keywords: Tricholoma or Clitocybe.

\section{References}

Knudsen H \& Vesterholt J (2012): Funga Nordica. Agaricoid, boletoid, clavarioid, cyphelloid and gastroid genera. Nordsvamp: 1-1083. 


\section{Tuber aestivum Vittad. (T. uncinatum Chat.)}

Summer Truffle (DK: Sommer-Trøffel, FI: ("Kesätryffeli"), IS: Sumartryffill, NO: Sommertrøffel, SE: Sommartryffel (Bourgognetryffel)).

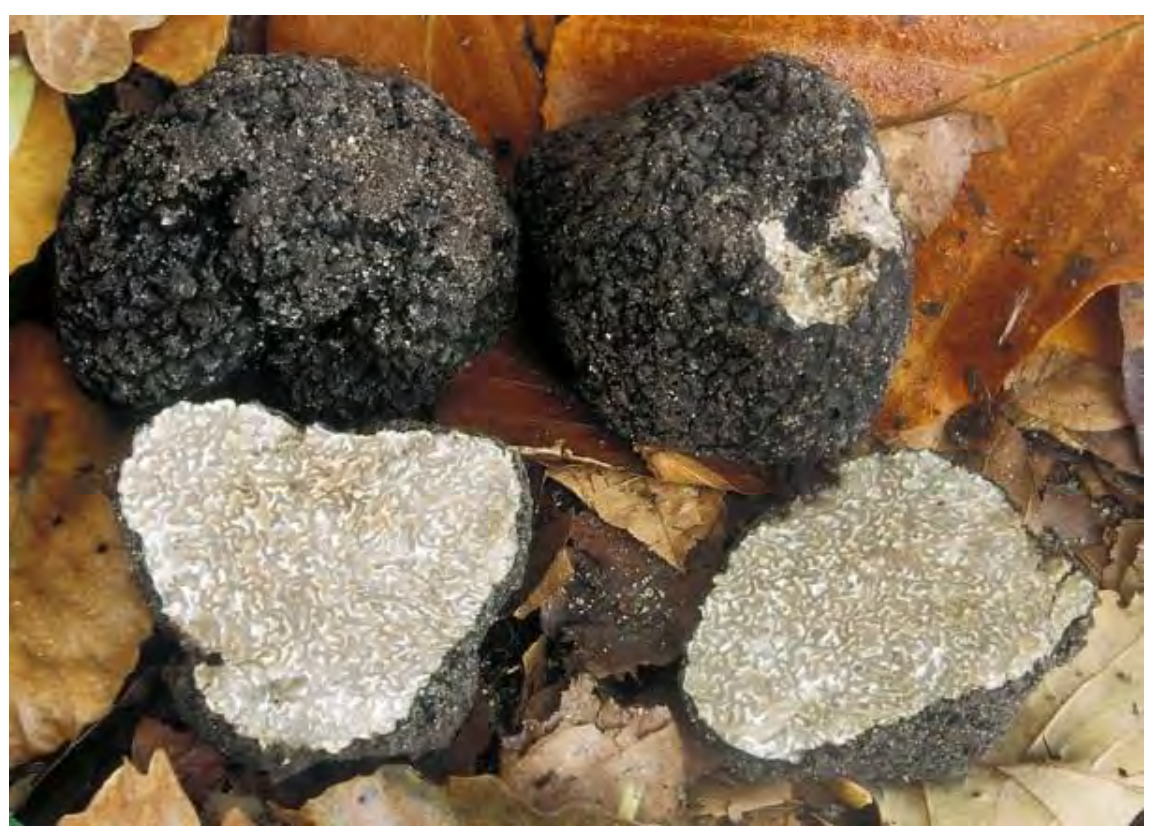

\section{Background and risk assessment}

Summer Truffle (Tuber aestivum) ${ }^{26}$ is an appreciated edible mushroom.

It may form mycorrhiza with different deciduous trees: e.g. species of Oak (Quercus), Hazel (Corylus), Beech (Fagus), Hornbeam (Carpinus), Hop Hornbeam (Ostrya), and Lime (Tilia). It grows in calcareous drained soils with a pH not lower than 7. It prefers some shading and grows, for example, in clearings of forests. It is a hypogeous mushroom, which implies that its fruiting bodies are to be found underground, where they may be harvested from late September to January. The mushroom is native to large parts of Europe, from Ireland to Russia and from North Africa to the Nordic countries, where it is found rarely in Sweden and

${ }^{26}$ According to Wedén (2004) and Wedén et al. (2005), Tuber aestivum Vitad. and T. uncinatum Chat. are synonyms. 
Denmark (Hall et al., 2007; Wang \& Liu, 2009; Wedén et al., 2009; Wehrlen et al., 2009).

Summer Truffle is widely and increasingly cultivated. Around $15 \%$ of truffle plantations in Italy are based on inoculated Summer Truffle (Bencivenga et al., 2009). Even at the most northern outposts of wild Summer Truffle, such as in Sweden, truffle orchards have been initiated. In Sweden the first fruiting body was harvested in 2005 on the island of Gotland, and since then the production of this truffle species has increased in Sweden. Some Summer Truffle inoculated trees have also been planted in Denmark, Norway and Finland (Wedén et al., 2009). The potential for cultivation of Summer Truffle and its limitations have recently been reviewed by Stobbe et al. (2013).

Inoculated truffle trees, e.g. Hazelnut (Corylus avellana) or Common Oak (Quercus robur) are produced in nurseries and are planted in orchards with environmental conditions similar to the natural habitats for Summer Truffle. Five to ten years after planting of infected seedlings the harvest may begin (Hall et al., 2007; Weden, 2009). Summer Truffle is commercialised as fresh, frozen, canned or mixed with foods.

There are no intoxications reported after consumption of Summer Truffle. However, these truffles do contain potentially bioactive constituents, in particular among the volatile organic compounds:

\section{Bioactive constituents}

Volatile organic compounds, including flavourings: There are many studies identifying and/or quantifying volatile substances in Summer Truffle. In total more than 50 volatile organic compounds have been identified (e.g., Cuellere et al., 2010; Diaz et al., 2002; 2003; 2009; March et al., 2006; Mauriello et al., 2004; Pelusio et al., 1995; Splivallo et al., 2007; Talou et al., 2001; and as reviewed by Wang \& Marcone, 2011). The diverging results presented in these publications may be due to genetic factors, degree of maturity and quality of the truffles, origin of the mushroom, storage conditions (time, temperature), host tree and not at least analytical method (Splivallo et al., 2011; Wang \& Marcone, 2011). Also post-harvest treatment of Summer Truffle, such as freeze-drying and subsequent rehydration, modify the aroma-profile as estimated by headspace-gas chromatography-mass spectrometry (Palacios et al., 2012). The major volatile constituents contributing to the flavour of the Summer Truffle are identical to, or structurally/biologically related to flavourings identified in other foodstuffs or used as food additives. These flavouring substances have been risk assessed by the European Food Safety Authority (EFSA) and/or by the Joint FAO/WHO Expert Committee on Food Additives (JECFA). They were found to be of no safety con- 
cern at estimated levels of intake. However, most of the sulfurcontaining volatiles could not be predicted to be metabolized to innocuous products. Therefore animal studies were considered and No Observed Adverse Effect Levels (NOAEL's) were determined in order to establish safety margins for the food use (EFSA 2012a, 2012b; JECFA 2000). Most studies on volatile substances in Summer Truffle only give relative quantities (percentages) of the single volatiles compared to the total amount of volatile constituents. However, Culleré et al. (2010) present quantitative data. In this study 22 aroma-active compounds were identified and quantitative data for all but one of them (dimethyl disulfide) were given. The most important aroma compounds were dimethyl sulfide (8 $\mu \mathrm{g} / \mathrm{kg})$, dimethyl disulfide (not estimated), methional (5 $\mu \mathrm{g} / \mathrm{kg}$ ), 3-methyl-1-butanol ( $5 \mu \mathrm{g} / \mathrm{kg}$ ), 1-hexene-3-one $(5 \mu \mathrm{g} / \mathrm{kg}$ ) and 3ethylphenol $(8 \mu \mathrm{g} / \mathrm{kg})$. The compound found in highest amount was 2phenylethanol, occurring at $71 \mu \mathrm{g} / \mathrm{kg}$ fresh truffle. However, the amount of aroma-supplying compounds is low in this mushroom, up to 100 times less than in Tuber melanosporum (Culleré et al., 2010). With an intake of $20 \mathrm{~g}$ Summer Truffle in a meal, consumed four times a month, which must be considered a high intake, there will be a very large safety margin for these aroma-giving compounds in relation to the NOAELs established in animal studies, and which were used for evaluation of the above flavouring substances by EFSA (2012a, 2012b) and JECFA (2000).

The structural formula of dimethyl sulfide is shown below:

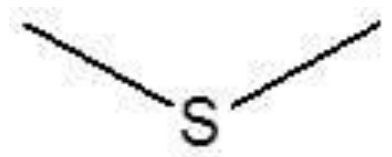

Dimethyl sulfide

Coumarins: A study on coumarins occurring in different Tuber species analysed 24 samples of Summer Truffle. The species contained 0.9-2.3 $\mathrm{mg}$ per $\mathrm{kg}$ of the simple coumarin, scopoletin (7-hydroxy-6methoxycoumarin), 34-84 mg per $\mathrm{kg}$ of the angular furocoumarin angelicin (isopsoralen) and $9.4-18 \mathrm{mg}$ per $\mathrm{kg}$ of the linear furocoumarin bergapten (5-methoxypsoralen). The identities of the three coumarins were confirmed by mass spectrometry and by comparison with authentic samples (Tirillini \& Stoppini, 1996).

Scopoletin (and its glycosides) is widely distributed in the plant kingdom and can be found in for example Cassava (Manihot esculenta), Coffee (Coffea spp.) and Sweet Potato (Ipomea spp.) (Gnonlonfin et al., 2012; Thier et al., 1968). The compound has antibiotic (antifungal) ef- 
fects (Peterson et al.; 2003 Gnonlonfin et al., 2012). It is not known whether it could have toxic effects in humans but any intake from this truffel is likely to result in very low exposure.

Angelicin is an angular furocoumarin found in some food plants. For example, parsnip (Pastinaca sativa) may contain levels between 1 and $28 \mathrm{mg}$ per kg fresh weight, and even much higher levels if injured or infected (Baumann et al., 1988; Ostertag et al., 2002; Peroutka et al., 2007). There are no data on oral administration of the compound angelicin to humans and no adequately controlled oral studies supplying angelicin to experimental animals (Søborg et al., 1995). However, it is known that topical application of angelicin followed by UVA irradiation may give rise to skin tumours in mice (Mullen et al., 1984). IARC has considered the potential carcinogenicity of angelicin and concluded that there neither were adequate studies to evaluate the carcinogenicity of angelicin (without UVA irradiation) in experimental animals nor any adequate studies in humans (IARC, 1986b). A worst case exposure scenario based on an intake of $20 \mathrm{~g}$ Summer Truffle, containing the highest level of angelicin found in the mushroom (84 $\mathrm{mg} / \mathrm{kg}$ ) would result in an exposure to $1.68 \mathrm{mg}$ angelicin per meal. If, for instance 4 such meals are consumed per month, this would correspond to an average daily intake of less than 4 microgram angelicin per kg body weight per day for a person weighing $60 \mathrm{~kg}$, which would constitute a very limited risk for potential adverse effects in consumers of Summer Truffle.

Bergapten and xanthotoxin (8-methoxypsoralen) are linear furocoumarins occurring in food plants such as citrus fruits, celery/celeriac, parsnip and parsley leaf and root in quantities from about 1 to $60 \mathrm{mg}$ per kg of apparently healthy fresh fruit or vegetable (Peroutka et al., 2007; Schulzova et al., 2012; Søborg et al., 1995).

The International Agency for Research on Cancer (IARC) has concluded that bergapten is genotoxic in vitro, and phototoxic and carcinogenic in combination with long-wave ultraviolet (UVA) irradiation. Overall IARC has concluded that there are inadequate data to evaluate the local or systemic carcinogenic effects of bergapten itself in experimental animals, and that evidence for carcinogenicity to humans is inadequate (IARC 1986a; 1987a; 1987b). The average daily intake of furocoumarins (mainly bergapten and xanthotoxin) has been estimated to be $1.3 \mathrm{mg}$ in the USA and $1.2 \mathrm{mg}$ in Great Britain, corresponding to 0.020-0.022 mg furocoumarins per kg body weight for a person weighing $60 \mathrm{~kg}$. These intakes lie 2-3 orders of magnitude lower than the lowest doses reported to be toxic in sub-chronic and chronic animal studies with xanthotoxin (in the absence of light), 25-30 times lower than the therapeutic doses of bergapten or xanthotoxin (0.5-0.6 mg per kg body 
weight) when used as drugs, and 10 times lower than the lowest phototoxic doses $(0.23 \mathrm{mg} / \mathrm{kg}$ body weight). Consumption of foods with the above average levels of furocoumarins was concluded not to represent a significant risk for phototoxic effects and the risk for skin cancer to be insignificant (DFG-Senate Commission for Food Safety 2004/2006). As the average intake of furocoumarins $(0.020-0.022 \mathrm{mg}$ per $\mathrm{kg}$ body weight) is 10 times lower than the amount required to reach detectable blood levels, it is unlikely that the average dietary intake of furocoumarins (including bergapten) constitute a cancer risk (Søborg et al., 1995). Based on virtually the same data, Dolan et al. (2010) more recently concluded that the risks for phototoxic and carcinogenic effects from dietary furocoumarins are low.

Based on the information available, it can be concluded that the highest level of bergapten found in fresh Summer Truffle $(18 \mathrm{mg} / \mathrm{kg})$ will result in low exposures. In a worst case scenario (consumption of $20 \mathrm{~g}$ mushrooms four times a month) the exposure would be about 1 microgram bergapten per kg body weight per day, which would constitute a very limited risk for potential adverse effects in consumers of Summer Truffle.

The structural formulae of angelicin and bergapten are shown below.<smiles>O=c1ccc2ccc3occc3c2o1</smiles>

Angelicin<smiles>COc1c2ccoc2cc2oc(=O)ccc12</smiles>

Bergapten

Mutagens: An Italian symposium report indicated that aqueous and, in particular, DMSO-extracts of Summer Truffle induce micronuclei in root tips of field beans exposed to the extract (Lanza et al., 2004). Such effects might indicate a genotoxic activity of compounds in the mushroom. However, as this information has not been confirmed in an extended study, it should be evaluated with care. Fratianni et al. (2007) tested aqueous and ethanolic extracts of fresh Summer Truffle for mutagenic activity in the Ames test, using the Salmonella typhimurium strains TA98 and TA100 with and without metabolic activation. The truffle extracts did not induce mutations in this test system under the conditions used. 


\section{Recommendation}

Red-listed in Denmark as near threatened.

Should only be marketed in the Nordic countries if it comes from cultivation or from countries where it is not red-listed.

\section{Listing 1}

\section{Database search information}

SciFinder by January 2012. Keywords: Tuber aestivum. PubMed by December 2012. Keywords: Tuber aestivum or Tuber uncinatum.

\section{References}

Baumann U, Dick R \& Zimmerli B (1988): Orientierende Untersuchung zum Vorkommen von Furocumarinen in pflanzlichen Lebensmitteln und Kosmetika. Mitteilungen aus dem Gebiete Lebensmitteluntersuchung und Hygiejne 79: 112-129.

Bencivenga M, Di MG, Donnini D \& Baciarelli FL (2009): The cultivation of truffles in Italy. Acta Botanica Yunnanica Supplement 16: 21-28.

Cullere L, Ferreira V, Chevret B, Venturini ME, Sánchez-Gimeno AC \& Blanco D (2010): Characterisation of aroma active compounds in black truffles (Tuber melanosporum) and summer truffles (Tuber aestivum) by gas chromatographyolfactometry. Food Chemistry 122: 300-306.

DFG Senate Commission for Food Safety (2004/2006): Deutsches Forschungsgemeinschaft. Toxicological Asssessment of Furocoumarins in Foodstuffs. Kaiserslautern University of Technology, Department of Chemistry: 1-30.

Diaz P, Senoráns FJ. Reglero G \& Ibánez E, (2002): Truffle aroma analysis by headspace solid phase microextraction. Journal of Agricultural and Food Chemistry 50: 6468-6472.

Diaz P, Ibánez E, Senoráns FJ \& Reglero G \& Ibaňez E (2003): Truffle aroma characterization by headspace solid-phase microextraction. Journal of Chromatography A 1017: 207-214.

Diaz P, Ibáňez E, Reglero G \& Seňoráns FJ (2009): Optimization of summer truffle aroma analysis by SPME: Comparison of extraction with different polarity fibres. Food Science and Technology 42: 1253-1259.

Dolan LC, Matulka RA \& Burdock GA (2010): Naturally occurring food toxins. Toxins 2: 2289-2332.

EFSA (2012a): European Food Safety Authority. Scientific opinion on flavouring group evaluation 08 revision 5 (FGE.08Rev5): Aliphatic and alicyclic mono-, di-, tri-, and polysulphides with or without additional oxygenated functional groups from chemical groups 20 and 30. The EFSAJournal 10(7)2837: 1-139.

EFSA (2012b): European Food Safety Authority. Scientific opinion on flavouring group evaluation 21 revision 3 (FGE.21Rev3): Thiazoles, thiophenes, thiazoline and thienyl derivatives from chemical groups 29 and 30. The EFSA Journal 10(2) 2437: 1-94.

Fratianni F, di Luccia A, Coppola R \& Nazzaro F (2007): Mutagenic and antimutagenic properties of aqueous and ethanolic extracts from fresh and irradiated Tuber aestivum black truffle: A preliminary study. Food Chemistry 102: 471-474. 
Gnonlonfin GJB, Sanni A \& Brimer L (2012): Review scopoletin - a coumanrin phytoalexin with medicinal properties. Critical Reviews in Plant Sciences 31: 47-56.

Hall IR, Brown GT \& Zambonelli A (2007): Taming the truffle. The history, lore, and science of the ultimate mushroom. Timber Press: 1-304.

IARC (1986a): International Agency for Research on Cancer. Monographs on the evaluation of the carcinogenic risk of chemicals to humans. Summaries \& Evaluations. 5-Methoxypsoralen. 40: 327-347.

IARC (1986b): International Agency for Research on Cancer. Monographs on the evaluation of the carcinogenic risk of chemicals to humans. Summaries \& Evaluations. Angelicin and some synthetic derivatives. 40: 291-315.

IARC (1987a): International Agency for Research on Cancer. Monographs on the evaluation of the carcinogenic risk of chemicals to humans. Genetic and related effects: An updating of selected IARC Monographs from volumes 1 to 42. 5Methoxypsoralen. Supplement 6: 377-385.

IARC (1987b): International Agency for Research on Cancer. Monographs on the evaluation of the carcinogenic risk of chemicals to humans. Overall evaluation of carcinogenicity. Un updating of selected IARC Monographs from Volume 1-42). 5Methoxypsoralen. Supplement 7: 242-243.

JECFA (2000): Safety evaluation of certain food additives and contaminants. Simple aliphatic and aromatic sulfides and thiols. WHO Food Additives Series: 44. Fifty-third meeting of the Joint FAO/WHO Expert Committee on Food Additives: 125-228.

Lanza B, Owczarek M, De Marco A \& Raglione M (2004): Evaluation of phytotoxicity and genotoxicity of substances produced by Tuber aestivum and distributed in the soil using Vicia faba root micronucleus test. Fresenius Environmental Bulletin 13: 1410-1414.

March RE, Richards DS \& Ryan RW (2006): Volatile compounds from six species of truffle - head-space analysis and vapor analysis at high mass resolution. International Journal of Mass Spectrometry 249-250: 60-67.

Mauriello G, Marino R, D'Auria M, Cerone G \& Rana GL (2004): Determination of volatile organic compounds from truffles via SPME-GC-MS. Journal of Chromatographic Science 42: 299-305.

Mullen MP, Pathak MA, West JD, Harrist TJ and Dall'Aqua F (1984): Carcinogenic effects of monofunctional and bifunctional furocoumarins. In: Photobiologic, Toxicologic and Pharmacologic Aspects of Psoralens. Eds. Pathak MA \& Dunnick JK. National Cancer Institute. Monograph 66: 205-210.

Ostertag E, Becker T, Ammon J, Bauer-Aymanns H \& Schrenk D (2002): Effects of storage conditions on furocoumarin levels in intact, chopped, and homogenized parsnips. Journal of Agricultural and Food Chemistry 50: 2565-2570.

Palacios I, Guillamón E, Garcia-Lafuente A \& Villares A (2012): Effects of freezedrying treatment on the aromatic profile of Tuber spp. Truffles. Journal of Food Processing and Preservation ISSN 174-4549: 1-6.

Pelusio F, Nilsson T, Montanarella L, Tilio R, Larsen B, Faccetti S \& Madsen JØ (1995): Headspace solid-phase micro-extraction analysis of volatile organic sulfur compounds in black and white truffle aroma. Journal of the Science of Agricultural and Food Chemistry 43: 2138-2143.

Peroutka R, Schulzova V, Botek P \& Hajslova (2007): Analysis of furanocoumarins in vegetalbles (Apiaceae) and citrus fruits (Rutaceae). Journal of Food and Agriculture 87: 2152-2163.

Peterson JK, Harrison HF, Jackson DM \& Snook ME (2003): Biological activities and contents of scopolin and scopoletin in sweetpotato clones. HortScience 38: 1129-1133. 
Schulzova V, Babicka L \& Hajslova J (2012): Furanocoumarins in celeriac from different farming systems: a 3-year study. Journal of the Science of Food and Agriculture 92: 2849-2854.

Splivallo R, Bossi S, Maffei M \& Bonfante P (2007): Discrimination of truffle fruiting body versus mycelial aromas by stir bar sorptive extraction. Phytochemistry 68: 2584-2598.

Splivallo R, Ottonello S, Mello A \& Karlovsky P (2011): Truffle volatiles: From chemical ecology to aroma biosynthesis. New Phytologist 189: 688-699.

Stobbe U, Egli S, Tegel W, Peter M, Sproll L \& Büntgen U (2013): Potential and limitations of Burgundy truffle cultivation. Applied Microbiology and Biotechnology 97: 5215-5224.

Søborg I, Andersson C \& Gry J (1996): Furocoumarins in plant food. Exposure, biological properties, risk assessment and recommendations. Nordic Council of Ministers TemaNord 600: 1-155.

Talou T, Doumenc-Faure M \& Gaset A (2001): Flavor profiling of 12 edible truffles. In: Food Flavors and Chemistry: advances of the new millennium. Proceedings of the $10^{\text {th }}$ International Flavor Conference, Paros, Greece: 274-280.

Thier H-P, Bricout J, Viani R, Reymond D \& Egli RH (1968): Scopoletin, ein Bestandteil des Rohkaffees. Zeitschrift für Lebensmittel-Unterschung und Forschund 137: 1-4.

Tirillini B \& Stoppini AM (1996): Coumarins distribution in four truffle species. Mycotaxon 57: 227-232.

Wang Y \& Liu P-G (2009): Achivements and challenges of research on truffles in China. Acta Botanica Yunnanica Supplement 16: 1-9.

Wang S \& Marcone MF (2011): The biochemistry and biological properties of the world's most expensive underground edible mushroom: Truffles. Food Research International 44: 2567-2581.

Wedén C (2004): Black truffles of Sweden. Comprehensive Summaries of Uppsala Dissertations from the Faculty of Science and Technology. Acta Universitatis Upsaliensis 1043: 1-54.

Wedén C, Danell E \& Tibell L (2005): Species recognition in the truffle genus Tuberthe synonyms Tuber aestivum and Tuber uncinatum. Environmental Microbiology 7: 1535-1546.

Wedén C, Pettersson L \& Danell E (2009): Truffle cultivation in Sweden: Results from Quercus robur and Corylus avellana field trials on the island of Gotland. Scandinavian Journal of Forest Research 24: 37-53.

Wehrlen L, Chevalier G, Besancon G \& Frochot H (2009): Truffle cultivation-forestry: A new strategy to produce the Burgundy Truffle (Tuber uncinatum Chatin). Acta Botanica Yunnanica Supplement 16: 97-99. 


\section{Tuber indicum Cooke \& Massee (T. sinense X.L. Mao)}

("Chinese Truffle") (DK: Kinesisk Trøffel, FI: ("Kiinalainen musta tryffeli"), IS: No Icelandic name, NO: No Norwegian name, SE: (Kinesisk tryffel)).

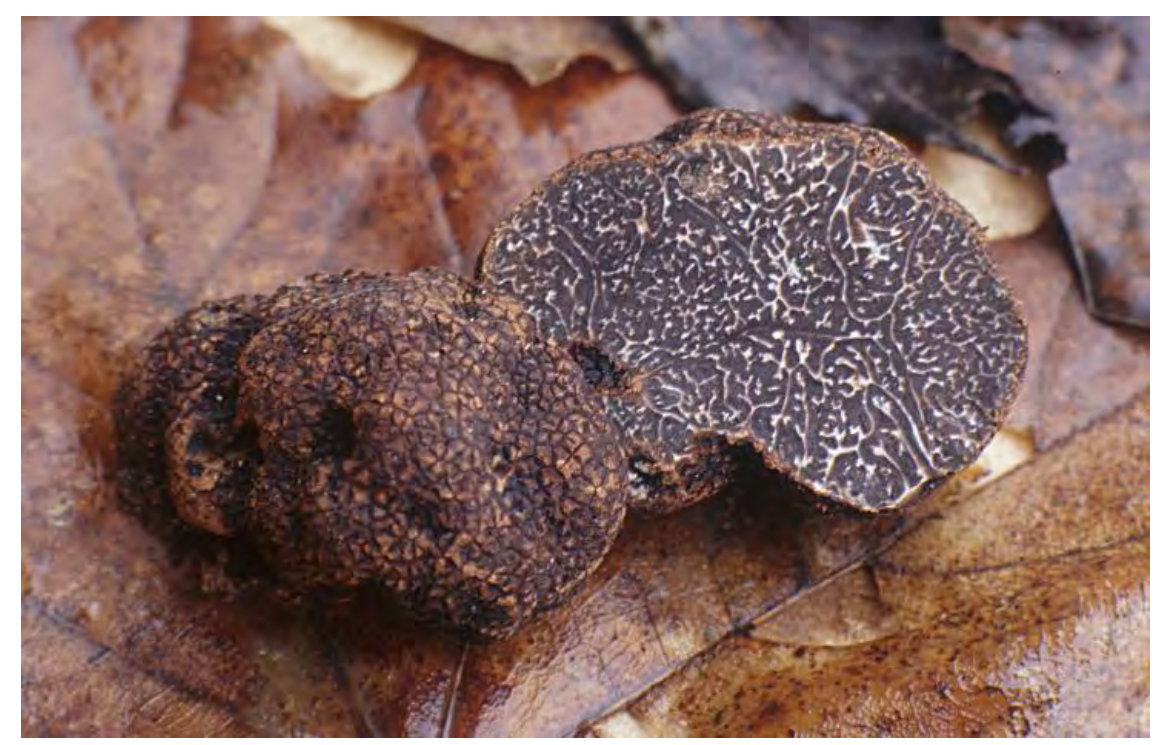

\section{Background and risk assessment}

Tuber indicum ${ }^{27}$ is an edible mushroom. The taste is rather bland, but as T. indicum is at least one order of magnitude cheaper than T. melanosporum and T. magnatum there is a large export to Europe and the USA. In France, for instance, the import of Chinese truffles may exceed the official production of T. melanosporum (Hall et al., 2007). Except for the different flavours of the two species of fresh truffles, it is almost impossible to distinguish T. indicum from T. melanosporum. This requires microscopic examination or modern DNA techniques (e.g. specific PCR) (Hall et al., 2007).

T. indicum forms mycorrhiza with many species of trees, both deciduous and coniferous, e.g. Fagaceae (Quercus spp.), and Pinaceae (Pinus spp.). It is often found in forests with Pine trees or Pine mixed with deciduous trees, usually in calcareous soils with clay and high $\mathrm{pH}$ at altitudes up to 3,000 $\mathrm{m}$ above sea level. It grows in the northwest Himala-

27 Tuber indicum is now considered the preferred name instead of T. sinensis (Chen et al., 2011) 
yas in India, but is especially abundant in the Chinese provinces Yunnan and Sichuan. Alone from Yunnan more than 300 tons are harvested each year. More recently China has also initiated cultivation of T. indicum and other Tuber species (Bonito et al., 2011; Chen et al., 2010; GarciaMontero et al., 2010; Hall et al., 2007; Wang \& Liu, 2009). T. indicum has a rather long shelf-life (Bellesia et al., 2002) and is mainly sold as fresh in the Nordic countries. It is also sold as preserved, sometimes fraudulently as T. melanosporum (Garcia-Montero et al., 2010; Hall et al., 2007).

There are no intoxications reported after consumption of $T$. indicum. However, T. indicum truffles contain potentially bioactive constituents, in particular among the volatile organic compounds:

\section{Bioactive constituents}

Volatile organic compounds, including flavourings: There are some studies identifying and/or quantifying volatile substances in $T$. indicum. In total more than 30 volatile organic compounds have been identified in the mushroom (e.g. Bellesia et al., 2002; Cuelleré et al., 2013; Palacios et al., 2012; Splivallo et al., 2007; Talou et al., 2001). The diverging results presented in these publications may be due to genetic factors, degree of maturity and quality of the truffles, origin of the mushroom, storage conditions (time, temperature), host trees and not at least analytical method (Splivallo et al., 2011; Wang \& Marcone, 2011). Whereas Bellesia et al. (2002) were unable to detect any sulfur-compounds in T. indicum using headspace-gaschromatography-mass spectrometry, such compounds were identified by three other research teams. Palacios et al. (2012) found dimethyl disulfide and dimethyl trisulfide, Culleré et al. (2013) identified dimethyl sulfide and dimethyl disulfide, and Splivallo et al. (2007) methylthiopropanal (methional). All four research teams conclude that the content of volatile organic compounds is lower in $T$. indicum than in other edible truffles, e.g., T. melanosporum.

The major volatile constituents contributing to the flavour of $T$. indicum are identical to or structurally/biologically related to flavourings identified in other foodstuffs or used as food additives. These flavouring substances have been risk assessed by the European Food Safety Authority (EFSA) and/or by the Joint FAO/WHO Expert Committee on Food Additives (JECFA). They were found to be of no safety concern at estimated levels of intake. However, most of the sulfur-containing volatiles could not be predicted to be metabolized to innocuous products. Therefore animal studies were considered and No Observed Adverse Effect Levels (NOAEL's) were determined in order to establish safety margins for the food use (EFSA 2012a, 2012b; JECFA 2000). 
Splivallo et al. (2007) quantified the major volatile organic compounds produced by $T$. indicum and accounted for in total $82 \mathrm{mg}$ per $\mathrm{kg}$ truffle: 3-methyl-1-butanol (33 mg/kg), 1-hexanol (17 mg/kg), 1-octen3-ol (16 mg/kg), 2-phenylethanol (8 mg/kg), trans-2-octenal $(7 \mathrm{mg} / \mathrm{kg})$ and 3-octanone $(2 \mathrm{mg} / \mathrm{kg})$, but only traces of the sulfur compounds. In their evaluation of the aroma-active constituents of different Tuber species, Liu et al. (2012) made use of several different approaches and characterized 12 aroma-active volatile constituents in T. indicum/T. sinensis. It was concluded that 3-(methylthio)propanal (methional), 3methylbutanal and 1-octen-3-ol were the key contributors to the aroma of $T$. indicum. The content of these three flavouring substances were 40/40, 340/100 and 40/36 mg per kg fresh truffle, respectively (Liu et al., 2012). With an intake of $20 \mathrm{~g} \mathrm{~T}$. indicum, consumed four times a month, there will be a very large safety margin for these aroma-giving compounds in relation to the NOAELs established in animal studies, and which were used for evaluation of the above flavouring substances by EFSA (2012a, 2012b) and JECFA (2000).

Steroids: A volatile steroidal compound, $5 \alpha$-androst- 16 -en- $3 \alpha$-ol has been isolated from T. indicum fermentation broth (Wang et al., 2008). It is not known, whether also the fruit bodies of $T$. indicum, like the fruit bodies of T. melanosporum and of T. magnatum produce $5 \alpha$-androst-16en-3 $\alpha$-ol (Claus et al., 1981).

\section{Recommendation}

No special recommendation.

\section{Listing 1}

\section{Database search information}

SciFinder by January 2012. Keywords: Tuber indicum or Tuber sinensis. PubMed by December 2012. Keywords: Tuber indicum or Tuber sinensis.

\section{References}

Bellesia F, Pinetti A, Tirillini B, Paolocci F, Rubini A, Arcioni S \& Bianchi A (2002): The headspace volatiles of the Asian truffle Tuber indicum Cooke et Mass. Journal of Essential Oil Research 14: 3-5.

Bonito G, Trappe JM, Donovan S \& Vilgalys R (2011): The Asian black truffle Tuber indicum can form ectomycorrhizas with North American host plants and complete its life cycle in non-native soils. Fungal Ecology 4: 83-93.

Chen J, Guo S-X \& Liu P-G (2010): Species recognition and cryptic species in the Tuber indicum complex. PLoSONE 6(1): e14625.doi:10.1371/journal.pone.0014625 $1-13$. 
Claus R, Hoppen HO \& Karg H (1981): The secret of truffels: A steroidal pheromone? Experientia 37: 1178-1179.

Culleré L, Ferreira V, Venturini ME, Marco P \& Blanco D (2013): Potential aromatic compounds as markers to differentiate between Tuber melanosporum and Tuber indicum truffles. Food Chemistry 141: 105-110.

EFSA (2012a): European Food Safety Authority. Scientific opinion on flavouring group evaluation 08 revision 5 (FGE.08Rev5): Aliphatic and alicyclic mono-, di-, tri-, and polysulphides with or without additional oxygenated functional groups from chemical groups 20 and 30. The EFSA Journal 10(7)2837: 1-139.

EFSA (2012b): European Food Safety Authority. Scientific opinion on flavouring group evaluation 21 revision 3 (FGE.21Rev3): Thiazoles, thiophenes, thiazoline and thienyl derivatives from chemical groups 29 and 30. The EFSA Journal 10(2)2437: 1-94.

Garcia-Montero LG, Diaz P, Massimo GD \& Garcia-Abril A (2010): A review of research on Chinese Tuber species. Mycological Progress 9: 315-325.

Hall IR, Brown GT \& Zambonelli A (2007): Taming the truffle. The history, lore, and science of the ultimate mushroom. Timber Press: 1-304.

JECFA (2000): Safety evaluation of certain food additives and contaminants. Simple aliphatic and aromatic sulfides and thiols. WHO Food Additives Series: 44. Fifty-third meeting of the Joint FAO/WHO Expert Committee on Food Additives: 125-228.

Liu R-S, Li D-C, Li H-M \& Tang Y-J (2012): Evaluation of aroma active compounds in Tuber fruiting bodies by gas chromatography-olfactometry in combination with aroma reconstitution and omission test. Applied Microbiology and Biotechnology 94: 353-363.

Palacios I, Guillamón E, Garcia-Lafuente A \& Villares A (2012): Effects of freezedrying treatment on the aromatic profile of Tuber spp. Truffles. Journal of Food Processing and Preservation ISSN 174-4549: 1-6.

Splivallo R, Bossi S, Maffei M \& Bonfante P (2007): Discrimination of truffle fruiting body versus mycelial aromas by stir bar sorptive extraction. Phytochemistry 68 : 2584-2598.

Splivallo R, Ottonello S, Mello A \& Karlovsky P (2011): Truffle volatiles: From chemical ecology to aroma biosynthesis. New Phytologist 189: 688-699.

Talou T, Doumenc-Faure M \& Gaset A (2001): Flavor profiling of 12 edible truffles. In: Food Flavors and Chemistry: advances of the new millennium. Proceedings of the $10^{\text {th }}$ International Flavor Conference, Paros, Greece: 274-280.

Wang Y \& Liu P-G (2009): Achivements and challenges of research on truffles in China. Acta Botanica Yunnanica Supplement 16: 1-9.

Wang S \& Marcone MF (2011): The biochemistry and biological properties of the world's most expensive underground edible mushroom: Truffles. Food Research International 44: 2567-2581.

Wang G, Li Y-Y, Li D-S \& Tang Y-J (2008): Determination of $5 \alpha$-androst-16-en-3 $\alpha$-ol in truffle fermentation broth by solid-phase extraction coupled with gas chromatography-flame ionization detector/electron impact mass spectrometry. Journal of Chromatography B 870: 209-215. 


\section{Tuber magnatum Picco}

White Truffle ("Alba Truffle") (DK: Piemonteser-Trøffel ("Hvid Trøffel", "Alba-Trøffel”), FI: ("Valkotryffeli"), IS: ("Tryffill”), NO: Kongetrøffel, SE: Albatryffel ("Piemontetryffel")).

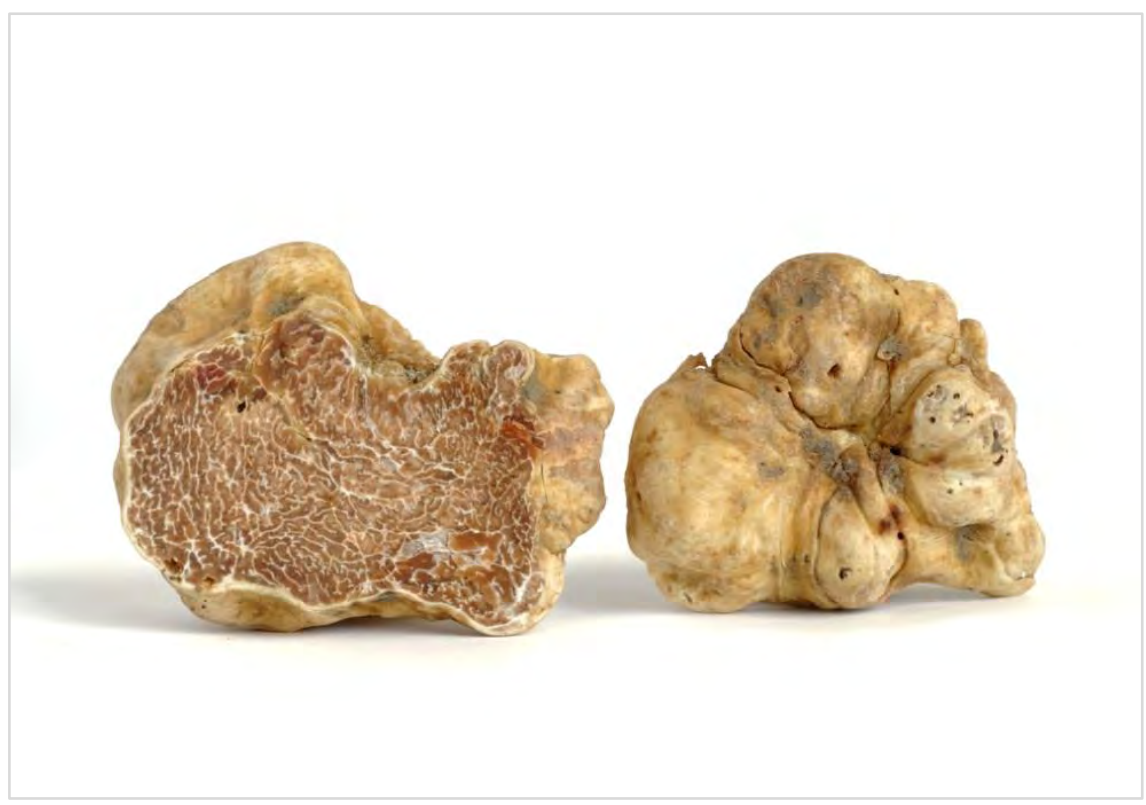

\section{Background and risk assessment}

White Truffle (Tuber magnatum) is an excellent edible mushroom, highly prized for its culinary properties. Due to its delicious taste and low world production (estimated 50-200 tons per year), it is one of the world's most expensive foods (Hall et al., 1998; 2005; 2007).

It may form mycorrhiza with different deciduous tree species: Italian Alder (Alnus cordata), Hazelnut (Corylus avellana), Hop Hornbean (Ostrya carpinifolia), White Poplar (Populus alba), European Aspen (Populus tremula), and species of Oak (Quercus spp.), Willow (Salix spp.), Lime (Tilia spp.) and others (Hall et al., 1998; 2007). It grows in shaded forests with little sunlight, in calcareous, porous, soft and moist soil with a pH of 7.5 or higher. It is a hypogeous mushroom, which means the fruiting bodies are to be found underground, where they may be harvested from October to December. It is native to Italy but is also found in Croatia and sporadically in France, Serbia, Slovenia, Hungary and Switzerland (Bragato et al., 2004; Hall et al., 2007; Wang \& Marcone, 2011). 
The occurrence of White Truffle in nature is declining, probably due to deforestation, reforestation with non-host trees, soil disturbance, ill adaption of the host trees and the mycorrhizal mushroom to new climate conditions, or a combination of these (Hall et al., 2004; Bencivenga et al., 2009).

Cultivation of White Truffle is difficult: There are very few orchards, and only a few percentages of cultivated truffles are White Truffle. The low production may be due to less successful inoculation in the nurseries, difficulties with establishing suitable grounds, and the long time required before truffles are produced, which is 15 to 20 years after planting of the inoculated seedlings of host trees. However, seedlings inoculated with White Truffle are planted to some extent in habitats of the wild-growing White Truffle (Mello et al., 2006; Bencivenga et al., 2009; Hall et al., 2004).

White Truffle is commercialised mainly as fresh, but to some extent also as frozen, canned or mixed with foods.

There are no intoxications reported after consumption of White Truffle. However, White Truffle contains potentially bioactive constituents, in particular among the volatile organic compounds:

\section{Bioactive constituents}

Volatile organic compounds, including flavourings: There are numerous studies identifying and/or quantifying volatile substances in White Truffle. In total more than 100 volatile organic compounds have been detected (e.g., Aprea et al., 2007; Bellesia et al., 1996; Gioacchini et al., 2008; Mauriello et al., 2004; Pelusio et al., 1995; Pennazza et al., 2013; Talou et al., 2001; and as reviewed by Wang \& Marcone, 2011). The diverging results presented in these publications may be due to genetic factors, degree of maturity and quality of the truffles, origin of the mushroom, storage conditions (time, temperature), and not least analytical methods (Splivallo et al., 2011; Wang \& Marcone, 2011). Storage of the mushroom for 8 days in sealed jars at $4{ }^{\circ} \mathrm{C}$ changed the flavour profile with formation of alcohols and acids, indicating ester hydrolysis and some decrease of important sulfur-containing flavourings such as bis(thiomethyl)methane and dimethyl sulfide (Piloni et al., 2005). Furthermore, yeasts habituating the fruiting bodies of White Truffle can produce volatile organic compounds, e.g. 3-methylbutanol, dimethylsulfide and dimethyldisulfide, also known from the truffle flavour. Such yeast flavouring substances may possibly contribute to the final truffle aroma (Buzzini et al., 2005).

The major volatile flavouring substances identified in White Truffle are identical with or structurally/biologically related to flavourings 
identified in other foodstuffs or used as food additives. These flavouring substances have been risk assessed by the European Food Safety Authority (EFSA) and/or by the Joint FAO/WHO Expert Committee on Food Additives (JECFA). They were found to be of no safety concern at estimated levels of intake. However, most of the sulfur-containing volatiles could not be predicted to be metabolized to innocuous products. Therefore, animal studies were considered and No Observed Adverse Effect Levels (NOAEL's) were determined in order to establish safety margins for the food use (EFSA 2012a, 2012b; JECFA 2000). Most studies on volatile substances in White Truffle only give relative quantities (percentages) of the single volatiles compared to all volatile constituents. However, Bellesia et al. (1996) do give some quantitative data. These investigators report that the content of bis(thiomethyl)methane, the characteristic flavouring substance in White Truffle, is $59-89 \mathrm{mg} / \mathrm{kg}$, whereas the level of dimethyldisulfide is $0.3-4.6 \mathrm{mg} / \mathrm{kg}$ and the level of dimethyltrisulfide $0.2-5.2 \mathrm{mg} / \mathrm{kg}$ fresh truffle. With an intake of $20 \mathrm{~g}$ White Truffle in a meal, which must be considered large, consumed four times a month, there will be a very large safety margin for these three aroma-giving compounds in relation to the NOAELs established in animal studies, and which were used for evaluation of the above flavouring substances by EFSA (2012a, 2012b) and JECFA (2000).

The structural formula of bis(thiomethyl)methane is shown below.

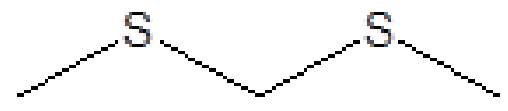

bis(Thiomethyl)methane

Steroids: A volatile steroidal compound, $5 \alpha$-androst- 16 -en- $3 \alpha$-ol has been isolated from the fruiting bodies of White Truffle in amounts of 59-62 $\mu \mathrm{g}$ per kg fresh mushroom. The steroid has a pronounced musk-like scent. It is the major pheromone of the boar, where it has been detected in testes and saliva (Katkov \& Gower, 1970; Prelog \& Ruzicka, 1944; Prelog et al., 1944). $5 \alpha$-Androst-16-en-3 $\alpha$-ol also occurs in humans, in testes, sweat and urine, primarily in males (Brooksbank \& Haslewood, 1961; Gower et al., 1994; Kwan et al., 1997) but it seems to be devoid of androgenic activity (Claus et al., 1981). It is estimated to be excreted with human urine (as glucuronide) at a rate of about $1 \mathrm{mg}$ per day by adult males and at a slower rate by women (Brooksbank \& Haslewood, 1961; Brooksbank et al., 1974). Therefore the potential biological effects of $5 \alpha$-androst-16-en-3 $\alpha$ ol after consumption of a meal containing White Truffle will be negligible 
in relation to the natural production in humans. For example, $20 \mathrm{~g}$ of the truffle would contain about $1 \mu \mathrm{g}$ of the steroid.

Coumarins: In a study on the occurrence of coumarins in various Tuber species, Tirillini and Stoppini (1996) did not find detectable levels of coumarins in White Truffle. This was in contrast to other Tuber species studied.

\section{Recommendation}

No special recommendation.

Listing 1

\section{Database search information}

SciFinder by January 2012. Keywords: Tuber magnatum. PubMed by December 2012. Keywords: Tuber magnatum.

\section{References}

Aprea E, Biasioli F, Carlin S, Versini G, Märk TD \& Gasperi F (2007): Rapid white truffle headspace analysis by proton transfer reaction mass spectrometry and comparison with solid-phase microextraction coupled with gas chromatrography/mass spectrometry. Rapid Communications in Mass Spectrometry 21: 2564-2572.

Bellesia F, Pinetti A, Bianchi A \& Tirillini B (1996): Volatile compounds of the white truffle (Tuber magnatum Pico) from middle Italy. Flavour and Fragrance Journal 11: 239-243.

Bencivenga M, Di MG, Donnini D \& Baciarelli FL (2009): The cultivation of truffles in Italy. Acta Botanica Yunnanica Supplement 16: 21-28.

Bragato G, Sladonja B \& Persuric D (2004): The soil environment for Tuber magnatum growth in Motovun Forest, Istria. Natura Croatica 13: 171-185.

Brooksbank BWL \& Haslewood GAD (1961): The estimation of androst-16-en-3 $\alpha$-ol in human urine. Biochemical Journal 80: 488-496.

Brooksbank BWL, Brown R \& Gustafsson J-A (1974): The detection of $5 \alpha$-androst16-en-3 $\alpha$-ol in human male axillary sweat. Experientia 30: 864-865.

Buzzini P, Gasparetti C, Turchetti B, Cramarossa MR, Vaughan-Martini A, Martini A, Pagnoni UM \& Forti L (2005): Production of volatile organic compounds (VOCs) by yeasts isolated from the ascocarps of black (Tuber melanosporum Vitt.) and white (Tuber magnatum Pico) truffles. Archives of Microbiology 184: 187-193.

Claus R, Hoppen HO \& Karg H (1981): The secret of truffels: A steroidal pheromone? Experientia 37: 1178-1179.

EFSA (2012a): European Food Safety Authority. Scientific opinion on flavouring group evaluation 08 revision 5 (FGE.08Rev5): Aliphatic and alicyclic mono-, di-, tri-, and polysulphides with or without additional oxygenated functional groups from chemical groups 20 and 30. The EFSA Journal 10(7)2837: 1-139.

EFSA (2012b): European Food Safety Authority. Scientific opinion on flavouring group evaluation 21 revision 3 (FGE.21Rev3): Thiazoles, thiophenes, thiazoline and thienyl derivatives from chemical groups 29 and 30. The EFSA Journal 10(2): 2437, 1-94.

Gioacchini AM, Menotta M, Guescini M, Saltarelli R, Ceccaroli P, Amicucci A, Barbieri E, Giomaro G \& Stocchi V (2008): Geographical traceability of Italian white truffle 
(Tuber magnatum Pico) by the analysis of volatile organic compounds. Rapid Communications in Mass Spectrometry 22: 3147-3153.

Gower DB, Holland KT, Mallet AI, Rennie PJ \& Watkins WJ (1994): Comparison of 16androstene steroid concentrations in sterile apocrine sweat and axillary secretions: Interconversions of 16-androstenes by the axillary microflora-a mechanism for axillary odour production in man? Journal of Steroid Biochemistry and Molecular Biology 48: 409-418.

Hall IR, Zambonelli A \& Primavera F (1998): Ectomycorrhizal fungi with edible fruiting bodies 3. Tuber magnatum, Tuberaceae. Economic Botany 52: 192-200.

Hall R, Zambonelli A \& Wang Y (2004): The cultivation of myccorhizal mushrooms success and failure. 5th International Conference on mushroom biology and mushroom products 12 (Supplement): 45-60.

Hall IR, Brown GT \& Zambonelli A (2007): Taming the truffle. The history, lore, and science of the ultimate mushroom. Timber Press: 1-304.

JECFA (2000): Safety evaluation of certain food additives and contaminants. Simple aliphatic and aromatic sulfides and thiols. WHO Food Additives Series: 44. Fifty-third meeting of the Joint FAO/WHO Expert Committee on Food Additives: 125-228.

Katkov T \& Gower DB (1970): The biosynthesis of androst-16-enes in boar testis tissue. Biochemical Journal 117: 533-538.

Kwan TK, Kraevskaya MA, Makin HLJ, Trafford DJH \& Gower DB. (1997): Use of gas chromatographic-mass spectrometric techniques in studies of androst-16-ene and androgen biosynthesis in human testis; cytosolic specific binding of 5alphaandrost-16-en-3-one. Journal of Steroid Biochemistry and Molecular Biology 60: 137-146.

Mauriello G, Marino R, D’Auria M, Cerone G \& Rana GL (2004): Determination of volatile organic compounds from truffles via SPME-GC-MS. Journal of Chromatographic Science 42: 299-305.

Mello A, Murat C \& Bonfante P (2006): Truffles: much more than a prized and local fungal delicacy. FEMS Microbiology Letters 260: 1-8.

Pelusio F, Nilsson T, Montanarella L, Tilio R, Larsen B, Facchetti S \& Madsen JØ (1995): Headspace solid-phase micro-extraction analysis of volatile organic sulfur compounds in black and white truffle aroma. Journal of Agricultural and Food Chemistry 43: 2138-2143.

Pennazza G, Fanali C, Santonico M, Dugo L, Cucchiarini L, Dachà M, D’Amico A, Costa R, Dugo P \& Mondello L (2013): Electronic nose and GC-MS analysis of volatile compounds in Tuber magnatum Pico: Evaluation of different storage conditions. Food Chemistry 136: 668-674.

Piloni M, Tat L, Tonizzo A \& Battistutta F (2005): Aroma characterization of White Truffle by GC-MS and GC-0. Italian Journal of Food Science 17: 463-468.

Prelog V \& Ruzicka L (1944): Über zwei moschusartig riechende Steroide aus Schweinetestes-Extrakten. Helvetica Chimica Acta 27: 61-66.

Prelog V, Ruzicka L \& Wieland P (1944): Über die Herstellung der beiden moschusartig riechenden delta-16-Androstenole-(3) und verwandter Verbindungen. Helvetica Chimica Acta 27: 66-71.

Splivallo R, Ottonello S, Mello A \& Karlovsky P (2011): Truffle volatiles: From chemical ecology to aroma biosynthesis. New Phytologist 189: 688-699.

Talou T, Doumenc-Faure M \& Gaset A (2001): Flavor profiling of 12 edible truffles. In: Food Flavors and Chemistry: advances of the new millennium. Proceedings of the $10^{\text {th }}$ International Flavor Conference, Paros, Greece, 4-7 July 2000: 274-280. 
Tirillini B \& Stoppini AM (1996): Coumarins distribution in four truffle species. Mycotaxon 57: 227-232.

Wang S \& Marcone MF (2011): The biochemistry and biological properties of the world's most expensive underground edible mushroom: Truffles. Food Research International 44: 2567-2581. 


\section{Tuber melanosporum Vittad.}

(Black Truffle, "Black Winter Truffle") (DK: Perigord-Trøffel ("Sort Trøffel"), FI: ("Mustatryffeli"), IS: "tryffill", NO: Perigordtrøffel, SE: Perigordtryffel).

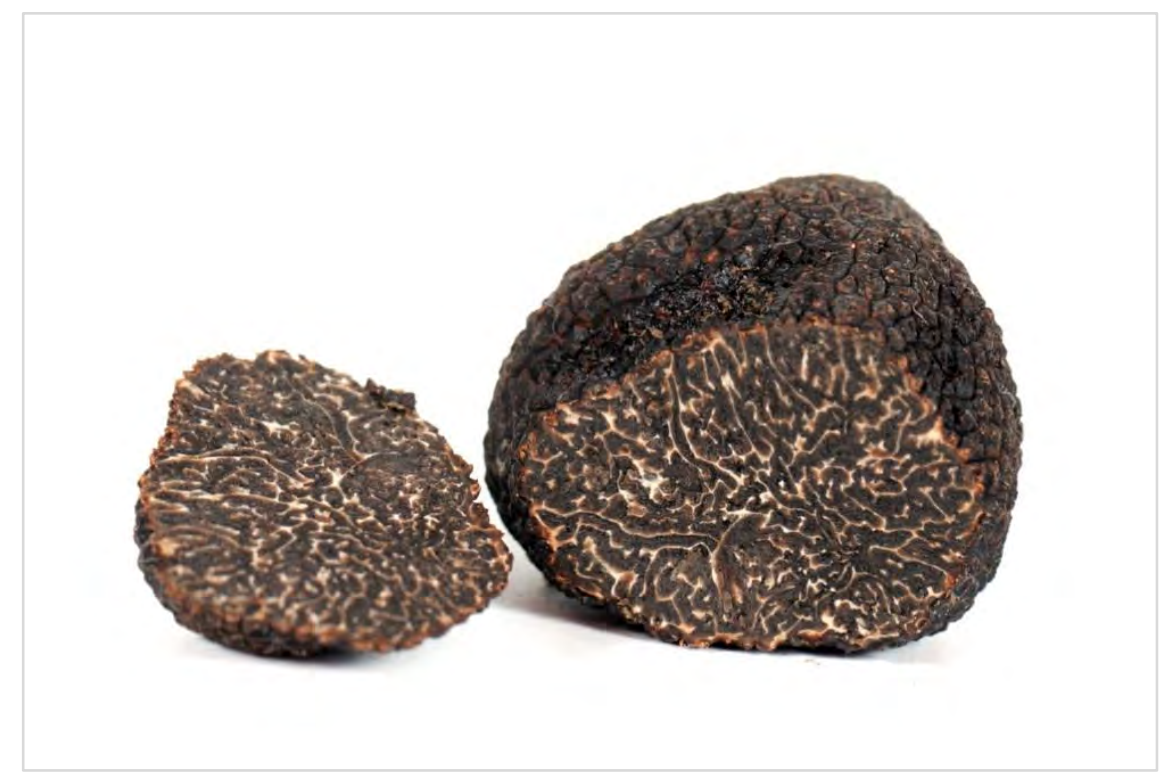

\section{Background and risk assessment}

Tuber melanosporum is an excellent edible mushroom, highly prized for its culinary properties. Due to its delicious taste and low world production (estimated to 150 tons per year), it is one of the world's most expensive foods (Hall et al., 2007).

It may form mycorrhiza with different deciduous trees: species of Oak (Quercus spp.), Hazel (Corylus spp.), Lime (Tilia spp.), Hornbeam (Carpinus spp.) and Hop-hornbeam (Ostrya spp.). It grows in bright forests on sunny flat slopes or plateaus with calcareous, well aerated and drained soils with a pH optimum of 7.9. It is a hypogeous mushroom, which means the fruiting bodies are to be found underground, where they may be harvested from late November to early March. It is native to France, Spain and Italy but also, to parts of the Balkans and Portugal (Wang \& Marcone, 2011; Hall et al., 2007; Mello et al., 2006).

The natural occurrence of T. melanosporum is declining, probably due to deforestation, reforestation with non-host trees or too dense planting, soil 
disturbance or ill adaption of the host trees and the mycorrhizal mushroom to new climate conditions (Hall et al., 2004; Bencivenga et al., 2009).

To-day most T. melanosporum truffles on the market are cultivated ones. Of the truffles marketed in France around 80\% originate from truffle orchards. Spain and Italy are other major producers of cultivated $T$. melanosporum. More recently T. melanosporum has been successfully cultivated also in many plantations in New Zealand, Australia and the USA, and other countries have initiated cultivation, e.g. China. Inoculated truffle trees, e.g. Hazelnut (Corylus avellana) or Downy Oak (Quercus pubescens) are produced in nurseries and are planted in orchards with environmental conditions similar to the natural habitats for T. melanosporum. Five to ten years after planting of infected seedlings the harvest may begin (Bencivenga et al., 2009; Hall et al., 2007; Mello et al., 2006; Wang \& Liu, 2009). In order to improve the yield of the precious fruiting bodies, research on identifying the soil and management of the plantations and not least on improving the process of mycorrhiza and fruit body formation is prioritized. Conditions for research have been facilitated by the recently published sequence of the T. melanosporum genome (Martin et al., 2010; Kües \& Martin, 2011).

T. melanosporum truffles are commercialised as fresh, frozen, canned or mixed with foods, e.g. edible oil, cheese, salt and meat products.

There are no intoxications reported after consumption of T. melanosporum. However, T. melanosporum truffles do contain potentially bioactive constituents, in particular among the volatile organic compounds:

\section{Bioactive constituents}

Volatile organic compounds, including flavourings: There are numerous studies identifying and/or quantifying volatile substances in T. melanosporum and totally more than 130 volatile organic compounds have been detected (e.g., Bellesia et al., 1988; Buzzini et al., 2005; Cuellere et al., 2010; Diaz et al., 2003; March et al., 2006; Jansen et al., 2009; Mauriello et al., 2004; Pelusio et al., 1995; Splivallo et al., 2007; Talou et al., 2001; Vernin et al., 2005; and as reviewed by Wang \& Marcone, 2011). The diverging results may be due to genetic factors, degree of maturity and quality of the truffles, origin of the mushroom, storage conditions (time, temperature), host trees and not at least analytical method (Splivallo et al., 2011; Wang \& Marcone, 2011). Freeze-drying and subsequent rehydration of T. melanosporum did apparently not affect the aroma-profile when estimated by headspace-gas chromatography-mass spectrometry (Palacio et al., 2012). However, freezing the mushrooms at -20 or $-80^{\circ} \mathrm{C}$ significantly changed the aroma of the thawed mushrooms both when estimated by physical-chemical methods and by a sensory panel (Cullere 
et al., 2013). Furthermore yeasts habituating the fruiting bodies of T. melanosporum can produce volatile organic compounds, e.g. 3-methylbutanol, dimethyl sulfide and dimethyl sulfide, also known from the truffle flavour. Such yeast flavouring substances may possibly contribute to the final truffle aroma (Buzzini et al., 2005).

The structural formula of dimethyl sulfide is shown below.

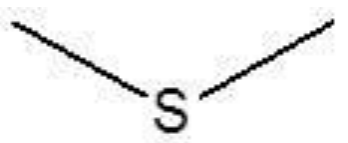

dimethyl sulfide

The major volatile flavouring substances identified in T. melanosporum are identical with or structurally/biologically related to flavourings identified in other foodstuffs or used as food additives. These flavouring substances have been risk assessed by the European Food Safety Authority (EFSA) and/or by the Joint FAO/WHO Expert Committee on Food Additives (JECFA). They were found to be of no safety concern at estimated levels of intake. However, most of the sulfur-containing volatiles could not be predicted to be metabolized to innocuous products. Therefore animal studies were considered and No Observed Adverse Effect Levels (NOAEL's) were determined in order to establish safety margins for the food use (EFSA 2012a, 2012b; JECFA 2000). Most studies on volatile substances in T. melanosporum only give relative quantities (percentages) of the single volatiles compared to all volatile constituents. However, a few investigators present quantitative data (Bellesia et al., 1998; Cuellere et al., 2010; Ney \& Freitag, 1980; Splivallo et al., 2007). The most recent of these four publications show that the typical T. melanosporum flavour is composed of at least 17 different aroma-giving substances (Cuellere et al., 2010). The most important of these 17 substances for the flavour were reported to be 2,3 -butadione $(0.70 \mathrm{mg} / \mathrm{kg}$ of fruit bodies), dimethyl disulfide (not quantified), ethyl butyrate 0.05 $\mathrm{mg} / \mathrm{kg})$, dimethyl sulfide $(0.19 \mathrm{mg} / \mathrm{kg}), 3$-methyl-1-butanol $(0.43$ $\mathrm{mg} / \mathrm{kg}$ ) and 3-ethyl-5-methylphenol $(18 \mathrm{mg} / \mathrm{kg})$. In another study, Ney \& Freitag (1980) identified dimethyl sulfide at a level of $8 \mathrm{mg} / \mathrm{kg}$. With an intake of $20 \mathrm{~g}$ T. melanosporum in a meal, consumed four times a month, which must be considered a high intake, there will be a very large safety margin for these aroma-giving compounds in relation to the NOAELs established in animal studies, and which were used for evaluation of the above flavouring substances by EFSA (2012a, 2012b) and JECFA (2000). 
Steroids: A volatile steroidal compound, $5 \alpha$-androst-16-en- $3 \alpha$-ol has been isolated from the fruiting bodies of T. melanosporum in amounts of 40-60 $\mu \mathrm{g}$ per $\mathrm{kg}$ fresh mushroom. The steroid can also be formed in fermentation broth of the truffle (Wang et al. 2008). The steroid has a pronounced musk-like scent. It is the major pheromone of the boar, where it has been detected in testes and saliva (Katkov \& Gower, 1970;

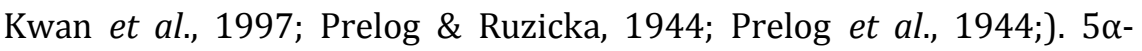
Androst-16-en-3 $\alpha$-ol also occurs in humans, in testes, sweat and urine, primarily in males (Brooksbank \& Haslewood, 1961; Gower et al., 1994), but it seems to be devoid of androgenic activity (Claus et al., 1981). It is estimated to be excreted with human urine (as glucuronide) at a rate of about $1 \mathrm{mg}$ per day by adult males and at a slower rate by women (Brooksbank \& Haslewood, 1961; Brooksbank et al., 1974). Therefore the potential biological effects of $5 \alpha$-androst-16-en- $3 \alpha$-ol after consumption of a meal containing T. melanosporum will be negligible in relation to the natural production in humans. For example, $20 \mathrm{~g}$ of the truffle would contain about $1 \mu \mathrm{g}$ of the steroid.

Coumarins: In a study on coumarins in different Tuber species 24 samples of Tuber melanosporum were analysed. The species contained 0.0-0.8 mg per $\mathrm{kg}$ of the simple coumarin scopoletin (7-hydroxy-6methoxycoumarin), 0-1.3 mg per kg of the angular furocoumarin angelicin (isopsoralen) and 11-21 mg per $\mathrm{kg}$ of the linear furocoumarin bergapten (5-methoxypsoralen). The identities of the three coumarins were confirmed by mass spectrometry and by comparison with authentic samples (Tirillini \& Stoppini, 1996).

Scopoletin (and its glycosides) is widely distributed in the plant kingdom and can be found in for example Cassava (Manihot esculenta), Coffee (Coffea spp.) and Sweet Potato (Ipomea spp.) (Gnonlonfin et al., 2012; Thier et al.,1968). The compound has antibiotic (antifungal) effects (Peterson et al.; 2003 Gnonlonfin et al., 2012). It is not known whether it could have toxic effects in humans, but any intake from this truffel is likely to result in very low exposure.

Angelicin is an angular furocoumarin found in some food plants. For example, parsnip (Pastinaca sativa) may contain levels between 1 and $28 \mathrm{mg}$ per kg fresh weight, and even much higher levels if injured or infected (Baumann et al., 1988; Ostertag et al., 2002; Peroutka et al., 2007). There are no data on oral administration of the compound angelicin to humans and no adequately controlled oral studies supplying angelicin to experimental animals (Søborg et al., 1995). However, it is known that topical application of angelicin followed by UVA irradiation may give rise to skin tumours in mice (Mullen et al., 1984). IARC has 
considered the potential carcinogenicity of angelicin and concluded that there neither were adequate studies to evaluate the carcinogenicity of angelicin (without UVA irradiation) in experimental animals nor any adequate studies in humans (IARC, 1986b). A worst case exposure scenario based on an intake of $20 \mathrm{~g} \mathrm{~T}$. melanosporum, containing the highest level of angelicin found in the mushroom $(1.3 \mathrm{mg} / \mathrm{kg})$ would result in an exposure to $0.026 \mathrm{mg}$ angelicin per meal. If, for instance 4 such meals are consumed per month, this would correspond to an average daily intake of less than 0.06 microgram angelicin per kg body weight per day for a person weighing $60 \mathrm{~kg}$. This would constitute a very limited risk for potential adverse effects in consumers of Tuber melanosporum.

Bergapten and xanthotoxin (8-methoxypsoralen) are linear furocoumarins occurring in food plants such as citrus fruits, celery/celeriac, parsnip and parsley leaf and root in quantities from about 1 to $60 \mathrm{mg}$ per kg of apparently healthy fresh fruit or vegetable (Peroutka et al., 2007; Schulzova et al., 2012; Søborg et al., 1995). The International Agency for Research on Cancer (IARC) has concluded that bergapten is genotoxic in vitro, and phototoxic and carcinogenic in combination with long-wave ultraviolet (UVA) irradiation. Overall IARC has concluded that there are inadequate data to evaluate the local or systemic carcinogenic effects of bergapten itself in experimental animals, and that evidence for carcinogenicity to humans is inadequate (IARC 1986a; 1987a; 1987b). The average daily intake of furocoumarins (mainly bergapten and xanthotoxin) has been estimated to be $1.3 \mathrm{mg}$ in the USA and $1.2 \mathrm{mg}$ in Great Britain, corresponding to $0.020-0.022 \mathrm{mg}$ furocoumarins per $\mathrm{kg}$ body weight for a person weighing $60 \mathrm{~kg}$. These intakes lie 2-3 orders of magnitude lower than the lowest doses reported to be toxic in subchronic and chronic animal studies with xanthotoxin (in the absence of light), 25-30 times lower than the therapeutic doses of bergapten or xanthotoxin (0.5-0.6 mg per kg body weight) for bergapten and xanthotoxin when used as drugs, and 10 times lower than the lowest phototoxic doses $(0.23 \mathrm{mg} / \mathrm{kg}$ body weight). Consumption of foods with the above average levels of furocoumarins was concluded not to represent a significant risk for phototoxic effects and the risk for skin cancer to be insignificant (DFG-Senate Commission for Food Safety 2004/2006). As the average intake of furocoumarins $(0.020-0.022 \mathrm{mg}$ per $\mathrm{kg}$ body weight) is 10 times lower than the amount required to reach detectable blood levels, it is unlikely that the average dietary intake of furocoumarins (including bergapten) constitute a cancer risk (Søborg et al., 1995). Based on virtually the same data, Dolan et al. (2010) more recently con- 
cluded that the risk for phototoxic and carcinogenic effects from dietary furocoumarins is low.

Based on the information available, it can be concluded that the highest level of bergapten found in fresh T. melanosporum $(21 \mathrm{mg} / \mathrm{kg}$ ) will result in low exposures. In a worst case scenario (consumption of $20 \mathrm{~g}$ mushrooms four times a month) the exposure would be about $1 \mathrm{mi}$ crogram bergapten per kg body weight per day, which would constitute a very limited risk for potential adverse effects in consumers of T. melanosporum.

The structural formulae of angelicin and bergapten are shown below.<smiles>O=c1ccc2ccc3occc3c2o1</smiles>

Angelicin<smiles>COc1c2ccoc2cc2oc(=O)ccc12</smiles>

Bergapten

\section{Recommendation}

No special recommendation.

\section{Listing 1}

\section{Database search information}

SciFinder by January 2012. Keywords: Tuber melanosporum. PubMed by December 2012. Keywords: Tuber melanosporum.

\section{References}

Baumann U, Dick R \& Zimmerli B (1988): Orientierende Untersuchung zum Vorkommen von Furocumarinen in pflanzlichen Lebensmitteln und Kosmetika. Mitteilungen aus dem Gebiete Lebensmitteluntersuchung und Hygiejne 79: 112-129.

Bellesia F, Pinetti A, Bianchi A \& Tirillini B (1998): The volatile organic compounds of Black Truffle (Tuber melanosporum. Vitt.) from middle Italy. Flavour and Fragrance Journal 13: 56-58.

Bencivenga M, Di MG, Donnini D \& Baciarelli FL (2009): The cultivation of truffles in Italy. Acta Botanica Yunnanica Supplement 16: 21-28.

Brooksbank BWL \& Haslewood GAD (1961): The estimation of androst-16-en-3 $\alpha$-ol in human urine. Biochemical Journal 80: 488-496.

Brooksbank BWL, Brown R \& Gustafsson J-A (1974): The detection of $5 \alpha$-androst16-en-3 $\alpha$-ol in human male axillary sweat. Experientia 30: 864-865. 
Buzzini P, Gasparetti C, Turchetti B, Cramarossa MR, Vaughan-Martini A, Martini A, Pagnoni UM \& Forti L (2005): Production of volatile organic compounds (VOCs) by yeasts isolated from the ascocarps of black (Tuber melanosporum Vitt.) and white (Tuber magnatum Pico) truffles. Archives of Microbiology 184: 187-193.

Claus R, Hoppen HO \& Karg H (1981): The secret of truffels: A steroidal pheromone? Experientia 37: 1178-1179.

Culleré L, Ferreira V, Chevret B, Venturini ME, Sánchez-Gimeno AC \& Blanco D (2010): Characterisation of aroma active compounds in black truffles (Tuber melanosporum) and summer truffles (Tuber aestivum) by gas chromatographyolfactometry. Food Chemistry 122: 300-306.

Culleré L, Ferreira V, Venturini ME, Marco P \& Blanco D (2013): Chemical and sensory effects of the freezing process on the aroma profile of black truffles (Tuber melanosporum). Food Chemistry 136: 518-525.

DFG Senate Commission for Food Safety (2004/2006): Deutsches Forschungsge meinschaft. Toxicological Asssessment of Furocoumarins in Foodstuffs. Kaiserslautern University of Technology, Department of Chemistry: 1-30.

Diaz P, Ibánez E, Senoráns FJ \& Reglero G (2003): Truffle aroma characterization by headspace solid-phase microextraction. Journal of Chromatography A 1017: 207-214.

Dolan LC, Matulka RA \& Burdock GA (2010): Naturally occurring food toxins. Toxins 2: 2289-2332.

EFSA (2012a): European Food Safety Authority. Scientific opinion on flavouring group evaluation 08 revision 5 (FGE.08Rev5): Aliphatic and alicyclic mono-, di-, tri-, and polysulphides with or without additional oxygenated functional groups from chemical groups 20 and 30. The EFSA Journal 10(7)2837: 1-139.

EFSA (2012b): European Food Safety Authority. Scientific opinion on flavouring group evaluation 21 revision 3 (FGE.21Rev3): Thiazoles, thiophenes, thiazoline and thienyl derivatives from chemical groups 29 and 30. The EFSA Journal 10(2)2437: 1-94.

Gnonlonfin GJB, Sanni A \& Brimer L (2012): Review scopoletin - a coumanrin phytoalexin with medicinal properties. Critical Reviews in Plant Sciences 31: 47-56.

Gower DB, Holland KT, Mallet AI, Rennie PJ \& Watkins WJ (1994): Comparison of 16androstene steroid concentrations in sterile apocrine sweat and axillary secretions: Interconversions of 16-androstenes by the axillary microflora-a mechanism for axillary odour production in man? Journal of Steroid Biochemistry and Molecular Biology 48: 409-418.

Hall IR, Zambonelli A \& Wang Y (2004): The cultivation of mycorrhizal mushrooms success and failure. $5^{\text {th }}$ International Conference on mushroom biology and mushroom products 12 (Supplement): 45-60.

Hall IR, Brown GT \& Zambonelli A (2007): Taming the truffle. The history, lore, and science of the ultimate mushroom. Timber Press: 1-304.

IARC(1986a): International Agency for Research on Cancer. Monographs on the evaluation of the carcinogenic risk of chemicals to humans. Summaries \& Evaluations. 5-Methoxypsoralen 40: 327-347.

IARC(1986b): International Agency for Research on Cancer. Monographs on the evaluation of the carcinogenic risk of chemicals to humans. Summaries \& Evaluations. Angelicin and some synthetic derivatives 40: 291-315.

IARC (1987a): International Agency for Research on Cancer. Monographs on the evaluation of the carcinogenic risk of chemicals to humans. Genetic and related effects: An updating of selected IARC Monographs from Volumes 1 to 42. 5Methoxypsoralen. Supplement 6: 377-385. 
IARC (1987b): International Agency for Research on Cancer. Monographs on the evaluation of the carcinogenic risk of chemicals to humans. Overall evaluation of carcinogenicity. Un updating of selected IARC Monographs from Volumes1-42. 5Methoxypsoralen. Supplement 7: 242-243.

Jansen O, Talou T, Raynaud C \& Gaset A (2005): Black truffle flavor: Investigation into the impact of high-boiling-point volatiles by GC-olfactometry. Food Flavour and Chemistry 300: 260-270.

JECFA (2000): Safety evaluation of certain food additives and contaminants. Simple aliphatic and aromatic sulfides and thiols. WHO Food Additives Series: 44. Fifty-third meeting of the Joint FAO/WHO Expert Committee on Food Additives: 125-228.

Katkov T \& Gower DB (1970): The biosynthesis of androst-16-enes in boar testis tissue. Biochemical Journal 117: 533-538.

Kües U \& Martin F (2011): On the road to understanding truffles in the underground. Fungal Genetics and Biology 48: 555-560.

Kwan TK, Kraevskaya MA, Makin HLJ, Trafford DJH \& Gower DB. (1997): Use of gas chromatographic-mass spectrometric techniques in studies of androst-16-ene and androgen biosynthesis in human testis; cytosolic specific binding of 5alpha-androst16-en-3-one. Journal of Steroid Biochemistry Molecular Biology 60: 137-146.

March RE, Richards DS \& Ryan RW (2006): Volatile compounds from six species of truffle - head-space analysis and vapor analysis at high mass resolution. International Journal of Mass Spectrometry 249-250: 60-67.

Martin F (and fifty more authors)(2010): Périgord black truffle genome uncovers evolutionary origins and mechanisms of symbiosis. Nature 464: 1033-1038.

Mauriello G, Marino R, D’Auria M, Cerone G \& Rana GL (2004): Determination of volatile organic compounds from truffles via SPME-GC-MS. Journal of Chromatographic Science 42: 299-305.

Mello A, Murat C \& Bonfante P (2006): Truffles: much more than a prized and local fungal delicacy. FEMS Microbiology Letters 260: 1-8.

Mullen MP,Pathak MA, West JD, Harrist TJ and Dall'Aqua F (1984): Carcinogenic effects of monofunctional and bifunctional furocoumarins. In: Photobiologic, Toxicologic and Pharmacologic Aspects of Psoralens. Eds. Pathak MA \& Dunnick JK. National Cancer Institute. Monograph 66: 205-210.

Ney KH \& Freitag WG (1980): Trüffel-aroma. Gordian 80: 214.

Ostertag E, Becker T, Ammon J, Bauer-Aymanns H \& Schrenk D (2002): Effects of storage conditions on furocoumarin levels in intact, chopped, and homogenized parsnips. Journal of Agricultural and Food Chemistry 50: 2565-2570.

Palacios I, Guillamón E, Garcia-Lafuente A \& Villares A (2012): Effects of freezedrying treatment on the aromatic profile of Tuber spp. Truffles. Journal of Food Processing and Preservation ISSN 174-4549: 1-6.

Pelusio F, Nilsson T, Montanarella L, Tilio R, Larsen B, Faccetti S \& Madsen JØ (1995): Headspace solid-phase micro-extraction analysis of volatile organic sulfur compounds in black and white truffle aroma. Journal of Agricultural and Food Chemistry 43: 2138-2143.

Peroutka R, Schulzova V, Botek P \& Hajslova (2007): Analysis of furanocoumarins in vegetables (Apiaceae) and citrus fruits (Rutaceae). Journal of the Science Food and Agriculture 87: 2152-2163.

Prelog V \& Ruzicka L (1944): Über zwei moschusartig riechende Steroide aus Schweinetestes-Extrakten. Helvetica Chimica Acta 27: 61-66. 
Prelog V, Ruzicka L \& Wieland P (1944): Über die Herstellung der beiden moschusartig riechenden delta-16-Androstenole-(3) und verwandter Verbindungen. Helvetica Chimica Acta 27: 66-71.

Peterson JK, Harrison HF, Jackson DM \& Snook ME (2003): Biological activities and contents of scopolin and scopoletin in sweetpotato clones. HortScience 38: 1129-1133.

Schulzova V, Babicka L \& Hajslova J (2012): Furanocoumarins in celeriac from different farming systems: a 3-year study. Journal of the Science of Food and Agriculture 92: 2849-2854.

Splivallo R, Bossi S, Maffei M \& Bonfante P (2007): Discrimination of truffle fruiting body versus mycelial aromas by stir bar sorptive extraction. Phytochemistry 68: 2584-2598.

Splivallo R, Ottonello S, Mello A \& Karlovsky P (2011): Truffle volatiles: From chemical ecology to aroma biosynthesis. New Phytologist 189: 688-699.

Søborg I, Andersson C \& Gry J (1996): Furocoumarins in plant food. Exposure, biological properties, risk assessment and recommendations. Nordic Council of Ministers TemaNord 1996:600: 1-155.

Talou T, Doumenc-Faure M \& Gaset A (2001): Flavor profiling of 12 edible truffles. In: Food Flavors and Chemistry: advances of the new millennium. Proceedings of the $10^{\text {th }}$ International Flavor Conference, Paros, Greece: 274-280.

Thier H-P, Bricout J, Vian R, Reymond D \& Egli RH (1968): Scopoletin, ein Bestandteil des Rohkaffees. Zeitschrift für Lebensmittel-Unterschung und - Forschung 137: 1-4.

Tirillini B \& Stoppini AM (1996): Coumarins distribution in four truffle species. Mycotaxon 57: 227-232.

Vernin G, Parkanyi C \& Casablanca X (2005): GC/MS analysis of the volatile compounds of Tuber melanosporum from Tricastin and Alpes de Haute Provence (France). Food, Flavor and Chemistry: Explorations into the 21st Century: 115-135.

Wang Y \& Liu P-G (2009): Achivements and challenges of research on truffles in China. Acta Botanica Yunnanica Supplement 16: 1-9.

Wang S \& Marcone MF (2011): The biochemistry and biological properties of the world's most expensive underground edible mushroom: Truffles. Food Research International 44: 2567-2581.

Wang G, Li Y-Y, Li D-S \& Tang Y-J (2008): Determination of $5 \alpha$-androst-16-en-3 $\alpha$-ol in truffle fermentation broth by solid-phase extraction coupled with gas chromatography-flame ionization detector/electron impact mass spectrometry. Journal of Chromatography B 870: 209-215. 
Tuber sinense X.L. Mao

See Tuber indicum.

Tuber uncinatum Chat.

See Tuber aestivum.

Volvaria volvacea (Bull.) P. Kumm.

See Volvariella volvacea. 


\section{Volvariella volvacea (Bull.) Singer (Volvaria volvacea (Bull.) P. Kumm.)}

(Paddy Straw Mushroom, Straw Mushroom) (DK: Spiselig Posesvamp, FI: Viljelytuppisieni, IS: Matsokka, NO: Grå sliresopp, SE: Halmslidskivling).

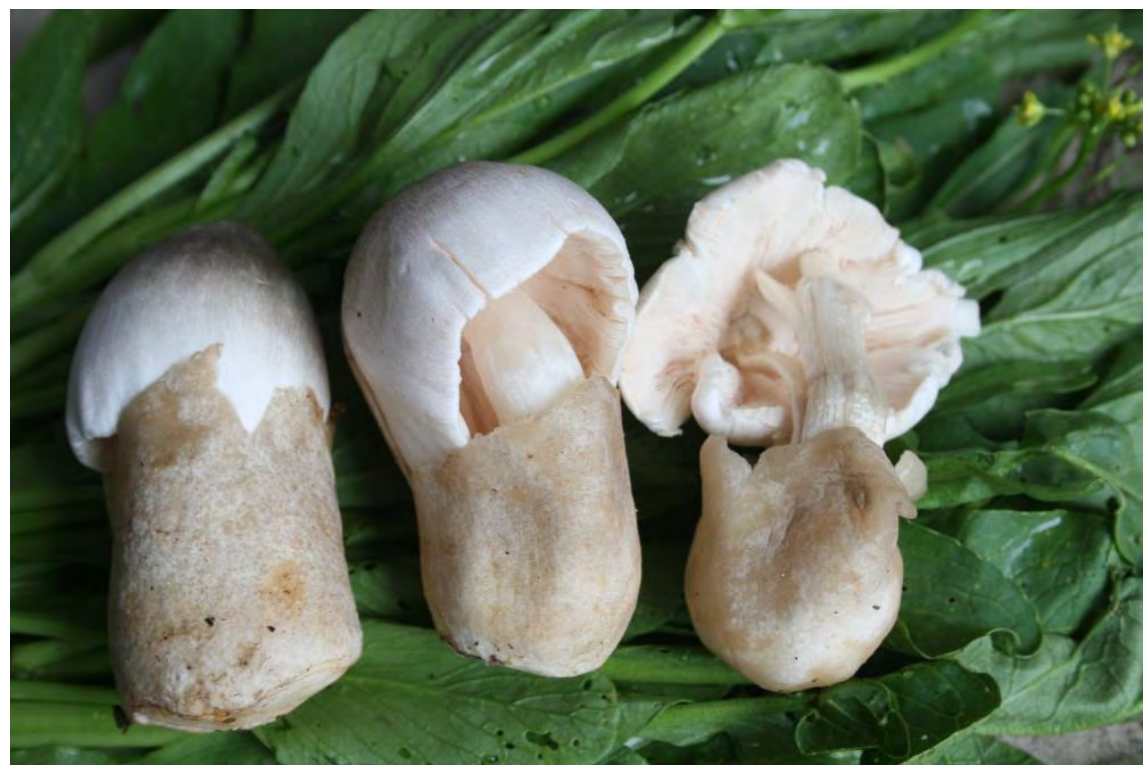

\section{Background and risk assessment}

Paddy Straw Mushroom (Volvariella volvacea) is an edible mushroom.

It is a saprotrophic mushroom, growing on grass leaves, e.g., from rice in Japan, Southeast Asia and East Africa (Hongo \& Izawa, 2006; Pegler, 1977).

There are no intoxications reported after consumption of Paddy Straw Mushroom, and no natural toxicant constituting a risk for humans has been identified in the mushroom. However, several bioactive constituents with potentially biological effects in humans have been identified in the mushroom.

\section{Bioactive constituents}

Ergothioneine: Paddy Straw Mushroom contains relatively high amounts of ergothioneine, $537 \mathrm{mg}$ per kg dried mushroom (mean of three samples) (Lo et al., 2012). Ergothioneine has in numerous in vitro and in a few in vivo studies been shown to have antioxidative and cytoprotective properties against a wide range of cellular stressors (Song et al., 2010). 
However, the physiological role of ergothioneine is not well understood For further data on ergothioneine, see Lepista nuda.

Statins: Lovastatin has been isolated in relatively small amounts from Paddy Straw Mushroom, $59 \mathrm{mg}$ per kg dried fruit bodies (Lo et al., 2012). For further data on lovastatin, see Pleurotus ostreatus.

Ribosome inactivating proteins: Ribosome inactivating proteins are enzymes that depurinate rRNA's. This depurination inactivates the ribosomes, thus inhibiting protein synthesis (Stirpe \& Battelli, 2006; Nielsen \& Boston, 2001). Yao et al. (1998) have isolated a ribosome inactivating protein, designated volvarin, with a molecular mass of $29 \mathrm{kDa}$ from the fruit bodies. Volvarin acts as an $\mathrm{N}$-glycosidase that depurinates rRNA and inhibits protein synthesis, which has been demonstrated in vitro in a rabbit reticulocyte lysate system. The protein also exerted deoxyribonuclease activity on DNA in vitro, as well as abortifacient effect when injected into pregnant ICR mice. It is not known whether volvarin is stable during processing of Paddy Straw Mushrooms.

Cytolytic proteins: Paddy Straw Mushroom contains a cytolytic protein, volvatoxin A. Volvatoxin A lyses human erythrocytes, causes ventricular systolic arrest on isolated toad hearts, and results in significant electrocardiographical changes in cats injected with the compound (Lin et al., 1973). Studies by Fassold et al. (1976) have shown that volvatoxin A inhibits calcium accumulation in the mitochondria of the heart muscle. Volvatoxin A consists of volvatoxin $A_{1}$ of $50 \mathrm{kDa}$ and volvatoxin $\mathrm{A}_{2}$ of $24 \mathrm{kDa}$ in the ratio 1:3 (Lin et al., 1973). Although both proteins are required for activity, Lin et al. (1973) demonstrated that the hemolytic (an probably cytotoxic, cardiotoxic and neurotoxic) activity is carried by volvatoxin $A_{2}$. Volvatoxin $A_{1}$ seems not to possess any significant biological activity. More recently a mechanism for the disruption of cell membranes have been proposed, based on the formation of membrane pores (Weng et al., 2004; $\mathrm{Wu}$ et al., 2006). It was proposed that volvatoxin $\mathrm{A}_{2}$ contains two functional domains. One is responsible for oligomerization of volvatoxin $\mathrm{A}_{2}$ proteins and the other for membrane binding and insertion.

Importantly, volvatoxin A is not heat-stable, and its biological activities are completely destroyed by heating at $100{ }^{\circ} \mathrm{C}$ for 20 minutes (Lin et al., 1973).

Lectins: Banerjee et al. (1982) demonstrated that extracts of mycelia from submerged cultures of Paddy Straw Mushroom had hemagglutinating activity on several types of erythrocytes (sheep, guinea pig, rat, mouse and goat) but not human, the effect being strongest on sheep erythrocytes. Subsequently, a lectin with hemagglutinating activity was isolated and characterized from fruit bodies of Paddy Straw Mushroom 
(Lin \& Chou, 1984; She et al., 1998). In the study by Lin \& Chou (1984) it was shown that volvatoxin has moderately inhibitory effect on tumour growth in mice inoculated with sarcoma 180 cells. Whereas Lin \& Chou (1984) reported that it had a molecular weight of $26 \mathrm{kDa}$ and consisted of two non-identical subunits, She et al. (1998) reported a homodimeric protein with a molecular weight of $32 \mathrm{kDa}$. The latter investigator showed that the hemagglutinating activity was inhibited by thyroglobulin but not by simple carbohydrates. The lectin has been shown to have strong immunomodulary activity as demonstrated by for example mitogenic activity (She et al., 1998; Ho et al., 2004). The lectin was quite stable at elevated temperatures, and $75 \%$ percent of the activity remained after incubation at $90^{\circ} \mathrm{C}$ for 30 minutes (Lin \& Chou, 1984).

\section{Recommendation}

No special recommendation.

\section{Listing 1}

\section{Database search information}

SciFinder by January 2012. Keywords: Volvariella or Volvaria. PubMed by March 2012. Keywords: Volvariella or Volvaria.

\section{References}

Banerjee PC, Ghosh AK \& Sengupta S (1982): Hemagglutinating activity in extracts of mycelia from submerged mushroom cultures. Applied and Environmental Microbiology 44: 1009-1011.

Fassold E, Slade AM, Lin J-Y \& Nayler WG (1976): An effect of the cardiotoxic protein Volvatoxin A on the function and structure of heart muscle cells. Journal of Molecular and Cellular Cardiology 8: 501-519.

Ho JCK, Sze SCW; Shen WZ \& Liu WK (2004): Mitogenic activity of edible mushroom lectins. Biochimia et Biophysica Acta 1671: 9-17.

Hongo T \& Izawa M (2006): Kinoko (Fungi) 1-383 (Japanese).

Lin J-Y, Jeng T-W, Chen C-C, Shi G-Y \& Tung T-C (1973): Isolation of a new cardiotoxic protein from the edible mushroom, Volvariella volvacea. Nature 246: 524-525.

Lin J-Y \& Chou T-B (1984): Isolation and characterization of a lectin from edible mushroom, Volvariella volvacea. Journal of Biochemistry 96: 35-40.

Nielsen K \& Boston RS (2001): Ribosome-inactivating proteins: A plant perspective. Annual Review of Plant Physiology and Plant Molecular Biology 52: 785-816.

Pegler DN (1977): A preliminary agaric flora of East Africa. HMSO, Kew: 1- 615.

She Q-B, Ng T-B \& Liu W-K (1998): A novel lectin with potent immunomodulatory activity isolated from both fruiting bodies and cultured mycelia of the edible mushroom Volvariella volvacea. Biochemical and Biophysical Research Communications 247: 106-111. 
Song T-Y, Chen C-L, Liao J-W, Ou H-C \& Tsai M-S (2010): Ergothioneine protects against neuronal injury induced by cisplatin both in vitro and in vivo. Food and Chemical Toxicology 48: 3492-3499.

Stirpe F \& Battelli MG (2006): Ribosome-inactivating proteins: progress and problems. Cellular and Molecular Life Sciences 63: 1850-1866.

Weng Y-P, Lin Y-P, Hsu C-I \& Lin J-Y (2004): Functional domains of a pore-forming cardiotoxic protein, volvatoxin $A_{2}$. Journal of Biological Chemistry 279: 6805-6814.

Wu P-T, Lin S-C, Hsu C-I, Liaw Y-C \& Lin J-Y (2006): Inhibitory effects of nontoxic protein volvatoxin $A_{1}$ on pore-forming cardiotoxic protein volvatoxin $A_{2}$ by interaction with amphipathic $\alpha$-helix. Federation of the Biochemical Societies Journal 273: 3160-3171.

Yao Q-Z, Yu MM, Ooi LSM, Ng TB, Chang ST, Sun SSM \& Ooi VEC (1998): Isolation and characterization of a type 1 ribosome-inactivating protein from fruiting bodies of the edible mushroom (Volvariella volvacea). Journal of Agricultural and Food Chemistry 46: 788-792. 


\section{Xerocomus badius (Fr.) E.-J. Gilbert (Boletus badius (Fr.) Fr.)}

Bay Bolete (DK: Brunstokket Rørhat, FI: Ruskotatti, IS: No Icelandic name, NO: Svartbrun rørsopp, SE: Brunsopp).

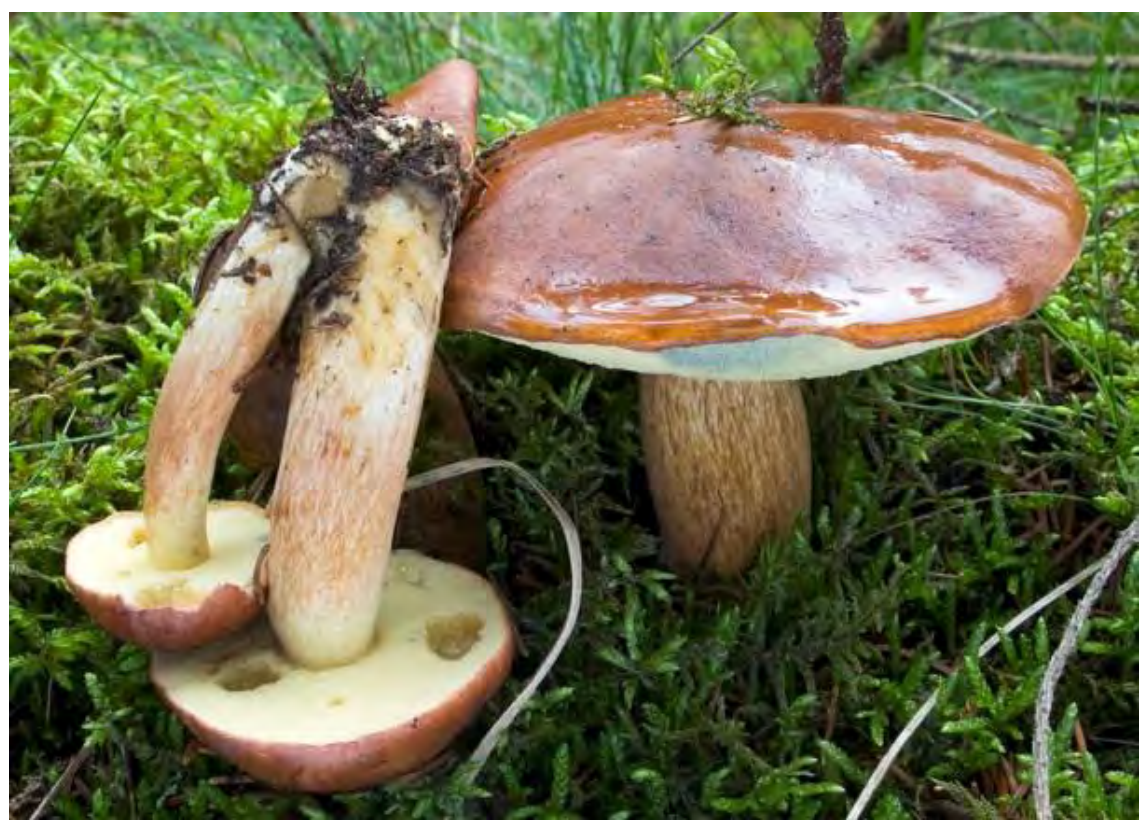

\section{Background and risk assessment}

Bay Bolete (Xerocomus badius) ${ }^{28}$ is regarded as a good edible mushroom, which is mainly sold fresh.

It forms mycorrhiza mainly with coniferous, but also with deciduous trees. Bay Bolete is common in the temperate/hemiboreal and southern boreal zones and occasional in middle-boreal area of the Nordic countries (Knudsen \& Vesterholt, 2012).

No intoxications have been reported after consumption of Bay Bolete, and no inherent toxicants have been identified in the mushroom.

One unusual amino acid derivative, N-ethyl- $\gamma$-glutamine has been isolated from Bay Bolete (Casimir et al., 1960). This compound has been

${ }^{28}$ Index Fungorum/Species Fungorum (2012) uses Boletus badius as current name but Knudsen \& Vesterholt (2012), ArtDatabanken (2011) and Danish Mycological Society (2012) use Xerocomus badius as preferred name. 
studied for its anticipated beneficial effects in in vitro and rodent studies, e.g. as referred to by Li et al. (2008). Whether the occurrence of N-ethyl$\gamma$-glutamine in Bay Bolete may lead to any adverse effects in humans is unknown.

Muszynska et al. (2009) isolated small amounts of the indole compounds tryphtophan, 5-hydroxytryphtophan, tryptamine and of the two metabolites of tryphtophan: kynurenic acid and kynurenine sulphate. High intakes of tryphtophan can damage the nervous system and contribute to induction of cancer (Stone et al., 2003).

\section{Recommendation}

No special recommendation.

\section{Listing 2}

\section{Database search information}

SciFinder by January 2012. Keywords: Xerocomus, Boletus.

\section{References}

ArtDatabanken (2011): http://www.artdata.slu.se/default.asp

Casimir J, Jadot J \& Renard M (1960): Séparation et caractérisation de la N-éhyl- $\gamma$ glutamine à partier de Xerocomus badius. Biochemica et Biophysica Acta 39: 462-468.

Danish Mycological Society (2012): Danish-Latin database on names for fungi. www. http://www.svampe.dk/

Index Fungorum/Species Fungorum (2012): http://www.indexfungorum.org/

Knudsen H \& Vesterholt J (2012): Funga Nordica. Agaricoid, boletoid, clavarioid, cyphelloid and gastroid genera. Nordsvamp: 1-1083.

Li J, Li P \& Liu F (2008): Production of theanine by Xerocomus badius (mushroom) using submerged fermentation. Science Direct LWT 41: 883-889.

Muszynska B, Sulkowska K \& Ekiert H (2009): Indole compounds in fruiting bodies of some selected Macromycetes species and their mycelia cultured in vitro. Pharmazie 64: 479-480.

Stone TW, Mackay GM, Forrest CM, Clark CJ, Darlington LG (2003): Tryptophan metabolites and brain disorders. Clinical Chemistry and Laboratory Medicine 41: 852-859. 


\section{Pictures and statements on poisonous mushrooms referred to in guidance list 3}

\section{Introduction}

In guidance list 3 on "Wild edible mushrooms, which may easily be mistaken for poisonous look-alikes and therefore are not regarded as suitable for commercial marketing," references are made to specific toxic mushrooms. These toxic mushrooms are not evaluated in this report, but a picture of each of these species is found below together with a short statement on their toxicity.

It has to be stressed, that one picture of a mushroom species will never cover all variations in the appearance of the mushroom in nature. The natural appearance may differ significantly and thorough knowledge of identification is an essential part of the safe trade and use of mushrooms as food.

The poisonous mushrooms are listed alphabetically according to their preferred scientific names.

List of toxic look-alikes referred to:

- Amanita pantherina (Panthercap).

- Amanita phalloides (Deathcap).

- Amanita virosa (Destroying Angel).

- Boletus legaliae (No English name).

- Boletus satanas (Devil's Bolete).

- Chlorophyllum brunneum (No English name).

- Clitocybe rivulosa (Fool's Funnel).

- Cortinarius rubellus (Deadly Webcap).

- Galerina marginata (Funeral Bell).

- Hypholoma fasciculare (Sulphur Tuft). 


\section{Amanita pantherina (DC.) Krombh.}

Panthercap (DK: Panter-Fluesvamp, FI: Pantterikärpässieni, IS: No Icelandic name, NO: Panterfluesopp, SE: Panterflugsvamp).

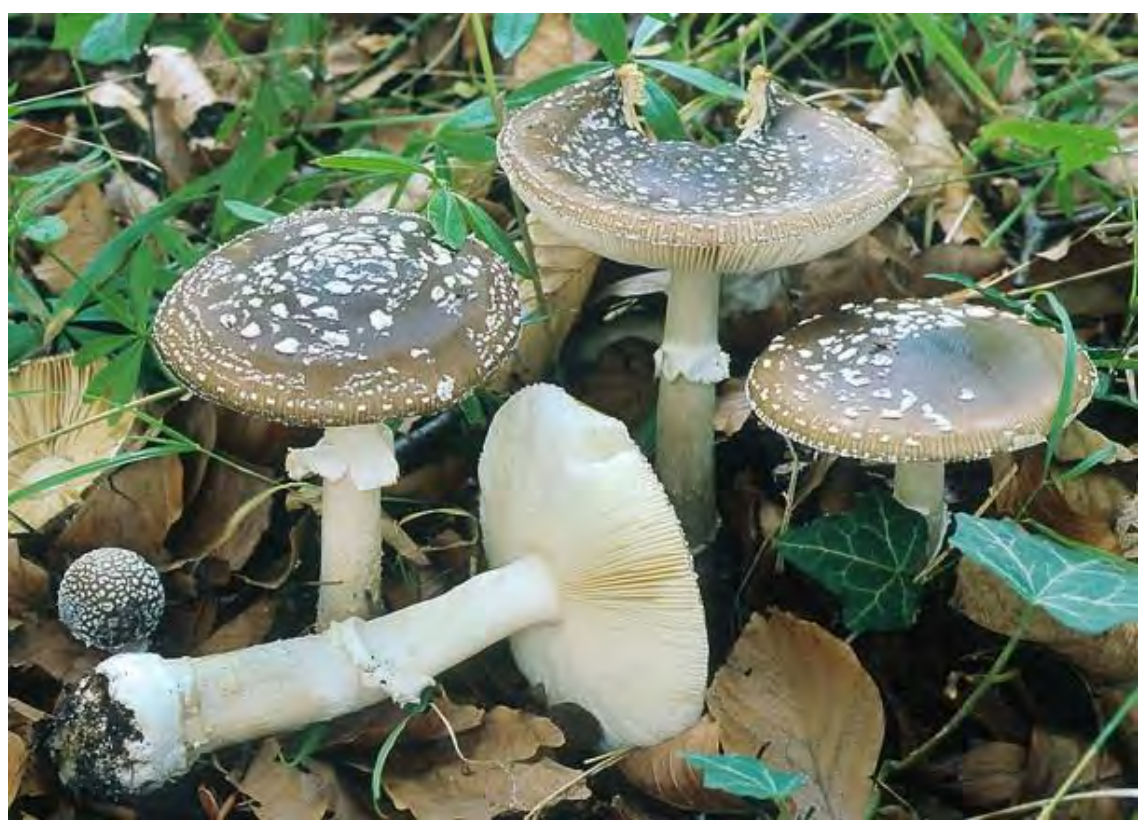

\section{Very poisonous}

Contains the neurotoxic isoxazoles, ibotenic acid and muscimol, which are the primary toxicants in the mushroom giving rise to neurotoxic effects with dizziness, ataxi, euphoria, anxiety, blurred vision and possibly tremor and convulsions. 


\section{Amanita phalloides (Vaill. ex Fr.) Link}

Deathcap (DK: Grøn Fluesvamp, FI: Kavalakärpässieni, IS: Vomuserkur (Grænserkur), NO: Grønn Fluesopp, SE: Lömsk flugsvamp).

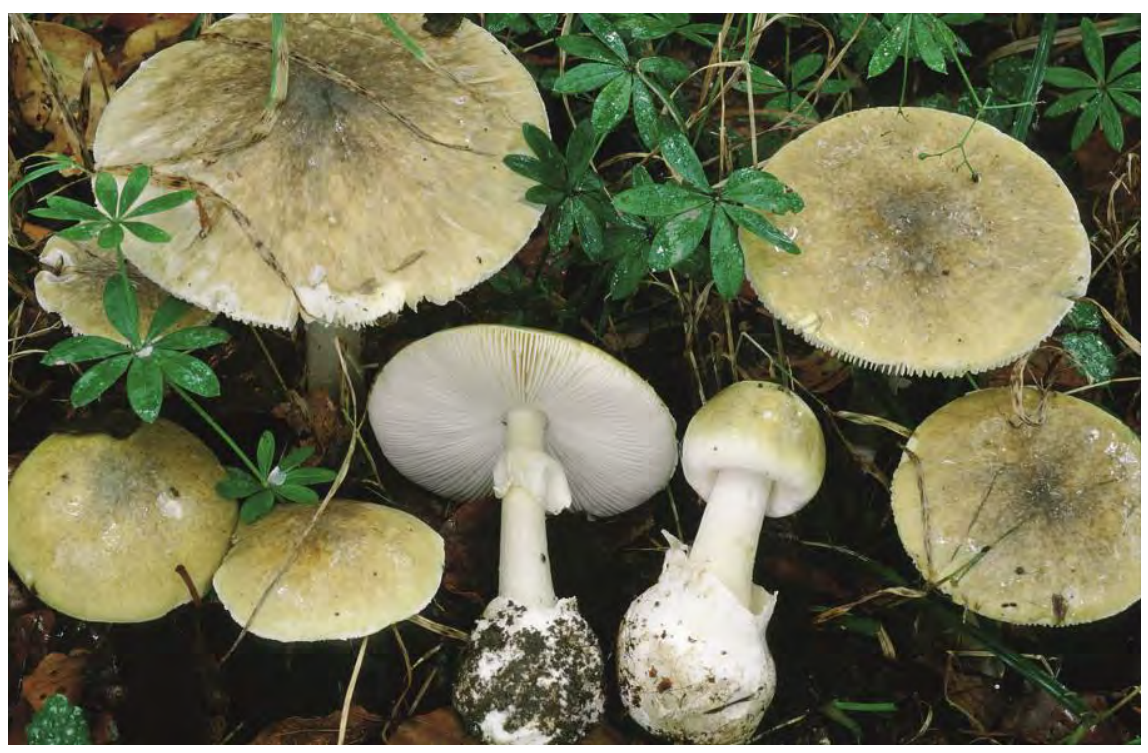

\section{Deadly poisonous}

Contains three groups of toxic cyclic peptides, of which the bicyclic octapeptides, amanitins, are the primary toxic constituents. The amanitins are cytotoxic compounds which primarily may give rise to very severe gastrointestinal and hepatotoxic effects, often with fatal outcome. 


\section{Amanita virosa (Fr.) Bertill.}

Destroying Angel (DK: Snehvid Fluesvamp, FI: Valkokärpässieni, IS: No Icelandic name, NO: Hvit fluesopp, SE: Vit flugsvamp).

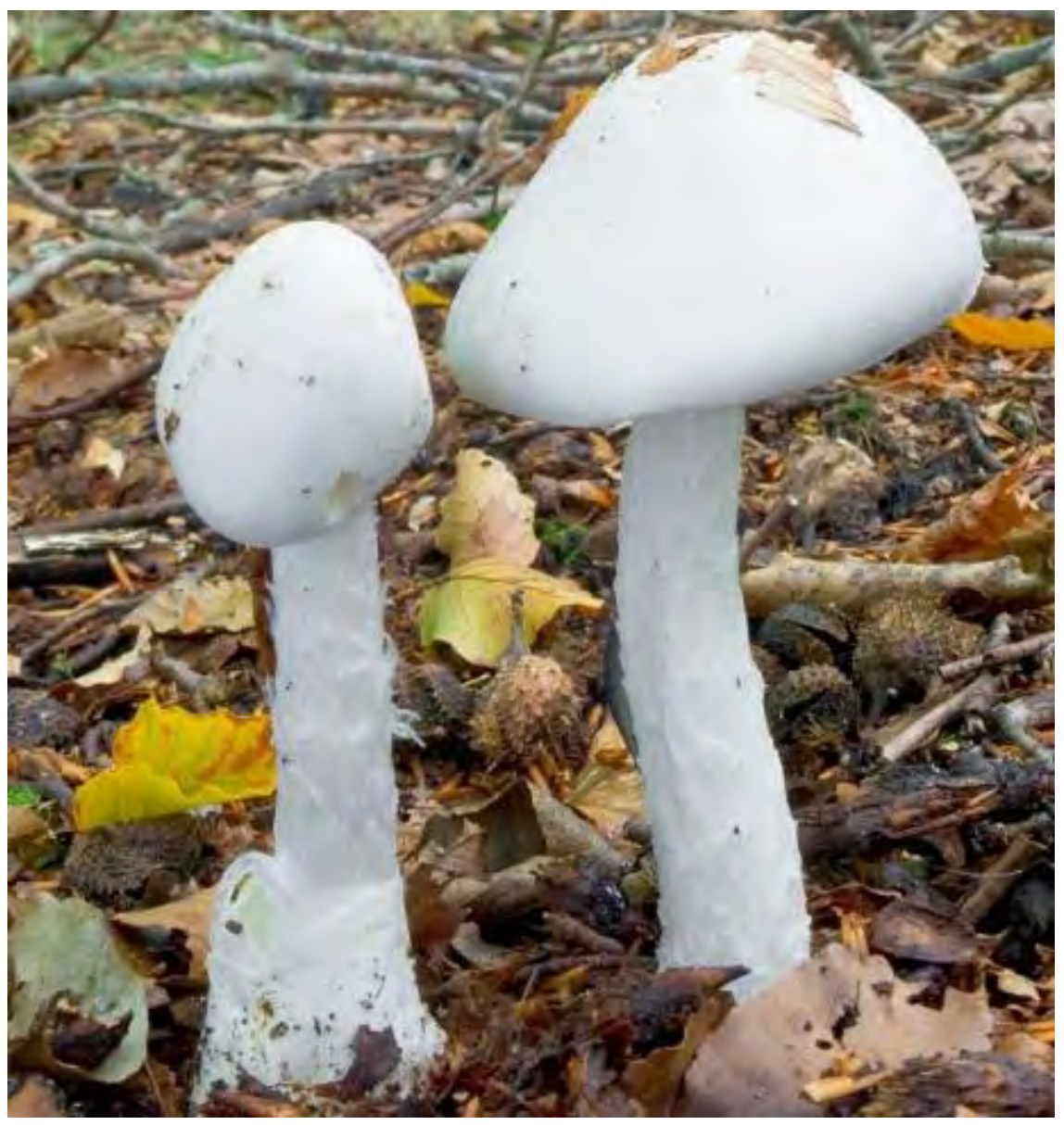

\section{Deadly poisonous}

Contains three groups of toxic cyclic peptides, of which the bicyclic octapeptides, amanitins, are the primary toxic constituents. The amanitins are cytotoxic compounds which primarily may give rise to very severe gastrointestinal and hepatotoxic effects, often with fatal outcome. 


\section{Boletus legaliae Pilát}

No English name (DK: Djævle-Rørhat, FI: No Finnish name, NO: No Norwegian name, SE: Falsk djävulssopp).

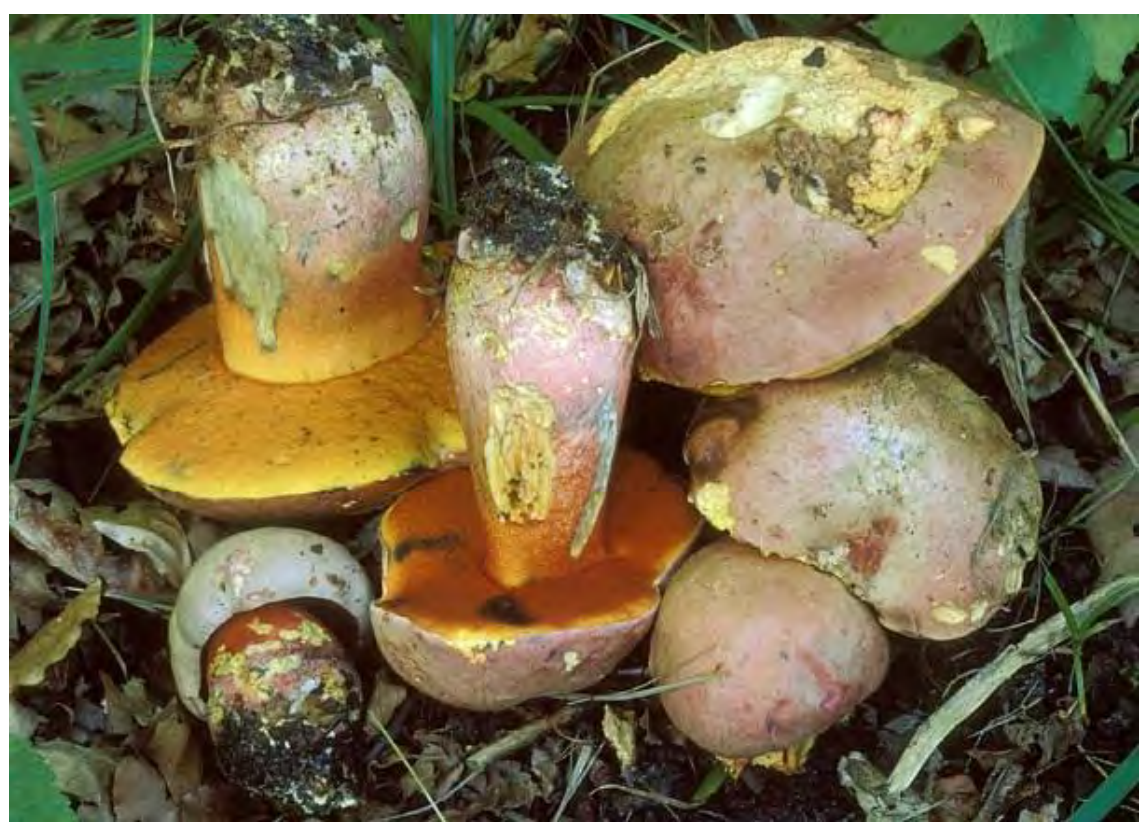

\section{Poisonous}

Gives rise to gastrointestinal adverse effects. Toxicant(s) unknown. 


\section{Boletus satanas Lenz}

Devil's Bolete (DK: Satans Rørhat, FI: No Finnish name, NO: No Norwegian name, SE: Djävulssopp).

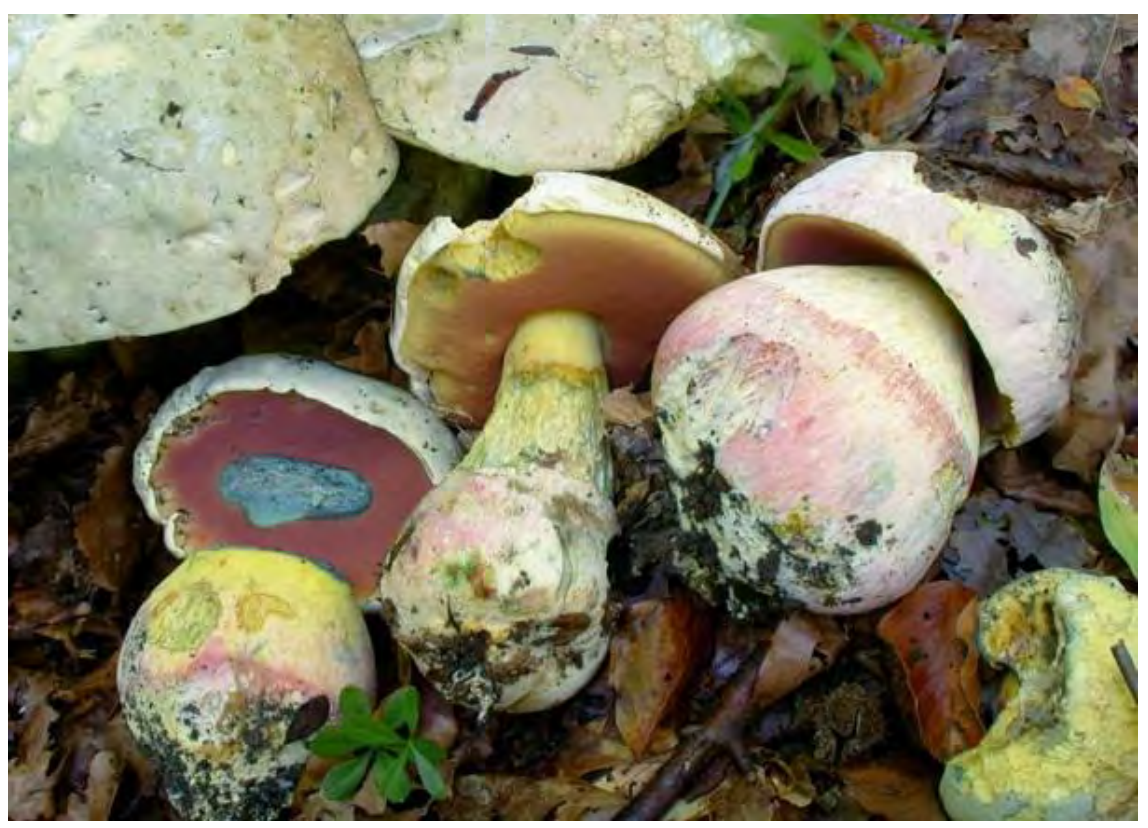

\section{Poisonous}

Contains bolesatine, a hemagglutinating glycoprotein (lectin), which probably is the toxicant giving rise to the severe gastrointestinal adverse effects, often seen after consumption of Devil's Bolete. 
Chlorophyllum brunneum (Farl. \& Burt) Vellinga (Macrolepiota bohemica (Wichanský) Kriegslt. \& Pázmány, Macrolepiota brunneum (Farl. \& Burt) Wasser)

No English name (DK: Giftig Rabarberhat, FI: No Finnish name. IS: No Icelandic name, NO: Lumsk parasolsopp, SE: No Swedish name).

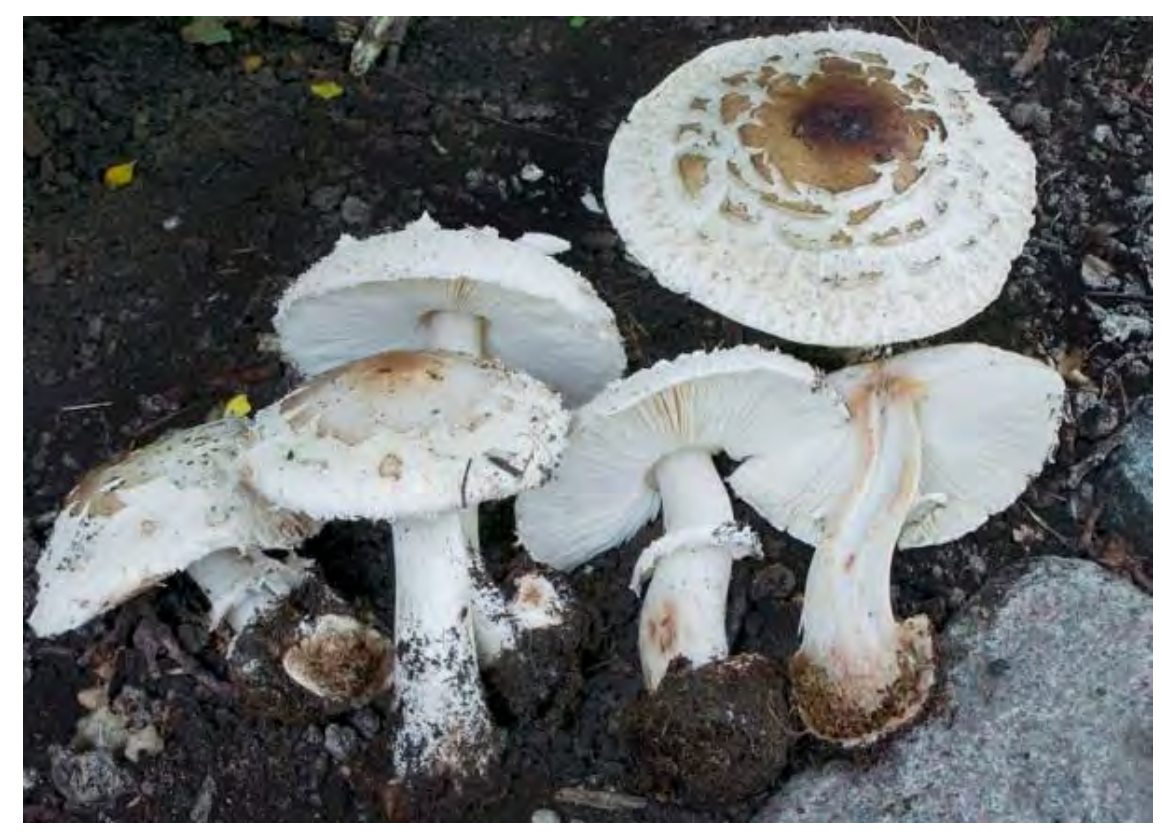

\section{Poisonus}

May give rise to gastrointestinal adverse effects. Toxicant(s) unknown. 


\section{Clitocybe rivulosa (Pers.) P. Kumm.}

\section{(Clitocybe dealbata (Sowerby) P. Kumm. s. auct.)}

Fool's Funnel (DK: Eng-Tragthat, (Bleg Tragthat), FI: Myrkkymalikka, IS: Mótrektla, NO: Lumsk traktsopp, SE: Gifttrattskivling).

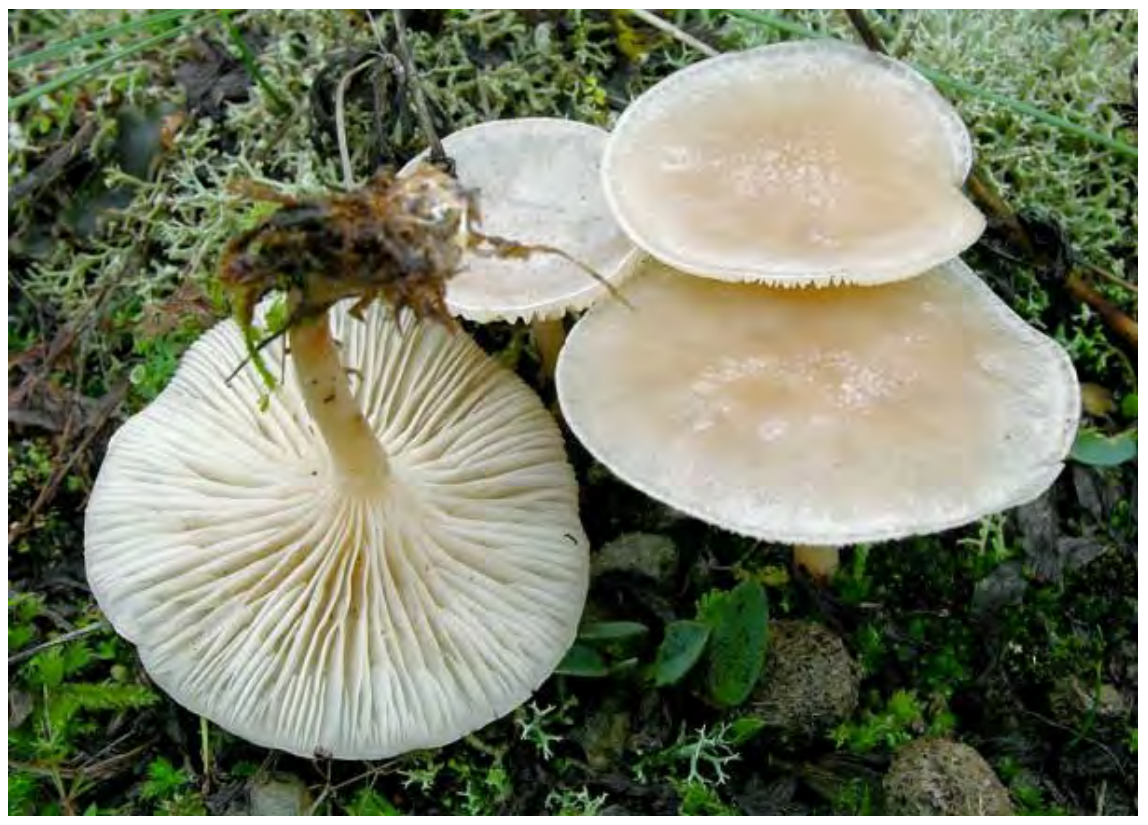

\section{Very poisonous}

Contains the neurotoxic quaternary ammonium compound L-(+)- muscarine which gives rise to gastrointestinal and autonomic effects. Severe poisonings including excessive respiratory secretion, bronchospasms and possibly cardiovascular collapse. 


\section{Cortinarius rubellus Cooke (C. speciosissimus Kühner \& Romagn.)}

Deadly Webcap (DK: Puklet Gift Slørhat, FI: Suippumyrkkyseitikki, NO: Spiss giftslørhat, SE: Toppig giftspindling).

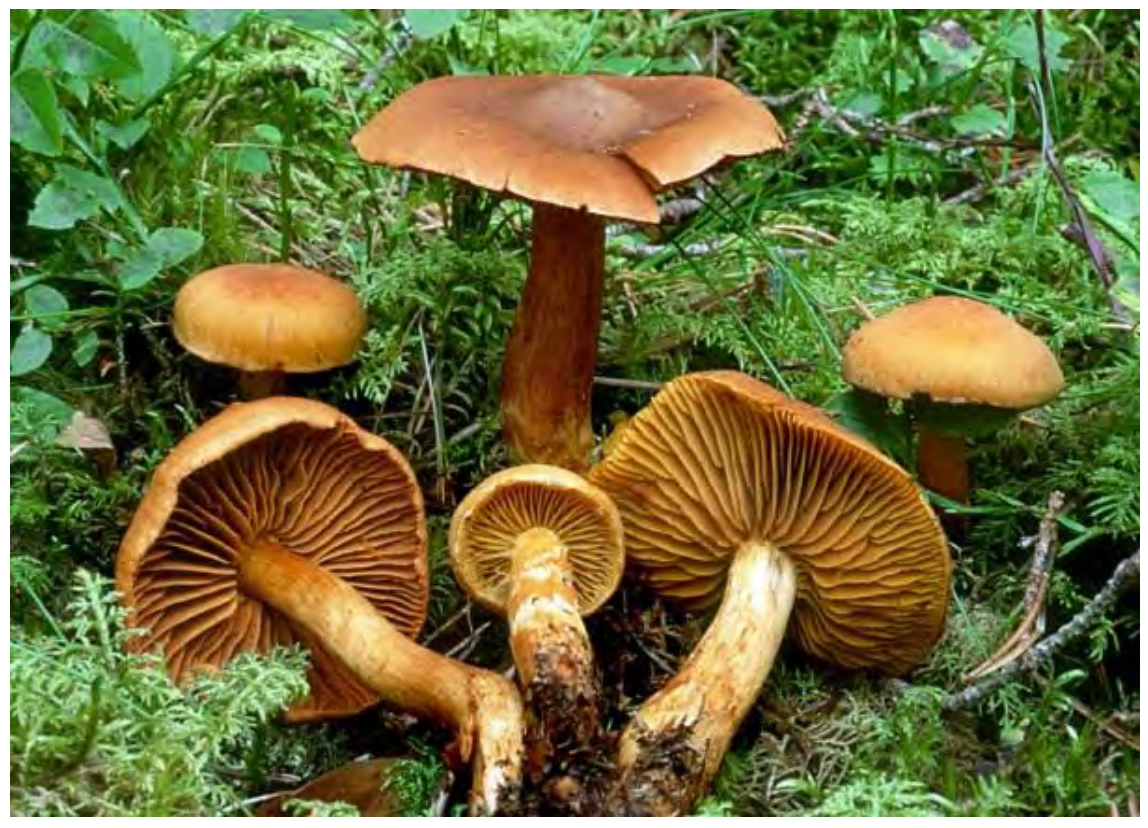

\section{Deadly poisonous}

Contains orellanine, a neurotoxic bipyridine compound, and other related compounds which after a very long latency period of 1-3 weeks may give rise to renal damage or even irreversible failure, sometimes with fatal outcome. 


\section{Galerina marginata (Batsch.) Kühner}

(Galerina autumnalis (Peck) A.H. Sm. \& Singer)

Funeral Bell (DK: Randbæltet Hjelmhat, FI: Myrkkynääpikkä, IS: Viðarkveif, NO: Flatklokkehat, SE: Gifthätting).

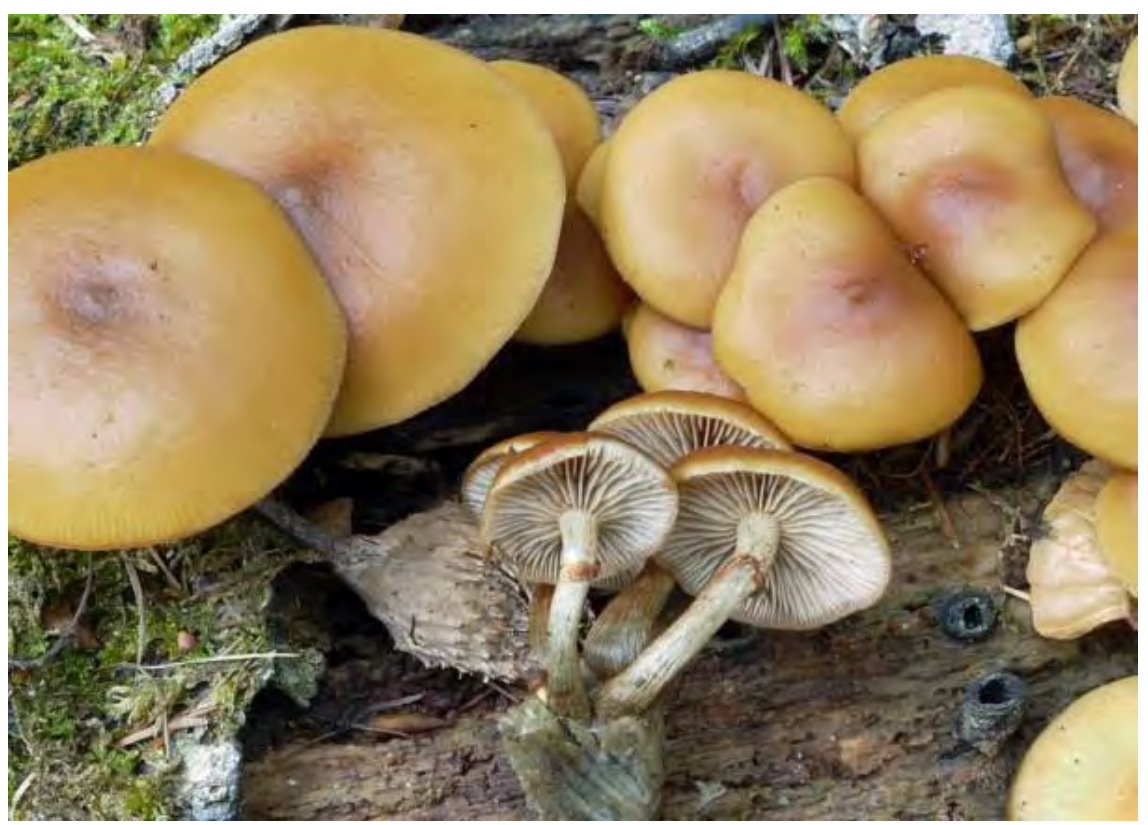

\section{Deadly poisonous}

Contains the toxic cyclic octapeptides, amanitins, which like for Deathcap primarily may give rise to very severe gastrointestinal and hepatotoxic effects, sometimes with fatal outcome. 


\section{Hypholoma fasciculare (Huds.) P. Kumm}

Sulphur Tuft (DK: Knippe-Svovlhat, FI: Kitkerälahokka, IS: Brennisteinsnollur, NO: Besk svovelsopp, SE: Svavelgul slöjskivling).

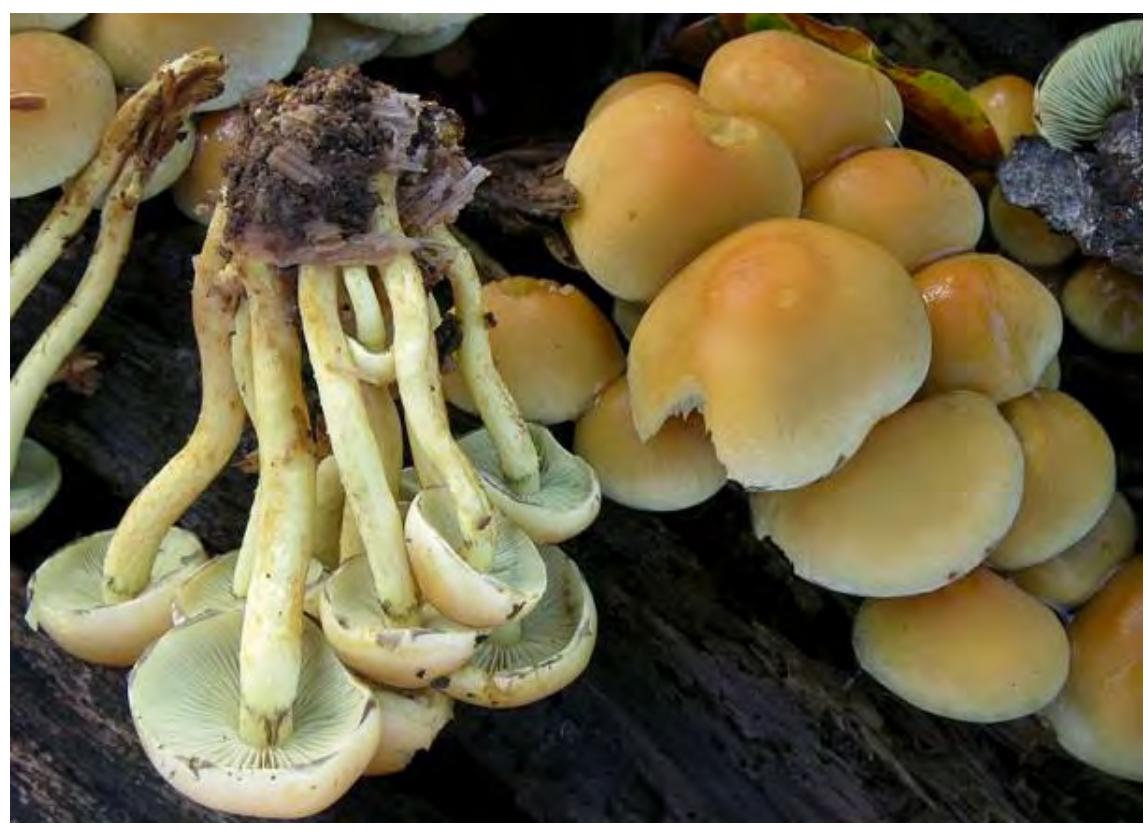

\section{Poisonous}

May give rise to gastrointestinal adverse effects. Toxicants unknown. 
Nordic Council of Ministers

Ved Stranden 18

DK-1061 Copenhagen K

www.norden.org

\section{Mushrooms traded as food. Vol II sec. 2}

Mushrooms recognised as edible have been collected and cultivated for many years. In the Nordic countries, the interest for eating mushrooms has increased.

In order to ensure that Nordic consumers will be supplied with safe and well characterised, edible mushrooms on the market, this publication aims at providing tools for the in-house control of actors producing and trading mushroom products.

The report is divided into two volumes:

a. Volume I: "Mushrooms traded as food - Nordic questionnaire and guidance list for edible mushrooms suitable for commercial marketing

b. Volume II: Background information, with general information in section 1 and in section 2, risk assessments of more than 100 mushroom species

All mushrooms on the lists have been risk assessed regarding their safe use as food, in particular focusing on their potential content of bioactive constituents.

TemaNord 2014:507

ISBN 978-92-893-2705-3

ISBN 978-92-893-2706-0 (EPUB)

ISSN 0908-6692

http://dx.doi.org/10.6027/TN2014-507

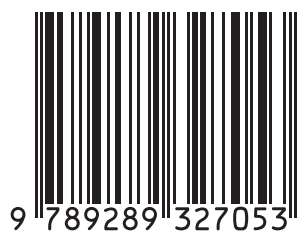

